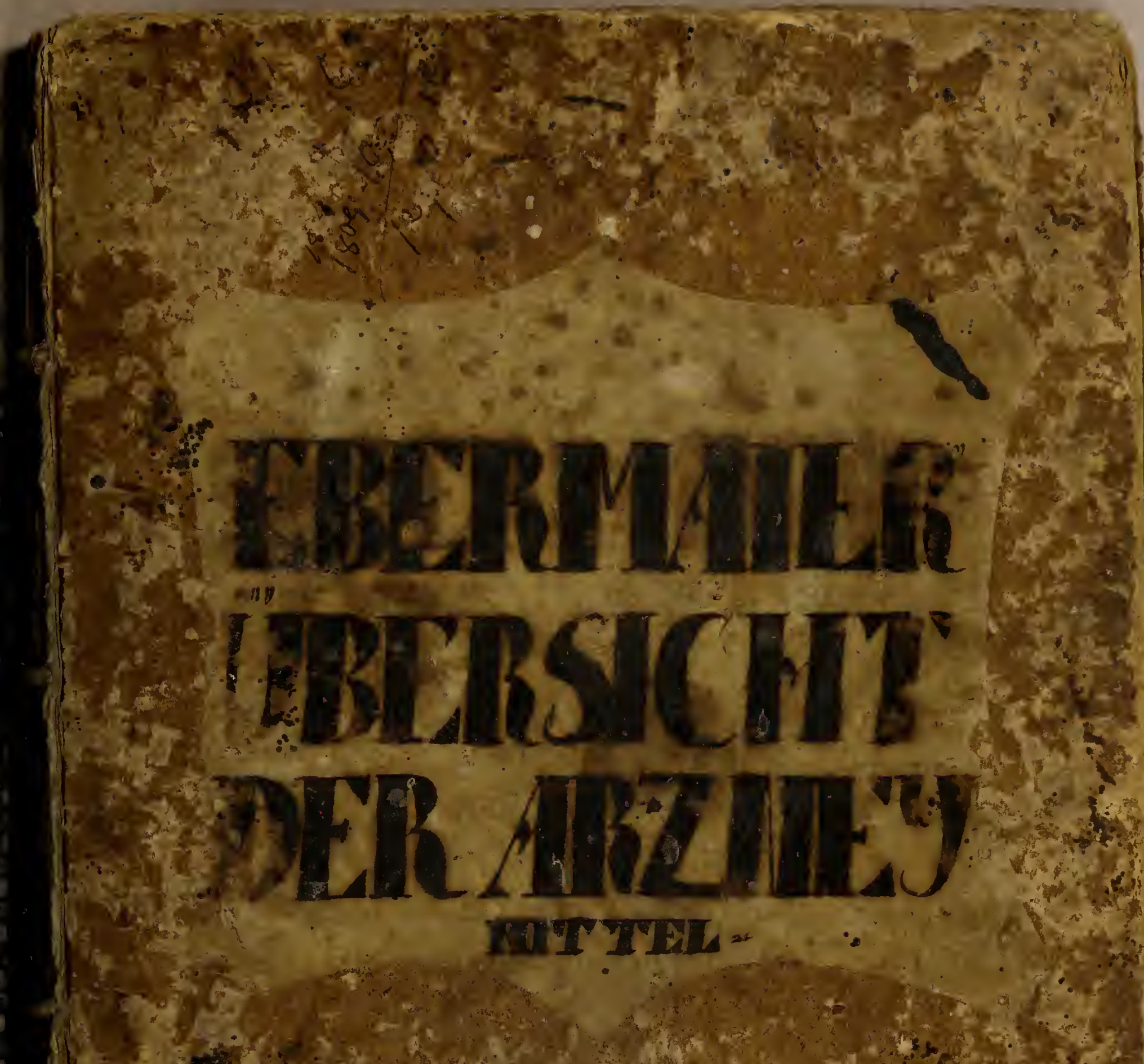




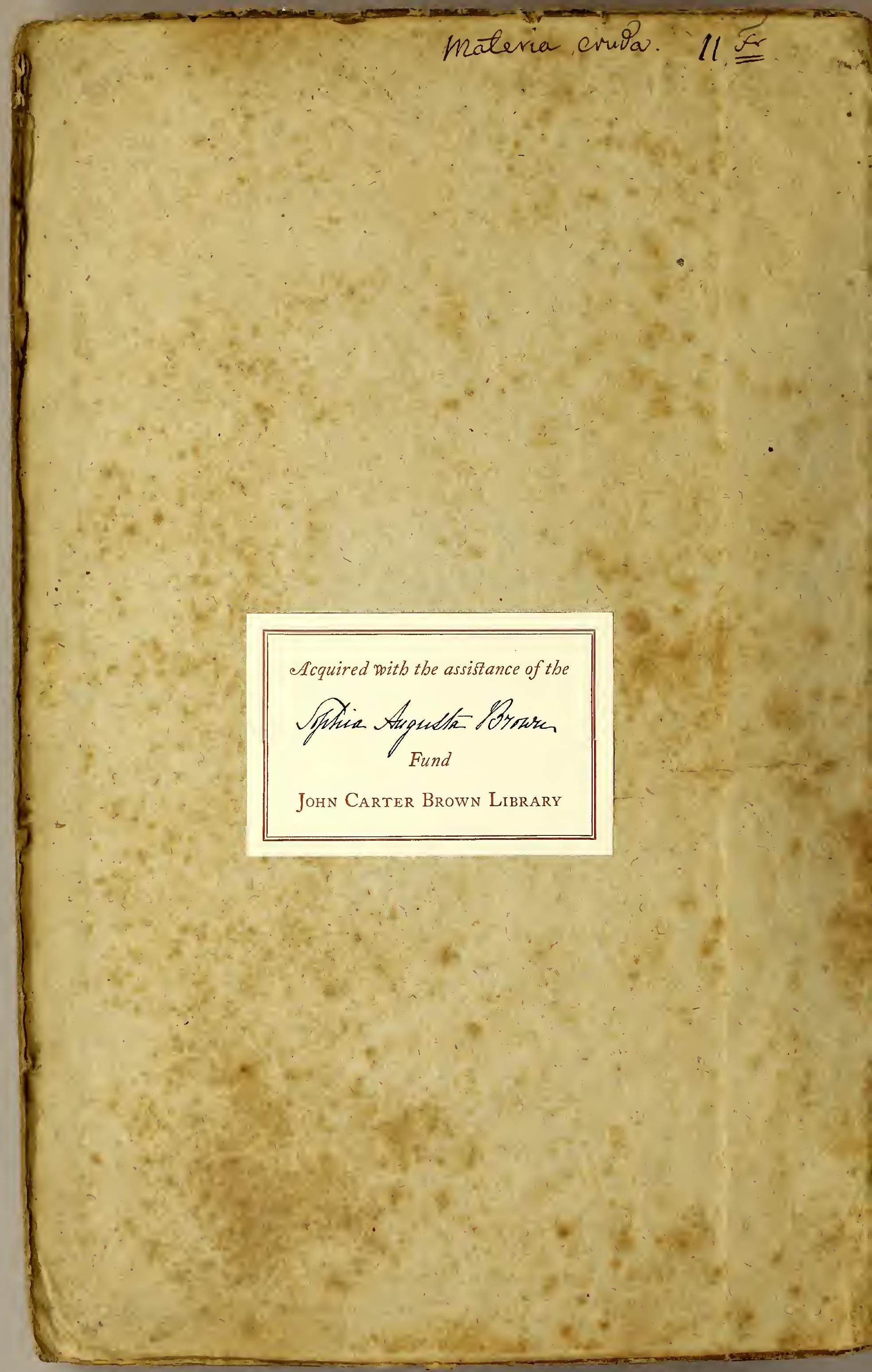





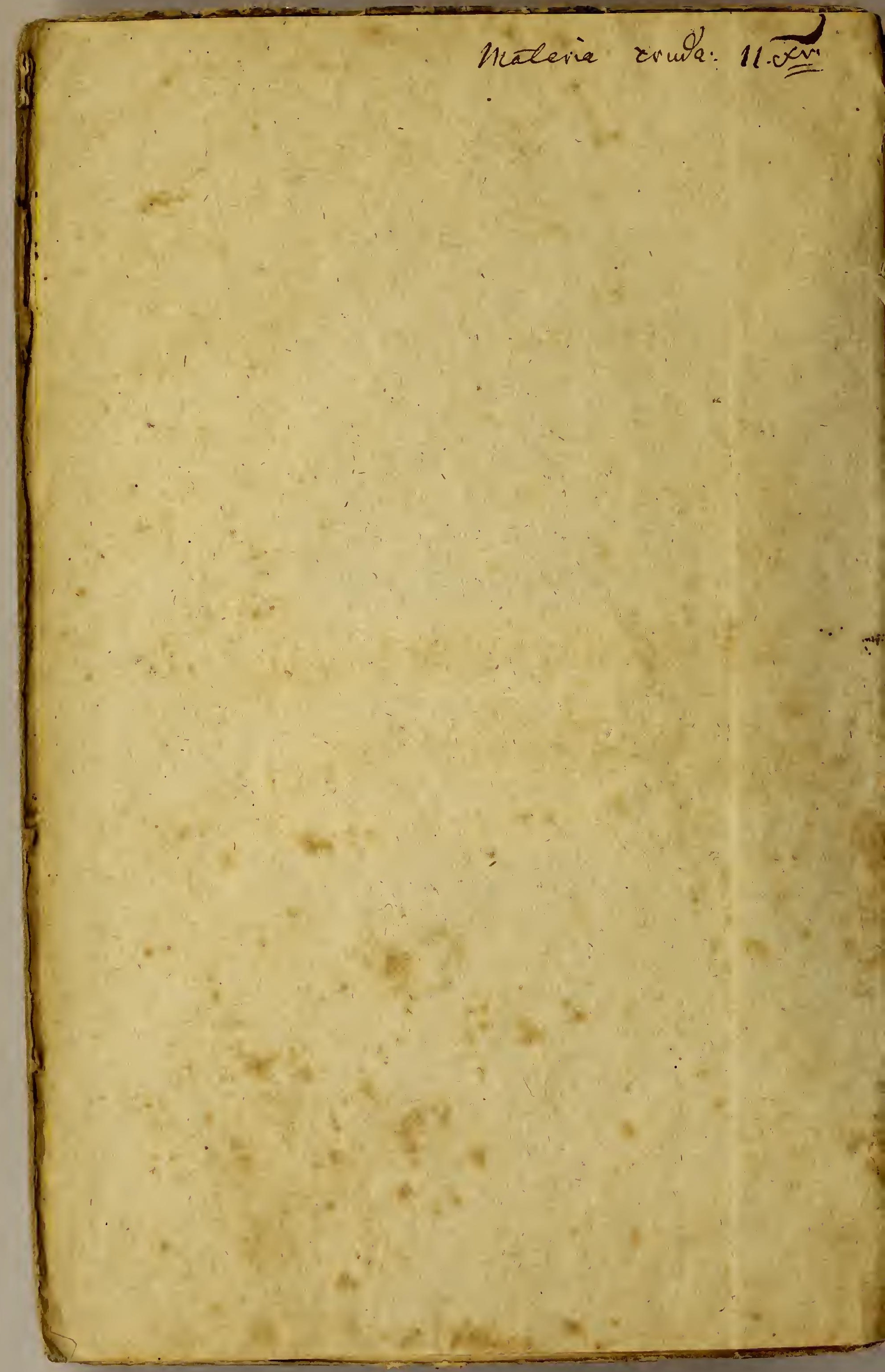




\section{Tabellarische Übersicht}

der Kennzeichen der Ächthcit ùnd Güte so wie

der fehlerhaften Beschaffenheit, der Verwechselungen und Verfälschungen sämmtlicher bis jetzt gebräuchlichen

e infach e $n, z u b$ e r e iteten und

\section{zusammengesetzten Arzneymittel.}

Z u in bequem e $\mathrm{n}$ G e b r a u c il e

$f$ ü $\mathrm{r}$ '

Ärzte, Physici, Apotheker, Droguisten und chemische Fabricanten e $\mathrm{nt}$ worfen

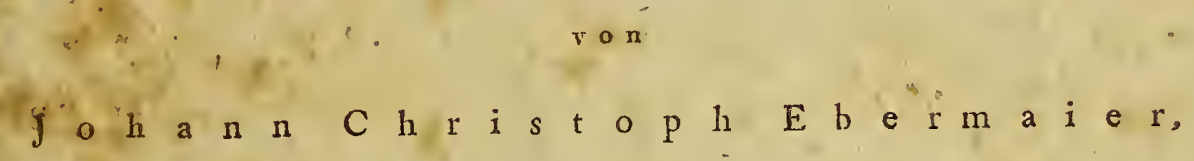

der Arzney - und Wundaržneygelahrtheit Doctor, Grofsherzoglich Bergischem Departementsphysicus im Departement von der Ruhr und practischem Arzte zu Dortmund, Hochgräflich Bentheim-Teklenburgischem Hof- und Medicinalrathe, der physicalisclen Gesellschaft in Göttingen, wie auch der Gesellschaft von Freunden der Geburtshülfe daselbst, ordentlichem Mitoliede, der botanischen Gesellschaft in Regensburg Ehrenmitgliede und der naturforschenden Gesellschaft in Jena Correspondenter.

Zweyte, durchaus umgearbeitete, verbesserte und vermehrte Auflage.

$$
L e \dot{i} p z i g, \quad \text { I } 8 \text { I } 0 .
$$

i ey Jolann Ambrosius Barth. 


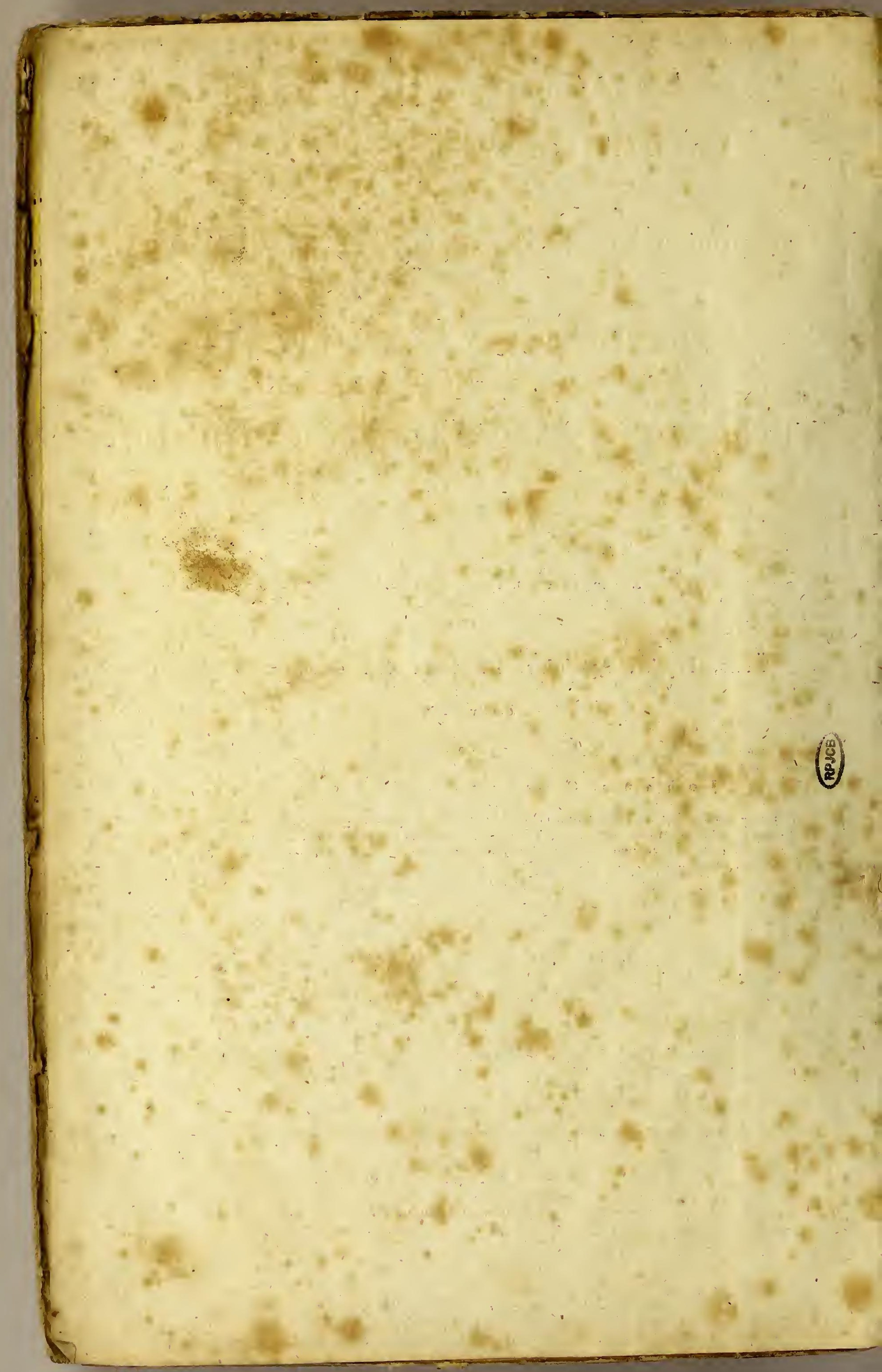




$$
D \text { e } n
$$

sämmtlichen verehrungswürdigen Mitgliedern

$$
\text { eines }
$$

Höchstverordneten Grols-Herzoglich Bergischen

\section{$M$ e d i c i n a l $\quad$ - $R$ a $t \quad h$ s.}

$$
\text { z u D üs s e } 1 \text { d o r } f
$$

$$
w \text { id } m \in t
$$

die $z$ weyte Auflage dieser.Schrift

$\operatorname{mis}$

der a ufichtigsten Hochachtug und Ergebenheit

$$
V \text { e r f a s s, e r. }
$$




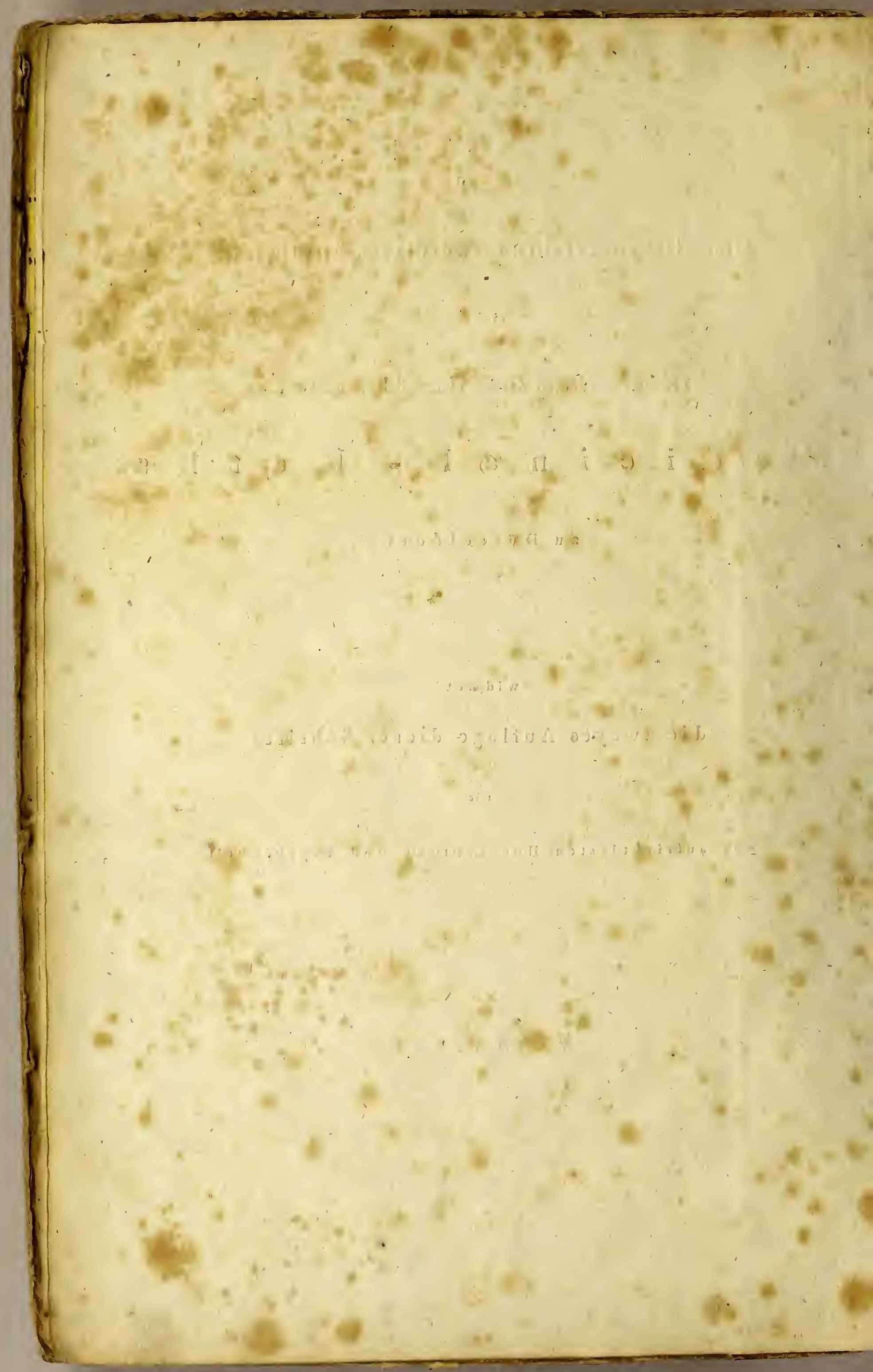




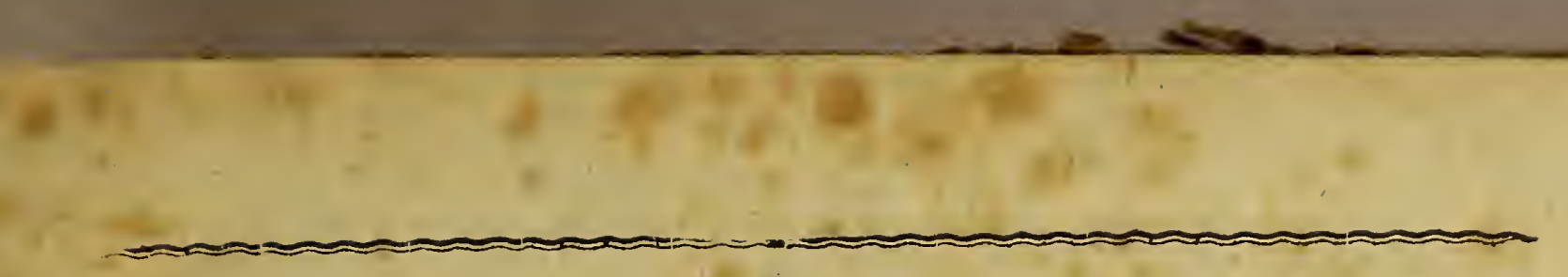

\section{Vorrede}

Die Gesundhit zu erhalten und die Krankheiten zu heben, durch welche das Leben der Menschen in Gefalr kommt, ist der grofse erhabene Zweck der Arzneikunde, das Ziel allex Bemühungen des praktischen Arztes. Mit so wenigen Worten sich dieser Begriff festsetzen lässt, mit so gerechtem Erstaunen verweilt dennoch der beobachtende Kenner bey der Betrachtung des grofsen Umfanges einer für die menschliche Gesellschaft wohlthätigsten Wissenschaften. Eine Menge von Hülfswissenschalten, davon jede ein eigenes Studium erfordert, überhaupt eine Masse von Kenntnissen aller Art, grofse Belesenheit und stetes Fortschreiten mit den neuesten Entdeckungen und Erfindungen müssen vereint dazu beytragen, um jenes Ziel zu erreichen und den Arzt fähig zu machen, seinen für die Menschheit übernommenen Pllichtes auf die befriedigendste Weise ein Genüge zu leisten.

Unter allen dem Arzte nöthigen Hülfswissenschaften steht aber die Kenntnifs der Arzneimittel mit Recht oben an. Wenn der Arzt nach vorher angestellter sorgfältiger Untersuchung seines Patienten, nach gehöriger Erforsclung der Krankheitsursachen und nach Abwägung aller dabey in Betracht kommenden Zufälle über das Wesen der Krankheit und ihre Behandlung ins Peine gekommen ist, so ist es die Arzneimittelkunde, die ihm die Waffen in die Hände giebt, wodurch er die Krankheit besiegen und den Tod entfernen kann. Es bedarf daher keines Beweises, wie unentbehrlich ilım dieser Theil der Arzneiwissenschaft sey, und wie sehr er sich bemühen müsse, die genaueste Kenntniss aller einfachen und zusammengesetzten Heilmittel, sowohl in Hinsicht ihrer Wirkungen und Kräfte, als auch der Gabe und der schicklichsten Form, in welcher sie ångewendet werden, zu besitzen.

Aufser dieser allgemeinen Kenntnifs der Arzneimittel uúfs der Arzt aber auch die Aechtheit und Güte derselben zu beurtheilen wissen. Er mufs im Stande seyn, die ächte Waare von der untergeschobenen, die verJälschte von der unverfälschten, die gut bereitete vòn der. nachlässig bereiteten unterscheiden zu können. Fr unufs die Prüfungsmittel kennen, wodurch die nicht selten vorkommenden Verwechselungen und Verfälschungen mancher einfachen und zusammengesetzten Heilmittel entdeckt werden können. Diese Kenntnifs schungen mancher einfällen, wo es darauf ankömmt, zu untersuchen, ob die Kranken die von ihm verordneten Mittel in dem möglichsten Grade der Vollkommenheit von dem Apotheker erhalten haben, oder nicht, neten Mittel in dem möten kommen. Nur die gewisse Ueberzeugung, dass dieses geschehen sey, kann ihn zu richtigen Resultaten führen und seinen Erfahrungen den Stempel der Walırheit aufdrücken, so wie der Kranke nur von solchen Mitteln um desto gewissere Hülfe erwarten kanı, je mehr sie allen Forderungen in Hinsicht ihrer Güte und Aechtheit entsprechen.

Von eben so grofsem Interesse ist diese Kenntniss für jeden Apotheker, der den hohen Werth seines Berufes kennt und in der möglichsten Erfüllung seiner Pflichten seine Elıre und seinen Stolz sucht. Durch sie kann er beym Einkaufe der rohen Arzneimittel den mannigfalligen Verfälschungen, welchen viele derselben ausgesetzt sind, entgehen; durch sie wird es ihm möglich, sich von der Güte seiner chemisch -pharmacevtischen Präparate, von der Richtigkeit seiner unternominenen Arbeiten zu überzeugen. Und welchem Apotheker sollte dieses nicht einë sehr angelegentliche \$ache seyn, da es einzig und allein die untadelhafte Beschaffenlıeit seiner Arzneinittel ist, wodurch.der gute Ruf seiner Apothele begründet und erhalten wird, und wodurch er sich das Zutrauen des Publikums versichern kann.

Von der Wichtigkeit dieses Gegenstandes überzeugt, haben vorzüglich in den neuern Zeiten mehrere achtungswürdige Schriftsteller es sich angelegen seyn lassen, denselben einer nähern Bearbeitung zu würdigen. Wir haben bereits verschiedene treffliche Anleitungen zur Beurtheilung der Aechtheit und Güte der ArzmeiWir haben bereits verschiedene treftliche Anleitungen zur Beurtheilung die Anzahl derselben durclı eine neue Schrift zu vermehren. Wenn man indessen bedenkt, dass den sämmtlichen hierüber erschienenen Sclıriften bey allem Fleifse, mit welchem in den mesiten derselben die einzelnen Artikel behandelt sind, ein sehr wiclutiges Requisit der Braucisbarkeit, das der Vollständigkeit fehlt, indem die eine Schrift diese, die zweyte jene, die dritte wrieder andere Artikel entluält, keine einzige aber das ganze Feld der Arzneimittelkunde umfafst, dafs man daher baynahe alle Schriften dieser Art besitzen müsse, um nur einigermafsen eine vollständige Uebersicht zu erhalten, so dürfte eine neue, möglichst vollständige Bearbeitung dieses Gegenstandes nichts weniger 
als überflïssig scyn, ja vieileicht einem wesentlichen Bedürfnisse dadurch abgeholfen werden. Selbst die vortreffliche Schrift der Herren vanden Sande und flalune mann, die vollständigste aller bis dahiz erschienenen Anleitungen zur Leurtheilung des Werths der Arzneimittel, hat demungeachtet noch eine beträchtliche Nachlese übrig gelassen.

Diese Gedanken sind es, welche der gegenwärtigen Schrift ihr Daseyn gegeben haben. Die tabellarische Form, in welcher sie abgefasst ist, hat in dieser Hinsicht unstreitig viele Vorzüge, da sie eine bequeme Uebersicht nicht nur des Ganzen, sondern auch der einzelnen Gegenstände zuläfšs. Dem Herrn Medicinalrath $H$ eineke in Halbersladt verdankt das Publikum nicht allein die erste Idee'dazu, sondern auch die Bearbeitung der erstern Bogen, so wie derselbe die ganze.Schrift geliefert haben würde, wenn nicht sehr hăufige praktische und Aintsgeschäfte ihn verhindert hätten, sie so bald, als der Herr Verlèger es wünschte, zu beendigen. Beyde waren daher so güıig, mir die Fortsetzung anzuvertrauen; und ich übernahm mit Vergnügen eine Arbeit, deren Gegenstand mir immer sehr wichtig gewesen war, und von der ich glaubte, dafs sie dem Publikum willkommen seyn würde.

Die Einrichtung dieser Sçhrift erhcllet deutlich genug aus ihrer Ansicht. In tabellarischer Form enthält nämlich die erst e Columne derselben die alphabetisch geordneten Namen nach der neuen verbesserten, in der Preufsischen Plıarmacopoe aufgestellten Nomenklatır, wobey indessen auch zugleich die bis dahin gebräuchlichen ältern Benennungen und die üblichsten deutschen Namen angegeben sind. Die zweyte Columne begreift die Merkmale der ächten Beschaffenheit des angegebenen Arzneimittels. Die dritte zeigt die Verwechselung und Verfälschung, von denen endlich die vierte die Kennzeichen und Prüfungsmittel die Verwechselung und liegt die Preufsische Pharmacopoe zum Grunde;' indessen ist dabei auch zugleich auf diejenigen Mittel, die nicht darin aufgenommen worden und die gleichwohl in manchen andern Ländern offcinell sind, die nöthige Rücksicht genommen worden. Die Namen der in der Preufsischen Yharmacopoe enthaltenen Mittel sind hier mit Cursivschrift, die übrigen mit gewöhnlichen Lettern gedruckt. Dafs in einigen Bogen diese Unterscheidung, der ausdrücklichen Bestimmung im Manuscripte zuwider, nicht genau befolgt worden, ist ein Versehen des Setzer's, welches indessen durch Unterstreichen diescr Namen leicht zu verbessern ist. Am Ende der Schrift findet sich eine vergleichende Uebersicht der ältern und neuern Nomen=klatur, um für diejenigen, denen die letżtere noch nicht hinlänglich bekannt ist, das Aufsuchen irgend eines Gegenstandes zu erleichtern.

Ich bin es mir bewufst, bey der Ausarbeituing dieser Schrift allen Fleifs angewendet, keine Artikel von Wichtigkeit übergangen und die bis dahin belsannt gewordenen Verwechselungen und Verfälschungen nebst ihren Kennzeichen und Prüfungsmitteln möglichst vollständig gesammlet zu haben. Indessen gestéhe ich gerihren ne, dafs sich hin und wieder noch wohl Zusatze finden lassen mochten, weenstandes selbst schreiben werden. Die möglichste Vervollkommnung dieser Schrift liegt mir aber sehr am Herzen, und ich ersuche deshalb alle diejenigen, welche sich mit mir für diesen Gegenstand interessiren, mir ihre Bemerkungen darüber, so wie 'die etwa noch hinzu zu Cügenden Artikel, vorzüglich die mir entgangenen oder weniger bekannten Verwechselungen, Verfälschungen und Prüfungsmittel nur in unfrankirten Briefen, entweder in einem Unschläge an die Verlagshandlung oder an mich selbst, gütigst mitzutheilen. Ich werde davon bey einer neuen Auflage oder in einem besondern Nachtrage zu der gegenwärtigen Schrift dankbar Gebrauch machen, und mich den Herren Einsendern um so mehr verpflichtet halten, je inniger ich davon überzeugt bin, dafs nur auf diese Weise die gegenwärtige Schrift immer mehr an Brauchbarkeit und Vollständigkeit gewinnen könne. Mit eben so dankbarer Bereitwilligkeit werde ich_die mir gegebeneil Winke der Recensenten benutzen.

Ich wünsche übrigens dieser Schrift eine gütige Aufnahme und empfehle sie und mich dem Wohlwollen der Leser.

\section{Thed a,} den I. April 1804.$$
\text { , d }
$$

\section{Dr. Ebermaier.}




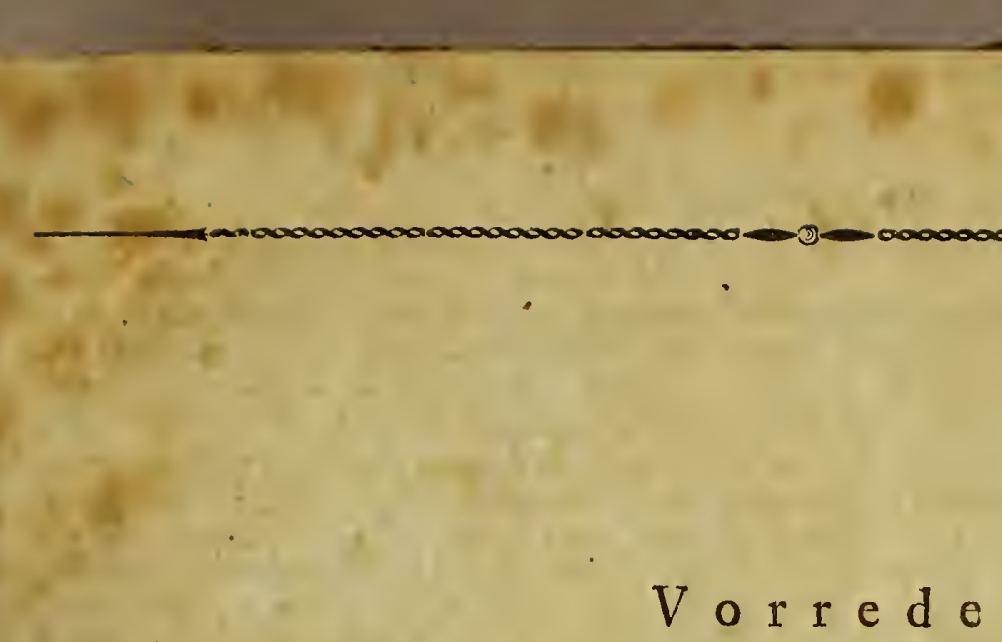

z $u$ I

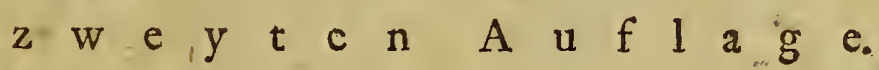

W

enn der Verfasser dieser Schrift auf der einen Seite den gütigen Beyfall, welchen man der ersten Aufla ge schenkte, und die eben so belelurenden als nachsichtsvollen Beurtheilungen, welche derselben in verschiedenen Zeitschriften von den achturıswürdigsten Gelehrten zu Theil wurden, gehörig zu schätzen weifs, so hielt er es auf der andern Seite für Pflicht, alles aufzubieten, umm der gegenwärtigen Auflage den möglichsten Grad der Vervollkommnung zu geben, und dieselbe so zu bearbeiten, dafs man sie d'em jeizigen Zustande unserer Kenntnisse über die Beschaffenheit ider Arzneimiltel angemessen abgefafst finden möge. Glaubt nun zwar der Verfasser seiner Seits überzeugt seyn zu können, diese gerechte Forderung, welche das Publicum bey jeder neuen Auflage einer Sclirift zu machen hat, möglichsterweise befriedigt zu haben, so wünscht er doch auch, dals die Leser seiner Schrift dieses finden mögen, weshalb er es für nöthig hält, über die mit dieser neuen Auflage vorgenommenen Veränderungen das hieher gehörige anzuführen.

Man hat, und zwar wohl nicht mit Unrecht, bey der ersten Aufage dieser Schrift es getadelt, dafs bey, den einzelnen Arzneimitteln nicht immer die Gattung von Dingen, zu vielcher das beschriebene Mittel gehöre, genannt, und bey den Arzneimitteln des Pflanzenreichs der systematische Nahme in der Regel nicht bemerkt worden sey. Beydes ist in dieser neuen Auflage durchgängig geschehen, und auf diese Art hoffentlich das Ganze um so brauchbarer geworden, indem dadurch die Beschreibung der characteristischen Kennzeichen eines Mittels, und sel ist die Merkmahle der Aechtheit und Güte desselben ganz unbẹżweifelt um vieles deutlicher und verständlicỉer werden. Wenn man z. B. sagt, dafs die Nelkenwurzel (Radix Caryophyllatae) vom. Geo urbano L. abstamme, so weils ein jeder, dem es nicht, an botanischen Kenntnissen martgelt, sogleich, von welcher Pflanze dieselben einzusammeln, und welches demnach die ächte Wurzel sey. Die nähere Beschreibung ihrcr sinnlichen Eigenschaften, der Gestalt und Farbe, des Geruchs, Geschmacks u.s. w. setzt ihn damn freylich in Stand, seiner Sache gewisser zu seyn, so wie sie dem weniger mit der Botanik vertrauten die nöthigen Fingerzeige giebt, die Aechtheit der Wurzel zu bestimmen. Auf eine ähnliche Weise liegt in der Angabe der Gattung, wozu ein Arzneimittel gehört, nicht selten ein Hauptcriterium über die Beschaffenheit eines Mittels. Eben aus dieser Ursache ist denn auch bey den zubereiteten Mitteln ganz kürzlich die Arl und Weise, auf welche sie erlangt werden, angezeigt, oder vielmelir nur angedeutet worden. Line ausfülnrliche Darstellung der Bereitungsmethoden dieser Mittel konnte hier freylich nicht her gehören; gewifs aber ist es, dals eine solche, wenn auch nur kurze Angabe der Bereitung dieser Mittel, der Beurtheilung über ihre Beschaffenheit ungemein zu Hülfe konunt. Dasselbe findet bey den zusammengesetzten Mitteln durch die Angabe ihrer Bestandtheile statt.

Aufserdem also, dafs der Verfasser bey der gegenwärtigen neuen Auflage seiner Schrift auf diese angeführten Puncte Rücksicht genommen hat, hat er es seine vorzüglichste Sorgfalt seyn lassen, die Erinnerungen und Winke, welche ilım über dieselbe in verschiedenen, ihm zu Gesicht gekommenen Recensionen und andern Schriften gegeben worden sind, zu behutzen. Es liegt; wie dieses auch in einer eben so gründlichen als belehrenden und berichtigenden Recension dieser Schrift, die sich im Berlinischen Jahrbuche der Pharmacie für 1806 befindet, gesagt wird, in der Natur eines solchen Werks, dafs neve Erfahrungen Berichtigungen und Zusätze darbieten; es ist auch wohl nicht zu vermeiden, dafs manches der Aufmerksamikeit entgehe. Um desto angenehmer und willkommner mufste daher auch dem Verfasser jene Pecension seyn, und er darf hoffen, durch ihre fleifsige Benutzung bey dieser neuen Auflage dem sehr verehrten Recensenten den besten Beweis seines lebhaftesten Dankes für dieselbe gegeben zu haben.

Schon eine fiüchtige Durchsiclıt diescr Ausgabe wird zeigen, dafs sie nicht blos eine neue hie und da verbesserte Auflage, sondern der Bemerkung auf dem Titel zufolge ein durchatis neu bearbeitefes. Werk sey. Es ist fast kein einziger Artikel, der nicht entweder ganz von neuem ausgearbeitet, oder doch den neuern Fortschritten unserer Kenntnisse über die Arzneimittel gemäls verändert, berichtigt oder verbessert worden sey. Dér Verfasser hat zugleich gesucht, dem Ausdruck melır Bestimmtheit und Correctheit zu geben. Manche neue Artikel, die in der vorigen Ausgabe fenlten, sind hinzugekommen. Dabey haben die zweyte und.dritte Columne auf jeder Seite, der gegenwärtigen Bearbeitung angemessenere und bestimintere Ueberschriften $\in \mathrm{r}-$ halten, und narnentlich war dićses bey der dritten Columne nöthig, indem ein Mittel nicht eben blos verwechselt oder verfälscht werden där, un unbrauchbar zu seyn, sondern auf manche andere Weise fehlerhaft beschaffen seyn kann. Auch die vergleichende Uebersicht der pharmacevtisch-chemischen Nomenclatur zu Ende der Schrift hat eine gröfsere Ausdelinung erhaltep. 
Der etwas veränderte Titel bestimmt dieses Buch auch für Droguisten und cliemische Fabrikanten. Beyden muls in der That äufserst viel daran gelegen seyn, eine genaue Kenntnils von denjenigen Waaren, womit sie durch den Weg des Handels die Apotheker versehen, zu besitzen, denn beyde, zumal heutiges Tages auch die letztern, lıaben auf die in den Apothek'en befindlichen Arzneivorräthe einen sehr wesentlichen Rinflufs. Wenn die Droguisten mehr, wie es gewöhnliclı geschieht, darauf säıın, dem Apotheker nur gute untadelhafte Droguen zuzusenden, wenn sie jede niedere Gewinnsucht bey ihrem Handel bey, Seite setzten, und nicht so häufig ganz schlechte verwerHliche Droguen statt guter Arzneimittel verkauften, wenn sie nicht dadurch, dafs sie von jeder'Waare mehrere Sorten, von der schlechtesten bis zur guten, fübren, es der Willkühr mancher Apotheker überliefsen, schlechtere Sorten statt der besten zu nehmen, wahrlich, es würden nicht so viele Klagen übeŕ die Untauglichkeit der Arzneimittel gehört werden. Wenn die Inhaber von chemischen Fabriken es sich zum unverbrüchlichsten Gesetze machten, nichts von chemisch - pharmacevtischen. Präpáraten zu versenden, was nicht im höchsten Gradę den Stempel der Reinlıeit, Aechtheit und Güte an sich trüge, es würcle weniger gegen die Sitte vieler Apotheker, dergleichen Präparate von den chemischen Fabriken zu beziehen, zu erinnern seyn. Eben deshalb ist es denn auch gewifs sehr heilsam, wenn sowohl die Droguereyhandlunger, als die chemischen Fabriken eben so gut wie die Apotheken, unter Aufsicht der medicinischen Policey stehen, wenn diejenigen, welche sich mit dem Droguereyhandel beschäftigen oder chemische Fabriken anlegen wollen, erstere in Hinsicht ihrer Wąarenkenntnisse, und letztere in Hinsicht ihrer Fähigkeiten dazu, vorher geprüft, ihre Nicderlagen von Zeit zu Zeit visitirt und die Waarenvorräthe untersucht werden, und es nicht geduldet wird, dals von jeder Waare mehrere Sorten geführt werden, sondern. nur eine und dieselbe vori untadelhafter Beschaffenheit zum Verkauf in die Apotheken vorräthig gehalten werde. In verschiedenen Läsdern ist bereits diese wohlthätige Einrichtung getroffen worden und es ist zu wünschen, dals sie allgemein eingeführt werden möge.

Irrt der Verfasser nicht, so glaubt er den Aerzten, und besonders auch denen, welchen als Physici die Visitationen der Apotheken übertragen sind,' durch diese Schrift einen zweckınärsigen Leitfaden zur Untersuchung der Arzneimittel in die Hände gegeben zu haben. Eine Beschreibung des Verfahrens selbst, welches bey den Visitationen zu befolgen ist, findet man in des Herrn Medicinalratls $N i$ ie manns Anleitung zur Visitation der Apotheken und der übrigen Arzneivorräthe, so wie der chirurgischen Apparate, welche medicinische Policeyaufsicht erfordern, Leipzig, 1807. Ueberhaupt ist in neuern Zeiten sehr vieles über die dpothekenvisitationen geschrieben worden. Man hat theils ihre Wichtigkeit zu bezweifeln gesucht, theils die Art und Weise getadelt, anf welche sie gewöhnlich vorgenommen werden, theils Vorschläge gethan, wie sie zweckmälsiger und ihren Absichten entsprechender eingerichtet werden könnten. So wahr es nun ist, dafs für den gewissenhaften Apotheker, für den, der in der treuen Ausübung seines so wichtigen Berufs seinen Stolz und seine gröfste Ehre sucht und findet, im Grunde die gewöhnlichen Apothekenvisitationen überflüssig sind, indem er ohnehin seine Pflichten kennt und ausübet, und eines solchen Sporns zur Pflichterfüllung nicht bedarf, so ist es doch eben so wahr, dafs nicht alle Apotheker so denken, und dafs es leider noch manche Individuen unter ihnen giebt, die bey der Bereitung der Arzneimittel nachlässig verfahren, und denen es gleickviel ist, ob ein Medicament die gehörigen Eigenschaften besitze oder nicht. Deshalb bleiben denn auch die Apothekervisitationen immer eine sehr nützliche Einrichtung, der sich um der Harmonie des Ganzen willen auch die geschicktesten und besten Apotheker unterwerfen müssen und gerne unterwerfen werden, und das um so mehr, da sie durch ihr hellleuchtendes Beyspiel ihre übrigen Collegen am kräftigsten zur Nacheiferung anreizen und ermuntern können.

Uebrigens wiederholt der Verfasser, dem es um die Vervollkommnung dieser Schrift ernstlich zu thun ist, auch hier die am Schlusse der Vórrede zur ersten Auflage gethane. Bitte an alle, die für diesen Gegenstand Interesse haben, ihm ihre Erinnerungen und Bemerkungen über dieselbe, nebst den etwa nöthig scheinenden Zusätzen, besonders'aber neu entdeckten Verfälschungen und deren Prüfungsmittel, gütigst mitzutheilen. Er wird davon für die Folge den dankbarsten Gebrauch machen, so wie er dieses schon jetzt von verscliedeneıı ihm zugekommenen Bemerkungen gethan hat, für deren Mittheilung er den Herren Einsendern den verbindlichsten Dank sagt. Er selbst wird fortfahren, jede neue Entdéckung und Bereicherung, die uns zur nähern Kenntnifs der Arzneimittel führt, für seine Schrift zu sammlen, und hofft dazu durch die ihm gnädigst verliehene Stelle als Departementsphysicus des Departements von der Ruhr im Grofsherzogthum Berg, in welcher Eigenschaft er mit nächstem seinen Wohnort in Dortmund beziehen wird, nicht wenig im Stand gesetzt zu seyn. Die Resultate seiner Bemühungen wird derselbe vorläufig in seiner pharmacevtischen Bibliothek von Zeit zu Zeit bekannt machen.

Möge dann auch die neue Anflage dieser Sclrrift sich des Beyfalls des ärztlichen und pharmacevtischen Pablicums za erfreuen haben und recht viel Gutes stiften! Dies ist der herzlichste Wunsch, mit welchem der Verfasser dieselbe dem Publicum übergiebt.

Rhed a,

im Januar, 1810.

Dr. Ebermaièr. 
Acetum. - Acctum camphoratum.

\begin{tabular}{|c|c|c|}
\hline $\begin{array}{c}\text { Namen } \\
\text { der Arzneymittel. }\end{array}$ & $\begin{array}{c}\text { Sinnliche Eigenfchaften derfelben } \\
\text { Merkmale ihrer Ächicheit und } \\
\text { Giite. }\end{array}$ & $\begin{array}{l}\text { Fehlerhafte Be- } \\
\text { fchaffenheit, Ver- } \\
\text { wechselung oder }\end{array}$ \\
\hline
\end{tabular}

\section{Deren}

Kennzeichen und Prïfungsmittel. Verfälfchung.

fallt er Schwererde entfeltu, die fich in Salpeterfiure anföst, im Glühefener aufpeterfaure annoset, im Glubefener aufWeinfteinfaure die Schwererde allein $2 u-$

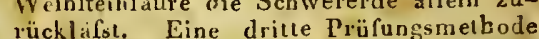
rucklatol. Eine dritte rufungsmeltode diefer immer fehr fclswierigen Uuterfa-
chung ift die Abdampfinng einer nicht zu geringen Menge des Effigs und dic Untersuchung der etwa gewonuenen Cryftallen auf Weinftein.

Mit fcharfen ätzenden Pflanzenftoffen, als Seidelbaft, Cpanifchem Pfeffer, Bertramswurzeln, Paradieskörnern, langem Pfeffer, Senf u. dol. die bey der Bereitung źugefetz werden.

Die Effigfieler bedienen fich zuweilen dergleichien fchädlicher Zuràtıe, um dem Effige metr Schärfe zu geben, die der Unkundige für natürliche Säure nimmt. Es
giebt verfchiedeue Methoden, diefes zu entileclien.

a) Beftreicht man die eine Lippe nit zuverlälig reinen, die andere Lippe aber mit deur anf diefe Art vcrfälfchten Eflig, fo bleibt nach dem Abtrocksen auf leizterer Lippe ein Breunen zurück, welches auf der Lippe ein licht ftat findet.

L) Extractform, fo bat der Rückltand eillen brenneulen Gefchrnack.

c) Im Verhälınifs . feiner Schärfe im Gefchmack, fattist er doch nur eine geringe Nenge Kali, und die ueutralifirte Flüfligkeit hat dani nicht blos einen falzigen, elwas ftecheuden, fonderu emen fremden, ätzenden, lange antralıeudeu Gefelinack

d) Narn if e $\mathrm{f}$ (S. deffen rollkommenen Efigbrauer, Erfurt, 1804.) follen, wenu nan ene Portion des zu prüfenden wenil nan elae Poft ausf.izt, ficl bald eine Menge der kleinen Elinglipges um ibn cine Menge der kein all der Elfig rein und - her verfammeln, im Fall der tillg rein und unverfalfchı fey; niemals aber wïrden die' fe hinzinkommen, wenn der Efig mit den
erwäbuten folarfen Subftanen oder Mine-

Statt des Weineffigs $\overline{\text { Man findet rliefes durcli Verdunften des Effigs }}$ ein wohlfeilerer|, bis zur Tıockne und Verbremung des Bier - oder $O b f t$ - Rückltandes. Zeigt diefer vesbrannte Rückeffor eflo, womit auch forwar es Weintifg; ift diefes aber tricht wohl der Weineffig
verfälcht wird." Der. Weineflig enthät uämlich Weinftein, welcber durch das Verbrensen zerfetzt wird und Kali zurickläfst. Bier - und Obftellig küuneu zwar Apfel- und WeinObltellg köunent zwas Aprel keinen Weinfiteinfure, enthalten anch keid Kali durch ftein, daher lie denn auch kein

diefe Behantlung liefern könuen.

Eis mi Bic'r - oder Obfeflig verfälfchter Weluellig fchäuml in cinem Probegläschen gegoften anf der Oberdäche wcit farker ind wirft viel mebr Luftbläschen auf, als reiner Weineflig. Der Rückftand eincs folchen zur Trocknc aligerauchten Eligs giebe beym Verbrennen mur fo virl Kali, als der Weineflig obrgefithe enthalten mochte und fol lich uach dern Quintititsverlältaife , Jolghich uach dern Weineflig. Dagegen wentger, als reinct Whosphorfure bey fich wovon man fich aut folgente Art ïberlich, wovoln man fich aut folgente Art uberzeugen kant. Man fet dem ellig ho viel von riner Anfïfung des Bleyzucker's hinzu, bis fich ein hinlänslicher Niederfehlag zeigl, welcher gebörig ansoewafchen, dnrch Gluben in einem kleinen schmelztiegel sich zu phosphoifaurem Bley ve'glafen liffst.

Mit Kupfer - und Der Eflig ift zuweilen durch Nachlalfigkcit Bleytheilen verun- und Uureinlichkeit der Fabrikasten und reinigt.
les Kaufmanns, und durcb die bey frinerVerfertignug gebranchten bleyernen, kupferueu oder meflugenen Gerätbfchaften, fo wie durch den Gebrauch eines mellingenen Irahues beym Abzaplen deffelben knpferoder hlezhaltig. Wie diefes zu entdecken, fiehe unter Acetum defibllatum.

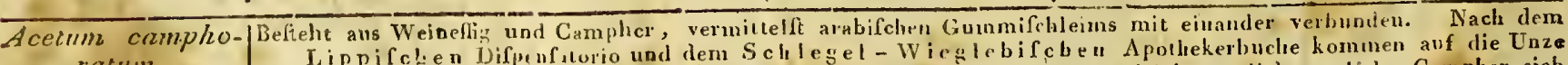
ratum. Camphireflig.

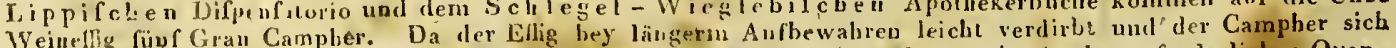

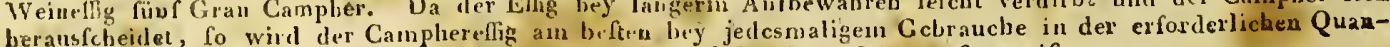
sitäb auf der Stelle zubereitet, worin denu auch bauptfachlich feine Güte zu fetzen ift. 


\begin{tabular}{|c|c|c|c|}
\hline $\begin{array}{c}\text { Namen } \\
\text { der Arzneymictel. }\end{array}$ & $\begin{array}{c}\text { Sinnliche Eigenfchaften derfelben; } \\
\text { Merkmale ihrer Achtheit und } \\
\text { Giite. }\end{array}$ & $\begin{array}{c}\text { Fehlerhafie Be- } \\
\text { fchaffenheic, Ver. } \\
\text { wechfelıng oder } \\
\text { Verfälfrimng. }\end{array}$ & $\begin{array}{c}\text { Deren } \\
\text { Kenuzeichen und Prïfungsmittel. }\end{array}$ \\
\hline \multirow[t]{4}{*}{$\begin{array}{l}\text { Acetum concen- } \\
\text { tratum. } \\
\text { Concentrirter oder } \\
\text { verftüliter Eflig. }\end{array}$} & \multirow{4}{*}{ 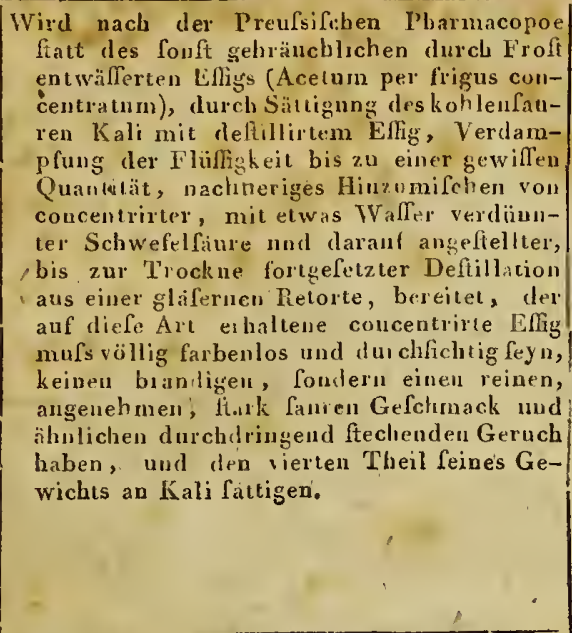 } & $\mid \begin{array}{c}\text { Mit brenzlichten } \\
\text { Theilen verunreinigt: }\end{array}$ & $\begin{array}{l}\text { Rührt von einern zu ftarken Feuer gegen En- } \\
\text { de der Deftillaticn her. Der brenzliche } \\
\text { Geruch und Gefchmack laffen diefen Febler } \\
\text { bald bemerken. }\end{array}$ \\
\hline & & $\begin{array}{l}\text { Mit Sclıwefelfäure } \\
\text { verunteinigt. }\end{array}$ & $\begin{array}{l}\text { Wird durch die Auflöfung der efligfaurea } \\
\text { Schwererde uud des effi faureu Bleyes ge- } \\
\text { trïbt. }\end{array}$ \\
\hline & & $\begin{array}{l}\text { Mit Salzfäure verun- } \\
\text { reinigt. }\end{array}$ & $\begin{array}{l}\text { Diefe rührt dann gemeiniglich vou dem ange- } \\
\text { wendeten Kali lier, befonders weun daffel- } \\
\text { be aus Pottafche bereitet war. Scbivefel- } \\
\text { fames Silber bewirkt in eirem folchen ver- } \\
\text { ftärkten Eflig einc Trübung. } \\
\end{array}$ \\
\hline & & $\begin{array}{l}\text { Mit metallifcluen } \\
\text { Theilen. verunrei- } \\
\text { nigt, befonders mit } \\
\text { Bler, wenn er nach } \\
\text { einer andern Me- } \\
\text { thode aus Bleyzuk- } \\
\text { ker bereitet wor- } \\
\text { den. }\end{array}$ & $\begin{array}{l}\text { Wie bey Acetum deftillatum. Will mau con- } \\
\text { centrirten Efig mit Ammoninmliquor anf } \\
\text { Kupfer prüfen, fo mufs man den Liquor } \\
\text { bis zur Ueberfättigung des Effigs zufetzen. }\end{array}$ \\
\hline \multirow[t]{3}{*}{$\begin{array}{l}\text { Acelum defilla- } \\
\text { Deftillirter. Effig. }\end{array}$} & \multirow{3}{*}{ 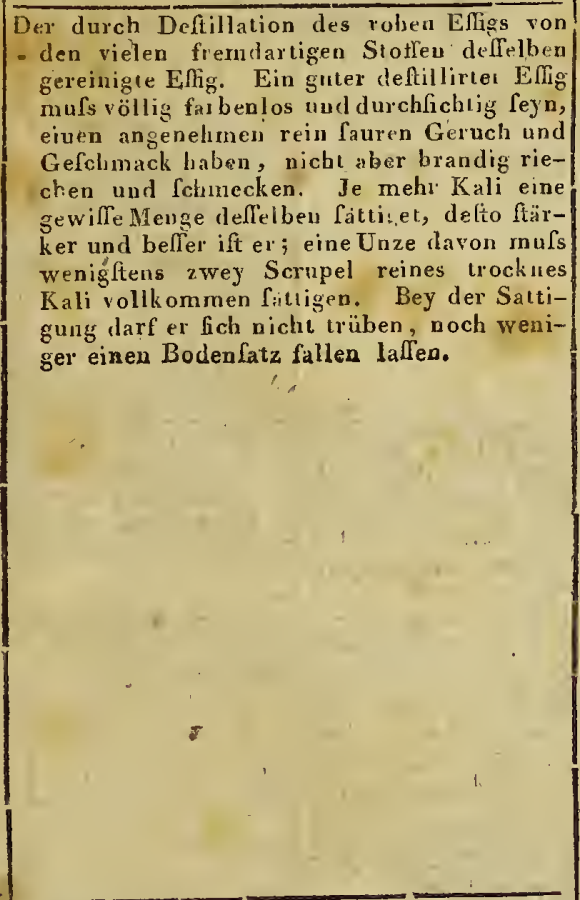 } & $\begin{array}{l}\text { Mit Kup fercheilen } \\
\text { verunreinigt. }\end{array}$ & 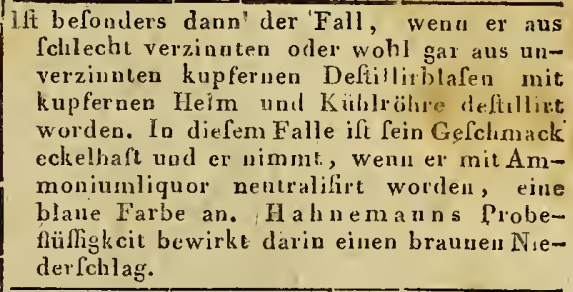 \\
\hline & & $\begin{array}{l}\text { Mit Bley verunrei- } \\
\text { nigt. }\end{array}$ & 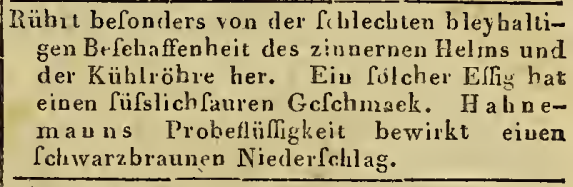 \\
\hline & & $\left\{\begin{array}{l}\text { Mit Zinn verunrei- } \\
\text { nigt. }\end{array}\right.$ & 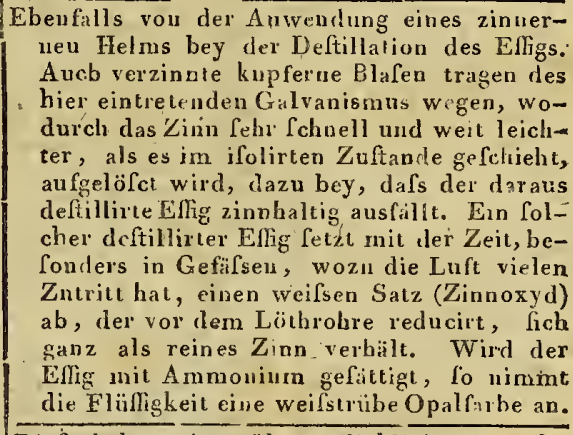 \\
\hline $\begin{array}{l}\text { Aceta medicata } 1 . \\
\text { infufa. } \\
\text { Medicinifche oder } \\
\text { Kxäutereflige. }\end{array}$ & 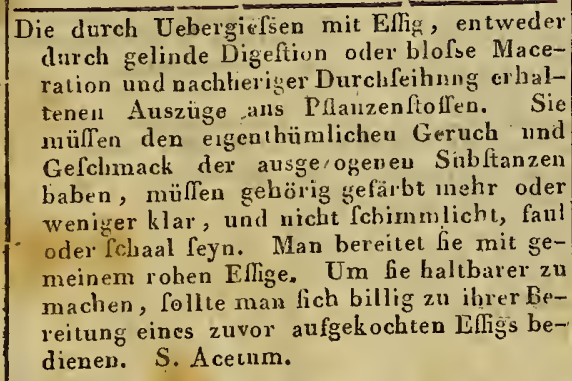 & $\begin{array}{l}\text { Statt durch Digeftion } \\
\text { find fie zuweilen } \\
\text { durch eine blofse } \\
\text { Abkochung berei- } \\
\text { tet, und dann die } \\
\text { flüchtigen Stoffe } \\
\text { mehr oder weniger } \\
\text { durch den zu hohen } \\
\text { Grad der Hitze ver- } \\
\text { jagt. } \\
\ldots\end{array}$ & $\begin{array}{l}\text { Diefe haben ein trüberes dicklicheres, Aufe- } \\
\text { hen. Gerwch und Gefchmack verrathen } \\
\text { überdem den Mangel der entwichenen lue- } \\
\text { figen Stoffe. }\end{array}$ \\
\hline
\end{tabular}

dienen. S. Acetnm. nelle Much nelken, Mench Forbe feyuack befitzen.

Acetum Rofarum. Rofeneffig. Ans Franzrofen und Effig bereitet, hat eine dunkelrothe Farbe und cinen etwas zulammenziebenden Gefchmack.

Acetum Rubi Idaei. Himbeereffig. Aus frifchen Himbeeren nnd rohem Eflig bereitet. Er mu[s eine angenehme hellrothe Farbe und einen erquickenden Geruch und Gefchmack befitzen. Beyn Oeffnen des Gefälses darf er nicht gähren noch einen Dampґ ausftofsen.

Acetum Rutae. Ranteneflig. 'Diefer ans der Gartenrạute und rohem Effig bereitete medicinifche Effig hat eine bräuuliche Farbe und den fpecifiken Gernch der Raute.

Acetum fcilliticum. Meerzwiebeleflig. Ans zwey Unzen getrockneten Meerzwiebelfchuppen und zwey Pfunden

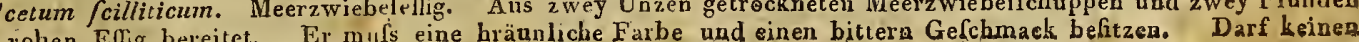
fchimmlichten. Ueberzug bekommen. 


\section{Acetum Saturninum. - Acidum boracicum.}

\begin{tabular}{c|c}
\hline Namen & $\begin{array}{c}\text { Sinnliche Eigenfchaften derfelben } \\
\text { Merkmale ihrer Ächtheit und } \\
\text { Güte. }\end{array}$ \\
\hline
\end{tabular}
Acetum faturni-|Nach der Preufsifclien l'larmacopoe aus ei-| Extractum Saturni. Bleyellig. Silberglütteflig. Bleyextract.

nen Theil Mrennige mil zwölf Theilen dà dell druten 'Theil der Fluffigkeit und nachdell dritten Theil der Fithifition bereitet. Der auf diefe hetigcr Filtration bereitet. Der auf diefe
Art bereitete. Bleyeflig mufs ganz. helle uud Art bereitete. Bleyefig muls ganz. helle uud durchsichtig feyu, einen fehr fïfsen zufam-
Acetum Lithargyrii. menzicheadcn Grefchmack haben, der freyen Lult ansgefetzl einen weifsen Satz geben, die Farbe des Lackmasanszugs nicht iöthen folceit wohl weifstrübe aber nicht blau gefubt werden. Eiu Glas, welches genau 1000 Gran Walfer bäl, mufs $1500 \mathrm{Gra}$ Bicjeflig fallen.

Acidum nceticum Alcohol Aceti. Acettum glaciale $I$ radicale.

Reine concentrirte Eflisfïure.

Effigalcoliol.

Eiseffig

Radicaleffig.

Die aus dem efligfauren Natro vormitlcl fcliwefelfauren Kalis nud concentrirter Schwefelfaure nebft eincm kleinen Zufatze von $\mathrm{Bt}$ aunftein durch Deftillation ans ciues Glasrecorte geronuérue concentrirtefte Efligfireciffchen Gewichts, iufserft flüchtigern und durchiringendem, doch rein effigtauund durchcringendem, doch rein ellia mWafer rein fiturem Gefchmack. Im höchft
Acidum benzaicrim.

Flores Benzoes.

Benzoefäure.

Benzoeblumen.

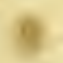

Acidum boracicum Sal fedalivum. Boraxfänre. Sedativfalz.

\section{Fehlerhafte $B e-$ Schaffenhcit, Ver- wechfelung oder Verfälfclung. \\ Deren \\ Kennzeichen und Prilfungsmittel.}

Mit rohem Effig oder Der mil rohem Weinellig bereitete hat allemit BierefJig bereitet.

Nicht gelörig gefàtmal wegen feines Gelialis an Extractivftoff eine mebr oder weniger dunkelweingelbe, und der mit Biereffig eitse braungelbe Farbe, dagegen der mit deftillirtem ganz farbenlos ift.

Rothet deu Lackmusiuszug, das damit gedurch Zuiritt der Kohls.

Luft fchon vicl Bley heramsgefallen ift.

Kupferlualtig. Wafler rein fiturem Gefchmack. Im hochl concentrirten Zuftande fcrielst lie noch vor dern Gefrierpuncte des Wallers bald in fchönen baum - oder federähnlichen, bald in derben eisartigen durchfichtigen Cryftal len, oft auch in-einer ftrahligtèu Mafle all:
Gelinde erwärmt ift fie entzündlich und verbiennt mit blauer Flamme.

Schwefelig oder brenzlichmiechend und fchmeckend.

Mit Schwefel - oder Salzfäuro verunreinigt.

it metallifchen Theilen verunreinigt.

\section{Die vach der Pr. Pharmacopoe, auf nalfem} Wege, durcl Auskochen der Benzoe mil kohlenfaurem Natrum und WalTer, nacbberiges Durchfeilıeu nal Sältigen der Fliurfgkeit mil verdünuter Scbwefelfaure erhaltene Benzoefaure, die nocb einmal in kochendcm Walfer anfgelöfet und cryltallifirt wird. Auf diefe Art bereitet, beftcht die reine Benzoefaure aus trocknen, lufibeftändigen, àulserft żarten, platten, Giberwes $s c n$, glänzeuden, nadelföruigen $\mathrm{Crjz}$ ftallen, von fchwachen benzoeartigern $\mathrm{Ge}-$ ftallen, einem mebr ficchend fisistichen, rache und eichen Gefchmaek. Verfchluckt als finerliclien Gefchmaek. Siften. Sie lïreizt die Ben zoefature zum Huften. Sie 10 fel fich in vier und 2wanzig Theilen kochendem, kaum aber bey $50^{\circ} \mathrm{Fahr}$. in vierhundert Theilen kalcem Waller auf. In Alcobol ilt fie leicht und vollkommen anflëslich. Ibre Autlörung röthet das Lakmuspapier, kaum abcr den Veilchenfaft: Die augezündete geiftige Aunlöfung derfellen-brenut mit helliother, rauchender, zuletzt finukenfpiüliender'Flamme. In einem filbernen Löfiel der Hitze ausgefetzl, läfst fie ficls mit einem, weifsẹn, Huften und Nipfen erregendeu Dampfe gänzlich vcribuclitigen, obse einen Ruckltand zu linterlaffen.

Die durch Sublimation erbaltene Benzoefinre bildet mebr leichte, fockeuartige Criftallen, und befitat den Geruch des Iarzes in einem hölern Grade.

Die eigcnthimliche Säure des Boraxes, welche aus der Auföfung deflelben vermittelfi Schwefelfiure abgefilieden worden. Sie bildet kleine, weilse, gläizende, fchupponförmige Cryftallen. line Saure äufsert fich durch den Gelchmack lalt bar niclit, allein fie neutrahtirl die Alcalien und Erden, wie je audere Sämre und rötiet die Lackmustinctur. $1 \mathrm{~m}$ Waffer if fie fchwer aufiöslich and erloudert $z$ wanlie Icliwer a kiltes, von kochendem abei zig Theile kaltes, von drittelialb Theilu. lu Weingeift if fie uur in geringr. Menge atitiöstich und dicfe Ainföfung btcunt mit einer fohönen gr นีъеn Flammu.
Af naflem Wege bereitet, enthät die Benzoefäure zuweilen etwas adhärifïure.

Hat man, wie einige es vorfchreibenzum A viskochen derBenzoe koblenftofffaures Kali angewen det, fo enthät die gewonnene Säure zuweilen fchwefel faures Kali.

Zuweilen ift fie mit Harztheilchen verunreinigt.

ie durch Sublimgtion bereitete ift nicht felten mit anhängendem brenzlichten Oele verunreinigt

Mit Jchwefelfaurem Natrum verumeinigt.

uweilen wird die Latige, aus welcher keine Säure mehr anfchiefsen will, zur Trockne abgeraucht und das $\mathrm{G}$ an ze für Eoraxfäure gebraucht. rende Schwefel-
Dies ift der Fall, weun er ans fchlechier Bleyglätte bereitet worden. Mit Ainnoniurntiiffgkeit vermifcht, entfeht alsdann eine blutue Farbe.

as ciftere von bey der Deltillation zerfetzter Schwefelfaule; das zweyte von nicht cehöriger Vorficht bcy dem Ende der Defillation. Beydes eutdeckt der Geruch una Gr.fclimack.

Wie bey Acetum conceutratum zu prüfen.

iefe rübreu vou den zme Eduction etwa angewendeten Metall - Efigfalzen nach andern Bereitungsmethoderi liex. Wäre demnach die concentritie Efigfriuse aus cryftallifirtem Grinfpan bereitel, fo wirde die au hinzngemifchte A mmoniumflüfigkeit entftehende blaue Farbe eiuen etwa verfteckten Kupfergehal t ficher entdecken, fo wie die I a linemannifche Probenlüfigkeit den Bleygebalt, in Fall fie ans Bleyzucker bereilet ware.

Man finclet dies, wenn man die Saure inic deftillirtem Walfer Ccliuttelt und diefes hernach mit einer Auilöfnug der falzfauren Schwererde vermifcht, worauf ein weifser Niederfchlag entftehen wird.

Diefes bleibı bey der Verflüchtigung der Säure zuruck.

Gebeu fich fchon durch das äufsere $\Lambda$ nfebem zu erkenuen.

Farbe und Geruch geben das leicht 24 en kenuen.

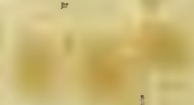

Schon einigermafsen an derm billerliclien Geclimack des Salzes zul erkcnnen, ficherer ber, wallerichte Antlüfung der Borisfiure dnrch falafure Scliwererdenauflöfung getrübit wird.

Vermuthet man eineu folcheu Fall, fu digeme man eine geringe Portion mit einer hinlinglichen Menge Alcolol und wicderhole'diefes fo oft, als der VVcongreift noch twas davon auflöf uud deshalb mit einer grïnliclien. Flamune brennt. Löfet lich

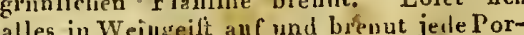
tion des alugesolencn Weiugeiftes grünlicht, fo iff die Säure rein 


\begin{tabular}{|c|c|c|c|}
\hline $\begin{array}{l}\text { Namen } \\
\text { der Arzneymittel. }\end{array}$ & $\begin{array}{c}\text { Sinnliche Eigenfchaften derfellen } \\
\text { Merkmale ilurer Aechtlueit und } \\
\text { Güte. }\end{array}$ & $\begin{array}{c}\text { Fehlerhafte Be- } \\
\text { fclıaffenlueit, Ver- } \\
\text { wechfelung oder } \\
\text { Verfälfclıung. }\end{array}$ & $\begin{array}{c}\text { Deren } \\
\text { Kennzeichen und Priifungsmittel: }\end{array}$ \\
\hline
\end{tabular}

Acidum citricum/Wird durch Sättigung des Citronenfaftes mit/Statt der Citronen-j Der $\Lambda$ ebnlichkeit inu Gefchmack wegen pllegt -cryftallifatum. Cryfiallifirte Citro- der erhaltenev citronenfauren Kalkerde mit nenlïure. vorher verdïnnter conceutrirter Schwefel-
fäure, nacbheriger Verdunftung der überltehenden Flüfigkeit und Cryftallifation derfelben erhalten. Die Cryftallen, welche die Citronenfäure bildet, lind nach $\mathrm{Diz}$ e rhomboidalifche Prismen, deren Fläcben fich unter eiuander in Winkeln von ohngefähr 60 Grad neigell, und welche an beyden Enden in vierfeitige Spitzen ausgehen, deren Seiten die körperlichen Winkel durchren Seiten die kör perlich en Winkel durchfchneiden. Sîe ifl luftbeftindig, zeigt 1,61 7
eigenthümliches Gewicht, fchmeckt fehr angenehm und noch etwas [chärfer fauer, als die Weinfteinfänre. Hundert Theile kaltes Waffer löfen 120 Theile, und fiedeudes eine nogh gröfsere Menge davon auf. Aufänglich find die. Cryftallen von den noch anhängenden Schleimtbeilen mehr odcr weniger gelb; fie werden aber durch öfteres Auflöfen, Kochung mit Kohleupulver, Filtration und Cryftallifation völlig weifs.

Acidurn muriaticurn.

Spiritus Salis acidus. Saurer Salzgeift.
Eine aus dem gemeincn Küchenfalze durch Zufatz von vier Theilen mit eben fo vielem Waffer ver diunter concentrirter Schwefelfäure durch Deftillation bis zur Trockne aus einer gläfernen Deftillirgeräth Cchaft, in deren Vorlage noch zwey Theile deftillirtes Wafler vorgcfchlagen, find, gefchiedcne, und nochmals über etwas Küchenfalz rectificirte Mineralfäure. Wird bey der Deftilficirte Mineralfáure. Wird bey der Deftil-
lation die Schwefelfäure, nür mit vier Fünftheilen ihres eigcnen Gewichis Wafer gcmifcht und kein Waffer vorgefcblagen', fo erhält man die rauchend e $S$ a l z fä ure oder den rauchenden Salzgeift (Acidum muriaticum fumans, Spiritus falis fumans) die fich von der erftern fchwächern Säure blos durch eine färkere Concentration unterfcheidet; fie befitzt alle Eigenfchaften der โchwächern Salzfäure, nur dals le far ke, graue, den

Die Salzfáure it in ihrem reinen Zuftande waffcrbell, farhenlos und vou einem kaum nerklich eigenartigen Gcruch. Der Luft ausgefetzt, zieht fie wenig oder gar keine Feuchtigkeit an fich, sondern dunftet vielmehr allmählig weg. Sie friert in der ftrengften Kälte -nicht, verwandelt weder die thierifchen noch vegetabilifchen Subftanzen in Koble, färbt fie auch nicht gelb, fondern zerbeifst und zerfrifst fie. Sie fällt aus der Auflöfung des Silber- oder Bleyfalpcters beyde Metalle in Geftalt eines käfichten Niederfchlags nnd bildet damit Hornflber- nod Hornbley. Mit Salpeterfäure vermifcht, löfet fie das Gold auf Mit den Alkalien, Erden und Metallen bildet fie ganz eigengearteté Salze, wovon die rnit den erftern, fo wie viele der mit letztern entftehenden, im Fener flüchtig find olıne zerlegt zu werden. Ibrer Stärke nach ift fie febr verfchieden; in dampfenden 'Zuftande ift ihr eigenthümliches Gewicht nach Bucholz fo befchaffen, dafs ein Glas, welches genas eine Unze deftillirtes Waller halten kamn, auderthalb Unzen von diefor Säne ka lem vermag im vor din Säre zu han ver dünten Zuftande kann ein lolches
eine Unze und zwey Drachmen faffen.

\section{fïure die Wein-}

fieinfäure. diefe wobl der Citronenfämre fubltituirt zu ler anfangs beydc Säuren nicht vcrfchiedon finden wollen. Es unterfcheidet fich aber die Citronenfänre vou der Weinsteinfäure dadurch, dals fe nicht wie diefe aus den gef'attioten Löfungeu des kohlenfauren, effigfauren ind falzigfauren Kali als wiedererzeugter Weinftein mit dem Kali niederfällt. Mit den Kalien bildet fie überdem leicht antlösliche Salze.
Mit, Eifen verunreinigt, weil das gewöhnliche Kochfal niemals rein, fondern immer eifenhaltig ift.
Mit Scluwefelläure erunreinigt.

Wird durch eine Aufiölung der falzfauren Schwererde entdeckt, die damit einen weiffen Boden fatz hervorhringt. Will man eine concentrirte Salzfiure auf Schwefelfäure prïfen, fo vergeffe man ja nicht, fie vorher gut mit destillirtcm $W_{a}$ ller zu verdünnen, denn ift die Sänre concentrirt, so entzieht fie der Schwererdenauflüfung das Walfer, und es fällt falzfaure Schwererde nieder, und es fallt falzlaure Schwererde nieder, die man leicht fur entfandene lchwefelfaure Schwererde halten könnte, obgleich diefes leicht zu entdecken ift, da fich die falzo faure Schwererde hald wieder auföfet, wen man mehr deftillirtes Wafrer hinzufetzt.

ie gelbliche Firbe, und vielleicht auch der fatiranähnliche Geruch der unreinen, beforders der verkäuflichen Säure, rühren von enthaltenen Eifentlieilcn (oder anch von einem kleinen Antheile oxydirter Salzfäure?) her. Man entdeckt das Eifen darin anz beften, wenn man die Sänre mit Ammonium neutralifirt und dann mit blaufaurem Kali oder mit Galläpfeltinctur verfetzt. Das erstere bringt darin einen blanen das Dweyte einen violetten oder schwarzen derfchlag liervor.

Die verkäufliche Säu- Die Laboranten deftilliren die Săure gewöhnre der Laboranten lich aus einer Mifchung von Kachfalz und enthält auch wohl calcinirtem Eifenvitriol, daher fie auch wohil Kupfer.

Mit Erden verunreimit Kupfer verunreinigt feyn kann. Diefes zeigt hich, wenn fie mit Ammoniumflürfigkeit verfetzt, bläulich wird.

nigt.

Acidum muriaticum. Oxygenatum $\mathrm{C}$ Oxydatum. Oxygenirte oder oxydirte Salzsänre.

Acidum nitricum. Spiritus Nitri aci-

ine durch Hülfe des fchrvarzen Braunfteinoxyds mit Sauerftoff bis zur Sättionng angefchwängerte, und dadurch vollkominen oxydirte Salzfäure, die entweder als ein hellgelber Dunft in Stöpfelğläfern anfgefangen, oder in kaltes Waffer geleitet, und fo in tropfbar flüfiger Geftalt dargeftellt wird. in Dunftgeftalt hat fie einen ganz eigenen ftechenden and erftickenden, den Lungen und Geruchsorganen äufserst gefährlichen Geruch. Sie zerftört in kurzér Zeit alle Pflanzenfarhen. Die thierifchen Theile fărbt fie gelh. Melirere Metalle, Spiefsglanzmetall, Wisınth u. . w. entzünden fich, wenn fie in diefen Dunft gebracht werden, mit fcliönem dun-

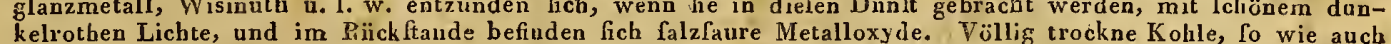

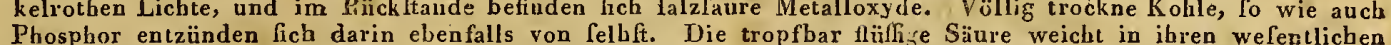
Phosphor entzünden fich darin ebenfalls von felbft. Die tropfbar flüflise Süure weicht in ibren wefentlichen
nicht von der Form ahbängigen Eigenfchaften, von der dunfïförmigen wenig ab. Sie liat einen erftickenden nicht von der Form ahbängifen Eigenfchaften, von der dunfifürmigen wenig ab. Sie liat einen erftickenden
Gernch und einen lerben, bitterlichen eigentlümlichen Gefchmack. Mit den Alkalien und Erden bildct fre eigene Nentralfalze, welche fich von denen mit gewöhnlicher Salzfäure bereitet, gar fehr nnterfcheiden.

Vach der Preufsifchen Pharfnacopoe aus acht Mit Scluwefelfäure/Wird durch eine Aufölung der falpeterfauTheilen reinem Salpeter. znit vier 'íheilen verunreinigt. $\mid$ ren Baryterde, welche einen unaudöslichen 


\begin{tabular}{|c|c|c|c|}
\hline $\begin{array}{c}\text { Namen } \\
\text { der Arzneymittel. }\end{array}$ & $\begin{array}{c}\text { Sinnliche Eigenfchaften derfelben; } \\
\text { Merkmale iłrer Aechtheit und } \\
\text { Giite. }\end{array}$ & 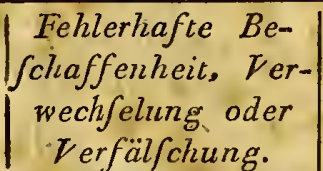 & $\begin{array}{l}\text { Deren } \\
\text { Kennzeichen und Prïfungsmittel. }\end{array}$ \\
\hline
\end{tabular}

Salpeterfiure.

Salpetergeift. geftellte Defillation bis zur Trockne aus eiver gläferuen Defillirgeräthfchaft, in deren Yorlage fich vier. Theile deftillirtes Waffer befinden, bereitet, worauf die übergegangene Säure durch salpeterfaurę Silberauflöfung gereinigt wird. Werden zwey Theile Salpeter mit einem Theil concentrirter Schwefelfäure der Deftillation unterworfen und wird kein Waffer vorgefchlagen, fo erbält man die concentrirte Salpecerfüure (Acidum Nitri concentratum, Spirilus Nitri fumans). Diefe letztere hat eine dunkelgelbrothe Farbe uud fiölst an der Luft ähnliche Dämpfe aus, ift aber in diefem Zuftande keine vollkommen mit Sauerftoff gefattigte Salpeterfäure, fonderu ein Theil derfelben, welcher ihr die rothe Farbe ertheilt, ift darin im unvollkommnen Zuftande vorhanden. Sie ift äberaus älzend und fauer, uud zeigt bey der Verdünnung mit Wafer verfchiedene Farben veränderungen, indem fich durch wenig zugefetztes Wafler die rotbe Farbe erft in blau veräıdert; diefe geht bey einer 'gröfsern Menge Wafler in grü über, und endlich verfeliwindet auch diefe und die Säure erfcheint waferhell. Durch eine fehr gelinde Deftillation wird fie von der damit verbundenen unvollkommenen Säure gereinigt und die in dcr Retorte zurückbleibende vollkommene Salpeterfäure ift nun wafferhell und ftöl'st bey der Berübrung mit de Luft weifse Dämpfe aus.

Dia verdünnte Salpeterfiare, von welcher eine noclı fchwächere Sorte unter dem Namen Scheidewaffer (Aqua fortis) bekannt ist, enthält keine unvollkommne Säure und erfcheint daher gleich bey der Bereitung

waflerbell.
Die völlig reine Salpeterfäure ift wafferDie völlig reine Salpeterfäure ift wafler-
hell und farbeulos, und von einem eigenthümlichen Geruch. Sie färbt die Haut und andere thierifche Subftanzen gelb und wirkt nach ihrer verfcliedenen Stärke mehr oder minder zerftörénd auf fie. Die Metalle löfet fie mit Entbindung von falpeterbalbfaurem Gas auf. Mit den verfchiedenen Alkalien bildet fie Salpeterarten, Ihro nen Alkatien bildet fe Salpeterarten, Thro vung mit Waffer fehr verfclieden. Nach $\mathrm{B}$ u c hol $\mathrm{z}$ fül\}en, wenn fie gehörig concentrirt ift, sechs, auch wohl fechs und eine trirt ift, fects, auch wohl lechs und eine viertel Unzc davon erft einen Raum, den
fünf Uuzen deftillirtes WaIter fchon anfüllen.

Acidum pliasphoriciim.

Acidum phosphori dilutum.

Phosphorfäure.

Verdünnte Phosohorfàure.

Prenfsifchen Pharmacopoe aús den 'Knochen vermittelft der Schwefelfäure ausgefchieden. Arn reinfien erbält man fi aber aus dem Phofphor felbft anf verfchie-
denen Wegen. Die reine Phofphorfäure ift farbenlos, ohne Geruch, von einem angenebrnen fäuerlichen, dem der verdünnten Schwefelfäure älınlichın. Gefchmack. Sie ist feuerbeftändig und nimmt, wenn fie naol dem Abdunsten $\mathrm{z}$ ur Trockne gefchmolzen wird, die Geltalt eines Glafes 'an, das aber an der Luft zerfliefst uud in Wafler gelöft, die Phofphorfaure unveröndert wieder darfiellt. Im trocknen Znftande mit Kohle deftillirt, liefert fie Phofplor. Im Kohle deftihirt, liefert he Phofploor. Im volkommen reinen $2 u f t a n d e$ darf lie mit Weiualkohol und reiucn kohlenfauren Al-
kalien vernifcht, fich nicht trüben, obgleich diefes br:y einer aus der Knochenerde gefchiedenen Sïure, wegen eines gcringen Antheils von Kicfel- und Thonerde, den fie bey der Austreibung des bey ibrer Bereituug nöthigen $\Lambda$ mnoniums durchs Schmelzen aus den Schmelzgefïfsen, in fich aufAcidum fuccinicumı. Sal Succini volatile Bernfteinfäure. Bernfteinfalz. nimrnt, wobl kaum fo gaus zu erwarten ift

Das ans dem Beruftein durch trockne Deffillation erlialtene und anf verfchiedene Weife von den aubingenden Oeltheilen gereifchiefst in kleiuen glänzeuden, nach der

Mit Salzfüure ver unreinigt.

Niederfchlag darin 'erzeugt, entdeckt.

Am fichèrfter entdeckt man diefes durch eine Anflöfung des fchwefelfauren Silbers, die einé folche Salpeterfaure mehr oder weniger trübt $Z$ war kan man fich auch biezu ger tribth $Z$ war kana man Gich auch biezu des Calpeterfauren silhers bellenen; da aber die Aunofung dellelben durcli die etwa zugleich oder allein vorhandene Schwefelfäure ebenfalls zerlegt wird, fo künnte diefes leicht zu falfchen Schliiffen verleiten, obgleich beyde Niederfchlage fich in ihrem Aeufsern fchon fehr von einander unterfcheiden.

Uebrigens ift nicht $z u$ vergeffen, dafs man die Salpeterfäure, wenn sie concentrirt ift, erft mit deftillirtem Wafler verdïnnen mür it Knochenerde, Selenit und phofphorfauren Neutralfalzen verunreinigt.

Pho Splıorichte Süure enthaltend.

icht gehörig, oder wohl gar. niclit gereinigt.

fällcht.

\section{fe, ehe man fie mit den Reagentien verfetzt.}

Wird mit deftillirtem Want verdünt durch hinzogegoflenen Weinalcobol trübe. Um zu willen, welcher von den erwäbnten Theilen fie verunreinige, verfuche man derenAuflöslichkeit in Waffer und fondere deshalb den Bodenfatz durch ein Filtum ab. Knochenerde bleibt nämlich ganz uvaufgelöft ; Selenit löfet fich fchwer, die phofpborfauren Neutralfalze aher lösen sich leicht im Wafler auf.

it Scluwefelfä̈ure Wird durcb falz faure Bary terden auflöfung entverunreinigt oder deckt, die in reiner Pbofpborfäure gar keiauch damit ver- ne Trübung hervorbringen darf.

Tröpfeli man zu einer verdünnten Phofphorfäure eine Auföfung des efligfauren Bleyes, fo entftebt ein weifser fchwerer Niedesfchlag, der fich mit zugefetzter völlig reiner Salpeterfäure wieder auflöfen mufs reichich

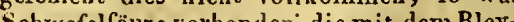
oxyd einen in Salpeterfaure nur wenig auf-

lösbaren Niederfchlag bildet.

teinen phofphorartigen Geruch und ftölst Dämpfe aus.

at eine braunere Farbe und vou dem nocb anklebenden Beínfteinöle eiuen unangenehmern und ftärkern Geruch. 


\section{Acidum fulphuricum concentratum. - Acidum fulphuricum dilutum.}

\begin{tabular}{c|c} 
Namen & $\begin{array}{c}\text { Sinnliche Eigenfchafien derfelben; } \\
\text { Merkmale ihrer Aechtheit und } \\
\text { Ger Arzneymitcel. }\end{array}$
\end{tabular}

Acidum fulphturicum concentratum Oleum Vitrioli. Concentrirte Schwefelfäure. Vitriolöl.

Eine Mineralfäure von einer flüfligen ölähnlicben Confiftenz, fehr beträchtlicher Schwere, und weun fie mit Waffer verdünnt ift, von einem fauren ftyptifchen Gefchmack. Es gieht davon zwey Sorten, nämlich: $x$ ) die aus dem Eifenvitriol durch Dcftillation gewonnene Schwefelfäure (Nor $\mathbf{r} \mathbf{h}$ ä u $\mathrm{fer}$, auch Sächfifches oder Deutfebes Vitriolïl). Sie bat gewöhnlich von zufällig hineingekommenen brennbaren Körperu eiue mebr oder weniger braune Farbe, riecht oft fehr fchweflicht, ftöfst bey Berührung dcr freyen Luft weifse Dämpfe aús und ift höchft ätzend. 2) Die aus dem Schwefel, nittelft eines Zufatzes von Salpeter, durch Verbrennen gewonnene Säure peter, durch Verbrennen gewonnene Saure (Englifches itrils waflerhell, ungefärbt, geruchlos, dampft nicht an der Luft, ift fchwächer als die erfte und faft immer von der Art ihrer Zubereitung bleyhaltig.

Bède Säuren mülfen za genauern chemifchen Arbeiten und befonders auch, wenn fie innerlich angewendet werden follen, gereinigt werden, welches durch eine vorfichlig angeftellte Deftillation gefchieht. Die auf diefe Art gereinigte Säure ift vollkommen durchfichtig und farbenlos, ohne Geruch und von einer dickflüfigen Befchaffenheit. Wird fie in Waller getröpfelt, fo erhitzt fie fich damit fehr ftark. Sie fangt mit Begierde die Feuchtigkoit aus der Luft an, und wird dadurch gefchwächt. Mit neutralifirenden Subftanzen erzeugt The die ihr zukommenden eigenthïmlicheu Neutralfalze. Mit Waffer verdünnt uud mit reinem Kali gefättigt, mufs fie nicht den mindcften Niederfchlag geben, und die nenuralifirte Tlüligkeit darf weder durch blaufaures Kali noch durch Hahnemanns Probefliffigkeit getrübt werden. Sie mufs Probeflinhgeit getrubt werden. Sie muls fo fchwer feyn, dafs ein Glas, welches eine Uazen der Säure angefüllt wird.

\section{Fehlerhafte Be- Schaffenheit, Ver- wechfelung ocier Verfälfchung. \\ Kennzeichen und Prüfungsmittel.} dener Schwofel- pulver kocht, und klar gefeihet zurn Anfäure, Scluwefelfaut rer Talkerde u.dgl. mit einem färbenden Stoffe und Bernfteinöl angemacht.

Mit Salpeterfäur
verunreinigt.
follen on feu $\mathrm{V}$ un verfallchten Sẳu oben vorgefchlagenen Prüfungsmittel, entdecken.

Kann bey der englifchen Schwefelfänre von ibrer Bereitung, bey der gereinigten aber davon herrübren, wenn fie vielleicht mit
Mit Salzfäure verunreinigt. Mit $T / L$
erde.

Mit Bley verunreinigt ; /gemeiniglich die englifche Sấure.

it Eifen und Kupfer verunreinigt, befonders dieNordhäufer Säure.
Acidiim fulphturi cum dilutum. Spiritus Vitrioli.

Verdünnte Schwefelläure. Vitriolgeifi.
Nach der Preufsifchen Pharmacopoe aus fünf Theilen deftillirtem $W$ affer und einem Thei concentrirter gereinigter Scbwefelfäure durch blofse Mifchung bereitet. Sie mufs ungefärbt, helle, geruchlos und von einen fcharf fauren Gefchmack feyn. Auch mux fie in glïfernen Gefäfsen aufbewahrt werden, weil fie aus den irdenen leicht Thonerde in fich anfuimmint. Das VerLältuifs de Säme zum Wafter ilt nicht in allen DifpenSame zum Walfer if nicht in allen Jipen-

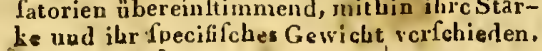

Statt der gereinigten concentrirten Säure wird zu ihrer Bereitung häufig eine ungereinigte angewendet. Salpeterfaure entfärbt und von diefer im Ueberflufs zugefetzt worden. Die nit Kali gefättigte und zur Trockne abgerauchte Schwefelfäure verpufft alsdann auf glühenden Kohlen.

If hauptfächlich bey der Englifchen der Fall, wegen unreiner Befchaffenheit des dazu gebrauchten Salpeters. Hält man einen mit Ammoniumfriinigkeit befeuchteten Papierfreifen über eine folche mit Waffer verdünnte Schwefelfäure, fo entftehen grauweifse Dämpfe. Die Auflölung von fchwefelfaurem Silber bewirkt darin einen weiffen Niederfcblag.

Findet fich gemeiniglich bey der Nordhäufer Säure, und rïhrt von dea Flafchen her, worin fe verfendet wird. Mit Waffer verdünnt, und init Fiali gefättigt fcheiden fich diefe erdigen. Theile ab. Doch foleiden fich dabey anch die etwa in der Säure enthaltenen Metalloxyde ab, weshalb die Unterfucbung weiter $\mathrm{zu}$ verfolgen.

Der in einer mit reinem Kali gefättigten verdünnten Schwefelfäure ietwa entftanden Bodenfatz ift alsdann in zugetröpfelter Salpeterfaure nicht gänzlich wieder auflöslich, weil das fchwefelfaure Bley unaufgelöft bleiben wird; ver fchwindet er dagegen, wenn die Salpeterfäure zugefetzt worden, fo kann das Bley nur' in äufserft geringer Menge vorhanden feyn, und verräth fich alsdann mit Hahneman ns Probefïligkeit durch einen fchwarzen, mit der Löfung des durch einen fchwarzen, mit der Lofung des weifsen Niederfchlag - Gemeiniylich fállt das Bley auch fchon zum Theil bey Verdas Bley, auch fchon zum Theil bey Verdünnung der concentrirten Säure mit. Waf-
fer zu Boder und macht einen mebr oder fer zu Boden und macht einen mebr ode z.u prüfen ift.

Zeigt fich in der mit Kali neutralifirten Schwefelfäure, mittelft Salpeterfäure bewirkten Wiederlöfung des erfolgten Bodenfatzes mit Hahneman $\mathrm{n}$ s Probefliif figkeit und-der Löfong des blaufauren Kali eine braune Trübung, fo war $\mathrm{K}$ upfer zugegen; bleibt lie aber mit der erftern ungeändert und giebt mit letzterer einen blauen Niederfchlag, fo enthielt die Säure Eifen ; bewirken beyde zugefetzte Reagentien dariu car keine Veränderung fo war blofs eine gas keine Verandure lirde zane Gegenwart des Kupfers in der' Schwefelfiture fchon, wenn man fienonium überfattigt und nocb deutlicher, wenn man den bey der Sättignng mit einem fixen Alcali entftandenen Prácipitat mit Ammoniumflüffrgkeit digerirt, durch die fapphyrblaue Farbe, welche die Flüffigkeit annimmt. Das Dafeyn des Eifens zeigt auch der Galläpfelauszug durch die fchwarze dintenfarbige Trübung in der mit Kali nentralifírıen Säure.

ie verdünnle Schwefelfüre ift dann natürlich auch nicht rein, welches um fo nöthiger ift, da fie zum innerlicheu Gebrauch angewendet wird, Man prüft fie auf die im roxigeu Titol angegebene Weife. 


\section{Acidum tartaricum. - Aerugo.}

\begin{tabular}{c|c|} 
Namen & $\begin{array}{c}\text { Sinnliche Eigenfchaften derfelben; } \\
\text { Merkmale ihrer Ächtheit und } \\
\text { Giite. }\end{array}$
\end{tabular} \mid

Acidum tartari-|Eine eigenthümliche Pulanzenfäure, die aus|M cumm.

Acidum tartari ef-

rentiale.

Weinfteinfäure.

Weinfalzfäure. dem gereinigten Weinftein durch Ueberdefsen mit Waler, Sattigung der zum Siefonderung des erlaltenen weinfteinfauren Adeps fuilla. Schweinefett.

Aerigo. Viride aeris. Grünfpan.

\section{Deren}

Kennzeichen und Priifungsmittel.

Verfälschung. denfelben durch verdiinnte Schwetelfäure weinfeiufauren Fiulfigkeit erhalten wird Oie reiue Weinfteinfäure fchiefst in blätterigen und rhomboidalifch $n$ Cryftallen mi es vier - oder fechsfeitige Tafelı, deren zwey gegenüber ftehende Seitenflächen verlängert lind.

Die Cryflallén müfen völlig ungefürbt weifs, oinigermafseu durch ficlstig und gläızend und klingend trocken fey॥. Sie müffen einen flarken uud ausenebm fauren, aber nicht ätzenden, Gefchmack und keinen Geruch befitzen. An der Luft dirfen fie fich uicht verindern, nicht verwittern oder fencht werden. Im Feuer müffen fie mit dem Geruch von verbrannten Zucker und Zurücklaflung höchftweniger, in Wafnen. $1 \mathrm{~m}$ Waffer ift die Weinfteinfäure leicht auflöslich; $z$ wey Theile deftillirtes Wafler mülfen davon einen Theil auföfen. Kochendes Waffer löfet ein gleiches Gewicht davon auf. Etwas fchwerer ift di Weinfteiufäure im Weingeift auföslich In deftillirtem Waller aufgelöfet, darf fie durch falz - oder falpeterfaure Baryterdenauflöfung nicht im misdeften verändert fonderung des erhaltenen weinfteinfauren Kalks, Scheiduug der. Weiufteinfanre aus und Verdnuftuog und Cryfrallifirung der fcharfeu Endfpitzen un; mehrentheils find fer durchaus unanflöslicher Kohle verbrenoder getrübt werden.
Mit fcliwefelfaurem und weinfteinfaurem Kalke verunreinigt. verunreinigt

Mit adhärirender $\mathcal{S a l}$ -
peterfüure verun-
reinigt.

Mit Apfelfäüre verunreinigt.

Mit Kupfer verunreinigt.

Mit Bley verunreinigt.

Mit Zinn verunreinigt.

Statt der Weinfteinfäure ein Gemifch aus gereinigtem W einftein und Scluwe felfäure, oder Sauerkleefalz ftatt derfelben.

Das aus den frifchen völlig geruchfreyen Fettwammen des $S$ chweins (Sus f crofa) durch Ansfchmelzung gewonnene Fett. Gntes Schweinefchmalz mufs frifch ausgefclimolzen, weifs, feft und von angenehmen, keinesweges bitterlichfeharfem Gefchmack feyn, auch weder ranzicht noch brenzlicht riechen.

Ein effigfaures, mit kolılenfaurem Kupfer vermifchtes Kupferoxyd, welches an verfchiedenen Orten in Deutfchland, in Holher ranziclut.
Zu alt oder fchlecht Eigenthümlich fcharf und unangenehm rie aufbewahrt und da-

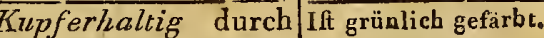

unreinliche Aufbewahrung in meffin genen oder kupfernen Gefäfsen.

Häufig unrein, mit Durchs Anfeben zu erkennen. Erfordert eine Weintreftern, Stük- gehörige Reinigung dùch Pülvels und Abken Reifern und fchlagen. hen Grade gelblich ofirbt.
Vermatien, wenn die Weinfteinfaure bey $m$ Koften derfelbeu die Zäbne merklich wölınlich etwas cryftállen, welche gefeusht werden. Sicher find an der Luet fleye Schwefelfäure durch die Auföfun des falpeterfauren oder falzfauren Baryts die, wenn nan fich vorher von der Abwefenhcit des Gypfes oder der fchwefelfauren Kalkerde ïherzengt hat, auch die geriugfte Spur vou Scluwefelfarue bey der WeiufteinCaure, durcb den Niederfchlag, welchen fle forsann in einer Anílöfung derfelben hervorbringt, entdecken laifst. - Giefst man fel'ner zu eincr Aulöfung der mit Cäure etwas aufgelöftes eflix faures $B$ ley eifolot ein weifser Niederfchlag der von linzugefelzter Salpeterfaure nicht ganz wieder aufyelöfet wircl.

Euchält die Weiufteinfäure ïberfaures fchwefelfames Kali, fo verräth fich diefes, weun unan eine kleine Portion verbreunt und givhet, fogleich durch den fchwefelleberal tigen Gefchmack des R̈̈̈ckftandes.

mit Gyps verunreinigte 'Weinfteinfiure

löfet fich uicht völlig in eiuer glercheu Menge kocheuden Waffer's aut" und Zuckerfãure oder Sauerkleefiure zu der verdinnten Auflifurg omifcht, bewirkt einen. Niedorfchlag. Um eiuen geringern Autheil Gyps oder weinfteinfaure Kalkerde zil entdecken, Weiufteinfaure verchnute $\Lambda$ ufónang de gen, und daun Sauerkleefaure hiuzutröpfelu, da dann auch ein Niederfchlag erfolgt. Löfet man die trockne Weinfteınfaure in höchft waller freyen Weingeifte auf, fo bleiben der Gyps und die weiufteinfanre Kalkcrde unaufgelöfet zurück.

ans davon herruhren, wenu etwa zurEntfarbung der eingekochten fauren Flüfligkeit Salpeterfaure angewendet worden if Verräth fich fchon durch den dicfer Säure eigeuthïmlichen Geruch.

ird an der Luft feucbt und fchmierig und ift überdem heftändig zum Fellchtwerden geneigt, auch wenn fie vou Schwefelraure völlig rein ift.

techon ans der alsdann gewöhnlich aus dem weilsen lchwach ins hlaulichtgrüne fallenden Farbe der Cryftallen zu erkennea; gewilfir aber, wenn man fie mit Amınoniurn überfättigt, oder eine Portion derfelben in einem porcellainenen $\mathrm{Ge}$ fchirr verbrennt, etwas glïhet und nun mit Ammonimnfülfigkeit digerirt, durch die eut ftehende blaue Farbe.

De Auföfung wird alsdann दurch augetröpfelte, mit Konigswalfer bereitete Goldauflöfung purpurroth niedergefchlagen.

fer Gefchmack und die to fehr verfchiedene und beym Weinfteine fo fchwere Anfioslichkeit im Waller. Beym Verhrenuen bleibt eine kalibaltige Koble zurück, wodurch iiherhaupt all durch fofte fautiolige Salze leichte 


\section{Aerugo. - Aether fulphuricus.}

\begin{tabular}{|c|c|c|c|}
\hline $\begin{array}{c}\text { Namen } \\
\text { der Arzneymitcel. }\end{array}$ & $\begin{array}{c}\text { Sinnliche Eigenfchaften derfelben; } \\
\text { Merkmale illrer Ächtheit und } \\
\text { Güte. }\end{array}$ & $\left|\begin{array}{cc}\text { Fehlerhafte } & \text { Be- } \\
\text { fchaffenheit, } & \text { Ver- } \\
\text { wechfelung oder } \\
\text { Verfölch ono }\end{array}\right|$ & $\begin{array}{c}\text { Deren } \\
\text { Kennzeichen und Prïfungsmittel. }\end{array}$ \\
\hline
\end{tabular}

Aether aceticus. Naphtha aceti. Elligäther.
Aether nitricus. Naphtha nitri. Salpeteräther。

Aether fulpluti$N$ a ' tha Vilrioli. Schwefeläther.

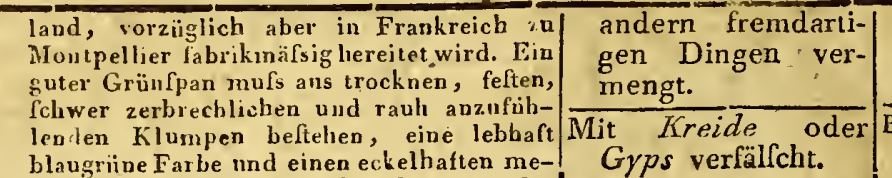
tallifch-fauren GeIchmack befitzen, an der Luft nicht feucht werden, keine fchwarze joder weifse Flecken entbalten, mit Waffer zu einem Brey quellen, fich nur in geringer MIenge im Waller auflöfen lafen, in Efig aber faft obne Rückftand gänzlich auf löslich feyn. Wirc die, mit deftillirtem Effig bereitete Anfl̈flung des Grünfpans zur Cryftallifation befürdert, fo esbalt man ein grünes metallifches Mittelfalz (A e rugo cryftallifata, Flores viride a eris).

Wird aus dem effic faurea Natuo vermittelfit der mit Alcohol gemifchten concentrirten Schwefelfumre durch Deftillation und $\mathrm{Ab}$ fchicidung des Aethers atus dent erbaltanen Deftillate durch hinzugenifolte Aetekalilange oder Kalk wallcr erbalten: Der reine Eelle, auf dem Wafer foliwimmende, nitherifche Fliulfigkeit dar. Er mufs einen

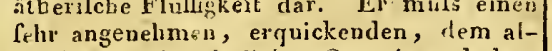
ten Rheiuwein alunlichen Geruch und dergleichen kühlenden, gewür' hiften, entfernt bitterlichen Gefchmack beititzen. Seiu fpeciffiches Gewicht, gesen deftillirtes
Waffer mufs $0,8+8$ feyn. In fieben Theilen deftillirtem Waffer mufs er fich vollkommen auföfen nnd init dem Alcohol in allen Verbältnifrea mifclèn laffen. Gegen den Scluwefel - und Salpeteräther zeigt er eisen geringern Grad ron Flüchtigktit und Verdunftbarkeit, kommt bey einem geringern Grade der Wärme zum Sieden und entweicht in Gasgeftalt. Beym Verdamplen
erregt er eive beträchtlichc Kälte und erregt er eine beträchtlichc Kälte und
brennt mit einer blaugelben ftark rufsenden Flamme, die wenn man fie kurz vorher ebe alles verbraunt ift, auslöfcht, Effig fiure, fonft aber beym völligen Trockenbrennen, eine Spur von Kohle zurïicklififst. Die Lackmustinctur darf der E/fisther nicht röthen.

Wird nach Hermb ft a dt ans' vier Theilen Alcohol und einem Theil rauchender $S_{a} I_{1}$ peterfaure durch fehr allmäblige Vermifchung, böchift vorfichtig angeftcllter DeNillation und Ausfcheidung des Aethers durch Vermifchung des Deftillats mit gleich vielem Kalkwafler erbalten. Eine ftrohgelbe, fehr leichte, ïberaus fliichtige, ätherifche Flifigkeit, von o,760 fpecififchem
Gewichte, einem fehr angenelmen, BorsGewichte, einem fehr angenelumen, Bors-
dorfer. Aepfeln ábnlichen, Geruch und eidorfer Aepfeln ábnlichen, Geruch und ei-
nem feurigen bitterlichen Gefchmack. In nem feurigen bitterlichen Gelchmack. In der Salpeteräther anf. Mit Alcohol verbindet er fich in allen Verbältuiffeu. $\mathrm{Er}_{\mathrm{r}}$ entzändet fich fehr leiclit und verbrennt mit gelber helllenchtender, aber vielen Rufs abfetzender Flamme. Beym Schüttela oder beym Oeffnen des ilin enthaltenden Glafes fíöfst er hänfige Inıftblafen aus und geräth in eine. Art vou Aufwallen.

Durch vorfichtige Vermifchung der coucentrirtell Schtwcfelfäure mit Alcohol, angeftrllte Deftillation der Mifehung und $A$ usfchiridung des $\Lambda$ ethers aus dem erbaltenen Defitillate mil eiuem Aetzkalihaltigen 'Waller

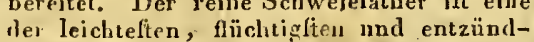
lier leichteften, linchtitiftean nnd entzündlichlen der trop baren flufigkeiten, völlig Walterhell und firbetllos, von eigenartis ltarken erquickendr.m angenehmen Geruch,
und einem erft kuihlenden, dauu durchdrinnud einem erft kühlenden, daum durchdringend feurigen, zolenzt trocknendem Ge-
fchmork. Er hit 0,752 fpecififches Gewicht, fchmirk. Er hit 0,752 fpecififches cewicht,
cerdumfpt folon in iler gewöhnlichen Temperatim iibrens fichneli nnd erregt beyn Verdunften eiue boträchtlicbe Kälte, indem
Freye Sänre eńthaltend. Wafjerhaltig. Mit Weingeift verdünnt.

chefiction rie-

Dleylhaltig, wenn der Fffigäther aus Bleyzucker nach andern Methoden bereitet worden ift.

Freye Süure enthaltend.

in merk. Anch der befte Salpeterather bekommt, bald wieder Treye Siure, wern bey cuthaltenden Giefifses die Luft Zutritt dazu erhält.

Mit Alcohol oder Wird anf ähnliche Weife, wie beym EffigSalpeterïthergeift äther ancegebeu worden, gepriilt. Aur entweder oder abfichtlichl| fchaffesheit des Salpaterätser's in Botraebt vermifcht zichen.

\begin{tabular}{|c|}
\hline \multirow[t]{2}{*}{ WVafferhaltig. } \\
\hline \\
\hline $\begin{array}{l}\text { Freye Süure enthal- } \\
\text { tend. }\end{array}$ \\
\hline $\begin{array}{l}\text { Mit fohweflichter } \\
\text { Süure vęunreinigt. }\end{array}$ \\
\hline $\begin{array}{l}\text { Mit iV eingeift ver- } \\
\text { dünnt. }\end{array}$ \\
\hline
\end{tabular}
ruhig hin, damit fich der Aether wieder

Gibt fich dureh Feuchuverdung des damis unter eiuander gefchittelten trocknen Kali zu erkenuen, aufsertem auch durch die zuriickbleikendc wäfyriahte Fenchtigkeit beym Verdunften eirns kleinen Quantität des Aethers in moltclever Termperatur.

Rüthet die Lackmustinctur's brauffet mit Kali'aunöfung und trübt dic darmit gefchuttelte Barytlöfung.

Hat einen unangenehmen fchweflichten Gcruch.

Die oben besm Elfiü̈ther aedachte P'rüfung zeigt diefes, wemu fich der auf äbulichc Art behindelie Scliwefclither dabey um mebr als dca zchuten Theil vermindert." ey der Aunöfung in verdünnter Scbwefelund die Kreide bildet mit diefem Aufö--
und fungsmittel Gyps, der za Boden fältt.

Dies zeigl fich, wenn etwas gereinigtes trocknes Kalf mit einer Portion dellielben gefeucht wird, welcies nicht leyn derf.

Gleiche Theile Aether mnd deftillirtes Wafler fchüttelt man zufammen in einem cylindrifchen wohl verftopften Glafe unter cinander. Das Gles mit dem dadurch entfandunen milchichten Gemengé ftellt mau dann vom Waffer abfciseile. Bemerkt mau nun eineú gröfsern Verluft, als' urn den fiebenten oder achten Theil feiner Malle, fo war er mit Weingeift verdüunt.

Iat der $\mathbf{E}$ ligitither ennen fchiwellichten Nebengevuch, fo ift er wahrfebentich in eivem falfchen Verlhältuiffe mit Hiilfe der Schwe-
felfiure durch Taufch verbindung bereitet felfiure durch Taufch verbind
und nicht gehörig rectificirt.

umifchng rou Il abinemann srohefiefigkeit bewirkt eineu fchwarzbraunen Niederfchlag; Schwefelfáure einen weifsen.

Grintich von Farbe; rethe die Lackmustinctur und färbt die Guajaktinctur mod das Grajakharz blan; braudet mat kohlenfáurem Kali auf. 
Aether fulphuricus. - Alumen ustum.

\begin{tabular}{c|c} 
Namen & $\begin{array}{c}\text { Sinnliche Eigenfchaften derfelben; } \\
\text { Merkmale ihrer Achtheit und } \\
\text { Giite. }\end{array}$
\end{tabular}

er, $n m$ dunftörmig zil erfoheiuen, dcn benachbarten Körpern ibren Wärneftoff entzieht, ift durch feinen weit umher fic vcrbreitenden Dunft fchon in der Entfernung bey Annäheruug eines brenneuden Lichts entzündlich und verbrenut dariu nit weifser lodernder, etwas Rufs abfetzenden Flanme. Vermöge feiner Leichtigkeit fohwinme er nicht. nur auf Waller, fonderu auch anf Alcohol und Schwefeläthergeift; es lä fst fich jedoch mit zebn Theile - Waller nur eiu Theil deflelben verm da er hingegen init den beyden. letztern in da er hingegen mit den bejden
jedem Verhal tnife mifchbar ift.

\section{Aloe.}

Aloe.

Alumen crudum

Poher Alaun.

Alaua.

Alumen ustum. Gebrannter Alaun

Ein ans den dicken tleifchichteu Blättern der Aloeplauzen (Aloe roicata and perfolia ta) theils durch freywillices Aus fliefsen, theils aber durch Auspreflen und Auskocben derfelhen erhaltener, eingedicktcr, harzicht-summichier Saft. Es lommen davoll in Handel verfchiedeue Sorten vor, deren Verfchiedenheit wohl hauptfächlich von der Art, wie der Saf aus deu Pllanzen erbalteu und verdick wird, abhängt.

1) Die S ocotrinaloe (Aloe fucco$t x$ in a). Sie körmmt in Kürbisfchalen von der Infel Sokotorah an der Küfte des glücklichen Arabiekss. Sie hat einc röthlichgelbbraune Farbe, auf den Bructs einen beiräcbtlichen Glanz und ift an den Kanten durchfcbeinend; 'sepülvert fieht fie golddurchlcbeinesd; gelb oder wird fe biegrim, in der Kalte ift fie har und zerbrechlich. Ihe Gefebmack ifi fehr bitter, etwas gewïrzhaft; der Gertuch fpeciffch, etwas balfarnifch und einigermal'sen dem der Myrrhe gleichkominend. In Alcobol ift fie vollkommen auflöslich; auch in kocbendem Waffer löfet fie fich völlig auf, aber uach dem Erkalten fcheidct fich das Harz wieder ab. Die befte Sorte diefer Aloe ift die helle Aloe (Aloe lum cida), welche durchfichtig und gelb, von allen die reinfte und befte Sorte, aber febr lèlten ift.

2) Die Leberaloe (Aloe hepatica). Man erbält fie gewöhulich aus Babbados, auch vou dem Vorgebürce der guten Holfnung ebenfalls in Kürbisfcbalen. Sie hat eine braune leberartige Farbe, die gegen die Mitte zu fchwärzlich wird, ift dunkler als die Socotriuifche Aloe, nicht fo glänzend, weniger durchifchennend, von einer feltern Subltanz, einen eckelhaft bitterem Gefchnack und ftarkern widerlichern Gerucb. Sie löfet fich nicht vellftändig in Alcohol auf, und auch nicht vollfiändi in Wafer. is Wonter Eing vos komme in Fenter gemeiniglich weich and kebrig und hat

Ein erdiges, aus Schwefelfäure, Thonerd und einem kleinen Theile Kali beftebendes, alus velwitterten oder gerölteten Alaunchiefern durch Kunft bereitetes erdiges Mittelfalz. Wir erbalten denfelben gemeiniglicb in grofsen, aus octaedrifchen Cryniglicb in grofsen, aus octaedrifchen ftallen befteheuden Malfen. Er muls weifs, beyuabe durchfichtig und nicht mit metallifchen Theilen verumreinigt feyn, einen füfslichherben, febr zufammenziebenden Der Alann entbält beynahe die Hälfte WaIfer; die Thonerde ift darin mit der Schwefelfure überfattiot, daher feine Auflöfung die blauen $P$ (an die.bla freyen Luft wird er mit einer weilsen mehligten Haut uberzogen, In Waller
auflïslich, nicht aber in Weiogeift. fillitionswa
Felulerhafie. Beccluafferiheic, Verweclifelung oder Verfälfchung.

Deren

Kennzeichen und Prïfungsmittel.

A n merkung. Herr Affeflor M ichael is in Magrieburg (Journal d. Pharm. B. X1.) gieht als ein Zeicben eincs wohlrectificirten, von Alcohol und Walfer fieyen Aethers an, dafs er fich mit oleich vel Terpentinöhl mifcben lafe, ohne fich wieder zu fcheiden, und Waffer odex: Weingeift abzufetzeu.

Statt guter Aloe zu- Dicfe ift die allerfchlechtefte Sorte; fie if weilen die Ro/s- beynahe ganz fchwarz, hat eiuen febr wialoe (Aloe cabal- drigeo, ungleich ltärkern Geruch und Gelina). fchmack, ift mit allerhand erdigen und fremdartigen Theilen verun reinigt und ift durchaus yum Arzneyrebrauch, fo wie die durchaus aum Arzneygebrauch, fo wie die weiche klebrige Unterforte der Leberaloe,
nntauglich.

Verfälscht

ack Ferber follen die Holländer die Aloe zuweilen mit Siifsholzfaft verfälchen; feit einiger Zeit fcheint dies aber nach Herrn Dör ffu r t bäufiger mit arabifchem Gummi zu gefchehen, wie der Gefchmack, die aulfallende Durchfichtigkeî́, Zähigkeit und dic belle Auflöslichkeit im Waller eine jet‘t öfter's im Handel vorkommenden AloeTorte zu erkennen gehen. Durch Vergleiclung mit ächter Aloe und durch die nich erfolgende gänzliche Auföslichkcit in Alcotiol, wie bey der Sncotrinifchen, wäre eine folche Verfälfchung übrigens leicht zu entdecken.

Aufserdem foll die. Aloe nach einigen Schriftetellern auch mit Geigeoharz oder Pech verfälcht werden. Doch ift eine folPech verilcht werden. Doch ift eine lolche Ver fallchung wohl an bezweifeln, da der Unterfchied bey eiuer blolsen Vermengung zu autralleod ware und ein Zulammenfchmelzen diefer Suhtanzen mit Alo nichi fatt finden kann.

Eifenhaltig.

Muibmafslicb fchon durch die gelbliche Farbe, ficherer aber zu erkennen, Wen mau dis Auföfung defelben mit Kali fät

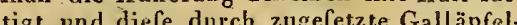
tige und Alefe durch zugefezte Gall ap ol aber blâulich getrübt wird.

Kupferhaltig. Die mut Ammoniumflüfrgkcit überf̈̈tigte Auflöfnng nimmt dann eine bläuliche Farbe an.

Anmerk. Der $x$ ömifche oder rothe $A \mathrm{I}$ a un, welcher nahe bey Rom aus einem harten Steine gewopnen wird, und welcher einige für deo reiuften halten, kommt gewöbnlich ia kleinern und unrevelmäfsigern Stïcken vor, und fchimmert einer beygemifehten, noch nicht hinlänglich unterfuchten Erdart wcgen, röthlich durcb. Der G avenhorft $f$ che rothe Alaun foll mit Kobalt gefärbt feyn nind ift deswegen zum Arzneygebraucb untaugliç.

Durch Se Cryftallifationswafler fondern aucb feine Schwefelfaure gäuzlich Salliationswafer neblein eite weifse, leichte fchwammichte, fehr
zerreibliche Mafle dar, die einen fcharfen zerreibliche Mafle dar, die einen fcharfen
ftyptifchen Gefchmack hat. verloren nnd befieht in 


\section{Ambra grifea - Ammoniacum depuratum.}

\begin{tabular}{|c|c|c|c|}
\hline $\begin{array}{c}\text { Namen } \\
\text { der Arzneymittel. }\end{array}$ & $\begin{array}{c}\text { Sinnliche Eigenfchaften derfelben; } \\
\text { Merkmale ihrer Ächtheit und, } \\
\text { Giite. }\end{array}$ & $\begin{array}{l}\text { Felulerhafte Be- } \\
\text { frhaffeñueit, Ver- } \\
\text { wechselung oder } \\
\text { Verfälfchung. }\end{array}$ & $\begin{array}{c}\text { Deren } \\
\text { Kennzeichen und Prïfungsmittel. }\end{array}$ \\
\hline
\end{tabular}

Grauer Ainber.

Verfälschung.

er glatte, ebeue, einlärbige; ganz weifse brechliches, doch einigernafsen zähes,
lockeres Concrement, das anf dem Meere, $\quad \begin{array}{r}\text { ganz weifser oder } \\ \text { oder fchwarze Amber von ungewöbulichem } \\ \text { Geruchc taugt nicht viel nnd ift auch wobl }\end{array}$ welches Africa und das mittägige Afien umfpült, theils fchwimmend, theils am Ufer oder an Felfen hängend, angetroffen wird, $\overline{\text { Nacligemacht aus al- }}$ über deffen eigentlichen Ur. Pruns man aber lerley wohlriechenGeruchc taugt nicht v

noch nicht recht einig ift. Wir erhalten den Anber in mebr octer weniger kleinen, leicbtell, unebuen Klürnpcben oder Stükken vorzuglich durch die Holländer. Der äclite Amber befict eine grane Farbe; if weifslich, gelblich oder fchwärzlich gefleckı, ftreifig und blättrig, und von aufsen mit emer fobwarzen Rinde umgeben. Er muls eiven folchen Grad von Zi:higkeit befitzeu, dafs er fich 2 war brechen, aber nicht zerreiben lifst. Bey der Siedhitze des Waflers mufs ex wie Oel fliefsen und dabey einen eigenthümlichen, angenehmen, durchriringenden Geruch verbreiten. Auch durch die Warme der Hand mufs er weich und biegfam iverden. Ër brennt mit heller Flamme und angenehmen Geruch und verfliclitigt fich auf einem olihenden Bleche mit weifsen Dämpfen beynahe oänzlich fo difs er blos piuire Spur lich, fo dafs, en zurbeklaft. len ift er faft ganz autoslich, weniger aber in Alcobol. Mit einer gluhenden Nadel durchifochen, mufs nicbts daran kleben bleiben und ans der Oeffnung ein woblriecbenties Oel fclivitzen.

Aumoniacrim.

Gummi ammoniacum.

Aminoniakgummi.

Gummiharz, welches wir ans Lybien, Abyfliuien, dem mittägigen Aegypten uud der Wüfte Barka erhalten, defien Mutterpflan e wahrfcheinlich (nach Willdenow vielleicht Heracleum gum $\mathrm{m}$ (feru $\mathrm{m}$ ) eine Doldenpflanze ift. Es Lat einen ziemlich ftarkeu, unangenebmen, balfamifiches einigermalsen dem Knoblatuch und Biebergeil ähnlichen Geruch, und einen anfangs füflicben, nacbher eckelhaft bitterliches, etwas fcharfen und barzichten Gcfchmack. Zwifchen den Fingern geknetet wird es weich, fchmilzt bey gelinder Wärme und brennt auf glubende Kohlen geftreut; in dér Kälte lälst es fich leicht pnlvern. Weder im Waffer noch im Weingeift ift es völlisg auflöslich; mit erfterm bildet es durch Reibcn eine milchichte Flüfrgkeit. Im Hanclel kommen davon folgende $z$ wey Sorten vor:

1) Die befte Sorte in Körnern (Ammoniacum in granis f. in lacrymis). Mallen, die ans einer Menge zufimmenueklebter, äufserlich röthlicher oder weifsgelblicher, inweudig milcbweifser, veilsgelblicher, inwendig milcbweilser, derber rundlicher Korncr oder logenanntex

Mandelu beft

2) In Kuchen odcr Broden (A mmoniacum in panibus). Grofse Stücke, die auswendig fchmutzig rothbraun ausfehell, inwendig aber ans weifs, röthlich und dunkelgelb geinifcht find, aucb mehr oder weuiger von deu befchriebenen Mandelin enthalten, zugleich aber mit Sand, Holaftücken, Sägefpänen ưd einem dem Jill ähulicheu Samen vermifcht find. Zum innerlichen Gébrauch follte nur die erfter innerlichen Gebrauch follte nur die erftere
Sorte in Kiirnern, oder die aus dcr zweyten abgefonderten reinen mantelförnigen Stücke (Ammoniacum electum) allgewendet werden.

Anmonincum de puratum. Gereinigtes Ainmo
niakgumıi.
Das iur IVinerszeit bey freuger Käle durch Pulvern und Abfieben von den dabcy be fintlichen fremarlargon Theilen gereivigte Ammoniahgummi. Es ftellt alsolann ein weifsliches Pulver dar, welches aber bald nach dem Jurchfieben wieder in cine felt Mintfo zufanmenback t.
Es foll ein verfälfchtes Ammoniakgummi geben, das aus einer Mifchung von ächtem Gummi mit weifsem Harz, Sägefpänen, Sand u. dgl. durch Anfeuchtung mit Branntwein in leinenen Beuteln mittelft einer warmen Prefle zufarmmen geprefst, beftehet.

Mit Mandeln beym Stolsen vermilcht.

eloforta wie der ächte Amber; hiliterlälst beym Verdampfen und Verbrennen mehr Afche uud Kohle, nnd hat dabey nicht den feinen augenebmen Geruch des ächten Ambers.

Gewöhnlich wurmftichig; 'beym Zerfliefsen auf kochendern Waller fondert lich diefes Mehl davon ab. Man erkennt dies falfche Ammoniakgummi
an der glättern Aufsenfeite, der braunen
Farbe, und vorzüglich daran, dafs die
weifsen Stücke den Gefchmack des ächten Ammoniaks nucht kaben. 
Ammonium carbonicum. - Ammonium muriaticum.

\begin{tabular}{c|c} 
Namen & $\begin{array}{c}\text { Sinnliche Eigenfchaften derfellen; } \\
\text { Merkmale ihrer Aechtheit und } \\
\text { Güte. }\end{array}$
\end{tabular} \mid

$\left|\begin{array}{c}\text { Fehlerluafte Be- } \\ \text { rchaffenheit, Ver- } \\ \text { wech,elung orler } \\ \text { Verfälfchung. }\end{array}\right|$

Kennzeichen und Prïfungsmittel.
- Ammonitum car-|Eiu tlüchtiges Laugenlalz, welches man verbonicum. mittelf eincs Zufatzes ron 2 wey Theilen $\begin{array}{cl}\text { Alcali volatile fic- } & \begin{array}{l}\text { Kreide aus dem Salmial durch Sublimation } \\ \text { erbält. Das reiue kohlenfaure Ammonium } \\ \text { cum. }\end{array}\end{array}$ monium. Laugenfalz.

legt fich bey feiner Gewinunng anfiuglich
bald in fchneeartigen weilsen Hlocken, bald in fechsfeitigcm Platten, bald in zufammeneben an, welche Auljige fich aber bey fortKohlenfaures Am-

Trockiles tlüchtiges gelıäuften glinzendell, rauten förmigen Blättgefetzter Sublimatiou allmalig $2 u$ einer immer dicker werdenden Rinde, öfters bi zu zolldicken, einiger:mafsen durch fcheinonden Brodev vereinigen, die zerbrochen ein firahliges, gleichfam aus zufamunengehäu her fen. Es muss lchneeweifs leyn, einen leh nen ftecheudeu, brcnnenden, harnartigen Gefolimack 'befitzen, an der Luft nicb feucht werden und in eiuem erbitztem Schmelztiegel fich vollkommen verflüchtigen, obne einen Rüelstand zu hinterlaffen. In deftillintem Walfer mufs es fich leicht und völlig auföfen, in böchftrectificirtem Weingeift aber unauföslich bleibeu. Mit Säureu muls es ftark und unter Kälteerzeugung aufbraulcu, olme dafs die mindefte Trübung entftelt. Das Kupfer löfet cs mit Mit himmelblauer Farbe auf und ertheilt auch dicfe Farbe alten übrigen Kupferauflöfragen, demen es beycmifcht wird. Hält gen, deuen es beygemifcht wird. Hält
man einen mit Salzfanre angefeuchtetes man einen mit Salzfäm angefeuchtete
Stöpfel darüber, fo entftelıen weifse $D a ̈ n-$ pfe um ilu herum. Es mufs in wohlverfchloffenen Gefälsen, an beften in mehreren kleinen mit eingerrebeueu Glasftöpfel verfelicacn Gläfern aubewabit werden.

Amumonitum Carbonicum pyrooleofum.

Sal volatile Cornu Cervi.

Brenzlicht - ölichtes konlenfaures Ammonium.

Hirfchhornfalz.

\section{Ammonium
riaticmm.}

Sal rammóniacum Salmiak. dem ätherartigen Thieröl ähnlichen, etwas dem Rufse von verbranntem Milt fublinint, iu mit thierifch-breuzliebteu Oehltheilen verbundenes kohlcnfaures Ammonium, welches bey der trocknen Deftillation des Hirfchborns oder der Knochen als Nebenproduct gewonnen and durch nochmalige
Sublimation über Kreide gereinigt wird. Eiu gutes Hirfchhornfalz, welches aufse den damit rcrbundcnen brenzlichteu Theilen ganz mit dem aus dem Salmiak gewonnenen koblenfauren Ammonium übcreinbommt, mufs trocken feyn, weifslich, aber nicht fchneeweifs aufehen und einen durchdringend flüchtigen, erquickenden, durchdringend flüchtigen, erquickenden,
dem ätherartigen Thieröl ähnlichen, etwas empyrevmatifchen, doch aber nicht ftinkenden und widrigen Gerueh haben. Mit
der Zeit ninmt es eine gelbbräunliche Farbe an.

Ein aus Salzfiure und Ammonium beftehendes Mittelfalz, welches in Aegypten aus in verfchicdenen Gegenden von Europa aber. durch Verbindung feiner Beftandtheile mittelft weebfelfeitıger Verwandifchaft fabiikmärsig bercitct wird. Ehedem wandte man blos den ägyptifchen Salmiak au, der aus runden feften Broden, die auf einer Seite eonver, anf der andern holl find, befteht, feîner vielen Uureinigkeiten wegen aber immer einc noclunalige heinigung nöthig macht. Jetat bcdient min fich hamptfäeblich des in den Salnniakfabriken bereiteten Salmiaks, wo er entweder durch Cryftallifation oder Sublimation erhalten wird. $Z u$ jenem - gelör de" Brau nfchweigifebe, ion den Gebrïdern GravenLor ft bereitete Salmiak, der in der Geftalt vou Zuckerbïien iu locker cryftallifirten Malleu vorkomint, mndurch fichtig und fchneeweifs ift Sublimirt erbält man ihn vosi $M$ agdeburg und von ler chemifelen Fubrik in Salzgitter, in durcbfebeinendeu, weifsen. und felır reinen Kurchen oder Broden, fo wie ihn auch die Englifeben und Franzöfifeben Fabrikeu auf

diefe Art liefern.
Der reine Salmisk hat cinen frbarf und ftechend falzichten Gcfohmack, ift an der Luft unveränderlieb, rcrlies, auf einem glühend heifsen Bleche s̈änzlich, fublimirt fich aber in verfeliloffeuer. Gefáfsen und

lit Salzfäure oder Han erfabrt diefes, wenn, man eine kleine noch unzerfetztem Pcrtion mit reiner Effog- oder Salpeterfäure

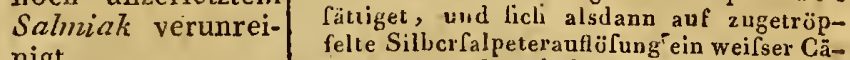
nigt. figter Satz (Falzichtfaures Silber) abfcheidet. Aus der Menge des niedcrfallenden Satzes lälst fich auf den grọ̈sern oder geringeru Antheil von Salzfäure fchliefsen. Eimen geringen Antbesl ron Salzfarure nimmt indefen das Ammonium wohl immer mit berüber.

Ablichtlieh beygenilchter Salmiak würde fieh auch dadurch zu erkeunen geben, dafs das Ammonium fich fchon in mif Wärme verflüclıtigt, der Salıniak aber fciner Snblimation eineh ftärkern Grad der Hitze erfordert.

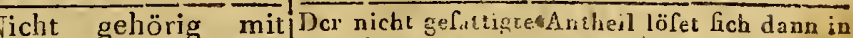
Kohlen äure gefättigt.

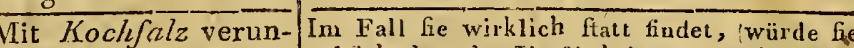
reinigt oder verfälchit.

Mit metallifchen Theilen verunreinigt.

tatt deffen ein Gemifch von Salmiak und Kali.

Tit Oehltheilen überladen oder nicht gehörig gereinigt.

ufällig auch wohl mit $\overline{\text { Wahrfcleinlich von zerbrochenen Gefáfsen }}$ Glasfpitzen ver- orler Sublimirgerütbfchaften. Bey der Aufmifcht gewefen. löfung in Wafer bleibt das Glas auf dem Boden licgen.

Mit fchwefelfauren Neutralfalzen verunreinigt.

Mit Kochfalz verfälfcht.

Tit metallifchen Theilen, befonders mit Eif $n$, Kupfer oder Bley verunreinigt.

Zuweilon auch mit
unreiner Soda vermengt. leicht bey der Vertluchtigung des Sal zes in einem bis $2 \mathrm{u}_{1 n}$ Glüben exhitzten Löffel erkleibt.

Werden durch die Trubung und Farbenänderung, die das blaufaure Kali in der wälsrigen Aminoniumauföfung hervorbringt, erkannt.

Wird an der Luft feucht, und verfliegt in der Hize nicht ganz, fondern hinterläfst falzfaures Kali.

Ift dunkelgrau oder bräunlicht, ölicht feuch und von einem fehr widrigeu empyrevma-

ie Auföfung siebt alsdaun mit $\int_{a}$ la faurc Barytaufl̈fumg einen unanflöslichen weifsen Niederfchlag. Bey der Sublimation bleibt ein Rückstand übrig.

Beym fublimirten Salmiak wohl nieht 2 beforgen, mehr bey dcm eryftallifirten. Wird bey der Sublimation zurückbleiben. und der Ruickftand leicht fü Kochfalz erkannt wer- Ruckltand leicht fur Kochlalz exkannt wer-

Sullte gar, wie es einmal der Fall gewefen (Rerl. Jabrb, d, Pharmacie, 1806. S. XLVIIL), ein in Kuchen gcfclimolzenes Kochfalz fiatt des Salmiaks betrügerifcher weife vorkonmen, fo würde dies durch die gar nicht erfolgeude Verflüchtigung und den Mangel des Anmoniumgeruchs, wenul etwas mit Kali zufammengerieben wird, fo wie'durch die übrigen bekannien fchafien des Ifochfalzes bald zu entdecken feyn.

Ein e i fe ula liger Salmiak hat cine mebr oder weuiger gelbliche $F$ arbe und leine $A u f-$ löfung wird dur ch Gralläp feltinctur fchwärzlicb gefärht. - Der Ku pergehal tentdeckt fich durch die blauliche $F$ arbe, welche die Auflöfung durch zugefor die $A$ utueng durch zugefere Am Ha $\mathrm{h}$ i $\mathrm{em}$ a $\mathrm{n}$ us Probeflüfrigkeit an.

leibt bey der Verftichtigung des Salmiaks zuriek und wird dann leicht durch das Aufbraufen mit Säuren crkannt, fo wie aus 


\section{Ammonium muriaticum. - Amygdalae amarae ct dulces.}

\begin{tabular}{c|c|c} 
Namen & $\begin{array}{c}\text { Sinnliche Eigenfchaften derfelben; } ; \\
\text { Merkmale ilhrer Aechtheit und } \\
\text { Giite. }\end{array}$ & $\begin{array}{c}\text { Fellerhafte Be- } \\
\text { chaffenheit, Ver- } \\
\text { wechfelung oder } \\
\text { Verfüllchung. }\end{array}$ \\
\hline
\end{tabular}

riaticum.

geftreut, eine blangrüoe Farbe mit. Er löfet fich bei mittlcrer Temperatur in zwe Theilen kaltem Waffer unter Kälteerzeusung und in sleichem Theile kochenden Wa Waller auf Die Unze Weiu zehn, Ged davon anf. Mit Kali oder mit gebranntem Kalke zula daraus ein fliichtiger Geruch, in dem das Ammonium frey wird.

Ammonium mu-
riaticum depuratum.

Gereinigter Salmiak.
Durch Auföfung des ägyptifchen oder anderer, eine Reinigung erfordernder, Sal miakarten in Warter, Klarfeihung der Flüffigkeit und Cryftallifation derfelben berei-
tet. Der fo gereinigte Salmiak fchiefs tet. Der fo ger einigte Salmiak fchiefst
alsdann in doppelt federartigen; aus fechsfeitigen Pyraraiden zu farnmengefetzten, gan weilsen, lockern, biegfamen Cryftallen an Die Kénnzeichen feiner Güte und Reinbei find diefelben, wie im vorigon Titel.

Ammonium muriaticum martiatum.

Flores Salis ammoniaci martiales. Eilenhaltiger Salmiak.

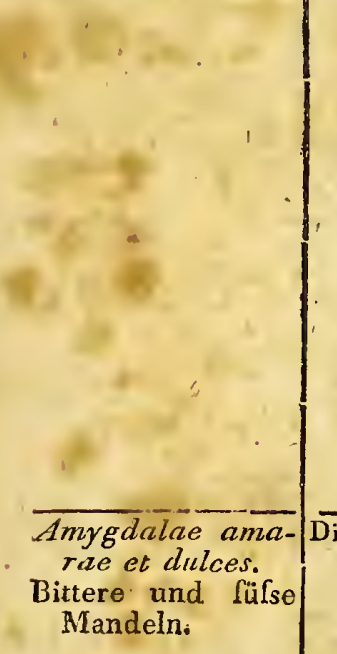

und Eifenoxyd befieliendes Salz, welches
und nacb der nenern Ausgahe der Preufsifchen Pharmacopoe durch Aniöfung von eiuem Theil reinen Eilen in einer hinreichenden Menge einer Mifchung von $z$ wey Theilen Salzfärare und einem Theil Salpeterfame, nacliberigcr Vermifchung diefer Auföfung mil einer Auflölung von funf $\angle$ ehu Theilen Salmiak und Abdunftung bis zur Trockne hereitet wird. (Die erfte Auflage fchrieb) vor, diefe ausgetrocknete $\mathrm{Ma} \mathrm{Cl}_{\mathrm{e}}$ zu fiublimiren und den erhaltenen, aus Cruften von verfchiedener Farbe, vom bochgelbeu bi zum bellgelben beftebeuden Sublimat zu eisena gleichförmigen Pulver zu, zerreiben).

Der eifenbaltige Salmiak muls eine angenehme lebhafte orange $F$ arbe, einen $\int_{a}$ ranarigen Geruch und einen ftechenden, fcharf falzichten, zufammenziehenden $\mathrm{Ge}$ climack babcn. In freyer Luft zieht er leicht Feuchtigkeit an, wird dem Sonnenlichte ausgefetzt, bläfer von Farbe, bekommt jedoch die vorige im Duukeln wicder, verflüchtigt fich in angemeflener Hitz völlig, ift bey $50^{\circ} \mathrm{Fahr}$. iu drey Theilen Waffer löslich und giebt mit Weinalcohol eine goldgelbe Tinctur, die angezüudet mit bellgelber sarbe brennt. Scine Anflölungen geben mit Gallusfänre enthaltendeu Flüffigkeiten dintenartige Mifchungeu. Er mufs in einem woblverfchlofsenen Gefalse an einem trocknen Orte aufbewahrt wer-m den.

e Kerne der pfirfichäbnlichcn Früchte des Milchmandelbaums (A m y g d a l us . c o mmunis). Platte, fpitzig cyrunde, inwendig weifse, auswendig mit einer braunea gefurchten, mit einem baricht - gelben Stauhe beftreuten Haut überzogene Samen, die an hrer Spitze - einen herzförmigen Keim haben und fich leicht in zwey Hälften fpalten laffen. Die $f \ddot{u} f$ se $n M$ a ndeln ten $\int p a l t e n$ laffen. Die $\int \ddot{u} \int \operatorname{sen} M$ and eIn,
welche von einer Varietät des Mandelbaums welche von einer Varietät des Mandelbaums mil gröfserer Frucht Lerkornmen, haben einen fehr angcnehmen, filfslicht-olichten Gefchmack mit etwas Gewirzbaftigkeit. Es giebt' davon in Hinficht der Gröfse mad Giite wieder manchcrley Sorten, voll denen man die I t a liän if chen und $V$ alencer als die gröfsten und wohlfchmeckendften den Provencer und $B$ arloadifchen vorziebt. Aufserdem erbält tna auch noch in Handel dic in einer leicht zerbrechlichen Schale eingefchloffenen K r a c b- oder chen Schale eingeichlolfenen $\mathrm{K} r \mathrm{ch}$ - oder ckende Mandeln, welchic von einer befonckende Mandeln, welchic von einer befonderen Spiclart des Mandelbaums abftarnmen follen. Die bittern Mandeln kommen von einer andern Varietait des gemeinen Mandelbauns mit klcinerer Frucht, Gnd kleiner als die fiifsen und hahen einen bittern Geichmack, der vorziiolich in ilırem rauhraunen Oherhäul en fteckt. Sowobl die füfsen als bitceru Mandelu liefern mit

\section{Deren}

Kennzeichen und Priifungsmittel.

den erbaltenen Cryftallen eiuer damit veutralifirten und verdonfteteu Auflöfung.

Chir. Zeitung, 1804

II. S. 455 .)

.

tatt durch Cryftallifation der klargefeiheten Flüfligkeit, durch Abdampfen derfelben bereitet.

Freye Salzä̈ure enthaltend.

Zu $\int c h$ so ach an Eifengehalt.

Nach Do 'si e's Meinung in Fabriken wohl aus gelbem Ocher oder gar gelb gebranntem Bleyweifs und Salmiak erkünftelt.

\section{Verdorben.}

in auf diele Art bchandelter Salmiak wird niemals von den etwa dabey befindlichen fremden Salzen gehörig gereinigt, erfcheinen können.

Man erfährt diefes, ween man etwas Eifenfaluniek erwärnnt, und während dern einen mit Walfer benetzten Papierftreifen daruber hält, durch den fogleich alsdann ent ftehenden weifsen Dampf. Noch ftärkèr zeigt fich diefer Dampf, wenn man das Papier mit Ammoniumflüffigkeit befenchtet.

Er hat alsdann keine lebhifte orange Farbe, fondern fielit mehr lichtgelh aus.

Wiirde hich fchon durch das nifsfarbene, fchmuzig gelbe Anfelien verrathen, fo wie man nacb den' angegebeueu Kennzeichen der Güte des ächten Liıèufatmiaks fehr bald ein folches letrïgerifches Gemifche würde beurtheilen könuen. $\overline{\text { Angefreffene }}, \overline{\text { wurmftichige, zerbrochene, zu }}$ alte oder fchlecht aufhewahrte Mandeln werden leicht ranzicht, bekommen dann einen widrigen Gefchmack und iuwendig gelbe Flecke, trocknen ftark zufammen und wcrucn feltr bart oder auch zäbe, bisweilen inwendig ganz gelb und wachsartig weich. inwendig ganz gelb und Wachsartig weich.
Dergleichei Mandeln dürfen nicht zum Arzneygebrauch angewendet werden. 


\section{Amygdalae amarae et dulces. -- Aqua Laurocerafi.}

Namana der Arzneymitiel.

Sinnliche Eigenfchaften derfelben; $\mid \begin{gathered}\text { Fehlerhafte } B c- \\ \text { chaffenheit }\end{gathered}$ Merkmale ilurer Aechtheit und $\mid \begin{gathered}\text { schaffenheit, Ver- } \\ \text { wechfelung oder }\end{gathered}$ Güce.

Deren

Verfälschung.

\section{K}

Amygdalae ama- Waller angeftofsen eine weifse Samennilcb rae et dulces.

\section{Amylum.}

Kraftmehl.

stärkentebl. und aus beiden erhält man
fen ein füfses mildes Oebl.

Der ans dem reinen Weitzen durcb kaltes Wafler ausgezogena, von dem Gewächsleim Waller ausgezogena, von dem Gewächsleim
absefonderte und fieywillis aus dem Wafabsefonderte und fieywillig aus dem Waf-
fer fich abgeferzte ganz feine Mehlitoff. Wir erbalten die Stärke aus den Stäilkefabriken in unförmlicheu Stücken vou verfchiedener Grö̈se, die fchneeweil's, leicht, weich anzufühlen, gerucb- und gefcbmacklos find und beim fchwächlten Drucke leicht nit Kuacken zerbrecben. In kaltem Waffer zerfallt fie fehr bald, mit kochendem abcr läfst fie fich zu einer durchlichtigen, klebrigen, bey der Erkältung geliefcrnden Auföfung, dem bekannten K l e ifte $x$ bringen. Eine gute Stärke imufs, zu einem böchft feinen Pulver oder Puder gebracht, in den Händen fanft knirfclicn, fich in aebi Theilen lauem Waffer milchweifs auflöfen und auf der Oberfäche, diefer Auflöfung nichts fcbaliges oder fouft freundartiges fcbwimmen laflen.

Aqua Calcariae ustae. Aqua Calcis ,iRalkwaffer.

\section{Aqua defillata} communis. Gemeines deftillirtes Waffer.

Durch Löfchen des frifchgebrannten reineu Kalks mit gemeiuem Waffer und Abgiefsen des üher dem zu Boden gefallenen Satze
völlig hellen und klaren Waffers bereitet. völlig hellen und klaren Waffers bereitet.
Ein gutes Kalkwafler mufs waflerhelle feyn, einen lüfslicht - alkalifchen, trocknenden Gefchmack babell, den Violenfaft grün färben, auf Beymifchnng eincs aufgelöften koblenfauren Kali fogleich milchweifs, und des aufgelüften Queskfilberfublimats poinmeranzenfarbig. getrübt werden. Man mufs es in wohlverltopften mit Blafe verbundenen oder verpichten Flalchen aufberiabren. Von gemeinem $W$ afler werden durch Deltillation $\mathbf{z w e y}$ Drittheile abgezogen; das ganz zuerft übergehende wird nicht benutzt. lin gutes deftillirtes Wafer mufs völlig helle und klar, und obne allen Geruch und Gefchmack fcyn. Es mufs die Lackmusfarbe nicht veräudern nnd weder von Kalkwafer und Kalianföfung, noch von aufgelöltern Sauerkleefalz, falzichtfaurem Baryt oder Silbervitriol getrübt werden. Durcb feftes: Verliopfen der Flafchen muls es vor dem Zutritt der Luft gelichert werden.

\section{Aqua Lauroce-} rafi. Kirfchlorbeerwa[ler.
Nach der Prenfsifchen Pharmacopoe werden hierzu von zwey P funden frifchen klein zerfchnittenen Kiffchlorbeerblättern mit hinlänglich zugefetztem Waller aus einer gläferven Retorte drey Pfund Waffer abdeftillirt. Das Kirf́chlorbeerwafler mufs, wie die frifchen zerriebenen Blätter, einen tarken balfamifchen, geftofsenen bittern Mandeln äbnlichen, betäubenden Geruch und gleichen bitterlichea Gefchmack baben. Aufser den übrigen Eigenlcbaften eines gut
deftillirten Waffers (S. Aquae deftillatae) deftillirten Waffers (S. Aquae deftillatae)
mufs es mit Vorficht bereitet feyn und mit mufs es mit Vorficht bereitet feyn und mit der gröfsten Sorgfalt an einem kühlen Orte in feft verbundenen Flafchen befonders auf-
bewahrt werlen. Seiner heftigen Wirkungen wegen darf es an Nicmauden obne ärztliche Vorfchrift verabfolgt werdea.
Mit gröbern unreinen
Sorten vermengt.

Mit erdigen Theilen vermifcht.

vit

Durch Anziehung der Kohlenfüure aus der Luft bey fchlechter Aufbewahrung fällt die aufgelöfte $K$ alkerde daraus nieder und das Waffer wird unkräftig.

Statt des deftillirten Waffers gemeines Brunnenwajer.

Oft ift es felir verdünnt unnd fchwach. teu in manchen Apotheken von verfebiedener Stirke und Gïte an. Olt ift es fo fchwach, dafs es nur cinen uubedeutenden Pfirfichbiättergeruch bat. Bey einem Mittel diefer Art kommt aber alles darauf an, dufs der Arzt die Stärke uud den Gehali deflelben kenne, um dis Dofis beftimmem an können und in feinen Erivarturgen nich zu kuphen und in feinen getanfchi werchen welcher daflelbe bereitet wordcn, der Geruch und Gefchmack des Wallers, die Vergleicbung mit eincin sut bcreiteten KirTcblorbecrwafler und die Zuverläfigkeit des Apothekers mülfen ihn hierin leiten.

Oft ift das Kirfchlorbeerwaffer deshalb fo fchwacb, weil es zu einer Zeit bereitet worden, wo die Blätter felbft nicbt febr wirkram find. Da der Kirfcblorbeerbaum bey uns entweder in Kellern oder in Gewächshäufern den Winter übcr aufbewahro wird, durf man das Wa Ter nicht eber wird, fu dure Augnit, weil fonlt weniger wirkfamer Stoff darin enthalten ilt.

Brenzlicht riechend.

Statt des Kirfchlorbeerwalfers ein con. centrirtes " WW affer von bittern Mandeln oder $P$ firfichkernen.
Zcigt der Geruch und Gefchmack.

Ein ächtes Kirfchlorbeerwafer hat nach B u cb b o 12 einer weit flüchtigern Geruch, als das Waffer von bittern Mandelu und Pfirfichkernen, fo wie der Gefcbmack uur etwas kernbaft und bey weitem beifsender, etwas kernban nid beg weitem beifsender, als das concentrirtefte Niandelwafer ift. Der Mangel au Kirfchlorbeerblättern darf
übrigens dena Apotheker nicht zur Entm 
Aqua Lauroccrafi. -- Aquae deftillatáe ex vegetabilibus fragrantibus.

\begin{tabular}{|c|c|c|c|}
\hline $\begin{array}{c}\text { Namen } \\
\text { der Arzneymittel. }\end{array}$ & $\begin{array}{c}\text { Sinnliche Eigenfchaften derfelben; } \\
\text { Merkmale ihrer Aechtheit und } \\
\text { Giite. }\end{array}$ & 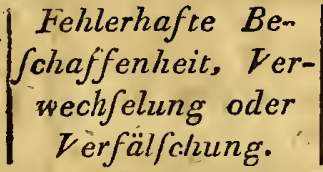 & $\begin{array}{l}\text { Deren } \\
\text { Kennzeichen und Prïfungsmittel. }\end{array}$ \\
\hline 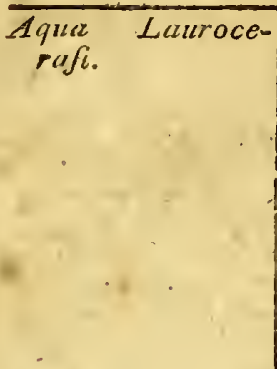 & - & $4 \sqrt{4}$ & 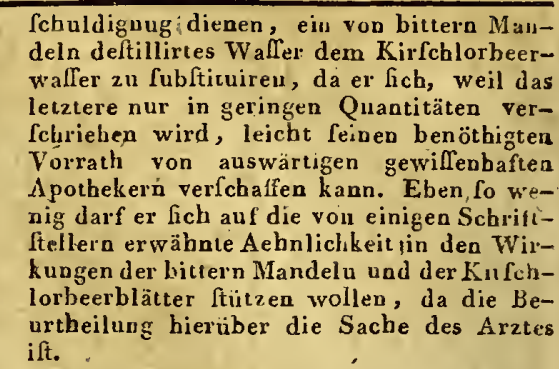 \\
\hline
\end{tabular}

Aqua picea.

Theerwaffer.

Aqua Saturnina. Aqua vegeto-mineralis.

Bleywafler.

\section{Aqua fulphurato} acidula.

Liquor probatorius $\mathrm{H}$ a hnemanni. Gefäuertes Schwefliclites. Waller. Säuerliches Schwefelleberluftwaller.

Hahnemanns Probellülfigkeit.

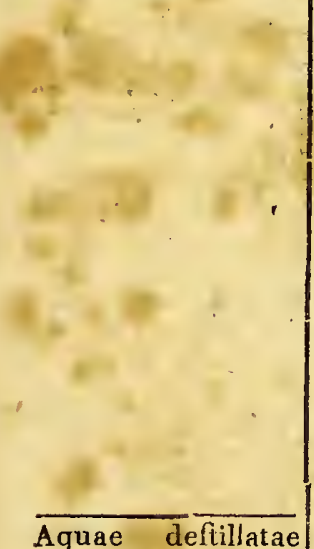

ex vegetabilibus fragrantibus.

Deftillirte Wälfer aus riechenden Pflanzentheilen.

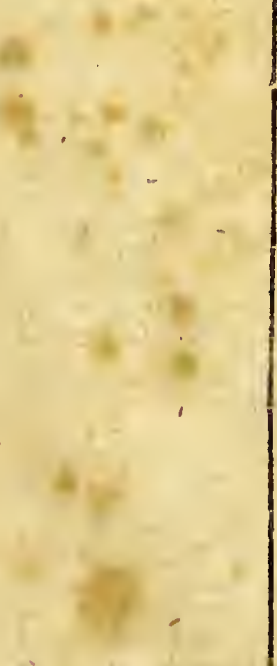

Wird durch Uebergielsen von reinem Theer mic gemeinem Waller bereitet, welche beyde untereinander gerühr werden und nachdem fich der Theer wieder zil Bodén gefetzt bat, das daüuber geftandene Waller abgego!fen wird. Es hat eine gelbliche Farbe und einen fäuren, bitterlich-brenzlichten Gefchmack und Geruch Das klare Waffer ruufs in gut verkorkten Flafchen aufbewabrt werden.

Durch Mifchung von zwey Pfunden gemeinem/Mit gemeinem Brun-/Hat eine weilstiche trïbe Farbe uad lturken deftillirteu Waller und einer halben Uuzc nenwaffer ftatt des Bodenfatz. Bleyeflig bereitet. Schwach opalifirend, deftillirten Waffers ohne weifsen Bodenfatz, den es doch mit der Zeit in geringer Menge fallen läfst. Von füfslicht zufammenzielicnden Gefchinacke.

Wircl anf die bekannte Weife, indem man fechzehn Unzen deliillit tes Waffer mit 2wey Drachmen Schwefelkalkerde und eben fo viel Weinfteinfänre anbaltend ftark fchüttelt und der abgegollenen völlig abgeklärten Flülfigkeit noch eine balbe Unze Weinfteinfäure zuferzet, bereitel. Sie mufs farbenlos und wafferbelle feyn, einen fanren Gefchmack und eiuen überans fturken lanten Eycrgeruch haben, und die geriugfte Spur des in irgend einer Flüligkeit-aufgeSpur des in irgend einer Flullgkeit-aufgelöften Bleyes augenblicklich durch einc
fchwarze flockichte Trubung verrathen. - Aufserdem macht fie auch mebrere ander Metalle durch Niederfchläge von einer beftimuten immer gleichen Farbe kennbar fie fchlägt Silber, Queckfiluer und Wis muth aus Salpeter- nud Efís fáure mit duokler Farbe, Queckfilber und Aetzfublimat mit. fchwarzer fchuell in weifs frch umändernder Farbe, Ziuk weifs, Braunfteil gelblich wcifs, Arfenik pomineranzengelb, und wenn etwas wemges Bley zugleich dabey ift, carmiuroth, fo wie Spiefsglanz ziegeltoth nieder. Auf das Eifen wirkt fie nicht. Sie mufs in kleiuern, augenblick lich feft zirgepfropften Gräfern, dere Körke mit gefclımolzenem Siegellack überzogen find, an einem teruperirten Orte aufbewahrt werden.

Durch Deftullation vón gemeinem Waller über riechbare oder ätherifche ölhalıige Kräuter Blumen, Samien u. dgl. gewonner. Gute deftillirte Wäler minlfen den Geruch der Subftanzen, worüber fie abgezogen find, und den ilunen zukommeuden Gefchmack in gehöríg ftarkent Grade befizell. Sie mülien vorliclitirg deftillirt und haltbar fey 1 , und in mit Papier verbundenen Krüge oder Flafchen au eiuem lühlen Oıte i.m Keller aufbewahrt werden. Im Ganzen genommen mullen he klar und belle leyn; einige gewirrafte Waller macheu zwar hierin eiue Ausnahme, dürfcu aber doch keinesweges mit Oeltheilen überladen leyn, fo dafs das Oel daranf lrecunfehwimmt. Vor alleu Dingen dürfen die deftillirten Wäller keiuen fremden Beygefchmack uod Nebengeruch haben; fie diirfen nicht laucr, fchleimicht, Init Schimmelüberzogen, nbelriechend oder gar faul heyn, welche teuden Wäfer' vorzüglich ausgefetzt find. bereitet.

\section{Unkräfịg geworden} curch längeres Aufbewalıren in nicht luftdicht verfchlof fenen Gefälsen.
Weifslicht-trübe, ohne den Geruch des geSclswefolten Wallerfoirsafes, mithin nich nach fauleu Eyern riecliend, und die vorgedachten Metille aus ihren Auföfungen. nicht viederfohlegerd.
Nicht gehörig fiark, oder durchis Alter und fchlechtes Anfbewahren unkräftig gewörden.

Brenzlicht durch einen zu holien Grad der Hilze bey dex Deftillation.

Mit Oelıheilen über fättigt.

Weingeifthaltig
Ihr Geruch und auch wohl Gefchmack it danu ziu geringe orler gauz ver [chwunden. Bey veralceten Wallern lehwimmen zugleic trïbe Flocken darin herum, oder es habe ficb Salz - oder Camphercryitalle am Boden angefetr.t.

Haber alsdanu eiuen ltark brenzlicisten Gerucb und Gefchmack und find fchlcchterdings verwerlicli. fchwimmen Oelaropfen; Geruch und Gefchmack find ftärker, als fie feyn follten.

Den einfachen deftillirteu Warfern wird zuweilen, damit fie fich befier halten follen, etwas Weingeift zngefetzt. Diefer Zufac: eut $\{$ pricbi aber nicht den $\Lambda$ b fichten des Aiztcs. Auch ift el, wenn die deltillirten Wälfer mit Vorficht bereitet und mit Sorzfalt aufbewahrt werden, unuöthig; überdem follen die WäRer dadurch eher fänerlich werden, als ohue diefen Zufatz. Belfer ift es dagegen, die deltillirter Wáfur ofterer frifch zu hereiten.
Milchicht und trübe; auf der Oberfäch

qua Cerasorum Ko Gartaris. Giren Wafer zwaurio Pfund abdefillirt. Ein angenehmes nach Kirfchkernen riechendes uud fchnecliendes Waffer. Statt dellen wird häufig cin vou bittern Mandelo deftillirtes Wafles. fubftituirt; in Geruci und Gefubmack kauru zu, eutdecien. 
Aquae destillatae ex vegetabilibus fragrantibus. -- Aquae minerales s. med.

\begin{tabular}{|c|c|c|c|}
\hline $\begin{array}{c}\text { Namen } \\
\text { der Arzneymictel. }\end{array}$ & $\begin{array}{c}\text { Sinnliche Eigenfchaften derfelben } \\
\text { Merkmale ihrer Ächtheit und } \\
\text { Güite. }\end{array}$ & $\begin{array}{c}\text { Fehlerhafte Be- } \\
\text { fchaffenhcit, Ver- } \\
\text { wechfelung oder } \\
\text { Verfälfchung. }\end{array}$ & $\begin{array}{c}\text { Deren } \\
\text { Kennzeichen und Priifungsmittel. }\end{array}$ \\
\hline
\end{tabular}

Aquae deftillatae ex vegetabilibus Iragrantibus.
Aquae deftillatae vinofae. Geiftige Wäfer.

Aquae minerales $x$ medicatae. Mineralwäffer.
Aqi., hamomillae. Chamillenwafler. Von zwey Dfunden treckueu Chamillenblumen werden mit genug lameu Waller zwanzig $P$ fund abdefililirt. Es mufs den eigenthümlichen, nicht unangenehmen Geruch der Chamillenblumen befitzen. " Subftituirt wird dafür zuweilen ein blofser Aufgufs der Ciramillenblumen oder das yon den Hnndscbamillen (Anthem is Cotula) defillirte Wafer, welches letutere durch den eigenen ftinkcaden und widrigen Gernch der Hundschamillon zu etkenuen ift.

Aqua Cinnamomi fimplex. Zimmtwafler. Nach der Pr. Ph. von einem Pfuude Zimmtcafsia mit genugfanen Wafler zu veun Pfundcu abdeftillirt. Es mufs eiuen fiark aromatifchen, etwas fiffsliehen Gefchmask nnd angeneh meit Zimuntgeruch befitcen. Wenn es lange fteht und recht gefittigt if, fo fch eiden fich mit der ind angeneh men Zimm tgeruch befitcen. Wenn

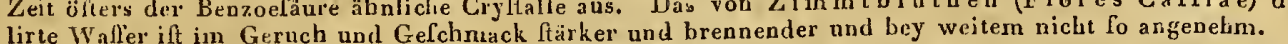

Aqua Cochleariae. Löflelkrantwaffer. Von funfzehn Pfunden bliiliendein Löffelkraut mit hinreichendern Wafler zu zehn Pfund abdetillirt. Mufs den cigenthünlichen Geruch und Gefchmack des Löffelkrauts befitzen.

Aqua Florim Aurantii f. Naphae. Poumcranzenblütbwafer. Von zwey Pfunden frifchen Pommeranzenblïthen werden mit Wafer zwölf Pfund abdeflillirt. Ein äufserft angenebm riechendes Waller, welches aber, wie inehrere andere defillirte Waffer feinen Woblgerucht nicht Logleich nach der Deftillation befitat,

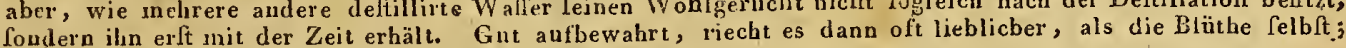
foudern ihn erft mit der Zeit erhäl. Gnt aufben
fein Geruch ift anbaltund und durchdringend.

Aqrea Focnicu/i. Fenchelwaffer. Vou einem Pfunde Feuchelfaamen mit Waffer zu zwanzig Pfund abdeftillirt. Befitzt ganz den Geruch und Gefchmack des Fenchelfaamens. Mufs keine darauf berumfchwimmende Oeltropfen enthalten.

Aqu Hyflopi. Ylopwafer. Von zwey Pfunden trocknem Yfopkraut mit Waffer zn zwanzig l'fund abdelilllit. Mufs den eigenthümlichen Geruch und Gefchmack des Y fopkrauts befitzen.

Aqua Maioranae. Majoranwafler. Wie das Yfopwaffer zu bereiten; nach Majoran riechend und fchmeckend.

Aqua Meliffre. 'Melifenwafer. Wie Aqua. Hyflopi zu beréiten. Ein febr angenehmes, nach Meliffe rie-

chendes uud Cchmcckendes Waffer.
Aqua Menthae Crispae. Kraufemünzwafer. Wie Aqua Hyfopi zu bereiten. Von kräftigem Münzgeruch Aqua Menthac Cris
und Gefchmack.

Aqua Menthae piperitae. Pfeffernünzwaffer. Von zwey Pfunden getrockneter Pfeffermünze nit Wafer zu Vierzehn Pfund abgezogen. Ein kräftiges Walfcr, wclches den eigenthümlichen bekannten Geruch und Gefchmack der Pfetfermünze befitzen mufs.

Aqua Petrofelini. Peterfilienwaller. Von einem Pfunde Peterfilienfaamen mit Wafter zu zwölf Pfund abdeftıllirt. Befitzt den eigenthümlichien Geruch und Gefchmack des Saamens:

Aqua Pulegii. Poleywafler.' Wue Aqua Hyfopi zu hereiten; von kräftigem Poleygefchmack und Geruch.

Aqua Rofarum. Rofenwalfer. Von vier Pfunden frifchen Rofenblumenblättern mit Wafer $\iota \mathbf{z}$ wanzig P find a gua Rofarum. Rofenwaller. ger Zeit entwickelt, befitzen.

Aqua Rubi Idact. Himbeerwaffer. Von zehn Pfund reifen Himbeercn mit Waffer zu zwanzig Pfuud abdeftillirt. Von angenehmen erquickeuden Himbergeruch und Gefcbmack, befonders wenp es eine Zeitlang geftanden bat.

Aqua Rucac. Weinrautenwafer. Wie Aqua Hyエopi zu bereiten: Mufs den kräftigen eigcnthümlichen Geruch und Gefchmack der Weiuraute befitzen.
Aqua Salviae. Salveywafler. Wie Aqua Hyfopi zu berciten; von eigenthümlichen SaIveygeruch und GeAqua Salviae.

Aqua Sambuci. Itollnnderblïthwafler. Von Hollundelblumen, wie das Chamillenwafer zu bereiten. Ein Waller von dern eigenthümlichen Geruch und Gefchmack der Hollunderblumen, welcbes aber fehr leicht verdirbt, lang und febleimig wirl.

Aqua Tiliae. Lindenblüthvaflęr. Wie das Cbarnillenblumenwaffer von Lindenblitthe zu bereiten. Hat einen angeuehmen Líndenbliithgernob; verdirbt aber leicbt.

Aqua Valerianae. Baldrianwaller. Von einem Pfunde Baldrianwurzel werden nach Tromms dor $\mathrm{ff}$ mit genugfamen Wafer vier Maafs abgezogen. Ein kräfiges Wafler von dem eigenthimlichen Gernch und Gefcimack der Baldrianwarzelu.

Die mit Waffer und einem Zufatze von Weingeif über gewilfe Pllanzenftoffe abgezogenen Wäfer. Sie müfen klar und helle feyn und den eigenthümlichen Gernch und Gefchmack der dazn gebrauchien vegetabilifchen subtanzen und des zugefetzten Weingeilis haben. Dabes millen fie, weil he auf diefe Art weit reicher an wefentlichen Oelen dargeftellt werdeu künuen, als die unit blofsem Waffer ubereiteten, flàrker vou Geruch und Gefchmack als diefe feyu. Der bey ihrer Bereituag anzuwendende Weingeift mufs völlig frey von ruch und Gelchmack als diefe fey. fich derfelbe fonf auch den damit bereiteten Waffern mittheilt und ihneu einen unangenebmen Gefchmack giebt.

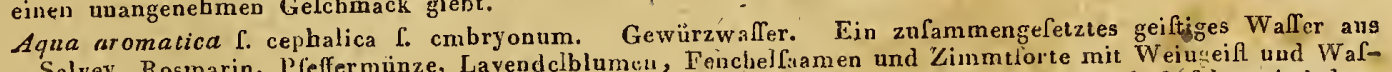
Salvey, Rosmarin, Pleffermünze, Lavendclblumeu, Fenchelf:amen und Zimmtorte mit Weiúeift uud Waffer durch Deftillation bereitet. Mnfs einen diefer Mifchung eutfprechende
klar und helle feyn und in woblver bundenen Gefafsen aulbcwalst werden.

Aqua Cinnamomi vinofa. Geiftices Zimıntwafer. Von einem Pfunde Zimmtcafsia mit zwey Pfunden, Weins

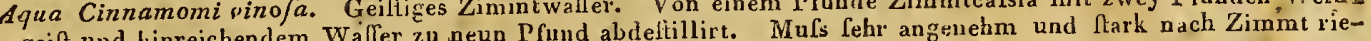
geift und hinreichendem
chen und fchmecken.

Aqua Mcnthae piperitae vino/a. Gciftiges Pfeffermïnzwaffer. You einem I'funde trocknen Pfeffermünzkraut, andertbalb Pfunden Weingeilt und genugfamen Wåfer zu fecis Pfund abyezogen. Von geiftigem Pfeffermüuz-

gerucb und Gefchmack.
Aqua vulneraria vinofa. Geiftiges Wund - oder Schufswaffer aus Salvey, Wermuth, Pfeffermünze, Faute, Aqua vulneraria vinofa. Geiftiges Wund Weingeif und Wa Ter durch Deflillation ber eitet. Mufs dell vermifchten Rosmarin und Lavendelblüthen rnit Weingeif und vorgefchriebenen Vegetabilien haben und ia felt zugepfropf-

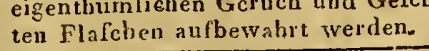

mit gasarigen, fatzigen, fchwellichten/Unkräftig geworden, Dies gefchieht hauptächlich, wenn die Krüge and matallifchen Theilen, dem Schoofse oder wohlganz ver- oder Flafchen, worin die Mineralwaffer and mctallichen Then W Wafer, welche oderfandt werden, nicht gehörig verkorkt der Erde entquillenden Wallé, doülneiche $\quad$ oder verpicht find, wodurch diefelben, nicht nur an ibrer Quelle als bulfreiche Mittel biinfig benutzt, foudern auch vou da aus, auf dié möglichfie Weife verwabrt, in Krïgen oder Flafchen, in die entfernte-
lien Gegenden verfandt werden. .Nach ihindem die darin entbaltenen gasartigen verlieren die $S$ a uerbrunnen ihr koh- 


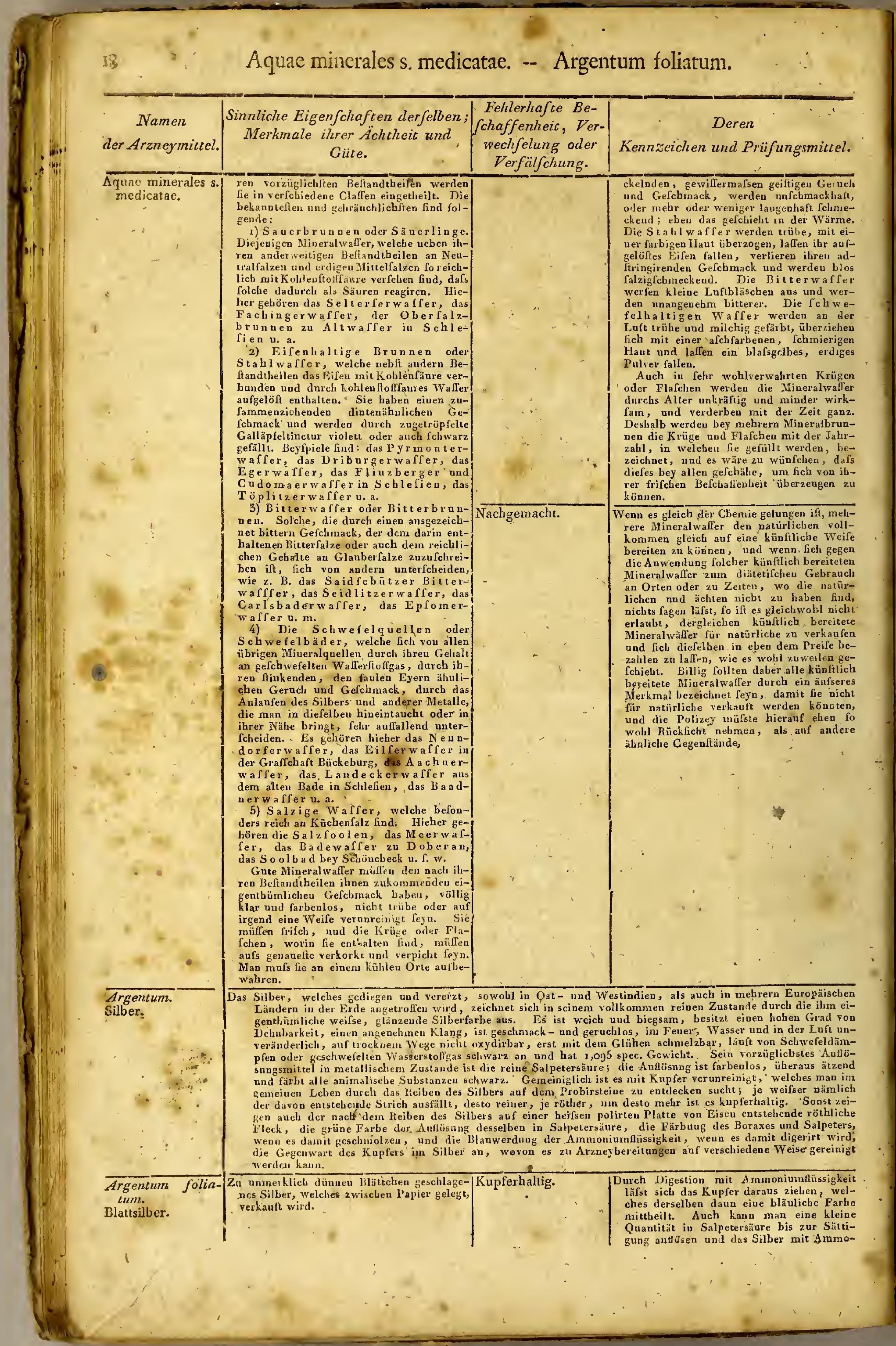


Argentum foliatum. - Arsenicum album.

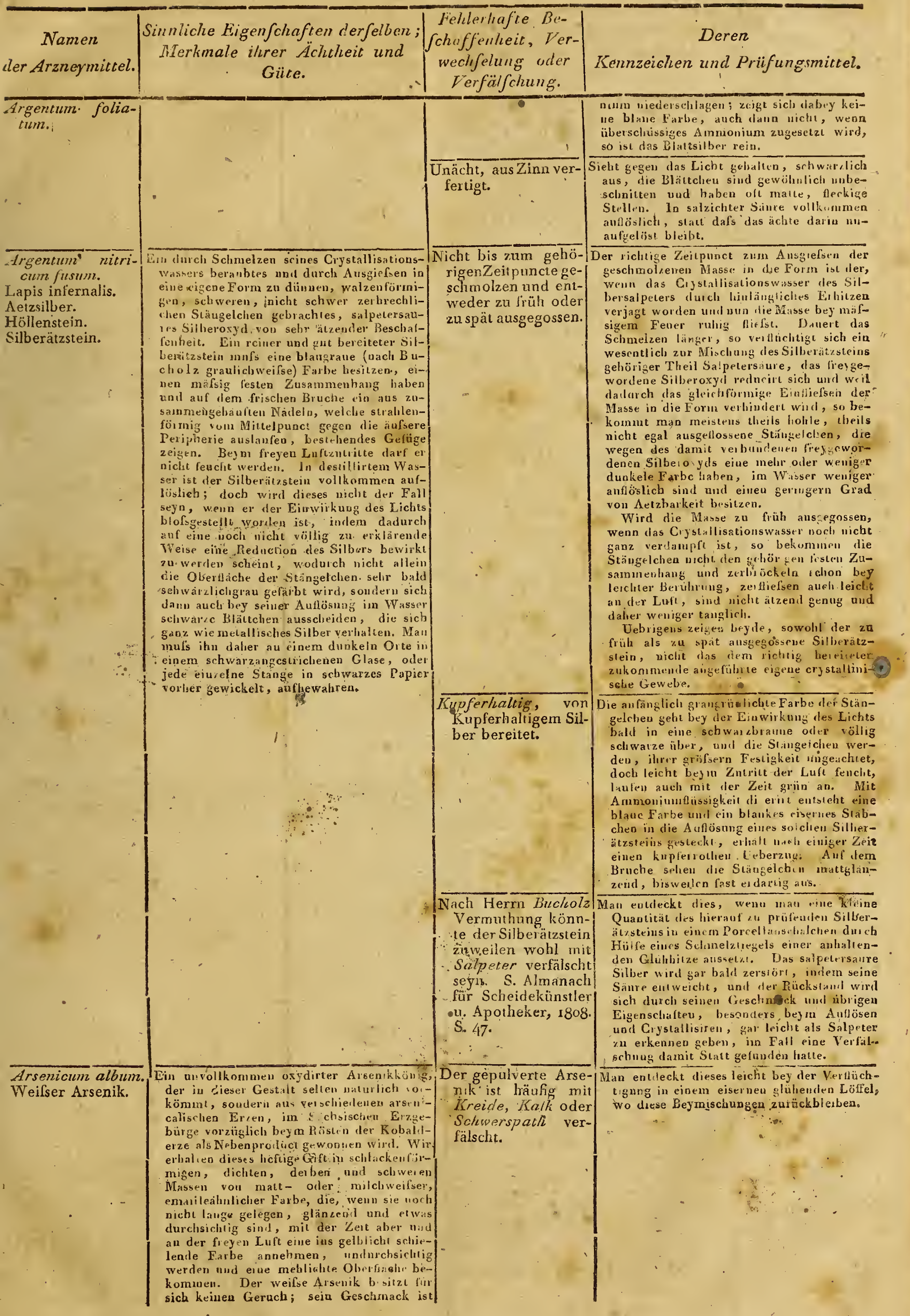


Arsenicum album. - Aurum foliatum.

\begin{tabular}{|c|c|c|c|}
\hline $\begin{array}{c}\text { Namen } \\
\text { der Arzneymittel. }\end{array}$ & $\begin{array}{c}\text { Sinnliche Eigenfchafien derfelben; } \\
\text { Merkmale ihrer Ächtheit und } \\
\text { Giice. }\end{array}$ & $\begin{array}{l}\text { Fellerhafte Be- } \\
\text { frhaffenheit, Ver- } \\
\text { wechselung oder } \\
\text { Verfälfchung. }\end{array}$ & $\begin{array}{c}\text { Deren } \\
\text { Kennzeichen und Prüfungsmittel. }\end{array}$ \\
\hline
\end{tabular}

Arsenicum album. anfaugs kaum melklicb, hernach aber wird er, scharf, beifsend, und zuletzc ätzend. Beym Daraufsclelagen springt er in unregelmäfsige, glasartig glänzende Stücke. Im Feuer oder anf glukenden Kohlen verfim Fer filegt er gatolich mit cinem weifsen, einen starken Knoblach Rauche. In Gestalt eincs nicht gan

Asa foelida.

Stinkasand.

Teufelsdreck.

Asphaltum.

Eitumen iudai-

cum.

Asphait.

Iudenpech.

Aurum foliatum.

Blatigold.

Coldscherum.
Ein Gummiharz, welches als Nilchsaft aus $S$ der verlet $\iota$ ten $W$ urzel des in Persien einheimischen Stinkas andsteckenkrauts (Ferula Asa foetida) fliefst und nacbdem es durch die Sonnenwärne und nacbdem es durch die Sonnenwarme an der Luft etwas erhälet ist, gesammlet wird. Wir erbalten den Stinkasant in grofsen unförmlichen Massen von einer zähen, wachsähnlichen Consisteuz, die aus glän-
zcnden kleinen Brocken zusammengebazcnden kleinen Brocken zusammengebatheils eine bräunlıcbe, gelbliche oder röthliche Farbe haben, einen starken, durchdrin enden, dem Knoblauch ähnlicben Geruch und einen eckelhaften, scharf bitterlichen Geschmack besitzen, sich mit dem Nagel sclabcn uud 2 wischen deu Fingern erweichen lassen. Frir die beste Sorte bäli erweichen lassen. Frir die beste Sorte bal
man die hellen Stücke von blafsröthlicher. man die hellen Stücke von blassöthlicher.
Fabe, welche mit zahlyeichen, scbönen, weifsen, rum Theil durchscheinend cn Brocken untermiscbi sind, die sich an der Flamme das Lichts lescht entzünden, unier Ausstofsung eines starken, mit dem eigenthimlichen Geruche versebenen Dampfs fast so lebbaft als Campfer breunen und eine geringe, leichte, etwas olanzende Kohle zmrucklasseu. Von schwachem Branntwein uud Essig wird der Stinkasant völlıg, aber mit bleibender Trubung aufgelöset; kalischer Weingcist und Salpeteräthergeist gcben danit eine gesättiçte Tinc1ur. Mit Wasser angerieben giebt er eine sclimutzige Milch, aus der sich aber die harzigen Theilc bald wieder abscheiden. Von den beysemischten holzichten Theilen wird er an besteu gereinigt wenn man ihn siebt.

Ein concretes Erdharz, welches auf dem todten und rothen Meere und auf einiogen anderen Landseen in südlichen Asien und Europa schwiminend gefunden wird, ehedern aus Aegypieu und Judäa zn nus gebracht wurde und jcixt auch, obgleich von geringerer Güte in einigeu Gebürgsgruben geringerer Gute in einigeu Geburgöisclen von Frankreich unil anderen Europaisclen St:iaten angetroften wird. Eine leichte, schwarze orler rothbraunscbwarze, leichte, zerbrechliclse, auf lem Bruche glänzende, glatte, trockue, im Aeufsel'n das Ansehen eives reiuen schwarzen Pechs habende suntstanz, die weder Geruch noch Geschmack hat, aber sobald sie gerieben wir'd, stark empyrermatisch riecht. Im Fener schmilzt cs leicht und verbrennt angezündet mit einel weifsen Flamme und einem nacb Steiniil riechenden Rauche, obue einen merklicben kobligen Rückstand zu hinterlassen. Mit rauchender Salpetersäure schäumt es stark auf, und bey der trocknen Destillation liefert es beynahe drey Viertel seines Gewichts, an einem lálslich stinkenden brenzlichten $O$ s: 1 . Im Wasser ist es unauflöslich und rer Weingeist zieht nur eine grinoliche Farbe aus.

Unmarklich dünne Goldbättchen, welche 2 wischen braunrothes dünues Papier gelegt verkauft werden. Blos in Goldscheidewasser und oxydirter Salzsänre auflüsbar. Mlan mufs von den Golifschlägern zum arzneylichen Gefrauche nur die Sorte Blattgold kaufcn, welche sie Feingold nenIs upfer legirt. tatt des guten Stinkasants eine ganz fälschung verdächtige Sorte.

Mit Stücken vion andern schlechtern Harzen und Gumniarten vermischt.

achgekünstelt aus weifsem Harz mi Knoblauchsaft oder etwas Stinkasant angestolsen und getrocknet.

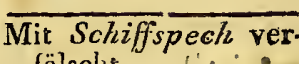
fälscht.

, , ,

MitKupfer legirt oder 1 st das Blattgold mit Kupfer verunreinigt so des ächten bekommt die Auflïsung in GoldscheideBlattgoldes soge- wasser'mit Ammoniumılüssigkeit übersätnanntes Metallgold. 'tigt, eine blaue Farbe. (Maa viarf nicht vergessen, dafs bierbey Knallgold entstebt.) Das Metallgold liiset sich in Salpetersäure anf und ein blankes Stück Eisen in die verdünnte Auflösung gelegt, bekommi nach dünnte Auflösung gelegt, bekommit aach einiger Zeit einent Kupleriberzug. Mol Ammóninmelüssigk 


\begin{tabular}{|c|c|c|c|}
\hline $\begin{array}{l}\text { Namen } \\
\text { Arzneymittel. }\end{array}$ & $\begin{array}{c}\text { Sinnliche Eigenfchaften derfelben } \\
\text { Merkmale ihrer Aechclueit und } \\
\text { Giite. }\end{array}$ & $\left|\begin{array}{cc}\text { Fehlerhafte } & \text { Be- } \\
\text { Schaffenheit, } & \text { Ver- } \\
\text { weclifelung oder } \\
\text { Verfälfchung. }\end{array}\right|$ & $\begin{array}{c}\text { Deren } \\
\text { Kennzeichen und Priifungsmittel. }\end{array}$ \\
\hline
\end{tabular}

Baccae Berberi- Dic in späteu Herbst reifenden Beeren des Berberitzs a nerdorns (Berberis vulgaris L.) Traubenförmig

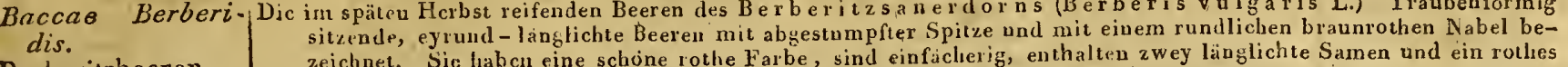
angenehm saner und etwas zusammenaiebend schmeckendes saftiges Fleisch.

Becce Juniperi. Die Beeren desgemeinen Wacholderstranchs (Jun iperas commun is L.) Runde schwarze giauende

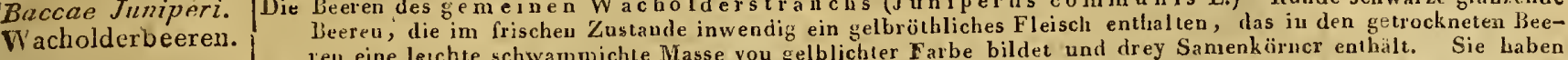
ren eine leschte schrammichte Masse vou gelblichter Farbe bildet und drey Samenkürncr enthält. Sie Laben ren eine leıchte schrammichte Masse vou gelblichter arbe bildet und drey Sanden der sich auch beym Verbrennen derselben a $\mathrm{K}$ ohlen in dex Luft verbreitet. Die grofsen runden schwarzen Beeren sind die besten; dic blassen, beyn Trocknen stark zusamnenschrumpfenden oder boht werdenden Beeren baben ibre Reife nicht gehörell, beym Trocknen stark zusam

Baccae Laturi. Die lrichte des Lorbeerbaums (Laurus nobulis L) Trockne, länglichrunde, schiwarzbraune oder Lorbeeren. schwärzliche runzliche Früchte vou der Gröfse kleiner Kirschen, die unter einer dïnnen zerbrechlichen Schite einen eyrunden röthlichbrauneu Kern entbalten, der in zwey' Theile zerfallt, einen eigenthümlichen, stark gewurzliafteu Geruch, und einen bittern, fettigea,

Baccae Myrtillo- Die Becreudes Bla ubeer heidels (Vaceinium M y rill us L.) Dise Beereri sind schwarzblau; mit einem feinen hlanen Stauhe iberzogen, rund, von der Grörse einer Erbse, oben mit einem doppelten concentrisclien Nabel bezeichnet, vielsainig, und enthalten eincn dunkelrotben, etwas süfslicb-sauer und ein wenig herbe scbneckenden Saft. Man braucht sie entweder frisch oder trocknet sie auct.

Heidelbeeren.

Baccae Sambuci.

Hollunderbeeren.

Baccae Sorbi aucupariae.

vogelbeeren.

$\overline{\text { Baccae Spinae cer- }}$ vinae.

Kreutzbeeren. Bceren des Scbwarzbolders (Sambucus nigra L. S Rundliche, schwarze, einfacherige, süfshchtsäuerliche Beeren mit einem sterntörmigen $\mathrm{Nabel}$, welche drey liugliclite, auf der, einen Seite erbabene, auf der andern etwas eckige Samen enthalten und eincu schwarzröthichen Saft liefern, ans welcbem das bekannte Fliedlermus bereitel wird. Getrockuet werden sie zuweilen Graua acles genawnt.

Die Becren des Vogelbeerspierliugs (Sorbus ancnparia L.). Rundliche Beeren mit einem etwas eingedrïckten Nabel, drey oder vier Samenfachern und in jedein befindlicheu zwey langlichten Sanenhörnern. Sio sınd fleischigt, liaben eine glänzende scharlachrotlie Farbe usd einen meblichten, etwas sänerlichen, bittern, ein wenig herben Geschuack.

Die Beeren des Purgirkrenz dorns Verwechselt mit den Diese haben in der Regel uur zwey Samen(Rhamnus catbarticus L.) Runde, Beeren des Faul. körner, die rund und etwas platt sind; $\begin{array}{lll}\text { e: hsengrofse, gläuzende, schwarze, an der } & \text { batums (R/Lamnus }\end{array} \begin{aligned} & \text { doch triflt man oft ein unvollkommenes } \\ & \text { drittes oder auch viertes Samenkoru darin }\end{aligned}$ Spicze mit eincr hervorstechenden Niarbe Frangula L.) bezcichnete Beeren, die ein saftiges, dun-
kelgrünes $\mathrm{Mark}$, einen violetten Saft und vier dicke, rundliche, glatte, auf der einen geneinen fiartrie- ein duukelviolettes mehliges Mark mit vier

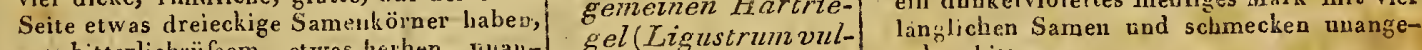
von bitterlichsüfsem, etwas herben, wan- $\begin{aligned} & \text { gel(Ligusirumvill- } \\ & \text { gare L.) }\end{aligned}$ nebrobitter.

gentrmen Geschmack und widrišem, den
Wanzcn ähnlicben Getucl. Sie reifeu in September.

BaccaeVitis idaeae.

Kernsbetren.

Preulselbeeren.

Balsamum cana- 1 . dense.

Kanadischer. Balsam.

Balsanum Copaivae.

Copaivabalsam.
Balsamum de $\overline{\mathrm{Mec}}$ ca s. Gileadense. Meckabalsam. Mechabalsam.
Die Dcreu vorn Preufselbeerheidel (Vaccinium Vitis id ae a L. Glatle, erbsenförmige, mit einem vierspilligen Nabel beseichuete Beeren, die ein tïnnes, schön hochrothes Oberbäutchen haben, iuwendig weifs und vierfächerig sind und einen rothen Saft von säuerlichem etwas herben Geschmack geben.

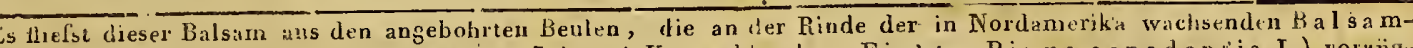

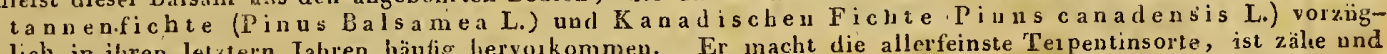
lich in itren letatern Jabren häufig hervokommen. Er macht die allerfeinste reipentinsorte, ist zälee und dickflussig, so dafs er sich zu Falsamiscb bitterlich.

Ein ans dem angebohrten oder geritzten|Zu alt geworden, und/Dnrchs Alter wird der Copaivabalsam zälıe Stanme des vorzüglich in. Brasilien wach- dadurch unkrältig. und dıck, trübc, und scliwächer von GeStamme fes vorzuglich in Brasilien wach-

paifera officinalis L.) ausfliefsender flüssiar Balsam. Der äcbte Copaivabalflussiger Balsam. Der acbte Copaivabalist weifs oder gelblich, vollkommen dnclisichis, von eigenthiimlicben angenelsmein sichtio, von eigenthinmlicben angeneliment Gcruch und einem ölicht-milden, schı wacl gewürzhaften, bintennach etwas charfen Geschmack: In absolutern Alcohol, inn Aether, in den atberischen O.len ist er vollkommen autlöslicli; aucb lifst er sich, mit fetten Oelen vermischen; von der ätzendcn Kalitauge wird er uicht verändert. Mit Wasser desillirt giebt cr ein Drittel bis zur. Hälfte seines Gewichts, leichtes, farbenloses, feines und gewürzhaftes äthefarbenloses, feines und gewurzhartes athe-
risches Oel. Am bestell ist der bier berisches Oel. Am besten ist der bier beschriebeue Brasilian is ch e Copaivabal s am; der'von den A ntiskochen der koramcude, welcher durchs Auskochen der Aeste erlialten zn seyn scheint, ist dicker,
soldgelb, nudurchsichtiger, von einem melır goldgelb, nudurchsichtiger, von einem mehr widrigen Geruch und taugt zum Arzueyge-
braucb nicht.
Mit einem ausgeprefs ten Oel, Miandet-, geist entdecken. Zu einein Ti:eile des zu Molın oder $N u f s \ddot{l} l \mid \begin{aligned} & \text { prïfenden Balsauns giefst man drei Theile } \\ & \text { tartarisirten Weingeist; ist der Balsam ächt, }\end{aligned}$ verfälscht.

Mit zugesetztem fei nen Terpentin verfälscht. so wird er sich rollständig, wewn gleich etwas triibe aufüsen; war er rnit feltem Oele verfalscht, so wird das Gemisch milchig wcrilen uod das Oel wird sich bald aufictem Bisden ansammeln.

Schwer zu entdecken, da sich ler Terpentin auch im Weingeiste nnd Aelher auflöset. Ein solcher Balsam ist elwas dicklicher und trüber; wenn snau ctwas davou auf rucb und Geschmack. Er sinkt alsdaun in knglichter Gestalt im Wasser zu Boden, statt dafs der frische Balsain auf dem Wasser schwimmt. glübendes Eisen briugt, so lifist sich beym Verdampfen der Terpentin am Geruche erkennen.

ron selbst oder nacb gemachten Einschnitlen aus der Rinde des im glïcklichen Arabien wacbsenden İ a ls a mstranchs (Amyris gileadensis) niefscnder Balsam, der nach andern Schriftstellern auch wohl blofs von den Bláttern des und kostharsten Arzneymittel ist, wie ihn gemeiniglich fïrstliche Personen aus der Tiirkey erhalten, in bleyerncn, viereckigeu, mil mancberley Figuren verzierten Flascbeu verwahrt. Er ist dumnfussiger als Terpentin, aber dicker als Copaivabalsam, und von einer citronengelhen Farbe, die etwas ins hothe spielt. Sein Geruch hält das Mittel zwischen Rosmarin, Salbey, Citronen und Muscatnïssen; дach andern riecht er wie ein Ge- 


\section{Balsamum de Mecca s. Gileadense. - - Balsamum peruvianum s. indicum siccum.}

\begin{tabular}{|c|c|c|c|}
\hline $\begin{array}{c}\text { Namen } \\
\text { deriArzneymittel. }\end{array}$ & $\begin{array}{c}\text { Sininliche Eigenfchaften derfelben; } \\
\text { Merkmale ihrer Aechtheit und } \\
\text { Giite. }\end{array}$ & $\begin{array}{c}\text { Fehlerhafie Be- } \\
\text { fchaffenheit, Ver- } \\
\text { wechfelung oder } \\
\text { Verfälfchung. }\end{array}$ & $\begin{array}{c}\text { Deren } \\
\text { Kennzeichen und Prüfungsmittel. }\end{array}$ \\
\hline
\end{tabular}

Balsamun de Mec- misch ron Zimme Nelken und Citren ca s. Gileádense. ben auf ein mit Wasser gefülltes Glas gebracbt wird, derselbe sich augenblicklich über der ganzen Wasserfläche
ausdehnt und sich dann mit einer Nadel gleich einer Haut daron abzielien lälst; eine Erscheinung, die als ein besonderes Merkmal seiner Aechtbeit und Güte angeseben wird. Sein Gesclinack ist bitter, zusammenzichend uud scharf. Geringere Sorten dieses Balsams sollen durch Auskochen der $Z$ weige und Blätter des Baums erbalien werden.

Balsamum peru- Dieser ungemein seltene und fast gar nichi|M vianum s. indicum albumb.

Weifser peruanischer Baisam.

Balsamim perilvianum s. indicum nigrum.

Schwarzer Peruanischer Balsam.
Balsamum peruvianuin s. indicum siccum.

Opobalsamum siccum.

Trockner Perubalsam. acbt 20 habende Balsam fliefst von selbst
aus den vorber verlctzten $Z$ weigen des in aus den vorber verlctzten $Z$ weigen des in
deo heifsesten Gegenden yon Terra firma deo heifsesten Gegenden von Terra firma bals ambaums (Myroxylon peruif erum.) Er ist von wcit dünnerer Consistenz als der Terpentin, hat eine weifsgelbliche Farbe, einen angenehm duftenden, dem Storax und der Benzoe ähnelnden Geruch und einen schärflichen, etwas den Geruch und einen scharflichen, etwas bitteru Geschmack. In Aether loset e sich schnell anf; die Auflösung ist aber etWas trühe und setzt eine weilse Materie ah. Bey der Destillation giebt er ein wesentli-
ches, sogleich iu Benzoesäure crystallisirenches, soglei
des Oel.

Wabrscheinlich dorch das Auskochen der zerscbuittenen kleinen Aeste, der Rinde, zerschuittenen kleinen Aeste, der Rinde,
des Holzes und viellejcht auch der Blätter des Holzes und viellejcht auch der Blätter
desselheu Baums, von welchem der im vodesselheu Baums, von welchem der in vo-
rigen Titel erwähnte weifse peruanisclie rigen Titel erwähnte weifse peruanisclue
Bulsam kommi, gewonnen. Er besitzt eine, in grölsern Massen scliwarzhraunrothe Farhe und ist fast undurchsichtig; in Tropfen ist er schön braunrosh, vollkommen klar und durchsichtig. Er hat die Dicke eines dünneren oder dickeren Zuckersaftes, und es scheint, dafs seine Consisalte viuler steuz vielleicht vorn Alter abhangt, so dals er sich zuweilen zwiscben den Fingern in feine, durchsichtige Fälen zieheu lälst. Sein Gesclumack ist anfangs ölicht -ge-
würzhaft, bald darauf scharf unt einen würzhaft, bald darauf scharf und einen
Reiz im Schlunde erregend. Der Geruch ist äufserst' angenelun, durchdringend balsamisch und dem eiues Gemiscbes von Vanille nnd Benzoe odcr flüssigem Storax äbnlich, besonders auch auf glühende Kohlen gesprützt. Man hat ihn bisher als ein Prodnct der vatürlichen Mischung aus ätberischen Oel und Harz bestebend, angesehen. Aus den hieröher angestellten Versuchen des. Herrn Lich te n berg (Berl.
Jahrb. 1806 . S. 22 u. f.) geht aber hervor, Jahrb. 1806 . S. 22 u. f.) geht aber hervor,
dals derselbe als ein eigenthümlich gedals derselbe als ein eigenthümlich ge-
jnischtes, einfach zusammengesetztes Prodact angesehen werden müsse. Seines theuren Preises wegen wird er oft verfiilscht. Der ächte Balsam sinkt in kaltem Wasser zu Boden; er trocknet nicht aus, wie andere Balsame, und behält immer eine gewisse Geschneidigkeit, wie man dies schoo at den Stöpseln der Standgläser bemerken kann. Im absoluten Alcohul is er nach Herrn Lichlenbergs Versuchen unter allen Verhältnissen vollkommen auflösbar; vom höchstrectificirten Weingeist werden dagegen fünf Theile gegeu einen Theil des Balsans zur Auflösung elfordert. Wird ein Theil des Balsams mit zwey Theilen Aether üher ossen, so färb solches sicb schwach bräunlich und es bleiht oiu unaufgelöster Rückstand ührig, der nun darauf gegossenen Aetber nicbi verändert. Rectificirtes Terpentinöl löset velbst iu dur Würne nur' $?$ davon anf selbst in dir Warne nur $\frac{\vec{x}}{2}$ davon anf Mandelul mahn elwas the da eiue schwarzbraune, extractartige, klebrige eiule scbwar

Entstelıt durch allıählige Eintrocknung des weifsen flüssigen Perubalsams (S. Bals. persv. alhum?., Wir erlaalteu ihn in kleinen faustgrolsen Kürbisscbaleu (Kalebas wiewolil unr selteu. Er ist trocken', zerwiewolh ullr seltew. Er ist trocken', zer-
reiblich, röthlich-gelb von. Farbc, von Gernche des flitssigen Balsams und vo schärferm bittererin Geschnack als der rachfolgende Tolubalsam, mit dem or öf-
Mit feinem Terpentin |Wenn man etwas davon a uf glühende Kohlen vermischt. oder glüliendes Eisen bringt, so wird der entstebende eigenthümliclie Terpentingeruch die Zumischung verrathen.
Mit Copaivabalsam verfälscht. verfälscht.

Mit braunem Zuckersyrup verfälscht.

Nachgekünstelt aus ejnemGemischemehrerer wohlriechender Harze, Balsame und anderer Ingredienzen, z. B. aus Benzoe, flüssigem Storax, Asphait und Copaivabalsam.
Mit feinem Terpentin
Mehrentheils mitBenzoe verfälscht. Mit Geigenharz.
Kanm anders, als durch Veroleichung mit ächtem Balsam, und den bervorstechenden Gernchl und Geschmack des Copaivabalsaus querur.h und Geschmack des Copaivabalsaums trirten Schwefelsäure, die man dazu vorw geschlagen hat, indem solche sich mit dem durch Copaivabalsam verfälschten peruanischen Balsam erhitzen soll, wohey ühelriecheude Dämpfe ausgestofsen würden; fand Herr Licbtenberg (a. a. O.) nicht ganz sicher, denn er sabe auch den reinen peruanischen Balsam sich mit jener Säure erhitzen, obschon schwächer, als wenn er mit Copaivabalsam versetzt war.

Verräth sich leicht durch den Geruch, wenn man etwas auf glübende Kohlen oder ein glübendes Eisen tliut.

Nach Herrn Lichtenbergs Versuchen sehr zu bezweifeln. Geschähe es doch, so würde dieser grobe Betrug dadurch entdeckt werden, wenn mit dem Balsam geschiitteltes Wasser' einen sülsen Geschmack annähme.

in solcher nach cekinnstelter Balsam wird an den gewühnlich schwächeru, miuder angeteu nach, brenzlichtem Geschmack und Geruch, der gewöhnlich röthliclıern oder völlig schwaren' Farhe, und einer entweder zu dicken oder zu dünnen Consistenz, so wie an den unehr oder weniger fehlenden Eigen Eigenschaften des achien perpanischen Balsams erkannt, und überlsaupt vom Kenner anch ohne weitere Untersuchuog leicht ron
dem amerikaniochen unterschieden. nehmen und mehrentheils, wenigstens hin-

Nur durch Vergleichung mit ächtem sicher auszumittelu.

Durcb den Geruch asf glübenden Kohlen zu entdecken. 


\section{Balsamum Tolutanum s. de Tolu. -- Baryta sulphurica nativa.}

\begin{tabular}{c|c} 
Namen & $\begin{array}{c}\text { Sinnliche Eigenfchaften derfellen; } \\
\text { Merkmale ihrer Aechtheut und } \\
\text { Guite. }\end{array}$
\end{tabular}

Balsamuin Tolutanum s. de Tolu. pobalsamum de Tolu. Tolubalsam.

ters verwechselt wird. $\mathrm{Er}$ löset sich in Aether und Weingeist auf.

in harzichter: Sait, welcher durcb Eiuschnitte in die Rinde des in der Provin Tolu in spanischen Westindieu wachsenden $\mathrm{b}$ a Is a m tolubaums (Toluifera $\mathrm{B}$ a $1 \mathrm{~s}$ a $\mathrm{mu} \mathrm{m}$ ) erlatten wird. Ursprüng-
Baryta muriatica. Terra ponderosa salita.

Salzsaure Barytoder Schwererde. Baryta sulphurica
nativa.

Spathum ponderosinn.

Schwefelsaurer Baryt.

Schwèrspath.

\section{Fehlertuafte Be.. Schaffenheit, Ver- wechfelung oder Verfälfchung.}

\section{Deren}

Kennzeichen und Prüfungsmittel. lich hat er die Dicke des Terpentins, eine gelbröthlichbraune, etwas grünliche und ins Rötltiche spieleurle Farbe, einen starken balsamischen, vermischten BenzoeJasmiu - und Citronengeruch, nnd einen erwärmenter ctwas siflich, erwary peilsenMau erhält ihn in kleinen Kürbisschalen Nau erialt inn in kleinen Kürbisschalen entweder balbilissig oder ganz ausgetrocknet. Weun dieser aclat ist, so mufs ex biegsam seyn, oder wenigstens sich $z$ wischen deu Fingern oder in Munde erweichen lassen. In Weingeist mufs er sicb vollisommen auflösen.

Verfälscht.

aus der Baryterde und Salzäure bestehendes Neutralsalz, welches, wenn die es entbaltende Salzlauge langsan abgedampft. worden, schöne, eisklare, länglicht-tafellüımıge, oder wenu sie geschwinder $a b-$ geraucht ist, kleinere, schuppenförmise Crystallen bildct. Die Crystallen haber eine vollkoinmen weifse Farbe, einen unangenéhmen bitterlich scharficn Gesclimack, bleibeu an der Luft trocken und werden vicht feucht, lüsen sich hey mittlerer Temperatur in sechs Theilen Wasser auf, erfordern aher dazu von kochendem kaum halb so viel, und we den im Fener nicht zalb so viel, und we den im Feter nicht zersetzt, aufser dafs jedoch bey anhalten-
dem Glibhen ein kleiner Theil salzichte dem Gluhen ein kleiner Theil salzichte
Säure entweicht. Die Aufösuug der salzSäure entweicht. Die Aufösuag der salz-
sauren Baryterde wird auf den geriossten sauren Barylerde wird auf den geringsten
Zusatz der Schwefelsäure und eines jeden diese Säure enthaltenden Salzes augenblicklicb zersetzt, und es scheidet sjcls wiederbergestellter Scliwerspath ab. Zu ibrer Aunösung mufs daher innmer destillirtes Wasser genommen werden; in diesem aber inuls sich dieselbe ohne Trübung aufösen, und völlig von Kohtensiure freyes Ammound vóllig von Kohlessiure freyes Ammo-
bium darf in der Aunösung keinen Nierterschlag bervorbringen. In Weinalcohol schlag bervorbringen. In Weinalcohol,
selbst in kochendern, ist dic reiue salzselbst in kochendem, ist dic reiue salz-
saure Baryterde unanfüslicb, nnd theilt saure Baryterde unanfüslich, nnd theilt
ihm blofs die Eigenschaft, mit gelbweifser Farbe zu brenuen mit.

n aus der Schwefelsäure und einer eigen. thümlichen Erde, der Baryt - oder Scbwereride, besteliendes Fossil, welches in den Metalleizuruben auf dern Harze und im Sächsischen Erzebürge als gewöbnliche Gangart verbomml, aufserdem auch in Gangart verkomml, aufserdem auch in
mehreren Ländle'n angetroffen wird. Der mehreren Ländern angetroffen wird. Der Schwerspath kornmt in vielerley Gestalten
vor, atn gewöhnlichsten aber in blättriger vor, an gewöhntichsten aber in blättriger
'Gestalt oder in mattgläuzenden, gelblictweifseu, röthliclsgelben, blafst othen, gratuet und sclıwärzlichen, derben Stückeu, als diclster Scliwerspatb. Er ist vier, bis vier nnd ein halb mal sehwerer als das Wasser, durch welche beträchtliche Schwere er sich von den Grypsen und dem Flufsspath unterscheidet. Im. Wasser ıst er vöIlig unanlöslicb. Im Feucr kuistert und lig unanflöslich. Im Feucr kuistert and zerspringt er mit Verlust seines Crystallsationswassers in zarte Sticke, die im
Dunkeln nicbt lenchen. Wird er nach Dunkeln nicbt leuchten. Wird er nach langem Glüben gerieben, so verhärtet el nicht mit. 'Wasser", wie der Gyps, löscht sicb aucb nicht odcr erhitzt sicb mit Wasser, wie der Kalkspath. Mı Säuren brat set der Schwerspatb nicbt auf, im Fall e uicbt mit luftgesänerten Erden verunreinigt ist. Die Scbwefelsäure entwickelt daratis keinen erstickenden Dampf, sondern löset ihu durch Kochen anf, läfst ibn aber bejm Zusatz vou Wasser sogleich wieder fallent Uebrigens fuhlt sich der
Schwerspath weich und salt an und, giebt
Mit metallischen Tlueilen, als Eisén, Kupfer und Bley vielleiclit auch woh zuweilen mit Arsenik verunreinigt.

Mit salzsaurem Kalke verunreinigt.

Mit salzsaurer Thon erde verunreinigt.

Mit salzsaurer Stron tianerde verunreinigt.

Mit Kalkspath ver- Lüset sich unter Aufbriusen in Salpetersäure \begin{tabular}{l|l} 
wechselt. & völlig auf. Gebrannt erhitzt er sich mit \\
Wasser.
\end{tabular} Mit Flu/sspat/l ver wechselt.

Mit Gypsspath verwechselt.

Mit Bleyspath verwechselt:

Mit Eisen stark verun reinigt.

Mit Kupfer stark verunreinigt.

Mit Braunstein ver. unreinigt.
Der äcbte Tolubalsam mufs auf glühende Kolllen geworfen einen reinen augenehmen $\mathrm{Ge}-$ ruch von sich geben und bintennach nicht wie Terpentin riecheu, in welchem Falle ex mit Geigenbarz verfälscht wäre.

die salzsaure Baryterle mit Fisen ode Kupfer verunreinigt, : so hat sie gemeiniglich eine ins Gelbe oder Grüne sich neigende Farbe. - Hahnemanns Probefliissiglscit, so wie geschwcfeltes $A$ mmonium bewirkea in der Aullösung einer-Init metillischen Theilen verunieinigten salzsauren Baryterde einen farbigen Niederschlag. -- Euthält.sie Eisen, so wird sie durcli blausaures Kali blau, und durch Galläpfeltinctur schwarz geforbt K upfergeh a l tentdcrk die blan Den welche auf Znmiscbuw von ätzendem mouium entstclst. -- B ley wird durch Habnemanns Trobeninssigkeit schwarz niedergeschlagen. - - Euthielte sie A r senik, so würde die Auflösung mit jener Flüssigkeit pommeranzengelb, durch ammoniacalisches Kupfer aber grü̈ gelh niedergeschlagen und diese Niederschläge wïrden auf glübende Koblen gebracht einen Knoblanclıseruch verbreiten.

Wird au der Luft feucht; der damit gekochte Weingeist brennt mit einer gelbrothen Farbe.

cuchtet ebcnfalls an der Luft. Die Auflösung giebt mit Aetzammonium einen erdigen farhelosen Niederschlag.

er mit ihr gekocbte Weingeist brennt als-

Die geglübeten Steine lenchten im Dunkeln. Schwefelsäure entwickelt daraus einen saureur elstickeulen Dainpf.

Lóset sich in fünfhundert Theilen kochendem - Wasser auf; auch in Scliwefelsäure, ohne dafs die Autlösung durch Zusatz von Was. ser wieder gefällt wird. Beym Brennen blähet er sich.auf und erbärtet nachher mit zugemischtem Wasser.

Wird durch aufgetröpfeltes gescliwefeltes $\mathrm{Am}$ monium oder $\mathrm{H}$ ah $\mathrm{n}$ em anns $P$ rohellüssigkeit schwarz, dagegen der Schwerspath weifs beibt.

Brisunlich, röthlich, dunkelgelb vou Farbe, oder mit einem starken braunrothen Anfluce verseben. Königswasser damit gekocht, wird durch Galläpfeltinctur schwarz gefärțt.

Grüulicb oder bläulich gefärbt, oder mit grünem oder blauem Anfinge verseben. Konigswasser damit gekocht und mit Am-
monium überșittigt, erbält einehlauc Farbe.

Giebt sich durcb eine ametlyyst- oder schwar braune Farbe zu erkennen. 


\begin{tabular}{|c|c|c|c|c|}
\hline $\begin{array}{l}\text { Namen } \\
\text { der Arzneymittel. }\end{array}$ & $\left|\begin{array}{c}\text { Sinnliche Eigen fchaften derfellen } \\
\text { Merkmale ihrer Aechtheit und } \\
\text { Giite. }\end{array}\right|$ & $\begin{array}{c}\text { Fehlerhafie } \text { Be- } \\
\text { /chaffenheit, Ver- } \\
\text { wechfelung oder } \\
\text { Verfälfchung. }\end{array} \mid$ & Kennzeichen & $\begin{array}{l}\text { Deren } \\
\text { und Prïfungsmittel. }\end{array}$ \\
\hline $\begin{array}{l}\text { Earyta sulphurica } \\
\text { nabiva. }\end{array}$ & $\begin{array}{l}\text { mit dem Stable keine Funken. Zur Aus- } \\
\text { scheidung seiner eigenthümlichen Erde mufs } \\
\text { immer ein möglichst reiner, ganz weifser, } \\
\text { mit beinem metallischen Anfluge überzo- } \\
\text { gener, auch inwendig nicht mit Erzpünct- } \\
\text { chen verunreinigter Scbwerspáth angewen- } \\
\text { det werden. }\end{array}$ & . & 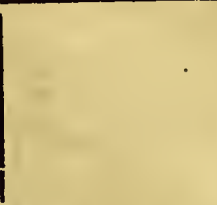 & \\
\hline
\end{tabular}

Bdellium.

Gummi Bdellii.

Bdellium.

in Gummiharz von einem noch unbekannten in Guinea, Arabien, Medien und Indien wachsenden Baume. Die bestc Sorte besteht aus kleinen, länglichtrunden Klümpchen, welcle äufserlıch eckigrunzlicht, röthlich, durchscheinend, von glattem Bruche, widrigem schwacben Gcruche und etwas widrigem, bitterlichen, dem venedisclien Terpentin ähneladen Geschmacke siud. Beym Kaven zerbröckelt es zwischen den Zichneist als das Lichte eutzinndet, breunt es hell und giebt einen balsamischen Geruch ron sich. Sorwo vell Wmen auföslich. Wasser nehmen eine groise Menge desselben auf und in laugensalziger Fissigkcit ibticher Die zweite gewönnlichere Sorte kommt in grofsen Klumpen von dunkelbraun rothlicher Fub zu uns, bielst auf dem Bruch wie Tischlerleinl aus, ist unreiner und ähnelt oft an Geruch and Geschmach einer unreinen Myrrbe. Je durchsichtiger, biegsamer und stärker riechenc̉ und schmeckend das Brelliun ist, um desto besser ist es. Man verfälscht es oft mit schlechter Myrrhe und vermengt es zuweilen mit arabischem Gummi, welches aber leicht $2 n$ erken'en ist.

Benzoe.

Gumini Benzoes. Benzoe.

Wohlriechender Asand.
Ein nach rorgemachteu Einschnıten aus dem St Stamme und deu Aesten des vorzüglich auf dcr Iusel Sumatra wachsenden Benzoe-
storaxbaums (Styrax Benzoin storaxbaums (Styrax Benzoin
Dryand.) schwitzendes Horz. Wir erbalten es in grofsen, trocknen, harten, docb brüchigen Massen, woran man noch die Eindrucke der Robrmatten, womit sie bedeckt gewesen, bemeskt. Die Stïcke sind aus wcifsen, gelblichen oder braunen und aus wionsen, gublich rothlichen rmandelformigen Kornern von verschied ener Grofse zusammengesetzt, die theils halbdurchsichtig, theils undurchsichtig sind. Der Gescrimack ist süfslich, harzig, balsamisch; der Geruch, besonders geerichen oder angezündet, durchdringend angenehm und balsamiscl. Im Weingeist wird die Benzoe völlig anfgel (jset; das Wasser, so wie fette und ätherische Oele zeigen wenig Wirkung darauf Der beym Schmelzen aufsteigende Dampfnimint in schick!ichen Gefäfseu anfgefangen eine feste, sebr lockere crystallinisclue Gestalt ante, nebrildet die sogcnannteu Benzoeblumen. Je durchsichtiger die Benzoestïcke sind, je mehrese und gröfsere weifse Körsind, je mehrere und gröfsere weifse Körner sich clarin befinden, um desto besser ist sie. Die feinste Sorte ist die sogellannte
Mandel benzoe (B o z zoe emygdalo ides.)

\begin{abstract}
guter Benzoe ei- Braune, schwäraliche, unreine und keine ne ganz schlechte weifsliche oder gelbliche Flceken inwenlig Sorte (Benzoe in- $\begin{aligned} & \text { enthaltendc grofse } \\ & \text { ein Kunstproduct. }\end{aligned}$
\end{abstract}

Bisonathum.

Marcasita.

Wismuth.

\section{in sebr sprödes, unter dem Haminer zerspri} Wasser ist, and schon bey schwachem Feuer, nodh che es gluhet, schelabar ist. An der Lumen Flanmlettrötblich an, rostet aber nicht merklicb. Im offen Feuer brennt es heym Grinten mit einer bismuthblucisen und dunkclgelben Rauche, der sich an ilen kiltern Tiegelwanden als ein weilsgeles), welches bey anbalmen) anlegt, und verändert sich dabey in eín gelbbräunlichtes Halboxyd (Wismuthasche), welches bey anhaitendem Fauer zn einem durchsichtigen braungelben Glase fliefset. Das vorzïglichste Anflösungsmittel des metallischen Wismuths ist die Salpetersäure; die Auflösung ist farbenlos und ätzend von Geschmach. Auch das
Königswasser uud die Essigsäure haben eine starke Wiıkung darauf; die übrigeu Säuren aber verbinden sich sehr schwer damit.

Bismuthim oxydatım album.

Magisterium Bismuthi.

Wismuthweifs.

Wismuthniederschlag.

\section{Durch Aufiösung des Wismuths in Salpoter-1} sänre ual Verd Hinnung dieser Aufösung mit destillirtem Wasser, wobey ein weifses pulver niederfall, welches ausge darstellt, bcicitet. Diescr Niederschlag ist nicbt, wic.man chećem glaubte, ein reines Wismichoxyd, sonderu ein vollkommen ncutralisirtes salpetersaures Wismuth, oder tralisirtes salpetersaures Wismuth, oder
mit Wismuthoxyd übersättigte Salpetersäure. Der Wismuthniederschlag mufs eiwe hlendende Wcifse und bey seiner ihm cigenthümlichen Scbwcre doch eine gewisse Lockerheit haben und sehr fein seyn. Jas damit geschüttelte destillirte Wasser darf die Lackmustinctur wicht röthen. In einom starken Fener mufs er für sich zu cinem braungelben Glase schmelzen uad in eimem gut bedecktcn Schinolatiegel mit Kohlen vermischt, sich gut reduciren lasses. Durch Einwirkuns des Lichts verliert er seine Weifse und wird gilb oder brännlich, er mufs desla:tb im Dunkelı getrocknet seyu und an hesteu in einem schwarz angestrichenen Glase mit eingeriebenen
Stopsel aufbewahts werden.
Mit Salpetersäure, die [Mehr oder minder grau, selb oder bräunlich, nicht frey von selbst schwärzlich gefärbt. Eben das ist \begin{tabular}{l|l} 
Schwefelsäure war, & der Fall, wenn der Niederschlag nicht \\
sorgfaltig getrocknet und aufhewahrt wird.
\end{tabular} bereitet, oder mic $\begin{aligned} & \text { sorgfaltig getrock net unshlag, welchen man } \\ & \text { So ist auch dcr Niederschla }\end{aligned}$ dem Niederschlage bcy Verdïunng der salpetcrsauren Aunödurch kohlensaure sung mit Biunnenwasser erbălt, gie von so Laugensalze ver- scböner Peschaffenheit, als der mit destilmischt.

$\overline{\text { Mit irgend einem }} \widehat{\text { Macht mit daranf gegossenem siedenden Was }}$ Satzmehle, gemei- ser einen Kleister.

ner Stürke oder Stärke aus Reis verfälscht.

Bleyoxyd enthaltend. Die Aufösung des Wismuthoxyds in SalpeSetropfelter, mit Silzsäure vcrmischter Schwe-
felsäure einen Niederschlag.

Anmerk. Giefst man die salpetersanre Wismuthantiösung zu einer schr vorthïnuteu filtrirten Antösung des Koclisal\%cs, so erhát man durch Tauscliverbinduvg ebenfalls einen selll weifen Niederschlag, or alzsares Wismuthoxyd isto 


\begin{tabular}{|c|c|c|c|}
\hline $\begin{array}{l}\text { Nownen } \\
\text { der Arżneymitiel. }\end{array}$ & $\begin{array}{c}\text { Sinnliche Eigenfchaften derfelben; } \\
\text { Merkmale ihrer Ächtheit und } \\
\text { Güice. }\end{array}$ & $\begin{array}{l}\text { Fehlerhafie Be- } \\
\text { fchaffenheic, Ver- } \\
\text { wechfelung oder } \\
\text { Verfälfchung. }\end{array}$ & $\begin{array}{c}\text { Deren } \\
\text { Kennzeichen und Priifungsmittel. }\end{array}$ \\
\hline
\end{tabular}

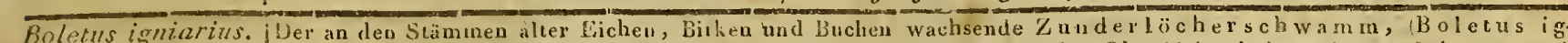
Feuerschwamm.

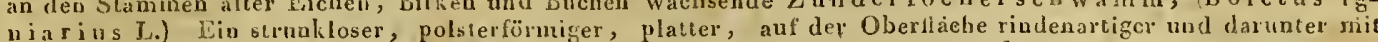

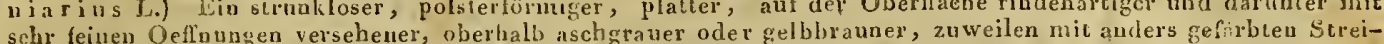
schr feinen Oeflnumen versehener, oberhalb aschgrauer oder gelbbraunex, zuweilen mit anders gefmblem Stretlen bezcichneter, iunerhalb weicher, am Rande weifslicher, wie auch auf der muter Seite weilser Sclswinm. Im friscuen Zustande hat, er einen schimmelartigen Geruch und bitterlicben Gcschmack. Maat sammlct itin im clie, trocknet sie und klopft sie mil einem bölzernen Ilammer möglichst weich. So rubereitet wird er als blut-

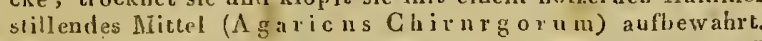

Boletus Laricis. Agsuricus aibus. Lerchenscliwamm.

Poletius Salicis. Weidenschwamin.

Bolus armenin. Armenischer Bolus.

Barax. Borax.

Boletus I ricis J a quin Ein am Shan aucis wohl an den Aesten des Lerchenhanms obne Stuel festsitzender Schwa sitzender Schwamm, der im frischen Zustanle rundlich, fach geworot an mit eruer farbigen, zolldicken, glatlem und nil weifsen, gelben und braunen Rivgen abwechseind gezeichneten finde überzogen ist; seine unte!e Seite ist mit mzahligen kleinen und feimen Löcherchen durchbohr. Zmin phrmacevtischen Gabranch wird

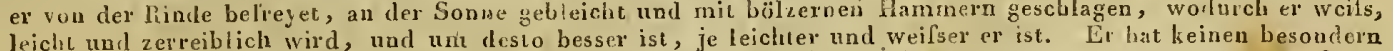
Geruch; sein Geschmack ist aufänglich süfslicit, nachlser scharf und eckelbaft bitter. Der schwere, mifofarbige, in billtell Stücken zerfallene und wurmstichige ist \%u verwerfen.

oletus suaveolens L. Ein au dev/Verwechselt mit ver-Die Firbe und der Gerno unterscheiden die Finde mehrerer. Weilienarten vom Ociober bis im Winter wachsender völlig stammloser Schwann run séhr abwechseluder Grörse und nochrentheils einfacher Gestat. Jung ist er gerneiniglich auf der küssenfrïruicen, uniichweilseu oder gelbtichca Oberitache mit setur leinen, weichen $\mathrm{H}_{a}$ aren beset $\% t$, thie sich atlmalig verlieren, so dafs er daun kabl und glate erscheint. Die innere weifse, oft ghlibriuulich geileckte Substanz sst gegen die Oberliäche hin dichu und fest wie Leder, uach der Unterfuche zu aber aus unz:hligeu feiuen, verscbiedenthch geformten Röhrchen zusamuten $\mathrm{e}$ setzt, welche auf der nutern, bisweilen brätulicher Seite des Schwammes, dis baic flach, bald concav, seltener convex ist intc runden, eckigen, ungleich weitcr Oeflunugen zeigen. Der Geschmack is milde, etwas schleimig - bilterlich; der Geruch angenebm, wewuirzhaft, veilchenartig, besonders nach einem Regen, Durc astion diesen Violengerch ist er, gegebenen Kentaeichen, leicht von andegn, auch an Weidenstamen wachsemlen Schwämmen zth unterscheiden. Die alten, rou Wirmern augefressenen und schwarz gesvorleven Schwämme sind verwerfich. ine selur feine 'Thouart von gelbröthlicher Farbe, welche sich feltig aufithlt, stark a der Zunge klebr, etwas ğäuzend uud leicht zesceiblich ist, jin Wasser zu eiscm feineı Brey zerfällı, abfärbı und mit Säuren uicht aufbrauset.

in eigenthürmliches, ans Loraxsäure und $\mathrm{Na}-$ trum bestehendes Neutralsala, in welcben das Natrum jorloch die Oberhand hat und nicht völli乡 mil Sacre gesättigt ist. Man gewint es aus dern rohen Borax odcr sogeschied enen andern. se Arten leicht. , Der Geruch des Irocknen Schwämmen, als Weirtenschwamms liffst sich bey dieser Boletus versicolor, , Prüfung durch Anfeucbten mit Wasser stärigniarizs. $L$. die 'ser erweclen.

igniarizs. L., die keinen angenehn
Geruch hiben.

Mit verschiedenen Schw ders gestaltet, haben alsch zum Theil eine Schwanmen als Bo- ganz audere Farbe, z. B. wer zulet $u$ geletus inglandis Bull., nanute, welcher pommeranzenfarbig auspolymorphus B. sielat.

elegans B., und odoratus Wolf. einiger in den Tibetanischen Geburgell in Persien Tiegenden Landseen durch allmälige Verdunstung erhält, vermittelst eines Zusatzes von Natrum intch Reinignug und Cirystallisation. . Der so gereinigte Borax (B O $\mathrm{r}^{\circ} \mathrm{x}$ a f $\mathrm{f} \mathrm{i} a \mathrm{a}$ a) bildet ziemlich grofse, weifse, feste, halbdurchsichtige, glänzende Cirystallen, die nur selten reguläre sechsseitice Säulen mit zwey schmalen und sechssetige Satenthichen und drcyseitivier breitern Seitentachen und datstelgen pyramidalischen Endspitzen darstellen. Er hat einell mitterliclien Geschnack, her laugenhaft bitterliclen Geschnack,
wird an der Luft nnit der Zeit unscheinbar und auf der Oberläche meblicht, löset sich bey mäfsiger Temperatur in zwöl Theilen Wasser, and in funf Theilen siedendem Wasser, niclat aber irn Weingeist auf. Mil Säurcn brausel er nicht auf, lärbt arer doch die blaen Plarzensäfte crün. aber Joch tie ter Alaun, lin Fer veriesis, blihe sich auf und liewirc erst tich fert eine leichise lockere us t.a.) In stärkerm Feuer niefst dieser zu einem durehsichtigen Glase, welches sich aber in Wasser aû̉öseu lälst.

Statt desselben ge-plst giöber, gewöhnlich blafsroth, doch auch meiner rother Bo- vou tieferer Farbc, matt' und gemeiniglich lus. in Stïcken, welche drey Zoll lang und zwey Zoll breit und dick siud, gcformt.

Mit Steinsalz ver- Er bewirkt dann aut glübeude Koblen geworfälscht. $\quad$ fen ein Knistern.

Mit Alaun verfälscht. Der Geschmack ist dann styptisch; der Veilcbeusaft wird davon roth gefärbt; er schmelzt schwer und nieht zu einer glasartigen Masse; die wälsrige Aufösung wird durch Kali uiedergeschlagen.

ie bohmen förmicen Samen der grofsen melouenarigen Früchte des im sädlichea America einheimischen, auf msh(Theoboma Gacao L.) reren westindiscben Inseln in grofser Merge gebauet werden 


\begin{tabular}{|c|c|c|c|}
\hline $\begin{array}{c}\text { Namen } \\
\text { der Arzneymittel. }\end{array}$ & $\begin{array}{c}\text { Sinnliche Eigenfchaften derfelben } \\
\text { Merkmale ihrer Ächtheit und } \\
\text { Guitte. }\end{array}$ & 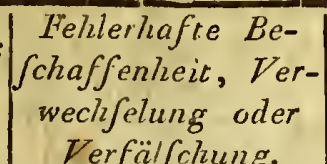 & $\begin{array}{l}\text { Deren } \\
\text { eichen und Priifun }\end{array}$ \\
\hline
\end{tabular}

Nuclei Cacao.

Cacaobohnen.

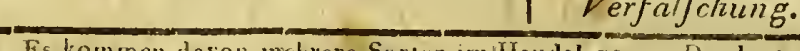

Es kommen davon metrere Sorten irulfaulel ror, Die besten Cacaobohnen sind mít einer raubeu, dưnuen, leicht zethrechlicheu, schwäralichothen und mit einer duskelgelb-grauen, oder mil eineıu sitberfarben glimmerartigen Pulver bestäubten Sclale ungcbeu, unter welcher der brauurotbgranliche, etwas glänzende, markige, lcicht brüchigc und in Kleine Stïcken zerfallende, rein fettige, angcnebm bitterlich schmcckènle Kern
beñndlich ist, der sich in Flügel zertheilen läfst, die noch mit einem zarten Häntcheu umbüllt sind. Von dieber Beschaffenbeit ist die er s le und beste Sorte, nämlich der Carackische Caca o Cacao Carague, de Caraguas), der in ledernen Zerronen aus der Provinz Venezuela oder Nikaragua in Neu-Spanicn kommt und den man noch in Hinsicht seiuer Gröfse in Handel in Grofs- und Klein - Caragua unterscheidct, obg!cicls dıese Caciosorte überhanpt mehr laug als dick, etwas platt, vou unebner Obeıfäche und härter, ölhalliger und schwerer ist, als die üurigen Sorten sind. Hierauf folgt als die zweyte Sorte der Berbici$s$ che Cacao, der von den Holländcrin auf der Insel Berbice sebauet wird. Die Bohnen sind kleiner, rumelicher, auf der Oberfäclee ebeuer und slatter, mit eincm'granen Pulver bestrenet, auch von angeneh bithern doch nicht so feinem Geschmack. Die d rit te Sorte macht der Cac a vo den In sische, vou den.Antillen, Martinique, Cayenne und Domingo. Diese Bohnen sind noch kleiner, wehr brcit als rudd, mit fast gabz glatier, nicht bestäubter, schwarzbrauner Schale, die viel fester an dem bitter und etwas herbe schmeckenden nicht so fetten Kerne bängt. Die vierte und schlechteste Sortc ist erdlich der Brasilianische oder Portugiesische Cacao, der lang, schmal, flach, dunkelbra ist erdlich der und bitterlich schueckt. - - Die schimmlicbten, inwendig weifslich aussehenden, dumpricht und fade schme-

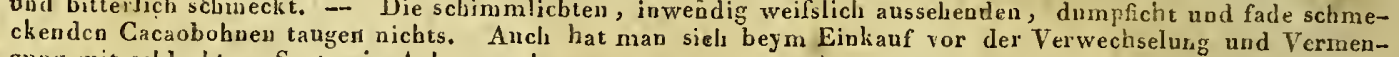
ckendcn Cacaobohnen taugen nichts. Auch hat man siels beym Einkauf vor der Verwechselung und Vermen-
gung mit schlechtein Sorten in Acht zu nehmen.

Calcaria.

Calx.

Kalkerde.

Iralk.

\section{Calcaria minuia- tica.} Sal ammoniacum fixum.

Salzsaurer Kalk.
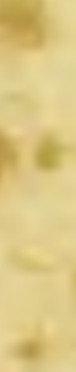

$\overline{\text { Calcaria sulphu- }}$

rata. Sulphuris

Calcareum.

Ge-chwefelte Kalk-

IKalkschwefelleber.

Calcaria sulpluzraro-stiliata. Calx Antimoniicum Spicisgianzschwefelkalk.
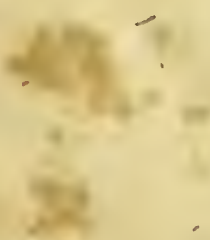

Calcuria ista. ne eigenthümliche mit Kohlensänre verbudene Erde, die im Miucralreiche sehr bäufig als ein halbbarter Stein von einer mehr oder weniger weifsen oder granen Farbe und einen grobsplitterichien Bruche, irn Thierreiche aber varzüglich in den Schalen der Schallhiere vorkommt. In reinem Wasser ist der hoblensaure $K$ alk nnauflöslich; mit Säuren brauset er stark auf; beym Brennen verliert er das darin enthaltese Wasser und die Kuhlensäure und bekomrat alsdann die nnter Calcaria usta bemerkten Eigenscliafien. Zuni Arzaeygebranch mufs man eineu von fremdartigen Theileu mö̈lichst reineu Kalk wählen, wie 2. B. den weifsen car ra-
rischen M armor, die Austcrschalen, Krebssteipe, reine Kreide Durch Aulösung und Sälligung von reiuer|Mit Thonerde verun-Die Aun̈̈sungo wird dann durch zugesetztes kolilensauren Kalkerde nit Salzsäure und reinigt. nachlériger Verdunstung bis zur Trockne bereitet. Der so erlialtene salzsaure Kalk
stellt ein weifses Pulier dar; welches eius
fer, veruneingt. stellt ein weifses Pulier dar; welches einin
nnargenehm bitteru Geschmack hat, die Feuchtigkeit der Luft schnell arzieht, sicb in andertialb Theilen kaltem nnd in weit weniger als es selbst wiegt, siedendem Wasser, so wie auch im Weingeist auflöset und in mäfsiger Hitce wie Wachs Riefst. Uebrigens lärst sich dej: salzsaure Kalk auch crystallisirc darstellen; er ist aber in auch crystallisirt darstellen; er ist aber in dieser Form so wenig Figuibestandig, dafs
er sich alch in dcm genau verschlossensien Glase bey jeder Abänderung der Witterung ebenfalls verandert und bakl als festé cry stalliniscle Masse, bald zum Theil oder ganz zerflossen zeigt.

as gleichen Theilcu gepulverten Austcrscbalen und reinem Schwefel durch vicrtelstündiges Weifsglühen in einem bedeckten 'Tiegel bereitet. Win gell,lichweifses, trockucs Pulver; welches an der Iufi und durch Säuren sehr bald zersetzt wird, indern sich dabey eine beträchtliche Menge Schwefelwasser'stoffgas cntwickelt, welches man an dem eigenthümlicbon Geruche desselben nach faulen Eyern bemert. Im Wasser is die Schwefelkalkerde auflösbar und die Aulösung, welche, ebenfalls deu Geruch Aulösung, welche, ebenfalls deu Geruch gelbe Farbe. Wegen ihrcr leichten Zersetzbarkeit mufs die Scbwefelkalkerde, deren Güte lediglich von ihrcm völligen Unzcrsetziseyn ablängt, î völlig luftedicht verschlosseneu Glasern aufbewahrt werden. iacla der Prenfsiscben Pharmacopoe aus an-
derthalb Unzen frisch gebrauntcm Kalk, derthalb Unzen firsch gebrauntcm Kalk,
eiver babon Unze pommeranzenfarbenen SpiefsolanzschwefeI nud zwölf Unzen Wasser in einem Porcellaingefäfs unter beständigcrn Umrühren über gelindeu Feuer bis zur Trockcuheit abgedampf, bercitet.

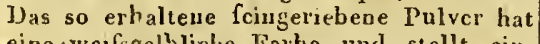
eine 'werfsgelłliche Farbe und stellt eiu, bis anf den Getalt von Spiefsglanzoxyd, dern vorigen (Calcaria sulplurata) ibuliches Mittel dal. Verdüuute Essigsäuse fället aus dcsscu Aunösung, noter Verbreitung eines Geruches von gescbwcfelte: $1, W$ asserstolfzas, pommeranzenfarbcuen Spicl'sglauzschwefel uud nachber wird - Spictsaluschwefel uud nachber wird durch zugcsetzles Kali noch Ka!kerde dar-
aus niedergesclulac a. In wohlverstopfton, nur besten iu Drachmenglüsern, vor dcm 'Lutrilt der Luft gesicher, aufuberwaltren.

\section{Sch} und afbewahrt und dadurch un-
kräftig geworden.

icht vorsichtig genug aufbewabrt und dadurch kräftig.

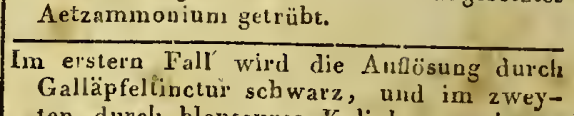
ten durch blausaures Kali braunroth ge-
fällt.

Dies findet sich, wenn man sie in Wasser antlïst, und lieser Anflösung eiue Säure zusetzt, wobey sich Scliwefel ausscheiden durch den Geruch zu erkeunen giebt, bäufig entwickeln mufs. Hat die Anflösung mur eine sehr blal'sgelbe Farbe, so ist dies - ein Beweis, dafs durch die Einwirkuug der Luft der gröfste Theil des Schwefels bereits ausgeschieden ist, und sie daher wieder ausgeschieden ist, und sie daher wieder
frisch bereitet werden.müste.

Auf dieselbe Werse, wie die geschwefelce Kalkerdle zu prüfen. $Z$ u dieser Prúfung ist indefs eine Auflösung.nicht uubedingt nothwendig, denn auch das trockne Priver wird, wenu cs mil einer mit Wasser verund sochwefelwasserstoff gas, welchcs sich dünuten Sänre übergosseu wird, Schwefelwasserstofigas entwickeln, wenn es dureh die Einwirkung der atmosphärischen Luft noch keine bcträchtliche Zersetzung erlitten hab.

ed durch starkes und auhalicndes-Bennen in Fener sebiner Kohleusänre no seines Crystallisationswassers bem dabte Kalk, welcher dadurch obngefalir um die Ililfte leichter wird, eiven scbarfeu brennenden Géschmack, 


\begin{tabular}{|c|c|c|c|}
\hline $\begin{array}{c}\text { Namen } \\
\text { der Arzneymittel. }\end{array}$ & $\begin{array}{c}\text { Sinnliche Eigenfchaften derSelbein } \\
\text { Merkmale ihrer Ächtheit und } \\
\text { Giite. }\end{array}$ & $\left|\begin{array}{c}\text { Fehlerhafie Be- } \\
\text { fchaffenheit, Ver- } \\
\text { wechselung oder } \\
\text { Verfälfchung. }\end{array}\right|$ & $\begin{array}{c}\text { Deren } \\
\text { Kennzeichen und Prïfungsmittel. }\end{array}$ \\
\hline
\end{tabular}

steru. Zum Kohleupulver müssen sie gehürig ausgegtuht und von aller Lult befreyt sejn; das Pulver muls in wohl verschlossenen gläsernen oder stemzenguen Gefäfsen vou verschiedener Grölse vor dem $\mathrm{Zu}-$ tritt der Luft möglichst gesiclieri an einem warmen Orte auflewahrt werden.

Carloo Spongiae. Sirongite ustae. Meerschwammkohle.

Gebramnte

Sclivämme.

Cardimomum mi-

Kleine Cardamomen.
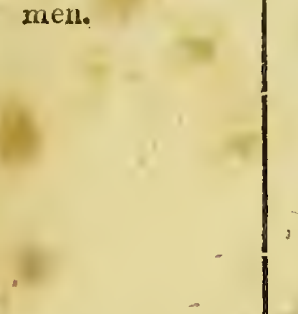

Caricae.

Ficus passae.

Feigen.
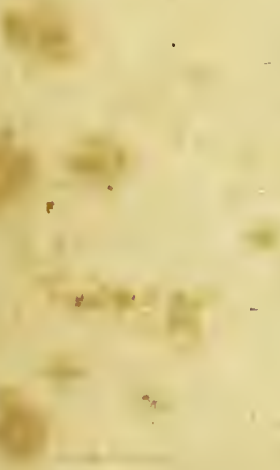

Caryophylli.

Gewirznelken.

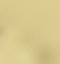

$$
\text { i. }
$$

mïssen grofs, schwer, leicht zerbrcch-

licls seyn, auswendig selir dumkelbraun,

inwcudig rothbraun aussclien, und weno

man sie mit den Nigelis drückt odcr ritzt,
etwas ïlichte Fenobtigkeit von sich geben. verengernde Samencapseln, welche inwendig in drey Fächcr abgetheilt sind, iu deren jedem zivey lieilen ziemlich viereckiIserlieh brauner, inwendig. weifser Samen liegcu, welche zerdrückt einen sebr staremen angenehm gewïrzhaften, etwas can Theräbulicheu, scharfen, bintenuach kübleuden Gesclumack haben.

ie in den heifscn Ländern woht sereiften, hal bgctrockneten fleischichten Früchte, odcr
vielnebr Fruchtböden des Fe i g en ba u ms (Ficus Carica L.), die wir in Kisten, Fässern oder Korbern gepackt crbalten, zusammengeprefst erscbeiveur. Sie seben schleimichtes, selir süfses, mit einer Menge henes, etwas zähes Tleiscb. In Tandel giebt es gewölnnlich dreyerley Sor'ten, nämilıcs: gelb, rund, meistens trockner als die andern sind. 2) Dic G e u u e s is chen,
noch gröfsar, gellier, aber länglich sind 5) Die Marseill er, welche kleiner, gelb und rund sind, an an enebmsten und süfsesten schnecken, sielı aber nicht läng er als ein Jahr conserviren. Zum Arzaeygesehr süfseu, etwas durcluscheinenden' Fcigen (Caricae pingues) auswählen.

ie noch vioht aufebrocbenen Blütheu mit Moluckischen Inseln $z_{n}$ Hause gchörenden Gew ürznelken banms (Eug ein i c ay oply 11 a ta Thunb.), welche erst im Rauche, und dann vollends an der Sonne malsig getrocknet, turscrlich schwarziaun, brann sind. Sie habèn die Gestalt eines kleinen Nagels und bestcheu oben aus einemn leicht abfallenten rundlichen Kuöpfcheu, das aus dex vierblättrigen noch geeberfalls vierblätrichen Kelche gebildet wird, welches an dem untern rundlicheu, ohngefähr eincn halben Zoll langen, gesen das Lnde scbmalern, auf ansetzt und von ejnem andern dickern und oberwärts vierspaltigen Kelche unschlosscbes Oel und haben, besonder's der uv tere 'Tfreil, einen star'ien eigenthürnliclien, an renchm balsimisclien Geruch und cincn brounend sewürah a fien, etwas bitterlichen, chure lange auf der Zunge nachblei-

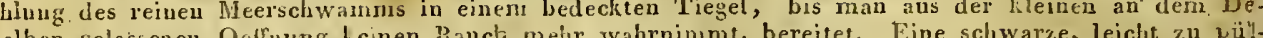
verude, lockere Masse olue sonderlichen Geruci, aber von unangenehineil salzichtem Geschmacke, welche dic Fenchtiskit der Luft anzieht und daher in einem wohl verkorkten Glase aufbewahrt werden mufs. Der Schwamm darf dabey nicht zu Asche gebıanint seyn, weil, el alsdaun völlig unwirksau ist. -- Andere lasSer klein seschnitten, in einer Kaffeetrommel stark rösten; daun haben die Situeke eine scbwarzbraune Farbe, einew brenzlicben Geruch, sind leicht und zerreiblich:

Fuchte des in Osliudien wachsenden Statt ihrer werden|Diese sind gegen anderthalb Zoll lang, dinu-

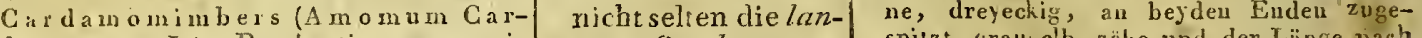
damomum L.) Dieyliantige, gegen ei- gen Cardamomen ntn halben Zoll lange uvd cineu viertel) (Cardamomimmlon-

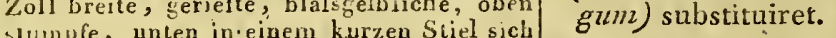
weifsgelblich aus nud haben ein etwas 1) die $S m y r u$ ischen, welche grofs,

So auch die runder Cardamomen (Cardamomum rotundizm2.)

pestreflic

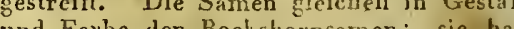

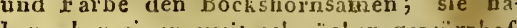
ben abcr einen weil schwacher gewhirhal kleinen Cardamomen.

Haben fast die Gestalt der Haseluüsse, sind doeh aber etwas dreykantig, leicht zerbrechlich und metr oder weniger sclb. Dic auf einer Seite eckigen, auf ber andein runden Samen besitzev eiuen mein bittern und stärker campherartigen Geschmacli und unangenehmern Geruch, als die der kleinen Cirrdamomen.

Veraltet und verdor- Die veralteten, trocknen, larten, sehr dunben.

keloen, genen, voller Milbcu sitzenden und davon angefresseneu, geschmacklosen oder bitterlich schmeckenden Feigên sind zum Alizneygebranch verwerflich. Was den Zuckelstaub, womit sich dic Oberfläche der Feigen zu überziehen pnegt, betrifft, so ist derselbe von der einen Seite betraclatet wobl als cin Merkmal ihrer Güte und Reife anzusehen; andererseits zeigl derselbe aber doch auch a $n_{x}$ dafs sie dem Verderbeu' uahe siud, weil ias Fleisch der Feigen um desto geschmachloser und zugleicl bitter er wird je melor dieser Ueber zug zunimmt.

Nicht im Rauche, sondern blos an der Sonne getrocknet. Mit solchen verfälscht aus denen scion das Oel destillirt worden. $m$.

Nachgekünstelt aus
schwarzer Biodrinde und einige Zeit in Gewïrznelliea tinctur eingeweicht. Nachgekünstelt aus einein Teige von ge stolsenem Piment mit Tragantschleim. Das leulver wird häufig, theils mit NelTenzimm (Casta), theils mit $\mathrm{Nel}$ kenpfeffer (Semen Amomii) verfälscht.
Diese sind nicht so sehwarzbraun, rüuzlich, schmatzig, leicht und weicis, und von minder gewürzhaftem Geruch und Geschmack. Ein Betrug; der sich durch die blassere Farbe solcher Nelken, durch ihre Leichtigkeit, durch den minder kräftigen Geruch und Geschmack und durch das mangelude Oel. beym Druck zwischen den Fiu, ern und beyn Stofsen zu erkenuen gieb.

chwerlich genau wie die achten gestalcet, leichter, schwammichter, żrö ölser, geschrnackloser und im Mörser leichter $z u$ J'ulver zerreibbar.

ehr ungestaltet, schon dadurcb leicht zu erkennen; sonst auch dadurch, dafs sie im Wasser zergehen.

Lä́st sich am sichersten durch Tergleichung mit ̈̈chtem Nelkenpolver erkíaneu. 1)ergleichen Pulves mïssen überhaupt nie duroh den Tandel bezosca, sonder v voll jedem A poibeker selbst baieitet werden.
Cassia caryophyllata.
Nellsenzimint.

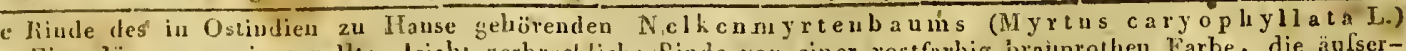
Fine diinue, wcnis gerollte, leicht zerbrechtiche findc von einer rostfurbig braunrocheu Farbe, die aufserlich etwas beller ist. Sie hat einen uelke
zugleicl, etwas adstringirenden Geschnack. 
Cassia cinnamomea -- Castoreum.

\begin{tabular}{c|c} 
Namen & $\begin{array}{c}\text { Sinnliche Eigenfchaften derfelben } \\
\text { Merkmale ihrer Aechtheit und } \\
\text { Guite. }\end{array}$ \\
\hline
\end{tabular}

Fehlerhafte $B e-$ Ichaffenheit, Verwechfelung oder Verfälfchung.
Deren

Kennzeichen und Priifungsmittel.

\section{Cassia
mea. \\ Zimmtcassia.}

Zimmtsorte

Sinesischer Zimmt.

Cassia fistula s fistularis. Rohrcassia. Purgircassia.

Zimmtsortenlorbeers Aesten des Cissia L.), der in Sumatra, Java, Ceylon u. s. w. wächst und dem wahren Zimmbaume sehr ahulicb ist. Anch die Riude hat mit dem ächten Zimmt in $\mathrm{Au}-$ sehung des Geruchs und Geschmacks sebr viele A elınlichkeit, nuterscheidet sich aber davon durch ihre dunklere Farbe, durch ihre mehrere Dicke und einen feurigern, im Munde lange anhaltenden Geschmack. Man erhält sie durch die Engländer in Pfundscbweren, drey viertel Ellen langen, an beyden Enden und in der Mitte zusammengebundenen Büudchen. Sic ist mit in mencebaric ist mit in nie Lange theils gerade durchlaufenden tbeils gewundencn, bellarbencn Adern, bezeichnet, von ebenem, blässerm Bruch,
bald in halbliniendicken, glatten Röhren bald in halbliniendicken, glatten Röhren
zusammengerollt, bisld in stärkern, über zusammengerollt, bisld in stärkern, über
eine Linie dicken und fiinf bis sechs Livien breiten plattern Stücken. Ihren eigenthümlichen Geruch und Gescbmack be hält sie sehr lange, und bey der Destilla tion liefert sie über doppelt so viel ätherisches $\mathrm{Oel}$, als der ächte Zirumt, welcbes Oel nebst dem dabey gewonneuen ölreichen Wasser sich von dem aus letzterm de stillirten nicbt unterscheideu läfst. bey ist sie viel wohlffiler, als der ächte Zimmt.

Die Frïchte der in beyàen Indien, in Arabien nnd den wairmern America wachsenden Robrcassia (Cassia Fistula L.) Einen bis zwey Fufs lange, einen Zoll und darïbcr dickc, walzeuförmige, gerade oder einwarts gekummte, braunschwarze Gliederhülsen, welche innerbalb ibrer harten, derhüsen, welche innerbalb Site mit einer holzicbten, auf der einen Seite mit einer
Nath versehenen Hülse zwiscben mehreren Nath versehenen Hülse zwiscben mehreren
Queel'scbeidewänden eingeschlosscn, ein Queer'scbeidewänden, eingeschlosscn, ein
weichcs, schwarzes, süfsschmeckendes Mark enthalten, in welchem die rundlichen, harten, gedrüekteı, glänzenden und braunen -Sameu liegen. Man schätzt vorzüglich die Levantische Rohrcassie, welche länger und dicker ist, und ein süfseres Mark enthält : Die meiste kommt jedoch aus Amerika.

m, friscben Zustande eine talgartige, weicbe, jedoch nicht fettige, sondern mebr gummichtbarzige, einigermafsen zäbe, schmie-rige Substanz von einem besonders widrigen, starken Geruch und bitterlichen, etwas beifsenden Geschmack, die sich sowohl bey dem mämnlichen als dem weiblichen $B$ iber (Castor Fiber L.) in zwey chen $B$ iber (Castor besondern, am Bauche auf leyden Seiten zwischen dem After und dem Schaambeine sitzenden Beuteln, deren jeder boch mit
eincm obcrn and kleinern, das. B ibergeilfett (Axungia Castorei) entbalienden, Nebenbeutel versehen ist, vorfindet. In den friscben Beuteln ist das $\mathrm{Bi}-$ bergeil weifs oder vielmelr schmutzig pommeranzenfarbig; in den durchs Räuchern getrockneten aber, wie es in Handel vorgetrockt, bar.

Man untcrscheidet zwey Sorten. 3) das Sibiriscbe oder Moscowitische (Castorenm sibiricum, moscowi$t$ ic $u$ m), mit welchem auch das Preufsische, Polnische und Deutsche übereinstimnt. Wir erhalten es in fast kegelförmigen, unten ruuden, getrockneten, dunkelbraunen, höckerichten, schweren Beu teln, die auswendig mit einer dicken, starken, festen, anf der Oberfläche sich durchaus glatt uud unverletzt anfiiblenden bäuticen Substanz umgeben sind. Wird ein solcher Beutel durchgcschnitten, so besteht derselbe im Innern'aus einem dichten steht derselbe Gewebe, in welchem die ejentliche SubGewebe, in welchem die eigenthiche Substanz des Bibergeils eingcschlossen und da-
mit fest verwacksen ist. Mit einem jeden

Rinde des in Ostindien, volriiglich i Mutterzimint (Cas- Nalabar wachsenden M t te rz immt 1 or sia lignea.) beers (Laurus Malabatbum Burm.) Lise, wie die Zimmtsorte aus röbrichten und platten Stucken bestehende, auf friscbern Bruche glatte, nicht faserichte Rinde, die sich von jener sowobl durch ibre dunklere Farbe, ranbere Oberfläche, weit schwächeru Geruch un $\mathrm{Ge}$ schmack, als auch vorzüglich und wesentlich durch den viclen Scblenm, den sie beym Kauen and Kochen mit Wasser gicbt, untcrscheidet, Der Aufgufs des Pulvers init kochendem Wasser erkaliet zur Gallerte Bey der Destillation erbält mar zwar milchichtes Wasser, aber es soll sich daron kein Oel absondern lasseu. Man hat davon ima durch ihre gröfsere und geringere Güte untcrscheiden.

Verdorben

Die Rohrcassia verdirht a) durchs Eintrock. nen des Marks, da dann die Hülsen leicht werden uod die Samenkörner beym Schütteln darin lilappern. Doch ist diese, so lange das Mark süfs bleibt und nicht ganz trockeu wird, noch nicht manz unbrauchbar. b) Durch saure Gälurung des Marks in welchen Falle es aun der in welchenn Falle sch Durt, anfressen won Wïrmert wird. c) Durcbs Anfressen von Wirmern, welches zum Sauerwerden Gelegenheit gicbt. Am leichtesten verderben die unreif abgc'nommeuen, düvuern, beym Trocknen rnnzlich gewordenen Frïchte.

$\overline{\text { Veraltet und dadurch }}$ verdorben.

Mit Bleystiickcluen, Steinchen u. dgl. vermengt.

Auf mancherley. Art verfälscht.

Schwarz, dürre, von geringem Geruche und Geschmack.

seschieht dieses nicht selten um die Schwere der Beutel zu vermebren. Man findet es, wenn man die Beutel öfnet und den Inbalt genau untersucht.

Das Bibergeil ist überhaup mauchen Verfälschuugen nuterworfen. Es giebt Betrüger, die aus deu frischen Beuteln das Bibergeil berausuehmen, und statt desselben feingesclnittcnes und getrocknetes Fleiscb oder getrocknetes Blue hineinfüll cn. Das englische Bibcrgeil, welches an sich schon von geringer Güte ist, soll sehr häufig nichts weiter als ein Kunstproduct aus Btbergeilpulver mit Ammoniak, Sagapen, Muterharz, Stinkasand, Diz Stinkasand, getrocknetem Blute, Drachemtut u.s. w. zusanet und in Ziegenbor- und Schaifgallenblasen gefullt, seyn. Der schwachere Geruch uud Geschmack, die äufsere dünnere Haut, die darin gemeiniglich frey und lose liegende Masse selbst, der Mangel des innern zellichten Gewebes, die bey einem solcben verfallschten Bibergeil fehlende, vorher angezeigte, innere Höhlung in der Mitte der Masse, dic meistens hellere Farbe derselben, so wie das Schmelnen in der. Hitre und das Ankleben beym Tauen an die Zäne, Wena ? beym Kauen an dio Zahe, wena viele Betrügereyen leicht entdecken. 


\begin{tabular}{|c|c|c|c|c|}
\hline $\begin{array}{c}\text { Namen } \\
\text { der Arzneymittel. }\end{array}$ & $\begin{array}{c}\text { Sinnliche Eigenfchaften derfellen; } \\
\text { Merkmale ihrer Aechtheit und } \\
\text { Güte. }\end{array}$ & $\begin{array}{l}\text { Fehlerhafte Be- } \\
\text { fchaffenheit, Ver- } \\
\text { wechjelung oder } \\
\text { Verfälfchung. }\end{array}$ & Kennzeichen & $\begin{array}{l}\text { Deren } \\
\text { und Prüfungsmittel. }\end{array}$ \\
\hline
\end{tabular}

solcher da gewesen und nur davon abgelöset worden. Jene Masse des Bibergeils fülset worden. Jene Masser des hängenden Bibergeilbeutel ganz aus, hat hängenden Dit in der Mitte eine Höhlung, durch aber in der Mitte eine Höhlung, durch
welche der innere Zusammenhang der welche der innere Zusammenhang der Masse aufgehoben ist, und welche Höhlung der eigentliche Character des äcbten
Bibergeils ist. Die eigentliche Snbstanz Bibergeils ist. Die eigentliche Snbstanz
des Bibergeils, abgesondert von dem bäutigen Zeligewebe, 'womit sie durchflochten ist, ist schwärzlichbraun, trocken, doch nicht dürre, fest, bröcklich, leiclt zerreiblich und von obgedachtem $\mathrm{Ge}$ schmack und Gerucb. Diese Sorte ist die beste ind übertrift an Gïte alles Bibergeil beste bracht wird.

bracht wird. Geringer als diese, sowohl im Preise
als in der Güte und Wirksamkeit ist 2) das als in der Güte und Wirksamkeit ist 2) das
Englische oder Canadiscbe Bibergeil (Castoreum a uglicum, canadense.) Wir erhalten es aus Canada über Englaud in kleinern, länglichten, sebr eingeschrumpften, mehr schwarzen, düunbäutigen Beuteln, deren äufsere bäutige Substanz ranb, dünne und lose ist, gleichsam als wäre die Haut abgezogen. auch findet sich keine Spur von daran auch fin wesenen Fettbeuteln. Beym Durchschneiden eines teutels findet man darin unendlicb viele kleine, ganz feine durchsichtige
Häutchcu, so dafs man anfangs getäuscht Häutchcu, so dafs man anfangs getäuscht
wird. Man findet abër bald, dafs jene wird. Man findet abẻr bald, dafs jene
Häute mit der darin befindlichen Substanz gar nicht verwachsen sind. Die oben bemerkte innere Hölllung fehlt bier ganz. Der Geruch ist weit scbwächer und mehr fettartig. Die Masse selbst ist mehr dürre und bart, zerreiblicher und heller von Farbe. - Der Apotheker mufs sich also lediglich an das Russiscbe Bibergeil halten ledich an das Russiscbe Bibergeil haiten und dieses in zugebundener Blase und in einem wohlverschlossenen Gefälse an einem kühlen Orte aufbewahren.

Ćateclutu.

Terra japonica, Catechu!

Ein aus den Rinden, Hölzern und Frïchten verschiedener indianischer Gewächse, vorzüglich wohl der $\mathrm{Cat}$ echum in ose (M imosa Catechu L.) und der Arekapalme (Areca Catechu L.) durch Auszochung mit Wasser und Abdunstung bis zur Trockne ber eitetes Extract. So wie
dasselbe im Handel vorkornmt, besteht es aus fester, barten, dichten, ungleichen, zerbrechlichen, schwarzbraunen, im Brucbe rothbraunen, gerucblosen Stücken, die einen herben, bitterlichen, zuletzt süfslich zusammenzieheuden Geschrizack haben. Ein gutes Catechu mufs auf der Zunge nicht ankleben, sondern vielmebr gänzlich zerfliefsen, in einem glïbenden Löffel bis auf einen geringen Rückstand gänzlich verbreneinen geringen Ruckstand ganzlich verbrennen und sicb in Wasser, Essig, Wein und schwachen Branntwein bis auf einige Un-
reinigkeiten, als Holzfasern u. dgl. auflöreinigkeiten, als Holzfasern u. dgl. auflösen lassen. Die geislige Auflösung darf durch Wasser nicht getrübt werden.

Cera alba.

Weifses Wachs.

Das durch Ausstellen des gelben Wachses a der Sonne bey fleifsigem Begiefseu mit Wasser gebleichte Wachs. Man erhält es gewöhnlich in der Gestalt von dünuen und runden Scheiben. Es hat eine sehr weifse Farbe, ist etwas durchsichtig, gerucblos und specifisch schwerer, härter, spröder und schwerflüsiger als das gelbe Wachs, mit welchem es übrigens in seinen chemi schen Eigenschaften übereinkoinmt.

Cera citrina.

Gelbes Wachs,
Das Wachs ist ein eigengearteter Pflanzen stofl. Von den Honighienen gesammlet und aus den Honizzcllen, nachdem der Honig abgesondert worden, durchs Ausschigelzen gewonnen, crhalteu wir das gelschmelzen gewonnen, crhalten wir das gel-
be Wachs gewöbnlich in cheibenförmigen
Mlit einer glänzenden, $\overline{K l e b t \text { an dex }} \overline{\text { Zunge an und zerfiefst darau }}$ braunrothen Thon- nicht; löset sicb in den angegebenen Flüserde verfälscht.

Mit Talg versetzt.

Nicbt so brüchir und spröde; der Talo riech vor, zumal auf glüLenden Kohlen. Aetzende Kalilauge löset nach $\mathrm{Hab}$ a eman den $T$ alg daraus auf und das Wachs scheiden Talg daraus auf und das Wachs sckeibey der Aufösung in Wasser wieder aus.

Es soll auch quweilen Durch $\mathrm{Hab}$ emanns Probeflüssigkeit leicht mit Bleyweifs ver- zu eutdecken, indẻm es damit eine metalfälscht werden. lisch glänzende schwärzliche Farbe annimmt.

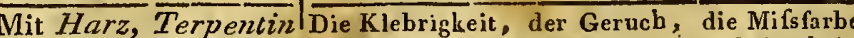
oder weifsem Pechl und noch mehr der Harz- und Pechgeverfälscht. schmack beym Kaven eines solchen Wachses geben diesé Verfälschung bald $2 n$ erkenuen. Aufserdem erfährt man es bey der so geringen Außüslichkeit der unverfälech- 
Cera citrina. -- Cerussa alba.

\begin{tabular}{|c|c|c|c|}
\hline $\begin{array}{l}\text { Namen } \\
\text { der Arzneymictel. }\end{array}$ & $\begin{array}{c}\text { Sinnliche Eigenfchaften derfelben; } \\
\text { Merkmale ihrer Aechtheit. und } \\
\text { Giite. }\end{array}$ & $\begin{array}{c}\text { Fehlerluafte Be- } \\
\text { scluaffenheit, Ver- } \\
\text { wechfelung oder } \\
\text { Verfälfchung.. }\end{array}$ & $\begin{array}{c}\text { Deren } \\
\text { Kennzeiclien und Priifungsmittel: }\end{array}$ \\
\hline \multirow[t]{4}{*}{ 'Cera citring. } & \multirow{4}{*}{ 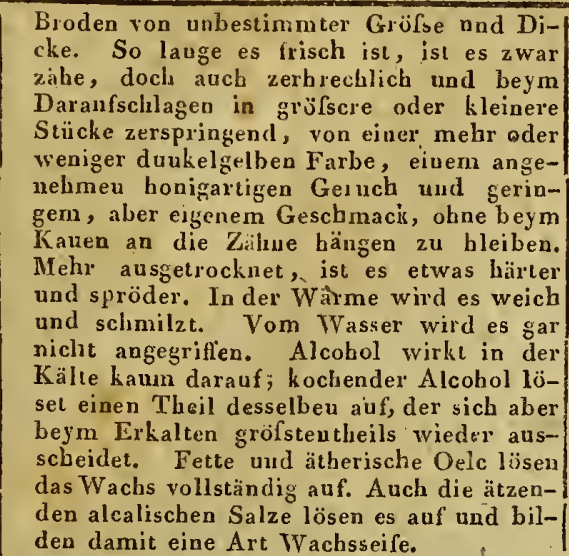 } & & 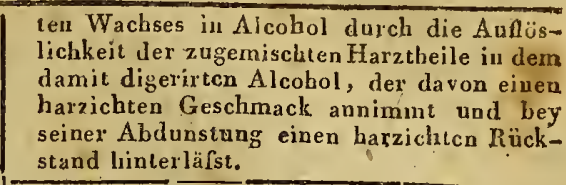 \\
\hline & & $\begin{array}{l}\text { Mit Mehl, besonders } \\
\text { mit Erbsenmehl } \\
\text { verfälscht. }\end{array}$ & $\begin{array}{l}\text { Blasser von Farbe, streng schmeckend, beyn } \\
\text { Daraufschlagen uicht in so grofse Stiuck } \\
\text { zerspringend, sondern in kleine krümlich } \\
\text { Stücke zerbröckelnd, Beym Schmelizer } \\
\text { soudert sich das Mehl.ab. }\end{array}$ \\
\hline & & $\begin{array}{l}\text { Mit erdigen Theilen } \\
\text { verfälscht. }\end{array}$ & Diese scheiden sich beym Schmelzen ab. \\
\hline & & $\begin{array}{c}\overline{\text { Mit }} \overline{\text { gepulvertem }} \\
\text { Scluwefel verfälscht. }\end{array}$ & $\begin{array}{l}\text { Auf Kohlen geworfen verbieitet sich' ei } \\
\text { Schwcfel geruch, }\end{array}$ \\
\hline
\end{tabular}

Ceratur

Wachssalbe.

Cereoli.

Wachskerzen.

Bougies.

Cerussa alba.

Bleyweifs

Das Cerat ist eine zumn äufsern Gehrauch bestimmite aus Wachs, Felt, Cacaohulter, Wallrath, Oel u. dgl. bestebende Mischung, die in Hinsiclit ibrer. Consistenz das Millel zwischen Pीaster und Salhe hält, indern sie weicher als jeues, aber härter als diese ist. Nach Verschiedentheit dcr Zuthaten ist das Cerat mohr oder wreniger zäbe und terpentinartig, oder melyr oder wenigin. weich und fettig. Die Bereitung kommt mut der eines Wachspflasters ganz überein ; nur wird die gesclmolzene Mischang gewöbnlich in eiue mit Oel ausgestrichene Papierpflasters ganz überein; nur wird die gesclmolzene Mischnog gewöbnlich in eine mit Oel ausgestrichene Papier-
capsel gegossen und nach dem Erkalten in Täfelcheu zerscbuitten. Es kommt dabey anf reinliche Arheit an, auf eine gehörige gleichförmige Mischung, und larauf, dafs das Fett oder Oel zu denjeuigen Ceraten, in deren Mischung dergleichen gehört, nicht ränzicht sey. Ersteres erkennt man an der reiuen uberall gleichen Farbe und letzteres am Gerinche.

Ceratum Aeruginis s. Cera viridis. Grünspancerat. Grüncs Wachs. Aus gelbern Wachse, Harz, Te-tin und Grünspan bestchend.^ MIurs eine schöne grüne Farbe besitzen und der Grünspan in demselben gehorig vertheilt seyn.

Ceracum ad Labia. Lippenpomade. Die Vorschriften dazu sind in den verschiedenen Dispensatorien sehr verschiedlen. Gemeiniglich wird die Lippenpomade mil zngesctztcr Alcannawurzel röthlich gefärht. Sie mufs daher ein a angenelime rüthliche Farbe und wegen des gewölhnlich darin enthaltenen woblriechenden Oels einen angenebmen Geruch besitzen, so wie deshalb auch in einem wohlverbundenen Porcellaingefáfse aufbeeinen angenehr

Ceratum Resinae Pini so citrinum. Harzcerat, gelbes Cerat. Aus gelhem Wachs, gemeinem Harze, Schöpsertalg und Terpentin bestebend. Mnfs eine schöne gelhe Farbe besitzen, die ihna nach verschiedenen Vorscoriften durch etwas zngesetztes Curcumäpulver gegeben wird.

Lange, dünne, allmälig spitzer zulaufende Cylinder, welche man aus feiner, zwar schon getragener, doch uoch dauerbafter Leincwand, die vorher nach den verschitedenen Endzwecken in verschiedenen Compositionen von geschmolzenen Plastermassen getaucht und damit getränkt, daun zerschnitten, bunstmḯsig zısammengerollt und darauf geglättet wird, bereitet. Sie werdeu vorzüglich bey Krankheiten der männliclien Haruröhre geund sarauf geglattet wird, bereitet. Sie werdeu vorzuglich bey Krankheiten der mannliclien Haruröhre gebrancht. Gute Wachskerzen müssen ganz allmälig dübner werden, völlig rund, fest, glatt und durchaus eben
seyn, eine Länge von acht bis eilf Zoll und an ibrem dicksten Eude höchstens die Dicke einer Scbreibfcder łaben, aufserdem aber zum Auswählen in verschiedener Dicke vorı äthig gehalten werdeu. Bey ihrer Bereitung bat man sich in Acbt zu nehmen, dafs uicbl elwas von der Masse an der Spitze bängen bleibt, weshalb auch die Gewohnheit einiger A potheker verwerflich ist, welche die Spitze, damil sie runder werde, nach seschehenem Glätten von neuem in die geschmolzene Masse tauchen. Denn weun gleich das hieraus an der Spitze eutstehende Kügelchen das Einbringen der Kerze in die Harnröbre erleichiert, so b!cibt es doch leichı nach dem Heransziehen der Kerze in der Blase zurück und kann alsdann den Kern zu Blasensteinen abgeben.

Cereoli saiurnini. Bleywachskerzen. Die Masse dazu besteht narh der Prenssischen Pharmacopoe aus gelbem

Wachse und Bleyessig, durch Schmelzen des Wachses und fleifsiges Umrübren mit dem allmälig hinzutröpfelnden Essig mit eiilander vereiuigt.

Cereoli simplices. Einfache Wachskerzen. Werden aus eincr Masse von gelbem Wachs und Baurnöl bereitet.

Ein koblensaures Bleyoxyd ron sebr weifser|Mit Gyps oder/Wenn bey der Anfösnug des Bleyweifs ins Farbe, beträchticher Schwere und einera Sclıwerspath ver- Essig-oder Salpetersäure mefır oder we-

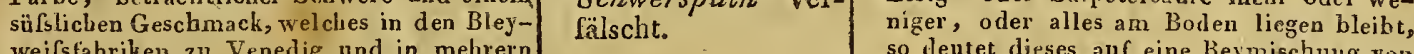

weilsfahriken zu Venedig und in mebrern Städten von Hollaud, Euglaud und Deutsch-
land fabriknärsig bereitet wird, indem land fabrikmälsig bereıtet wird, indem zerfressen läfst. Man erhälit es in verschiedcren Formen. Das Veuetian ische (Cerussa rencta) kommt in kegelförmigen, mit blauem Papier nnwickel teu Massen vor. Das $S$ chieferweifs (Ccrussa in lamiris, Schifera a lba) bestelıt in kleinen länglichen odcr geblätterten schet benartigen, leichı zerbrechlichen und zerreiblicheil Stüchen von schneeweifser Färbe. Das Cremu itzcrweifs (Cerussa cremesia) ist mit GummiWasser zu regelmäfsigen, viereckigen, wasser $2 u$ regelmä sigen, viereckigen,
pfundschweren Tafeln angemacht und geformt.

Je schwerer und weifser das Bleyweifs ist, um desto reiner ist es. Reines und unverfälschtes Bleyweifs ist im Wasser fast unauföslich. In reiner Essirgäure und Salpetersäure ist es röllig auflöslich und schiefst mit ersterer zu Bleyzucker au. Beym Gluhen verwandelt es sich mit Vellust der Kohlensäure, erst in Mastikot oder Bleygelb, daun bey langsamen Fortglühes

Mit Kreide, Kalk oder Thon verfälscht. so deutet dieses anf eine Beymischumg vou Gyps oder Scliwerspath, oder auch daf man blofs Schwerspath oder Bleyvitriol, welchcr letztere ans ciuigen Fabriken fü ächtes Bleyweifs versautt wird, vor sich fiat.

Cun das Bleyreifs ächt war, so wird reine Salzsiure die gesättighten Auflösungen desselbeu in Essig- oder Salpetersänre, röllig als salzigsaures Bley od"r. Hornbley uiederschlagen, und Schwefelsäure wird die
über dem Niellerschlage stehende klare über dem Nierlerschlage stehende $\mathrm{klare}$
Flüssigkeit nicht weiter trüben. Erfolgt Flüssigkeit nicht weiter trüben. Erfolg Kreide orier Kalk, und wenn zwar nich auf Zusetzung der' Schwefelsänre, aber hiz terdrein auf Beymischung einer Kaliauflösuug ein Niederschlag erfolgt, Thon. Man kann auch das Bleyweifs, pum es an priifen mit dï das Bleyseifs, um es z. priren, mit diche ziren, welche die Kalk wa Thonch

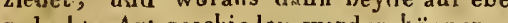
gedachte Art geschielen werdes können.

Uchrigens ist die Farbe eines solcbe verfälschten Bleyweifses uicht so schön weifs, sondern mehr gelblich; seine eigen- 


\section{Namen $\mid$ Sinnliche Eigenfchaften derfelben; $\mid \begin{gathered}\text { Fehlerhafie Be- } \\ \text { Schaffenheit, Ver- }\end{gathered}$ deriArzneymittel. Merkmale illrer Aechtheit und Güte. wiechifelung oder Verfälfchung.}

\section{Deren}

Kennzeichen und Prïfungsmittel,

thümliche Scbwere ist geringer; es fühlt, sich weniger schwer und sanfter in der Hand an und ist irnmer bärtlicher. $\mathrm{Br}$ r der Wiederherstellung des Bleyes durch Schmelzen des Bleyweifses mit Leinöl bleiben alle dergleichen erdigen Beymischungen, so wie der Gyps und Schwerspath, und auch die weilsgebrannten Knochen, womit nach einigen Schriftstelleru auc wohl das Bleyweifs verfälscht werdeu soll, in der Schlacke znrück.

Herr Bucholz (Journal der Pharmacie, XVII. St. 2: S. 1 u. f.) giebt noch folgende Prüfungsmethode des Bleyweifses auf Kreide an, die sich auf die beynahe gänzliclıe Unauflöslichkeit des salpetersauren Bleyes in gutem Weinalcohol gründet. Man nimmt eine bcliebige Menge des zu prüfennimmt eine bchiebige Menge des zu pitúnden Bleyweifses, übergieist es mit zehn Theilen destillirtem Wasser und giefst so
lange reine Salpetersäure hinzu, als noch lange reine Salpetersäure hinzu, als noch
ein Aufbransen erfolgt. Solle bey überschüssig gegenwärtig seyender Salpetersäure und bis zum Sieden erfolgtem Erhitzen noch etwas beträchtliches unauf̧́elöst bleibren, so ist dieses böchst wahrscheinlich Gyps oder Schwerspath. Die Auflösung wird nun filtrirt und zur Trockne abgedampft. Das erbaltene trockne Salz setzt man in einem schicklichen Gläschen mit mall in einem schick dem vierfachen seines Gewichts gewöhnlchem guten Alcohol in Berührung und schüttelt das Ganze einige Minuten. Hier-
durch wird. sich, im Fall Kreide beym Bleyweifs war, der sich gebildet habende salpetersanre Kalk vollkommen in dem Alcohol auflösen. Die Aufösung zur Trockne verdunstet und bis zur Zerstörung aller Salpetersäure dcn Rückstand in einem Gläschen geşlübet, wird reinen Kalk in ätzeuchen geslühet, wird $\mathrm{r}$.
dem Zuslande liefern.

Niederschlag, der sich wie salzsaures Silber verhielt, Eestand daher dieses falsche Bleyweils aus einem Gem kolzlenstoffsaurem und salzsaurem Bley.

Cetaceum.

Sperma Cet:

Wallrath.

Cllocolata.

Chocolacie.

-

Eine eigenartige Fettsubstanz, die sich in ei-joft ist
genen Bebältnissen der Kopfknochen und
zicht.

genen Bebältnissen der Kopfknochen und
längs dem Rückgrate des Pot tfisches

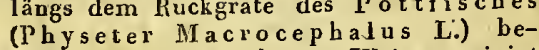

findet. Auf die gehörige Weise gereinigt

und zubereitet, besteht der Wallrath aus einer ganz weifsen, spröden und zerbrechlichen, talgartigen, glänzenden, und gegen das Licht gehalten, durchscheinende Substanz in mebr oder minder grofsen Stücken von erystallinisch-blătrischüpfrig, webe. Er fuhlt sich sanft und sch thranig,
aber nicht fcttig an, riecht etwas aber nicht fcttig an, riecht etat hickt unangenehm und hat eiuen eidoch niclit unangeneh in und hat eiuen ei-
genthïmlichen ülichten Geschmack. In genthiumlichen 'ülichten Gärme schmilzt er leicht, wird aber in der Kälte wieder bart. Vorn Schwefeläther wird er beynabe gänzlich aufgelöset, crystallisirt sich aber nach einiger Zeit wicder beraus. Auch in fetten und ätherischen Oelen, so, wie in starker. Schwefelsäure, ist er autóslich. calien spröde Seifen. Die Auflösun de Walleaths vom Weingeist ist melhr sclieinbar, denn er löset kaum ein?, Achtel öliges Wescn darans auf. Um ihn zu pulvern, mufs mán einig 3 Tropfen Weingcist zusetzen. Er mufs in verstopften Flascheu im Keller aufbewalirt werdeu.

Wircl auf die bekannte Weise durch Zerreiben der vorher entschälten Cacaobohnen in einem gelinde erwärmten eisernen Mörser
oder der eigends dazu bestimmten Chocooder der eigends a azu bestiumten Ceinoco-
lademaschine bis zu einer vôllig feinen und gleichartigen Hinzumischung von Zacker und dem an jeden Ortcn lgelrräuchlichen Gewür'zzusatz, und daranf erfolgender Er'starrung des in einzclnen Portionen von bestimmten Gewicht abgewogenen Teiges in flache oder cylindrische Formen untcr den gewtichokolade mufs einc dunkelbraunrötblicle Farbe haben, auf der Obernäche glatt seyn, eine durchans gleichförunige, zarte und Mit weifsem Wachs
verfälscht.

$\because+1$

Vielleicht auch mit der Wallrathähnlichen Masse aus lange im Wasser macerirten Fleische (Leichenwachs), wovon es nach Liclutenberg. Fabriken in England geben soll.

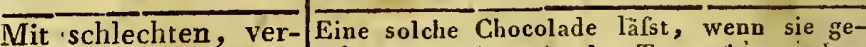
dorbenen oderauch kocht worden, in der Tasse cinen griesnicht gehörig gerei- sigen, ercligen Bodeusatz fallen; welches nigten Cacaoboh- auch geschielit, wenn ein sehr schlechter nen bereitet.

Mit zu stark, bis zum
Anbrennen gerü-

Er bat alsdann einen ranzichten Geschmack und Geruch, siebt gelblich aus
zum Arzneygebrauche untauglicli.

Hat eine mattweifsè Farbe, ein nicht so blättriges Gewebe und ist weniger zerreiblich. Giebt mit Schwefelsäure eine milchichte triibe Aufösung. - - Nach Herrn Dö r ffurt ist 'iudessen eine Verfälschiung des Wallialhs mit weilsem Wachse nicht wahroft noch niedrigerm Preise stelit.

öset sich bey $60^{\circ}$ Reaum. nach F ou rcroy iin halb so vielem Weingeiste auf, nnd als der Wallrath ( $\left(50^{\circ}-35^{\circ}\right.$.)

Farinzucker dazu gebraucht worden., Sind die Kẹirne der Cacaobohnen nicht gehörig abgesondert, so bindert iare harte und hornartige Beschaffenheit die Wirkung des Reibens und Abkochens und sie finden sich oft noch ganz auf dem Boden der Tasse. Sind ganz verdorbene Cacaobohnen dazu genommen, so merkt man dies bald an den minder angenehmeu, oft "mulstrigen $\mathrm{Ge}$ schmack. gerü-l erzeugt sich brenzliches $\mathrm{Oel}$ und die Boh- 


\begin{tabular}{|c|c|}
\hline $\begin{array}{c}\text { Namen } \\
\text { der Arzneymitcel. }\end{array}$ & $\begin{array}{c}\text { Sinnliche Eigenfchaften derfelben; } \\
\text { Merkmale ihrer Ächtheit und } \\
\text { Güte. }\end{array}$ \\
\hline Chocolata. & 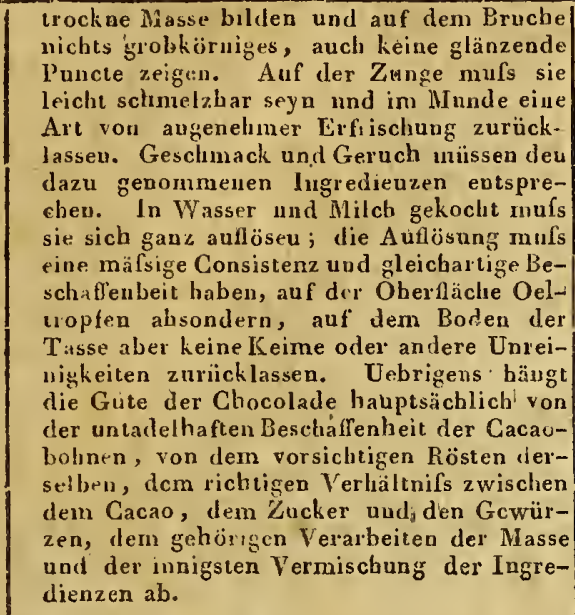 \\
\hline
\end{tabular}

Cinnabaris.

Cinnabaris factitia. Hydrargyrum sulplinratum rubrum.

Zinnober,

\section{Fehlerhafie Be- fcluaffenlieit, Ver- wecirfelung oder Verfälfchung.}

steten Cacaoboh- $\mid$ nen verlieren dadurch scbr viel von ihrem nen bereitet. eicentbümlichen augenehmen Geschinack. Die damit verfertigte Chocolade bekomm eine mehr oder weniger schwärzliche Farle, einen bittern Geschmack und giebt ein le, einen bittera Geschmack und giebt ein chem die nöthige ölichte Beschaffenlıei fehlt.

Mit metallischenTheilen verunreinigt.

Dies ist bäufig der Fall, wenn das Reiben der Cacaobobnen nicht, wie es eigentlic seyn sollte, in emer eigenen Chucolademaschine, soudern in eiuem eisermen oler ar ming gar metallenen Mor Durch das gewaltsanc Stolsca werden gewobnlich metalithenle abysofsen, die man oft scbon in der troct. Chocolade beym Zerbrechen deutlich siebt, noch Inebr aber, wenn die Chocolade gekocht worden, da sich diese Tueile auf dem Bodeu der Tasse absondern.

Mit dem Rückbleibsel von demA uspressen der Cacaobutter bereitet.

Mit irgend einem mehlichten, Stoffe, Getraydemehl, Kraftmehl, Kartoffelmehl u. digl. verfälscht.

Ans chis Theilen reinen Quecksilber und einem Theil Schwefel durch Sublimation auf die bekannte Weise bereitet. Die so erhaltene sublimirte Masse bat eine dunkel cochenillrotle Farbe und ein compactes im Bruche dunkclroth grau - glänzendes, strabliclit - faserförmig- crystalliniscbes $G e-$ webe, ist luftbeständig, ohne Gerucb nnd webe, isc la fibestion Geschmack, anch selbst an den Kanten micht durchscheinend, rauh anzufúbleu und von wcnigstens 7,000 spec. Gervichte. Mic Vasser aufs feinste zerriebcn bildet sie ein ciufarbiges hochrothes Pulver, welche Farbe bey dem in Fabriken hereiteten Zinnober (Vermilton) bcronders. schöin ist, ohnerachtet dieser sciner hâfigen Verfül schungen wegen nicht zum Arzneygcbrauche taarlich ist.

Der prïparirte Zinnober (Cinnabaris praeparata) stellt in seinem reinen und unverfälschten Zustande ein lebbaft carmoisinrothes Pulver dar. Er ist weder in Wasser, Weinalcohol, fetten und ätheriscicn ser, Weinalcohol, fetten und äthen Aunösungen der ätzendeu nud milden Alcalieu anfiöslich; auch in den melıresten Säuren ist e unauföslich und nur die Salzsäure zerstört ibn und änciert dessen Mischungsver hältnil's so ah, dafs salzichtsawres Quecksilheroxyd und Scliwefelsäure entsteben. Auf cine metallene Platte gestreut wird e beym $600^{\circ}$ Faurenh. unter erstickenden Dimen schnel Dingle ohye vorler an sch brennt in nocb

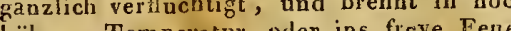
böherer Temperatur oder ins frcye Feuer geworfea, mil blauer Tlanue. in versublossenen Gefufsen Iäfst er sich völlig a

Mit Drachenblut ver fälscht.

Mitrothem Scluwefe? arsenik verfälscht. it $M e$ fälscht.

an den Mangel des Oels in dem Cacaoteige durch thierische Fetie z11 ersetzen. Die Chocolade nirnmt davon einen Käsegeruch an und der Kenner wird leicht diese Verfälsclung durch den Geschinack entdeckion.

Verbreitet im Muude einen teigichtcu Geschmack, riecht beym Kochen schon beym ersten Anfwallen wie Leirn und wird nach dem Erkalten gallertartig.

t keine so schön rothe Farbe sondern schielt mehr ins Pommeranzenfarbige-r brennt mit mehr iss Pommer rothlicher sich durch hen Bleyoxyd, welches sicb darch seine Reellucirbarkeit mit Oeln oder Koble zu Bley rom etwa dem Zinnober beygemisch ten Ziegelmehl unterscheidet, theilt dem damit gekochten Essig einen siifsen Geschmack mit und das aufgenommene Bley wird durcl II ahue manns Probeflüssigkeit schwarz niedergeschiagen.

Herr Professor Grindel giebt folgende Probe an. Man girsse auf den zerriebenen Zinnober starke Salpetersaure; wird der Ziunober uur etwos dunkler, so ist Mennive beygenischt. Eine urofse Monge Mennige beygenir che Eine grofse ene branue Farbe.

Verbreitet auf glühende Kohlen'gestrent, einen balsamisch-barzigen Gcruct, giebt ausgeglutit einen kohlichten Riückstand, and theilt den damit in die Wärme gesetzten Weingeist einc lunkelrothe Farbe mit.

Schwertich zumal wenn er in geringer Men ge dcm Zinnober beygcmischt ist, durch den auf glühendien Kohlen entstehenden Knoblauchsgeruch auszamitlelu. Sicherer enideckt man diese Verfälschung, wern muu eine kleine Portion mit füuf Theilen mau eine kleir Salzsaure, der etwas Salpetersaure zugemischt worden, dicerirt, dic Aufosmng filtrirt und mit kohleusaurem Kali das Quecksilheroxyd abscbeidet, die nentrale filtrirte Flïssigkeit aber mit $\mathrm{H}$ ah neman ns Probeflüssigkeit und eincr Kupfersalmiakauflosung vermischt. Eutbielt der Zinuober Arsenik, so fällt im erstern Falle ein citronengelbes, im zweyten aber ein grïngelbes Pnlver zu Bodeu, das im Filtro gegelles locknen auf slïhende Kohlen geworfen, den Arseuikgeruch verbreitet.

Mit Colcothar oder Beyde bleiben bey der Vertlichtigung im TieZiegelmehl ver- gel als erdige Pulver zurück. Der Eiscnfälscht.

kalk löset sich in Salzsänre auf und die Auflösung bekomint durch Galläpfcltinctur eine schiwarze Farbe.

A nulle diese Verfälschungen finden vorzüglich bey der als Pulver yerkänlichen, schwerlich bey dem nocb ganzen Zinals Pulver b a is a brauchen. 


\begin{tabular}{|c|c|c|c|}
\hline $\begin{array}{c}\text { Namen } \\
\text { der Arzneymittel. }\end{array}$ & $\begin{array}{c}\text { Sinnliche Eigenfchaften derfelben; } \\
\text { Merkmäle ihrer Ächtheit und } \\
\text { Güte. }\end{array}$ & $\mid$\begin{tabular}{cc|} 
Fehlerhafie & Be- \\
fchaffenhcit, & Ver- \\
wechfelung oder \\
Verfälfchung.
\end{tabular} & $\begin{array}{c}\text { Deren } \\
\text { Kennzeichen und Prüfungsmitiel. }\end{array}$ \\
\hline $\begin{array}{l}\text { Coccionella. } \\
\text { Cochenille. }\end{array}$ & 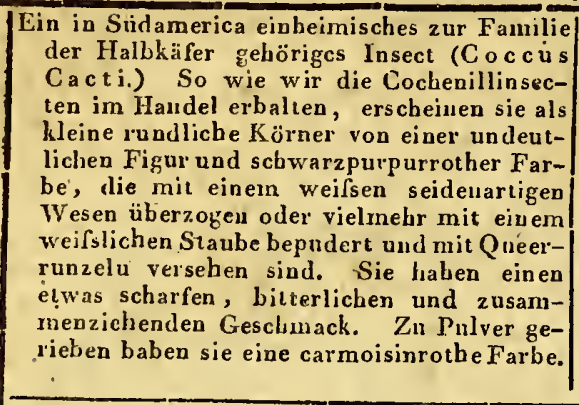 & \begin{tabular}{|l|} 
Statt der wahren Co- \\
chenille der soge- \\
nannte Silvester, \\
ein neuerlich in den \\
Handel gekomme- \\
nes Material, das \\
wahrscheinlich ab- \\
sichtlich zu dieser \\
Verfälschung erfun- \\
den.
\end{tabular} & 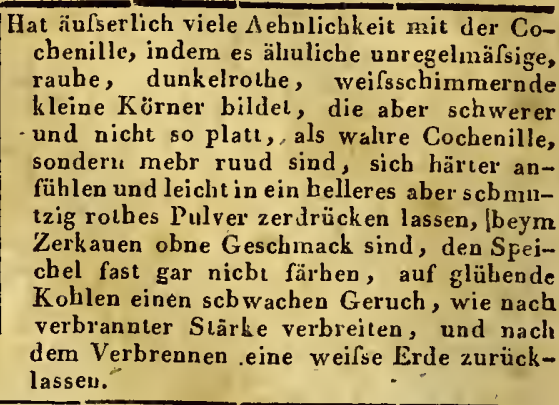 \\
\hline
\end{tabular}

Poma Colocynthis dum.

Coloquinten.

Colocynthis praeparata.

Trochisci Alhandal. Coloquintenpul-

ver.

Colophonitum.

Geigenluarz.

Conchae.

Austerschalen.

Conchae praeparatae.

Präparirte Austerschalen.

Conservae.

Conserven.

Kräuterzucker.

Cornu Cervi.

Hirschhorn.
Die getrockneten, von ibrer iufsern grüngelben Schale befreyten kuglicbten Früclste des Coloqui (Cucumis Colocynthis L.), einer in Ostindien usd der Levante wachsenden Planze. Sie baben die Gröfse eincr Pornmeranze, sind mit einer gelblichweifsen, lederartigen Haut üherzogen und enthalten indriy schmeckt, viele länglichtrunde, schwachen, sulslichen, eckelbaftco Gerucb bat und mehrere Fächer bildet, in welchen Am besten sind de, platte, harte, gelb- oder rollichbraune, glatte, süfsöliclite Samen befindlich sind. grolsen, sehr weifsen, noch unversehrten, recht trocknen und leichten Colo-

Das vermiltelst des Schleims von arabischem Grimmi angestofsene und durch Pulverisiren der erbaltenen teigartigen und wohl ausgetrockneten Masse zum feinsten Pulver gebrachté Coloquintenmark. Auf füuf Theile Coloquintenmark pecbnel man einen Theil Gummi. Ein weifses, sehr bitteres Pulver, welches in einem verstopften Glase an einem warmen Orte anfbewahrt werden mufs. "Sonst verstebt man, auch darunter die
aus der Masse bereiteten Küchelcinen.

Wird theils aus dem sich an die Fichten-|Mit gemeinen Pech Nıcht so hart und spröde, dunkler von Farbe, bäume (Pißus sylvestris L.) anse- $\begin{gathered}\text { vermischt. } \\ \text { und mit dem eigentbümlicben Pechgerucbe }\end{gathered}$ tzendem Waldweilurauch, theils aus dem narb der Destillation des Terpentinöls 2nrückbleibenden gesetzle Schmelzung, bis die Feuchtigkeit nigt,

verdnnstet uud alles hlar geworden ist, be-

reilet. Ein trockues Harz in, grolsen Stü-

cken von éiner bald weifsgelblicben, bald mehr oder weuiger braunen Farbe tes Geigenbar 2 mnls fest, auf frischem Bruche glänzend, durchscheinend, reibber glanzend, durchscheinend, zerreibbar, in Fulver gerieben mehr oder wcniger weifsgelb, und im Weingeist auflös-
lich seyn. Auf glühenden Kohlen giebt lich seyn. Auf glühenden Kohlen giebt es
einen barzigen terpentinartigen Geruch. versehen.

Die Gehäuse der bekannten A ustern (Ostrea edulis L.) Zweyklappige, fast scheibenförmige, äufserlicb schmutzig - graue, gleichsam gestreifte, runzlichte, inwendig glatie, glänzende, weifse, zum Theil flache, zum Theil bauchige Schalen von kalkerdiger Beschaffenbeil. Sie nüssen vor ibrer Präparation mit Wasser wohl ausgekocht und mit einer Bürste von allem anklebenden Schmutze gereinigt wcrden.

zu dem sorgfältig gereinigteu und gepulverten Austerschalen, welche dann auf dem Präparirstein mit Wasser zu dem feinsten Brey gerieben, und aus diesem vermituelst eines weifsblechernen. Triclstcrs auf weifses rieben rieben, nüsseu diese den bücbsten Grad der Zartbeit und Feinheit bemerken lassen und vollkommen
ryeifs seyn.

Diejcnige Arzneybereitung, wo frische Pflanzantbeile, Blätter, Blumen, Früchte oder auch Wurzeln in einem steinernen Mörser mit einer h̆̈̈lzernen Keule zu einem feinen Breye zerstofsen und mit vorber fein einem fsenem Zucker vermiscbt werden, so dafs die Mischung eine Art von Latwerge, jedoch von dickerer Consistenz vorstellt. Man verwahrt die Conserven in einem mit Blase fest verbundenen Glase on dickerer Consinen Gefäfse an eiıem 'kühlen trocknen Orte auf. Gut bereitete und verbuncienen Glase oder porcellaineganz, müssen aber docb so trocken seyn, dafs der Zucker sich und aufbewalafte Conserven dürfen nicht den eigeuthümlichen'Geruch und Geyn, dafs der Zucker sich darin ein klein wenig candirt; sie müssen durch die Gährung verloren báhen, woduch der daria befiudlichen Pfanzentheile weder durchs Alter noch durch die Gährung verloren báhen, woduch sie leicht sauer und scbimmlicht werden, besenders wenn sie zu viel Flüssigkeit enthalten. Auf jeden Fall dürfeu sie nicht in zu grofsen Quantitäten vorräthig gehaltea werden, Weil sich diese Arzneyform ihrer Natur nach nicht langc gia erlıält.
Conserva Cochleariac. Löffelkraulconserve.

Conserva Cochleariac. Löffelkraulconserve. Aus einem Pfunde frischem Löffelkraut und drey Pfunden weifsen Zucker hereitet. Hat eine grüe Farbe und mufs den eigenthümlicheu Gescbmack des Löffelkrauts
besitzen.

Conserva Rosarum. Rosenconserve. Aus einem Theile von den frischen Blumenblältern ilcr Frauzrose und schmack. as juhrlicb abfallende, nacb dem Alier des|Das verkäufliche ge-|Enthält mehrere gana weifse Späue von gröThicres mehr oder weniger ästige Geweilhe raspelte Hirschhorn fserer Härte, ist beynahe ganz weifs ind

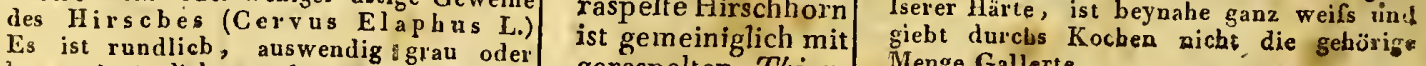
braunscliwärzlicht und rauh, inwendig weifslich, und hat eine zwischen Horn und Knuchen in der Mitte stehende Festigkeit. Es wird heutiges Tages wohl nur blos zum geraspelten Hir schhorn (Coruu Cervi ras patum) angewendet, welches der Apothekcr aus idcn ganzen Stücken selbst sollte raspeln lasseu. Wenn dieses selbs solle raspeln lasseu. Wenn dieses acht nad unverfilscbt ist, so besteht es aus lituler grauschwäılichen nnd grauweifslichen Schuitzeln oder Spänchen, urind ist geraspelten Thierknochen vermengt:
Menge Gallerte. 
Cortex Angusturae. -- Cortex Cascarillae.

\begin{tabular}{c|c} 
Namen & $\begin{array}{c}\text { Sinnliche Eigenfchaften derfelben; } \\
\text { Merkmale ihrer Achtheit und } \\
\text { Giice. }\end{array}$
\end{tabular}

insgenseiu noch mit einigen Stuckchen Hirschlorn vernischt.

Die Rinde der drcyblattrisen Bon- St
plaudie (Bouplandia trifoliata plaudie (Bouplandia trifoliata
Willden.), eines auf dem festen Lande Willden.), eines auf dem festen Lande des suidlicheu America wachseuden Baums. Wir erbalten dirse limde in dichten, festen, wenig gebogenen, nicbt zusammengerollten Stücken, die ohogefälur vier bis sech' Zoll lang, bis zn auderchalb Zoll breit, und eine bis zwey Linien dick sind. AeuIserlich sind diese Stücke gel bweilslich, ge-
spi enkelt und mit kleinen queerlaufonden splenkelt undinit kleinen queerlaufenden
Furchen verselien, inwendig hellbramn oder gelbbräunlich, auf frischem Bruche eben, gelbbräunlich, auf frischem Bruche eben, duskelbrauner gefürbe. Ihr Gescbruack is durclidringend, abcr nicht unangenehu bitter, gewürzbaft, únd lange die Empfindung von Wärme auf der Zunge zurücklassend; der Geruch einigermafseu widerlich. Sie läfst sich lesche pulvern und das Pulver sieht frisch, wie gute gepülverle hlsabarbe aus, wird abcr nach einiger Zeit blässer, und riecht weil starker gewurzlaft ais die gance Rincle. Diese ächte Angusturariude, braun ell, fürbt, enthält keinen Gerbestoff auch ist sie frey ron Gallussäure. Ibre mit auch ist sie frey ron Gallussiure. Ibre mit Wasser gemachte Infusion ist heilbraun und sung cinen citrongelben Niederschlag, wird aber durch'schwefelsaures Eisen nichil verändert. Das Dccoct davon hat eine schön licbtbraune Farbe, farbt das Lcincn gelb und läst beym Erkalten einen strobgelben Satz fallen. Der Alcohol zieht eire schün hellbranne Tinctur heraus, von angenehmen bitcern, etwas gewïrzbaften Gesehm: die durch Wasser sehr stark getrübt wird.
Felulerhafte Be-
rhaffenheit, Ver-
wechselung oder
Verfälchung.

tatt der ächten commt seit einiter Docte

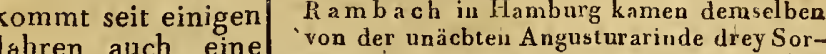
von der unacbtell Angusturarinde drey Sor-
ten vor. Die erste bestand aus Stücken falsche Angtustura-1 von verschiedener Beschaffenbeit; eiuige rinde im Handel waren dïnner und zerbrecblicher, von vor, die nicht nur in anfsen durch darauf befindliche Flechten ihren Arzueykräl- grau, weifs, gelb und rostfarben gefleckt, ten, sondern selbst von inncn aber scbwarz, ihr Geschmack in ihrem äulsern An- ziemlich bilter aber nicht merklich'scbarf, schen und in ihren das Putver davoa bellbräuulich; die gröübrigen Figenschaf- fsere Anzahl der Stücke sah auf der äufseten von der ächten ren Seite eben so ans, auf der innern aber Rinde sehr ab- gelblich, ancb wohl hellbraun gleich der weicht. achlen Riude, besals aber eine üboraus starke, die der Quafsia noch übertrelfencle widrigc Bitterkeit, welche sich heym Kosten erst nach einigen Stmoden völlig verlor; durch Kauen wurde die Rinde bleicher, nnd ibr Pulver war bellgelb, einzelne Stïeke waren inwentlig gauz dunkelbraun und schmeckten fast eben so bitter als die der zweyten Art, beide aber buten leinen der keinen scharfe Geschnack das Pulver dieser letze:n Sticke war schmulzig graubrann. Der Gertuch von allen zusammengenommen batte Aehnlichkeit mil dem der ächten Angustura, war aber viel stärker. Die zweyte und dritte Sorte balten in ins fsern Ausehen und dem sebr bittern Geschmack, der aber gar nicht scharf war, die Beschaffenheit der ziveyten Art in der ersten Sorte. Die Aufyüsse dieser drey Sorten waren nichl so klar und batten einen starken unangenehm-bittcrn Geschinack, wurden durch schwefelsaures Eisen shwarzrün grun getarbo und dich gelblich niedergesconochung firle das Leinen gar nicht, hatte eine thellbraune sclinezige rache, liefs eiuen yraubraunen Bodensatz fallen und hatle einen abscheulich billern eckelhaften Gcschimack. Die erhaltenen Tincturen schmeckten sehi bitter und wurden durcl Wasser nur wenig getrübt.

Die Wirkungen dieser falschen Angusturarinde sind Schwindel, Angst, Ermattung und ein unaugenehines Gefübl von Beweglosigkeit, Erorechen, Fieber, Zit tern und krampflafte Zuckungen. tern und kranplo inufs sich dather beym Einkauf der. sturarinde ror allen Dingen von der Aecht unäclien hïten. $\overline{\text { Coricices Aurantio- }}$ rimn.

Pommeranzenschalen.

Cortex Caribueus. Caraibische Rinde.

Die getruckneten Scbaleu der reifen Pommeranzen (Poma.A urautiorum), welche aus Spanien', Ita-

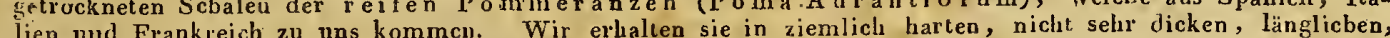
lien und Frankreich zu uns kommcn. Wir erhalten sie in ziemlich harten, nicht sehr dicken, langlicben, spitzig - eyrunden Stücken, deren Oberläche ins einer dunkelgelben oller braunlichen, mit vielen Lochern

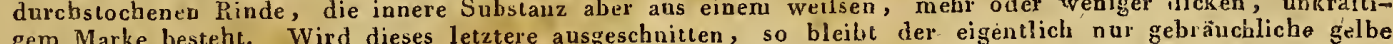
gem Marke besteht. Wird dieses letztere ausgeschnitten, so bleibi der eigenthch nur gebrauchliche gelbe rindigs: Theil (Flavedo Cort. A urautiorum) zurïck. Es hat derselbe einen angellehmen gewurzbaften Geruch und einen aromatischen, erwärmenden, gelinde bitterlicheu Geschmack. - Eine avdere im Handel
vorkommende Sorte sind die Curassaoschalen (Cortices Aurantiơn curassaviensium) welclie weit dünner siod, weniger Mark entbalten und sicb durch ibre Gröfse so wie durch ihre braunere Fasbe und angenehmere Bitterkcit auszeichnen.

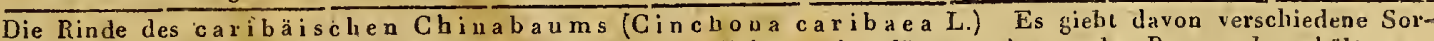
ten, je nachden die Rinde von dem Stamme, den dickern oder dïnnern Aesten des Bauns abgeschält worden. Die vom Stamme besteht ans nur wevig gebogenel, sechs bis acht Zoll langen, gesea audertbalb Linien dicken und dentlich ans zwey verschiedcnen Lagen zusammengesetztcn Stiickeu, wovon die üufsere Lage dieker als ilie iunere, sich bis auf eine Linie uuter der getbliclien, ungleichen und rauhen Oberhau erstreckt, zwischen deu Fingern zerreibbar, unschmackhaft und schwannicbt, die innere aber bart und erstreckt, 2wischen deu Fingern zerreibbar, unschmaft süfslich, hinterdrein aber stark bilter schmeckend ist. Die Rinde der Zweige ist halb rinnenförmig gerollt, mit einer dünnen, schrnutzig grauen Oberbant, worauf zuweilen verscbiedene Flecliteu befindlich simd, bekleidet, und es lärst sich darunter nur eine einworau zarbe entdecken. An der. Pinde von den kleinern $Z$ weigen sind alle diese Theile zarter und blafsfarbiger. Das Pulver der Rinde kommi in der Falbe dem der gewöhnlichen Fieberrinde zarter und blalstarbiger. Das Pulver der oder zusammenziehenden Geschmack konute Herr Dörffurt

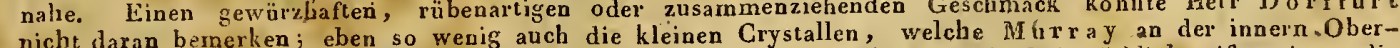
nicht daran bernerken; eben so wenig auch die kleinen Crystallen, welche Muflich röthlichweifse, inweudig fläche derselben beubachtet taben will. Schlecbtere Sorten sind a) eine äufserlich röthlichweilse, inweudig bemeinen Cbinarinde und eincn äufserst unangenehinen bitiern Gesclimack besitzen soll.

Cortex Cascaril Die Rinde der Cascarillkiutia (Clutia Eluteria L.), eines in den wärmern Gegenden von Amcrice wachsenden, sehr ausehulichen Strauchs. So wie wir dieselbe im Hadel erbalten, besteht sie aus meb oder weniger znsammengerollten, einige Zoll langen und kaum eine bis drey Linien dieken, im Durchmes- 


\begin{tabular}{|c|c|c|c|}
\hline $\begin{array}{c}\text { Namen } \\
\text { er'Arzueymitiel. }\end{array}$ & $\begin{array}{c}\text { Sinnliche Eigenfchaften derfelben } \\
\text {. Merlimale ihrer Ächtheit und } \\
\text { Giite. }\end{array}$ & $\left|\begin{array}{c}\text { Fehlerhafte } \text { Be- } \\
\text { fchaffenheic, } \\
\text { wecly felung, oder } \\
\text { Verfällchung. }\end{array}\right|$ & $\begin{array}{l}\text { Deren } \\
\text { Kennzeichen und Prüfungsmittel. }\end{array}$ \\
\hline
\end{tabular}

Cortex Cascaril-1 ser einen halben bis ganzen Zoll haltenden, festen und schwcren Stücken. Aeufserlich ist sie weifslichlae. aschgrall, mit eiver runzlichten Oberbaut überzogen, mit Queerstrichen bezeichnet und hin und wieder nit Flechtcn bcselzt; iuwendig ist sie bräunlich rostfarben, leicht zerbrechlich, auf dem Bruche gleich, glïnzend und harzig. Ihr Geschmach ist bitter, etwas beifsend und gewürzhaft erhitzend; der Gernch für sich scbwach gewürzhaft, frisch gepulvert aber, und vorzüglich auf glühende Kohlen gestrcut, stark, angenehm gewüralıaft und bisamartig. Das Pulver hat eine bräunlichgraue Fashe.

Cortex Chinae braVon eincm noch unbekaunten Banme. Sie besteht nach Comparetti und Hagen ans flachen, unregelmifsisiliensis. gen, dijmen, breiten Stücken von verschiedener Gröfse. lhre Oberfäche ist glatt; mit einem weifslichen odel graulichen Iräulchen bedeckt, worunter sich ein aschgraues, ius gelbliche fallendes Gewebe, das schwammicht wid selir leicht zerreibhar ist, befindet. Die hieranf folgende inuere Lamelle ist dunkelbraun, lart, dicht, zcıbrechlich und schwer. Der Geruch ist unangenehm dumpf und der Geschmack äufserst bitter. Das Wasser wird, sohald man die klein geschnittene Rinde hineinlegt, sogleich rolh gefärbt und
bitter. narinde.

CortexChinae fiavus s. regins. Die Rinde des im spanischen Anerica einheimischen herzblattrigen Chiuabaums (Cinchona cordi-

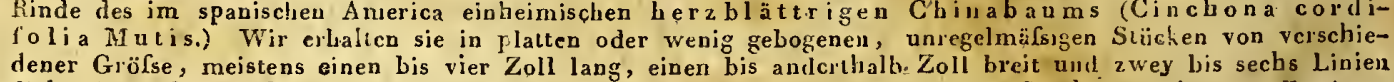
diçk, bisweilen anch darunter einige"kleine dünue; etwas zusammengerollte Stücke von jüngern Zwcigen. Niur wenige Stücke sind mit einem rostfarbnen oder röthlichbraunen Obesbäutchen, das vicle kleine Queerspalten nnd einige der Länge vach laufende Risse hat, auch mit weifsliclıen oder graulichen Flechten besetzt zu seyn pflegt, noch ganz oder zum Tueil überzogen. Die gewöhunlich vom Oherhäutchen entbliifste Pinde sieht anfserlich bräunlichgelb oder rostfarben aus und die gröifsern Stücke sind hic und da höckericht; in fewissen Richtungen gegen dás Licht gelıaltell baben manche Stiicke auf der Oherfläche ein schirn-
meruties Auselien. Die inwendige Oberfläche ist bey dichern Stücken flach, bey düunern mehr ausgeliölt,

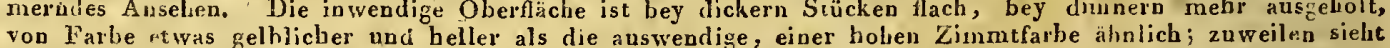
von Farbe mtwas gelhlicher und beller als die auswendige, einer hohen Zimmtfarbe ähnlich; zuweilmn sielit
man anch beyde Farben, gelb und blaunstreifig sich in einander verlieren; selten ist sie etwas ins Rothe man anch beyde Farben, gelb und blaunstreifig sich in einander verlieren; selten ist sie etwas ins Rothe
fallend. Die gauze Rinde bricht leicht, und $z$ war bey kleinen dïnnen Sticken glatt, bey den gröfseren etfallend. Die gauze Rinde bricht leicht, uld zwar bey kleinen dinnen Sticken glatt, bey den gróseren etdünner oder dicker sind. Das Gewebe der Rinde ist fasericht, sie lä́st sich trocken und spröde anfülien, nit 'den Tingeru etwas pulvericht reiben und leicht zu einem zimntfarbigen Pulver stofsen, das die Haut gelb farbt und angefeuchiet hrauu anssiebt. Der Geruch ist zwar nicht hervorstechend, doch gewürzbafter, arten. Der Geschmack ișt beträchtlich, doch ansenehm bitter, und mehr reitzend gewürzbaft als zusamnemziehend:

Die hier bcscbrievene Chinarinde ist die unter dem Namen der gelbeu oder Königschinariñde in Deutschland gewöhnlich vorkommencle Riucle. So wie es aber aufser der Königschinarinde und der nachber folgeuden bramen und rothen Chinarinde noch mehrere andere Chinaarten (Herr Vauquelin unies suchte degeuden bramen und rothen Chimarinde noch mehrere andere Chinariten (Herr a uquelin uniersuchte deren a chtzebu, S. Berlin. Jabrb. d. Pharm. 1807 . S. 47 u. f.) giebt, die jedoch bey uns entweder gar nicht oder nur selten vorkommen, so giebt es anch nach Mutis noch eine eigeulliche gelbe Chi ua, die von der beschriebenen Königsclunarinde nuterschiedeu ist, im Handel aber mur seln selten vorzukommen
scheiut. Nach der. Beschreıbung von Mutis sieht dieselbe in wendig strohgelh, nafsgemacht aber lebhafter blafs goldyelb aus, sclmeckt rein bitter und färbt den Speichel bcym Kauen blafsgelb; auf dem Bruche ist sie zum Theil bolzig, zum Theil harzig; sic ist ein wenig zusammengerollt, je nachdem sie mehr oder weschreibuug abwcichende Sorten del Köniģclinarinde vorkommen, die aber ohnstreitig weniger ächt sind. Znweilen sell dieselbe mit der Angnstmrarinde verwechselt werden, welches man aus der.Vergleichung der sinolichen Vigcnschafien von beyden erkeunen kann.

In neteriz Zૈsiten hat mau sich sehr bemïhet, aufser den physischen Kennzeichen der Aechtheit und Güte der yerschieden Chinasorten anch gewisse chemische Eigcuschaften aufunfinden und fest zu setzcu, un

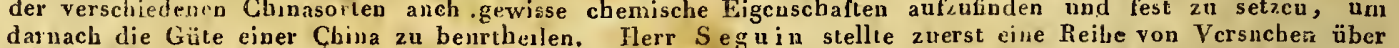
dajnach die Gute einer Chima zu benrtheilen. Herr Seguin stelle zuerst eine Reilse von Vcrsnchear über diesen Gegenstand an. Nach seinen Versuchen (Berlin Jahrb. d. Pharm. 1803, S. 264) besitzt der wälsrice
Aufgufs der guten Chinasorten/dusschliefslich die Eigenschaft, den Lohaufgufs zn fällen, wäbrend die schlecbien hiugegen die Leimanflösung niederschlagen; man könne daher aus der grǘseru cder geringern Menge des Niederschilags nicht blofs anf die Beschalfenheit dieser Rinden überhaspt, sondern auch anf die relative Güte verschiedener. Sorten derselben schlicfsen. Va quelin (Berlin. Jahı b. 1807 a. a. O.) zeigte inlessen durch zahlreiche Versuche, dafs diese Angaben nicht unbedingt richtig seyen, weil es wirksame, das Fieber vertreibendc Surten von China gebe, die den Lohaufgufs nicht fällen. Mau könne nimmlich die yerschicdenen Chinasorten in Hinsicht auf ihre chemischen Eigenschaften unter drey Abtheiluugeu bringen, ind zwar a) in solche, die den Gerbestoff, aber uicht die Leimanflösnng niederschlagen; b) solche, welche die Leimaulosang, aber nicht den Gerbestof fällen, und c) solche, die zugleich den Gerbestoff, den I eim und den Bréchweinstein füllen. Herr Bucbolz. (Álinanach für Scheidekünstler und A potbeker, 1803

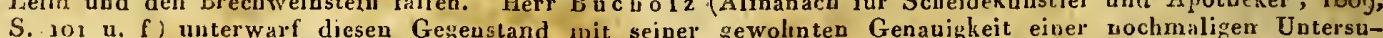
chung und bemübete sich vorzüglich, die finit seiner gewohnten Genaugheit eiver vochmaligen Untersu-

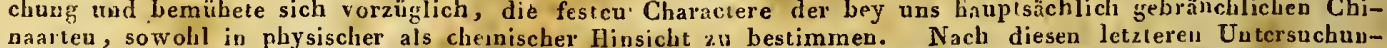
naarteu, sowohl in physischer als chemnischer Hinsicht au bestimmen. Nach diesen letzereu Uutcrsuchun-
gen exgeben sich bey dcr oben beschriebenen Königschiuarinde folgende chemische Keunıeichen, aus denen gen ergeben sich bey dcr oben beschriebenen Königschinarinde folgende chemische Keunceichen, aus denen
unan anf ihre Güte schliefsen kann. Der kalre Aufgul's aus einem Theil Pulver und acit Theilen Wasscr durch vier und zwanzigstündiges Stehen und Filtriren gemacht, iś last wasserklar, nur wenig ins ,Röthlichselbliche schielend, schmeckt doch schwächer als das Decoct, und bewirkt unter den sosileich anzuführenden Reagentien hlofs mit dem Galläpfeldecocte eincu reichlichen blafsgelblich gramen Niederschlag. Das aus eiuem Theil dieser Rinde nit sechzehn Theilen clestillirtem Wasser bis zu acht Uuzen rücksuändiger Flïssigkeit gemachte Decoct ist noch warm hellcr uad blässer als das Decoct der lirauneu Chiua; erkaltet crischeint es trühe, blafsgelb, ins Röthliche ziehend, und verlält sich in Hinsicht seiner clucmischeu Eigenschaften folgendermafsen. i) Mit denz Gallïpfelabsude erfolgt ein sehr hänfíer blafs rötblichigelber ins Gcuatiche schielender Niederschlag; Granliche schielender Niederschlag; 2) mit der schwefelsanren Eisenaullosung cin bl('Sgrauer; 3) mit der Leinaufösnng ein sehr reichlicher und flockichter röthlighgelher; 4) mit der Anlösung des schwefelsauren
Kupfers ein dersleichen etwas dunkler gefübter; 5) mit der Auflösung des Breclıweinsteins ein blafs röthlicbyelber, der sich indessen erst nach langer Ruhe absetzt; 6) mit dem sauerkleesauren Kali entstelit eine geringe Trühung, und 7) wird das backmuspapier stark davon gerötlset.

Corlexclina fus cus s. officinalis. Cortex peruvianus.
Braune Chinarinde. Gewölnniche Chinarinds.

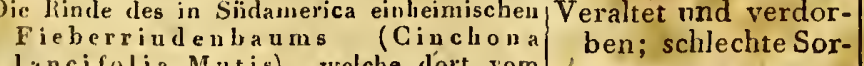 lincifolia Mutis), welche dort rom 'ten statt guter.}

Monat Septenber bis in Novemher ab-
geschalt, fetrocknet und in Thicltuatue genähct, nach Euı opa/gesandt wird. Eine colde mit Chinarinte angefüllte Thicr-
blant heifst eine Zcronne, und wiegt

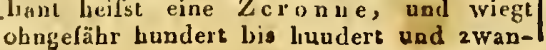

mehr ciner Cbina die angegeheuen Eigenschaften mangelı, uin desto schlechter genschaften mangeln, un desto schlechter
ist sie. Allc Chinarincle, die allswendig ist sie. Allc Chinarincle, die answendig
glatt und wie polirt, scliwarz, blafsgelb glatt und wie polirt, schivarz, blalsgelb
oder rothschillernd; inwendig weifs oder oder rothschillernd; inwendig weils oder
grau aussielit, so wie diejenige, welche grau aussielt', so wie diejenige, welche
zähe oder schwamniclıt, iuf dem Bruche fasericht, holzicht oder mehlicht, die zerfressen oder modrig ist, die gazz geschmack. 


\section{Namen der Arzneymictel. \\ Sinnliche Figenfchafien derfolben; Merkmale ilurer Aechtheut und Giice.}

zig L'tund. Es finden sich darin Rinden vou älterı und jungen Bäunen und Zweigen motermischt, foiglich grobe, mittlere lcuten ansosucht und als verschiedene Sorten von Chinariblen verkauft werden. Zum Arzacygetrauch mufs imm
Fiehlerhafie Be..

chluaffenlueit, Ner-

wechfelung oder

Verfälfclung. und feine Rinteo, welche von den Kauf-

beste ausgervahlt werden.
Eine gute Chinarisde bestebr, nachdem

Eine gute Chinarisde besteht, nachdem sie vom Stamm oder don Zweigen genommen worden, ans melı oder weniger znsammengerollten, harten, trocknen, schweren, vicht leirht zerhiechlichen Stucker von rer Dicke einer Feilerspule bis zu der eines Fingers nud dartiber, und von einen bis.zu drey nud mebrern Zoll lang. Aeufserlich ist sie rauk, uneben höckericht und Ther Trierlich leinchagrinirten, feingeaderten und weifsfeinchagriurtcn, feingeaderten uod weirsgellechten Oherhatchen bekleidet; anf
der in wendigen Seite ist sie glatt, hellrostbräunlich, selblich oder brämlich zimmafarben. Jie beste und feinste Sorte in röllig oder doch. gröfstentheils geschlussenen dünnern oder dickes u Pöhren bricht glat Euden eill faseichter Bart steben bleibt. Auf dem Brurlae bemerkt man zwischeu dem Oherlüutcheu una der Rinde in einem dunkeiu Kreise gcuen die Sonne gehalten, kleiue glanzende Puncte, auch zeichnet sie sach durgb eine im Verhattnils ibrer Dicke Geschmack ist hitterlich, etwas herbc und inild zusanmenziehend, balsamisch und lange anf de1 Zunge zurückbleibend; der Geruch specitisch, einigermafsen'lumpfich schimmelartig, doch vieht unangene sourleru kräftig und etwas gewürzhaft.

Der kalte Aufgufs dieser Cbina aus einem TheilPulver und achtTheilen Wasscr ist nach $B$ uchulz beynahe ungefarbt, odèr weniystens doch nur blafs weingelb, sclinieckt und rieetit wic eiu schwach Chinadeeoct, un bildet mit einem hellen Gallap feliecocte eiDecoct, aus einesn Fibeil Rinde mit sechsDecoct, aus einesn Theil Rinde mit sechszehn Thei!cn Wasser 7 or Halfte eiugekocht, bereitet, isc im warmen Zustande hraun-
lichröthlich, akaltet aber trizhe und von lichröthlich, elkaltet aber trizhe und vou bleicher, btafs röthlichgelber ins Bräunlifast wie die China selbst und verhält sich foigtn eimige Reagentien, wie folgt; 1) mit eivem Galläpfeldecoct zeigt sich ein reichlichtr, blafs rörhlichgrauer Niederschlas

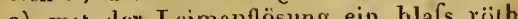
licbselber; 3) mit der Aufüsung des reilicbolber; weuiger angenebm grüuer, schneller oder weuiger angenebm grumer, schneller oder langsimer erfolgender Bodensatz; der Aufiösung des Erechweinsteins ein bald melr bald weniger stark und melar oder weniger schnell sich absondernder gelblichweifser ins Grane fallender, und 5) rnit dcr Auflösung des schwefelsanren Kupfers ein röthliçggelbor Niederschlag, der sich indessen zuweilen auch sehr langsam absondert; endlich wird 6) das Lackmuspapier stark davon gerüthet.

papier stark davon gerüthet. lichtzimmtfarbcn, das von den geringern Sor marbe ähulich als mufs nie in zu grofser Menge vorräthig gehalten nud in verstopften Gläscru subewabrt werden. tatt der ächten China kommt seit einigen Jahren unter dem Namen China nova eine wohlfeilere Pinde im Handel vor, womit jene auch wohl verfalscht wird.

Auf mancherley Weise durch Beymischung von fremden Kinden verfälschit.

gekocht und wiedex getrocknet.

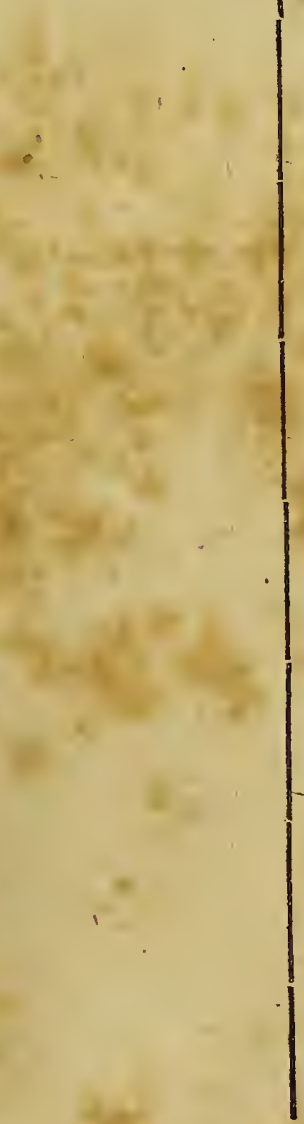

\section{Deren}

Kennzeichen und Priifungsmittel. los oder setrr bittel, eckellaft und sehr ad-
stringirend schmeckt, die beym Katen schleimicht ist, ist entweder veraltet und schleimicht ist, ist entweder veraltet und
vcrdorben oder stark verfälscht und dabcr verwcrflich.

Hat eine fast anf der äufseru und inneru Seite gleiche Farbe und einen merklich schwachen Geschmack.. Gewisser üherzengt man sich davon, wenn inan eine kleine Menge derselben mit Wasser auszieht und die Menge des aus den klaren Auszuge erbaltenen Extracis mit der, welche gute Riude davon liefert, vergleıche. Die Abkochung einer solchen China ist heifs weniger Lraun gefarbt und nach dem Erkalten nicht wie sie es von guter China seyn muis, trübe lehmfarben, sondern fast durchsirhtig.

ach eıner darïber in der Salzbarger Med. chir. Zue ilung (1805, Nro. 43.) won Wien aus beknnot genachiten Anzeige ist dieselbe auswendig mehr glatt, inwcndig röther und dunkler"; ihr Ceschmack ist schleimiclit und bitter, olne Aroma. Der Absud dayon ist dunkelbrann, wie die Rhabarberfiactur, nod macht scinall einen Łäufigeu Bodlensatz. Der Geschmack dieses Absuds ist blofs bitterlich. Auch Herr Prof. Trommsdorff ( $\mathbf{T}^{\prime} \mathrm{h}$ a r m. Waarenku'nde, Aufl. 2, S. 172 erwahnt einer veuen aus Suriuan kommenden Chinarinde in langen, starken, röhrenförmig zusaminengerollten, auf der
Oberläcbe dusiselgranen, inwendig blafs aussebenden, leicht in Splitter zu zerbrechenden Chinarinde von sehr bilterm Geschmacke, der kaum zusammenziehend sey und äterhanpt wenig Aebulichkert mit dem Chinageschmack labe.

Scbon ii ilnem Mutterlande soll die Chinarinde, ehe sie einmal nach Europa kömmt, durch verschiedene andere ibr beysemischte fremde Rinden, zu einer Zeit mehr, zur andern weniger, verfälseht werden. Anch in den Europäiscben Handelsstälten geschiebt es nicht selten, dafs dieselbe beym Surtiren, um das Gewicht au vermehreu mit andern Rinden verfälscht wird. Man soll sich dazu besonders der Rinde des Mehlbeerbaums (Crataegus Aria L.) bedicuen, welche auswendig weifser, 111wendig röther und von stärker zinsammenziebendeu Geschmacke als dic Chinariude ist. Auch die Rinde der $\mathrm{R}$ ofscastanie (S. Cortcr Hippocastani) soll man darunter jnischen. Herr $B$ ucholl. (a. a. O.) erwibut einer ihm vorgekommenen 'Verfilschung, wo eine Parthie Chinarinde auf den ersten Blick das Ansehen der feinsten Chiná hatte und dennoch bey genauerer Untersuchung mit melur als dem vierten Theil einer Weidenrindeuart so täuscliend vermcogt sich zeigte, dafs so täuscliend vermengt sich zeigte, dals Auge dazu nüthig war, um die VerfälAuge dazu nüthig war, um tie Verfalschuog zu erkeunen. Eiuer meiner pharQuantität Chiuarinde, der ebentalls gcoen dew vierten 'Theil der in der Läugc zurbrochenen Stücke von der angeführten China nov a dergestalt beyremengt war , da $f_{5}$ das Ganze wie eine sehr feine Cluind aussah.

Zuweilen scllen sogar die Stücken van veralteter China, oder die derselben beygemiscbles falschen Rinden mit einer Alocaullösung oder mit andern bittern Abliochangen angemacbt seyn. Ein widrig bitterer Gescbmack würde indessen diese Verfälschung bald zu erkennen geben. Eben so lássè sich auch gauz falsche Rinden, die für sich statt ächter Chinn wohl verkauft werden möchten, z. B. Mahagonirinde, durch die Vergleichung nit dev charactistischen Keunzeichen der ächten Chinariode leicht eylsenaen. 


\section{$38^{\prime}$ Cortex Chinae fuscus s. officinalis. - Cortex Chinae Sanctae Lu ciae.}

\begin{tabular}{|c|c|c|c|}
\hline $\begin{array}{c}\text { Namen } \\
\text { derifzneymitrc!. }\end{array}$ & $\begin{array}{l}\text { Sinnliclue Eigenfchaften derfelben; } \\
\text { Merkmale inurer Aechcheit und } \\
\text { Giite. }\end{array}$ & \begin{tabular}{|} 
Fehlerhafie Be- \\
schaffenheit, Ver- \\
wechfelung oder \\
Verfälfchung.
\end{tabular} & $\begin{array}{c}\text { Deren } \\
\text { Kennzeichen und Priffungsmittel. }\end{array}$ \\
\hline $\begin{array}{l}\text { Cortexclumac fus- } \\
\text { cues s. afficinalis. }\end{array}$ & • & AlsPulver verkäuflich. & 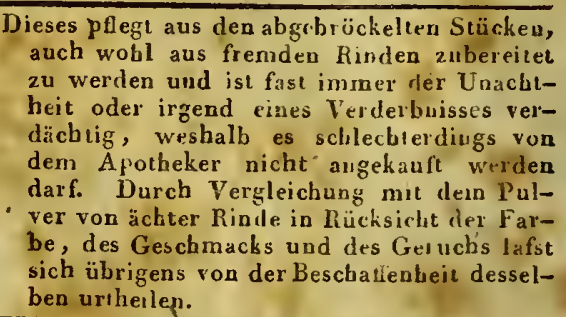 \\
\hline
\end{tabular}

CorlexChinae martinicensis. Chinclina Piton. Bergchinarinde.

\section{Cortex Chinae ru-} ber.

Rothe Chinarinde. $\cdot$

Ortex Chinae St. lie.

Chinarinde von St. Fé.

Cortex Chinae Sanctae Luciae.

Wabrscheinlich die Rinde des in Guadelupe und Martinique wachsenden Bcrgchinabaums (Cinchona In ontana.) Diese seit 1777 in Eurupa hekannte und von deu Franzosen so sehr geriihnte Bergchina besteht in zolllangen, röbrichten, von ilıer Oberbaut entblöstcn, Gänsekieldicken Stucken, welche eine cranlicbte, ins Brauue fallende Farbe baben. Der Geschmack ist anfangs angenehm gewür chaft, nachher eckelhaft bilter; der Geruch schwach, etwas balsamisch. Im Bruche ist sie kurzfaserig.

Die Rinde des auf der Iusel Sct. F é sichpefters sind der ro-pie genaue Ansicht cler Gestalt und der Farbe bänfigfindenden rotben CLin ab a ums then Chinarinde Inufs bierüber Aufklaruug geben.

(Cincboua oblongifolia Mutis.) Sie wurde zuerst im Jahre 1779 , da ein Spanisches Schiff, welches mit derselben de fiel, bekannt. Sie besteht iu gröfsern schweretu und dickern Stücken als die gewölntiche China; dabey siud die Stïcke weoiger zusammengerolit nur liuneuförIrig, zwey bis drey Linien nud darüber dick, und im Bruche taserig. Die braune Farbe fallt weit stärker ins Rothe hinein, und kömint der dnnkeln Cassienrinde gleicl. Man bemerkt daran otfenbar drey verschiedene Lagen, wovon die erstere oder dic Oberbaut düne, rauk, queerrissig, runzlicbt und vou einer schmutaig rothbranueu oder weifsgraneu Farbe, ofters mit ciner gelblichweifsen oder graulicheu Flechte besetzt ist. Die zweyte mittlere Lage oder die eigentliclie Kinde ist dicker, fester, duakler, lothbraun nnd barzicht die dritue oder innere Lage, der Splint,
ist holzig, faserig und tseller, als die ubrigen Lagen, doch duakler wie bey der hraunen China. Der Gcruch ist dieser gleich doch schwächer, ihr Geschmack aber is weit stärker, bitterer und mebr znsammenziehend und der Speichel wird davon beyın Kauen röthlich gefärbt. Zuweilen findet man anch dïnne, und feinrobrichte Stïcke damit vermischt, welche durchaus roth nnd sehr kraftig sind. Das Pul lavon bat eiue duake Der kalte filtrirte Aufguts der rothen Chinarinde ist wenig oder doch nur blaf'sröt!hch gefürbt, nnd fallet aus dem Gall-
äp felibsude eineu ziemlich reichlichen röthlichweifsen Nieller'schlag. Das Decoct derselben ist in noch heifsem Zustande röther als das der braunen Chiua und erkaltet trübe, blafs oranienroth. Es verhält sich geten verschiedene Reagemtien folgendemaIsen. 3) Mit Galläpfelabsud erfolgt ein sclir bäuficer, schmutzig röthlichgelbér Niederschlag; 2) mit der Leimautiösung ein blafs ziegelfarbener, der durch inehr zugesct 2 tc Leimanflösung wieder verschwindet 3) mit dor Aulöisung des schwefelsanreu Eisens ein häufiger grüner oder doch ins Grinliche fallender; 4) mit der Auflösung Grinliche fallender; 4) mit der Auftösung
des Brechweinsteius ein geriuger blafsgelbdes Brechweinsteius ein geringer blafsgelbröthlicher; und 5) mit der Auflösung des scluwefelsamren Kupfers ein blafs bräunlichröthlicher, sich langsam setzeuder Nieschlag. Das Lask muspapier wird dadurch gerötbet. Der Weinalcohol zieht einen oranienrothen harzinglichen Stoff beraus und wird dadurch eben so gefirbe

gröbere Stücke der gewöhnlichen Chinarinde, oder gar fremde Kinden beygemischt.

\section{chlechte oder veral-} tete gewöhnliche Chinarinden, oder auch Rinden von andern Bäumen werden zuweilen mit rother Bolarerde, oder dem Pulver von rothem Sandelholz bestreut, oder mit Fernambuckholz - Abkochung gefärbt und für rothe Chinarinde verkauft.

Das aus Englandkom- Man überzeugt sich von dieser Burtrigerey, mende verkäufliche wenn der minder'bittcre und zusammenPulver der rothen ziehende Geschmack ein sonst dem ächten Chinarinde soll ins- an Farbe gleighkornmendes rothes Chinagemeirı verfälscht pulver sic ver:mutheu läfst, inden man ein Quentchen desselben mit einigen Unzen seyn, Wasser ausziebt, und den rothen klaren dem Pulver der ge- Auszug mit elwas Sauerkleesalz oder Sanerwöhnlichen China- kleesäure veruischt, worauf die rothe Farrinde mit dem vier- be des Auszugs mit Erscheinung eines weiten Theil gebrann- fsen Niederschlags sonleich verschwinden ter Biterende wird, wenn es auf die an ter, Biltererde ver- wird, wenn es auf die angegebene Art nachsetzt, bestehen. gemacht war. Es darf daher die rothe Chinarinde nie als Pulver angeliauft werden.

\section{and wird dadnrch eben so gefarbt.}

iSt. Fé wachsendell Chinabanms mit grofsen Früchten (Cinch on a langen Stiicken vor. Aeufserlich sind in ziemlich flachen, etwa eine halbe Linie dicken und fünf bis sechs Zoll ist briunlichgclb, märsio zähe, faserig, un ter allen

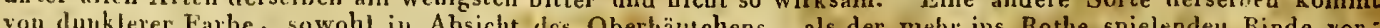
diese ist anch nicht sehr bitter aber desto mulh herbe und soll eigentlicb von St. Fé de Bogeta komrnen, daher

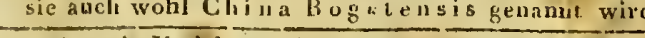

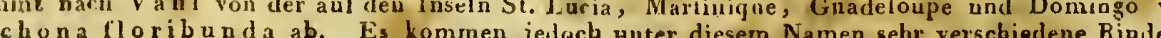

chona lloribunda ab. Es kommen jedoch unter diesem Namen sehr verschieclene. Rinden im Handel vor. 
Cortex Chinae Sanctae Luciae. - Cortex Geoffreae surinamensis.

\begin{tabular}{|c|c|c|c|}
\hline $\begin{array}{c}\text { Namen } \\
\text { der Arzneymittel. }\end{array}$ & $\begin{array}{c}\text { Simnliche ligenfigaften derfellien } \\
\text { Merkmale ihrer Aechcheic und } \\
\text { Giite. }\end{array}$ & $\left|\begin{array}{cc}\text { Felnlerhufte } & \text { Be- } \\
\text { rchaffenheit, } & \text { Ver- } \\
\text { wechfelung oder } \\
\text { Verfälfchung. }\end{array}\right|$ & $\begin{array}{c}\text { Deren } \\
\text { Kennzeichen zund Priifungsmittel. }\end{array}$ \\
\hline
\end{tabular}

St. Lucianrinde.

lletr l'ufessor Il a ge n brschreibt die ächte folgendermafsen. Dem äufsern Ansehen nacis ist sie dem Nelkenzimmt selır ăhnlich. Die längsten Stücke sind über zehn Zoll lang, in Ansebunğ der Dicke eiver Mittelsorte der gew öhnlichen China gleich, mehrentheils aber noch dïnuer. Nur wenige sint als eine leöhre zusammencerolit, die meisten haben eine rinuenförmige Gestalt. Die Farbe ist aut der äufsen Scite rostbraun, anf der

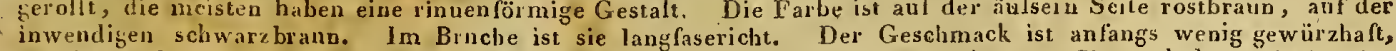

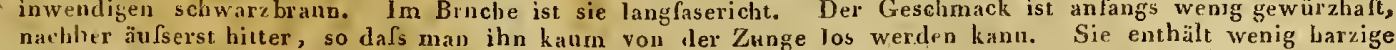
nachher äufserst hitter, so dafs man ihn kaurn vou der Zunge los werden kinnt. Sie enthält wenig barzige
Theile, liefert aber desto melir Extract. Sie ist oft mit der Martinikschen und der Caraibischen Ciuna verTheile, liefert aber
wechselt worden.

Curlex Cinnamomi

Cinnamomum acutum.

Die Rinde des vorzüslich anf der lnsel Cey-1Mit schlechtern $\overline{\text { Rin-lSind dicker, härter, vou Geruch und Ge- }}$

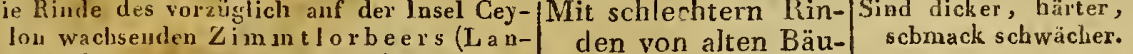
rus Cianamo uum L.) So wie der men, den Stämmen Zimmt in liandel vorkommt, besteht der- und dickern Zwei-

sclbe aus lingen Röhreu von, einem bis
zwey Fufs, welchc rneistens melhrere in

Zimmint.

Aechter Zimmt.

2wey Fuis, welche neistens meltrere in
einandcr steck.cnde Rituden enthalten. Die- Dur

se Rinden sind dinne, fast wie Royalpa- Durch Destillation se -

pie, holiclut hinoe, last wie Royalpa- nes Oels beraubt.

im brucke splitternd, trocken, leicht, hart,

stark zusarninengerollt, ant beyden Seiten

von einer gelbrotibräuulichen Farbe, nud

besilzes eiven süfolichen, gewürztafter,

erwärmeniten, etwas stecienden, hinten-

nach kaurn merklich zusammenzielienden

Geschmack, und einen äufserst angcneb-

men, feinen, durchidringenden und bals:-
misch, erquickenden Geruch. Uu!er dem

Kauen zmnfs der Speichel davon nicht

sclileiniclıt werden; auch der wälsrige
Aufgufs darf nicht schleinicht seyn. Zumi

Aurgnfs darf nicht schieinichit seyn. Zumi

deo answählen, welche dünne, kaumet-

was dicker als Royalpapier, biegsam und

von starkem Geruch und Gescbmack sind.

$D$ as divon bereitete Pulver mufs schü̈n

gelbrothbräunlicb scya, noch augenelimer

und durchdringender als der ganze Zimmt

riechen und sogleich im Anfange anch stär-

ker und lieblicher schmecken.

Geruch und Geschrwack sind uicht so stark

Geruch und Geschrwack sind nicht so stark und stechend, sonderu scbwach und fade;
die Fal be ist blässer. Durclis Verpacken solcher tihres Oels beranbten Röhren unter andern guten Zimmt, sincht naan diesen Betrug zu verstecken, der dann um so sclswerer zu entdecken ist, da jene wieder einigen Geruch und Gesclmack vou dem gitten Zimint anuebmen.

Tit verschiedenen an- $\overline{\text { Der hlafsbräunliche, dickrindige, sehr scharf }}$

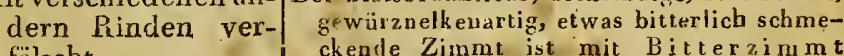
fälscht. oder Culilavanrinde; fler härtere, ein weraig dnukelfarbigere, glatıbrüchige, feuriger selmeckesde, mil $\mathrm{Zimm}$ isorte; der beyn Kaueu nud im Anszuge scileimicht werdenle, dunkelbraune rnit Muttex zim mat verfalscht.

Cortices Citri

getruckneten Schalen der bekanten Citroul (S, Poma Citri.) Answendig, wo sie frisch hellyelb sind, setien sic im getrockuten Zustande dunkel bränuhchgelb ans; inwendig sind sie noch mit dem kraftlosen markigen Theil der Gitronen versehen, von welchem sis durch Musschneiden befreyet werden miissen. Da während deIn Trocknen, das in der Zellen der geiben Schale liegende àtherische Oel zum Theil entweicht, so ișt der Gerucla und Geschmack uicht so balsamisch und gewirzhlaft als im frischen Zustande. Maan mufs dirjenigev Schalen answählen, welche noch bitterlich nud erhitzend schmecken, keine scbwarz Flecken baben, nicht wurmstichig und nicht durchs Alter oder anf andere Weise verdorben sind.

Cortex Costi ara Rincle vou der Warzel der schönen Kostwurz (Costus speciosus Smith.), einer Ingwerähnlichen in Ostiudıen waclsenden Pfanze. Wir erhalten sie in kurzen, dicken, festen und schweren ussamméngerollten Stücken, die äufstrlich eine gelbliclıweifse, inwendig einc dunkelgelbe Farbe haben. Ibr Greruch ist angenebun sewurzhaft und veilchenartig; der Geschmack aronatiscls scharf. Die festen, schweren ind angerebun gewurzhat und veilchenartig; der. Geschmach aronatiscli scbarf. Die lesten, schweren ind

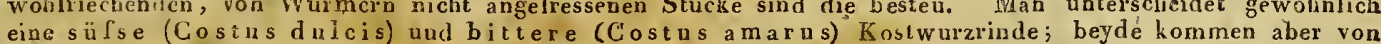
eine sïfse (Cosils dulcis) und bittere (Costus amarus) Kostwurzrinde; beyde kommen aber von
einer. und derselben Pfanze her, und der Unterschied zwischen beyden, welcher zumal nach einigen einer. und dersolben Pfanze ther, und der Unterschied $z$ wischen beyden, welcher zumal nach eínigen
Schriftstellern, nutr eingebildet seyn soll, berulhet blors auf das verschiedene Alter nuil den verschiedenen Standort der: Mutterpflanze. Den oben angefübrtea weifsen $\mathrm{Zimmt}$ (Canclla alba)'darf man nicht damit verwechseln.

Cortex Culilabani s. Culilawan. Kulilabanrinde. Bitterer Zimmt. Cortex Frangulae.
Faulbaumrinde.

\section{Cortex Fraxini.
Eschenrinde.}

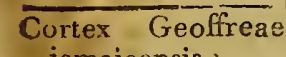

jamaicensis.

Jamaicanische

Wurmrinde.

Kollbaumininde.

Cortex Geoffreae
surizamensis.

on dem in Ostindien wachseuden Kulilabavlorbeer (Laurus Culilaban L. ) Die, von der änfsern, runzlichten, mit Warzen besetzlen, graulich - weifsen Rinde befreyze innere Rinde, welche wir in etwa anderibalb bis zwey Zoll breiten, eine Linie dickeu, ettwcler ganz platten oder etwas gebosenen Stücken erlıalten. Sie ist leicht, bricht faserig, besitżt eine braune Zimmtfarbe und bat einen gewiirzhaften, nelkeuatigen Geruch und Gescbmack.

Die von der anfsern, mat weifsen Puncten besetzten, dunkelgrünen Oberbaut befreyete iumere Rinde cles in Dentschland üherall an feuclsen Orten wachsenden Faulbaums (Rhamnus Frangula L.), welche im frischen Zustande gelb, getrocknet aber braunroth awssielit. Sie hat einen bitterlichen, etwas adstringırendschleinnichtcn Geschmack, einen beym Reiben unangenelunzn Grouch, und färbt dass Wásser, den Weingeist und den Sprichel beym Kauen dunkelgelb. Sie wird zuweilen fälschticherweise von der Ablkirsche (Pronus Padus, L.) eingesammlet.

Die Rinde der Hochesche (Fraxinus excelsior L.) Eine raube, rissichte, zcrbrechliche Rinde, auswendig von einer aschgranen, ins Grüne spielenden Farbe und mit hellcn, Lückerichlıen Pluncten besetzt; inwsodig, sielit sie weirsgelblich aus. Sic besitzt keinen Gerncb, aber einen bitteru, schleinicht $\sim$ zusammenziehtenden Gesclinack. Der wälsrige und geistige Auszug hat, grgen das Licht gętalten, eine blafsgelbe Farbe; gegen einen dunkeln $K$ örper gehalten, changirt ex ins Himmelblaue. Man ziebı die Riucle der ältern Aeste deneh der jünzern $Z$ weige vor, und reinigt sie vou der Oberhaut und deu ihr anhängeuden. Moosen untl Flechiten.

Die Rinde der Jamaicanischen Ge of froye (Geoffroy a iuermis L.) Sie kommt in Stücken vor, welche einige Zoll bis einen Fufs lang, bald 10ach, bald zusarameugerollt, nach einiggen der Cascarille, nach andern dem Nelkenzimuzt älublicl, selten übcr eine Linie dick, von aufsen grau und mit kleiucn Hrigelchen besetzt, inwendig schwarzlich oder braungrau uud mit Furchen durchzogen sind. Sie hat bisweilen rothe orler rostfarbne Flecheu, ist faserig und nicht sehr zähe. Der Geruch ist schwach, etwas widertich, vorzüglich wenn sie gepulvert wirrl; der Geschmack unangenehm, fade und bitterlich. Im frischrn Zustande soll sie eckelhaftsiilstich und schleimig schmecken. - E Eine rhabarberfarbene, sehr bittere Sorte ist verwerflich.

e Rincie des Surinamscben Wur inrinden bauns (Geoffroya surinamensis L.) Man erhält diese Rinde, welche vom Stanme und den dicken Aesten des Bammes genommen wird, in langen prattell Stücken, welche wenig oder gar nicht gebogen sind. Die äufsere Farbe ist von den anfsitzenden Flechten gran
oder gelblich ; nimmt man diese weg, so erscheint eine rothbraune oder braungraue Oberbaut, je nacbdem 


\section{Cortex Granatorum. -- Cortex Sassafras.}

\begin{tabular}{|c|c|}
\hline $\begin{array}{l}\text { Namen } \\
\text { der Arzneymittel. }\end{array}$ & $\begin{array}{c}\text { Sinnliche Eigenfchaften derfelben; } ; \\
\text { Merkmale ihier Aechtheit und } \\
\text { Guite. }\end{array}\left|\begin{array}{cc}\text { Fehlerhafie } & \text { Be- } \\
\text { chaffenheit, } & \text { Ver- } \\
\text { wechfelung oder } \\
\text { Verfälfchung. }\end{array}\right|$ Kennzeichen und Prïfungsmittel. \\
\hline $\begin{array}{l}\text { Surinamsche } \\
\text { Wurmrinde. }\end{array}$ & 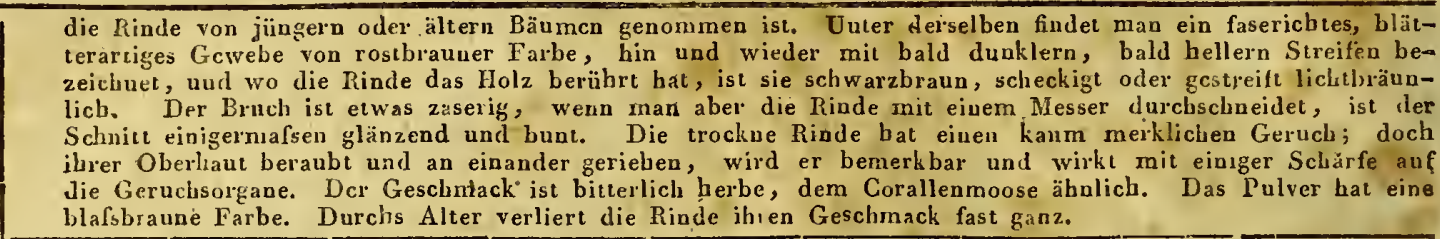 \\
\hline $\begin{array}{l}\text { Cortex Granato. } \\
\text { rım. } \\
\text { Granatäpfelscha- } \\
\text { len. }\end{array}$ & 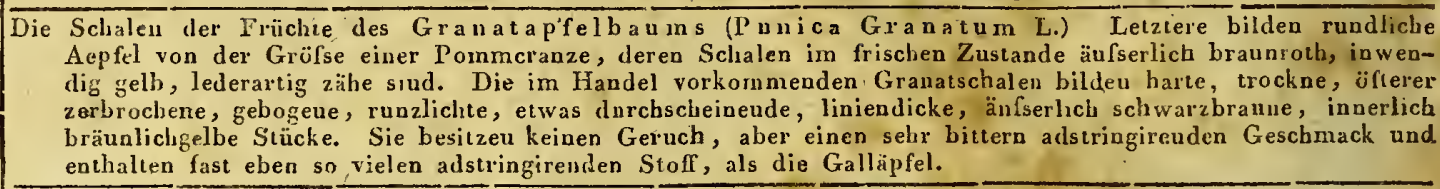 \\
\hline $\begin{array}{l}\text { Cortex Guajaci. } \\
\text { Guajakrintle. }\end{array}$ & 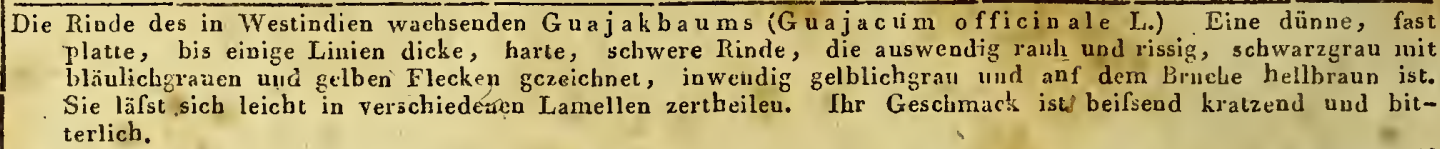 \\
\hline $\begin{array}{l}\text { Cortex Hippoca- } \\
\text { stani. } \\
\text { Rofscastanienrin- } \\
\text { de. }\end{array}$ & 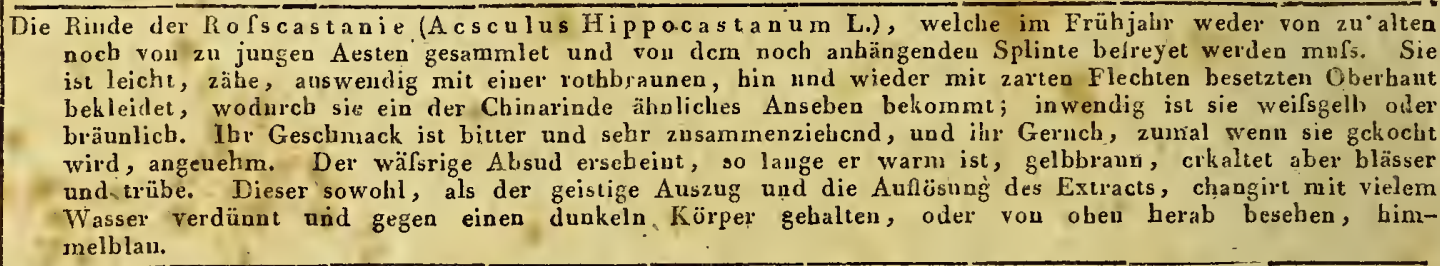 \\
\hline
\end{tabular}

Cortex Mahagoni.
Mahagonirinde.

Die Rinde des im südlichen America bäufig wachsenden Ma hagonibaums (Swietenia Mahagoni L.) Nan erialt sie theils in beyuabe lachen, fufslangen, rauben und graubraunen, rom Stamme und den dickern Aesten genoinmenen, theils in etwas platt+rn, licht graubriuulichicn röhrichten, spannenlangen und noch kürzcru, von den dünıeru Aesten und Zweigen geschälten Stücken, wovon die grüfsern mehrentheils ilures äufsern scliwammicliten Gewebes beraubt sind, und dann auf der auswendigen Seite eine nur wenig dunklere rothbraune Farhe, als anf der. inwendigen besitzen. Uebrigens ist diese Rinde von blättrichter Textur, zähe, geruchlos, in den röhrichten Stïcken kaum einer Linie dick, und kommt im Ansehn und Geschmack ziemlich mit der Cbinariyide überein, anfser dafs sie etwas bittrer ist.

Cortex Mezerei. Die Rinde des Kellerbalsseidelbasts (Daphe Mezereum L.) Sie besteht in langen, meist zusam-

Seidelbastrinde.

Kellerhalsrinde. mengerollten Stucken von der Dicke eines Pfeifenstiels bis zu der eines Finger's. Die Rinde selbst ist diiuu, leiclit, twas gestreift, ausweudig mit einem grünlichen Oberhäutchen bedeckt, woruuter eine dunkelgriune Snbstanz befindlich ist; inwendig besteht sie uus einem gelblichweissen, zähen, faserichten Baste. Sie hat keinen Geruch abor einen brenpeud scharfein Geschmack. Frisch, oder wenn sie trocken ist, in Essig geweicht und auf die Haut gelegt, erregt sie Röthe und zieit Blasen. Man sammelt sie im Frühjahre. Auswäts a Gärts wird sie vou ander'n Arten derselben Gattung, namentlich

Cortex Quassiae. Rinde des Quassienbolzes (S. Lig- Statt ihrer die Rinde

Quassienrinde. ten Flecken besetzt und lärgst mit dem Korallensumach Holze sehr fcst zusarumen, da hirgegen

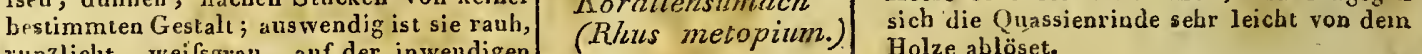
runzliclıt, weifsgrau, anf der inwendigen Seite gelblichgrau, ïbrigens leicht zerHolze ablöset. et: vom Gescbinack, der den des Holzes woch übertriff.

Cortex Quercus.

Eichenrinde. änfserlich aschfarben, rauh, hin und wiedcr mit weifslichten Moose besetzt uud auf der inwendigen Seite frisch wcifslichgelblich, getrocknet aber braunroth ist. Sie bat einen zusammenziebeuden bittern Geschmack und den bekannten Lobgerich. Die gefurchte, rissige, frisch braune und gewühulich ganz mit Moos bedeckte Rinde von ältern Aesten und dem Starnme, soll von minder kräftiger Wirkung seyn, obgleich die Meinungen hierüber getbeilt sind.

Cortex Salicis fra-

die gilis.
gartex Salicis fraim Aprịll und May von jungen Bäumen, die zwar an feuchten aber nichi au sumpfichten Orteu stehen, einsammeln und sogleich im Luftzuge tircknen mufs. Sie ist glatt und gläuzeud, sieht im frischen Zustande grïu oder grïnlichgelb, röthlich oder braunıöthlich aus; getrocknet aber hat sie eine braune Furbe und ist 'inwendig bleichgelb. Sie bat einen süfslicht-balsamischen Geruch und einen bitter'n, etwas scharfen balsamischeu, bintennach zusammenziehenden Geschmack. Die Rinde der alten Zweje ist weifsticht, etwas glänzend, stärker und dicker, wenigcr balsamisch und bitter, aber mebr zusarumenziehend schmeckend.

Cortex Salicis lauvorigen äbnlich, von noch stärkcr balsnmiscbcu, zusanm
Kommt von der Lorbeer weide (Salix pentandra L.)

Lorbeerweiden-

rinde.

Corlex Sambuci inierior.

Innere Hollunderrinde.

Cortex Sassafras.

Sassafrasrinde.

Man sammlet diese Rinde im Frühjahr von den mittlern Zwcien des Scliwarzholders (Sambucus nig r a L.), nachdem sie von dem dïnuen, hellgrauen, ruvalichten und weicheu äufsern Häutchen befreye worden sind. Sie ist grïn und saftig, nnd bat in frischen Zustande einen scharfen, nauseösen und unangenehmen Geruch und einen aufangs siifslichten, lieruach bitterlichen Gescbmack, welcher lange auf der gie wird melnentheils nur firsch angewendet,- doch zuweilen aucl getrocknet aufbewabret, in welehem Zustande sie aber schwäclicr von Gesclimack und nicht so wirksam ist.

Die Riurde des Sassafrashol\%es (S. Lignum Sassafras.) Eine dicke, runzlichte, äufserlich graulichRinde des $S$ s a f a sholzes (S. Lig a franbol\% bekleidet ist. Sie übertrift das Holz an kriftugem Gcluch und Ceschmack und besilzt eine gröfrere Wirksamkeit als dieses, weshalb sie of für sich allein verordnet wird. 


\section{Cortex Simarubae. -- Crocus.}

\begin{tabular}{|c|c|c|c|}
\hline $\begin{array}{c}\text { Namen } \\
\text { er Arzneymittel. }\end{array}$ & $\left|\begin{array}{c}\text { Sinnliche Eïgenfchaften derfelben } \\
\text { Merkmale ihrer Ächtheit und } \\
\text { Güte. }\end{array}\right|$ & $\left|\begin{array}{c}\text { Fehlerhafte } B \text { Be- } \\
\text { chaffenheit, Ver- } \\
\text { wechfelung oder } \\
\text { Verfälfchung. }\end{array}\right|$ & $\begin{array}{c}\text { Deren } \\
\text { Kennzeichen und Priffungsmittel. }\end{array}$ \\
\hline
\end{tabular}

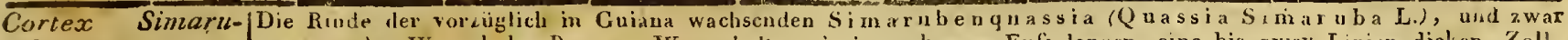
bae. $\quad$ von der Wurzcl des Baums. Wu erbalten sie in mchrercn Fufs langen, eine bis zwey Liuien dicken, Zollbis Handbreiten, gröfstentheils flachen, seluer etwas gerollieu, des bequemen Verschickens wegen mehrfach in die Länge zusanmengebogeuen Stückeı. Sıe ist sebr lcicht, locker, faserig, biegsam, sehr zähe und schwer zu julvern. Aenfscrlicb ist sie weifslichbraus oder bräunlicligelb, mit runden war icben Erund schwer zu pulvern. Aenscrlicb ist sie weilshchbraun oder branlichgel der inwendigen Seite niehrenhabenheiten besetat und einem hasserlarbigen Oberhautchen "erseluen; au der inwendigen Seite niehentheils glatt, zuweilen auch noch von ansitzendem Splinte oder abgeriebenen Fasern rab. Sie hat keinen
Gcruch, aber einen durchdringenden bittern Geschinack. - Anf beyden Obertichen branne, beyın Kauen Gcruch, aber einen durchdringenden bittern Geschinack. - Auf beyden Obertiticben branne, beyn Kaueu
kam merklich bittere, oder sonst voll der gegebenen Besclareibung abweicheude Stücke sind falscb und verwerfich.

Cortex Soymidae. Die Rinde des in Ostindien wachsenden Soymidaban u (Swietenia iSoymida.) Sie kornmt in Stückcn

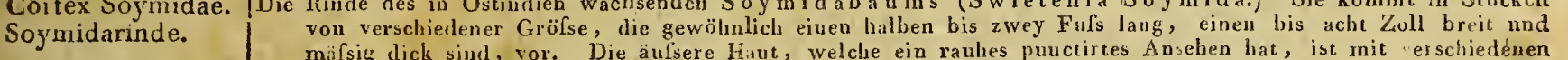
mïrsig dick sind, vor. Die äufsere Haut, welche ein rauhes puuctirtes Ansehen hat, ist mit erschiedénen Flecluten besetzt, sebr diinne und ascbgral, au Stellen, wo sie abgeriehen ist, zeigt sich die othe Farbe
der Rinde. Die eigentliche Rinde ist biüchig, dabey selur dicht, und hat einc schwirzlich geflamme rothe Farbe. Inwendig ist die Rinde glatt, weifslich, und im Queerduchschnitie zeigt sie verschiedene Lagen. Wenn die Rindo durch einen Zufall feucht geworden ist, so wird sie braun und sebwäzlich. Bisweiler findet man daran aucls wobl etwas bartes Gmimi. Sie besitzt eineu angenebmen schwach gewurabaften Geruch, und cinen sebr bittarn, etwas lualsamischen, zusammenziehenden Geschmack.

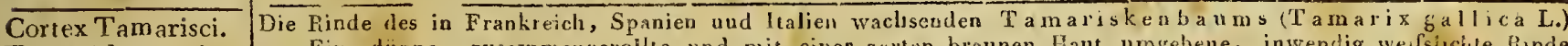

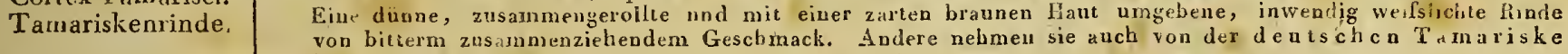

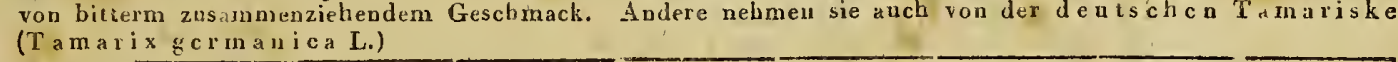

Cortex Tecamez. encm noch unbekannten Baume im Spaniscben Anerica. Man erbält sie iu meistens röl:renförmigen, of mebrmals zusarnmengerolitcu Stücken von der Starke eiues Fingens bis 2.1 einem Zoll im Durchuessej", öfters eine balbe Elle laug. Auswendig ist sie mit einem dïnen, feinen, grlatien, braulicharinen Óberhäucchen bedeckt, das hier und da mit weirsen Tlecken versehen ist; anter demselben befinclet sich eine Lage von scliön hochgelber, lockerer, kurzfaserichter Rinde, auf wrlche nock inwendig eine zwejte statte, dunkelhrame, ins Schwarzliche spielende Lage von festerem Gewebe folgt, uelche etwas glanzemi in Bruche ist. Die ganze Rinde ist über eine Linie dick, weniger faserig auf dem Broche als die Könits - und rotbe Chinarinde, und bat keinen merklicheu Geruch; das hoehgelb thababerfarbige Pulver riecht indessen etwas gewürahaft. Der Geschmaek ist beträcbtlich bitler nnd gewürzhaft.

Cortex Ulmi inteDe von der âfsera, spröden, rauhen, braunen, geschimach - und gerucnloseu Oberriule befreyte innere, dem

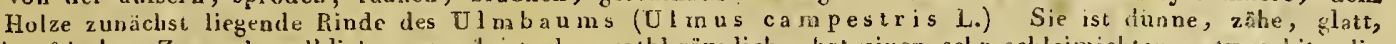
in frischen Znstande gelblich, getrockiet aber roiblrännlich, hat einen sels schleimirbten, etwas bit erliclien unil auch zusammenzichenden Gescinack, aber kënen Gerucis. Man mufs sie im Fubjabre von den dinnen Aesten nicht üher zebn bis zwölf Jahre altcr, oder ron dem Stanme junger Baume sammlen. Von den Materialisten erbält man sie oft init der äufsern Obeırinde-bekleidet.

Ulnurinile.

Cortex iं interanus Wintersche Rinde.
Wortex

Die Rinde der in Patagonien und an den Verwechselt mit dem
Küsten und anf den Inseln des Magellani- weifsen Zimumt.

schen Meerbusens wachsenden Ge wi $x$ zniutere (Wintera aromatica L.) So wie man sic etlält, besteht sie in aufgerollte:, festen, barten Stücken von verschierleuer Läuge und vou einer balben Linie-bis zu dreyviertel Zoll steigender Dicke. Auswandig ist sie. aschgrau oder graugelb, batul ruculicht, bald glatt; inwendig zimntfarbig und faserig. Gerieben bedig zimintarbig unt faseris. Gerieben besitzt sie eillen argenehmen vermiscblen Wärnelken- und Cascarilgerucb. Ihr Gescbmack ist feurig, breuuend, lange im
Muade anbaltend, loch etwas minder scharf gewürzhaft und bitter als der weifse Zinnt.

\begin{tabular}{|c|c|}
\hline weifsen Zimmt. & 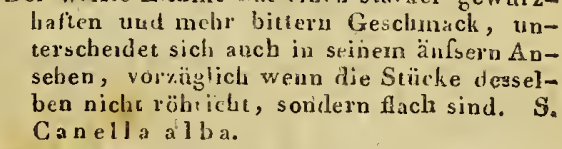 \\
\hline $\begin{array}{l}\text { Mit der Culilawan- } \\
\text { rinde oder dem } \\
\text { Bitterzimmt. }\end{array}$ & 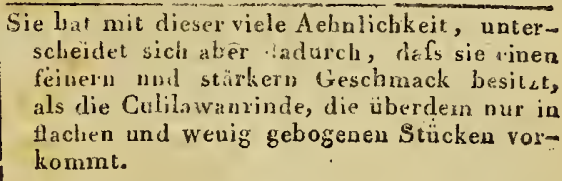 \\
\hline , & $=$ \\
\hline
\end{tabular}

Bildet in England, Frankeich, Italien wud andern Ländern ganze Gebirge. Die Kreicie ist eine ziemlich rcine to kohlensanre Kalkerde, entbäl aber auch wobl ene geringe Mcnge Kieselerde oder Thonerde mnd bisweilen

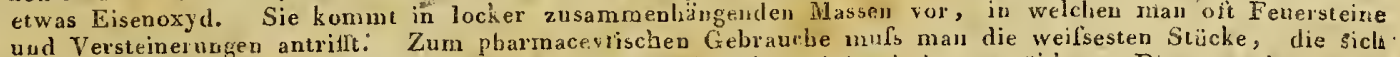
und Versteinerungen antriflt: Zum pbarmacevischen Gebraurbe muls man die weilsesten Stäcke, die sicls. vollig in Saipetersüure auflösen, leicht zerreiblich und nicbt steinig sind, answählen. Diese werien geric-

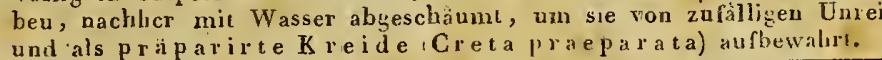

ie den Blumen des in Persien, der Tirkey lorblumen, langge- liche, baligribe oder rothgelbe, aber nicht und im südlichen Europa wild wachseu- schnittenen Gra- mit den characteristischen weifsgelulichten den, in verschiedenen Ländern mit vielem natblumen, Ringel- Eudspitzen versehene Fidendarnuter. DeriFleifs sebant wercienclen Herbstsaff- licher erkenat man diese Verfalschung bey raus (Crocus sativus var. ant um- blament.

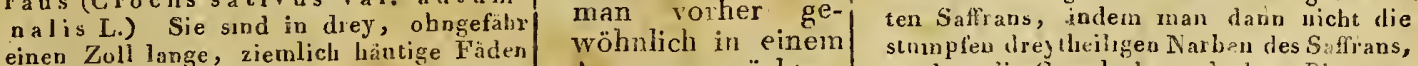
etheilt, die unten eiu dünes Encie ha- Auszug von ächtem sondem die Grstalt der gedachten Blumenbch, almölig cine keilfömige Gestalt an- Saffran hat weichen theile daran erkeunt. Die Ringeiblimen

nehmen und sich in eine aligestumpfte, ge- lassen.

kerlute, weifsgeibliche Spitze endigen. Im frisclien Zustande sind sie eben und gleich; getroctinet sind sie anf mancherley Wcise gekrümmt und in einander gedrebet, vou gerinem Gewicht, weder fencht sam, lassen sich weich und elwas fettig anfiblen und sind sclawer zu pulvern. Die Fintie dieser getrockneten Fäden ist dunkelroth oder rutbgelb und etwas glänzend, an beyden Enden aber weilsgelblich. Mei-
stens sind einige helle Fâden mit unter-
Mit Fasern von ge- Man findet dann scbwärzliche Fadeu darunter kochtem geräucher- und beym Vesbrenncn auf Kobleh entsteht ten Rindfleische ein stinkeuder Gcruch, wie von verbreuvermischt.

Mit Weingeist ausge- Wenn die Ansziehnng nicht so stark gescheder getrocknet als fsen Theil seiner Farbe vertoren hat, oder ganzer Saffran oder wenn der schon ausgezogene Saflian mit dessen Pulver. zogenund dann wie- bea ist, dafs der Sattran daciurch einen gro- 


\begin{tabular}{|c|c|c|c|c|}
\hline $\begin{array}{r}\text { Nam } \\
\text { der Arznej }\end{array}$ & mitrel. & $\begin{array}{c}\text { Sinnliche Eigenfchaften derfelben; } \\
\text { Merkmale ihrer Ächiheit und } \\
\text { Giite. }\end{array}$ & {$\left[\begin{array}{c}\text { Fehlerhafte Be- } \\
\text { frhaffenheit, Ver- } \\
\text { werhselung oder } \\
\text { Verfälfchung. }\end{array}\right.$} & $\begin{array}{l}\text { Deren } \\
\text { Kennzeichen und Prüfungsmittel. }\end{array}$ \\
\hline Crocus. & & $\begin{array}{l}\text { mischt. leym Reiben färben sic die Fin- } \\
\text { ger und heym Kauen den Speicliel stark } \\
\text { dunkelgelliroth, und in geringer Menge ei- } \\
\text { ne grofse Nenge Wasser goldgalb. Anfser }\end{array}$ & 0 & $\begin{array}{l}\text { an zu erkenuen, dafs die Firbe etwas ble } \\
\text { ser, der Geruch und Geschmack gering } \\
\text { ist und er uicht mebr das Wasser so sta } \\
\text { goldgelb farbt, als ächter Saffran. }\end{array}$ \\
\hline
\end{tabular}

Cuhebae.

Die-Beeren des auf den Pbilippinen, auf Java, Guiana u. s. w. wachsenden Cubebeupfoffers (Piper Cube b a L.) Getrocknet, wie sie zu uns kommen, sind sie rund, melir oder weniger run licht, von der Gröfse einer kleinen Erbse und mit einem dinnnen Stiele versehen, von grauschwärzlicher odler dunkelbrauncr Farbe. Ihre äufsere, leicht zerbrcchlicbè, dünne, adrichtnetzförmige, ruazliche Schale umschliefst einen runden, glatten, harten, liraunen oder schwärzlichen, innerbalb gelblich - weifsen oder schmutziggrauen ölichten Kern. Die Schale riecht angenehm, schmeckt aber wenig; der Kern bingegen hat einen bitierlichen, gewüizhaften, scharfen, beifsenden, hinterdrein einigermafsen kühlenden und den Speichel herbeylockenden Geschmack. Gute Cubeben müsseu grofs, schwer, wenig runzlicht nud weder veraltet noch verdorben seyn; der Kern mufs die Schale vö̈llig ausfüllen. Die unreif gesammleten, kleinern, sebr rnnzlichten, mit zusammengeschrump fien Kernen haben eine weit geringere Wisksamkeit.

Cupruin.

Wird fast in allen Gegenden der Erde theils gediegen angetroffeu, theils aus seiuen Erzen gewonnen, thi ils aus den Cämentwassern durch Eisen abgeschieden. Es hat dieses Metall in seinem reinen Zustande eine bräunlichrothe Farbe, ist glänzend, märsig hart, elastisch und stark tönend, betrïchtlich zälie, sehr debubar und geschmeidig, anf'dem Brucbe fein gekörnt, und gerieben oder erwärmt von cinem eigenthümlichen, widrigen Geruch und Geschmack. In freyer Luft und im Wasser wird ès von einem grünen Rost überzogen oder wie durch Kohlensäure in ein grüncs Oxyd verändert. Es wird von allen Oelen und Fettigkeiten und von fast allen Flüssigkeiten angegriffen nnd vou allen Salzen, sowobl saurcn als Kalien, besouders auch von ammoniacaliscben Mittelsalzen, nicht nur im metallischen, sondern auch im oxydirten Zustande mit griuner oder hlaulichter Farbe aufgelöset. Aus jeder Anfiösung wird es beym Zutritt der freyen Luft, durch ner oder haulicher

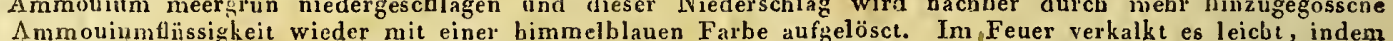

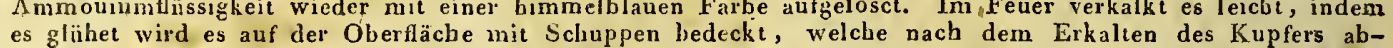
es glïhet wird es auf der Obertlache mit Schuppen hedeckt, welche nach dem Erkalten des Kupfers ab-
springen und Kupferbammerschlag genannt werden. Zum Schrnelzen erfordert es eine starke Hitze und es sclmilzt nicht eher, als bis es weifsgluhet, wobey es mit einer blaugrünlichen Flamme breant. Wird es in Flusse mit Zink vermischt, so wird es gelb und aus dcm verschiedenen Verhältnisse dieses und anderer Zusätze entstchen das Messing, der Tomback, Prinzmetall u. s. w. Legt man in die Auflösungen des Kupfers eit polirtes Eisen, so wiid dasselbe mit eincr Kupferrinde überzogen.

Cuprum 'sulphurico-ammoniatztm. Cuprum ammonis-

Schwefelsanres Am moniumkupfer. Kupferammonium
Eiu drey faches, ans Sch wefelsäure, Ammonium. und Kupferoxyd bestebendes $\mathrm{Sal} z$, welches durch Auflösung von einem The1 Kupfervitriol in drey Theilen bocheudem Wasser, al'mäligern Hinzumischen von Aetzammoniumfinssigkeit bis zur Wiederauffüsung des anfangs eutsteben Jen grünen bis zum driten Theil und Vermischung mit einer gleiclien Meuge Weiualcohol, mit einer gleichien Menge Weinalcohol,
wobey der Kupfersalmiak sich in Crystalwobey der Lupfersalmiak sich in Crystal-
len abscheidet, die alsdann gesammlet len abscheidet, die alsdann gesammlet
werden, bereitet wird. Der Kupfersalmerden, bereitet wird. Der Kupfersalmiak bildet kleine, lingliche, vortt eflich
blane, nadel formige Crystallen, (nach eiblane, nadel förmige Crystallen, (nach ei-
nigen Schriltstcllerv vierseitige Siunlen mit nigen Schriltstcller vierseitige Süulen mit
vier Ftächen zugespitzt.) Sie baben den vier Fläclen zugespitzt.) Sie haben den
stechenden Geruch des Ammoninns und stechenden Geruch des Ammoniuxns und einen anfangs scliarf alcalischen, hin kn fergeschunack. Weil das dabey befiudliche Ammonium so leicht verlliegt, so müssen si: in encm aufs genaueste verschlossenen Stöpselglase aufbewalrt wcrden. Line lobluaft dunkel hinmelblaue Farhe und volltommene Auflüslichkeit im Wasund volliommcne Aufüslichlkeit im Was-
ser sind die Keunzeichen der Gǘte dieses bewahrung verdor- sc blossenen Gefälsen anfbewabit, so verben. fliegl, zumal an einem warmcn Orte, das A mononium nach und nach, und das Kupferoxyd mit netutralem schwefelsauren Am:moninm bleibt als eiv grangriumes, nicb mehr völlig im Wasser lösliches Pulver zurück, welches, da es nun cine ganz andere Wirkung liey der Anwendung hervorbringt, nicht dispensirt werden darf.

Anmerk. Der Kupfersalmiak wird 2uweilen anch durch Abrallchen der Flüssigkeit bereitet nnd bildet alsdann eine dunkelblaus unförmliche Masse. Es ist aber diese Darstel lungsart drshalb verwerflich, weil schon während der Pereitung ein Thell des Ammoviums verAlegt und dabor gleich apfänglich ein feblexbaftes Präparat erhalten wird. 


\section{Cuprum sulphuricum. - Electuaria.}

\begin{tabular}{c|c} 
Namen & $\begin{array}{c}\text { Sinnliche Eigenfchaften derfellen; } \\
\text { Merkmale illrer Äclutheit und } \\
\text { Güte. }\end{array}$
\end{tabular}

Cuprum sulpluturicum.

\section{Vitrioluen}

letmins. de Cypro.

Schwefelsaures

Kupfer.

Kupfervitrio].

Blauer Vitriol.

Dactyli.

Datteln.

Decncta.

Decocie.

Abkochungen.

Elaeusacchara. Oelzucker.

Electuaria. Latwergen.- richti $i_{-}$Dereiteten und unverdorbeu aufbewahren Mlittels.

in aus Schwefelsänre und Kupferoxyd bestehendes metallisches Salz, welches nac Theile Kuplerspänen und dyoy aus einem centriver Schwclelsäure, die mit einander vermengt und ans eincr gläsernen Retorte die schwedichte Säure davon abgezogeu wird, worauf man die zurückgebliebene Masse iu kochendem Wasser anflöset, filtrurt nud crystallisirt, bereitet wird. Der Kupfervitriol bildzt schrägwürdlichte oder längficht rantenförmige, breite, sechsseitige Ci ystallen vov cinrr scliöneu, durcbsichti hinmelblauen Farbe, die einen metalliscl widrigen, etwas beifseud säuerlich zusammcuzlehenden Geschmack Laben, in mit lerer Temperatnr lerer Temperatnr noch nictit völlı vie Wasser zur Lösung erfordern, im Wein-
gcist keine Auflöslicbleit zeigen, ihm aber wenn er darïber abgebrannt wird, die Eigenschaft mizlueilen, mit einer grünen Flamnxe zu breuucn. Durch die Einwirkung dex Luft westlen die Crystallen nach und nacb unscheiubar lund glanzlos, auch mit eiuem weifsen Bescblag belegt. Theile und in höherer katum 2 wey Theil furcbten Kern. in dem Oelzucker rein wieder finden mufs. zerrieben werden. Dieser so erbaliene Citro
als der mit dern' wesentlichen Oel berestete.
Fiehlerluafte $B e-$ schaffenheit, Verwechfelung oder $V$ erfälfchung.

\section{Deren}

Kennzeichen und Priifungsmittel.

Der verkäufliche Wenn der an der Luft entstebencie Beschlag blane Vitriol ist ge- anf der Oberfäche des hupfervitriols mebr meiniglich mit Ei- gelb als weifs ist, so reigt dies eine Versen oder Zink ver- unleinignug mit Eisen an, welchen der unreinigt. scbwärzlich grïne Satz, den Ammoninmflïssigxeit in dessen Lösung, und das diutenartige Gemisch, welches Galläpfelausbeweisen.

Herr Frofessor G’ötling giebt folgende Prüfongsnethorle an. Maı löse etwas Kupfervitriol in destillirtern Wasser auf unil tröpfele ätzende Ammoniumflüssigkeit binzu; es wird sich die Mischnng zwar anfangs trüben, aber durch mebr hinzugegossenes Ammoniam löset sich alles rviedcr gossenes Ammonism luset sich alles viedcr zn eitue durclisichtigen blauen Flussigkeit
auf, wenn er völlig rein ist. War aber auf, Wenn er vollig lein ist. War aber Eisenoxyd vorhandeu, so wird ein schwar--
zes an der Luft gelb werdendles Eisenoxyd zes an der Luft gelb werdendes Eisenoxyd
nieslerfallen, und ist das Niederfallende weifs, so ist Zinkoxyd vorhanison gerveseu. - Der Recensent der ersteis Aufjage ( 1806 , S. L.) macht hierbey aher die Bemcrkung, dafs auch das Zinkoxyd in monimm teicht anflöslich sey

Die Frúchte der Dattelpalme (Phoenix dactylifera L.) Länglicbe Früchte von der Gestalt der Eicbeln, abcr gröfser nuł dicker. Sie sehen äufserlich röthlichgelb aus, lahen ein süfses, zuckerartiges, schleimicht schmeckendes Fleisch und enthalten in demselbeı einen steiularten, der Länge nach ge-

Flüssige Arzuey miltel, welghe durcb Kochen einer Flüssigkeit, gemeiniglich des Wassers, mit festen Substanzen bereitet werden und aus den lctztern vermittelst dieser Behapllng wrksame Theile in sich aufgenommen habeu. Nach der gröfsern oder geriugern Menge dieser aufgenommeneo Theile, nach der kürzern oiter lángern Abkochnng, nach Beschalfenheit der verordneten Arzneykörper selbst, hat das Decoct eine mehr oder weniger gesältigle, dunkle, undurchsicbtige Farbe und einen gesingern oder stärkcrn Gcschmack, wodurch es sich von einem Aufyusse unterscheidet. Bey der Bereituog eines Decocts kommt es hauptsichlish daranf an, dafs es nacls den Pegeln dor Kunst mit Anfrnerksamkeit und Sorofalt verfertigt sey; dafs die abzrkachenden Substanzeu ibrer verschiedenen Natur znfolge gebörig verbreitet uod mit der gebörigen Menge Flussigkeit abgrkocht werden; dafs das Decoct genau bis auf deu vorgeschriebeuen Punct unter langsamen, nicht zu stürmischen Krohen eirgekocht sey, dann gebörig colırt werde nnd nach den Erkaltuv die ilım zukommenden eigenthumlichen Ejgeuschafien au Farbe, Geschmack und Geruch besitze. Felılerhaft ist es, weur, wie es wohl zuweilen geschicht, der Apotheker zu den Decocten schlechte verlegene Dioguen anwendet, in der Meinung, dafs sie zu einem Decocte leicht gut genug wïren; wenin er sich zu diesem Endw weck mit Fleifs geriugere Sorten derselber vonocte leicht gut genug wiren; weni er sich zu diesern Endzweck mit Fleifs geringere Sorten derselbeu voo den Droguisten kommen lafst; oder wenn er sich gar statt
der vorgeschriebeuen Rinden, Wurzeln, Kräuter u. s. w. der von dem Rulvern dieser Substanzen zurückder vorgeschriebeuen Rinden, Wurzeln, Kräuter u. s. w. der von dern Pulvern dieser Snbstanzen zurtick-
bleibenden sogenannten Remauenzen, zu den Decosten bedient. Eben so tadelnswerth ist es, wenn etwa bleibenden sogeaannteu Remauenzen, zu den Decocten bedient. Eben so tadelnswerth ist es, wenn etwa
bey einem bäugen Gebrauch des einen oder andern Decocts eine Quadtität desselben in Vorrath bereitet wird, nod weno das Verbälinifs einer einzelnen Verordning nachher nicht damit übereinstinmt, für jedes verorduete Decoct so viel Wasser hinzugesetzt wird, dafs obugefähr die Proportion herauskommt. Da dies alles, zumal bey den übrigen Zusåzen, die gewöbnlicb dem Decocte hinzugemischt werden, nicht leicht auszumittelı ist, so kommt es bey einer so wirksamen Arzneyform, als die Decocte darbietęn, hanptsächlich auf die Accuratesse und Zuverlässigkeit des Apotheker's an.

Eutstehen durch Zusammenreiben und inuiges Vermengen von zerstofsenem Zucker und ätherischen Odev. Nach der Preufsischen Pbarmacopoe kommen auf zwey Loth feinen weif.en Zucker zwauzig Tropf n Oel. Sie dürfeu nicht anf zu lange Zeit in Vorrath bercitet werilen, weil sonst ein grofser. Theil des nit dem Zucker verbundenen Oels verloren geht. Diejenigen, welche ebeu nicht hanfig gebraucbt werden, bereitet man am besten nach obigem Verhältuifs erst bey jedesmaligem Gebrauch in-der erforderlichen Quantitit. Ihre Güte hängt von der Beschaffenheit des dazu verwendeten Oels ah, dessen Geruch und Geschmack man

Elacosaccharum Anisi. Aniesölzncker. Aus zwey Loth Zucker und zwanzig Troufen ätherischem Aniesöl bereitet. Auf gleiche Weíse werden bereitet: Elaeosaccharum Cinnamomi, Foeniculi, Menchae piperi-

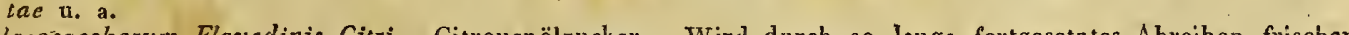
Elaeosaccharum Flavedinis Citri. Citronenölzucker. Wird durcb so lauge fortgesetztes Abreiben friseher Cutronen anf Zuckerstückcben, bis diese mit der ölichten gelben Substanz der Citronen binlänglich geschrvängert sind, bereitet, worauf die 'Zuckerstücken alsdann zur gleichmäfsigen Zertheilung des Oels fein
zerrieben werden. Dieser so erbaliene Citronenölzucker ist weit angenelımer von Geschmack und Geruch,

ie Latwergen bestehen aus einer Verbiurlung von mehreren Arzneymitteln au einer wichen dicknüssigen Misse und werden bauptsächlich aus verschieilenen pulverförmigen Substanzen mit Honig oder Znckersïften bereiund werden bauptsächlich aus verschierlenen pnlverfömigen Substanzen mit Honiog oder Znckersinten bereitet. Es kommt bey den Latwergen darauf an, das J) die vorgeschriebenen Arzneymittel dazu gleichformig und wohl unter eimander vermischt, und allc Ingredienzen von der erforderlichen Gütc und in der ge-
börigen Quantität, ohue dafs etwas feble, dazu genommea wcrden, welches sich freylich nicht leicht durch eine Untersuclinng ausmitteln lassen wird, wenn nicht etwa solche Stücke derselhen ganz weggelissen worden sind, die sich durch Geschmack nod Geruch sehr auszeichnen; 2) dafs sie die gehörige Consistenz, gewöhnlich die Dicke eines maifsig steifen Honigs haben, so dafs man mit der Messerspitze oder mit einern Spatel etwas davou abnehmen kaun, ohne dafs es von den Seiten berabfliefse; 3) dafs sie nicht verdorben sind. Die Latwergen müssen den friscben, reinen Gerucb und Geschmack ihrer Bestandtheile haben. Sie gehen, wenn sie nicht gehörig anfbewahrt werden, wenn sie an einen warmen Orte stehen, oder anch, wenn wesige dieses esige ruch an. Durch zu langes Aufbewabrè, besonders in Gefäfsen, die nicht dicht genug oder nicht gehürig 


\begin{tabular}{c|c|c|c} 
Namen & $\begin{array}{c}\text { Sinnliche Eigenfchaften derfelben } ; \\
\text { Merkmale ilhrer, Ächtheit und } \\
\text { Güte. }\end{array}$ & $\begin{array}{c}\text { Fehlerhafte Be- } \\
\text { chaffenheic, Ver- } \\
\text { wechfelung oder } \\
\text { Verfälfchung. }\end{array}$
\end{tabular} \mid Kennzeichén und Prüfungsmittel.

Electuaria. verschlossen sind, trocknensie a s, wobey die flichtigen riechbaren Theile mehr oder weniger verloren gehen wal die Latwergen unkräftig und unbraucbbar werden. Es kommt daher sebr darauf an, dafs die gatwergen an kühleo Orten in wohlverwahtten steinzeugnen oder porcellainenen Gefäfsen aufbewabrt und um ibr Verderben zu verhïten, nicht in zu grofser Menge vorräthig gebalten werden.

Electuarium aromacicum s. stomachicum. Gewürzlatwerge. Bräunlich von Farbe; stark gewürzbaft von. Gerucl und Geschmaok.

Geruch und Geschmaok.
Eleciuarium Senna s, lenitivum. Senvesblätterlatwerge. Von schwarzbrauner Farbe und sürssäuerli-

Eleciuarium e Senna s. lenitivum. Senvesblätterlatwerge. Von schwarzbrauner Farbe und

chem Geschmack, zugleich nach Senncsblătt'pulver und Auissamen riechend und schmeckend.
Electuarium Theriaca. Theriak. Braun von Farbe, vou starkem aromatischen Gerugb und Geschmack. Eine Unze entbält ohngefähr fü̉n Gran Opium.

Elemi. Elemi. Elemi.

Elemiharz.

\section{Elixiria.}

Elixire.

Es lommen von diesem Harze im Handel zwey rerschiedene Sorten vor. 2) Das
Ostindiscbe oder orientaliscbr Ostindiscbe oder orientalischr
(Elemiorientale), welches von dem in Aetaiopien und Ostindien wachsenden Mobrenölbarzstrauch (Amyris) Zeylanica L.) berrühren soll. Man erhält es in länglich runden, zwey bis vier Pfund schweren, mit Schilf oder Palmbittern umwickelten Klumpen; es ist von balloduchsichtig, ausweodig hart, aber inwelldig zähe und weich, besitzt einen angenehmen, fenchel rtigen Geruch und eigenehmen, fenchel rtigen Geruch und ei-
nen balsamischen, gewürhaften Geschmack. In Weingeist und in Oelen is! schmack. In Weingeist und in holuchten es bis auf die beygemischten holzichten
Theile völlig auflöslich. 2) Das gewöhnliche Westindische Elemi (Elemi occidentale), welcbesman von dcrn in Garolina, Brasilien und Nenspanien einlacimischen Elemiölbarzstra ucb (Amy r is eleinifcra L.) erlalten soll. Grofse in Kisten gepack te Stücke, die aus einer zusammengebackenen Masse bestelien von welcher einige Theile halbdurchsichtig und weingelb ich, andere weifs, undurchsicblig, körnig sind, oft mit Rindenstiickcbcu und Holıspanchen vermișcht, übrigens aucb fast ginz in Weingeist und Oelen auföslich. Es ist weich, wie frisches Harz, und läfst sich schneiflen; durchs Alter wird cs lart, zerbrechlich und zerreiblich, erweicht sich aber in der. Wärme leicht. Der Geruch ist dillartig balsamiscb; der Gescbmack bitterlicb. Etwas erwärmt, léuchtet disscs Harz im Finsteru, und man bemerkt das Phosphoresciren desselhell am deutlicbsten, wenn man mit einem spitzen Instrumente darman mit eine
über hinfährt.

Flussige, uicht ganz dïnue, sondern etwas dickliche, jedoch tropfbare, geistige oder weinigte Arzneymittel von dunkler, brauner oder schwär,licher Farbe, öfters auch trübem Ansehen, deren Mischung aus dern Aus, dunkicr, brauner oder schwar,licher Fartich aus dem Pflanzenreiche, zusanmengesetıt ist. Bey ihrer Beur-

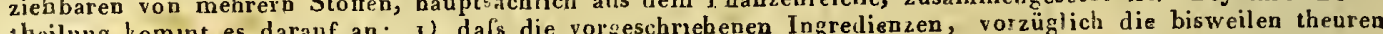
thing Gewiis des Gerch den geistigen Elixiren guter Weingeist und wesenheil des dem Branstwein eigenthümlichen Foel Gesclatsie gut aufbewalurt und nicht verdorben sine, welches die Art der Aufbewahruug selbst und die Bescliaffentieit der Elixire zu erkennen giebt. -- Die Gewolnbeit einiger Apotbeker, die Llixire und Tiucturen
nicht abzuklären, sondern auf den Stolfeu, die dazu vorgeschrieben siud, stehon zu lassen, giebt Veranlassung zum Nachbrauen und ist daher verwerflicb.

Elixir Aurantiorum compositum s. visceralc. Visceralelixir. Von einer schwarzbraunen undurchsichtigen Farbe und gewürzbaft-bitterm Geschmack. Mit Mallagawein, nicht nit Franzweiu odex Weingeist zu bereiten.

Elixir ex Succo Liquiritiae s, pectorale. Brustelixit. Von brauner undurchsichtiger Farbc und süfsem Gelixir ex Succo Liquiritiae s. pectorale. Brustelixil. Von brauner undiält an einer Unze das Lösbare schmack, nach Anisammon
aus zwey Gran Opium.

Emplastra.

Pflaster.

Feste, zähe, zuın äufserlichen Gebrauch bestimmte Massen, die sich in Eelinder Wärme schon zwischen den Fingeın erweichell und dann leicht auf Leder oder Leiuewand zu einem dünnern oder dickern Uebrange Fingern erweichell und dan licer Form nach Verschiedenleit ihrer Misclung und Bereitung mebr orler weausstreichen lassen, und in die

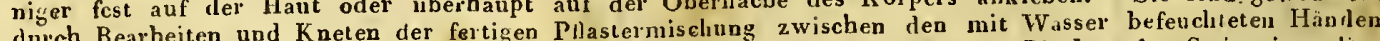
durch Bearbeiten und Breter Bleche oder Steive in cyliu(Malaxirea), und Ausrollen derselben auf eiche wordeu. Gut bedrische Stangen odle Relle hart und trocken seyn und reitete Pflaster missen cin zusamey gclinder. Wärme hingegen sich leicht zusammendrücken lassen, weich die Finger nicht beschmutzen, bey gclinder War. Spatel bcquem ausbreiten nder streicben lassen, und an urid dehnbar werden, sich nnit einem Messcr odel. Spatel bequem antricben werden, so wie nacl L.r an ier dem Leder, der Leinewand oder dem Spidcnzellge, wornuf sie gestricben werden, so wie nact dir. an ter Haut wohl anklebcn. Zum völligen Schmelzen und Flüssigwerden missen sie scbon eineu zim Bleykalk gehörig

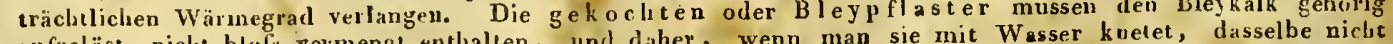
aufgclöst, nicht blofs velmengt entlalten, und diher, wenn man sie mit Wasser knetet, dasselbe nicht rnilchicht machen. Bcy ibrer Bereitung darf wedcr zu viel noch zn wenig Wasser zùgesel,t seyn; im er-

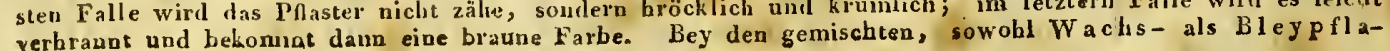




\section{Emplastra. - Euphorbium.}

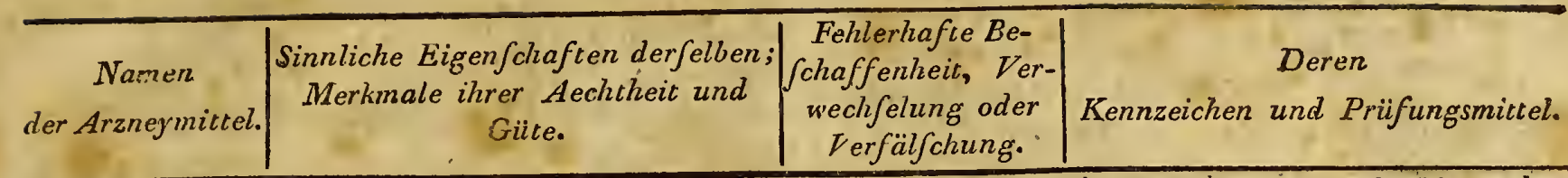

Emplastra.

pflastern ist es ein. Fehler, wenn deren Mischung nicht gehörig gleichförmig und das Pflaster daun nicht durcbgängig von eincrley Farbe, sondern bröcklicbt und buntfarbig ist. Gute l'flaster müssen vielmebr inwendig uud auswendig einerley Beschaffeubeit und Consistenz haben. Sehr zu rügen ist es, wenn der A potheker bey der Bereitung der Paaster manche Ingredienzen, z. B. die vorgeschriebenen Harze und Schlenuharze ganz, oder zum 'Theil daraus wegläfst, oder wenn er weuiger davon nımınt, als die Vorschrift befiehlt; oder wenn er, in der Meinung, dafs es bey den Pflastern nicbt darauf ankame, die Ingredienzen von der schlecbtesten Beschaffeuhcit dazu verwendet, und wohl gar die- einem-Pfiaster eigenthünliche Farhe auf eine fälschliche Weise erkünstelt wird, wie z, b: 'bey dem zusammengesetzten Diachyloupflaster nach des älter'u Vorschriften durch Orlean statt des biuzumischenden Saffraus. Werden Campher und flüchtige Oele, die z.1 einigen Pfastern konmen, vor dern gehörigen Erkalten der Pflastermischung zugesetzt, so entweichen sie in der Hitze und clas Pflaster verliert den eigenthümlichen Geruch, den es haben

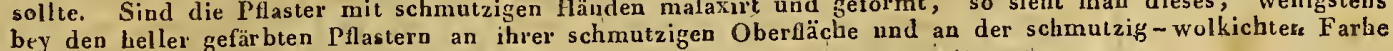
bey den heller gefärbten Pflastern an ihr
im lunern der durchschnitteuen Stangen.

Emplastrum Ammoniaci. Ammoniakpllaster. Grau-brännlich-gelb, sehr zähe, von harzicbtem Geruche.

Emplastrum Anglicanum. Englisches Pflaster. Ein gutes Englisches Pflaster mufs spiegclglatt und glänzend seyu, 2 wischen fenchten und warmeu Fingern sogleich kleben, fest auf dem feinen Tallet baften und von der Hant beym Waschen uicht so leicht vom Wasser losgeweicht werden. Schlecht bereitet sieht es runelicht und geknittert aus, 'ist spröde nnd brïchig, löset sich vom Taffet ab und klebt nicht gut. runzlicht und gekitert aus, ist sprode newärpilaster. Von stark gewürzbaftem Geruche nacb Kreidmplastrum aromaticum s. stom Pfeffermünzöl!

Emplasirum Cantharidum ordinarium s. vesicatorium ord. Spanischfliegenpflaster. Grünlichgrau von Farbe; Emplastrum Cancharidum ordinarium s. vesicatorium ord. Spanischfiegenpfaster. Grintich mufs sowobl auf seiner Oberärine als im Bruche eine, gehörige
scben Fliegen zeigen. Es darf nicht zu alt und dadurcb trocken und bröcklich seyn, sondern mufs sich noch gut ausstreichen lassen.

Emplastrum Cantharidum perpetuum s. vesicat perp. Anhaltendes Blasenziehpflaster. Mufs nicht zu bart seyn und in geölter Blase oder in einer nit Blase verbundenen Büchse aufbewabrt werden.

Emplastrum Cerussae s. album coctum. Bleyweilsplaster. Muís schön weifs seyu. War das dazu verwandte Bleyweifs unit Kreide verfälscht, so ist das Plaster bröcklich und sandig, ancb bemerkt man darin die Kreide als ein weifses Pulver.

Emplastrum Celacei. Wallrathpflaster. Aus weifsem Wacbs, Schöpstalg und Wallrath bestchend, Wird in papierne Capseln gegossen und mufs schön weifs und nicht ranzicht seyn.

in papierne Capseln gegossen und muls schön weils Grün von Farbe, nufs gleichförnig gemischt seyn, einen betaubenden Scbierlingsgeruch babeu ulld darf nicht mit Scbimmel überzogen seyn, wie es oft der Fall ist.

Fall ist.
Emplastrum foetidum s. resolvens. Stiukasantpflaster. Nach stinkendem Asant riecbend.

Emplastrum foetidum s. resolvens. Stiukasantplaster. Nach stinkendem Asant riecbend.
Empiastrum Hydrargyri s. mercuriale. Mercurialptlaster. Blaugran. von Farbe. Auch durchs Microscop Empiastrum Hydrargyri s. mercuriale. Mercurialptaster. Blaugrau. von Farbe. Aucb durchs Microscop müssen darin keine unzertheilte Quecksilberkügelcheu zu seheu seyn. Ist der Mangel

Emplasiım Hyoscyami. Bilsenkrautptaster. Grüli, nach Bilsenkraut dumpf betäubend riechend. Nieht

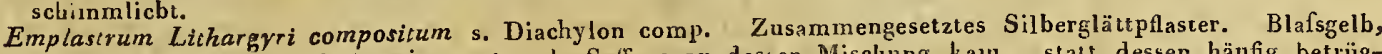
nicht hocbgelb von Farbe; wie sonst, da Safran zu dessen Misclung kam, stalt dessen häufig betriig licberweise Orleau genonmen wurde, der ihm dann eiue rothgelbe Farbe gab und zugleich die Weglaslicberweise Orleau genommen wurde, sung der gehi

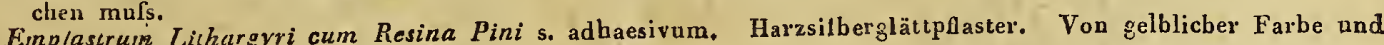
dem bekannten Harzgeruch. Emplasirun Litharayri simplex s. Diachylon simplex. Einfaches Silberglattplaster. Weilsticbt und gut klebend, zumal da nach Emplastrum.Meliloti. Melilotenpflaster. Dunkelgrün, stark nach Meliloten riecbend.
Emplastrum opiatum s. cephalicum. Opiumplaster. Braun von Farbe; nacb peruvianischem Balsam riecliend. In zugebundener geölter Blase aufzulıwahren.

Emplastrum saponalum. Seifenpflaster. Gelblich-weifs von Farbe; nach Campber ricchent. Emplastrum sulphuratum s. nigrun sulphuratum. Schwefelpflaster. Von brauschwarzer Farbe und starkem kräftigcn Gerucb. Mufs in einexn fest mit Blase verbuudenen stcin Łeugnen Gefafse aufbewabr
werden.

Emulsiones.

Flussige Arzueymittel von einer mulchartigen Beschaffenheit, welche, durch Zerstofseu und Zerreiben ans festen, schleimicbt - ölichte Theile enthalteuden Mitteln unter allinäligem Hinzumischen einer wälsrigen Fcnchtigkett bereitet werden. Man nnterscheidet zweyerley Arten, nämlich 1) die eigentlicbe $S$ a men- oder

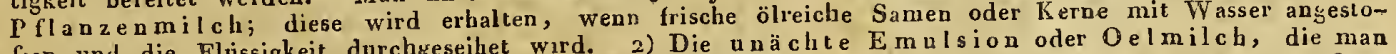
fsen und die Flussigkeit durchgeseihet włrd. 2) Die unächte E mulsion oder aus ölichten, fettigen oder barzichteu Substanzen, den Mors und durcb Beyhulfe eines schicklichicn ZwiOelell, natürlichen Balsamen u. s. w. durch heiben Gumi, des Eygelbes u. $s$. w. mit Wasser bereitet. scbenmittels, wie z. B. des Schleirns von arabischefülig bereitet seyn. Zu der erstern Art dürfen keine Beyle Arten müssen nacb den Regeln der Kunst sorgfalig bereitet seyn. Zu den; die Emulsion inufs eino ransige, wurmstichige oder angcfressene Samen oder Kerne genommen werden; die Emulsion mufs eino gleachtörmige Beschaffenheit und das Auscbn einer 1 einen frischen Milcb haben, mebr oder weniger süslich, nie aber sänerlich scbmecken, und, zumal im Kühlen, eine ziemliche Zeit num sersetzt bleibeu, so diass also nicht gleich nach ihrer Bereitung die ölicht - scbleimichten Theile sich absonderu und auf der Ober-
fiache herumscbwinmen. Auch die Oelmilcb mufs sich nicht sogleıch in ihre Bestandtheile trennell. Die Oele, welche dazu vorgeschrieben sind, müssen rein, trisch, ụnd von aller Ranzigkeit frey seyn. Die Gummiharze müssen anfs feinste zchrieben werden, so dafs ein möglichst gleichartiges Ganze herauskommt. Alles

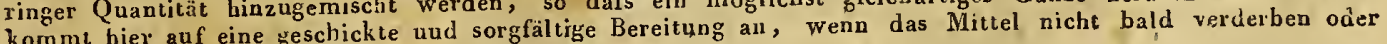
widerlich einzunebmen seyn soll.

Euphorbium. Ein Gumn Milchsaft aus der geritıen Rinde der im heifsesten Africa und in Aethiopien wachGennen Euphorbienwolfsmilch (Eupborbia officinarum L.) fliefst und daun an der Pilanze erbarlet. Wir bekommen es aus der Barbarey in dichten, ledernen Säcken. Es besteht aus erbsengrofsen, barlet. . Wir bekommen es aus dëf Ba Stücken von verschiedener, kuglicbter, länglicher, eckiger oder ästiauch wobt etwas kleintro od groen der Planze ger Gestalt. Diese Stucke sind von dern Ä̈sern versehen. Sie baben auswendig eine schmutziggelbliche hänfig ausgeliöhlt oder mit zwey kleinen Löchern versehes, srock, zerreiblich, leicht und insgemein mit erdioder roubräurliche, inwendig weifslicbe Farbe, sind trocken, Fur sich riecht das Enphorbium nicht; an- 


\begin{tabular}{|c|c|c|c|c|}
\hline $\begin{array}{l}\text { Namen } \\
\text { er Arzneymitcel. }\end{array}$ & $\begin{array}{c}\text { Sinnliche Eigenfchafien derfelben; } \\
\text { Merkmale ihrer Aechtheic und } \\
\text { Gïte. }\end{array}$ & \begin{tabular}{|} 
Fehlerhafte Be- \\
chaffenheit, Ver- \\
wechselung oder \\
Verfälfchung.
\end{tabular} & Kennzeichen & $\begin{array}{l}\text { Deren } \\
\text { und Prïfungsmittel. }\end{array}$ \\
\hline
\end{tabular}

Euphorbium.

gezündet verbreitet es einen eben nicht unaugenehmen Geruch und brennt mit heller Flamme. Beym Kaneu scheint es anfänglich gesibmacklos zu seyn, nachher aber verursacht es einen äufserst ätzenden unil brennenden Geschmack, der sebr lange anbält uud sich nur durch Ausspülen des Muades mit Oel mildern lässt. Seine Schärfe ist so grofs, dafs das beym Zerstofsen aufsteigende Pulver, wenn man sich nicht sehr sorgfältig davor schintzt, ein sehr heftiges und anbaltendes Niesen erregt und das Gesicht entzündet. sehr sorgfältig davor schïtzt, ein sehr heftiges und antral
Die blässern, gröfsern, trocknern Stücke siud am besten.

Extracta.

Extracte.

Die Extracte werden theils durch Uebergiefsen und blofses Ausziehen oder dnrch Ablochen von vegetabiliacben Körpern mit Wasser, oder auch durch Digestion mit Wasser und Linzugesetztem Weingeist, und nachbcriges Verdunsten der durchgeseiheten klaren Flüssigkeit, theils durch Eindicliung des aus frischen

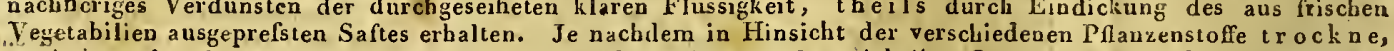
weiche oder d ü n u e Extracte bereitet werden sollen, ändert sich ibre Consistenz ab, indem die trockWe iche oder d ü nere Extracte bereitet werden sollen, ändert sich ibre Consistenz ab, indem die trock-
ne n Extracte eine solche Consistenz, dafs sie sich zu Pulver zerreiben lassen, die weiche die Dicke ne Extracte eine solche Cousistenz, dals sie sich zu Pulver zerreiben lassen, die weiche die Dicke
eines steifen Honigs oder Muses, und die dïnnen oder sogenannten Honigsäftel(Mlellagines) nur eines steifen Honigs oder Muses, und die dïnnen oder sogenanten Honigsätel(Mellagines) nur
starke-Syrupsdicke und alsa nocb einige Flïsigkeit haben müssev. Da die Extracte, wean sie gut und istake-Syrupsdicke und alsa noch einige Flïssigkeit haben müssen. Da die Extracte, wenn sie gut und
regelmärsig zubereitet sind, zu den wichtıgsten officinellen Arzneymitteln geböreu, so erfordert ibre Zubereitung, sehr viele Sorgfalt und Genaugkeit, und man bat daher bey der Untersuchung über ihre Güte und Aecbtheit hauptsächlich auf folgende Puucte Rücksicht zu nehmen. Gut bereitcte Extracte müssen nämlich den eigentlürnlichen Geruch und Geschmack der Vegetabilien, woraus sie bereitet worden, in gehörirom Grade besitzen, keinen fremden, besonders keinen brenzlichten Geruch und Geschmack baben, welchen sie sebr leicht bekommen, wenn bey deren Eindickung der Grad der Hitze zu stark war, und sie daher etwas anbrannten. Unter dieseı Uuständen geht dann der eigenthümliche Gernch mchr oder weniger verloren, vorzüslich wenn die Pflarizen viele riechende Bestanitheile baben, die erhalteu werden sollen; aucb hekommen sie eine schwarze Farbe, die sie eigentlich nicht waben, sondern vielmehr uur dunkelbrann ausselien müssen. Sie dürfen bey ibrer Lüsung in reinem Wasser keinen pulverichten Satん fallen lassen, sonst entbalten sie gemeninlicb pulverige Theile der Substau, woraus sié bereitet worden, in sich, oder sonst entbalten sie gemeniglich pulverige Theile der Substauz, woraus sie bereitet worden, in sich, oder sind gar mit: dem Pulver davon verfälscht. Vor allen Dingen durfen sie nicht metallhaltio seyu; metallhaltige Extracte zeicbnen sich gewöhnlich durch eiuen sehr eckelhaften Geschinack aus. Sind die Extracte kupferhaltig, wie dies bey unvorsichtiger Bereitung in kupfernen oder messingenen, yoder durchy Aufderșelben in reinem Wasser auflöset, ind eine blank polirte eiserne Messerklinge in die Aubösung eintauclt; war das Extract kupferbaltig, so wird das Messer uach einiger Zeit mit einer rothen Kupferhau überzogen, erscheinen. Docb mufs; um diese Probe richtig anstellen zu können, oftmals etwas reiner Essig zugesetzt werden, weil das Kupfer in den Extracten nicht immer durch Sämcn, sondern auweilen durch setzt. Sicherer noch, aber umständlichcr, ist die Prïfing der Extracte auf Kupfer durch Verbreusung eines. Theils derselben zu Asche, aus der inan dann durch. Digestion mit einer gehörigen Menge Ammoniumnes Theils derselben zu Asche, aus der man dann durch Digestion mit einer gehorigen Menge AmmoniumAufösung zu erkeunen giebt. Sind die Extracte eisenbaltig, so giebt dies theils der zusammenziebende Aufösung zu erkeunen giebt, Sind die Extracte eisenbaltig, so giebt dies theils der zusammenziebende
Geschmack des Extracts 7.0 erkennen, theils kann man es dadurch erforbchen, dafs man eine mit Wasser Geschmack des Extracts zu erkennen, theils kann man es dadurch erforbchen, dafs rnan eine mit Wasser
gemachı Lösıng dieses Extracts mit sehr vielem Wasser verdünt, und dann ein paar Tropfen Gralläpfeltinctur hinzutröpfelt, da denn, wenn Eisen vorhanden war, die Flïssigkeit gleich schwarz wird. Durchs Alter und durch scblechte. Aubbewahrung iu Gefáfsen, die nicht gehörig dicht oder verschlossen siad and an zu warmen oder durmpfen feuchten Orten śteken, vcrderben die Extracte, indem sie entweder austrocknen, oder sauer und schimmlicht werden, auf beyde Art aber ibre eigenthümlichen Kräfte verlierev. INach der verschiedenen Berists rige, theils in Lösung olne beträchtlichen Bodensatz, nicht aber die beyden letztern. - Zur Aufbewabrung der Extracte dürfer keine metalleue, sondern steinerne, porcellainene oder gliiserne Gefärse gebraucht werden; auch müsdürfer keine metalleue, sondern steinerne, porcellainene oder gliserne Gefarse gebraucht werden; auch müsund so das Extract durch eil metallisches Mittelsalz verunreinigt werdeu könnte. Extracte, die Leiclit schimmlig werden, können davor durch eine Haut geschiit\%t werden, die nach deru Abdampien zur geliörigen Consistenz bey dem erforderlicben Hitzegrad, welchem man das Gefäfs, woriu das Extract aulbcwahrt wird mit demselben aussetzt, seine Oberfläclue deckt.

Excracıum Absinthii. Wermuthextract. (Wässerig.) Glänzend, braunschwarz von Farbe, unangenebm salzi bitter von Geschinack; löset sich nicht ganz helle im Wasser anf.

Excractum Aconiti. Eisenhutextract. (Eingedickter Saft.) Hat eine dunkel grünlicu-braune Farbe und

frisch bereitet einen durchdringend - reizenden Geschmack.
Extractum Aloes s. Aloe depurata. Aloeextract, (Wässerig.) Von trockner zcrieibbarer Beschaffenbeit, Extractum Aloes s. Aloe depurata. Aloeextract. (Wässerig.) Von trockner 2crieibbarer Beschaffenbeit, einer rothbraunen Farbe; selor bitterm Geschmacke und eigenthumlichell Aloegertuch. Zerrieben stellt es ein sctiön gelbes Pulver dar, dals sich in kaltem destillirten Wassen leicht volfornmen kar aunöset. Statt desselben wird zuweilen gewöhnliche Aloe genonnen, deren Aunösuo

vollkounmen geschieht, indem sicb ein starker harziger Bodensatz abschieidet.
Extracıum Angelicae.' Angelikwurzelextract. (Geistig-wässerig.) Vou brauner Farbe und eigenthümlichen starken Angelikwurzel-Gerucb und Geschmack. Ueberhanpt-müssen alle geistig-wäfsrigen Extracte, welchc zum Theil künstliche ächerisch-ölicbte Gummibarze darstellen, gut und frisch hereitet, den Geruch und Gesclinack der Substanz, woraus sie bereitet sind, im hohen Grade besitzen und von gelbbrauner, rothbrauner oder scliwarzbrauner Farbe uud gleichartigcr, fast durchsiclıtiger Beschaffenheit seyn.

Extractum Angnsturae. Angusturaextract. (Geistig-wässerig.) Von dunkelbrauner Farbe und eigenthümlicheu Angusturarindengeschmack.

Excraccum Arnicae. Woblverleihextract. "Geistis-wässer̄ig.) Braun von Farbe ; vou bitterlich-scharExtractum Arnicae. Wohlverleihextract. (Geistis-wässer̆ig.) Braun von Farbe, von bir

fem, im Scbluude etwas kratzendem Geschmack. Wird alls der ganzen Pilanze bereitet.
Excractum Belladonnae. Belladonnaextract. (Eingedickter Saft.) Vou grünlichbrauner Farbe, bitterlichem, etwas salzichten Geschmack und bet:abendem Geruch.

Extracıun Calami. Kalmuswurzelextraç. (Geistig-wässerig.) Von branner Farbe und eigenthümlichen

Kalmusgerucb und Geschmack. Cardobenedictenextract. (Wässerig.) Dem Wermuthextracte ibnlich,
Exiractum ('ardui benedici. schmeckt aber reines bitter, giebt mit Wasser keine gauz Lelle Lisung. Erwas Salpeter entlíaltend.

Extractnm Cascarillae. Casearilleuextract. (Wässerig.) Hat einc Chocoladeuliraune Farbe, ein griefslichtes Ansehen, einen aromatischen Geruch und den gewürzbaft bittern Geschnack der Cascarillrinde. Nimmt jnit' der Zeit eine festere Beschaffenbeit à, löset sich nicht ganz leichit iu Wasser auf und gieht eine trübe Aufösung.

Extracıun Centaurit minoris. Tansendgüldenkrautextract. (Wässerig.) Glänzend, dunkelbraun von Farbe, etwas schar f biuter minoris.

Extractum Chamomillae vulgaris. Chamillenextract. (Wässerig.) Ilat ein mattglänzendeb graubraunes Ausehen und einen etwas widerlich salzobtbitterlichew Gesehmack. 


\begin{tabular}{|c|c|c|c|}
\hline $\begin{array}{c}\text { Namen } \\
\text { der Arzneymittel. }\end{array}$ & $\begin{array}{c}\text { Simnliche Eigenfchaften derfelben, } \\
\text { Merkmale ihrer Aechtheit und } \\
\text { Giite. }\end{array}$ & $\left|\begin{array}{c}\text { Felnlerhafte Be- } \\
\text { fchaffenheit, Ver- } \\
\text { wechfelung oder } \\
\text { Verfälfchung. }\end{array}\right|$ & $\begin{array}{c}\text { Deren } \\
\text { Kennzeichen und Priifungsmittel. }\end{array}$ \\
\hline
\end{tabular}

Extracta.

Extractum Chinae americanum. Südannericanisclies Chinaextract. . Wird in Südamerica wahrscheinlicb aus der frischeu Rinde bereitet und kömat riber Spaniel nach England. Es bat eine dunkle Farbe, ist schön durchsicbtig, im Munde sehr auföslich, frey von allei Brenzliehkcit, vou reinem, der bestén Chinarinde gleiebkowmenden Geschmack und Geruch, halbweicher Consistenz, schwer iu kaltem, leicht iu koehenden Wasser auflöslich und die Auflösang von zwey Drachmen desselben in einem Nöfsel Wasser gleict t in allen Eigeuschaften einer Abkochung von einer Un/e der besten China.

Extractum C/cinae aquosum. Cbinaextract. (Wässerig.) Hat ene hellchocoladcubraune Farbe und eino dicbte, elwas zäbe Consistenz. Der Greschnack ist augenehm bitter, etwas säuertich gelinde cusammenzieliend, der Riude, gleich; die Auflösung ist trïbe und rolbbran, eınem Chinaabude nicht unalinlich. Scines theureu Preises wegen ist es mancheu Yerfälschungen unterworfél. Häufig beuntzt man dazu die Rückstände von den Abkochungen der Cbina und die bey der Bercitung des kalt bereiteten Chiuaextrácts durcb Wasser bereits ausgezogene Chiua. Das Extract ist dann naturlich weit weniger wirksaru nnd schwächer von Geschmack, schimmelt auch leicht und verdirbt bald. -- Zuweilen setzt man der China beym Auskochen Laugensalz hinzu; das Extract beliommt davon einen scharfsulzigen Gescbinack und tiue scbwarzbraune Farbe, die Consistenz istract beliommt davon einen scharfsulaigen Gescbinack unit der Zeit zeigt sich anf der Oberfläche etwas flïssiges, welches gröfstentheils zerflossenes Kali ist; auch schimZeit zeigt sich anf der Oberfläche etwas flïssiges, welches gröfstentheils erflossenes Kali ist; auch schim-
melt ein solches Extract leicht und brauset init Sauren anf. -- Zuwcilen ziebt man auch wohl die melt eiu solches Extract, leicht und brauset init Saureu auf. -- Zuwcilen ziebt man auch wohl die
Chiua erst mit Weingeist und dann mit Wasscr aus, vermischt beyde Anszinge und kocht sie ein; die Auflösung im Wasser geschieht dann nur nuvollständig und der durch den Weingeist ausgezogene barzichte Theil bleibt' am Boden liegen. -- Oft werden dem Chinariudeuextracte ganz andere Extracte, namentlich von der Weidenrinde, der Eiclsenrinde und der Rofscastauienrinde substituirt, deren unterscbeidende Kennzeichen man weiter unten finder.

Exiractum Chinae frigide paracum, Kaltbereitetes Chinaextract. Durch Uebergiefsen der gepulverten China ruit kaltem Wasser, fleifsigem Unrühen und Quirlen, nachherigcro Durchseihen unil gclindem Verduusten des kiar filtrirten Aufgusses bis zur gehorigen Consistenz bereitct. Das auf diese IVeise erhaltene Extract ist glänzend, gelbrölhlichbran von Farbe, durchsichtig und giebt in Wasser eine klare hell-

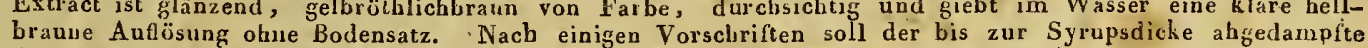
Auszug Antosung ohue Bodensatz. Nacb einigen Vorschriften soll der bis zur Syrupsdicke abodampite Auszug ganz düune auf mehrere Porcellaintellcr gegossen und in Luftzuge durch-Sounenwirme so eiu-
getrocknet werden, dafs er als eiue völlig trockne Masse von den Tellern mit einem Messer abge:chaht werden kann. Man hebt ilu sowobl dickflussig als pulverförmig eingetrocknet in tinem genau verstopfteu Glase auf.

Exuracium Colocynthidis. Coloquintenextract. (Geistig wässerigr.) Aus dem Marke der Colocjuinten bereitet, schwarzbraun von Farbe, von hüclsst bitterm Coloquintengeschnirack.

Extractum (iolumbo. Columbowurzlextract. (Geistiö wässerig.) Vou dunkelhrainer Farbe und eigenthümlichen Columbowurzelgeschinack.

Exiractum Conii maculaci s. Cicutae. Fleckenschierlingextract. (Eingedickter Salt.) Dunkel grünlichbraun von $F$ arbe, die sich besonders in dessen Lösungen za erkennen giebt; von widrig dumpfigen, betäubenden Scierlingsgeruch und eckelhaftem Geschmack. Mufs nicht schimmlicbt seyn und jalsrlicb frisch bereitet werdeu. Unkrätig ist das bey eirem zu boheu Hitzgrarle eingedickte Extract, wodurch es

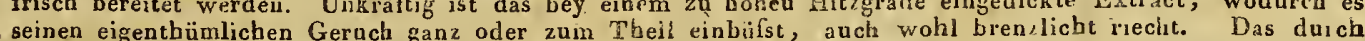

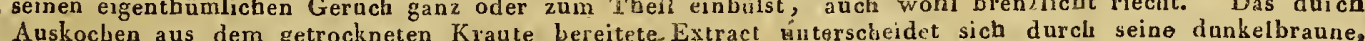
nicht grünlichbraune Farbe; cs giebt in Wasscr eine nelur klare Lösung, bat nn einen schwachen Geruch und ist bey weitem nicht so wirksam, als des eingedickte Saft. Man sehe auch darauf, dafs das Extract nicht aus falschen Planzen bereitet werde. S. Herha Conii maculati.

Extractum Corticum Aurantiorum. Pommeranzenscbaleuextract. (Geistig wässerig.) Braun von Farbe, von eigenthümlicben Geruch und Geschmack der Pommeranzcnscbalen.

Extractun Croci. Safranextract. (Geistig wässerig.) Von braunrother Farbc und bittcrlich gewärzhaftem Geruch und Geschmack; theilt dem Wasser in geringer Mcnge einc reine goldgelbe Farhe mit.

Extractum Dulcamarae e stipitibus. Bittersüfsstengelextract. (Wässerig.) Branngelb von Furbe, glänzend, durchsichtig, von bitterlich-sitfsem Gescbmack.

Extrastum Ferri pomaiumi. Eisenextract mit Apfelsaft. Aus reiner Eisenfeile mit dem Safte von sauren

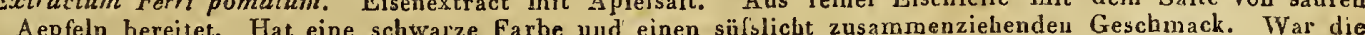
Eisenfeile mit Kupfer oder Messing verunreinigt, so wird anch das Extract kupferbaltig seyn, welches Eisenfeile mit Kupfer oder Messing verubreinigt, so wird anch das Extract kupferhalig seyn, welches man auf oben angezeigte Weise fiudet

Extractum Fumaviae. Erdrauchextract. (Wässerig.) Hat eine schwarzbranne Farbe, ist gew öhnlich oben von balbflüssiger, unteu aber fester grieslichter Beschaffenheit, und hat eipen salzigbittcrlich unangenehmen Geschmack.

Extractum Gentianae. Gentianwurzelextract. (Wässerig.) Hat eine dinnkelgoldgelbe Farbe, mattglänzendes Ansehen, scheint durchsichtíg, giebt jedoch mit Wasser heine klare Auflösung und schmeckt äufserst, Jucb nıcht unangenehm bitter.

Exiractum Graminis s. Mellago Craminis. Queckenwurzelextract. (Eingedickter Saft.) Hat die Consistenz eines dicken Syrups, viele Aehnlichkeit mit einem guten Niöhrensaft und eincn angenelımon süfsen Geschmack. Mufs sich im Wasser klar auflösen.

Extractum Gratiolae. Gottesgnadenkrautextract. (Wässerig.) Zeigt eine glänzende Oberfläche, ist schwarzbraun, ein wenig grieslicht, undurchsichtig, und von eip̣em anfangs süfslichteǹ, nachber aber äufșerst braun, ein wenig griches.

Extractum Hellenii s. Enulae. Alantwurzelextract. (Geistig wïsserig.) Braun von Farbe, von gewürzhaftem Geruch und scharf bitterlichem Geschnack. Wird gerne schimmlicht.

Extractum Hellebori nigri. Schwarzè Niefswurzelextract. (Geistig wässerig.) Von schwarzbrauner Farbe und scharfem, bitterlichem, eckelbaftem Geschmack.

Extractum Hippocastani. Rofscastanienrindenextract. (Wässerig.) Ist im äúfserlichen dem Cbinaextracte sehr ähnlich, bat aber eiuen mehr zusammenzielseudern und bittern Gescbmack. Löset nıau davon zehn Gran in einer Unze Wasser anf, so schillert die Auflösung mit einer vortreflich bimmelbłanez Falbe.

Exuractum Hyoscyami. Bilsenkrautextract. (Eingediekter. Saft.) Dnokel grünlich-braun von Farbe, undurchsichtig, von betâubendem Bilsengeruch und bitterlichem Geschmack. Mufs bey der gelindesten durcbsichtig, von betáubendem Bilsengeruch und Theil seiner Wirksamkeit verliert.

Wäme bcreitet seyn, weil es senst den gröfsten Theil seiner Wirksamkeit verliert.
Excracum Levisfici. Liebstöckelwurzelextract. (Geistig wässerig.) Brạn von Farbe; von eigenthümlichen Geruch uud Geschmack der Wurzel.

Extractum Ligni Campechiensis. Campechenholzextract. (Wäfsrig.) Besitzt ein rotbbraunes, glänzendes Arsehen, einen sïfslichen, etwas zusammen/iehenden Gescbinack, und gieht mit Wasser eiue fast dunkelrothe Aufösung, die mit mehr Wasser verdünmt, ins Violetce spielt. Nimmt hinterher ene festere Beschalfenheit an, darf aber aucb gleich anfänğlich nicht zn weich eingekocht seyn, weil es sich sonst niclit bält.

Exicactum Ligni Gunjaci. Gnajakholzextraet. (Wässerig.) Enthält immer eine Portion harzichter Theile, die ibm ein griefslichtes Anselien geben. Es hat emue braunschwarze Farbe und dem unverkennbaren Geschmack des Guajakholzes. 


\section{Extracta. -- Faba Pechurim.}

\begin{tabular}{|c|c|c|c|c|}
\hline $\begin{array}{c}\text { Namen } \\
\text { aer Arzneymittel. }\end{array}$ & $\begin{array}{c}\text { Sinnliche Eigenfchaften derfelben; } \\
\text { Merkmale ilırer Aechtheit und } \\
\text { Güte. }\end{array}$ & $\left|\begin{array}{cc}\text { Fehlerliafte } & \text { Be- } \\
\text { fchaffenheit, } & \text { Ver- } \\
\text { wechfelúng oder } \\
\text { Verfälfchung. }\end{array}\right|$ & Kennzeichen & $\begin{array}{l}\text { Deren } \\
\text { und Prïfungsmittel. }\end{array}$ \\
\hline
\end{tabular}

Exıracım Lighi (uassiae. Quassiaholaextract. (Wüsserig.) Hat eine griefslichte Beschaffenpeit, eine gelb:raubraune Farbe, einen äufserst bittern, lange anbaltenden, ein wenig salzigen Geschmack, gernciniglich einige Wochen nach der Bereitung obenauf etwas flüssiger, trocknet jedoch mit der Zeit ger'e zu einer lichtgelbbräunlichen festen Masse Curcumä - noch Lackmuspapiers, bildet mit den AufAuflösung desselben ändert weder die Farbe des Curcumit zugesetzter Schwefelsäure Spuren von salzichlösungen des Eiseus in Säuren keime Dinte, und läst mit actiefert, so worden demselben beym Auskoter Säurc bemerkeu. Da das Quassienholz nur weuig Ext, um die Quantität des Extracts zu vermelıren, chen betrïglıcherweise zuweilen Gertianwurzeln zugesetzt, um die Quantitat des welches sich aber dem Kcnner bey Vergleichung mit ächtem Extract im Geruch gestofsenen Quassiapulver erbenncn giebt. - In gleicher Absicht wird 2nweilen das Extract mit fein gestorsenen Quassiapulver vermengt, welches sich bey der. Auflösung im Wasser zeigt.- Nicht selten ist das Quassebene Weise zu durch das langc Kochen in kupfernel Kesseln sehr kupferhaltig, welches auf ohen angcoebene Weise zu
prïfen ist.

Excracıum Marrubii albi. Weifsandorncxtract. (Wässerig.) Mattglänzend, granbraur von etwas griefslichter Beschaffenheit und bitterm, etwas seifenartigem Geschmack.
Extractum Millefolii. Schafgarbenextract. (Wässerig.) - Dem vorigen ähnlich, aher von bitterlichem etíwas

salzigen Geschinack.
Extractum Myrrhae. Myrrbenextract. (Wässerio.). Durch Uebergiefsen der gepulverten Myrrhe mit Wasxcracium Myrrhae. Myrrhenextract. (Wasserien zichicen Sntze abgegossenen und durchgeseiheten Fliissigkeit bis zur pulverbaren Trockenheit bereitet. Mufs

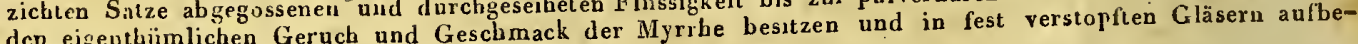
den eigentbiimlict wahrt werden.
Exiractum Nucum Juglandinm. Wallnufsextract. (Eingedickter Saft.) Wir̉ aus den noch unreifen mit Wasser angestofsenen Walla üssen bereitet. Das Extract luat

besitzt einen bittern, herbeı zusanmenzicliendell Geschmack. ist ist, einen "ufserst durcbas erbaltene Geschmack und eine groser BeschaffenLirtract fuct beit so leicht sebimmejt, so ware es woh bessenen Gefán zuge turch Son

Fxurex wie das Myrrhenextract bereitet. Mufs den Geruch Extractum Opii. Wäsriges Mohnsaftextract. Wird wie das Myrrhenextract heresten.

Geschmack des Opiums besitzen und siob im Wasser vollkommen a) Braun von Farbe; von eigenthümli-

Extractuin Pimpinellae. Pimpinellwurzelextract. (Gei

chen Gerueb und Geschmack der Pimpinellwurzeln.

Extractum Qu'rcus. Eicbenriudeextract. (Wässerig.) Hat ein braunrothes mattglăneades Auschinack, einen lobneır dem Chimaextract ühnlichen, aber weit stärer zusammenziehender Eısenaufösung vermischt, Dinte artigen Geruch, und gieht mit Wasser eine rothbrauntrube, mit einer Eu E

Extractuin Rhei. Ribabarberextract. (Wässerig.) Mufs der Haltbarkeit wegen bis zur Stăke einer PlllenEs hat cine braungelbe Farbe, den eigenartigen Geruch und Gemasser eine nicht mit Sruren brausende, mit zngesetztem Kali scha Zuweilen wird der Rhabarber fälschlicherweise, in der Meinung, dunkelbre um mebr Extract zil elian tract mit Wasscl glcich eine brauniothe AMtos eine ganz schlechte verdorbene Rhahaber genor Rhababerrückund den Tincturen übrig gehliehenen bereits anșgezogenen, oft schimmlicht geworich aher bey Vergleistände beygeseliet werdeu. Ein anf solche Weise erbaltenes Extract unterscheidet schimmlichten Geruch chung mit einem ächt bereiteten sehr auffallend durch seined minder starken, or schimmichen Geruche und deu faden Geschmack. "Zusammengesetztes Rhabarberextract. Besteht nach der Pr. Pharm. aus drey Exiractum Rhei compositum. Zusammengesetztes Rhabarberextract. Besteht napuenseife Hat die Consistenz Theilen Rhabarherextract', einem Theile Aloeextract und eben so viel Jalappenseife

einer Pill nmasse, ciue loranschwarze Farbe nnd einen pckelbaft hittern Gescbmack.

Extracium Salicis laureac. Lorbeerweidenrindeextuact. (Wässerig.) Hat eine dunkelbraune Farbe und eine dem Chinaextracte ähuliche Beschaffenbeit, sclimeckt jedoch merklich zusammenziehender, zuletzt süfslich, und riecht fast, wie frischer Urin.

Extractum Saponariae e Radicibus, Seifenkrautwurzelextract. (Wässerig.) Hat ein mattglänzendes, lichtgelbgraues Ausehen, läfst sich in Fiaden zieben, . schäumt beym Auflösen und schmeckı scbleimicht, seifeuartig, eckelluaft und hintennacl cin wenig scharf. Extractun Squillae. Meerzwiehelextract. (Wässerig.) schmàk und giebt eine etwas schleinichte Aufösung.Extraçum Taraxaci liquidum. Taraxacunextract. (Eingedickter Saft.) Hat die

Syrups, eine schwarzbraune Farbe und einen hitterlichen seilenartigcn Geschmack.

Extiactum Taxi e foliis. Taxushlätterextract. ' (Ein
durcbicbtig, von bitterlichem Geschmack. Extractum Tormentillae. Tormentillwurzelextract. (Wässerig.) Hat einen stark zusammenziehenden Geschmack und färbt den Speichel braunroth. Trocknet bald zu einer lesten, pulverbaren, rotbhraunen Masse ein. Extractum Trifolii aquatici. Bitterkle be nnd eineu reinhittern Geschmack.
Exıracium Valerianae minoris. Baldrianwurzelextract. (Geistig wässerig.) Hat eine braunschwarze Farbe
und wenn es vorsicbtig bereitet ist, ganz den eigenthïmlicben Geruch und Gescbmack der Baldrian-

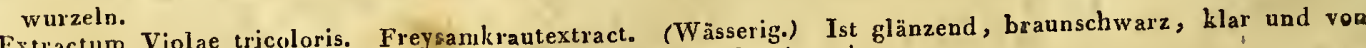
schleimicht bitterlichem, nachhcr eckelhaft süfslichtem Gescbmach.

Faba l'echurim s. Pichurim.

Pechurimboline.

Brasilianische Boh

Muskatenbohne.
Wir crbilten die Pechurimbohnen, der u
Mutterpflanze noch nicht genau hestinumt Mutterpflanze noch nicht genau hestinimt ist, aus Paraguay und Erasilien durch die l'ortugiesen. Es sud vicht die gauzen Yrüchte, souderu die läuglichtey förnigeu fruchtherne, deren jede fillicht zwey enthall. Auf der einen Seite siud sie erhaben, auf der andern etwas vertieft oder ach wobl gefurcht. An beyden Euden siucl sie abgestimplt, einen bis and crthalb Zoll lang, acht Linien breit and otliche

\begin{tabular}{|c|c|}
\hline $\begin{array}{l}\text { erwechselt mit der } \\
\text { falschen Pechu- } \\
\text { rimbohne aus Ame- } \\
\text { rica. }\end{array}$ & $\begin{array}{l}\text { ächten aus America im. Handel vorkom- } \\
\text { menden Pecburimbohne, die noch um die } \\
\text { Hälfte gröfser. als die beschriehene erste } \\
\text { Sorte, auswendig mehr runzlicht und bläs- } \\
\text { ser, iuwendig. aber duukler gefärbt und } \\
\text { bittrer und schwächer gewrürhalt als die } \\
\text { zwcyte Sorto seya soll. }\end{array}$ \\
\hline
\end{tabular}
erwechselt mit der Mehrere Schriftsteller warnen vor einer unfalschen Pechll- achten aus Animber die noch um die Hälfte grö́ser als die beschriehene erste ser, iuwendig.aber dunkler gefarbt und zwcyte Sorte seyu sell. 


\begin{tabular}{|c|c|c|c|c|c|c|}
\hline $\begin{array}{c}\text { Namen } \\
\text { Ier Arzneymiticl. }\end{array}$ & $\begin{array}{c}\text { Sinnliche Eigenfchaften derfelben; } \\
\text { Merkmale ilurer Ächclieit und } \\
\text { Giite. }\end{array}$ & $\begin{array}{c}\text { Fehlerhafie Be- } \\
\text { fchaffentheit, Ver- } \\
\text { wechselung oder } \\
\text { Verfälfcluung. }\end{array}$ & Kennzeichen & $\begin{array}{l}\text { Deren } \\
\text { und Prüfungs }\end{array}$ & & $e l$ \\
\hline $\begin{array}{l}\text { Faba Pechurim s. } \\
\text { Pichurim. }\end{array}$ & 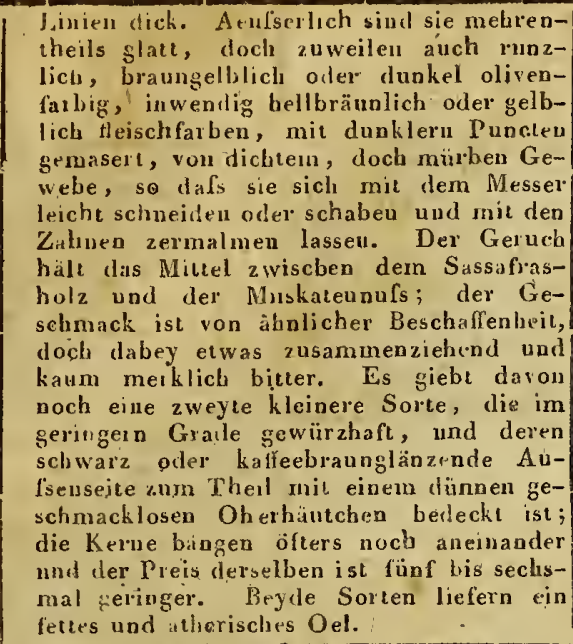 & , & ' & , & $\begin{array}{l}: \\
: \\
6 \\
8\end{array}$ & 1 \\
\hline
\end{tabular}

Faba:Sancti Ignatij. Die Samenkerne der birnenfürmigen Frichte des auf deu Philippuischen Inseln wachsenden Bitterig azSct. Ignazboline. $\quad$ b a u $S_{1}$ (I 5 a ti a a mar a L.), welche seit 1699 durch die Jesuiten behanut geworden sind. . Sie sind. länglich, fast eınen Zoll lang, doch auch kleiner, etwas platt, anf der einen Scite erhaben, auf der andern rieteckis und ein wenig zusammengellückt. Aeufserlich sind sie fein gestreift, lichtbraun, wie mit einem festanfsitzenden Mehl bestreut oder mil einer Art gelblichen Filz beset,t, wovon sie ein asehgraues Ausehen habeu; inwendig sind sie hart, glanzend, vis fast hornartiger Beschattenheit, mit eillem braum nen Harze durchdrungen, so ¿lafs sie brann - oder schwarzgrünlich ausseben. Sie baben ennen iufserst bitteru Geschmack und euthalten narcotischen Stoff. Die gröfsern, schweren, die noch gauz unversebrt siud, sind am bester.

Fel Tauri inspissatium.

Eingedickte Ochsengalle.

\section{Frrrin!.}

Eisen.

Die in Wasserhade oder aut scliwachem Durch Fäulnifs ver-[Sie riecbt und schmeckt dann sehr faulicht Kohlfeuer uuter stetem Umiuliren bis mir| dorben.

Dicke eiwes Extracts abgedunstete Ochsengalle. Hat eine gelbbraune Farhe, ei- Kupferhaltig. nen wisirigen dach nicht faulichten Geruch und eimen äulserst bittern $\mathrm{Ge}-$ schmack.

Das Eisen, welches unter allen Metallen am lanfizsten in der Natur verbreitet ist, komint in seivem ansigeschmolzenen $\mathrm{Zu}$ stande in gemeinem Leben uuter s.hr verschietlener For'un por, worunter sich besonders das $R$ ohe is en, das g es ch miedete Stangen-odcr Stabei sen und der $\mathrm{Stahl}$ von einander lurch gewisse abweichentc Eigeuschafteu auszeichnen.

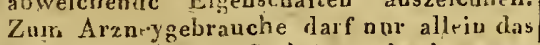
Zurn Arsnrygebrauche darf nor all rin danstc und vollkommenste Eisen angewende werien.

Das reine Eisen ist ein festes, dichtes, elastisches, klingendes Metall, auswendig meist.ns grauschwäralich, inwendig oder auf dem Bruche grauweifslich und giänzerd. Nach dem Golde ist es das zäheste Metall, besitzt eine beträchtlicbe Gescbrneidigkeit nud ist sieben - bis achtmal scbrneidigke waser. In feuchter und in Wasser wird es mit einem braunrother Ros! überzosen, der es mit der Zeit zerbrechlich machs. Es wird vom Magnet zerbrechlich machi. Es wird vom Magnet
angczosen, und kann selbst zum Maguet angczogen, und kann selbst zum Maguet
wercien. In allen Säuren, besonders in der Salpetersäure, ist es anflöslich, nnd drese Auflösungen werden durch vegetabilische adstringilerude Substauzeu, als Galläpfet, Granalsclialen u, s. w. schwarz nifdergeschlagen. Durch Kali wird es aus seinen A ufösungen his ein schmuligoriunes Oryd durch blansanres Kali aber blau farbeu getallt. Unter allen Metallen bat es die gröfste Verwandscliaft zum Scbwees die grolste Eerwandschat zum erforder eine sehr starke Hitze, ebe es $21 \mathrm{~m}$ Flufs kommt, wird vor dem ebe es $2 u m$ Flufs kommt, wird vor dem Schinelzen erse werch, und läfst sich da-
lier schweifsen. Wird es lauge gegliibet, lier schweilsen. Wird es lauge gegliben, schuppichten Hau bedeche, die huch wiederboltes Härnmern yol dem Eisen absfringt und nuter dem Namen $\mathrm{H}$ a $\mathrm{m} \mathrm{mer-}$ schlas bekanut ist.

Das Stangen - odler Stabeisen 1afst sích Das in ter Kalle als in der Wirne unter dem Hammer strecken, hat eine graum

Roh- oder Gulse is en statt des geschmiedeten Eisens. Stahl statt des ge
schmiedeten Eisens

-
Wie bey den Extracten 20 prüfen, -- Darf
duichans nicbt iu knpfcrnen Gescbirren eingedickt werden.

Vou in hr oder weniger lichtgratur Farbe bis zum dunkelo unil selbst grauschwazen, an polirten Stellen ins Blaue spirlenil. Auf dein Brache niche faserig, sondern ruebr oder weuiger feinköruig. Selut hart und klingend, aber zugleich höchst spı̈̈de nnd d her weder kalt noch warn uncer dern fianmer dehubar.

Die fem polirten Stellen desse ben haben eineu weifsen lichtgrauen, nicht ius blane schirlendell Glanz; der Brnch ist feinköro ni:, matssthimmcynd. Er ist specifisch schwerer, färtér tind spröler als geschmiedetes Fisen

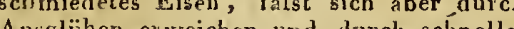
ch schinelle Abkühleu in Wasser nach dem Glühen wieder härten: Bey der Bereitung des Stahls soll man sich häufig llcs Arseniks bedienen. Ein solcher arsenikhaleiger Stahl. würde sich ladurch erkenucu lassen, dafs aus der Aajösung desselben in Salpetersüure durch H a h n e un a n s Probefüssigkfit ein gelber durch Kupfersalmiak aber ein gelburune Bodensatz gefallt werden wïrde. 


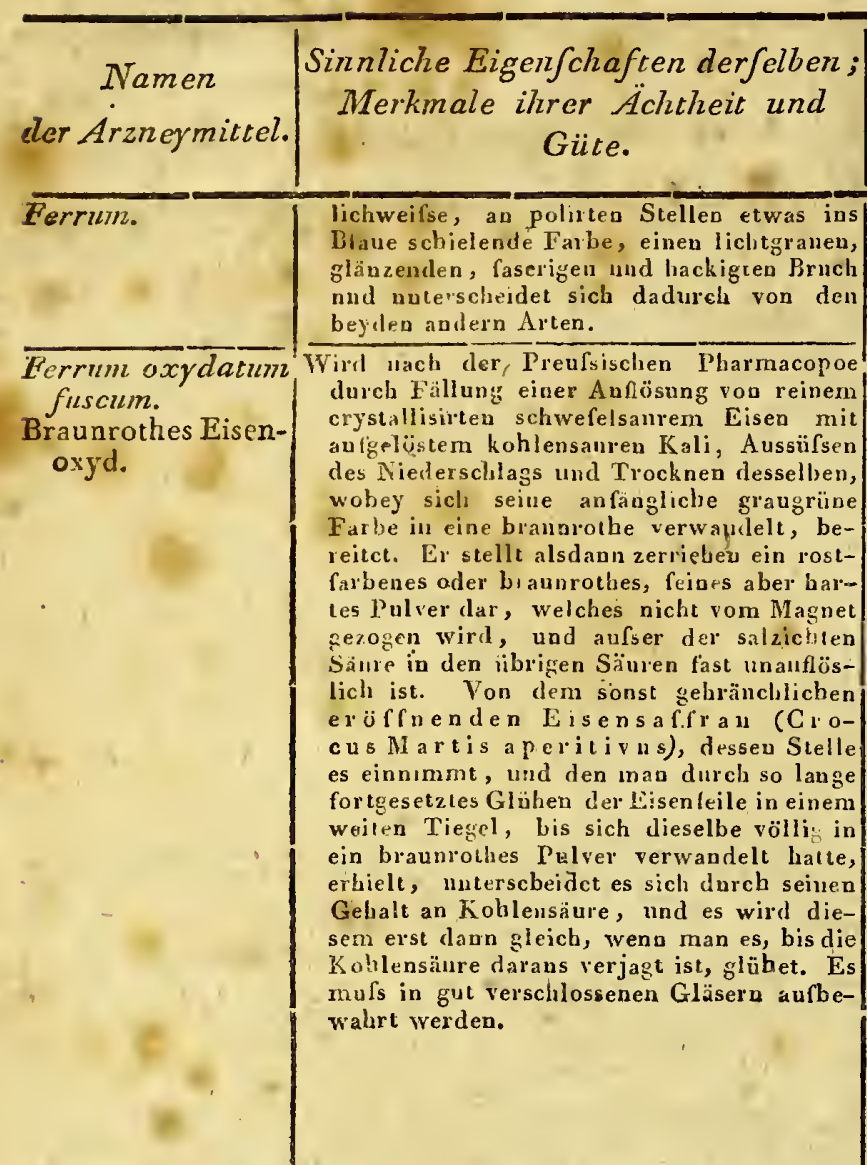

Ferrum oxydula.

tum nigrum.

Aethiops martialis.

Schwarzes oxydu-

lirtes Eisen.

Eisenmohr.

\section{Fierrum pulvera}

tum.

Limatura Martis praeparata.

Eisenpulver.

Pripparirte Eisenferle.

Ferrum purum li matum. Limattra Martis. Iisenfeile.
Ferrum sulplutricum crystallisa-
cuma.
Fehlerhafie Befchaffenheit, Verwechfelung oder Verfälschung.

\section{Kennzeichen und Prüfungsmittel.}

Nach der Preufsischen Pharmacopoe durcb mairsiges Tranked des bramrotien Eisenstillation des getrankten Pulvers aus einer beschlagenen gläsernen Retortc bey alinäbeschlagenen gläsernen Retortc bey allmälig bis fast znm Glülsen vermehrten. Fener
und bis zur Trockanteit der Masse fortgeund bis zur Trock antieit der Masse fortge-
setzt, worauf alsclann der erkaltete völlig setzt, worauf alsslaun der erkaltete vöilig
scliwarze Rïchstand feingerieben wird, bescliwarze Rïckstand feingerieben wird, be-
eitet. Lin unvollsonmenes Eisenoxyd, 1eilet. Lin unvolilsommenes Eisenoxył,
welches ein sammtschwarzes, gleichförnnig feines, nicht klimmprichtes Pnlver darstelleu, ganz vom Mnget gezogen, sich duichs Gliiben beym Lnftzutritt in rothes Eisenoxyd verwandelu, tınd in allen Säuren, ohoe Wasserstoffgasentwickelung, leicht andïsen lassen murs Der feuchien Luft ausgesetzt, biclit es in einc so fcste Masse ausammen, dafs es uicht aus den Gefáfsen zusammen, dafs es uicht ans den Gefafsen
lierinsgebrachit werden kann. Es mufs dalier ansgebracht werden kann. Es muls da-
lier in einem wohlverstopften Glase au einem trocknen Orte aubewahrt werden.

\section{Durch anhaltendes fleifsiges Stofsen der rei-} nen Eisenfeile in einem eisernen Mörser and Beuteln durch Lemewand 211 bereiten. E:n schwarzgranes, hartes, metallis oh glänzendes Pnlver, welches sicb durclsans vom Magnet anzielien und leicht in Süuren

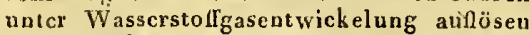
lassen'mufs.

Un' las Lisen zun A zueygebranche vorzubereitcu, wird es mit der Feile zerkleincr, and beifst dann Eisenfeile. Diese sollte sich billig jeder Apotheker sclbst absichtlich bereiten lassen, nicht aber diejenige aufkanfen, welclie bey versclícilencu Eisenarbeitern ab(ällt, da diese überhaupt sehr uncin und vorzäglich se uberlaupt sehr unicin und vorzuglich woit Kupfer oder Messing vermengt ist, schlagene Ausziehen mil dem Maguet nicht sclilaşene Ausziehen min
gebörig gerreinigt wird.

in aus Schwefelsấn nnd Eiseu hestelıendes mallisches Salz, welches rlomboidnlische, durclssichtige, schïn gesätligt
grujue Crystallen bildet, die einen bitter-
Kupfer-oder Zinkhaltig, "wenn das dazu gebrauchte braunrothe Eisenoxyd von dicser Be. schaffenheit war.

Zu sehr oxydirt.

Zuweilen soll dem Ei senmolurgallussaures Eisen (der aus gelöstem Eisenvitrool mit Galläpfelauszug bewirkte Niederschlag) substituirt, werden.

\section{Rostig.}

Kuplerhaltig, wenn mit Kupfer verunreinigte Fisenfeile dazu genommen worden. Mit Kupfer oden
$M e \int f i n g$ verunreinigt.

\section{$\overline{\text { Kupfertallitis, wenn }}$} das angewandte $\mathbf{E i}$ sen nicht rein war oder wenn statt des
Um dieses zu finden, lüse man ctwas davon in salzichter Säure anf nnd übersältige eineo kleinen Theil dieser Anllösnug mit äıenden Ammonium; bleibt die über dern Niederschlag stehende Flüssigkeit furbensie aber sogleietı oder nach cinigen Stunden blan, so beweist dies $K$ u p fergcla alt. Der Zink läfst sich entdecken, weun man das Oxyd mit Kohlenpulves mengt utd glibliet; es redncirt sich dabey der Zimk und brenut, indem er sich verflichtigt, mit lebbafter Flamue. Aucls kanu man ilın cntdecken, Wenn man die Auflösung des Eicenoxyds mit kolilensaurem Kali lansam tall. Zuerst schlint sich das Eisenoxyd mit dunkley Farbe nieder; das Ziukoyd hingegen reigt sich erst gegen das Ende der Präcipitation nit weifser Farbe, wclches schon verdachtig macht; men, scheide dic Flüssigheit von dem Niederschlage durchs Filtrum ab, und setze derselben etwas blaus unres Kali zul dies schlägt das Zinkoxyd weifs nieder, nod sollte aucb noch ein kleiner Eisengehalt einen blawen Nieder'schlas bewïiken, so wird dieser doch mit dem lilausanren Zinkoxyd gemengt, sebr blafs ausfallen.

Man entdeckt dieses auf die im rorigen Titel angegebene Weise.

An merk. Der Eisenmobr kann auch knfferbaltig seyn, wenn er nach einer andern Methode, indem man Eisenfeile in einem Tiegel zum Glähea biingt, und auf das glühende Eisen 211 wiederholtenmaleu in kleineu Portionen so lange Wasser schüttet, bis alles in ein matteb, schwartes nnd zerreibliches Pulver verwandelt ist, und wenu in diesem Falle die Eisenfeile nait Kupfer oder Messing veruureinigt war. Durch letzleres wird das Präparat aucli zinkhaltig.

Der vollkomunuer oxydirte $A$ ustieil wird alsdann vom Magnet niclut angezogen.

as gallussaure Eisen wird nicht vom Magnet gezogen; seine Farbe' wird durch Säurcn vernichtę, und darin gelöst, wird es durch kohlensaure Alcalielı, so wie aus der Anllösung in kocliender Aetzkalulauge mit Sauren sclıwarz abgesondert. Dör ffin t nenes deutsches Apotheherbucb, Tb. 11. Abth. 1. S 817 . Dies zeigt die rothbranne Farbe. Siehe dem foigenden Titel.

Sie theilt alsdann der damit digerirten $A$ nımoninmulussigkeit eine blaue Farbe mit. Dasselue geschieht, wena etwas weniges in Salpeter-oder Sclıwefelsäure aufgelöset nnd dieser Aufiösnng so lange Ammonium z.ugesetzt wird, bis der Geruch desselben merklich hervorsticht. Ein in die Auflösung dersclben gestelites polirtes Eisen wir
mit einem Kupferbeschlag äbcrogen.

in in die Aufösung gestelltes blankes Eisen wird dann mit einem Kupferbeschling überzogen, und die Anflösung mit Ammo- 
Flores Acaciae. -- Flores Chamomillae romanae.

\begin{tabular}{c|c} 
Namen & $\begin{array}{c}\text { Simmirhe Figenfchafien derfelben } \\
\text { Mertimale ihrer Ächcheit und } \\
\text { Güte. }\end{array}$
\end{tabular}

Vitrivlum Martis lichberbsincrichen, hintenuach stark zufactitium.

Crystallisirtes

schwefelsaures

Eisen.

Eisenvitriol.

\section{Flores Acaciae.}

Schlehenblumen.

Flores Anthris

Rosmarinblumen.

Flores Arnicre.

Wohlverleihblunien.

Flores Aurantiorum s. Napliae.

Pormmeranzenbläthen.

Flores Cassiae.

Clavelli Cinnamoaii.

Zimmtblüthen.

Cassiablumen.

Flores Cllamomil-
lae romanae. sammenziehenden Gescinack habeu, sich ohne Trüburg in mitterer Temperatur in sichs Theiten Wisser, aher gar nicht in Weingesst auflissn, au der Luft leicht in ein getbliches Pulver zertitlen und sicl daut nicht mebr iu VWasser klar autlösen lasseu. Auch die Aullösung läfst au der Lull Eistucher falleu.

Die Blumen des Schleluendorns (Pruuns spinosia L.) Kleine knrgestielte, mit cincm eiablätrigen, fünfsp.ltigen, s.umpt aurückgeschla,cuen Katche und fiin: weifst'n, rumllichen, hobten, obeu eingekertiteu Kroublattern nul den ihrigen Reliuctingstieiten rersehene Blumen. Sie kommen gewöhnlich schon im Aprol berror, baben irn frischen Zustande eimen lieflichen Gerrich und bille-rmandelartigrn Geschmack. Man sammlet sie, ele sie noch gauz anfuesohlossen sin $l$.

Violectröthliche Lippenthumen, welche im May (hos marinus officinalis L.) bis au die Spitze der Stengel hervorbrecten. Sie habun einen-zeslipp.yen Kelch mil fast gamz gerader Ober- mad gespaltener. Unterlippc, und eine rachenförmige Kron" mi

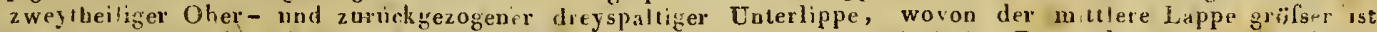
Gevacb und Geschmsck sind stark lurclodringend, campherarliog, gewürzhaft. Der Kelch, als der winksansie. Theil, ist olighlich mis esnzusamrinlew.

Die Blumen des Fallkrantwoh lver-jVer leill (Arnica monlana L.) Gélbe, zusanumengesetzte Blumen, die ans langest, schmalen, dreymal gezähnten Strahlenblïmchen, deren jetles tr̈nf Staubiaden, ohe sichtliche Stanhgefäfse, nud ejzen Staubweg in einer Röhre euthailt, und aus röhichten, meistens dreyspaltugeu ob?un fetarichten Scheidentiumclien bustehen, wie deriten Scheidentumclien bustehen, wie man dies im frischen Zustante oder nach deon Aufweachen der getrockneten Blumen crkeunen kann. Man sammlet die vou den Kelchen befriglen Blumen usd
gab soust den Voigthadischen (Flores Arnicae Plaweusis) den Vorrong. Frisch haben die Blumen einen e! was widrigrñ gitruckuet aber', besonder's zwischen den Firgelu gerieben, eincu schwachen, batsami schen, reireucleu oft niesenerregend ruch. Ibr Geschmack ist sinfslich bitter ind scharf.

Die ans fünf länglichten, dicken, saftig̨en,
veifseu, abstehen leu blumenblattern bostrheuten Blumenkronen des Pommpranzenbaums (Citrus A urantium L.), welche im frischen Zustande eiuen silhe angenehmen, duchdingenden $G e$ bue urd bitterlichen. Geschmack hahen Dilrchis Trockucn gelit der Geruch dies's. Dirchis Trockucn gelit der Geruch dieser B'umen gröstentheils verloreu; - sie. Wer-
den daluer entweder frisch zur Destilladen daber entweder frisch zur Destiliation des Wassers augewtidel, oder dazn undequetschi eingesitzen anfbewahrt.

De getruckneten noch uncntwickelı́lı blütherknospen oder Kelclie des Zimmtlorbecrs. ( $L$ a urus Ci un a in o.n um L.), von ciner hraumothen ocler dunkelrostbrannen Falbe. Sie sehell wie kleine zwey oder diey Linirn grofse Nägel aus, habeu einen ruudlichen Kopf von der Gröfse eines Pfeffer-oller Hanf'kurus, der von dern nock nicht entwickelten, sechsmal scliwach gekerbten Ketche' Iningeben ist, sich allmailig in einen diunnell Schwanz endigt, nnd auch oft noch mit einem kleinen Stiele verselien ist. In dern Kopfe befinles sich ein rubler Körper, der mit einemes ncm Nabet bezeichnet ist, und der Ueberrest des Staubwrges zu seyn scheint. Gre rueh und Greschrnack sint der Zimmatrincte
ähulicb, doct ist der letztere minder znähulicb, doch ist der letztere minder $211-$ fsinder innt nichic so augeuehn Das Pulver ist etwas dunkier als das der Zimmtrinde.
Fehlerhafte $\mathrm{Be}-$ wechfelung oder verfälfchu'ng.

selbst bereiteten dafs letutere vorriecht, wird blanlich geverk̈̈uflicluer Eî- lärbt.

senviriol genom- Die I'robe auf gegenwäıligen Zink kann men worden, der anfdie ohen beym bramuoilen Eiscnoxyd und der vom $\mathrm{k}$ ammelsberge nicht selten Zink enihält.

att derselben wer- Dirse kommen in ziemlich langen trauben-

den zuweilen die förmigen Buschel" liet vou nud besitzen eTirsclue (Prun!ls Padnis L.) eingesammlet. nen starken widrigeu Geruch. chaffenheit, I'erfast immer Kupfer Blumen der Alul-

erwechselt mit den/Frisch sind diese leicht incth deubotavisclien Blumen dessiulur- Character und die Verschiedenheit moluealants (Inula dy- rer siunlichen Eigeoschalles, alsidor Gealants (Intalt, der Frbe, des Gruchs nud Gesentericn) nnd des schmacks zu minterschedien. Der Ruhualant Weidenhlattalants träs seine Blumen mit kürer Strahtent (Inula salivina L) ) blümenen seme Blumen mil kurzeru Strahlentrichterfïrmigen, micht ristor finf trichteruing

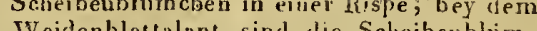
Weidenblattalant sime die Scheiheublimchen ebenfalls trichterfürnigs. Getrucknet habes dicse Blumen ein hellergelbe Farbe und keiucu so scharfen unil reizenden Gesclimack uul Gerucl.

Mit den Blumen des Die Strableublumen sind + mugenförmig nud geflrcklen Ferkel- fümal geränut, Getrocknet sind sie den Grauts (frypocluca- ,Woblvileihblumen an Furbe sehr ähnlicb, ris maculata L.) aber der eigerthimliche Gexuch und Geschmack febil.

Gemeiniglich ver- Spielen ius röthliche, riecheu scbwächer.

mischt mit Citronenbliithen.

Mit Apfelsinenblii- Sin' langlicher, mehr milchweifs; der Gethen.

Mit Pampelnus sblï- Haben einen wollichten Stiel und riecheu nicht then. so stärls.

Mit einer alus Eng- Dieselbe Gestalt nnd Farbe, abri weit gesinland kommenden gerer Geruch und Geschmack, un i wenig land kommender or gar kein ühcrisches Oel mehr liefernd, die schon eine stillation erlitter zun gebep.

haben scheint, lälscht.

Die zusammengesetzten, strahlicbten Blu- Gefüllt menküpe der F, elelih a in lle (An t bemis nobilis L.) mit fast ebenem, spreu- 
Flores Chamomillae vulgaris. -- Flores Rosarum incarnatarum.'

\begin{tabular}{|c|c|c|c|}
\hline $\begin{array}{c}\text { Namen } \\
\text { der Arzneymitcel. }\end{array}$ & $\begin{array}{c}\text { Sinnliche Eigenfchaften derfelben; } \\
\text { Merkmale ilhrer Ächtheit und } \\
\text { Güte. }\end{array}$ & 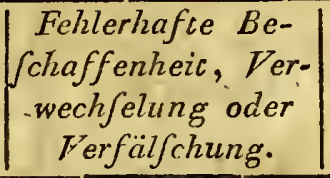 & $\begin{array}{c}\text { Deren } \\
\text { Kennzeichen und Priifungsmittel. }\end{array}$ \\
\hline $\begin{array}{l}\text { Römische Clia! } \\
\text { lenblumen. }\end{array}$ & 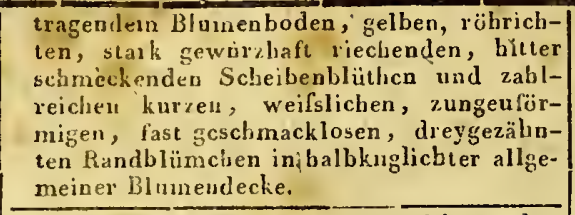 & 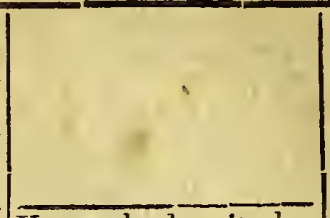 & . \\
\hline $\begin{array}{l}\text { Flores Chamomil- } \\
\text { lae vulgaris. } \\
\text { Gemeine Chamil- } \\
\text { lenblumen. }\end{array}$ & $\begin{array}{l}\text { Die Blu } \\
\text { (Ma i } \\
\text { samm } \\
\text { mit s } \\
\text { trohlc: } \\
\text { bittert }\end{array}$ & $\begin{array}{l}\text { Verwechselt mit den } \\
\text { Blumen der wolıl- } \\
\text { riecluenden Clua- } \\
\text { mille (Matricaria } \\
\text { suaveolens L.) } \\
\end{array}$ & $\begin{array}{l}\text { Unterschei } \\
\text { gene nn } \\
\text { cben un } \\
\vdots\end{array}$ \\
\hline • & 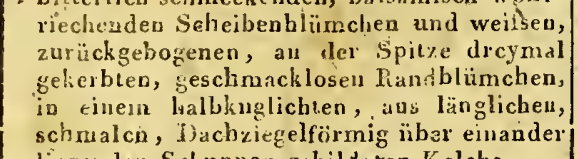 & $\begin{array}{l}\text { Mit den Blumen der } \\
\text { Ackerchamille } \\
\text { (Anthemis arven- } \\
\text { sis L.) }\end{array}$ & \\
\hline & - & $\begin{array}{l}\text { Mit den Blumen der } \\
\text { Hundschamille } \\
\text { (Anlloemis Cotnla } \\
\text { L.) }\end{array}$ & $\begin{array}{l}\text { boden ist, wie bey der vorigeu, } \\
\text { end ; die Blameuköpfe sind grä- } \\
\text { en einen unangenelumen widrigen } \\
\text { nd erwärmend bitterlicbeu Ge- }\end{array}$ \\
\hline 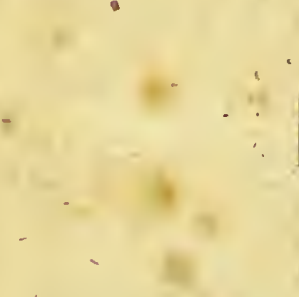 & 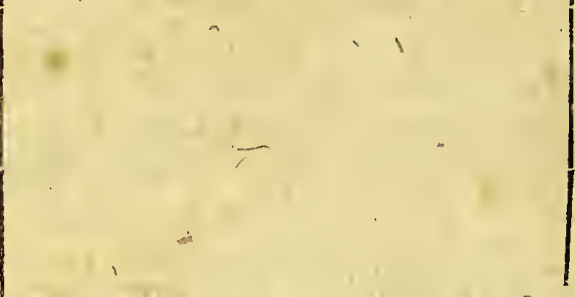 & 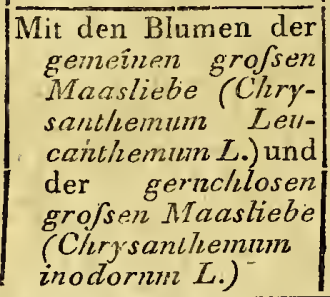 & 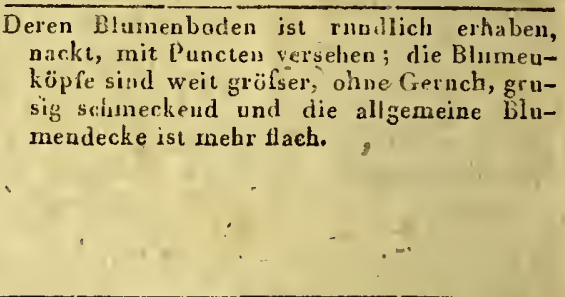 \\
\hline
\end{tabular}

Flores Granati s. Balaustia.

Granatblumen.

Flores LavenduLavendelblumen.

\section{Flores Filiorum} convallium. Mayblumen.

Flores Malvae ar lioreae.

Prockrosen,

Flores Malvae verneine Pappelblumen.

Filores Melilolicitrini.

Melilotenblumen.

Flores Millefolii. Schafgarbenblumen.

Flores rihoeados. Klatschrosen.

Tores Rosnrum incarnalarum.
Blumen des Granatapfelbanms (lunica Granatum L.) Grofse, im frischen Zustande glänzend finftheil,gen Kelche, obine Geruch, wou zusammenziehend herben Geschnacke.

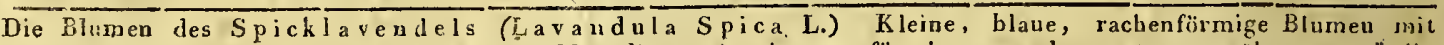
zweyspaltiger Ober - und drejspaltiğter Unterlippe, in einem eyförmigen, rauhen. etwas gęäbnten, grünlicben Kelche, die entweder öhrenförmig an ihrem Stengel sitzend odler abycstreift aufgehoben werden. Si baheu einen auzenefim gewür\%balten Geruch nưd beifs hittern Geschrnack, nnd müssen vor dem völligen Aufluluhen eingesammler werden. - Die Spickblüthen (Flores Spicae) kommen vou einer Abart

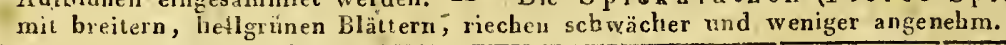

Die Blumen der Mayblumenzake (Coavallaria majalis L.) Rundlichglockenförmige, weifse, sebr woblriecleendé, in traubenförmigen Aébren nach einẹr Seite sitzende, kleinc Blumen. Beyn Trocknen nehrnen sic eine gelbliche Fatbe an und verfiercil itren angenehmen Gcruch.

Die Blumen der fiosenpappel (A l cea rosea L.) Ziennlich' grofse Blnmen mit einem doppelten, dicken haarichten Kelch, wovon der äufsere sechsspaltig, der innere grö̈sere fünfspaltig ist, und fïnf verkehrt herzfürmigøn, abstehenden Blumenblättern. Naı bat diese Blumen von allen Farben, wäblt -aber zum Arzneygebrauch diejenisen, welche eine dunkelrothe Farbe haben. Sie besitzen einen schwachen Geruch und einen scbleimichten, săzicht - zusammenziehenden Geschmack.

Die-Blusaru der Kleinen-Kàsemalve (Ralva rotundifolia L.) Klcine malvenautige Blumen mit bald weifsen, bald blänliçhen oder weifsrüthlichen Bluınenblättern und einem doppelten Kelche. Sie werden auch von der R ofsmalve (Malvasylvestris L.) gesammlet; diese haben eine rothe Farbe und sind etwas gröfser. Der Geschmack von beyden ist schleimicht.

Jie Blunen des gelben Steinkle e (Trifolinm melilotus officinalis L.) Man samnlet die blübendcu Ilaupt - uud Nebenstiele mit den gelben; kurzgestielten, traubenähulich herablänğenden Piumen, die fineu fünfzalunisen Kelch und eine schmetterlings'örmige Krone haben.' Sie besitzen 'einen eigentbümlichen

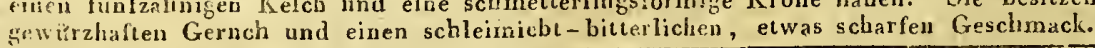

Die Blatheo der gemeined Schalgarbe (Acisillea Millefolin mL L) Sie bilden flacbe oder ebene Blumnenbüschel voller hleinen zusammengesetzten Blunen "mit strahlicbter Krone, aus etwa fünf kurzen, an der Spitze ein parmal wenig eingesclunittenen Randblimchen, unit rïbrichten grünlichgelben Scheibenblümchrn bestebcud, die auf einem syrenartigen Frnclıtboden sitzen und nit eineni ovalen, ans eylörmigen, am

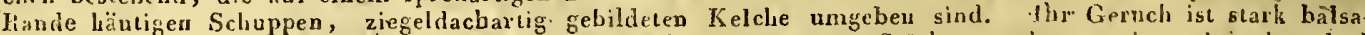
luisch; der Geschmack campherartig, gew ürzluaft und bitterlich. -- Stärker, melir campherartig; aber doch augenebmer und balsamischer jst der Gernch dor gleichfalls bitterlich gewiirzinaft schueckendeu Blumen der Edclochafgarbe (Achillea nobilis L.), welche irn Gaum den vorigeu sehr älınlich sind, sicb aber durch dcu stärkern angenehmen Gerıch, durch die mehr erhabene Wölbung der Blumenbüschel und durch die selbcre Fab be der Scheibeubliimclen unterscheiden lassen.

Jie fast eyıunden, im trischen Znstande|Verwechselt mit den|Diese Verwechselung ist wegen zu grofser lebbaft rothen, getiocknet aber dunkelro- Blumen des zwei- Aelnlichkeit der Blumen scliwer zu verthen, am Grunde rnit einein sshwarzen fell/afien wilden meitlen, hat aber auch nicht viel z.n bedeu-

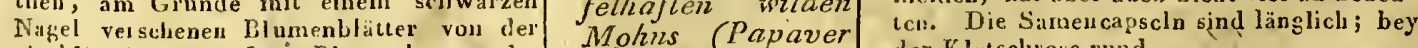
\begin{tabular}{l|l} 
virmblattrigen grofsen Blomenkrone des & Mohns (Papaver \\
dubium L.) & dcr Kl.tsclurose rund.
\end{tabular}

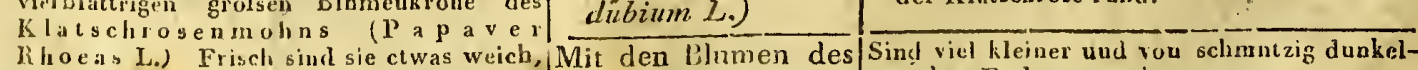

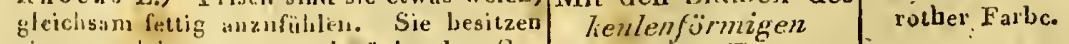

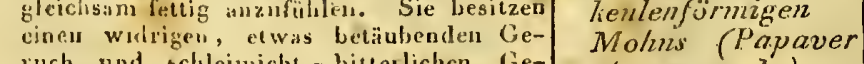
ruch wad ochleimicht - bitterlichon Ge- Argemone L.)
schmach.

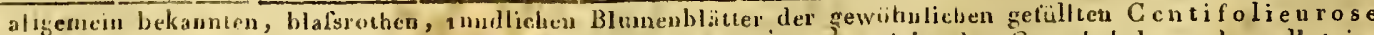
(Riosa centifolia L.), die eineu eigenen, sethr augenethen, eryatickenden Geruch habea, der selbst in 
Flores Rosarum incarnatarum. -- Folia Ilicis aquifolii.

\begin{tabular}{|c|c|c|c|}
\hline $\begin{array}{c}\text { Namen } \\
\text { der Arzneymittel: }\end{array}$ & $\begin{array}{c}\text { Simnliche Ergenfchafien derfelben, } \\
\text { Merhmale ilhrer Aechtheat und } \\
\text { Cuite. }\end{array}$ & $\left|\begin{array}{cc}\text { Fehlerhafte } & \text { Be- } \\
\text { fcliaffenheit, } & \text { Ver- } \\
\text { weclifelung oder } \\
\text { Verfälfchung. }\end{array}\right|$ & $\begin{array}{cl}\text { Deren } \\
\text { Kennzeichen und Prïfungsmictel. }\end{array}$ \\
\hline
\end{tabular}

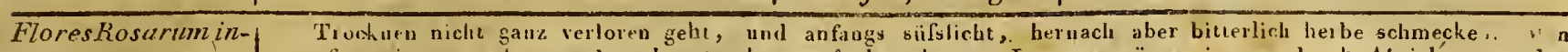

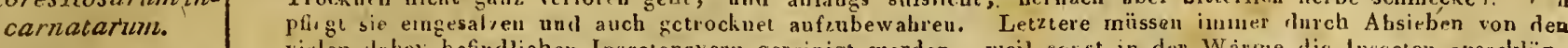
vielen lahey befiudlichen Insecteneyern gereinigt werden, weil sonst in der Wárne die lusecten atuschlüpteri Inul die Blitter zeriresseu.

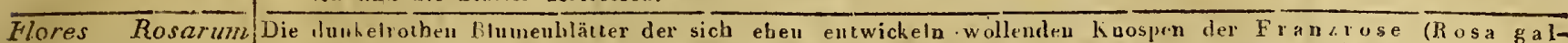

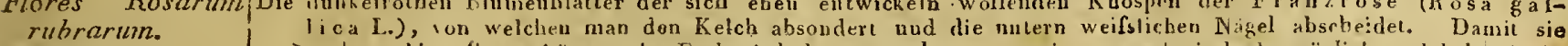
rubrarum.
Essigrosen. auch nachier íhre schäne rothe Farbe bebaltcn, trocknet man sie so geschwiud als möglich und liebt sie in verschlossene: Gefásen vor dem Zutritt der Lnft und des Lichts aul. Sie zeichuen sich durch einen zu-
sammeuziehenden Geschmack aus.

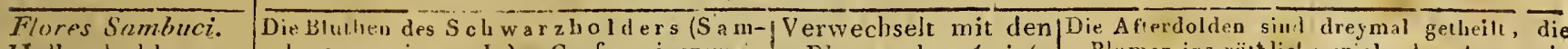
Holltunderblumen. L u $\mathrm{ns}$ u igra l.o) Grofse, iusgemein Blumendes Attich- Blumen ins röthliche spielend und ran wi-

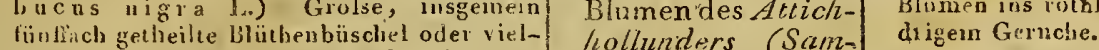
fïnthach getheilte blïthenbüschel oder viel-
nelur Aftrrdolden, mit vielou Bleinen, funfspaltigen, weifscu, getrocknet gelb- Mit den Blumen des Diese habeo eine gelbliche outer griinliche

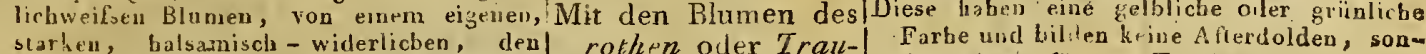

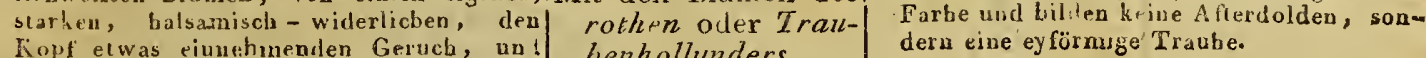
Kopf etwas eiunthmenden Geruch, un! benhollunders

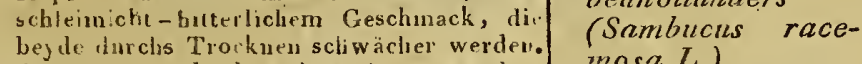
Sie müssen schoell, obne sie zu wenden, mosa $L$.)
getrarknet weidel.

Flores Tanaceri. getrorknet weidell. hainfarmblumen guldcelben, ans fast lanter röhrichten blümchen znsammengesctzieu Blumenköpfe des Rainfarrns (Tavacetnm vn ls are L.), mit tünspaltigen zurickgebugeuem R'nde und zuweilen anch einigeu urideutich dreyspalugen Strahlblimchen, welche in halbkugel för mige z1egeldachartige Kelche geschlossen, feste Blumenkuöpfe bilden, dir anfangs in der Mitte eingelieft, wachher aber erhöht und gewälbt erscheinen. Sie

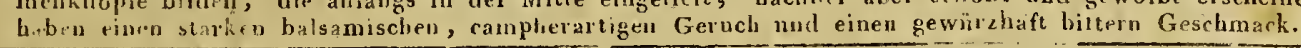

Flores Tiliae.

Lindenblüitien.

Flores Ulmariae. Geifsbartblumen.

Flores l'erbasci. Königskerzenblumen.

Wohlkxautblumen.

Flores Violnrum. Blaue Veilchen.

\section{Folia Aurantii. \\ Pommeranzenblät- ter.}

Bliithen des Lindeubaus (Tilia enropae a L.) Kleine, grünlicheilne Blumen, die anl einem langen Stielchen hervorkomnen, an welchen ein langes, schuales, trockues, weifogrünes Blatt mit angewachsen
ist. Frisch besitzen ste eiuen höchst angenebmeu, stilishichen, erguichenden, in eiuer bezräclulich En Entfer-

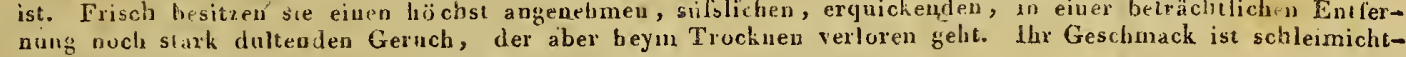
si:fslich.

Die Blumen des Jobauniswedels (Spiraea Ulunaria L.) Unächi schinmaruge Blumenbüschel, deren einzelue biumen panen fïnfzähnigen, zurückgeschlagenen Kelch und pine aus fünf rundlichen, hachen, wei-

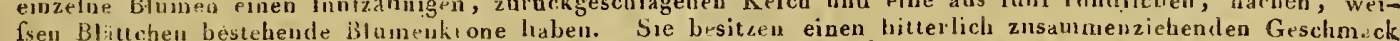
und emeu den Pommeranzin ühen nahe kommenden, schr angenehmen Gernch, Weslualb sie anch ein und eueu deu Pommeranzinb üthen nahe
wohlriechencles destillites W: sser liefirn.

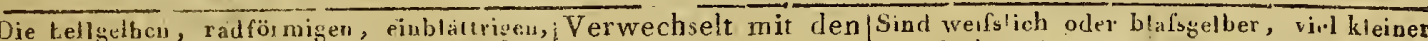
kmzröhrichen, zarten, fünflappigen blu- Blumen der WV eifs- und ohne einen angeuebmen Geruch. menkrotien, tie man bey trochuel rVitte- lierze (Verbascum

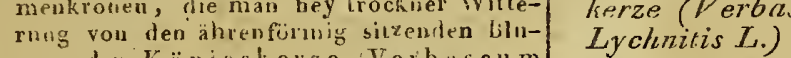

upen dor Königskerze Veib is cum m

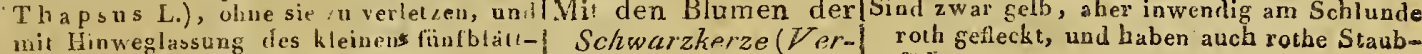

mit Hinweglassung des kleinens finfblall- Schwarzkerze (Ver-
rigen Kelclis eiusammlet. Sie hahen eiletu rosenartigen Geruch und einen schleimicht-siifslichen Gescbmack. Man streue sie düun aus, trocknet sie schnell und verwaht sie in verschlosseuen Gefofsen, damıt sie nicht ibrc schöne gelbe Farbe vermit sie
lieren.

Die sehr angenebm riechenden, dunkelbraunen, vou i rem funflittrigen kelche befreyten Blumenblates dorion Btumeukrone des $M$ àrzeilcheus (Viola odorata L.), deren unteres Blätchen odorata L.), deren geboten ist. Weun am Giunte horntormig gebos das Tiocksie getrocknet werden, sch müssen sie nen schnell geschehen; anch müssen sie dan in einem wobl verschlossenen Gefafse aufhewahrt werden, weil sie sonst gitre blase. Farbe verlieren.

Die Blatter des Pommeranzeubaums (Citus. Aurautiou L.) Eyronde, schar zugespitzce, fesie, zähe, auf der ober' Seite loblaft glïrzend griune, auf der untrubleich m.tt rüue Rlätter, wel che an Gruncle zu beyilen Seiten heizlümige Flügel oder kleine Blatlansätze haben, wornber sie lischen dis Lichi gohalten zeigen sie durclisichrige l'uncte oder mit ätheriochen Oel gefille Bläschen. Zwischen den Fingern geriehen besilzen zis einen argeneline halsanischen Geinch; ihr Geschmack ist gew irzhaft bitte:. fäden.

Verwechselt mit den Blumen des HuridsVon beyden sind die Bitumenbläller gröfser veilchens (Viola canina) und des Rruchueilchens (Viola hirta L.)

Vermischt mit den $\overline{\text { Unterscheilen sich rorzïglich durch die feh- }}$ Blättern ides Citro- lendeu herzförmigen Blattansätze. nenbaums (Citrus medica $L$.)

Mit Apfelsinenblät- Sind lanzettrörmig spitzig und $\overline{\text { die Blattstiele }}$ term. $\quad$ nui schwach gellïgelt; ihr Geschmack is Mit Pampelnufsblät- Sind weil gröfser ansgeschnitten, am Ende tern. stump f
Folia Ilicis aquifolii.

Stechpalmenblätter.

Hlaller der Steclipalme (Itex Aquifolıum L.) Eylinmige, echige, geälinte, am Rande ringsherm mil emen haten, spröden Saum nmgebene, und an den herrorrigenden Zäbuen mit harten Staclueln besel,le, etwas wellentörmig gebogene, lederartig dicke, feste, steife, kurzgestielte Blätter, mit glatter

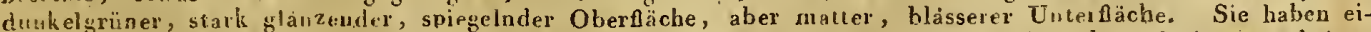
neu etwas scharlen, gelinde zusammenziehenden, bitterlich schleimichten Geschmack und fast gar heinen Gerucb. 


\begin{tabular}{|c|c|c|c|}
\hline $\begin{array}{c}\text { Namen } \\
\text { der Arzneymittel. }\end{array}$ & $\begin{array}{c}\text { Sinnliche Eigenfchaften derfelben; } \\
\text { Merkmale ihrer Aechtheit und } \\
\text { Güte. }\end{array}$ & $\left|\begin{array}{c}\text { Fehlerhafte Be- } \\
\text { Schaffenheit, Ver- } \\
\text { wechfelung oder } \\
\text { Verfälfchung. }\end{array}\right|$ & $\begin{array}{c}\text { Deren } \\
\text { Kennzeichen und Priifungsmittel. }\end{array}$ \\
\hline
\end{tabular}

Folia arrocerasi. Lhe Blatter des Kirschlorbeers (Prunus Lauro-Cerasus L.) Eyrunde, längliche, einförmige, fas

Kirschlorbeerblätter.

Folir Ouercus. Eichenblätter.

Folia Sennae. Sennesblätter:
Folia Uvae ursi. Bärentraubenblätter.

Formicae.

Ameisen.

Fruculs $\Lambda$ caciae. Schlehen.

Pructus Cerasorumu acidoriun. Saure Kirschen. unaus eschnittene, weitläuftig, am Rande fein sägeartig gezäbute, vier his sechs Zuil lange, und zwey bis drittehalb Zoll breite, auf der obern Seite lebhaft dunkelgrune, glänzende, auf der untern matrgrüne, feste, drittelal Zoll breite, auf der obern seige, ziemlich steife, saftige Blätter, welche unteu auf dem Rücken nach dem Stiele zu ruit zwey lederartige, ziemlich steife, saftige Blatter, wion verseben und unter den Blattuerven rothfleckicht sind. Im friscben Zustande habeus sie unverletzat

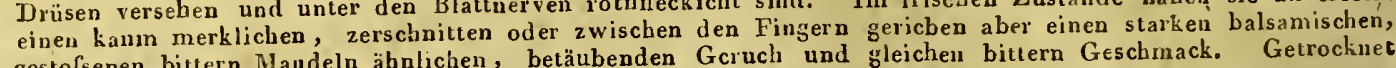
riechen und schmecken sic fast gar nicht.

Die bekannten länglichen, oben breiteren, am Rande buchtigen, spitze Winkel und stumpfe Eckיn bildenden, glatten, lebbaft grünen, gestielten Blätter der zielsendem Geschmack, aber fast obue Geruch. mehreren Gegenden von Arabien einheimischen Sträucher, nämlich der $r$ und blät trigen Senuetcassia (Cassia Senna)

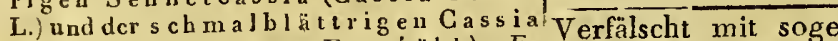
(Cassia lanceolata Forskäh.) Es nannten Arguel. kominen von den Sennesblättern mehrete Sorten im Handel vor, die in Hinsicht $d e r$
Gröfse, Gestalt nnd Farbe von einander abweieheu. Dahin gehören :

1) Die Alexandrinischen Sennesblätter (Folia Seunac AlexanMarseille, Livorno und Venedig zu uns und werieu für die besten gehalten. Sie sind eyrund zugespitz.t, in der Mitte gerippt, eiuen balben bis ganzen Zoll lang und einen viertel Zoll breit, glatt und sanft anzufïhleu, von grüner ins Gelbe spielender Farbe, eivem eigenen etwas widrigen Geruch und bitterlichen, ctwas scharfen, schlcimichten, den mehresteni eckellıafteu Geschmack.

2) Die I taliän ischen oder Proven$z$ al i schen Senncsblät ter. Sie sind breiter, stumpfer, düunes érbechlicher, starker und velfacher gerippl, besizen eine grïuse $F$ arbe und encn inetr süfslicht leimichten als bitterlicheu Gescbmacl. Sie sind häufo mit den ẩbulichen Blättern, an?sind haufg mit dea abistich

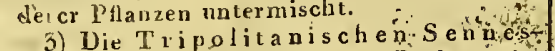
3) Die Tripolitanis a Künigreich Tripolis ges:mmlet, sind gröfser und weniger zusespilıt, als die Alexandrinischen, auch süuer vou $F$ al he, rauher in Aufublen und schwäcber rou Geruch.

4) Die Arabischen oder Mochanischen, welche fast noch einmal so lang, aher schmäler und spitziger, schwäclser von Gernch'und geringer an Kriften sind, von Gernch ten werden. us Uva ursi L.) Kleine, kurgestielte, verkehrt eyrunde, an Gruude schmälere, nach der stumpfen Spitze zu breitere, keifürmige, dicke, steife, ziemlich harte, canzrandige, meistens am Rande etwas 11äche ist dunkelgrün, die Untertläche hellgrün und mit feineu netzförmigen Adern glatt und glänzend. Frisch getrockllet haben sie einen schwachen süfstol, älunlichen, hinternach kaum merklichen Gernch; ibr Geschinack ist bittcilich zusammenzieGeschina
bend. sempervirens $L$.) drinae.) Dirse kommen vou Cairo über

Die Blätter der Sandbeerbäre (Arburückwärts gekrïmmte Blätter; ilure Ober-
Verdor und daher zum Arznejuehrauch untauglich sind die branngefleckten, zergewordeuen Senuesblälter.

Dies sind die Blätter einer gar nicht zur Sennagattung gehörigen Pflanıe, welche Herr 1806 , S. 104 u. f.) Cynanchum ol a ae1806 , S. 104 u. f.) Cynanchuin ol a efolium nennt. Sie werten nach den seiwer Anwesenbeit in Aegspten darüberzu machen Gclegenbeit hatte, den ichten Senuesblättern, schon in ibrem Vaterlande beygemisclut. Nach seiner Beschreibung siud dieselbru schrnal, zugespitzt, blalsg! ün, rauk und haben einen scharfen, bittern, willerlichen Geschrnack.

Tit den Blättern des Man hat bisher geglaubt dafi die SenuesblätBlasenbaums (Co- ter wohl mic diesen Blättern - verfaischt lutea arborescens L.) werden müchten. Herr Bucholz (Almanach $f$. Scheidekünstler n. A potheker, iso4 S. 243) ist aber nicht der. Meinung, dafo sie d. 243 int abendt wer bey dazu anger Untersuchung der ganen Senmebrinaliger Unt nesblatter niemals diese, sich durch ilire velkehrt berzformige, an der Silze ausgerandete und mit einem feinen weichen Stachel verseliene Gestalt sehr unterscheid
Blätter unter denselben bemerkı hat.

Zerstiickelte Sennos $\frac{1}{\text { Diesè woblfeitere Sorte soll gewuhnlich mit }}$ blütter (Foliza Seiz nae parvae) statt 1 Pfanzen, verfälscht seyn, welches sich nicht ganzer. gut an den zerstickelten Blättern erkeınen
läfst. Man thut daber besser, sie nicht zu brocheucn, ganz unreinen und ganz gelbnagattung gehorigen Plia uabu. d. Pharm. läfs't. Man
gebraucben.
Mit den Blättern der Prenfselbeere (Vaccininm Vitis idaea $L$.) verwechselt.

Mit den Blättern des Buxbrumis (Buxus
Diese sind gröfser, düner, eyruud, so dafs sic am Gruade breiter und nach der stumpfon Spitze m schmäler sind, uncl auf der

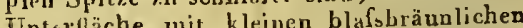
oder brannschwärzlicheu Tuncten getüpfelt. Gröfser, eyrund oder rundlich, holler grïn, auf der Uuterflälhe we ler netzförmig geadert noch braun getiip felt, baben frisch eider unangenehmen Geruch nud einen bitterlich - williwen, nicht zusanmenziehenden Gescbmack.
(-

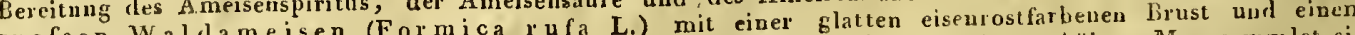
grofsen Wal d ameisen (Formica rufa L.) mit einer glatten eister schyvarzranen Ifiuterleib, weil diese mehr saure und atherisch blichte Thile enter eiucm Ameisenhaufen gelegter, mit Honig bestriohener Stabchen, ode entwed reinigt die eingesalo ten der $G$ a $r$ te u a meisen bedienen.

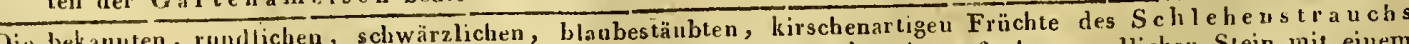

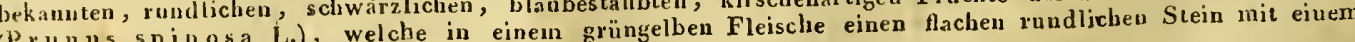
bittermadelartig schmeckrnden Kern enthalten.

Von (T) De Cerasus L.) werden zum Arz-

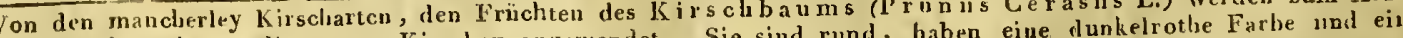
ueygehrauch nur die sauren Kirschen angewendet. Sie sind rund, sehr saucr schmeckendes steisch mit einem blatrothen Safe, spityter, elwas gedrichtert, terlich schineckesden Keru einschliefot. 
Fructus Cynosbati. -- Gallae.

\begin{tabular}{|c|c|c|c|}
\hline $\begin{array}{c}\text { Namen } \\
\text { der Arzneymitcel. }\end{array}$ & $\begin{array}{c}\text { Simnliche Eigenfchaften derfelben; } \\
\text { Merkmale ihrer Aechthent und } \\
\text { Güte. }\end{array}$ & $\mid \begin{array}{c}\text { Fehlerhufte Be- } \\
\text { rchaffenheit, Ver- } \\
\text { wechfeluing oder } \\
\text { Verfälychung. }\end{array}$ & $\begin{array}{c}\text { Deren } \\
\text { Kennzeichen und Priifungsmittel: }\end{array}$ \\
\hline
\end{tabular}

Fructus Cynosbati. Die im Herbst reifcnden, carminrothen, glatten, siifs-säuerlich, ein wenig zusammenzieheud schmeckcnden,

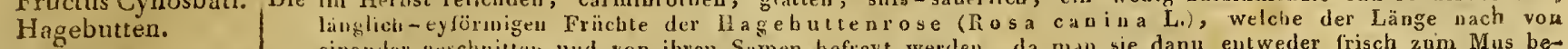
einauder geschuitteu und vo
nutzit odter sie trocknet.

Fructus Juglandis Die bekanten uoch nureifen Frïchte des Walluufsbanms, welehe jun Junius oder Julins, wenu sie sich noch immaturi. $\quad$ leicht mit eitrem elfenteiuernen Pfricmen durchstechen lassfn, ifingesammlet mid dibey die ganzen und tieUnreife Wallnüsse. ckeulusen aussewaiblt werden. Man benatzit sie theils zum Extract, theils zum Eumachen.

Fructus Morortun. 0 Die im Herhste, jedoch uicht zu gleicher Zeit reifenten, eytörmig-länglichten Frürhte des schwarzen Maul-

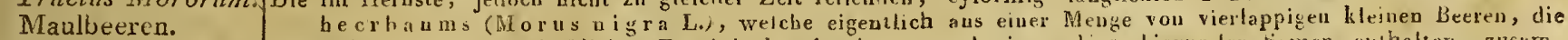

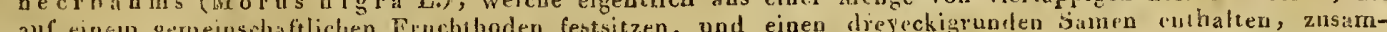

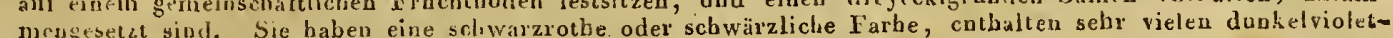
teı jaft und scbmeckea sänerlich-süfs.

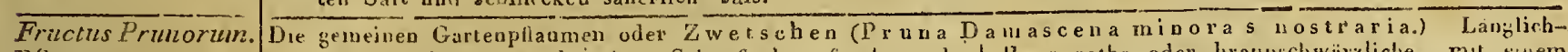

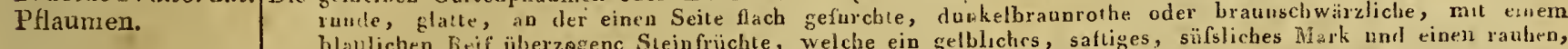

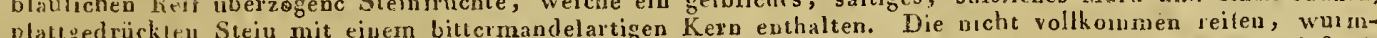
stichigen und mander saftigen sind zu verwerfen. Bey den gcbackenen hat man darauf zu selieu, dafs sie nichlit verbranut sisid.

Fructus Ribium ru- Die bekauuten, tranbenföimig sitzenden, kleinen kugetrunden, genabelten Beren des Johtianisheerbrorum.
. Strauchs, vou durcbsichtig rother Farbe. Sie enthalten nuter einer dünen Haut eiu selir saffiges Johannisbieeren. Fleisch,

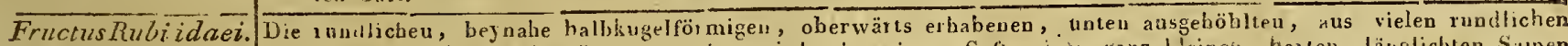
Himbeeren.

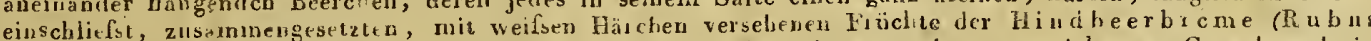

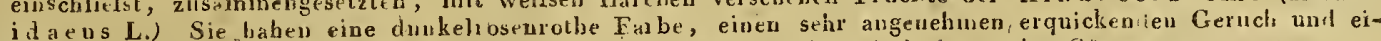
nei lichlichen süfssaucilichen Geschmack. Die wildwachsenden sind deneu in Gärten gezogenen vorzu-

Fuligo splendens. Spiegelrufs.

Ofenrufs.

Gnlbanum. Gummi Galbani. Mutterharz. Galbanharz.
Gallae.

Galläpfel. ziehen. ziehen.

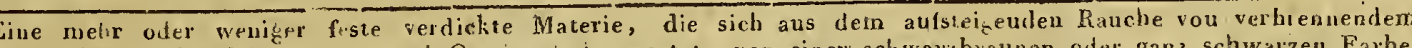
Holze au die Scbomsteu- nud Caminwauce ansetzl, von einer schwarzbranen oder ganz schwarzell Farbe,

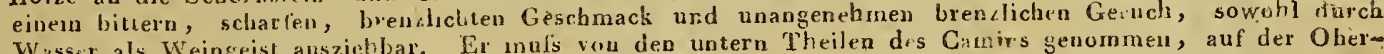
jäche ślanzeud und on allen anhängenden frenden Theilen, Kalk, Lehn 11. s, w. wobl gerenuigt seyn. Ein als Milisait aus der queer durchschuit-jStalt des ächten und Diese siehr schunutzig nind dnakelbraui ans,

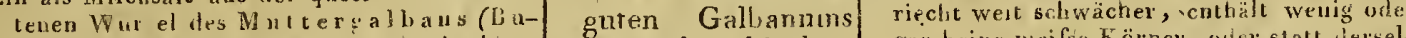
bon $G$ alhatsum L.), einer in Arabiell, eirte sehr schlechre, Syrieu und der Barbarey Wachendent unreine, of mitAmSchi mptianze, liefsendes, bald ertarten- ton des Scliteimliarz, von einem eigenthünti- moniakgem mit einem andern chen, slarken, den meisten Menschen utdrigen, Gel urbe wad billerlichem, scliat-
fcu, erwarmet den Gesrlmack. Es ist wefcu, erwarneed den Geschimack.
der im Wasser allein uoch im Weingesst der im Wasser alleull woch in Weing eist vicht hallborre michichte Mischung und mit 1. terem eine blaungcbe Tiuctur. ans zwey Theilen Weingeist uni einem Theil Wasser, der Katitiuctur and rem äthe ischen Weiugeist aufgelösct.' Durch Wäıme wird es erweicht und zerflicfst; an der Flamme

3) luKörnern (Galbanum in gra-

nis.) Kleine, höchstens haselnulsgrofse, kuglichte, hatbdurchsichtige, auswendig gelhlichweifse oter gelbröthliche, inweudig weifstuche, etwas zälie, wachsharte
trockne Stücke. Die beste, aber selteme So, te.

2) In Klumpen oder Ku cben ( $\mathrm{G}$ a lbannm in massis.) Besteht ans gröfsern Massen, die entweder ans weifs- oder bräunlichgelben, his laseluufsgrofsen, elwas durchscheinenden Köınern fïr sich Was furcischeinenderter oder mittelst eiuer untertinander gebackt, durchs Alter bräunwetchern, gelonden Masse rereiniga, hesteleu. lich werdenden Masse rereinige, helor weifoDiese Sorte ist desto besser, je melor weilo-
liche Stücke in einer blafsgethfichen Masse und je wruiger Samen und andere ölters beygemiscbte Uureiuigkeiten sie enthält.

Uebrigens darf das Galbanuru werler zu weich norh gar srlimierig seyn. Es mufs sich in strenger Kalte zu Pulver stolsen und durch Absieben zu gereiuiglem G I han (GaIbanam depuratum) darstelleu lassen.

darstelleu lassen.

nen insects verantafste, an den Blattern

Geringere Sorten.

gan keine weifse Körner, olior slatt ciersel-
ben Stücke des an seinen Kpnuzeichen an ben Stïcke des an seinen Krnuzeichen an muterscheiden en Ammoniahs oiler enes
rotben Schleimbarz,s; isi sebr weich, mit Holzspanen, Sand, Samenkörueru und̨ vieaus Sicilien kom-
menden Schleimliarze von rother unterscherdeu.

l as be verfälschte Sorte.

as gereinigte Galbanum ist oft mit allen Unreinigkeiten gepulvert, oder aurh noch absichtlich beym Pulvern ini Mundeln, Bolinenmelul u. dyl. versetzt.

Mach Bucbolz ist dies durch Aunösung de Galbantms in Essig zu erkennen, wobcy die Unreinigkeiten odcr auch die erwähnt. II Zusätze oben auf schwimmen.

t.u Zesser noch wohl wird diese Prüfung dorch Auesser in Kalitinctur, versüfsten SäuA cu oder einer Mischung rou Weingeist mit Ycu oder einer Mischung vou das Galbanum Wasser angestelit, wodurch das Galbanum ganz anfoeg̈st wird, die beysenischien
fremien förper aber zurückbleiben, Vgl. auch Ammoniacum depuratum.

Diese siud bey den verkäuflichen Galläpfeln (Galla $\mathrm{e}$ in sortis) gewöhnlich den bessern bejgemischt. Italiänischea von gelbgrïnlıcher oder 


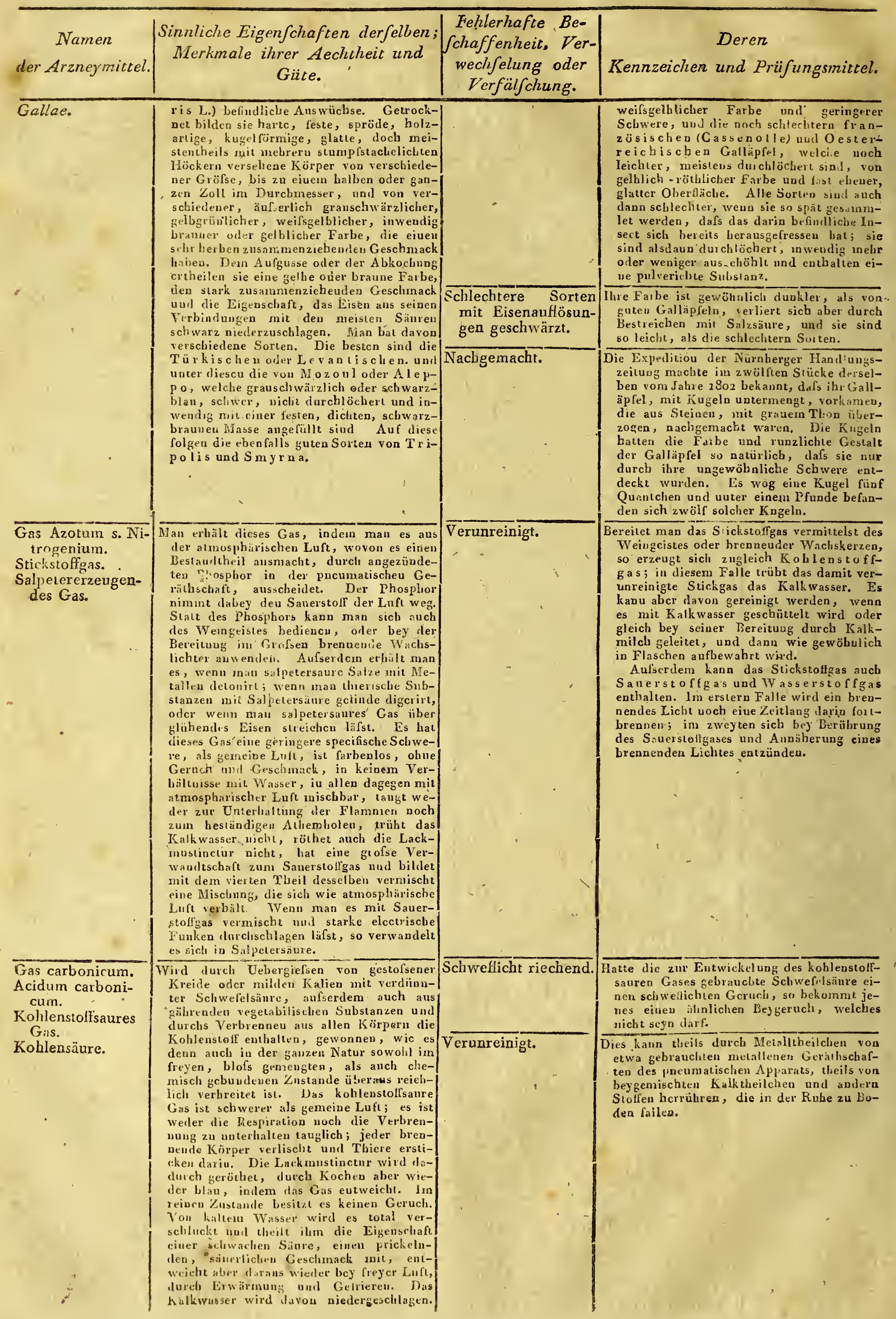




\begin{tabular}{|c|c|c|c|}
\hline $\begin{array}{c}\text { Namen } \\
\text { der Arzneymittel. }\end{array}$ & $\begin{array}{c}\text { Sinnliche Eigen fchaften derfelben; } \\
\text { Merkmale iltrer Ächtheit und } \\
\text { Giite. }\end{array}$ & $\left|\begin{array}{c}\text { Fehlerhafie Be- } \\
\text { frhaffenheit, Ver- } \\
\text { wechselung oder } \\
\text { Verfälfchung. }\end{array}\right|$ & $\begin{array}{c}\text { Deren } \\
\text { Kennzeichen und Priifungsmitcel. }\end{array}$ \\
\hline Gas cartjonicum. & 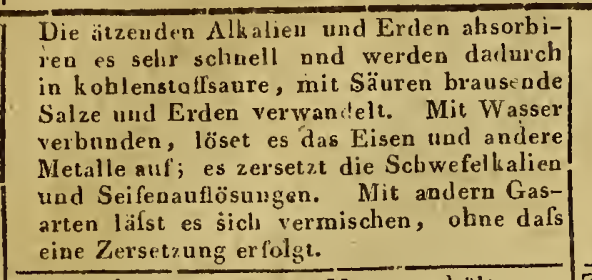 & & 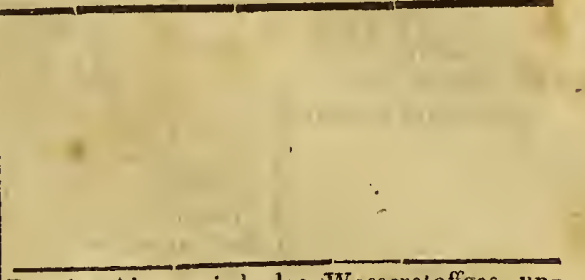 \\
\hline \multirow[b]{2}{*}{$\begin{array}{l}\text { Gas Hydrogenium. } \\
\text { Wasserstoffgas. }\end{array}$} & \multirow[b]{2}{*}{ 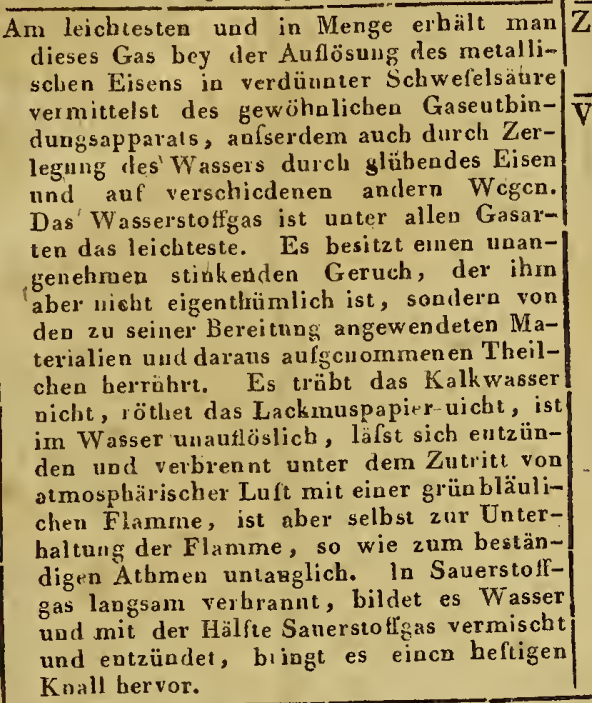 } & Zu alt. & $\begin{array}{l}\text { Durclis Alter wird das Wasserstoffgas un- } \\
\text { wirksamer und soll in Stickstoflyas ans- } \\
\text { arten. }\end{array}$ \\
\hline & & $\begin{array}{l}\text { Verunreinigt. } \\
\\
\end{array}$ & 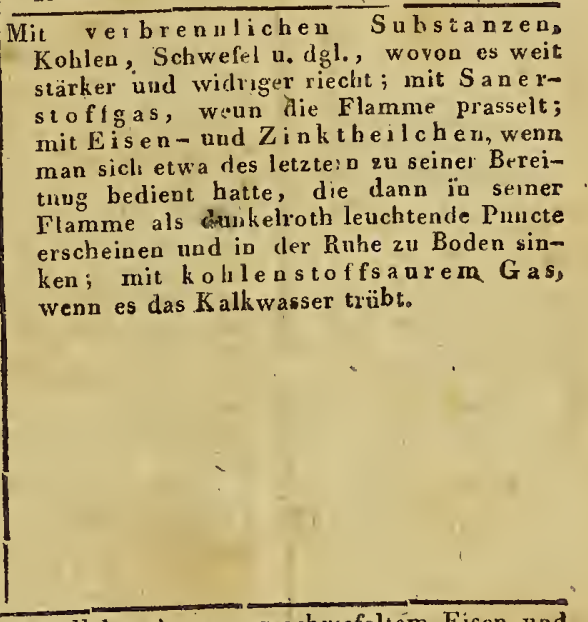 \\
\hline
\end{tabular}

Gas Hydrogenium sulphuratum.

Gas Hydrothionicum.

Geschwfeltes

Wasserstoffgas.

Hydrothionsaures

Gas.

Gas oxygenium.

Sauerstoffgas.
Glandes Quercus. Eichejn.

Globuli Tartari martiati.

Globuli martiales.

Eisenweinsteinkugeln.

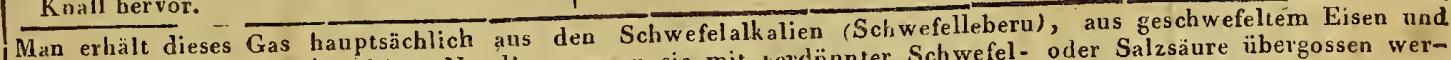
cınigen andern geschwefelten Metallen, wenn sie mit verdünnter Schwefel- oder Salzsäure übergossen werden. Es besitzt dasselhe einen stinkentlen Geruch wie faule Eyer, taugt nicht zum beständigen Athmen, röthet die Lackmustinctur, zersetzt die Seifen, löset sich in kaltem Wasser ä̈r, werlöschen darin : mit Erden verscbluckt und bildet damit eine besondere Art Salz. Brenn in Sauerstoffgas verbrannt wird, so Sanerstoffgas vermischt, giebt es eine Knalluft, nnd wean es lan mit dern Schwefel nnd verwandelt ibn in bildet siclı Wasser'und schweflichtite Säure. Es verbindet sich mit dern wird wieder fest Durch oxy eine Art Oel; allmälig entweicht es aber wieder daraus und der Sch Schwefel ab. Da es sich wie eine dyrte Salzsänre und Salpetersäure wird es zersetzt und es scheidet sich Schwefel ab. Da es sion

Saure verbält, so erbielt es nach Herrn Prof. Trommsdorf den Namen Hydrotbionsaure.

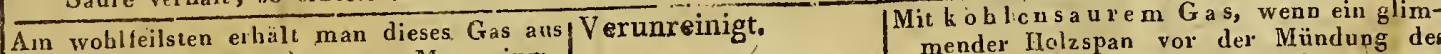
dem gepulverten schwarzen Magnesiumdem gepulverten scas in einer beschlagenen oxyd, weun dieses in finer glasernen oder irdencn fiot das sich entken Glühbitze ausgesetzt und daschen wickelnde Gas unter Wasser in Flaschen allfgefangen wird. Aufserdem crbält man es auf dieselhe Weise aus dern rothen Quecksilberoxyd, den salpetersauren Salzen und den oxydirten salzsauren Silzen. Es ist schwerer als die atmosphärische Luft, besitzt weder Farbe noch Geruch und Geschmack, ist im Wasser unanflöslich, wirkt auf Kalkwasser und Lackmuspapier nicht, kanu ohoe Niclstheil von papier nicht, Thieren respirirt werden, befördert die Verbrennung aller entzinibefordert die lichen $K$ urper im hohen Grade, und desseldabey; inclem sich der Sates entben mit der Süurefabigen Basis des entzüadeten Körpers verbirrdet, entmischt. Gliminende Körper, z. B. Schwamm, Korkbolz a. dgl. hrennen darin, so wie selbst Metalle, als Eisen, mit der viermal länger dasio, als in einem gleichen Unfänger daria, Die strengflïssigsteo Körper können mit demselben IItsigster Es muls in wohlverpichten Maafsbonteillen aufgeboben werden. Gasrecipienten nur mit schwachem Glanze Gasrecipienten frisches Kalkwas er dadureh getrubi wirl; mit Stickst offgas, wenn getrubt wryefelkali zusammengebracht abes mit Schwerelkali zasammes mit dem Schwesorbirt wird, so daldet und das Stickstotr- fel Schwefelsäure bildet und das Stickstorgas allein zurückbleibt; mit leichten
Bra unstein partikel cben.; die sich in der Ruhe von selbst absetzen.

$$
\text { in der Ruhe von selbst absetzen. }
$$

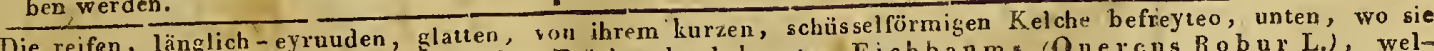
in Kelcbe fest gesessen, etwas rauhen Früchte des bekannten Eichbanms ( $Q$ uercus Robur L.), welche in einer lederartigen, bcllgelhbräunlichen Schale einen, mit einem braunröthlichen Obertatchen schmekleideten, weifsen, eyförmigen, aus 2 wey Hälften bestehenden, bittor uud herbe zusammenziehend schme

ckenden Ker enthalten. arch wiederloltes Uen oder anch Jurch Kochen eines solchen Gemenges bis zur Consistenz eines dicken Exstein mit Woraus sodann gewöhnlich Unzenschwere Kugeln gemacht werden, bereitet. Sie habene de grane Farbe, sind im Wasser scliwer auföslich und besitzen einen eisenhaft zusammenzieheuden Gescbmack. 
Gummi Mimosae. -- Gutti.

\begin{tabular}{|c|c|c|c|}
\hline $\begin{array}{c}\text { Namen } \\
\text { der Arzneymittel. }\end{array}$ & $\begin{array}{c}\text { Sinnliche Eigenfchaften derfelben; } \\
\text { Merkmale ihrer Ächtheit und } \\
\text { Güte. }\end{array}$ & $\begin{array}{c}\text { Fehlerhafte Be- } \\
\text { chaffenheic, Ver- } \\
\text { wechfelung oder } \\
\text { Verfälschung. }\end{array}$ & $\begin{array}{c}\text { Deren } \\
\text { Kennzeichen und Prüfungsmittel. }\end{array}$ \\
\hline
\end{tabular}

Gummi Mimosae. Ein wabres, reines Gummi, welches von/Vermischt mit dem/Mebr braungelb, zaher, hlebriger, von etGummi arabicum. selbst aus der Rinde zweyer, im steinigten Mimosengummi. Arabisches Gummi. Arabien und in verschiedenen Gegenden des Innern von Africa wachsenden Bäume, der Nil- und Senegalmimose (Mi mosa nilotica et Senegal L.) schritzt. Wir erbalten es in trockneu, festen, spröden, halbdurcbsichtigen, farhenlosen oder weifsgelblichen, aucls blafsgelben oder rotbbriunlichen, auswendig öfters ruuzlichen und rissigen Stücken von kugelichter, eyförıniger Gestalt bis zur W allnufsgrörfse, oder auch länglich wurmfïrmig. Zerschlagen zeigen sie ejnen mischeligen, glasartig glänzenden Bruch durch Feurhtigkeit werden sie zähe, lösen sich in Wasscr völlig durcbsichtig, in IVeingeist und Oelen aber or nichi auf Wien Sie bahen unen Gesclimack und gar keinen Geruch und lastcn sicb sebwer pulvern. Ain Lichte entzunden sie sicb nicbt, scbmelzen auch nicht uber Feuer, sondern glimmen blofs and vorkohlen endlich unter Aufblähen und Ausstofsen eines schwarzen brenzlichten Rauchs. Je duichsichtiger und beller oder ungefärbter die Stückell sind, um desto besser sind sie. Im Handel kommen übrigens verschiedene Sorten vor, nämunich:

J) Feines arabisches Gummi. eintändischenGum was widrigem Geschmack, wicht mit Wasmi, das aus unsern ser eine miuder hise Aullïsing Pflaumen-, Kir- möclıte es woht scliwer seyn, gute, weifse, schen -, Apricosen- reiuere, sebürig ausetrocknete Sı̈̈cke, wie und Pfirsichbäumen sie hisweilen unsere Plaumen und Aprikoausschwitzt. senbäume geben, von ächlem arabischen Gunmi zu unterscbeiden. Bey dem starken Verbrauche des arabischen Gummi ist es übrigens nicht zu fürchten, dafs denselben eine grofse Menge von dem Gummi dieser Bäome zugesetzt werden nöcbte, da sie es in einer verhaltnifsmãfsig viel zu geringen Quantität ausschwitzen.

GummiTragacanthace. Tragant.

Gutii.

Gummi Guttae. Gummigutt.
Länglici gedrehete, weifse, fast farbenlose, selir reine, nicht allıngrofse Stücke. 2) S e ne gal g u m $\mathrm{m}$ i. Besteht aus durchsichtigern, farbenlosern, gewöhnlich auch grö́sern, kugelichten oder halbkugelichten Stücken. Nach einigen Schriftstellern soll es ron der Senegalminiose allein genommen werden, nacb andern auch von der Nilmimose; in seiner Grundmischuug kommt es ganz mit dem arabischen Gunmi überein.

3) Barbarisches Gummi. Kleinere und gröfsere, mehr oder weniger gelhe und braune, durcbsichtige und indurchsichtige, unter einander gemengte Stücke.

4) Gemeines Din t e $n$ g um m i. Tleine, undurclssicbtige, schmutzig - weifse, braune oder schwärzliche, zum Theil bitterlich schneckende Stücke.

Nur die beyden er'sten Sorten dienen zum innern Arzueygebrauche.

iu aus dem Stamme und den dickern Zweigeu des auf den Inseln des Archipelagus wachsendeu Tragantstrauchs (Astragalus creticus L.) ausschwitzeurler, sich sogleich verdickender wahrer Scbleim. Wir erbaltcn. den Tragant in trocknen, barten, zäben, runzlicbten, plattrundlicben, bandförmigen', wurm förmig gedreheten und in einander geschlungenel Stückes, etwa eine Linte breit und einen Zoll und darüber lang, die gew ̈̈hnlich hobl sind. Sie haben einen faden, scbleimichten Geschmack und keinen Gerucl. In kaltem. Wasser schwillt der Tragant an, löset sich nicht völlig durchsichtig auf, und setzt bald einen gallertartigen, schleimichten Bodensatz ab. In Weingeist, Aether und Oelen erfolgt gar keine Aulösung. Man hat ihn im Handel von verschiedener Güte, nämlich:

3) Weifs oder blafsoelblich, halbdurcbsichtig ( $\mathrm{Tr}$ a g a c a tha ele cta.)

2) Graugelblicb, gelhbraun, rüthlich und unreiner.

5) Theils dunkelfarbige, schmutiig gelbe, braune, selbst scbwärzliche Stïcke, theils kleine Bröckelchon, die von den besten Sorten abgefallen sind, mit vielen Uureinigkeiten vermischt. (Tragacantha in sortis, Ginmide Balsora.) Diese Sorte taugt zum Arzueygebranche nicht.

Fin yerbärter ommiclıbarziger Pflanzen-Statt des guten eine/Kleine Stïcke und Bröckelchen mit Unrei(n) saft in graugelblich bestaubten unformi- ganz schlechte Sor- nigkeiten vermischt und ofters von schmuchen Kuchen oder dicken, wie Waclisstock gewundenen Massen, der auswendig dnnkel saffrangelb, inwendig elwas beller gefärbt, iu dünuen Stücken und an den Kanten durchscheinend, trocken, brüchig, auf dem Brucbe glänzend, zerreiblich, zwischen den Zäbnen zähe ist, den Speichel gelb färbt, durch Wälme nicht schmilzt, sich am Lichte aber anzünden läfst, und mil weifser rufsabsetzender Flamme brennt, anfangs kaun merklich, binterber aber etwas sclunf uurl zulctzi süfslich schmeckt und cin Gefülıl vou Troskeulseit in Munde zurückläfst Er läfst sich im Wasser (unter trüber bleichgelber Farbe), im Wciugeist (als klare dunkelgelbe Tinctur), uud geist (als klare dunkelgelbe Tinctur), und
iu Aetzlauge (l) ntroth) aunösen. Man iu Aetzlauge (blutroth) aunösen. Man
unterscheidet das selten zu uns kommende unterscbeidet das selten zu uns kommende
Siamsche oder wahre (von Stalagte.

as amerikanische Gummigutt ist ebe falls yerwerflich. brauch ganz verwerficb.

Dieses soll von melırern Arten des $\mathrm{H}_{\mathrm{a}} \mathrm{r}_{\mathrm{t}} \mathrm{b}$ e u $\mathrm{s}$ (z. B. Hypericum bacciferum und ca ye nneuse L.) vielleicht auch wohl ven einigen Euphorbienarten sesamulet werden, und zwar dieselbe, docl etwas bläsden, sere Farbe har dien aber nicht diw scharen drastischen Eigenschaften un Krafte des gewöbnliehen Gumnigutts besitzeu, dasckmecken, 


\begin{tabular}{|c|c|c|c|}
\hline $\begin{array}{c}\text { Namen } \\
\text { der Arzneymittel. }\end{array}$ & $\begin{array}{c}\text { Sinnliche Eigenfchafien derfelben; } \\
\text { Merkmale ilırer Ächcheit und } \\
\text { Güte. }\end{array}$ & $\left|\begin{array}{cc}\text { Fehlerluafte } & \text { Be- } \\
\text { fchaffenhcit, } & \text { Ver- } \\
\text { wecífelung oder } \\
\text { Verfälfohung. }\end{array}\right|$ & $\begin{array}{c}\text { Deren } \\
\text { Kennzeichen und Prïfungsmictel. }\end{array}$ \\
\hline Gutti. & 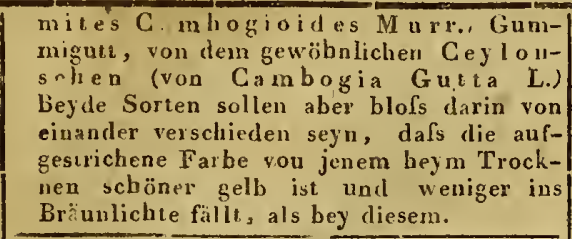 & 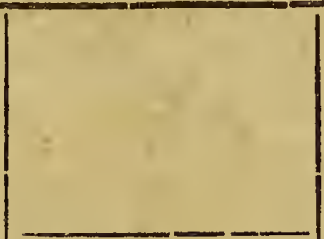 & \\
\hline $\begin{array}{l}\text { Helmintocliorton. } \\
\text { Ftrcus Heiminto- } \\
\text { chortos. } \\
\text { Wurmmoos. }\end{array}$ & 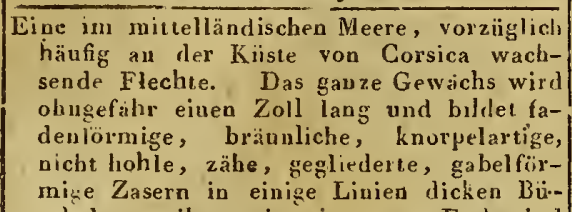 & $\begin{array}{l}\text { Verfälscht mit der } \\
\text { castantenbraunen } \\
\text { Flechter (Lich } \\
\text { castaneus Leersi.) }\end{array}$ & 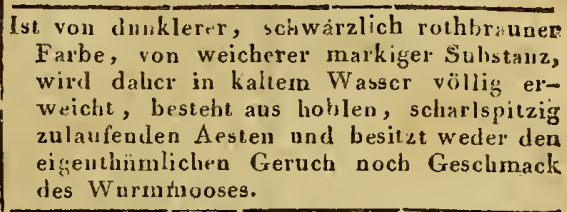 \\
\hline & $\begin{array}{l}\text { schela; au ihrem einen zartesten Ende sind } \\
\text { die Fuserm in einander geschlungen, liegen } \\
\text { an ihrer Dasis borizontal, oberwärts aber } \\
\text { sind sie aufgerichtet und pfriemenförmig } \\
\text { spitzig, die Spitze ist zwey- oder drey- } \\
\text { spaltig; nnd da, wo sie sich theilt, kuo- } \\
\text { tig. Sie baben einen salzig widrigen Ge- } \\
\text { schmack, und dunpfig widrigeu Gerncb. }\end{array}$ & $\begin{array}{l}\text { Mit dem Corallen- } \\
\text { moose (Corallina } \\
\text { officincalis L.), wel- } \\
\text { ches von einigen } \\
\text { auch Wurmmoos } \\
\text { genannt wird. }\end{array}$ & 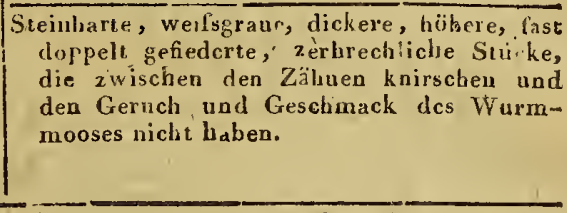 \\
\hline
\end{tabular}
schmack, unil dunpfig widrigen Gernch. In Wasser geweich $\ell$, schwellen sie auf, entfalten sich, nnd verliercu allmilig die bi aune Farbe, welche sie dem Wasser mittheilen. Wegen etwas beygemischten Meersalzes knistern sie geliude auf gluhende Koblen. Gewolinitich sind kleine Sand und andere Unteinigkeiten dannter gemengt, weshalb das Wurmmoos, wenn es hiervon nicht zuvor gereinigt worden ist, mit Säuren aufbrauset und, beym Kanen knirscht, wobøy es sonst zäbe undl weich ist.

Herba Abrotani. Eberraute.

Herba Absinthii. Wermuth.

Herba Aconiti. Eisenhütleinkraut.

Die vielfach getheilten, falleuförmigen, weifslichgrïnen Blätter vom Stabwurzbeyfufs IArte misia A brotanum L.), oder gewöhnlicher die Spitze der mit dergleachau Blättern dicht besetzien $S$ tengel (Summitates), die man vor dem Bliihen einsammlet. Das Krant bat eijen bitterlich-gewürzhaften Gescbmack und einen starken, den Kopl einnehmenden, etwas widrig-balsamischen Geruch, der sicb zwar bejm Trocknen vermindert, abcr nicht ganz velliert.

nimerk. Aufserdem hat auch nelertichst Herr Decandolie (Berliu. Jahrb. d. Pharm. 1807, S. 119; zu beweisen gesuclt, dafs das für ein eiufaches Arziey mittel gehaltene Wurmuoos, wie es Seesewachse, uamentlich verschiedene Arten vou Tangen, Ulven und Ceramien enthalte, deren quatitatives Verhattaifs so verschieden sey, dafs man zuweilen kaum den achten Theil, uiemals aber delur als den dritten Theil wirkliches Helmintochorton in einer Quantität des verkáuflichen Wurmmooses vorfinde.

Die Blatter des gemeinen Wexmuths Artemisia Absinthium L.) Vielfach zertheiltc und schmal z.erschuitene Bläter, die oberwärts grüutich-ascbgr,u, nnterwärts aber s!bergran, wie nit einem weifsen

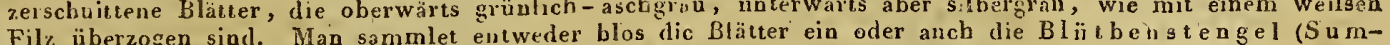
Filz überzogen sincl. Man sammlet entweder blos dic Blätter ein oder anch die Blï $\iota$ benstengel (Summitates Absinthii) mit ibren kleinen zusammengesetzten, fast kugelförmigen, an zarten Blumenstielen herabhängevden, gelben, ungeschweiften Blumesköpfchen. Kratut und Blumen
bittern, gewürzhaften Greschmack und einen bleibenden starken widrigen Geruch.

ach der P1 eufsisclieu Pharmacopoe soll das/Verwechselt mit den/Sie ind nicht so tief cingeschnitten, als die

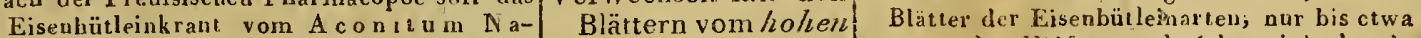

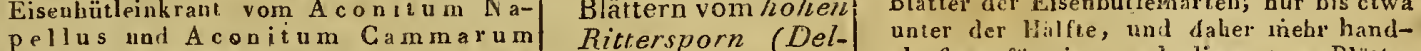
pellus und A conitum Cammarum Rittersporn (Del-) unter der Halfe, und daher mehr handL.' genommen werden, indessen sind diese beyden Arten nach Herrn Willdenow in Deutschlaud sehr selten und dagegen A couitum neomontaum und tanricnm L. gewóbulich in Gärten ankutreften. Ueberhaupz siurl die genciunten vier Arten des Eisenbütleins ihreı Gestalt uach sich so äbulich, dafs deren Verwecbselung schwerlich verhindert werden kann, und iberdem scheint es, dafs die blan blühenden Arten desselben Liemlıch in itver Wirkung ibereinkommen Die Blatter rer Wirkung nbereinkommen sind gestielt alier vier genannten. Arten sind gestielt (blofs bey Aconit. Cammaram die oberu am Blumenstengel ungestielt), lief füufspaltig, mehr fuger - als haudfïrmig ; die bierdurch entstehenden Abtheilungen sind wieder tief eingeschnitten und zwar bey Acon. Napellus schmal linienför$\mathrm{mig}$; bey Acouit. Cam marum breit, läuglıcb dreytheilig nisd gezähnt; bey Acouitum neorántaum keilförmig, kurz, ungleich und gezähnt; , bey A conit. tauricum breit, sehr tief A conit. tanzettörmig. Die Oberflächen der Blätter sind dunkelgrün, die Interflächen hell rün, bey A con. CamUnterflächen bell rün, bey A con. Cammarum obne Glauz, hey den ibrigen Arten aber glänzend. Inv Gesclimack ist bitterlich und scharf. Friscb aelnithen habell sie einen widerlichen, einigermaloen stinkenden Gernch. Die in din Gut ten vorkommende Pfanze ist meistens Aron. ne om o $\mathrm{t}$ a 11 u $\mathrm{m}$, und wahrscbeinlich auch diesplł,e, mit welcher $S t \ddot{o} \cdot k$ die von ihm beschriebenen Versuche angestellt hat.

Mit den Blättern vom Auch liese Blâtter sind handförmig, haben Wolfseisenhut $(A-$ ein bellere Grïn, und siad mit werchen conitumn Haren yersehen. Die Blumeu baben eine num $L$.) Lycocto Selbe Farbe. 


\begin{tabular}{|c|c|c|c|}
\hline $\begin{array}{c}\text { Namen } \\
\text { der Arnneymittel. }\end{array}$ & $\begin{array}{c}\text { Sinnliche Eigenfchaften derfelben; } \\
\text { Merkmale ihrer Ächtheit und } \\
\text { Güte. }\end{array}$ & $\begin{array}{c}\text { Fehlerhafte Be- } \\
\text { Schaffenheit, Ver- } \\
\text { wechfelung oder } \\
\text { Verfälfchung. }\end{array}$ & $\begin{array}{c}\text { Deren } \\
\text { Kennzeichen und Priifungsmittel. }\end{array}$ \\
\hline
\end{tabular}

ferba Althaeae. Die Blătter der Eibischal the (Alth a offic inalis L.) Rnndlich dreyechige, gestictte, stumpf-sägeAlthäkraut. $\quad$ förmig gezähnte, mit einem äufserst weichen aschfarbigen Filze über $\_$gene, graugrïne, vielen Schleim enthaltende, fast geruchlose Blätter.

Herba Anagalli-
Gauch
Gaueil.

Herba Arnicae.
Fallkraut.

Herba Basilici.

Basilienkraut.
Anagallis arvensis L. Die ganze kleine Pllanze mit darniederliegeudem, ästigen, viereckigen Stengel, woran die $\mathrm{Zwei}-$ tischen, ganzrandigen, glatten, lehhaft grünen Blätter gegeu einander über sitzen, dic auf der untern Seite, schwärzliche durchscheinende Puncte haben. Eigentlich let werden; mit seinen langrestielten, einzeln stehenden, schön zinnestien, einzeln stehenHeinen Blumen versehen, voriaubig. Es bat einen etwas scharfer, bitterlichen Gesat einen et was scharfen, bitter
schmack und keinen Geruch.

erwechselt mit dem|Diese Planze hat eyrund-berzförnige, ge Hühnerdarm (Al- stielte Blätter, die am Rande haarig und sine media L.) nicht punctirt sind; der Stengel ist rund und etwas bebaart; die Blüthen sinả klei

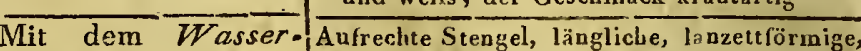

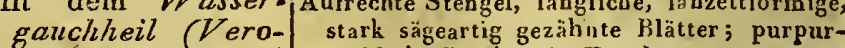
nica Anagallis L.) röthliche Blüthen in Trauben.

Die Blitter des Fallkrautwohlverleih (Arnica montana L.) Länglich-eyrunde, auf beyden Seiten kurzhaarige, auf der obern Fläche dunkelgrïne, öfters mit kleiuen rothen Flecken bezeichıete, auf der untern blafsurüne, gerippte Blätter, mit vällig ungetheilteu Rande. Sie besitzen einen stharfen, bitterlichen Geschmack, aber keinen Geluch. Man sainmlet nur die Wurzelblätter vor dem Blühen ein.

Die fufslohe ästige Planze des gemeineu Basilienkraus (O cymum Basilicum L.) nuit gestuelten, eyrundspitzigen, ganzrandigen, glatten, punctirten, hellgrünen, 2.uweilen ins Purpurrothe schielendeu Blättern, von einem feinen, sehr angenehmen Geruche, der bey versichtigem Trocknen nicht verloren geht, und majoranäbnlichen, gewürzhaften, etwas scharfem Geschmack. Statt dessen auch die etwa halb so hohre, ebenfalls ästive Pflanze des kleinen Basilienkrauts (Ocymum minimum L.), mit vielenkleinen, eyruinden, ganzlandigen, bellgrünen Blättern, vou äbnlicbem, aber noch feinern und augenebmern Geruch eyruinden, ganzl

Herba Belladonund Geschmack.

Belladonnablätter.

Tollkirschen - Blätter.

Bell ad on a sclilaf-/Verwechselt mit den/Sie sind nicht so grofs, langgestielt, eyrund, beere (Atropa Bellaronn L.) Bläterndester nicht lanzettförmig zngespitzt, sondern Grofse, an der Wurzel acht bis zehn Zoli lange und halb so breite, am Stengel Zor bälıvifsmäfsig kleinère, kurzgestielte, ey-

raftige, ganzrandige, jung etwas wollichte, Mit den Blättern des vöilig ausgewachsen auf der obern Fläche Hyoscyami Scopo"ganz glatte, duokelgrïne, auf der untern lii.

Fläche feinhaarigc, blässergrïnc Blätter, ron betäubendem Geruche urd ein wenig
schalf zusammenziebendem Geschmack. Blättern des gemei- nicht lanzettförmig zngespitzt, sondera

nen Nachtschattens. (Solan

eigen sich mehr aus dem eyrunden ins lan-

zettförmige, sind nur selten am Rande etwas ausgeschweift, völlig glatt, weuig gläuzenri. Die gauze Planze ist unbehaart, statt dafs die belradonna überall weichhaarig ist.

Herba!Cardui benedicti.

Cardobenedictenkraut.

Herba Cardui tomentosi.

Krebsdistelblätter.

Herba Centauriz minoris.

Tausendgüldenkraut.

Herba Chamaedryos.
Edelgam ander.

Herba Chamaepi.

thyos.
Schlingkraut.

Herla Chenopo-

dii ambrosiacis.

Botryos' mexica-

nae.

Traubenkraut.

anfserst bitter schmeckende, frisch etwas widıig riechende, blühende Kraut der Benedictflockblume (Ceut a ure a benedicta L.) mit aufsitzenden, länglichten, ziemlich breiten, geaderten, rauben, an beyden Seiten spitzlappig - ausgescliweiften, am Rande stachlichten, gezähnten, mattdunkelgrünen Blättern, wovon die oberu mit ihrem Grunde an dem rundlich-wollicht-rauhen, zuweilen röthlichen Stiel etwas herablaufeı, die nutern gröfsern auf der Erde liegen, und den zusammengesetzten, röhrigen, gelben Blumen, die mittclst ibres bauchigen und länglicb-eyförmigen, glänzend-grünlicben, aus dachziegel(örmig übereinancier liegenden-Schuppen zusammengesetzten, stachlichtiten Kelchs an die zunächst anliegenden Bläıter, durch ein spinnenartiges, klehricht - wollichtes Gewebe sich anschliefsen.*

Die Blätter der Krebsdistelzeliblume (Onopordium acanthium L.) Grofse, eyrundlängliche, scharf ausgeschweifte, am Rande gebogene, mit laugen Stacheln besetzte, wollichte, weifsgrünliche, ziemlich bitter schmeckende Blätter, die zu beyden Seiten am Stengel herablaufen.

Die ganze Pflanze des Tausendgüldenzians (Gentiana Centaurium L. Chironia Centaurium Curtis) mit den Blumen. Sie hat einen, einfuchen, aufrechten, einen balben bis ganzen Fufs bohen, oben sich in zwey Nebenäste theilenden, hohlen Stencel, auf welchem die pfirsichblüthrothen Blumen sitzen, die uben an der Spitze einen flachen Straufs bilden. 'Die Blätter sind länglich-eyförmig, zugespitzt, gegeu einander iber stebend, dreyrippig, glatt, ganzrandig, vou ibrem Grunde aus am Stengel berablaufend und einander über stehend, dreyrippig, glatt, ganzrandig, vou ibrem Grunde aus am Siengel häutigen Fortsätze ihm ein beynahe viereckiges Ansehı gebend: Die l'flanze besitzt keine» durch die feinen häutigen Fortsätze ihm ein, beynabe vi
Geruch, aber einen reinen, scharf bittern Géschmack.

Das ganze Kraut des Bat hengelgamanders (Teucrium Chamaedris L.) nit keulälnlich-eyförmigen, fast eingeschnittenen, gekerbten, gegenüberstehenden, ranken, kurżyestielteir, sebr duukelgrünen Blättern, von etwas zusammenziehenden, balsamisch - gewörzhaftern Geschmacke und schwachem balsamischen Geruch.

Geruch. eckigen Stengel und dreyspaltigem, linienfürmigen, ganzrandigen, sattgrünen, frisch etwas klebrigeu, harzicht riechenden und bitterlich schmeckendeu Blälleru. Die kleine» Blümchen der übrigens auch niedrigen l'lauze sind gelb. Das blibeude Kraut vom Ambergä use-/Verwechselt mit dem|Die Blätter desselben babeu eiuen schwächern fufs (Cbenopodium a mbrosioi- gewöllnlichen

des L), mit einfachen, geblätterten Traubenkraut Traulienblütben, und gestiel ten, lanzettfürmigen, usespilzteu, glatten, weitläıftig und sägeartig gezähuten, frisch heltgrinen, getrocknet etwás geiblichgrünen Blïttern. Die ganze Pflanze besitzt einen durchlringenden, fiichtıgeu, aurberartigen Germelı uod bitter erwä̀meuden, gerwürzhaften, nicht unangenehmen Geschmack. lis werien auch wohl nur blos tie Blätter vor der Blüthe eingesammiet. (Chenopodium Botrys L.) Geruch und Geschinack, sind langlich mit etwas kurzeon Haaren besetzt, $110\left(b_{13-}\right.$ ben an beyden Seiren tirfe und stumpfe. Aushöbluugen oder Buchten. Die Pflanze ist.im frisclien Zustande etwas klebrig allzufühlen. 


\begin{tabular}{|c|c|c|c|}
\hline $\begin{array}{l}\text { Namen } \\
\text { der Arzneymittel. }\end{array}$ & $\begin{array}{c}\text { Sinnliche Eigenfchaften derfelben } \\
\text { Merkmale ihrer Aechtheit und } \\
\text { Giite. }\end{array}$ & $\begin{array}{c}\text { Fehlerhafte Be- } \\
\text { fchaffenheit, Ver- } \\
\text { wechselung oder } \\
\text { Verfälfchung. }\end{array}$ & $\begin{array}{c}\text { Deren : } \\
\text { Kennzeichen und Priifungsmittet. }\end{array}$ \\
\hline
\end{tabular}

Terba Cicutae vi-pDie Blätter des Giftwüt herichs (Cic nt a virosa L.), einer äufserst giftigen, an Gräben, Teichen und ir rosae.

W asserschierling. Wuthschierling. stehenden Gewässern wachseudeu Pflanze. Dunkelgrüne, glatte, glänzende Blätter, die sich in drey bis vicr längliche, schmale, lanzettförmig-zugespitzte, an Rande scharf gezühnte, an der Spitze mit weifslivicr längliche, schmale, lanzetfförmig-zugespitzte, am Rande scharf gezihnte, an der Spitze mit weilsli-
chen Auszahnuugen verschene kleinere Blättchen theile日. Frisch balien sie einen starken, Dilläbnlichen chen Auszahnuugen verschene kleinere Blättchen theiles. Frisch bahen sie einen starken, Dilläbnlichen getrockuet verlieren sie beydes fast gn̈nżlich. Die Wurzel ist knollicht; änfserlich der Sellerywurzel ähulich, besteht aus einer kurzen, dicken Hauptwurzel, die mit Ringen oder Fúrchen nmgeben ist, zwischen denen sich im Winter kleine Grübchen zeigen, aus welchcn im Frühjahre mehrere Keime und Fasern entsteben; inwendig ist sie weifs, in verschiedene Fäcber getheilt, lleischicht, und entbält eineu weifsen ätzelıden Milchsaft, der beym Ansfliefseu an der Luft erst gelb, dann braunröthlich wird, und in surzer Zeit einen höchst widrigen Geruch verbreitet. Der Stengel ist rund, glatt, gegen einen Znll dick, bohl, mti feinen Linie weifs und röthlich gestreift und mit Knoten verseben, aus denen die Stielblättcr entspringen, deren Stiele ihn mit ihrer ausgehöhlten Haut, wie eine Sclıcide, urngeben. .Die weifsen und zusammengesetzten Dolden entspringen allemal eineın Blattstiele gegeuüber und haben gerändelte IJlımenstiele.

Herba Clematidis erecine s. Flam mulae Jovis. Brennkraut. Aufrechte Waldrebe.

Tlerba Cochleariae.

Löffelkraut.

Herba Conii maculati s. Cicutae maculatae.

Schierling.

Erdschierling.

Gefleckter Schier-

ling.

Die Blätter der Brennwaldrebe (Cle $/$ Verwechselt mit den
matis erecta L.) Gefiedcrte Blatter,
Blättern der gemeidie sich in ein einzelnes Blättchen endigen die kleinern Blättchen sind eyruudlanzettförmig, gäuzlich unzcrtheilt, ganzrandig glatt, langgestielt, stehen bis auf das obeglatt, langgestielt, stehen bis auf das obe-
re einzelne Blättcben gegen einander iiber, und baben auf der Oberfäche eine dunkelund haben auf der Oberfiache eine dunkelhellgrïne Farbe. So lange sie frisch sind ist ihr Geschmack äufserst scharf und auf der Zunge Blasen und Brennen erregend; getrocknet aber weniger brennend, blos sauersüfslich und etwas zusammenziehend schmeckend. Die Pflanze wä̀chst aufrecht; ihre Blumen bilden zu Ende der Stiele weifsc Sträufse. Nach der Prenfs. Pharmacopoe wird das blübende Kraut eingesammlet.

nen Vv aldrebe

(Clematis Vitalba L.)

Mit den Blättern der Kriechwaldrebe (Clematis Flammula L.)

Mit den Blättern des SumpfluahnenfiSes (Ranumculus
Flammula L.) in beuutzt entweder'nur die Wurzelblätter des Löffelkrauts (Cochleari officinalis L.) oder die ganze blühende Planze. Die Wurzelblätter sind langgestielt, berzförmig rundlich; die an dem ästigen und eckigeu Stengel sitzenden Blat ter sind kleiner, ungestielt, länglicht, etwas ausgeschweift, buchtig, gezähnt. Beyderley Blätter sind glänzeud grün, saftig und besitzen einen eigenen, bitterlichsalzartigen, beifsenden Gesclmack; zerriebcn haben sie einen eigenthümlichen, scharfen balsamischen Geruch. Getrocknet sind sie ganz, unwirksam und verliereu Geruch und Geschmack.

Die Blälter des an ungcbauten Oerter'n, an Mauren, Zännen, Wegen und auf verfallenen Stellen wachsenden. Fleckenschierlings (Gonium maculatum I.) Grofse, lauge und glatte, gefiederte, mit etwas dicken, unten arn Stengel de Pflanze riznenförmigen Stielen versehen Bläıter; die untern Blätter stehen abwechselud und sind drey- bis vierfach gefiedert die obern stehen gewöhnlich gegen einander ïber und sind nur zweyfach gefiedert beyde aber laufen nach der Spitze $z u$ in ein einzelues zugespitztes Blättchen'alts. Die kleinern Blätıcheu sind lauzettförmig, halbgefiedert-gezähnt und glatt. Auf der Obernäche sind die Blätter dunkelgrïn und etwas glänzend, auf der Unterfäche und etwas glänzend, auf der Unterfach abër haben sie etwas hervorstetiende telrippen und sind blafsrrun. Gequetseb oder zerrieben geben sie eiuen eigenth ron lichen, besonders widrigen Grilch von Flie, engch ähnlich ist; ihr Gesclinack ist süfslicht, etwas scharf und eckelbaf Der Stengel der Pflanze ist' rund, hobl, ästig, von frischgrüner Farbe, glatt, nicht behaart, mit schwachen Furchen'bezogen, und so wie die tntern Blatistiele sehr und so wie die untern blatstiele bräunlireichlich mit purpurfarbnen oder braunlichen Flecken besprengt, die sich oft etwas
sie Wurzel gleicht scharf anfühlen lassen. Die Wurzel gleicht
in etwas der Petersilienwurzel, ist weifs, spindelfớrmig, etwa einige Spannen lang, oben gewöhnlich Daumensdick, läuft unten in ein paar Abtheilungen ans, und ist munculus Ficaria L.) L.) ie an den gefiederten Blätteru dieser sich um andere Gewächse herumscliliugenden Pflanze befindlichen kleincrn Blättchen sind nicht eyrund, sondern mehr herzförmig und dicker, lederartig, auch meisten etwas lappig eingeschnitten und mit einer weifsen Wolle bedeckt.

Die Blätter dicser chenfalls um andere Gewächse sich, windenden, aber zärter gebauten und niedrigern Pflanze siud zwar unten am Stengel duch gefieder, aber nu gemeiniglich in drey Lappen zertheilt; die obersten sind lanzettring und ganz unzertheilt. Sie haben irisch ebenfalls sehr brennenden

fache, nicht gefiederte, lauzettförmig und gerippte, ganzrandige, zuweilen sägrartig gezzhnte-Blatte1, von denen nur die Wurzelblitter gestielt, die obern aber laufell, Einzelne, selbe, glanzende Blumen.

Verlälscht mit den/Dies geschieht oft von deu Krantersammaru, Blättern des Feig- weun sie nicht genug Lötfelkraut ánschafwarzenkrauts ( $R a$ - fen können. Sie haben eiue mehr herzuicrenförmig rubdliche Gestalt, sind ungleich in der Mitte oft mit einem schwarzen Fleck bezeichnet und dabey von mebr unangenebmen bittern als krefsartigen scharfen Gemen bitter

Verwechselt mit den Bläıltern des bollichten Kälberkropfs CCluczerophyllum bulbostum

attgrüne, glänzende, glatte, dreyfach gefiederte, an den. Rippen rauhe Blätter, deren Fiederchen auch fein zertbeilt, an de Spitze jeder einfacben Fieder und der Einschnitte knorpelartig sind. Die Blattstiel sind rauh und entspringen à̀s langen ge-
streiften und mit einein häutigen Rande versehenen Schciden. Der Steugel ist $z$ war auch rotbgefleckt; aber er ist negliedert, an deu Knoten zwischen den Gliedern auf an den Knoten zwiochen den geschwollen, unl-an den drey mie When Gliedern ganz pauh und borstig. Die Wur zameu sind nach obet zu dünner, längä. Sameu sind nach obeh z1
licht, glatt und gestreift.

Mit den Blättern des Grofse, schwarz - oder gratugrune, oft gowilden Körbels fleckte, dreyfach gefiederte blätter mit lan(Clunerophyllum sylvestre L.) Blattscheiden und haarige Blattstiele. Det Stengel gefurcht, ungefieckt, unten twas scharf anz ufühten, oben hinauf glatt: Die Wurcel ist dick, lang, weifs nnd gewürzhaft scharf. Die Samen sind schwarzglänzend, glatt, lanzettförmig.

Mit der Gleifse oder Glatte, schwarzgrüne, auf der untern Fläche Hundspetersilie (Aethusa Cyna- mit eingeschnittenen strich för migen Blättpium $L_{\text {: }}$ ) chen. Die Wurzel spindelföımig; der Stengel ästig, rund, glatt, gestreift, zuweilen wie angehaucht violettfarbig; die Blattstiele aus gestreiften, am Rande häutigen, an der Spitze zweyfoh gezahnten Scheiden hervorkommend. Die allgemeine 


\section{Namen Sinnliche Eigenfcliaften derfelben der Aisneymittel. Merlimale ilnrer Aechtleit und Guite.}

\section{Fehlerhafie Be- cliaffenheit, Ver- wechfelung oder Verfälfcluung.}

\section{Deren}

Kennzeichen und Prïfungsmitiel.
Sherbe Conit-ma- mit einigen Seitentaser'a besetzt. Sie ent-1 vilíi:i. bält, weun sie jung ist, eine m milchwe-
fscn $S_{\text {ift }}$ und that anfangs eineu süfslich-
Herba Daturae 's siramonii. Stechapfelblätter.

Herba Digitalis. Fingerhutkraut.

Herba Erysimi.

Wegsenfkraut.

Herba Farfarae

Tussilaginis.

Haflattichb!ätter.

Herba Foeniculi.

Fenchelkraut.

Jerba Frnnariae. Erdrauch. Herba Gratiolae.
Gottesgnadenkraut. ten, nachlher aber scharf werlenden Geten, nachlher aber scharf werlenden komschmack. Die weifsen Blumendolden kom-
men aus den Winkeln und oben hervor; meu aus den Winkeln und oben hervor;
die allgemeinen sowohl als die kleinern die allgemeinen sowohl als clie kleinern Dolden baben cine mchrblättrige Húlle und sind etwas flach. Die einzel nen Blürmchen gen und ungleichen Blättchen. Die beynahe kugliclite frucht hesteht ans zwey, auf einer Seite flachen, auf der andern

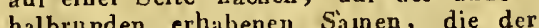
Länge nach gestreift und in die Qneere geLänge nach
ketbt sind.

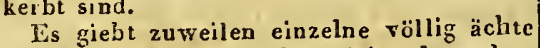
Ls giebt zuteilen einzelne völlig achte
Schierlungsplauzen, die nicht den oben Schierlungspflauzen, die nicht den oben bemerkten eigentlämlichen Geruch besitzen; diese werden nit Recht als unwirk.
Mit dem TI asserschierling (Cicuta
virosa $L$.)

Blumendolde hat keine Hülle; die Hülle der kleinern Dolden aber besteht aus drey sebr langen, schmalen, an der einen Seite hlerabhängenden Blättchen. Die Ganze Polanze hat, wenn sie nicht gequetscht ist, 'keinen, und dann keinen Schierlingsgerncti. Man vergleíche die oben bey $\mathrm{H}$ erba $\mathrm{C}$ icutae virosae gegebene Beschreibung.

Anmerk Anfserdem soll der Schierling noch verwechselt werden : nit dum Wasserfenclecl (Phellandrium aquncicum L.); mit

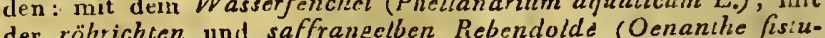
der rohrichten und saffrangelber Rebendolden Körbel (Scandix losa u. crocaia L); Init dem mohiniechenden Ko odorala L.); mit dem peloponesischen Liebstockel (Ligusicum peloponense L.); mit dcm berauschenden und rauhen Köbel (Chacrophyllum temulentum 11. hirsutum L.) Lis wird indessen der wahre Schierling durch die gegebenen Kennzeichen leicht davon unterschieden werden könuen.

Die Blätter des Tollstechapfels (Datura Stramoniun L.) Grofse, gestielte, breite, eyfürmige, auge-

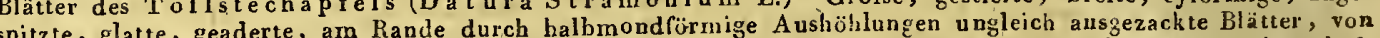
spitzte, glatte, geaderte, am Rande durch halbondriglı und eckelhaftem Geschmack. Müssen ihrer hefduukelgrüner Farbe, einem betäubenden, widrigen Gerucl
tigen Wirkungen wegen sehr sorgfältig anfzehoben werden.

Die wechselsweise stehenden Blatter des $\mathrm{r}$ o-jVerwechselt init den|Sind dicker, auf beyden Seiten wollicht, thea

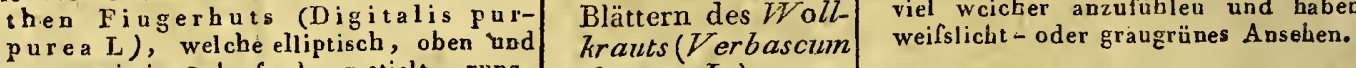
unten spitzig zulaufeud, gestielt, runzlicht, auf der obein Seite dunkelgrün und weich, auf der untern blässer und etwas rauh mit feinen Haaren besetzt, an Pande etwas ungleich sägeförmig gekerbt, und übrigens ziemlich grofs sind. Sie baben einen eckelhaften scbarf bitterlichen Geschmack.
scheck

Die Blätter des Wegesenfs (Erysimum officin a le L.) ron unregelmä́siger Gestalt. Die untern Blätter sind gröfser als die übrigen, und anf beyden Seiten in gegenüberstehende Lappen zertbeilt, die au iluren Ründern wieder viele eckige und liren Randern wervorragnen haben; höber am Stengel sind sie kleiner, spondenföram Stengel sind sie kleiner, spondenförmig, am Pande unordentlich gezälnt und
auf den Flächen borstig. Sie liaben eiue rnattgrüne $F$ arbe und einen salzartigen bitterlichen Geschmack.

Die Blätter des Brandlat tictrrofshufs (Tussilago Farfara L.) Ziemlich grofse, beynahe berzförmige, am Rande eckige und gezähnte, auf der Oberfläche hellgrüne, unten wollichtweifse. Blätter, fast geruchlos, aber von einem schwach zusammenziebenden, etwas bitterliclien, schleimichten Geschmack. Sie komment.

thapsus $L$.)

Tit den Blättern des Sind mit kleinen Borsten besetzl, scharf anBeinwelıls (Sym-) zufühlen knd am Rande uvgekerbt. phitum officinale L.)

Verwechselt mit den Gestielte, behaarte, urd dergestalt eingeBlättern des wilden schrittene Blätter, dafs die obern Lappen Senfs (Sinapis ar- immer sö̈lser als die untern sind. vensis $L$.)

Die Blätter des Fencheldills (Auethum Foeniculum L.) Lange, gefierlerte, ästige Blätler, deren Blättchen sebr zart uad haarförmig sind. Der Geruch etwas gewürzbaft, der Geschmack süfslich.

Die ganze Pfanze (Fumaria of $\mathrm{icinalis} \mathrm{L.)} \mathrm{mit} \mathrm{wechselsweise} \mathrm{doppelt} \mathrm{gefiederten,} \mathrm{weichen,} \mathrm{saftigen,} \mathrm{matt-}$

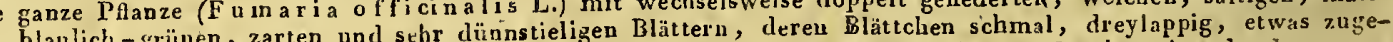
blaulich - grünen, zarten und sthr dunnstieligen Baten, bittern, etwas scharfon Geschmack, der beym gerundet lanzettförnis sinıl. Das frische Kraut bat einen bittern, etwas scharfon

trockueten mcrklicher sal zicht - bitter ist. Gcruch ist elien nist zin ber hä einen höhern, ästigern, viereckigen Stenan sammlet die ganze Planze (Gratiol a of $\mathrm{fic}$ in al is L.) nach einigen vor dem
Blühen, nach andern während dem Blühen Blühen, nach andern während dem Blühen
eln. Sie hat einen viereckigen, glatıen, eln. Sie hat einen viereckigen, glatten,
gegliederten, ästigen Stengel. Die Blätter gegliederten, ästigen Stengel. Dic Blätter
stehen kreuzförmig gegen einander über sind länglich - lanzettförmig, zugespitzt, sägeartig gezähnt, glatt, ungestielt, au der Unterfläche mit drey merklich erhabenen Rippen versehen und baben eine lebhaft grüne Farbe. Aus den Winkeln der Blätter, vorzüglich oben am Stengél, komBlatter, volzugglich oben am Stengel, kommen auf ziemlich langen, dünen, einblumigen Stielen dic rachenformigen, weirsoder röthliche spielenden Blumen hervor Die ganze Planze hat eineu unmerklichen Geruch, aber einen durckdringead-bittern, ocharfen Geuchrnack.

\begin{tabular}{|c|c|}
\hline $\begin{array}{l}\text { Fieberkraute (Scu- } \\
\text { tellaria galericu- } \\
\text { lata L.) }\end{array}$ & $\begin{array}{l}\text { gel, der mit rückwärts geküümten Bor- } \\
\text { sten wie die Rückschärfe der, kurzgestiel- } \\
\text { ten, herz - lan ettförmigeu, gekerbten, } \\
\text { runglichten, glatten, parweise stehenden } \\
\text { blätter bekleidet ist. Die Blumen sind } \\
\text { blau, lippenförmig, und sitzen paarweise } \\
\text { in den Blattwinkeln nach einer Seite zuge- } \\
\text { kehrt. }\end{array}$ \\
\hline $\begin{array}{l}\text { Mit dem schildför- } \\
\text { migen Ehrenpreis } \\
\text { (Veronica scutel- } \\
\text { lata L.). }\end{array}$ & $\begin{array}{l}\text { Ist durch seinen runden Stengel, seine zwar } \\
\text { etwas lanzettförmigen, aber nur wenig zu- } \\
\text { gespitzten, am Grunde ungezähnten, am } \\
\text { Ende fein gezackten Blätter, so wie durch } \\
\text { seine sebr Jockern, ästigen, weifsen, oth- } \\
\text { gestreiften Blumentrauben, die werbsels- } \\
\text { weise an den Seiten der Stengel stehen, } \\
\text { leiclt davon zu unterscheiden. }\end{array}$ \\
\hline it de & $\begin{array}{l}\text { Wohl nur selten, da sie gar zu sebr verschie- } \\
\text { den daron ist. Vergl. Herba Violae trico- } \\
\text { loris. }\end{array}$ \\
\hline
\end{tabular}




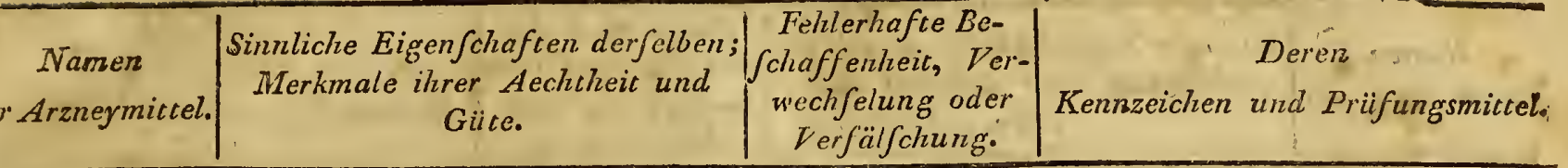

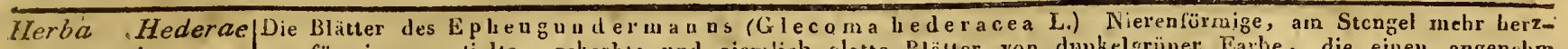

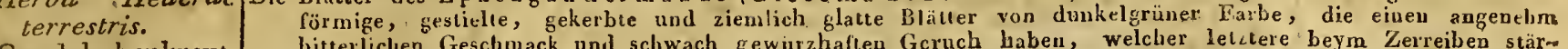

Gundelrebenkraut. bitterlichen Geschmack und schwach gewurzhaften Gcruch haben, welcher letıtere beym Zerreiben stär
ker wird.

Herba Hyoscyami Die anf den runden, ästigen, haarigen Sten-|Verwechselt rait den|Die Blatter siud kleiner, stumpfer, wol-
nigri.

schwaries Bilsenkraut,

\section{Herba IIyperici. Johanuiskraut.}

\section{Herba Hyssopi.} Isopkraut.

Herba Lactucae
virosae.

Giftlattich.

\section{Terba Linariae.} Leinkraut.

Herba Ledi palusiris.

Wilder Rofsmarin.

Yorschblätter. den und ihn halbumfasseuden Blälter des fsen Bilsenkrauts

$\mathrm{Scb}$ arzbilsens (Hyoscyamus ni-

S 1 ) Sie sind liulichbreit, ge e d.) Sie sind lanolichbreit, zugesegen die Spitze zu ganz graulicbgiün, auf Gegeu die Spitze zu ganz graulicbgitu, auf
iler Unteriläche heller glänzend, dick, sehr weich, mit Adern durcbzogen, und sehr weich, mit Adern durcbzogen, und
fast fettig klebris anzifiuhlen. Ibr Geschnack ist weichlich fade, der Geruch äulserst wilrig betäubend. Die Wurzelblätter siud gestielt.

Das blihende Kraut des Jobannishartheu (Hypericum perforatum L.) Der Stengel desselben ist gerade, platt, «weyeckig, etwas holzig und mit vielen Nebenstielen besetzt, die kreuzweise aus dei Blattwinkeln entspringen, gegen einander ïber stehen und nach oben einen Straufs bilden. Die Blätter, welche ebentalls gegen einander übor stehen, sind eyförsuio, länglicht, ungestielt, tanzrandig, bellä und iberall nit durchsichsio (a) rangelben Blumen sitzen straufs förmig am Jangelben Blnmen sitz
Ende der Nebenstiele.

(Hroscyamus al-

bus L.), welches jedoch nicht so gemein ist, als das schwarze.

\author{
Ver
}

Verwechselt mit dem quadrangulare $L$.

em Uncerscheidet sich durch den einfachern, viervantigen Stengel, der nicht so holzig ist, und sich nicht in so viele Aeste theilt?

Das Kraut des Ispeuis ops (Hyssopus of ficinali's L.) Scbmale, lanzettförmige, glatte, ganzraudige, nngestielte und lebhaft grüne Blätter, von einem angenebrnen, gewürzaften Gernch uud b.ttellich gewü z-
liaften Geschmack. Man sammlẹt das Kraut mit den Spitzen am sebicklichsten vor dem Aufbrenen des Bliithe ein.

Die Blatter des Giftlat i chs (La c tucja M virosa L.) Harte, steife, beynahe etwas eyförmige, ungestielte, an Rande buchtige und sägeförinig gezähute, auf der Mittelrippe, sowohl der Ober - als Unternäche mit baiufigen Stacheln besetzte Blätter, von denen besonders die untern, welter, von dẹnen besonders die untern, welche aucli gröser und breiter sind, dunker rere Fufs bohe Stengel ist rund, bart, ästig, aufrecht, uutcrwärts mit Stacheln besetzt und mit blutrotben Fleckes, die nacbher schwarz werden, bezeichnet. Die zusammengesetzten gelben, ins rötblicbe spielenden Blumen kommen eu Ende des Stengels und der Zweige hervor. Die rganze Pflanze bat einen sehr widrigen betäubenden Geruch und cnthailt einen bittern

milchweifsen auf der Zunge, brennend

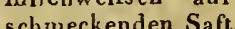

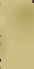

$$
.
$$

Dic unordentlich abweclselnd stehenden B!ätter des S'ump porsts (Ledum a luslre L.), einer strauchat tigen, auf tor
Mit dem wilden Lat-Am Stengel aufsitzende, ungestieite, blautich (Lactuca Sca- grüne, glatte, ungltichte, am Rande riola $L$.), der je- buchtig leraheschlitite cind nur auf der Mittelippe der Unterfläche mit Stacbeln doch in manchen besetzle Blitter. Unten am Stengel sind Dispensatorien als sie mehr eyrunllich; oben am Siengal aber offizinelle Pflanze i mehr lanzettföinig, weniger ausgeschitvorgesclurieben wird, ten und auf der Mitielrippe nieltt so stachvon einigen Botani- licht. Sämmtliche Blatter siud etwas gekern blos für eine zabnt nad netzförmig geadet, uud entVarietät gehalten halten ebenfalls einen scharf hitteru milchwird, und nach dem weifsen Saft, haben pives widıigen GeZeuonisse verschie- ruch und einen scbarfen litterliclien $\mathrm{Ge}$ dechmack. Die noch jungen Pflanzen haben dener Aerzte mit unten am Stengel zarte Staclılı und längdem Giftlattich ei- lich gezähnte Blätter, die an den ältern nerley Wirkung ha. abfallen. Die Pflanze ist viel gemeiner, ale ben soll, welches indessen noch eine nähere Bestimmung erfordert, verwechselt.

Mit der Gänsenistel (Sonchusoleraceus L.) moorigen und nässen Bruchen waclisenden Ptlanze. Schmale, strichförmig-lanzett-
törmige, den Rofsinarinblättern ähnliche, auf der obern Secle glatle und dunkelyrüne, auf dex untern aber rabe, mit einer eiserrostfarbuen Wolle überzogene und daher braungelblicbe, am haude umgeschiagene, brangelblicbe, am hande umgeschielte, ziemlich barte und feste Burzgestielte, ziemlich harte tht feste

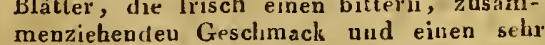
menziebendeu Gesclimack und eiren sehr nehmenden Geruch liaben.

Das dünustenglichte blïbende Kraut $\mathrm{An}_{\mathrm{n}}$ tirrhin um Linaria L.) mil seiuen gehäuft sitzenden, stiellosen, lanzettlörmi gleichbreilen, oben leblaft grünen, unten gleichbreilen, oben lebliaft grunen, unten fien, an der Spitzo über einander sitzen-
Verwechselt mit den Blättern der $P_{0}$ lejblätrigen Andronteda (Androtheda polifiolia $L$.)

Mit den Blättern der brabantischen

Myrike (Myrica Gale L.)

Mit den Blättern des Immergrïnamsels (Polygala cha maebinxus L.) erwechselt nint der sentuolfsmilch ( $F_{u-}$ phorbia Esula und Pliorbia Esula und
Die Blätter baben keine Stacheln aul der Mutelrippe, eiue lebhaft griue Farbe, und besitzen nicht den eigenthümlichen widri-
gen Gcruch der beyden erwähnteu Latt chgen Gcruch der beyden erwähnteu Latt charten. Die P'flamze ist ein gewöhnliches in
Gärten vorkommendes Unkraut. Sind aul der Usternäche nicht mii jenter rostfarbigen Wolle üherzogen, sondern au beyden Stiten glatt, unten bläulichweifs, geâlert, lanzettförmig zugespitzt /und geruchlos.

Kleine lä vglicht - ey lüı mige, glatte, am Rande etwas gezähnte Blätter.

Sind ejrund, oben spitzig zulaufend uud mis eıner in dünze Faden sich endigenden Rippe bezeichuet.

Sie baben zwar wobl ähnliehe Blätter, unterscheiden sich aber durch ihren botanischen Character selir davon, enthalien eiven scharfen Milchsaft, und lassen sick nicht gut danait vertwechsele. 


\begin{tabular}{c|c} 
Namen & $\begin{array}{c}\text { Sinnliche Eigenfchaften derfelben } \\
\text { Merkmale ihrer Ächtheit und } \\
\text { Güite. }\end{array}$
\end{tabular}

den, bellgelben, mit orangefarbnen Flekkeu bezeichneten Blumen, die einen langen zogerpitzten Sporn baben. Es hat einen unangenelimen bitterlichen Geschmack, und unangenelimen bitterlicher der aber beym Trocknen vergebi.

Herba Lini cathar- Die gauze Pllauze (L in m catbarticum tici. Purgirlein.

Herba Lysim
purpureae.

Rother Weiderich.

Herba Majoranae. Majoranblätter:

Tlerba Malvaie. Pappelkraut.

Merba Mari ver Amberkraut.

Mastixkraut.

$\overline{\text { Terba Marrubi }}$ allit.

Weifses Antornkraut.
L.) mit dïnnem, geraden, fadenförmigen, ohen fast zweygetheilt - geästetem Stengel, ten, ganzrandigen, lebbaftgrünen Blätter ungestielt gegeu einander über steben, und an astielt gegeu einander uber steben, und an den Spitzen der obern Abtheilungen die einzelnen, kleinen, weifsen, fünfblättrigen Blumen kleine Rispen bilden. Die Pflanze bat keineu Geruch aber einen bittern
schmack und eine leblaft grüne Farbe.

Die Blätter des Weiderichblutkrauts (Lythrum salicaria L.), an deren was scharf anzufühleuden Stengel sie gegen einander über steben und denselben nmfassen. Sie sind lanzettförmig. zugespitzt, etwas" scbmal, auf der untern Flä̀che ein wenig weichbehaart, vou lebhaft grüner, uniten etwas bellerer Farbe und von krảuterartigem, geliude zusammenziehendent, terartigem, geliude zusammenzieh, ohue Geruch. Die scbïnen
Blumen hilden lange Aehren. drey bis fünf Fuls hohen, eckigen und etschleimicht bitterlichem Geschion purpurotien (Malva rotundifolia, Li) Langgc-, Ro gelappte, meistens schwach gefaltete, zabnartig gekerble, glatte Blätter von schniutzi dunkelgrïner Farbe und scbleimicbten Geschmack. Kleine röthlich - weifse Blnmen. vulgare L.) gegeniiberstebenden Blätter, welche eyrund, am Rande nngleich und

\section{Fehlerhafte Be- schaffenheit, Ver- wechfelung oder Verfälfchung.}

Deren

Kennzeichen rind Prifungsmittel.
Verwechselt mit dem viertheiligen Lein (Linum Radiola L.)

Mit dem halbzehnfädigen Hornkraut (Cerastium semidecandrum $L$.)

Verwechselt mit den Die Panzze isi kleiner, bat lanzectförmige Blättern des Ruthenweiderichs (Lythrum virgatum L.)

Mit den Blättern des Diese sind anf beyden Seiten harig, weich $\begin{array}{ll}\text { Sumpfstachys (Sta- } & \text { anzufüblen, und an Rande mit rundlichen } \\ \text { Zähnen verseben. Die Blumen ssind lip- }\end{array}$ cluys palustris L.)
Viel kleiner und zarter; die Btunen liaben nur Yier Blumenblätter, eiusn vierblättrigen Kelch, vier Staubfaden unil vier stanhwefach sind.

Hat eyrunde Blätter und ist überall baarıg. Bläter, die abel schmöler sind, nnd traubenförmige Blumen. penförmig.

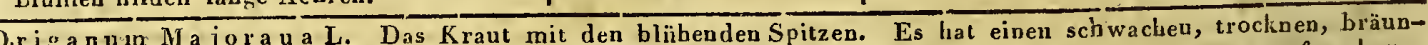
lichen, eiue bis zwey Spannen holien Stengel, an welchem die kleinen, eyrund-länglichen, stumpfen, kurzgestielten, ganzrandigen, elwas wollicliteu, wei $s$ grünlicheu Blätter gegen einander üher sitzen. Dickleinen blafsgelben, rachenförmínen Blïmchen bilden zu Eude des Stengels und der Nebenstiele rundliche dichte Bischen runden und wollichten Deckblättern sitzen. De Geruch der ganzen Pflauze ist augeuehm, stark gewïrzhaft; der Geschınack scharf bitterlich gewürzhaft.

Geruch der ganzen Pranze, weit e Blälter der kleinen Käsemalve Mit dien Blälser, und die obersten gemeiniglich in

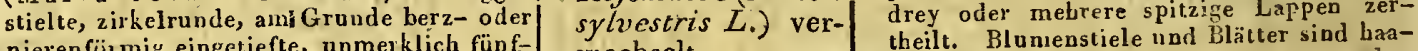
nierenfïmig eingetiefte, unmerklich fünfFarbe.

Das Kraut mit den Blumen des Katzengamanders (Tencrium marum L.). Sehr kleine, eyrund-zugespitzer merfiache lebbaft griue, anf der Unterfẩclıe, so wie die Biattstiele nnıl Aestchen, mit einem weifsen Filz ïberzogene Blätchen. Die kleinen traubenartigen, purpurfarbnen Biumen bängen an $\mathrm{dem}$ diłnnẹ, bolzigen, harten und ästigen Stengel nach einer Seitc zu. Die ganze Pflanze hat eiuen brcnnend und scharf gewirzten, hitterlicheu Geschmack uis einei durchdringendeu vermischten Mastix- und campherartigen Gerucli. . Mals in einem dicht verschlossenen Glase aufbewahrt werden.

Diean rent wirl 3 e an dem vectiothethe hat sonders sehr wollichten Stengel des $\mathrm{Ma}$ a- Schwarzballote riennesselandorns (Marrubium (Ballota nigra L.) ein scliwăraliche, rundlicb gekerbt, auf beyden Seiten weifsbebart, weich, ziemlich dick, oberhalh griin, runzlicht und kraus, untertialb weirs wollicht, obeu am Stengel kurz-, am untern Theile aber langoestielt sind. Frisch zerrieben besitzen sie einen balsamischen, augenebrnen, einiger mafsen moschusartigen Geruch, der sich aber beim Trockner verliert; ihr Gesclumack ist bitter-nond etwas scbarf salzicht; die weifsen rachenfürnigen Blumen umgeben den Stengel in dicheinen eigenen widrigen Geruch; die an dem viereckigen, kreuzförmig geästeten Stengel gegenüberstebendeu Blätter sind viel grơsser, melır berzförmig, auf der Unterilächo nicht weifswollicht und am Rande spitzig sezähnt.

Tit den Blättern der Dresesind zwar anch auf der Unterfiäche weifs-

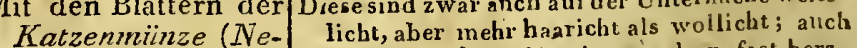
peta Cataria $L$.$) sind sie nicht eyförmig, sondern fast her?-$ förmig und am Rande spitzig gczälınt. Die gauze Pflanze hat einen starken inüuzartigen Geruch.

Merba Matricariae.

Mutterkraut.

Herba Melissae. Melissenkraut.

Herba-Melissac turcicae:

Türkischo Melissenblätter.

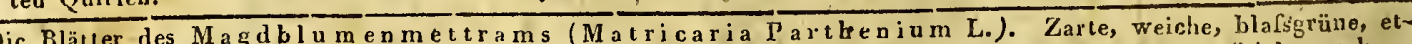
Wa was raube, haarigte, dem Wermuth ähnliche, ungleich geferlerte oder abwechsitcon Blätchen zusaminengede, und ans mehreren einzeln gegenüberstehenden, eyrundeu, rief engeschnittenen Blätchen zusaminengesetzte Blätter, vou einem balsamischen Geruche und bittern Geschmacks. Man sammlet gewuhn jungen Zweige mit den Blätern und den Cham
oller unächteu Schirm bildenden Blumen ein.

Die Blatter der Citronenmelisse (Melisosa officinalis L.). Eyrunde, am Grunde meistens berzlörmige, et etwas haarige, gefurchte, am Rande sägenartig gezăhnte, oben lebhaft grüne, unteu blàssere,

ie gesen einander über sitzenden Blätler des/Verwechselt mit den/Sind herzförmig, auf der untern Fliche wcif́-

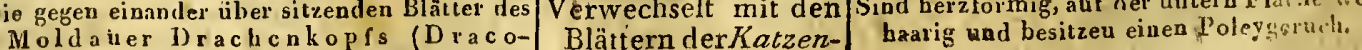
ceptalum Moldavica L.). Längli- münze (NepetaCache, schmale, lanzeltförnig zugespitzte, an Rande weitlïuftig mit kurzeu S̈̈gezähneu, dic sich bey den obern Blätlern oft in

tariaL.) 


\begin{tabular}{|c|c|c|c|}
\hline $\begin{array}{c}\text { Namen } \\
\text { alerArzneymitcel. }\end{array}$ & $\begin{array}{c}\text { Sinnliche Eigenfchafien derfelben; } \\
\text { Merkmale ihrer Ächtheit und } \\
\text { Güte. }\end{array}$ & $\begin{array}{c}\text { Fehlerhafie Be- } \\
\text { fohraffenlicit, Ver- } \\
\text { wechselung oder } \\
\text { Verfälfchung. }\end{array}$ & $\begin{array}{c}\text { Deren } \\
\text { Kennzeichen und Priifungsmittel. }\end{array}$ \\
\hline $\begin{array}{l}\text { Herba Melissae tur- } \\
\text { cicae. }\end{array}$ & 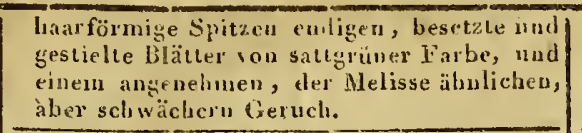 & & \\
\hline $\begin{array}{l}\text { Herba Menthae } \\
\text { crispae. } \\
\text { Krausemünze. }\end{array}$ & 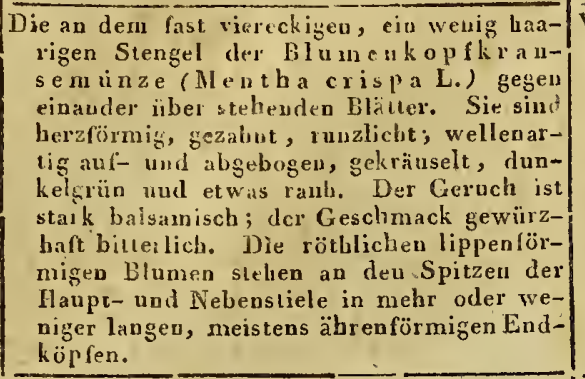 & \begin{tabular}{|} 
Verwechselt mit den \\
Blättern der spitz- \\
blättrigen Mü̈nze \\
(Mentha sativa L.) \\
\end{tabular} & 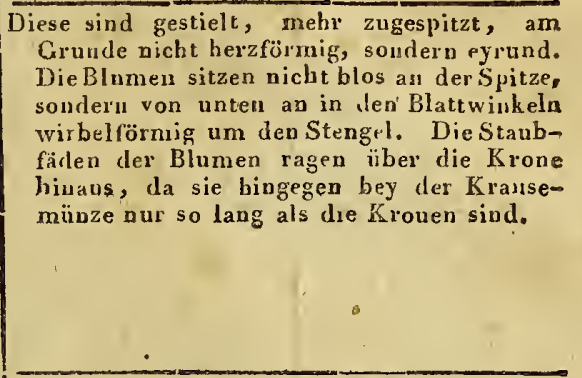 \\
\hline \multirow[t]{4}{*}{$\begin{array}{l}\text { Herba Menthae } \\
\text { piperitae. } \\
\text { Pfeffermünze. }\end{array}$} & \multirow{4}{*}{ 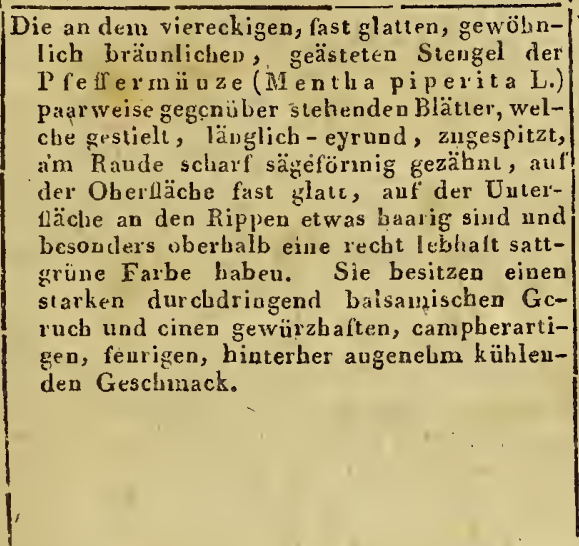 } & \begin{tabular}{|} 
Verwechselt mit den \\
Blättern der griinen \\
Miinze (Mentha \\
viridis L.) \\
\end{tabular} & $\begin{array}{l}\text { Ungestielte, sclmaalere, lanzenförmig zinge- } \\
\text { spitzte, of drey bis vier Zoll lange Błätter } \\
\text { von schwächerm Geruch und Geschmack. }\end{array}$ \\
\hline & & $\begin{array}{l}\text { Mit den Blättern der } \\
\text { wildent Miinze } \\
\text { (Mentha sylvestris } \\
\text { L.) }\end{array}$ & $\begin{array}{l}\text { Stiellose, dickere, weifslich-hellgrüne, oben } \\
\text { ruuzlichte, unten filzige Blät.er. }\end{array}$ \\
\hline & & $\begin{array}{l}\text { Mit den Blärtern der } \\
\text { W assermiinze } \\
\text { (Mentha aquatica) } \\
\text { L.) }\end{array}$ & $\begin{array}{l}\text { Sind vollkommen eyruud, weich behaart nod } \\
\text { milder von Geruch uod Geschmack. }\end{array}$ \\
\hline & & $\begin{array}{l}\text { Mit den Blättern der } \\
\text { Batsammiz̈nze } \\
\text { (Mentlla gentilis } \\
\text { L.) }\end{array}$ & $\begin{array}{l}\text { Sind eyförmig, mit feinen Haaren besetzt, } \\
\text { oben und unten zugespitzt und sitzen obne } \\
\text { Sticle gegen einander über. }\end{array}$ \\
\hline
\end{tabular}

Herlia Millefolii. Schafgarbe.

hierba Nasturtii aquatici. Brunnenkresse.

Herba Nicotiana s. Tabaci.

Tabaksblätter.

Herba Oreoselini. Grundheil.

Bergpetersilie.

ie theils als Wurzelbläter hervorkomnenden, theils an dem eckigen, weichharioen, bisweilen rötblichen Stie abwechselnd aufsitzenden Blätler der Schafgarbe (Achillea Millefolium L.). Sie siod doppelt gefiedert, lang uud schmal, mit gleichbreiten gezahnten Einschnitten versehen, uuten etwas rauh, von grasgrïner Farbe, balsamiscben Gernche und etwas aromatisch bitterlicls scharfem Geschmack.

Das frische Kraut der Bru te (S is m m r u (C) glatten, ruden, on rotblichen Stengel, de mit einern ästigen, eckigen, röhrichien, damine pratensis sich zuweilen anch ohen in Aeste aushreigestreiften, hin und her gestrecklen mad aufsteigeudeu Stengel. Die ziemlich dikken, dunkelgruneu, safigeu und glatten Blätter silzen weclsselsweise und besteben nach Art eines gefiederten Blattes aus rundlichen, oft etwas länglichen, zuweilen mehr berzförmig eingetiefteu, zu zwey bıs vier Praren gegeneinander über sitzendes Blättchen, von denen das am Ende sitzende weit gröfser ist, als die übrigen. Die ganze Pflanze hat im friscleen Zustande eiganze Pflanze hat im frisclien Zustande eibesoudtrs zerdrückt, einen Lölfelkraut ähnlichen Geruch, die beyde aber im Trocknen verloren geben.

tel, zoweilen obne Zweige ist, Die Blätter siud glatt und gefiedert; die untern bestebeu aus lun bis aebt Paaren kleiner rundlicher oder aucb länglicher' Blättchen mit eineın eckigen Endblältchen, die am Stengel aher aus sebr schmalen lanzettförmigen Blättchen.

Mit der bittern Man erkennt sie an dem weniger echigen, nicht Ganchblume (Car-) hohlen, höber werdenden und geradern Stiedamine amara $L$.$) le, von rundlich oder herzförmig gelapp-$ ten, am Randc etwas stumpfeckigen Wurzelblätleru nud mebr eyruuden, stump gekerhten Stengelblättern, und dem merklich bittern Geschmack.

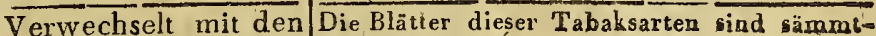
Blatter des Virgiuientabaks (Nicotiana Tabacum L.) Groise, langge oder etwas wellenförmige, starkgerippte, klebrichie, anf beyden Seiten baarichte, all dem Steughl oder den Zweigen ahwechselnd aufsitzenie und folglich ungestielte Blätter ron lebhaft griuer Farbe, scharfem eckelhaftem bittein Gescbusack und besonderm, starken, widrigen, betäubenden Geruch, Beym Trocknen nebmen śie eine gelbe Farbe an

Die Blätter des Grundheilvogelnes (Atbamantha Oreoselinum I.) Glatte, sich auseinander sperreude, villfach gefiederte, aus kleinen, knzen, $l_{a 1}-$ zettförmigen, cyrund-länglichen, ‘reyoder fünffach eingeschnitlenen, etwas stejfen Blättchen bestebende Blätter, an langen, aus offnen bäution Scheiden eutsprisgenden Hauptstielen, die bey jeder Abtheilung gleichsam geknickt uud rïckwärts gelnog gleichsam getickider stump we Winkel bogen, alle gegeneinander stumple Winkel machen, und dem ganzen Blatte ein mebr
rundliches, als flaches Ansehen geben. Dia rundliches, als flaches Ansehen geben. Die
Blätter haben eine sattgrüne, glänzende Blätternvon andern lich gestielt.

Tabaksarten, dem Sirancle - BanernJungferm- und Soldatentabak (Nicotiana fruticosa, rustica, punicula$t a$ und glutinosa L.)

Verwechselt mit den Die Blätler sind nur zweymal gefiedert nnd Blättern des Silan habev von Grund aus getheilte schmählere (Peucedanum Si- Blättche» ; sie sind nicht so znrückgebolaus L.) gen und taben auch nicbt das auseinander gesperrte Anseben, weil die kleineru Blättchen uicht von ein ander hslehen Blumen sind gelblich and die l'Alane wächst auf feuchten Wiesen. 


\begin{tabular}{|c|c|c|}
\hline Namen & $\begin{array}{c}\text { Sinnliche Eigenfchaften derfellen; } \\
\text { Merkmale ilırer Ächtheit und } \\
\text { Güte. }\end{array}\left|\begin{array}{c}\text { Fehlerhafte Be- } \\
\text { schaffenheit, Ver- } \\
\text { wechfelung oder } \\
\text { Verfälfchung. }\end{array}\right|$ & $\begin{array}{l}\text { Deren } \\
\text { Kennzeichen und Prüfungsmittel. }\end{array}$ \\
\hline Merba Úreo & 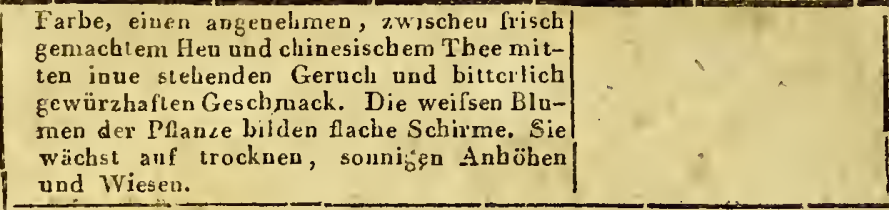 & \\
\hline $\begin{array}{l}\text { Orerba Origani } \\
\text { spanici. } \\
\text { Spanisch Hopfen. }\end{array}$ & \multicolumn{2}{|c|}{ 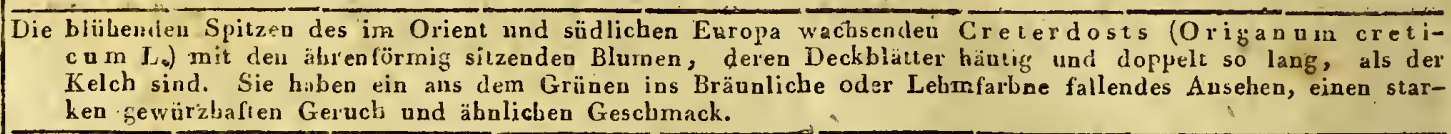 } \\
\hline $\begin{array}{l}\text { HerbaOrighnivinl- } \\
\text { garis. } \\
\text { Dostenkraut. }\end{array}$ & \multicolumn{2}{|c|}{ 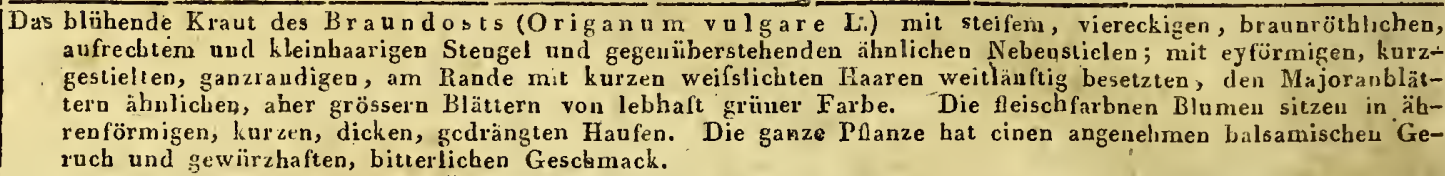 } \\
\hline
\end{tabular}

Herba Petroselini. Petersilie.

Herba Plantaginis majoris.

Breite Wegebreitblätter.

Herba Pulegii. Poley.

Herba Pulsatillae nigricantis. Schwärzliche Küchenschelle.
Vou der bekanuten Petersilie (Apium|
Petroselinnm L.) Glatte, glänzendgrüne und doppelt gefiederte Blätter, die Wurzelblätter des ersten Jahrs bestehen aus keilföı migen, dreyspaltigen, ziemlich stum-
pfen, die votn zweyten Jahre aber aus gleich breiten, in gleich!reite Qneerstücke zerschuitteuen Blätchen. Die grïnlichen Blumen bilden Rache, etwas convexe Dolden. Die Blätter haben, so wie die ganze Plianze, einen starken, angenehmen, gewür $\angle$ haften Ger'tacb und Geschmack.

Die Blätter des grofsen We gebreit's (P l a at a o o major L.). Länglich - eyıunde, glatte, etwas dicke, langogcstielte, fünfoder siebenmal gerippte, mehrentheils ganzrandige, zuweilen stumpf gezähnte Blätter, auf der Oberiläche von dunkelgrüner, auf der unteru Seite vop blafsgrüner Farbe. Sie haben keineri Geruch, aber einen etwas zusammenziehenden, bitterlichen sal artigen Geschmack.

Das blübeude Kraut (Mentha Pulegium L.) Init aus der Wurzel häufig hervorkommenden, runden, fast glatien, meistens auf der Erde liegeuden Stengeln mit den gegenüberstehenden, eyrund - lằnzettförmi gen, stumplen, seicbt - gezabnteu, rauben, kurrgestielten Blättern von sattgrüner Farbe und quirlförunig sitzenden, röthlichen oder violetien, anch weifsen Blumen, dereu Stanbfäden länger als die Krone sind. Die Pflanze hat einen eigenen, durchdriugend starken, etwas widrigen Geruch und einen heifsen gewürzhaften, hiutennach kühlenden Geschmack.

Man sammlet gewöhnlich die ganzc Pflanze (Anemonc pratensis L.) ein. Ihre Blätler sind zweyfach gefiedert, denen dex gellien Mobre nicht unäbnlich, und aus vieltbeiligen, gespaltenen, schimalen Blättchen zusammen gesetzt. An den aus der Wurzcl kommenden langen Hauptblattstielen stehen die zweyten Blattstiele parweise gegen cinan ler $̈$ über, und sind mit ganz schralen, kurzen, noch einmal gespaltenen, raulien, abwecbselud gegen über stehenden Blăttclien besetzt. Die Hauptstiele cntspringen aus weilsen, scheidenartigen, mit glänzenden Llarien besetzteu Ansätzen。 Zwischen diesen Wurzclblättern stehen die Blumen auf eiufachen, rundeu, mit weichen weifsen Haaren bekleideten, zottich ten Stengeln, von denen jeder eive etwas niederbängeude tief dunkelblaugefärbte Blume trägt. Die Blumen haben keinen Kelch; sonder n nur sechs, aufserbalb rauke, an der Spitze zuräck gebogene Blomenblätter. Nicht weit vou der Blume sitzen rund um den Stengel eine Menge schmaler, etwa einen Zoll langer, an der Spitze gespaltene, zotZoll langer, an der Spitze gespaltene, not-
ticlite Blitter und bilden eine etwas ent trchte Bliitter und bilden eine etwas ent ${ }^{2}$ fernte llülle der Blume. Alle Theilc dicses fast geruchlosen Krauts bcsitzen frisch einen scharfen und beifsenden Geschmack, und man empindet schon beym Zer'stampfen desselben, noch mehr aber bey der Eindickung des Safter zum Lxtraet ein

\section{rwechselt mit der Wird, so lange sie jung ist, leicht mit de Gleifse od. Hunds- Pelersilie, wornuter sie häufg wäclst, ver- petersilie (Aethul- "wechselt. Da sie anch mit dem Schiel- ling kerwechselt wird, so ist ibre Bc-
schreibung oben bereits gegeben. S. Her- ba Conii maculati.}

Mit dem Schierling Vergleiche die eben angegebenen Kennzei(Conizm macula- chen des Scbierlings. trum L.).

Verwechselt mit den Siud auf bejden Seiten weich behaart, wolBlättern des Mittel- licht auzufihlen, liegen dicbt an der Er wegebreits ('Llantago media L.) de und baben kürzere Sticle.

Verwechselt mit der Sie unterscheidet sich durch die gröfsern, Achermiinze (Men breitern, gröistentbeils nur an der obern breitern, Blätter,

erwechselt mit der gemeinen Küchensclielle (Anemone Pulsatilia $L$.) iese hat zwar mit der schwärzlichen $\mathrm{K}$ iichenschelle sehr viele Aehnlichkeit, unterscheidet sich aber dadurcb, dafs sie iiberall haariger ist, fast aufgericbtet stehende, hellfarboere und grọ̈sere Blumen hat, deren Blätter an derSpitze nicht umgebogen, sondern gerade sind. Die ein zelnen schmalen Blättchen der Wurzelblätter siud länuer wie bey jener, Es besitzt indessen auch ger wie be jerich die gerkomint, eine fast gleiche Schärfe, wie die schwärzlich $\mathbf{S u ̈ c b e a s c b e l l s . ~}$ 
Herba Pulsatilla nigricantis. -- Herba Scordii.

\begin{tabular}{|c|c|c|c|}
\hline $\begin{array}{c}\text { Namen } \\
\text { der Arzn eymittel. }\end{array}$ & $\left|\begin{array}{c}\text { Sinnliche Eigcnfchafien dersellen; } \\
\text { Merhmale ihrer Aechineit und } \\
\text { Giite. }\end{array}\right|$ & \begin{tabular}{|c|} 
Fehlerhafte Be- \\
rchaffenheit, Vet'- \\
wechifelun oo oder \\
Verfälfchuıng.
\end{tabular} & $\begin{array}{c}\text { Doren } \\
\text { Kennzeichen üinci Prïfungsmittel. }\end{array}$ \\
\hline $\begin{array}{l}\text { Herba Pulsatillae } \\
\text { nigricantis. }\end{array}$ & 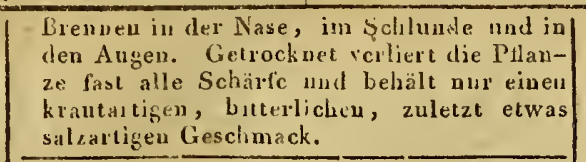 & & \\
\hline \multirow[t]{2}{*}{$\begin{array}{l}\text { Herba Pyrolae. } \\
\text { Wintergrün. }\end{array}$} & \multirow{2}{*}{ 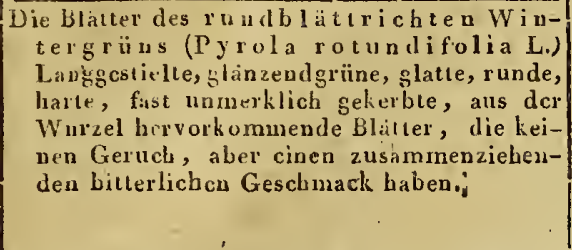 } & \begin{tabular}{|} 
Verwechselt mit den \\
Blättern des k/ei- \\
nern VVintergrïrss \\
(Pyrola minor $L)$.
\end{tabular} & 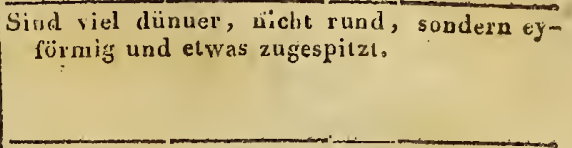 \\
\hline & & $\mid \begin{array}{c}\text { Mit den Blältern des } \\
\text { Sinngrins } \\
\text { minor L.) }\end{array}$ & $\begin{array}{l}\text { Eyförmige, spitcige, kuragesticlle, an dem } \\
\text { forthriechenden, überall Wurzel schlagen- } \\
\text { den Stcos̆ct gegen einander über steliende } \\
\text { Blärter. }\end{array}$ \\
\hline
\end{tabular}

Herba Rhododendri.

Schneerose.

Alprose.

Blätcr der Sibiriscben Scbueerose (Rbododendron chrysanthum L.), eines kleinen, auf den höclısten uud kältesten Gipfeln der Schneegebirge in Taurien und Sibirien wachsenden Strauclis. Eyruncie, adrichte, kurzgestielte, steife, am Rande eingebogene Blätter, die anf der Oberfiache etwas raub und hellgriin, auf der Unterläche glatt und blalsgrün sind, den Lorbeerblättern ähneln, ziemlich einzeln und abwechselud steben, einen enternt rbabarberähnlichen Geruch, und herben, merklich bilteru Geschmack baben. Man erlält gewöhnlich aus Rufsland dic Blätter sammi den Blumenhiospen an spanneulaugeu, federkieldickcu, mit einem bräunlichen Oberhäutchen bekleideten Zweigspitzcn, welche letztere mehr zusammeıziehend und scharf scbmecken, als die Blätter selbst. Die rosibraunwollichten Blumenknospen steheu zu Ende dor Zweige zwisches den Blättern auf eigenen fünf bis zehn, fasł doldenartig, beysammeu stelienden Blumenstielen.

In nenern Zeiten hat man, theils wcgen des holien Preises, theils wegen der zuweilen bemerkten Kraftlosigkeit der wabrscbeinlich zur unrechten Zeit eingesammleten other verfalscbten Sibirischen Scbireerose, die Blätter der folgenden zwey. Arten angeweudet, und will davon eben so gute Wirkungen, wie von jenen bemerkt haben:

j) Gröste Alprose (Rhododendron maximnmL.) Eyrunde, glänzende, stumpfe, gerippte, am

Rañde scharfe, zurücksebogene Blätter. Dieser Strauch wächst nicht nur iu Sibirieu, sondern auch in Nordamerica auf felsigen Gebürgen, und kommt auch zur Zierde iu maschen Gärlen rou Deutschland Nordamerica auf felsigen Gebürget, und kommt auch zur Zierde iu maschen

2) RosifarbacAlprose (Rbododendron ferringeum Li.) Wächst auf den Schweizer-Alpen, in Oesterreich und auf den Pyrenäischen Gebürgci, kommt ebenfalls in 'unsern Linstgebüsclien vor, trägt rosenfarbige Blumen, und bat kleinere ovale, anf der untern Seite anssalzartige oder rostfarbig punctirte Blättei.

Herba Rorismarinis. Anthos. Rosmarin.

Herba Rutae. Raute.

Weinraute.

Herlua Sabinae. Sadebaumblätter.

Herba Salviae. Salbeyblätter.

Herba Sapona-

seifenkraut

\section{Herba Scordii.}

Scordienkraut.

Lachenknoblauch.
Die Blitter des Rosmarinstrauchs (Rosmarinus officinalis L.) sind ungestielt, schimal, gleichbreit, lanzeltförmig, am Rande angesclłlagen, auf der obern Seite dunkẹgrün und in der Mitte gefurcht, auf der unteru Seite dagegen in der Mitte gerippt und weifslich-filis. Sie baben einen starken, halsamischen, erguickendeu Gcruch und emen feurigen, bitterfichen, campherartigen Geschmack.

Die Blätter der Gartenraúte (Ruta graveolens L.) Doppelt zusammengesetzte, grau-oder mattblauguine, gesticlte Blatter, mit melr oder weniger getheilten oder gespaltenen leeilfürmigen, an der Spitze
breitern 1uvillichen Blättchen, und einem tief in drey Lappen gespalteuen Endblätechen, wovon der mit-

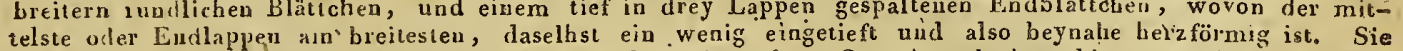

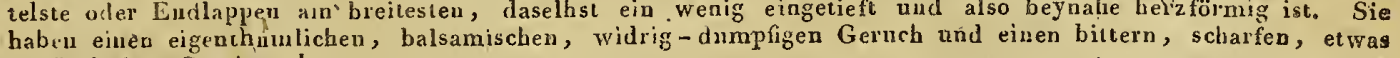
gewürzhaften Geschinack.

Die Syitzen der Aeste des Sade a n ms!Mit den Blättern vom Bey len jungen Fflanzen und an deu unte:n (J uniperus $S$ abina I. I.) mit den kreuz- Bermudischen und Theilender $Z$ weige des erstern, steben (J uniperus Sabin a L.) mit denkreuz- Bermudischen und Thellender Zweige des erstern, steben weise gegen über stehenden, aufrechten, Virginischen a die etwas platlgedrücklen Blitlter zu dreynadelförmigen, dicken, kurzen, spitzigen, W Wacholder (Juni- en, an den ällern Pilanzen und obern dunkelgrïneu, a den Zwcigen fortaulen- perus Bernutiana Thcilen der Zweige 211 weyen, wie bey den, augedriickten Blättern, weicbe im- per Barebaum. Die Blätter des zweymet parweise in einer Sebeide eingeschlos\begin{tabular}{l|l} 
sen und am Grunde zusammengewachsen & zuweilen aus Un- \\
kunde vermischt. & sammon. Beyde. Arten sind au ibren \\
Zweigen mit eiuer rothbrantichen
\end{tabular}

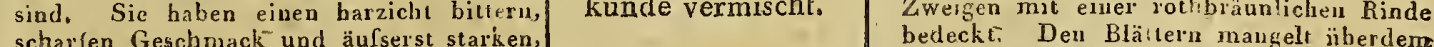
widrigen, etwas betäıbenden Geruelı. der den Sadebanmblättern eigeutbümliche Geruch und Geschmack

Die an den vierecki ril ranhen. geästetem Stengel der Edelsalbey (Salvia of ficinalis L.) gegenuber stehenden eyrund-lanzellförmigen, unzertheilien, runzlichen, fein getierbten, dicken, warrichten und gestielten blatter von graublanlicligrüner Farbé, einem starken, einigermafsen campherartigen Geruch und bitterlich gewürzhafien, schwach zusammcnzieheuden Geschinack.

Die an den vielen aus der Wurzel hervor- Verwecaselt mit der/Der Stenge! ist ranh und haaricht; die Blätkommenden, knieförmig abgetbeilten, getrennten. Lych- ter sind lasg-eyförmig zugespiizt, mattástigen, liohlen, glatlen, elwas streifi nis oder dem soge- grin-weifstichl, raub, weichbefiaart, nicht gen Stengelu-des Spricbelseifen- nit drey Rippen verschen und nicht so grofs, krauls (Saponaria officinalis Lo, Tannten wei/sen wie die des Seilenkrabls. Die Blumen sigegen einanter ülerstehenten Blattc. Seifenkraut (Lych- tzen einzeln und nicht in Büseheln zusamSie sind glatt, eyrugd-lanzettiörmig, un- nis dioica .) . ( men. Männliche und weibliche Blumean gezalbnt, yon lebhift griner Fube!und git drey aus der Easis enispringeuden Mittelippen bezeichnet. Sio liaber keinen Geruch, besitzen aber emell elwas seifentGeruch, besizen aber ertell thas stienhaften, schletmichuen, bisterier Die Blugen und kratzendell Geschmack. Die Blumen kommen auf kurzen Stielen alls deischeln, sowobl an Hauptstengcl als an den Nebenstielen lierror.

finden sich auf verschiedeneu Pllanzcn, wiewohl aach einige Pfianzen $Z_{\text {witterblumen }}$ tragen. Gewöhnlich sind die Blumen weifs; es gieht abcr auch eine $\Delta$ bart mit rothen Blumen.

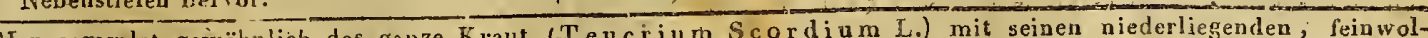
ligen, etwas viereckigen, weitschweifigen Stengeln, und den länglichen, fast stiellosen, sägeartig gezäbn-

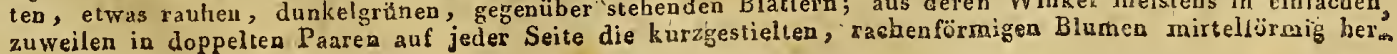




\begin{tabular}{|c|c|c|c|}
\hline $\begin{array}{l}\text { Namen } \\
\text { er Arzneymitcel. }\end{array}$ & $\begin{array}{c}\text { Sinnliche Eigenfcliaften derfelben } \\
\text { Merkmale ilırer Aeclulieic und } \\
\text { Güte. }\end{array}$ & \begin{tabular}{|c|} 
Felllerhafie Be- \\
Schaffenlieic, Ver- \\
weclifelung oder \\
Verfälschung.
\end{tabular} & $\begin{array}{c}\text { Deren } \\
\text { Kennzeiclzen und Prüfungsmittel. }\end{array}$ \\
\hline
\end{tabular}

- rerbe Scordito

Herba Scordii. $\quad$ rorkommen. Das Kraut bat frisch einen knoblauchartigen, gewürzbiften Geruch urich ctwas scharfen, sebx Herba Serpylli. Quendel.

licldpoley.

Die blühende Pfianze (Thymus Serpyllum X.) mit den kleinen, llachen, eyrunden, fast stiellosen, am Grunde mit steifen Härchen besetzten, bald lebbafter- hald mattgrünen Blältern, einem kriechenden, stumpfechigen, etwas rauben, oft rötblichen Stengel vnd an deu Spitzen quirlörmig in Köptchen vereinten purpurfarbigen Elnmeu. Die ganze Pllanze besitzt im frischen Zustande eincu sehr augeuebmen durchdringenden Gèruch und gewürzhaftell Geschmack. Es giebt davon nach Beschaltenheit des Bodens und dem höbern oder niedern Standort manche Abäuderungen, vou deuen man das Serpyllum Citrinum vorziebt.

Hérba Solani ni- Die an dem unhewebrteu krautartigen, ruadlicbeu, znm Theil eckigen und gestreiften, in viele Aeste sich ansgri. schattenkraut. breiterden Stengel des gemeinen scbwarzen Nachtschatten (Sulanum nigum L) sitienden eyförmigen, entweder chen, schwarzgrïnen Blätler, welche einen eckelhaften; etwas betäubenden Geruch und weichlich-faden Gescbmack haben. Die weifsgränlicben, zuweilen violetten Blumen hincerlassen schwarze, saftige nud rielsamige Beeren.

Anmerk. Es giebt von dieser Pflanze verscbiedene, zum Theil beständige Abarten, die sich durch die Form der Blätter, die Farbe der Blumen, Cestalt und Gröfse der Beeren, unterscbeiden.

Herba Spigeliae.

Spigelie.

Wermkraut.

Es giebt hievou im Handel zwey verschiedene Sorteu und von beyden erbält man das Kraut nebst der Wurzel. 1) Die Brasilianische Spigelie (Spigelia Anthelmia L.) Eine einjibrige, in südlichen America, vorzüglich in Brasilien einheimische Planze. Sie bat eine kleine, langzasericlite Wurcel, einen krautartigen Stengel und efförmig zugespitzte, etwas raube, ganzrandige, 2 wey bis siebeu Zoll 1 inge und eiuen bis zwey Zoll breite, auf der Unterfläcbe blaugräne, oben zu vieren in cioen Winkcl beysammcn stchende, fast geruehlose und fade bitterlich schmeckende Blätter, 2) Die Marilaudische Spigelie (Spigelia marila udica L.) Bey dieser, welche in Virginien, Mariland und Carolina wäclst, ist die Wurzel horizontal, einfach, ungleicb und vielfaserig; rler Stengel einfach gerade, gerundet, vierkantig; die Blatter sind länglichlund, zugespitzt, einige Zoll lang, glatt; ungesticlt; pantweise gegeuäber ștchend, auf der blafsgrunen Unterfäche mit erbahenen, sämmtich aus der Hauptrippe der Lánge narb acsgehendes Rippeb bezogen und habeu, wie die Wurzel, einell bitterlichen, widrigen, gicicbsam modrigen Gerueh und Gebezogen und habeu, wie die Wurzel, einen bitterlichen, widrigen, giticbsim modrigell Gerueh and Ge-
scbmack. In Absicht der wurmtreihenden Eigensclaften beyder Pfiancen giebt man der leiztern den Vorzug. -- Sie soll zuweilen mit den Blättern des Seifenkrauts (S. Herba Saponaria), die itir eísigermafsen äbnlich seben, vermischt vorkommen. Die vorber bemerkte Entstebung der Rippen auf der Unterseite de Blätter geben aber ein tichtiges Unterscheidungszeichen ab, weil auf der Uuterseite der Blätier des Seifen-
krauts nur allemal drey Rippen statt finden, die aus der Mittẹlippe nicht entspringen, sondern abgesondert aus der Basis des Blattes bervorkommen.

Herba Tanaceti.

Die Blätter des gewöhnlichen Ra infarrn (Tanacetum vulgare L.) Doppelt gefiederte, flache, län liche, aus länglichen, geschlitzten, sägeartig gezähnten Blättchen bestehendé Blätter, zwischen welchen an dcn Blattsticlen noch hin und wieder kleine, spitzige, zabuartige, weifslichte Afterblätchen befindlich, usd die, so wie die Blattstielc, meistens mit mebr odler weaiger feinen, weifsen, nicht kurzen, weichen net und von lebhaft grüuer, zuweilen dunliclgrüner Farbe sind. Sie habeu einen starken, balsamiscben, campher artigen Geruch und bitcern gewüraliaften Gescbmack:

An merk. Eine Abart desselbeu mit krausen Blättern (Tanacetum crispum, engliscluer

An erk. Eine Abart desselbeu mit krausen Blätern (Tan acetnm cris in che Rainfarrn.

Herba Taraxaci.

Löwenzahn.

Pfaffenröhrchen-

kraut.

Herba Taxi.

Taxusblätter.

Herba Theae.

Thee.

Theoblätier.
Herba Thymi.

Thymian.
Die aus der Wurzel hervorkommendeu, langen, meistens auf der Erde niederliegenclen Blätter des bekannten Löwenzabns (Leontodon Taraxacam L.) welche sebrotsagefüruig, mit bogenförnig sich berabwärts beugenden Einschnitten versehen, glatt und schön grïn sind.' Sie enthalteu frisch eincu milden, salwarts beugenden Einschnitten
zicbt-bitterlichen Milschsaft.

Die dicht an eizander stchenden Blätter des Eibenbaums (Taxus baocat a L.) Flache, strichförmige ganzrandige, arz Rande dcm Ansehein nach'zurückgebogene, steife, bärtliche, einen bis audertlalb Zoll Sanzrandige, arı Rande dcm Anschein nach'zurückgebogene, steife, härtliche, einen bis audertlalh Zol lange, spitzige, den Tanneublătterü äbnliche, nur elwas breitere Nadelblätter, , welebe anf der an eingen

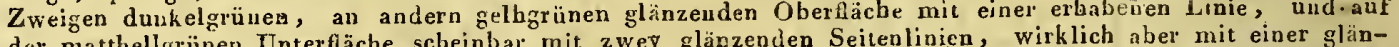
der matthellgriinen Unterfäche scheinbar mit $\mathbf{z}$ wey glänzenden Seitenlinicn, wirklich aber mit einer glänzenden Mittellinie bezeichnet, an der Basis zusammen gezugen nnd mit einem sehr kurzen an den Zweigen berablaufenden Stiele versehen sind. Ibr Geschynaek ist widerlich klehricht-schleinicht, bitterlich,
hintennach etwas scharf; ibr Gernch, wenn sie frisch und nit etwas Wasser eingessofsen sind, dumpfig und betänhend, doch aber nur scbwach.

Unter dem sehr bekannten Namen The e bekommen wir die auf eisernen, üher Oéfen erhiczten Platteu gedörrten, und unter dem Dörren, damit sie ein krauses Ansehen bekommen, zwischen dea Hâñlcn gerollten Blätter des in China und Japan einheimiscben. Thecstrauclss (Thea Bobea L.) Es giebt davon ism Handel sehr varseliedeue Arten, und diese verschiedenen Sorten rühren wabrseheinilich theils von der Versebiedenbeit der Cultur und des Bodens, theils vou der verschiedenen Zeit der Sammlung und der daber rührenden Gröfse der Blätter ab, je gröfser diese sind, un desto, schleehter ist cler Thee. Man hat indessen drey Hauptsorten des Thees, nänlich 1) Kayserthee, Theeblitthe, Blumeuthee (Thea caesare Diese Sorte ist die feinste und beste, inderm $z u$ derselhen die zartesten uad biaum entfalteten, schon zu Apsgang des Febrnars und Anfangs März abgeptückten Btätter genommen werden. Sie komint in schon zu Apsgang des Febriars nnd Anfangs Marz abgeptüchten angenelsmen Geruch und einem balsamischen, zusammengerollcen, mattgrinen Blättern vor, von einem sehr angenelsmen gelindo adstringirenden Geschnack, ist aber nur sebr selten acht renzielsenden Geschmack und rosenartigen Diese Sorte ist dunkelbraun oder scbwärzlich, hat einen zusammenziehenden Geschmack und rosenartigen Gerich. Untersorteu davon sind: der Sootchuen--(Sutschong) Thee, der Pecko, Congo und ge-

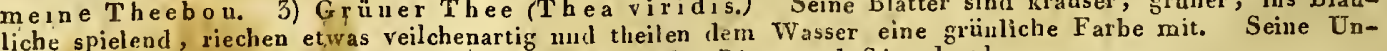
tersorten sind: der Hy-tiann-(Heysan) Thec, der Bing uad Singlothee.

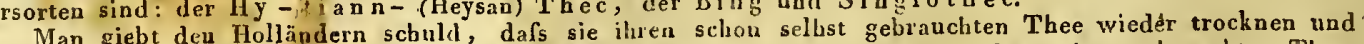

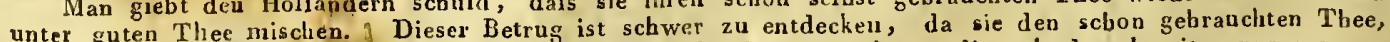
ob er gleich eine blässere Farbe bat, unter eine solche Sorte mischen, die mit dem bereits ausgezogeneu Thee einerley Farbe hat.

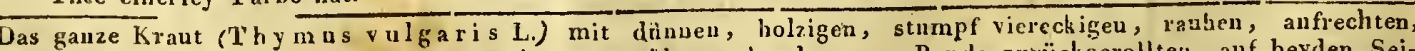
ästigem Stengel, mit lïnglich-cyrnnden, gegenïlıer stehenden, am Rande zurückgerollten, auf beyden Seiten getüpfelten oder mit bohlen Puncten verschenen, ungestielten Blättcrn, und weifses oder blafspurpurröthlichen Blumeu in kurzen quirlförmigen Aehren. Es bat einen sehr gewrüzhaften balsarnischen Goruch und Geschmack. 


\begin{tabular}{|c|c|c|c|}
\hline $\begin{array}{l}\text { Nazien } \\
\text { der Arzneymitrel. }\end{array}$ & $\begin{array}{l}\text { Sinnliche Eigenfchaften derfelben, } \\
\text { Merkmale ihrer Aechthueit und } \\
\text { Güte. }\end{array}$ & $\begin{array}{c}\text { Fehlerhafie Be- } \\
\text { fchaffenheit, Ver- } \\
\text { wechfelung oder } \\
\text { Verfälfchung. }\end{array}$ & $\begin{array}{c}\text { Deren } \\
\text { Kennzeichen und Priifungsmittel. }\end{array}$ \\
\hline
\end{tabular}

Herba Toxicoden-1Die Blätter des Gifı su ma bs (R hus Toxicodeudrum L.), welche neucrlichst als Areneymittel eingefülır dri.: Giftsumachblätter. sind. Sie bestehen ans diey pestielteu grofsen Lappen, die aut der Olserflïche glatt uud dunkelgrün, unsind. Sien

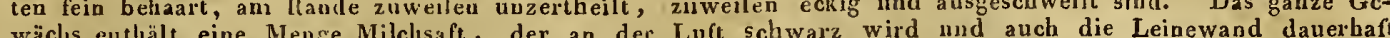
wäclis enchint eng and Leinewand dauerbaft schwarz färbt. Manch Nenschea stad die Ausdtnstuagen und die Beruhrung dieses Gewächses so schädlich uod machtheilig, dals davon eill heftiges Brennen und Jucken in den davon betroffenen Theilen entsteht, die in der Folge," so wie der ganze Körper, davon aufschwcllcn. Man mufs daher die frischen Blätler, welclıe kurz vor-dem Blühen eiuzusammlen sind, niclt mit hlofsen Häuden aufassen. Der W urzelsumach (Rhus radicaus L.) soll blofs eine Varietät des Giftsumachs seyn und in seinen Wirkungen danit ïbereinstimmen. Beyde sind in Nordamerica zu Hause, kommen aber auch in unsern Gärten gut fort.

Herbre Trifolii ji- Die Blätler des auf feuchten Wiesen wachsenden Fieberklees (Mie vyanthes trifoliata L.) Länglichbrini.

Bitterklee.

Fieberklee.

Herba Verbasci.

Wollkraut.

Herba Verbenae.

Eiserhart.

Herbu Veranicae Ehrenpreis.

Herba Violae iricoloris s. Jaceae.

Dreyfaltigkeits-

kraut.

Freysamkraut.

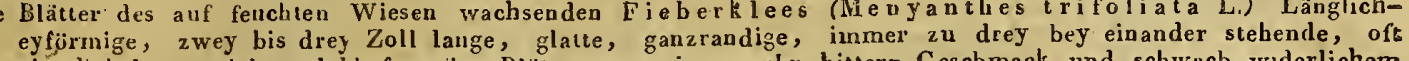
ziemlich langgestielte, lebbaft grüne Blätter von eincm sehr bittern Gescbmack und schwacb widerlichem Gerucb.

Die am Stengel herablanfenden Blätter der/Verwechselt mit den|Sind vorwe stumpf, auf der Oberfläche runzKönigskerze (Verbascum Thap- Blätternder $W$ eifs- licht und hellgrün, auf der Unterfäche sus L) Sie sind lang-eyförmig, zuge- kerze (Verbascum nur weifs hestäubt.

spitzt, ruuzlicht, am Rande stumpf ge- Lychnitis L.)

kerbt, auf beyden Seiten mit einem weiriecben im frischen Zustande sebwacb be-) Scltwarzkerze (Ver-) nur etwas weifslich und haarig.

\begin{tabular}{l|l} 
riecben im \\
tätibend und besitzen einen schleimiclit- \\
bitterlichen, ein wcnig zusammenziebendeu
\end{tabular} bitterlichen, ein wenig zusammenziebendeu Geschmack.

Die an dem Stengel gegenübersitzenclen Blätter des gemeinen Eiserharts (Vorbena officinalis L.) Sie siud länglich, zerrissen-vierspaltig, ungestielt, von dunkelgrïner Farbe, obne merklicken Geruch uud von schwach zusammenziehendem bitterlicben Geschmack.

Die an dem gestreckten, einen bis auderthalb Spannen langen, holzichten, runden Stengel gegenüberstelienden blätter des Theeeluenpreises (Veronica officipalis L.) Sie siud länglich eyrund, etwas ranh, gekerbt, von mattgriner Farbe, scliwachem Geruch und bitterlich zusammenziehenden, etwas balsamischen Geschmack. Man saminlet sie im Frühjabr, nimmt auch wobl die ganze Pflance, "verwirft aber die grübern Stengel.

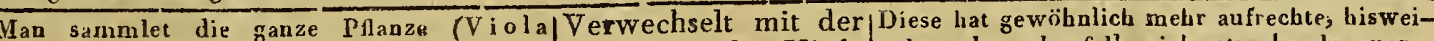
tricolor L.), zuweilen selbst mit der Ackerviole (Viola len aber ebenfalls sich streckende ausgeWurzel, ein. Der mit seinen darniederliešenden Aesten sich weit ausbreitende, dreyseitige sicengel hat abwechseln I berwuterlaufende, langliche, ey förmige, schma-

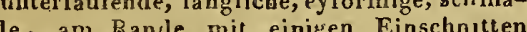
arvensis $L$.) le, am Ransle mit einigen Einschnitten versebene Blätter, die an dem Grunde nocli rin paar Blattansätze haben, welche an beydeu Seiteu in verscbiedene Lappen zertheilt sind. In den Winkeln der gelb-
lichgrüuen Blitter entspringen die lavgen viereckigen Blumenstiele, deren jeder eine drey - oder $\mathrm{z}$ wey farbige, entweder violettblaue, gelbe unil weilse, oder blaue und gelbe, aus fiuf Blumenb!ätteru bestehende Blumenkrone trägt. Das Kraut bat einen hitterlichen, "klebrichten, etwas schär flichen Geschmack und geriebeu einen Pfirchen Geschmack und gerieb
sicbleruähnlichen Geruch.

Herba Vulvariae $s$. Atriplicis Ioetidae.

Stinkende Melde.

Tirudines vivae. Blutigel.

ie an dem auf der farniederliegenden, gestreiften und mebligen Stengel des Sicickgäusefufses länglich-eyrund, gezabnt a die unten dagegen ziemlich herzförmig, oft so breit als lang und fast rundlicht; sie laufen, wie die ähnlicb gestalieten Afterblätter am Stiele hernnter, die úrn diẹ Hälfte kleinern Blumen sind zweyfarbig schwefelgelb, und weifs, celtner zugleich blau。

(Cbenopodium Vulvaria L.) sitzenden, langgestielten, dreyeckigen oder rautenförmig-eyrunden, glattrandigen, mit glattrandigen, mit eineın weilslicben Ganch eingesalzener und in Fänlnifs gehender Fische nicht unähnlich jst, nud einen eckelbaften Geschmack. Beyde verlieren sich durchs Trockuen.

Hirudo medicinalis L. Ein längli-/Verwechselt mit dem Er unterscheidet sich durch seiue gelbbraune cher, weicher, schleimiger, etwas plat- gemeinen Blutigel Farbe und durcb acht schwarce in einem ter, an beyden Enden stump fer und nacktér Wurn, von der Dicke einer Federspule und darüber, and $z$ wey bis lirey Loll lang. Er ist aus lanter rin förmigen Zoll lang. Er ist aus lauter ringrormigen sich bis zu einer drey facben Länge ausstresich bis zu einer drey facben Lange ausstre-
cken, wieder zusammeuzieben und einen Kreis bilden kann. Am vordern Ende, wo das aus zwey biegsamen Lefzen und einer dreyeckigen Mündung, in welcher drey scharfe im Mittelpunct zusammentreffende Zähne liegen, bestehende Maul sitzt, läuft der Körper scbmäler zu; am hintern dickern Eude bat er einen ringhintern dicke Ea de roimigen Ans dunkelbrane orler brauuschwark bs; auf jeder Seite desselben befinden sich vicr Streifen, von denen der erste gelbroth ist, der zweyte ebenfalls, aber dabey mit scbwarzen Puncten besetzt; der dritte ist schwarz, der vierte aber gelb, bey einigen ist der dritte Streif getbeilt. Die Zwischenräume dieser Streifen sind gelleckt und der Bauch oder, die untere gemeiner Blocirkel wrn das Maul stehende Puncte.

ta L.)

Mit dem Possblutigel Dieser ist an ganzen Rucken schwarz, nur am (Hirudo sanguisth-
Raude gelb und unten schmutzig oliven-
grün. Er sangt zwar begieriger an, allein ga L.) sein Bifs und Saugen ist sehr schmerzbaft.

A nmerk. Die wahren Blutigel müssch in Frilliling oder Sommer bey Sonncuschein aus bellen, kiessandigen Bäcben gesammlet, in ein geramices, bis zum dritten Theil mit reinem Flufswasser angefülttes Zuckerglas geschüttet, lose verbunden und oft mit frischem Wasser versehen werden. Die aus stehenden Sümpfen ge nommenen Blutigel erregen heftige Schmerzen und Entzündung. 


\section{Hordeum praeparatum. -- Hydrargyrum aceticum.}

\begin{tabular}{|c|c|c|}
\hline der Arzneymictel. & \begin{tabular}{c|c} 
Sinnlıche Eigenfchafien derfelben; \\
Merkmale ithrer Aechtheit und \\
Giite.
\end{tabular}$\left|\begin{array}{cc}\text { Fehlerhafte } & \text { Be- } \\
\text { fchaffenheit, } & \text { Ver- } \\
\text { wechfelung oder } \\
\text { Verfälfchung. }\end{array}\right|$ & $\begin{array}{l}\text { Deren } \\
\text { Kennzeichien und Prïfungsmitıcl: }\end{array}$ \\
\hline & \multicolumn{2}{|l|}{$\begin{array}{l}\text { Fläehe des Wurms ist grauschwärzlich und } \\
\text { gelb tnarnorirt. }\end{array}$} \\
\hline $\begin{array}{l}\text { Hordeum praepa- } \\
\text { ratum. } \\
\text { Gerstenkraftmehl. }\end{array}$ & \multicolumn{2}{|c|}{ 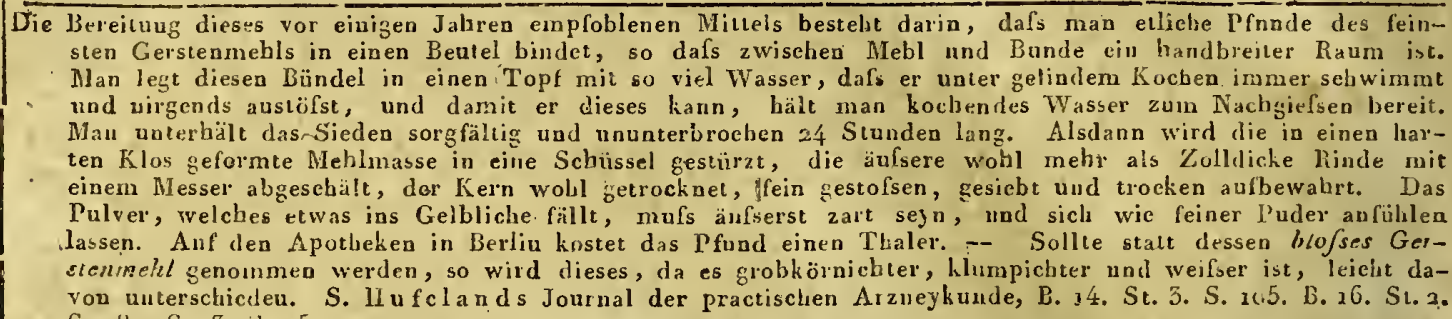 } \\
\hline
\end{tabular}

Hydrargyrum s.
Mercurins vivus. Quecksilber. S. 181. St. 3. i. 159 .

Das Quecksilber wirl entweder gediegen oder/Mit Bley, Wismul/L/Ist die Verfälsobung nur einigermalsen bemit Schwefel mueralisirt, in lstrien, Unga! $n$, Spanien, Otiudien u s. w. angetrofTempera silberweilses, glänzeudes, in der siges, aber undurchsichtiges Metall, welches sich kalt anfühlt, die Finger niclst nafs macht, bey dent geringsten Druck sicb in macht, bey dem geringsten Druck sicb in
viele kline Kü̈eletsen zertbeiit, nach dem Golle und der Llatina das schwerste Metall Golle und der Platina das schwerste Metall
ist und schon bey inä́sigem Teuer sicú vollkommen verfiürhtiget. Die Salpetersäure ist das vorzinglichste Auflosangsinutel desselben; in coucentrirter und erhitzter Scbwefelsậu re verwandelt sicb erst die Oberfläehe desselben in ein weilstiches Pulver nnd $2 u-$ letzt in ein trocknes $\mathrm{Salz}$; die Salzsäure greift es niclat geradezu an, ist aber doch mit seineu Oxyılen näher verwaudt als die Salpeter- nnd Schwefelsäure, und ent..ieht iluen diese aus ikren Anfösungen. Es vereinigt sich vermitlelst des Reiliens und der Wärme fast mit allen Metallen. Mit Scliwefel vareinigt es sich sowohl durch Reiben als durch Scbmelzen, und bildet iamit nach Maafsgabe des Verfabreus Sehwefetmuhr oder Zinnober. Ein sutes und reiues Quecksilber mufs einen bellen; nicht matten Clanz besitzen, auf einem Popien oder einem Poreellainteller inmer in rundes, kugelförmigen Troufen un cmein uesch fortrollen; die Kưseln müssen sich bey der geringsten Annäherung wieder vereinisen unit viebts pulverichtes zurüclassen. Durcb Leder gedrüicht, darf fast nicht das mindeste siaubichte oder unreine Wesen zu-
rückbleiben; es darf llie Finger nicht berückbleiben; es darf lie Finger nicht beschmutzen, wenn man ste damit reibt; in vinem eisernen Lülrel über Feuer gehalten, mufs es aicht knistern, so verdampfen; das destillirté Wasser, wenn es damit gesclüuttelt oder gerieben wird, nufs hell und klar bleiben; dem Essig darf es keizen süfslrenen Geschmack mittheilen. Selir starke Schleime macben das Quecksilbcr, weil es sich in unendlich kleine Theile mectranisch trennen läfst, mit Wasser mengbar.

oder falscht.

iinn .rerdas âufsere Anselien. Es sieht dann auf der Oberiläche matt aus, und ist, wie mit ciuer schwärzliclıen Haut oder Staube ül)erzogen, läuft läışer auf einer Schalc oler Papier nud zieht einen Schwanz uach sich, der cinen schwárzlichen Stitub biuterlälst; es bleibt auch wohl bie und da terlaist; es bleibl auch wohl bie und da tallische Zäpfchen stelien oder die Kügeltallische $Z$ äpfchen stelieu oder die kugel-
chen vereinigen sich doch nur langsam; es chen vereinigen sich doch nur langsam; es
beschmutzt bcym Angreifen die Fiuger; beym Durchpressen durch Leder bleibi ein Pulver zurück; reines Wasser damit gerieben, wird schmutzin; sein Gewicht ist specifisch leichtur. Wird es in' einem glübenden eisernen Löffel verdamplt, so beweiset und zeigt der Rückstand die Verfalschung. Koclıt man es mit Essig, so bezeugt der demsetben milgetbeilte süfse Geschmack, und die voin Zngiefsen ron Geschmack, und die voin Zngielsen ron hende schwärzliche Farbe, dafs das Queckhende schwärzliche Farbe, dafs das Queck-
silber mit Bley, vermischt war. Die nuf silber mit Bley, vermischt war. Die nuf Quecksilber gegossene Salpetersäure zerfrifot das danit versetzte $Z \mathrm{i} n \mathrm{n} z \mathrm{u}$ einem - weifsen Kalk. Bey einem mit Wismutb verfälschicen und in reiner. Salpetersäure aufgẹlösten Quecksilber schlägt hinıtıegossenes destullirtes Wasser ein weifses Pulver (Wismuthnieilerseblag) niedes. Win solclues verfailschtes Quecksiliger taugt zum Arzneycebrauch nieht.

Unrein.

uweilen ist das Quecksilber an und fiir sich recbt unt, aber nit darauf laftenden Staube, Schrutz, Fäserchen, Fetla u. del verrumigt, Tis lafot sich darou

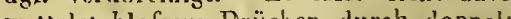

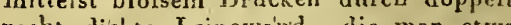
dic man etwas beleucitct, Leder, oder indeur man es durch eine trichterförınige, unten ganz engmiiudige Tute von Papier wiederbolt laufen lïfst, säubern. Vom anhäมgenden Fettschmutze befreyet man es durct Schüiteln mil etwas Aetzkaliauflösung, nachberiges WVaschen mit ein wenig Essighaltigem Wasser und Wiederabtrocknen auf Fliefspapier, oler amel, indem man es in einer eisernen oler anch, indem inan in Prane anter und das aus denn crkalteten Gemisch beym siukende gereinigie Quecksitber sammlet.

Hydrargyrumaceticum.

Mercurius acetosus Essigsaures Quecksilber.
Ein atıs Essigsäure und Quecksilberoxyd be-|Nichtvorsichtiggenug/Wen stebendes metallisches Salz, welches wejfse, sılberglän zende Crystallen in dïnneı,
slimmerartigen Blättclien von verschiedestimmerartigen Blattclien von verschiedeauch in Körvern mo feinen Nadeln crystallisirt. Es ist siliwer auflöslich irn Wasser, so lafs in mittlerer Temperatur zu ei nem Theile vierzig Theite Wasser crfor-
derlich sind, um es aufzulöscu. Im Weinderlich sind, $1 \mathrm{~m}$ es aufaulöscn. Im Weingeist ist es völlig unauflöslich. Sein Ge-
sclınack ist herbe metalliselı. Dic gesättigte Anfisung III Wasser wird in der Siedlitze zum theil zersetz.t und von kolslensanem Kali braun, von Aetzkati gelb, vou itzender und milder Ammonimmfiusrrgkeit weif $f_{s}$ niedergeschlagen. Bey dem aulbewahrt.

sichtig aufbrwabrt und nicht in gut verchöror

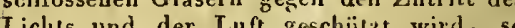
Lichts und der Lint geschiczt wird, so
wird es undurchsichtig, läuft an und wird schivarz.

Anmerk. Die Preulsische Pharmacopoe schlïgt zur Bereitung dieses Salzes die Anwendung des rothen Quecksillberoxyds vor, nach weicher Methode abcr dic Crystallen wcnirer ausgezeichnet und unregelmälsis sind und man dabey keine vollkommen gesattigle Salzinasse erlaalt. Weit besser ist zur Berettung des cssigsauren Onecksilbers das koblensaure Ouecksilbernxyd, welches man erbill, wcnn man eine heifsbereitete Auftösung des Quecksibers in Salpetersänre durch koblensaures Kali oder Natrum fällt, und den entstandenen gelben Niederschlag wohl aussüfst uud trocknet. 


\begin{tabular}{|c|c|c|}
\hline $\begin{array}{c}\text { Namen } \\
\text { ler Arzneymittel. }\end{array}$ & $\begin{array}{c}\text { Sinnliche Eigenfchaften derfelben } ; \\
\text { Merkmale ihrer Ächtheit und } \\
\text { Giite. }\end{array} \mid \begin{array}{c}\text { Tehlerhafte Be- } \\
\text { chaffenheit, Ver- } \\
\text { wechfelung oder } \\
\text { Verfäl.fchung. }\end{array}$ & Kennzeichen und Prïfungsmittel. \\
\hline & 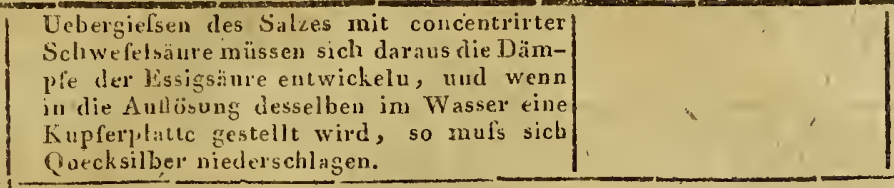 & \\
\hline Icalisa- & \multicolumn{2}{|c|}{ 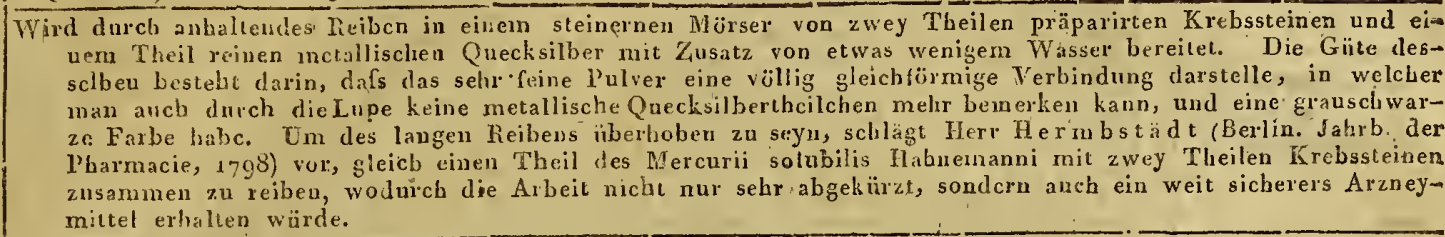 } \\
\hline $\begin{array}{l}\text { m ci- } \\
\text { ackii. } \\
\text { inereus } \\
\text { igranes } \\
\text { eroxyd. }\end{array}$ & \multicolumn{2}{|c|}{ 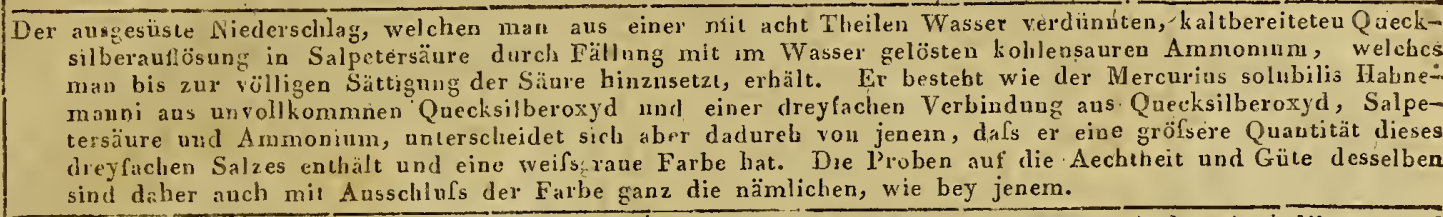 } \\
\hline & \multicolumn{2}{|c|}{ 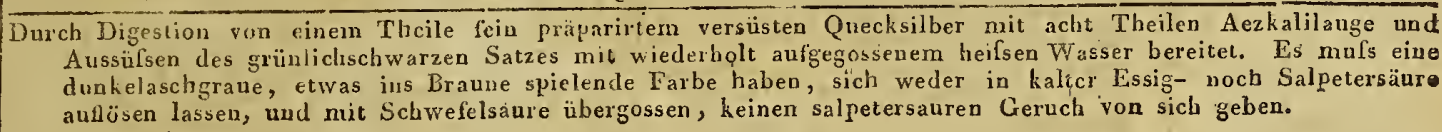 } \\
\hline
\end{tabular}

Mos cali.

Moskitis schwarzes

Q uecksilberoxyd.

Hydrargyrum cinicrenm S a un d e$\mathrm{ri}$.

Mercurins cinereus s. niger $\mathrm{S}$ a u nderi.

Saunders granes Quecksilberoxyd.

Hydrargyrum mntriaticum corro. sivum.

Niercurius sublimatus corrosivus. Aetzendes salzsaurcs Quecksilber.

Aetzender Quecksilbersublimat. Sublimat.

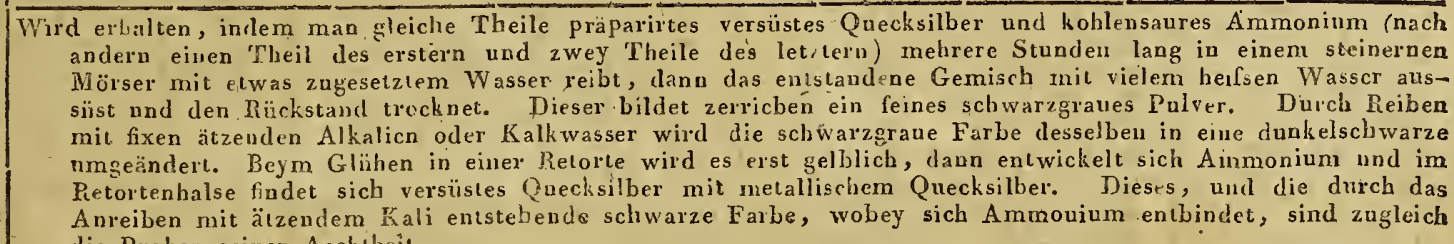
Anreiben mit ätzendem Kali entstebende schwarze Farbe, wobey sich Ammouium entbindet, sind zugleich dic Proben seiner Aechiheit.

Ein aus vollkommuen Quecksilberoxyde und Der in Fabriken be- Es widersprecben jedoch diesem Vorgeben die Salzsäure besteliendes, dureb Sublimation reitete ätzende Erfabrugeu der bewäbrlesten Chemaker nnd bereitetes Quecksilbersalz von eiuiem crys- Quecksilhersubli- vorzüglich hat der für die Chemie zu früh \begin{tabular}{l|l|l} 
tallinischen, aus paralellen Spiefsen und & mat soll zuweilen & verstorbene Rose den Ungrupd desselben \\
überzeugend dargetban (Grens Plarma
\end{tabular}

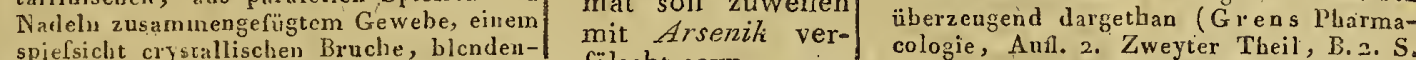

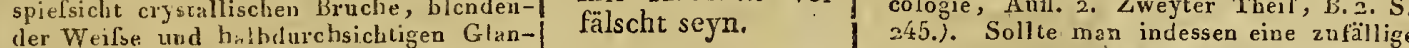
Verunreinicung des ïtzenden Sublimats mic se. Ans der waibrigen farte sung schielst es bey volliger Sattigung und Seschwinder Abdamprung in festell, lan-
gea, nadelförmigign, zugeschärften, oder. geu, nadelförmigigen, zugeschîrften, odes
langstrakligeu, ibgestutzlen, und bey langsamen Verdunsten, in auf der Oberiläche samen Verdunsten, in auf der Oberiache-
entstehenden, 1 achiher sich am Boden begebenden; kïrzerv, fencht noci biegsamen getrockne: luftbeständigen Crystalieu an. Es hat heinen Gerucb, aber einen berben, eckeltaft melallischen, sein Genufs ist, besonders trocken, selion zu einigen Granen tödtlich. Ein Theil desselben erfordert sechszehn bis zwanzig Theile kaltes, dert sechszehn drey Theile siedendes Wasser zu seiner Aunfösung. Der. Weing eist löset es, wic 2 zu 5 , oder bey $65^{\circ}$ Falur. die Unze 192 und in der Siẹdhitze 42t Gran auf. Di wälsrige Auflösung wird durch kobiensauitzevde fixe Allalien gelb, durch Kalkwasser rötblichgelb, durch inildes Ammanium wcifs, und durch frischen Harn fablgelb nierlergescllasen. In verschlossenen Gefï $\Gamma_{s e n}$ invifs sich der Sublimat yollkommen fifsen lis in Holland uud Venedig in Grofsen bereitet.

Arsenik befürcliten, so wuirde man letzteren am sichersten entdecken, wenn man einen Theil des Sublinats mit 3 oder 4 . Theilen Weinal es hol od, reinemSch we felätb er (worin sich der reime Sublimat eben falls auflüset) z um Kochen bringt. Ist der Sublimat rein, so löset er sich völlig ṭariu auf. Bleibt ein Rückstand, so kann dieser vielleicht auck mildes oder versistes salzsaures Quecksilber, welches der Aetzsublimat żuweilen anch enthalten kann, seyn. Man giefse deshalb die überstehende Flüssigkeit von dem Bodensatze ab. Das versüste Quecksilbe wirl mit Kalk wasser angerieben, schwatr. Won Von dem Darch

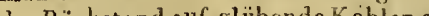
verbreitet, so wie darlurch, dafs eise durch verbreitet, so wie darlurch, dals eire durch Kochen mit destillirtem Wasser bereitete
Lösung desseliber mit $\mathrm{H}$ a h $\mathrm{nem}$ an 11 s I'robeftïssigkeit gelb, mit schwrefelsaurem oder Ammoniumkupfer aber grün niedergeschlagen wird, und anel diese absesonderten Nieder'schläge auf glühenden Kohleu den beliannten Knoblauchgeruch vcrbieiten. Einen des Arscuikseltalts verdäcbtioen Sublimat geredezu anf orthende Koblen zu blim gen

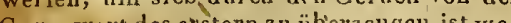
Gegen war die Gesundheit so aufserst nachgeiligen Dämpfe des Sullimats nicht antheiligen Dample des Sullimats nicht an-
zurathen, und diese Probe izberdem in zurathen, und diese probe überdem in
mancher Hinsicht für sich allcin nicht bestimmt genug.

Der Aetzsnblimat ent- Dies kann bey den sehr verschiedenen Mehält auch wohl mildes oder versiistes salzsaures Quecksilber. tbolen, die man in den Fabrikcn zur. Be-
reitung desselben anwendet, zuweilen der reitnng desselben anwendet, 20 weilen der
Fall seyn. Nlan überzengt sich davon, wie Fall seyn. Man überzengt sich davon, wie
schon vorber bemerkt ist, dadurch, dafs bey der Auföosnng in Alcobol oder Schwem 


\section{Hydrargyrum muriaticum corrosivum. -- Hydrarg. muriat. praecipitatum.}

\begin{tabular}{c|c}
\hline Namen & $\begin{array}{c}\text { Sinnliclre Eigenfchaften derfelben; } \\
\text { Merkmale ihrer Aechtheit und } \\
\text { Güte. }\end{array}$
\end{tabular}

Hydrargyrum mu-

riaticum corro-

sivum.

Hydrargyrum mu-

riaticum mite.

Mercurius dulcis.

Calomelas.

Mildes oder versüs-

Quecksilber.

Hydrargyrum muturiaticum mite praeparatum.

Mercurius dulcis praeparatus.

Präparirtes versüs tes Quecksilber.

Hydrargyrum mariaticum praecipitatum.

Mercurius praeci-

pitatus albus.

Weifser Queck

berpräcipitat.

Weilser Präcipitat
Wird auf die bekannte Weise aus ätzendem Quecksilhersublimate und reinem Quecksteht aus uovollkornmnen Quecksilberoxyd und Salzsïure. Der versiaste Quecksilbersublimat bildet feste, schwere, nach der Gestalt des Glases; worin die Sublimation geschehen, geformte, derhe Brode, die auf der aufsern, dem Glase zugekehrt gewesenen Seite weifs, zuweilen ein wenig ins nen Seite weirs, zuweilen spielend oder silberfarbig schillernd, Graue spielend oder silberfarbig schillernd auf der andern innern Seite aber etwas rauher, glänzend, gelblich, kaum an den untern dünnen Rändern ein wenig durchscheinend, auf dem Bruch crystallinisch, und ans dicht aneinander liegenden, vierseitig prismatischen, mit gleichvielflächigen Endspitzen versebenen Crystallen zusammengeset zt sind. Bricht man die noch lauwarmen oder wieler erwärmten (Brode an einem finstern Orte in Stücken, oder reibt sie stark, so rerhreitet sich ein starkes dunkelrothes Licht, Fein zerrieben hat das gelbliclie Farbe, wird im Sonnenlichte grau, durchs Kochen mit Salmiakhaltigem Wasser aber wieder weifs. Es hat weder Geruch noch Geschmack und ist im Wasser baum löslich, so dafs 1152 Theile siedendes Wasser erst einen Theil aufnehmen. Weingeist nimmt nichts davon anf. In eiWem rlöhenden Iölfel über Kohlen gehal nem glinhenden Lollel uber Koblen gebalten, mers es $v$ ollig mit einem weich pfe verfliegen und sich in verschlossenen Gefailsen vollkommen autsubleiden. Veränderung zu erleidene ohne eine Veränderung 2u erleiden. Milde Alkalien machen es gran; die ätzenden und frischbereitetes Kalkwasser aber schwarz. Digerirt man ein halbes Quentclien init funf Quentchen destillirtem Wasser und sechs Grä Salmiak in gelinder Wärme, so mufs das Wasser nichts davon aufnehmen und die abgegossene reine Flüssigkeit darf weder durch ätzende Ammoniumflüssigkeit, noch durch Kaliaufösung getrübt werden.' silber durch Snblimation bereitet und beversüste Quecksilber gewöhnlich eine weifsdes Salmiaks, auszukocben. guter weifser Quecksilberpräcipitat muf

\section{Deren}

Kennzeichen und Priifungsmittel.

fel̈̈ther cin Riclstand bleibt, der mit Kallwasser zusammengerieben, schwarz wird.

urch Beymischung von anhängendem ätzenden Sublimat verunreinigt, oder auch nicht völlig versüst, wie es besonders bey dem käuflichen nicht selten der Fall ist.

Grau von Farbe.

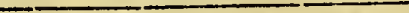

Gewöhnlich hält man das versüste Quecksilber von eiram darin enthalten sejn könnenden Antheile des ätzenden Sublimats frey, wenn es mit Kalkwasser, dünner Aetzhalilauge oder ätzender Ammoniumflüssigkeit gerieben, sogleich eine scbivarzeSamintfarbe anuimmt. Diese Prohe ist aber nicht völlig entscbeidend, da die entstehende Pommerauzenfarbe des erstern, so wie die wie die gelhe des zweyteu and die weils Farbe beym dritten Prufugsmittel, wo durcli sonst die Gegenwart les ätzende Sublimats angeceigt wuirde, von der üherwiegenden Schwarze des rcrsusten luecksilhers verschluckt wird.- Die sicherste Probe bestebt daher nach Herin Dö r f fu r darin, dafs man einen Theil des versüsten Quecksilbers mit zwölf bis zwanzig Theilen reinem destillirten Wasser oder Weinalcohol einige Minuten in einem Glaskölbchen wher die Flammc eines Lichts kocht und uch dem Erkalten die hellibgegosseund uach dem Erkalten die hellabgegossene und filtrirte Flussigkeit mit einer doppelten Menge Kalkwasser mischt. Zeigt sich dann dabey keine orangenfarbne Trubnng, so kanu man der Nichtogenwart einer Spur von ätzendem Suhlimat völig versichert seyn. Hat man, wie eiuige einpfeblen, dem Wasser oder Weingeist etwas Salmiak zugesetzt, dann verrath nicht eine orangenfarhne, sondern weilstichte Irübung der mit Kalkwasser ges Aetrublima lösung das Zugegenseyn der Beitung eine Rührt davou her, wenn bcy der Bereitung elae zu grofse Menge metallisches Quecksilber giebt, mit Salpeters;ure erhitzt, rothe Dämpfe.

im höchsten Grade fein zerriebener, zu einem unfülilbaren Pulver gebrachter versüster Quecksilbersublimat, obneGeruch und Geschmack und von weifs el blicher Farbe. Das blolse Zerreiben des versüsten Quecksilbersulblimats ist aber icht alin Schatten getrocknet und in cinem mit sencm kochenden destillirsen Wasser geborig alio aufbewalirc, werden. 'Andere schlagen vor, theils um die schwarzen Papier uberzogenem Glase sorgfiots zu erleichtorn, theils um das Grauwerden des Prijparats Ausziehung des ctwa anhängcnden Aetzsublimats zu erleichtern, theis un zu verhüten, dasselbe mit zehn bis 2 wöf rathen, das versüste Quecksilher mit Wcingeist, ohne Zusatz

in dúrch kohlensaures Natrum aus einer Auflösung ron gleichen Theilen ätzendem Quecksilbersublimar und Salmiak niedergeschlagenes, aus Ammonium, Salzsäure und Quecksilberoxyd bestehen des Quecksilberpräparat, welches gewöhnlict nur als äufserliches Mittel angewendet wird. Ein schwer seyn, eine scbrieeweilse Farbe, keinen Geruch, einen kaum merklichen, hintennach ein wenig metallischen Geschmack haben, und sich zwischen den Fingern zn einem feinen, ungreillichen, stark weifs
machenden Pulver zcreihen lassen. Im machenden Pulver zcrreihen lassen. Im Wasser ist er nur in setri geringer Mene Wirkung darauf. In riafsig starker Salpeteroder Salzsänre löset er sich vollkommen auf. In einem glübenden eisernen Lölfel cine balbe Stunde über lebendige Kohleo gebalten, mufs er sich völlig verflücbtigen, ohne irgend cinen Rïckstand $\mathrm{zu}$ hinterlassen. Mit Kalkwasser gerieben, wird er Alkali oder Kalker gel gerieben, mufs sich aus demselben Amunonium euthinden, welaus demsellon A A dern auch durch Hie Dämpfe bemerkbar dern aucht, welche ents'eben, wenn nan über macht, welche ents'eben, wenn Juan über
die Reibschale eine mit concentrirter Salz-

\begin{tabular}{|c|c|}
\hline $\begin{array}{l}\text { it mildern salzsau- } \\
\text { ren Quecksilber } \\
\text { verunreinigt. }\end{array}$ & 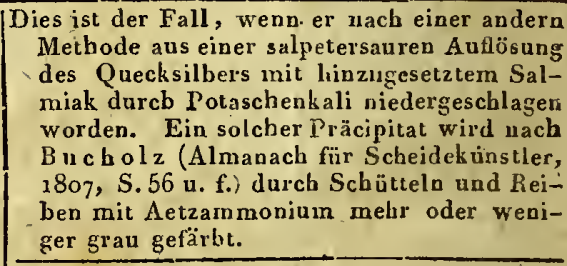 \\
\hline $\begin{array}{l}\text { Nicht mit Zusatz von } \\
\text { Salmiak, sondern } \\
\text { blos durch Fällung } \\
\text { der salpetersauren } \\
\text { Quecksilberauflö- } \\
\text { sung mittelst Koch- } \\
\text { salz oder Salzsäure } \\
\text { bereitet. }\end{array}$ & $\begin{array}{l}\text { Ein solcher Präcipitat entbirndet mit Aetzkali } \\
\text { oder Kalkerde gerieben, kein Ammonium; } \\
\text { anch wird er im Wasser weit leichter aur } \\
\text { löslich seyu, wie er sich dann, überhaunt } \\
\text { dem ätzenden Snblimat mebr nähert. Mit } \\
\text { ätzendcm Ammonium zusanmeugerieben, } \\
\text { nird eill so bereiteter Präcipitat gleich } \\
\text { schwarz. }\end{array}$ \\
\hline $\begin{array}{l}\text { er in Fabriken be- } \\
\text { reitete Quecksil- } \\
\text { berpräcipitat ist zu- } \\
\text { weilen mit Gips } \\
\text { oder Kieselerde } \\
\text { verfälscht. }\end{array}$ & $\begin{array}{l}\text { Verfliegt in diesem Falle in eixem Löllel·tiber } \\
\text { Kohlen gehalten nicht ganz, sondern hin- } \\
\text { terläfst einen Rückstand. In Salpetersäure } \\
\text { geschieht die Aufösung nur unvollkommen } \\
\text { nud es bleiht ein Rest unaufgelöset zurïck. }\end{array}$ \\
\hline it Kreide. & $\begin{array}{l}\text { Der beym Vcrdampfeu übrig bleibende Rest } \\
\text { brauset mit. Säuren auf. }\end{array}$ \\
\hline & Die salpeter \\
\hline
\end{tabular}


Hydrargyrum muriaticum praccipitatum. -- Hydrargyrum oxydulatum nigrum. 73

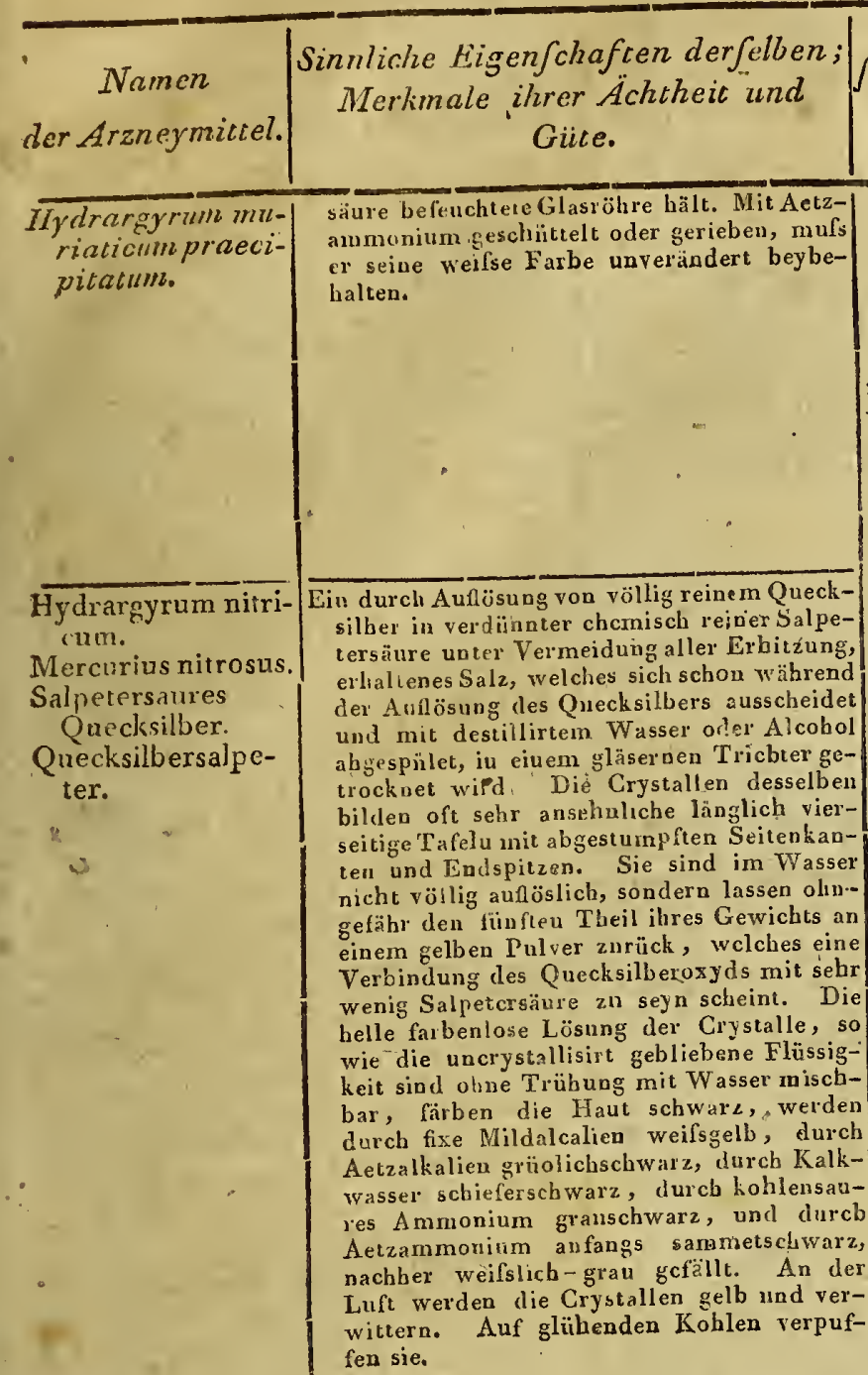

Hydrargyrum oxydatum rubrum.

Mercurius praecipitatus ruber.

Rothes Quecksilberoxyd.

Rother Quecksilberpräcipitat.
Hyclrargyrum oxydulatum niErum.
Ein Quecksilberoxyd von einer scbönen hochrothen Farbe, welches nach der. Preulsischen Pharmacopoe durch Abdunsten eirer salpetersauren Quecksilberauflösung bis zur Trockne und so lange fortgesetztes vorsichtiges Rösten ler gepuiverten Masse in einem släsernen oder irdenen nicht glasurten Geschirre, bis dieselbe die gelörige rotlse Farbe angenorumen bat, bereitet wird. Man erbält das rothe Quecksilberoxyd auf diese Art als ein glcichförmiges, glanzloses, sehr feires Pulver, da hingegen das vorzüglich in den Holländiscleen

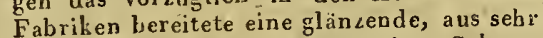
feimen und kleinen glimmerartigen Schupfeinen und kleinen shwere, zusammengepen bestebende, scbwere, backene, aber leiebt zerreibliche Masse bildct. Es bat keinen Gerucb, aber einen berben, unangenehmen, scharfen Geschmack. Durch die Einwirkung des
Lichts wird es dunkler und schwärzlicht Lichts wird es dunkler und schwarzlicht unauflöslich. Schwefelsäure loset kaum etwas davon auf. Salzige Säure und Salpetersäure lösen es leicht ohne Aufhrausen auf. In ciner Retorte erhitzt, mufs dasselbe, wenn es gut bereitet ist, keine Salpeterdämpfe mebr ansstofsen, bey dem Glühen Sauerstoffgas entwickeln und sicb eudlich Sanz als metallisches Quecksilber verhuchtigen, obne einen Rückstand fzo res mufs in einem wohlverbinterlase aufbewahrt und gegen di stopften Glase audbewahrt und gegen Einwirkung des Lirhts geschüzt werden. gentlich kein reines Quecksilberoxyd, sondern eiue Verbindung vou sehr fein zertheiltem metalliscbem Quecksılber, unvollkommnen Quecksilberoxyd nnd einem

\section{Fehlerhafie Be-} chaffenheic, Verwech elung oder Verfälfchung.

\section{Kennzeichen und Prïfungsmittel.}

dergeschlagen. Beyın Verdampfen bleibt ein gelber Ruckstand, der mit etwas Pech ela gelber ficks oder Fett vermischt, durch Schmelzen ein Bleykorn erzeugt. Schmilat man den mi Alkali vermengten Präcipitat so lange, bis kein Dampf mebr aufsteigt, so bleibt ebenfalls ein Bleykorn zurick.

Mit Wismutlloxyd. Aus der mit vielern destillirten Wasser vermischten salpetersauren Auflösugg fällt ein weifser Niederscblag zu Boden.

Mit Kraftmehl. , Ist viel leichter und hinterläfst bey'm Verdampfen in einem glübenden Lö̈fel einen koblichten Rückstand.

Mit unreiner SalpeBey der Bereitung dieses Salzes ist es durchans nothwendig, zur Auflösung des Queck silbers die reinste Salpetersänre $2 u$ nehmen. Deun sollte diese Salz - oder Schwefelsäure enthatteu, so entsteht im ersteu Falle ätzender Quecksilbersublimat, im zweyten aber scbwefelsaures Quecksilberoxyd, welche beyle weit itzender als beroxyd, welche beycle weit atzender als das salpetersaure Quccksilber wirken. Dasselbc 1st der Fall, wenn statt des destillirten Wassers zur Verdünnung der Auflösung gemeines Brunnenwasser genommen wird, wegen des darin enthaltencn Kochsalzes und Gypses. Die Gegenwart der Salzsäure erfäbrt man durch etwas in die Auflösung gefröplelte SilberauAösung: das Silber wird sich mit der Salzsäure verbinden und einen schwer auföslicten Niederschlag bewirken. Die Gegenwart der Schwetelsäure lann durch Barylauflöder Schwerelsare kann durch Barylaufoeinen scbwer aufiöshchen Niederschlag hervorbringt.

A nmerk. Schr wichtig ist der Unterschied, wenn statt der naltberiteten Autlösung idas Quecksilben in der Salpetersäure durch Wärme aufalösct wird Sie giebt alsdann platt nadeldücb Whare aufgelose wird örmige ode spiclsichte, an der Luft ebenfalls gelh werdende und bey der Aufosung in Wasser zerselzt werdende Crystallen. Diese beifs bereitetc Auflösung färbt die Haut dunkel purlurroth. Die Alkalien und das Kalkwasser fällen daraus das Quecksilberoxyd mit rotbgelbar Farbe, welches seine starke Oxydation beweiset. Die Auläsuug ist weit ätzeuder und fressender, als die kalt bereitete und darf daber ja nicht für jene substituirt werden.

s kommt nicht sel-1Das aufsere Anseben eines mit Mennige verten mit Mennige fälschten rothen Quecksiberaxyds ist mivoder auch mit Eng- der glänzend und weniger schuppenartig lisclier Silberglätte slimmernd; mit Silberglätte verfälsch isclher Silberior der Betrug schon mehr versteckt, da verfälscht vor. Ansehen hat, doch wird die Farbe dann nicht so schön roth soyn. Durch beyde Zusätze wird indessen der damit digerirte Essir sïfich schmeckend und ein darnic Essig verralschies Oxyd veralegt beym chane nicht gallz. Wacbs, Fett oder Koblen und gühet es in einem Schmelatiegel, so bleibt. ein Bley korn zurük. Nach Herra Grindel wird ein, auch nur mit der geringsten Menge Mennige verfälschtes rotbes Quecksilberoxyd durch etwas starke Salpetersäure bra u n gefärbt.

Mit Zinnober.

Löset sich in Salpetersäure nicht völlig auf und verräth sich durch die heym Verfüchtigen auf einem gliibenden Eisen sich zeigenclc blane Scluwefelamme und den Schwefelgeruch. Wird dasselbe mit Aetzlauge gekocht, so riecht die ahgegossene Laugc nach faulen Eyern und entwickelt diesen Geruch nocb stärker dmeb binzugesetzre verdünnte Schwefelsäure, wobey sicb Schwefel niederschlägt.

Mit Ziegelsteinmehl. stand, der leicbt erkannt wird.

Mit zu wenig hinzuge- $\overline{\text { Der Niederscblag erscheint d'ann nach dem }}$ setztem Anmonium Trocknen nicht schwarz, sondern oliven\begin{tabular}{l|l} 
präcipitirt. & grün und nimmt durch Einwirkung der \\
Luft noch mehx Sauerstoff in sich auf, wo-
\end{tabular} 


\section{Hydrargyrum oxydulatum nigrum. - Hydrargyrum sulphuratum nigrum.}

\begin{tabular}{|c|c|c|c|}
\hline $\begin{array}{c}\text { Namen } \\
\text { der Arzneymittel. }\end{array}$ & $\begin{array}{c}\text { Sinnliche Eigen fchaften derfelben; } \\
\text { Merkmale ihrer Ärhthert und } \\
\text { Güte. }\end{array}$ & $\left|\begin{array}{c}\text { Fehlerhafie Be- } \\
\text { fchaffenheit, Ver- } \\
\text { wechselung oder } \\
\text { Verfälfchung. }\end{array}\right|$ & $\begin{array}{c}\text { Deren } \\
\text { Kennzeichen und Prüfungsmittel. }\end{array}$ \\
\hline
\end{tabular}

oxydulatum ni- monins nnil Quecksilberoxyd, das sicb

grum.

Mercurius solubilis ge dabey befindet. Man erhält es durch

- Ha hnem an n i. Fiillung : aus, einer verdinuten kaltbes eite-

Schwarzes Queck- ätzender Ammonimmlüssigkeıt, die aber

silberuxyd.

Hahnemanns auf-

Iösliches Queck-

silber.

nux so lange hinzugesetzi wird, als ein

srbwarzer Niederschlag erfolgt. Es bildet

kelschwarzcs, fein an: $u$ fuhlendes Pulver,

welches sich durch gelindes Reiben und

Drïcken in der flacben Hand durch die

Wärme grö́stentbeils wieder , u meralli-

schem Quecksilber herstellen läfst, sich in

verschlossenen Gefäsen der Hitze ansge-

setzt, vöłig verflüchtigt und ohne eiven

Sublimat zu lieferu oder einen Rïcksiand

zu biuterlassen, ebenfalls inetallisclı reducirt. Ehen das geschiebt, wenn es nit einenlicht oder in gelinder. Wärme in cinem Mürser gerieben wird. In heifser Essigsäure löset es sicb zurn Theil auf nnd fallt daraus als ein scliweraufösl.ches Salz bey dem Erkalten nieder. Seine übrigen Eigenschaften und Tugenden besteben nach Herrn $F$ ischer (Handb, d. pharm. Praxis, Anf. 2. S. 337) darin, dafs ätzendes Kali aus dicmselben Ammoninrn, Schwefilsaure aber bey máfsiger Erhitzung Salpetersäure daraus entbiadet; dafs es bey der Behandlung mit Salpetersäure deu Gückstand hinterlärst; dafs es durcb die Lupe b.tracbtet keine metallischen Quecksilberkigelchen zeigt, und der Luft und Finwirkung des Lichts ausgesetzt keis ius Gelbe sich neigende Far be auuimmt.

Hydrargyrum phosphoricum. Mercurius phosjhoratus. Duch doppelte Wablverwandischaft bereitet, indem man zu eincr helfsbereiteten lösang so lange eine $\Lambda$ ufiösung des plosphorsauren Natrums (bey welcher das imphorsaure Natrums (bey welcher das im-
mer pridominireude Natrum in diesem mer pridominireude Natruaz in diesem
Salze vorher durch etwas zugeset/te SalpeSalie vorher durch etwas zugeset/te Salpe-
tersäure vollkommen gesättigt worden ist) tröpfelt, als nocb Tribung und Niederschlag erfolgt, worauf der niellergefallene pulverförmige $S_{a t z}$ wohl ansgestifst und getrocknel wirt. Das reine phosphorsaure Qnecksilber mufs ein weifses, geruchloses, zwar twas millisch, keiuesweges abee zwar "twas mitallisch, keiulesweges abea salzicht schmeckendes, in kochenden. WasWeineist hat gar keine Wirkung darauf. Durch sicdendes W asser darf es nicht gelb werden. Auf güulieudev Kohlen mufs es sicb unter Verbreimng ei ises phosphorischen Geruchs verflïchtigeu. Durch Destillation mit Kohle erhält man daraus Phosplsor nnd metallisches Quecksilber, und es darf sicb komut bey suiper Bereitung auf die vollkornmene Reinigkeit der Materialien au, die dazu gebraucbt werdeu.

Das infabrıken bereigelbe Farke annimmt. Er lüset sicb völlig, oder doch nur mit äufserst wenigem Rückstande in der Salpetersaire inf. Von dem richtig bereitetrn $\mathrm{Hab}$ a manus chen auföslıchen Quecksilber ibt er üburbapt setrr vel schieden.

Durch zu lange fort- In diesen Falle euthalt der Niederschla $2 u$

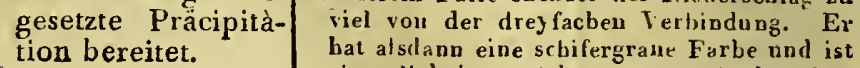

tete Hahnemann-

scie Quecksilberoxyd soll oft nichts anders seyn als mit Actzlauge gekochtes und dadurch schwarz gewordenes präplorirtes versüfstes Quecksilber.

tatt dessen auch wohl mirteralischer Molut.

Zuweilen soll es mit Kohlenpulver ver fälscht vorkommen

Mit schwe felsaurem Quecksilber von den dazu angewandten schwefelsäurehaltigen Materialiẹ verunreinigt.

Mit salzsäurehaltigen Qnecksibersalzen verunreinigt, von derselben Ursache wie oben.

Nicht gehörig ausgesüIs Gelb gefärbit.

at alstann eine schifergrane Furbe und ist eigentlich jetzt nichts auders, als der oben angefnhrte Mercurius cinereus Blackii. S. Hydrargyrurn civerenrn Blackii. Bey der cer andiung mit Salpeter'säure hinterlialst er eine gröfsere Menge des weifseu Rüclistan-

monium, mit Aetzkali gerieben kein Amgeführte Hydrargyrum cinereum

Ein ganz anderes Präparat, welches sich im Feuer mit bläulicher Flanme und eincm Schwefeigeruch vertluchtigt. S. Hy trargyrum sulphuratum nigrum.

Kam zu glauben, würde sich aber beym Verflücbtigen durch den Rückstand leicht zu erkennen geben.

Wird durcls kochendes Wasser gelb. AuSserdem findet man diese Vernurennigung, weun man das plosphorsaure Quecksilber mit seinem doppelten Gewichte reinen, ion Schwetelsäure fresen kohlenstoffsatren $\mathrm{Na}$ trum und einer gehörigen Monse destillirtrum und einer gehörigen Méfe destillir-
tem Wasser einige Zeit sieden läfst, daun tem Wasser einige Zeit sıeden läfst, daun
die Flüssigkeit filtrirt, das ühernüssige $\mathrm{Na}-$ troun mit reiner Salpetersäure neutralisirr, und nur eine Auflösung von Baryt in über. schüssiger Phosph'rsäure binzutröpfelt. War in dem Salze Schwcf.lsäure gecenwärtig, so entsteht jetzı ein Niederschlng Soust ilann man uuch wur ine slisaure Barytaution mion Bary cben, ob der entstandene Niederschlag wieder in ibersehissiger Salpetersinare anföslich ist, oder nicht; in letzteru Falle ist dic Gegenwart der Schwefelsäuxe erwiesen.

s entsieht alsdanu bey der bemeıkten'Destillation ein weifser Sublimat, welcher weiter 20 priffen ist. Man vergleicbe das bey Hydrargyrum nitricum sesagte.

Hat alsilann einen salzichten Geschnack, welches nicht seyn darf.

Dies ist der Fall, weun has Phosphorsaure Natrum nicht vorler mit Säure sesalttigt wurde, wo dann die gelbe Farbe ron dern frey n vosollkoumneu Quecksilberoxyd herrülırt. Eiu solcher Niederschlag darf zuin arzneylicbeu Gebrauch vicht angewen-

Ifydrargyrum
stibinto - sulpluturatum.

Aethiops antimo-

nialis.
Spiefsglanzmohr.

Hydrargyrum sulphuratum grimin. det werden.

\section{Av} us zwey Theilen feinem geschlämmten rohen Spiefsglanz, eidem Theil Quecksilber und eben so vielem rei-
wen Schwefel, duch langes anhal tendes Reiben bereitet. Es inufs ein feines, durchaus schwarzes, schweres Schwefel, duch langes anhaltendes Reiben bereitet. Es inufs ein féines, durcbaus schwarzes, schweres Pulver darstelleu, in welchem man anch mit der Lupe keiu Qnecksilberk $\ddot{b}_{5}$ elchen wahruelimen darf. zturickliteliegel geglübet, caul's das Quecksilber und der Sclawefel vertliegen und uur Spicfsolauzasche icklsteiben.

Nach der Proufsiscben Pharmacopoe aus glei-|Er soll zuweilen mit Giebt sich durch den Rïristaud beym Ver-

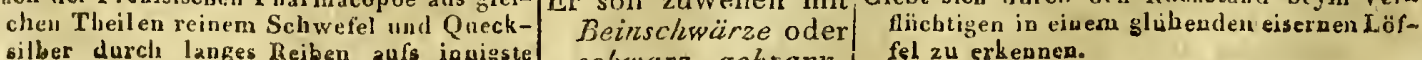
silber durch langes Reiben aufs inuigste schwarz gebrann- 
Hydrargyrum sulphuratum nigrum. -- Ichthyocolla:

\begin{tabular}{|c|c|c|c|}
\hline $\begin{array}{c}\text { Namen } \\
\text { der Arzneymittel. }\end{array}$ & $\begin{array}{c}\text { Sinnliche Eigenfchaften derfelben } \\
\text { Merkmale ihrer Aechtheit und } \\
\text { Gïte. }\end{array}$ & $\left|\begin{array}{c}\text { Fehlerhafte } \text { Be- } \\
\text { fchaffenheit, } \\
\text { wechfer- } \\
\text { Ferfälfchung. }\end{array}\right|$ & $\begin{array}{l}\text { Deren } \\
\text { Kennzeichein und Priffungsmittel. }\end{array}$ \\
\hline $\begin{array}{l}\text { Hydrargyrum sul- } \\
\text { phuratum ni- } \\
\text { grum. }\end{array}$ & \multirow{2}{*}{$\begin{array}{l}\text { verbunden, bereitet. Ein feines, durch- } \\
\text { aus schwarzes, hernch- und geschmacklo- } \\
\text { ses, im Wasser und Alcobol unaulösliches } \\
\text { Pulver, wobey man selbst mit bewaffnetem } \\
\text { Auge kcin metallisches Quecksilber meht } \\
\text { erkennen darf. Im Feuer verflüchtigt sich } \\
\text { der Mineralmohr mit bläulicher Flamme } \\
\text { nod Schwefelgeruch, und entzündet sich } \\
\text { schon, ehe das Gefäfs glühet. Er mufs da- } \\
\text { bey ganz verłliegen, ohne eınen Rückstand } \\
\text { zu hinterlassen. }\end{array}$} & $\begin{array}{l}\text { tom Elfenbein ver-1 } \\
\text { fälscht werden. }\end{array}$ & \\
\hline $\begin{array}{l}\text { Aethiops mineralis. } \\
\text { Schwarzes Schwe- } \\
\text { felquecksilber. } \\
\text { Mineralmohr. }\end{array}$ & & \multicolumn{2}{|c|}{ 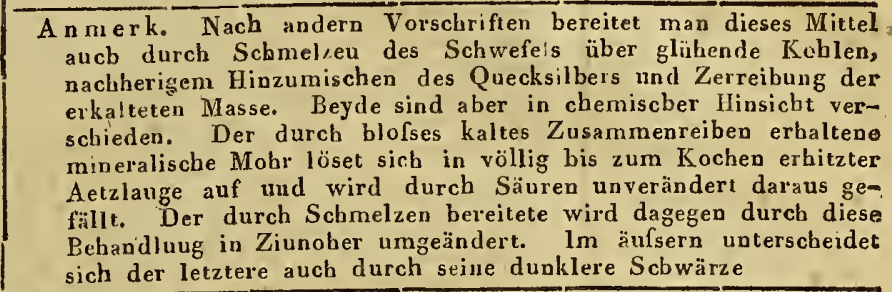 } \\
\hline
\end{tabular}

Hydrargyrum sulpluuratum rubrum.

Rothes Schwefelquecksilber.

Hydrargyrum sulphurizum Havum. Turpethum minerale.

Gelbes schwefelsaures Quecksilberoxyd.

Mineralisclier Turpith.

Hydrargyrum tartaricuin.

Tartarus mercurialis.

Weinsteinsaures Quecksilber.

Ouecksilberwein.

stein.

Siebe Cinnabaris.

in schefelches aus denz Qnecksilbervitriol durch kochendes destillirtes Wasser abgesoudert tund der entstehende gelbe Niederschlag wohl ausgesüfst und im Schatten getrocknet wird. Es abgesoudert und der entstebende gelbe Niederschlag, wel hes einen metallischen Geschmack hat und heftiges stellt alsdaun ein scliön schwefelgelbes Pulver dar, welcer eich, wird im Sonnenlicht leicht grau- oder Brechen und Purgiren erregt. Es ist kaum im nach dem Erkalten wieder gelb, fast glühend gemacht stölst

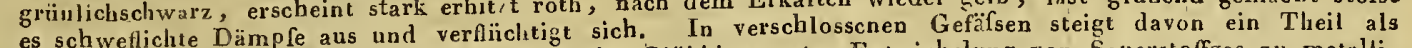
es schweflichte Dämpfe aus und verfichtigt sich. In verschlosscher Gidelung von Sauerstoffgas zu metalliweifser Snblimat anf. Das Uebrige wird in der Git Kochsalz sublimirt, giebt es ätzendcu Quecksilbersublischem Quecksilber bergestelli. In Verbindnug mit Kochsalz Es mufs gegen die Einwirkung des Lichts mat, wobey schwefelsaures Natrum am

ird bereiter, indem man zu einer Auflö-/Mit Salpeter verun-/Dieses ist der Fall, wenn die nicht crystalli-

Fitrargyrum tartarisatum.

Mercurius tartarisatus $\mathrm{Se} 11 \mathrm{i}$.

Tartarisirtes

Quecksilber.

\section{Ichiluyocolla.} Colla Piscium. Hausenblase. sung des rartarisirten Weinsteins oder des reinigt.

Seignettesalzes so lange eine heils bereitete salpetersaure Quecksilberauflösung tröpfelt, als sich noch ein Niedlerschlag zeigt, diesen clarauf absondert und ein parmal mit wenigem kalten Wasser abspült, ihn dann auflöset und die schnell fltrirtc Außösung aufloset und die schnell fltrirtc Audosung zum Crystallisircn bringt, worauf die ethaltenen Crystallen zwischen weilsem Druckpapier getrocknet werden. Es bildet dieses Salz weirsglänzende, schuppichte Crystallen, wclchc auf Koblenfeuel den eigenartigen Geruch der brenalichten Weinsteinsäure verbreiten und auch bey der Destillation, wobey znletzt metallisches Quektsiber anfistergt, dieselben Producte, wie die Weinsteinsäure lieferu. Von dem essigsauren Quecksilber unterscheidet es sich nicht nur durch seine Cryscheiderm dadurch, dafs stallenform, son es mit einer Aufosung der essigsauren

Kalkerde einen Niederschlag giebt, Wel-
cher weinsteinsaure Kalkerde ist.. um neue Crystallen zu erhalten. Es schiefst daun zuletzt mit dem weinsteinsauren Quecksilbcr auch etwas Salpeter an, weil dieser bey dem Aussüifsen des Niederschlages gemeiniglich nicht völlig entfernt werden konnte. Der Salpetergebalt wird sich übrigens durch Verpnffen des Salzes anf glühende Koblen zu erkennen geben.

tht aus $z$ wey Theilen gereinigtem Weinstein und einem Theil reinem Quecksilber, die, mit etwas wenigem Wasser angefeuchtet, durcb anhaltendes Reiben zum feinsten Pulver gebracht werden. Man darf darin auch durch die Lupe keine metallisclien Theile entaecken und mit beilsem Wasser thergossen, welches auch durch die Lupe keine mets blos oxydulirtes und bein metallisches Quecksilber ausscheiden.

Fin aus der Schwimmblase des Störspchlechtere Sorten|Unterscheiden sich von der ächten und guten (A c i penser S t u ri o L.) und des durchs Auskochen durch ihre gelbe Farbe und geringere DurchSewrjuga (Acipenser. stellatns von Flofsfedern, sichtigkcit. Auch die Ungarische HauSingewejden, Häu- senblase ist bey weitem nicbt so gut als die L.) ausgekocht verdicbteter Leim; nacb Russische; sie ist noch einmal so grofs uud dumnen Hautchen verdicbude, zusarnandern die innere, glanzende, zusammengcrollte und fetrocknete Haut der Hansenblase in runden, gewundenen, bufHansenblase in runden, gewundenen, bufförmig gestalteten, fingerdicken, ans ver-
schiedenen zusammengerollten Blättchen schiedepen zusammengerollten blattchen bestebenden Massen von weifser oder weifsgelblicher Farbe, mehr oder wentger durchsicbtig und ganz olne Geruch. Im Wasser oder brasu einer zähew und steifen Gallerte ruf, die, wenn sie flüssi ist, selu fest zusammenleimt. Gute und untadelhafte Hausenblase ist weifs, bornartig durcbscheinend, trocken, yöllig geartig durchscheinend, trocken, aus dünnen Häuten. Die beste Sorte kommt aus ten und Gräten gro Iser Seefische bereitet, namentlich vom dick, als diese, aber gelb oder bräunlich Hausen (Acipenser Huso L.) vom Ster let (Acipenser ruthentis $L$.) und vom Wels (Silurus von Farbe und gar nichı klax. 


\begin{tabular}{|c|c|c|c|}
\hline $\begin{array}{l}\text { Namen } \\
\text { ler Arznegmittel. }\end{array}$ & $\begin{array}{c}\text { Sinnliche Eigenfchaften derfelben } \\
\text { Merkmale ihrer Aechtheit und } \\
\text { Güte. }\end{array}$ & \begin{tabular}{|c|} 
Fehlerhafte $B e-$ \\
fchaffenheit, Ver- \\
wechfelung oder \\
Verfälschung.
\end{tabular} & $\begin{array}{l}\text { Deren } \\
\text { Kennzeichen und Prüfungsmittel. }\end{array}$ \\
\hline
\end{tabular}

Infusa.

Aufgüsser

Flüssige Arzneymittel, die durch Uebergiefsen gewisser Substanzen mit einer Flüssigkeit entweder dnrch blofses Maceriren iu der gewöhnlicben Temperatur der Luft, oder durch Digestion in scliuler Warme und uachberigem Durcliseihen bereitet werden, und dic daher in $k$ alt-oder warmbereitete Aufgüsse zerfallen. Sie untersibeideu sich vou den Decocten dadurcl, dafs sie pur die tlüchtigern und feineren Bestaudihesle der extrabirten Species enthalten und dafs bey ihrer Bereitung kein K/scheu statt findet. Deshalb wendet man die Infusion wur bes solchen Arzneysubstanzen an, die das Koch.n nicht gut vertragen köunen, namentlich bey den aromatischen und riechbaren Vegetabilien, deren wirksame Theile durch das Kochen verloren gehen

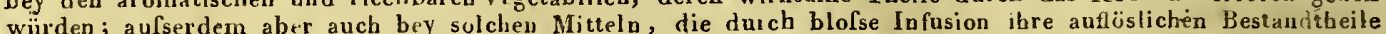
leicht von sich geben. Die Aufüusse sind daher auch nicht so gesättigt an Farbe und Bustandtheileu, als die Decocte, sondern beller von Fab und nach ihrer eigenthämlichev Natur mehr or er weuiger durchsichtig. Man hat übrigens bey den Ausgússen dahin zu sehen, dafs sie gehörig nach der Vorschrift verfertiget uud die zu extrahirenden Ingredienzeu in der ihnen zukommendeu Güte und zweckmälsigg vorbereitet, dazu angcwendet werden; dais bey den warm bereiteten Aufgüssen eine gelinde, nie den Grad des koclienden Wassers erreichende, Warme angewendet werde; dafs die Gefafse, worin der Aufgufs bereitet wird, gehörig verschlossen seyen, dimit die Hüchtigeu Theile nicht entweschen köınen, dafs endlieh sowohl die warm als kalt bereiteten Aufgüsse nach Maasgabe der zu extrahirenden Sprcies, die ihnen zukommenden Eigeuschaften in Farbe, Geruch uud Gescbmack besitzen. Vor allen Dingen kommt es larauf an, dal's der Apotbeker nicht, wie es so häufg geschielıt, die zu extrabiren den Species mit der bestimınten Flüssigkeit, statt sie rnit nicht, wie es so haufig geschielit, die z11. extrabiren den Species mit der bestiminten Absicht des Arztes; das letzterer zu infundiren, darnit koche. Ls ist tis gon Mittel wird dadurch gesatligter an Farbe und Bestandtheilen, ron ten len diejenigeu, welche er eigeullich linein, die der Arzt nicht darin haben will, theils und vorzugich gehen diejenigeu, welche er eigeunlich
beabsichtiget, durch die beym Kochen stärkere Hitze verloren; es ist daler nicht, was es eigentlich sejn soll und sciner Nitur nach aurh seyu mufs.

Zufusum Sennae compositum.

Zusaminengesetzter Sennaaufgufs.

Kuti aceticum.

Terra foliata Tartari.

Essigsaures Kali. Geb!älterte Weinsteizerde.
Ein Seunaaufgnes mit hin rugesetzler Mauna
uud Seignctusalz. Eine durchsichtig branuud Seignctısalz. Eine turchsichtig brau-
ne Flüssigkeit von einem süslich-salzigem Geschinack.

Ein aus reinem hoblensanren $\mathrm{Kali}$ und destilIrrtem Eșsig bereitetes Neutralsalz.

werfses, in Wasser und Weiugeist Ieich aulüsliches, wicht crystallisches, sondern aulüsliches, wicht crystallisches, sondern genehm erwärinenden, gelind salzichtem Genehm erwärnenden, gelind salzichlen Geschmack und einem eigentbümlichen he-
fonartigen Gcruch An der Luft zerfliefst f:nartigen Gcruch An der Luft zerfliefst
es sehr leicht. Die Auflüsung desselben darf die Lackmustinctur nicht rocb and die Fernambuhtinctur nicht violett oiler das Curcumäpapier braun färbeu, auch durch binzugegossene Säuren, ausgenommen durch die Weinsteinsäure, keinen Niederschlag gebcn, und von der im destillirten Wasser aufgelösten salzsauren Barjterde so wie voun Hydrolhionsauren Wasser nicht getrübt werden. In Weingeist aufgelïset darf es keine fremde Salze zuruicklassell. darf es keine frende Salze zurucklassen
Giefst man aufgelöste reine Weiusteinsäure Giefst man aufgelöste reine Weilusteinsäure
in eine Auflösung der Blättererde, so mufs sie eiuen weifsen Niederschlag, welches Weinsteinrahm ist, machen, uud die darüber stehende Flïssigkeit mufs freyer Essi seyn. Es muls dieses Salz in wohlverschlossenen und verbundenen Gläsern an einern trocknen Orte gegeu den Zntritt der Luft geschützt, aufhewabrt werden.

Anmerk. Strenge genommen darf die Aufï̈sing dieses Salzes weder durch den salzáuren Baryt noch durch das salpetersapre Silber getrübt werden. Allein da es nicht aus chemisch reinem Kali, sondcrn gewöhnlich aus gut gereinigle Pottascbe bereitet wird, und diese immer einen geringen Autheil von schwefel- und salzsanren Salzen enthält, so findet man diese anch in Zem essiggauren Kali, und sie werden durch die genanuten Reagentien angezeigt. Eine sebr geringe Men dieser Salze kann indessen hierbey wols! sehwerlich in arzneylicher Hingich Nichsehwerlich in arzneylicher Hinsicht Nachtheil bringen. - So ist auch eine etwas
graugelbliche Furbe dieses Salzes, wenu graugelbliche Furbe dieses Salzes, wenu es die übrigen Proben seiner Güte aushält, schwerlich als ein grofser Fehler
dessilben atzusehen; nur darf es dabey werler eiuen brenzlighen Geruch nocb Gesclumack zeigen.

Durchs Kochen bè-
reitet.
$\mathrm{Zu}$ alt und verdor-
ben.

Zu einer grumichten Masse eingedickt.

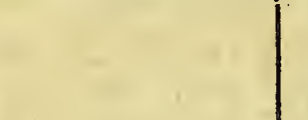

MitmetallischeuTheilen, vorzüglich mit
Bley, verunreinigt.

salzsauren Salzen verunreinigt.

Mit essigsaurem Kalk verunreinigt.

Mit tartarisirtem Veirstein verfälscht.

st dunkler von Falbe, weniger klar und durchsichtig, vou Geschunack unangenehmer.

Riecht saner, ist trübe, kahmicht, melı oder weniger gährend und hat eiuen Borensatz. Das Mittel bält sich überhaupt uicht lange und sollte billig jedesmal frisch bereitet werden.

in so bereitetes essigsaures $\mathrm{Kali}$ ist mehr oder weniger grau, gelb, bräunlich nnd empyrermatisch; der am Boden des Abrauchgefälses festsitzende Tbeil trocknet wegen der stärkern Hitze eher ein, als die ïbrige Masse; es verbrenut daher als grofser The Masse; es verbrcnut daber ein grolser Theil der Essigsare und gert verloren, wodurch als den achten Theil ungesättigtes Kali als den achten Theil ungesätigtes Kal Curcumäpapier brann färbt.

Wenn Bley darin euthalten ist, ein Fall, der nicht selten bey dem aus cliemischen Fabriken gezogenen Salze statt findet, weil
es in denselben wohl aus Bleyzncker nicht anf die sorgfiltigste Art bereitet wird, so wird die Auflösung desselhen durch $\mathrm{H}$ a huemauns Probetlüssigkeit schwarz niederseschlagen, odcr es eatsteht durch hinzugesetzte Schwefelsäıre ein wrilser, in Salpetersäure unanflöslicher Bodensatz. Ist das Salz mir Eisen veruureinigt, so ist es gewöhnlich ist es gewohnich gelbliche, un lösung desselben wird duch Gallappeltinktar schwarz, durch blausanirs Kal aber blan gefarbt. - Enthált es $\mathrm{Kupfes}$ so hat es eine giuntichweifse Farbe und färbt die Ammoniumflüssigkeit blau.

Die Aufösung wird alsdann von der salzsanren Barytaufösung, so wie von der salpetersaureu Silberaufösuug getrïbt.

In diesem Falle bewirkt sie iu einer Aullösung des kohlensauren Kali eine weilse sung des
Trübung.

Aufser dem schärfern und bilter eı n Geschnıack gicbt es bier folgende Kemzeichen. Die Auflösung wird durch concentrirte Essigsäure getrübt un der Borlensatz ist Weinsteinrahm. Auch Schwefel- und Salpetersteinrahm. Auch Schwefel- und Salpeter-
säure trüben die $\Lambda$ uösuog. Iu Weingeist säure trüben die $\Lambda$ nü̈suog. Iu Weingeist
aufgelöset bleibt der tartarisirte Weinstein aufgelöset bleibt
an Buden liegen.

Zuweilen wird sogar der blofse tartarisirte Weinstein fur die Blattererle genominen. Man entdeckt dieses durch die völligeUnauflösliclikeit in W eingeist, und Jurch den Mangel des eigenthïmlichen Essiogeruchs, weun gel des igenting zu dem trock nen Salie etwas concentrirte Schwefelsaru bigzugenisch wird. Hilt man ein mit allfyelostern Anrmonium befeurlitetes 'Papier über dic Mischung, so benerks man keinen Dampf, welches danm 
Kali aceticum. -- Kali carbonicum purum.

\begin{tabular}{c|c} 
Namen & $\begin{array}{c}\text { Sinnliche Eigenfchaften derfelben } \\
\text { Merkmale ihrer. Ächtheit und } \\
\text { Güte. }\end{array}$
\end{tabular}

Kali carbon.
crudurn.

Cineres clavellati.

Gemeines Kali.

Pottasche.
Kali carbonicum netutrale.

Alcali vegetabile crystallisatum.

Neutrales koblensaures Kali.

Crystallisirtes kolilensaures Kali.

Kali carbonicnnil purum.

Sal Tartari.

Kohlensaures Kali

Weinsteinkali.

Mildes Kali.

$\left|\begin{array}{c}\text { Fehlerlafte } \text { Be- } \\ \text { fchaffenheit, Ver- } \\ \text { wechfelung oder } \\ \text { Verfälfchung. }\end{array}\right|$

Deren

Kennzeichen und Priifungsmittel.

geschieht, welsu wirklich essiggaures Kall

dabey befindlich war.

Un don Uutersckied nicht so leicht bemerklich zu machen, soll es nacb $\mathrm{Sch}$ a ub (Abhandl. über ảie Güte und Verfälschungen der Arzneymittel, S. 350) Apotheker yeben, welche die beym Abrauchen des tartarisirten Weirstèins ebenfalls entstehenden blätterartigen Schuppen absondern und Ifür essigsantres Kali verbrauchen.
Dieses giebt das Gefühl zu erkennen.

Fenclut.

Mit Sand oder Kie- Giebt in doppelt so viel heifsem Wasser aufselerde geflissent- gelïset und filtrirt, beym Zugiefsen verselerde geflissent- $\begin{aligned} & \text { getriset und filtrirt, beym Zugiefsen ver- } \\ & \text { dünuter Schwefelsäure einen gallcrtartigen }\end{aligned}$
lich verfälscht. lich verfälscht. : $\quad \begin{aligned} & \text { dünuter } S c \\ & \text { Bodeusatz. }\end{aligned}$ hernach in eigenen dazu eingerichteten Oefen calcinirtes feuerbcständigcs Laugcusal leichten, löcherichten, eckigeu, zerbrechleichten, lächerichten, eckigeu, zerbrechgraubliulicher, schmutzig-weifser, blaugraubliulicher, schmutzig - weifser, blaugrünlich gefleckter Firbe nud von salzigem, schmac's, die an der Luft leicht feucht werden und zerfliefsen und die bekanoten auszeichuenden Eigenschaften der Laugeusalze haben. Es ist indessen đie Poltasche kein Jeines Gewäcbskali, sonder'n mit verschiedenen fremdartigen Theilen verumreinigt, zuweilen uch mit Kohlen, Asche, Erde ader Sand vermischt. Auch entiält sie reoder Sand ver uneiniglich noch frem $\mathrm{K}$ ali cee Salu, besonders schwefelsaures Käli uad die UngariKati. Am besten hält man die Ungari-
sche und Pohluische lottasche. Die reinste enthält z.wey Drittel bis drey Vierte! reines $\mathrm{Kali}$, und ein Viertel bis eiu Drittel fremde Salze und Uureinigheiten. Je weten Menge Säure erforden t wird und je weniger Rïckstand bey dcr Aullösung, in einer gleichen Menge Wasser bleibt, je mehr sie überhaupt sich dor Beschaffenheit eines re
nen Kali nähert, um desto bosser ist sie.

Mit Tlzonerde. Wird ans der gesättigten helleu Aufö́snng einer damit verfälschten Pottasche durch ätzendes Aminonium gefälli.

Mit Koclesalz.

Verrälh sich durch einen weit mildern, mehr salzichten als laugenhaften Geschmack, durch das spätere und langsamere Anzieben der Feuchtigkeit ans der Luft uud durch das Knistern auf olïhendeu Kolulen. Die mil Salpetersäure gesätiste Autlösuug Die mil Salpetiong macht mit schwefulsatarer Silberaunosung eiluen Niederschlag, woron 264 Gran 100

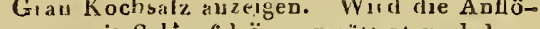
sung 1 init Schwefelsaue gesäıtı́t und dann crjstallisirt, so schiefst r'st schwefelsaures Kali und dann schwefelsaures $\mathrm{Na}$ trum all.

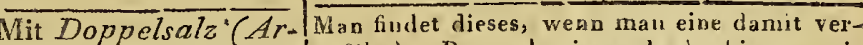
canum duplica- falschte Pottasche in sechzehu bis zwanzig

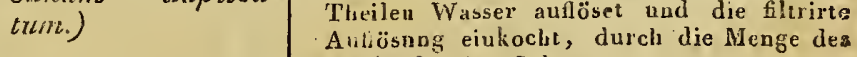
Antiösnng eiukoclst,
atisclisefsenden Salzes.

Mit ausgelaugées Dergleichen Beymischungen bleiben bey der Asche, Grpsu. dgl. Auliösurg iu gleschen Theilen Wasser ztMan fand die Pott- Aus der mir Salpetessure gesättigten AunöWir erhalten die l'otlasche aus den Paltniger Pottasche zur Sätti nug einer bestimmasche sogar Arse- sung wirl alstann rumch Kupfersalmiak asche sogar Arse- Scheeleus Gin und durch Halnenithlialtig. (Sirhe Sches Pubélïsigkeit Optrment geTrom $\mathrm{m}$ d orf malt.

Journal d. Pharm.

B.8. St. I. S. 187.)

A merk Genalts der Pottasche fustet man bey Schaub (Ueber die Güte und Verfälschons eiufucher und zusinmenges. Arzueym. B. 2. S. 15 -

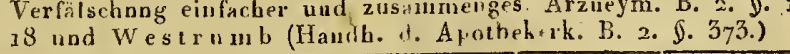

Gip vollkommen mit Kohlensäure gesättigtes Kali, welches mall edhät, weun m " las gewöhnhche reiue Kali in init Kohlensäure geschwängertem Wasser andöset. und dann die Auflösung zuı Ciystallisation befördert, in init Kohlensare geschangerte Kali auf flache Teller gestrent, in bewohuten Zimmern so lange der Luft oder wenn aussetzt, bis es zerllossen ün weifse Crystallen von einer regeinäfsig vierseitig-sänlenförmigen Gr stall, die wird. Es bildet sebr schone weilse Crystallen von einer regeimalsig vierseitig-sanntern eher etwas verwiteiuen milden alkalischen Geschmack haben, an der Luft nicht tructit werden, somerich aüen lassen, ubrigens tern, sich in fünf bis. sechs Theilen kaltem Wasser, in Alcohol aber - gar nicht anfösen lassen, ürigens aber den Veilclsensaft giüı und die Curcumälinctur braun färben. Seine inbrigell Kennzeichen der Güte und Fieinteit sind dieselben, wie bey dem gewöhnlichen Kali. Die Crystallen müsea in enen fest venstopften Glase aufbewahrt werden.

Wird auf verschierlene Weise, entweder Statt de

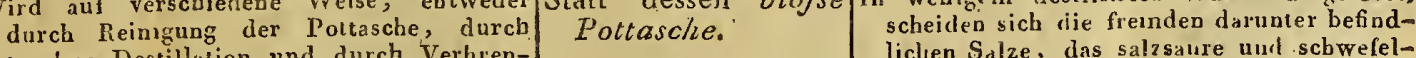
trockue Destillation und durch Verhren-
lichen Salze, das salasalure uurt scbwefel-
sanre Kali, die Kieselerde, Thonerde, der nung des Weinsteins in offeneu Gefärsen und Auslaugung des Rückstandes, oder auch durch Detonation des Salpeters mit Weinstein gewonnen, und ist nie völlio mit Kohlenstoffsäure gesättigt, weil die mit Ke, die zur Gewinnung desselben nötbi ist, imer wieder einen Theil davon fortist, immer bildet treibt. Gebürig bereitet, bildet es ein sehr weifses, trocknes, ziemlich scbarf, harnartig und, bitterlich schmeckendes, geruchloses, an der freyen Lnft völlig zerfliefsbares, in kaltem destillirten Wasse sich vollkommen und durchsichtig auflösendes $S_{a l 2}$, welches, da es nicht crystallisirbar ist, gewöhnlich in eingedicktem Zustande als zerriebenes Pulver aufbewahrt wird. Die Aufösung desselben darf mit ingetröpfelter Schwefelsänre nicht gallert-

n rur selen wird das kohlensaure Kali so reiu erlualten, dafs die dafs Selbst das Weinsteinkali, das reinste, welches der A potheker anSul Salpeter säure zuwenden im Stande ist, wird Es wäre dabej wohl zu weit geganrou jenen Reagentien getrubt. Es ware dabes wö̈usung mit diesen gen, wenn man ein solches Kat, sofort als unbrauchbar erklären wollte, 


\section{Kali carbonicum purum. - Kali nitricum crudum.}

\begin{tabular}{|c|c|c|c|c|}
\hline $\begin{array}{c}\text { Nemen } \\
\text { ier Arzneymitcel. }\end{array}$ & $\begin{array}{c}\text { Sinnliche Eigenfchaften derfelben; } \\
\text { Merkmale ihrer Ächlheit und } \\
\text { Güite. }\end{array}$ & \begin{tabular}{|c|} 
Fehlerhafıe Be- \\
fchaffenheit, Ver- \\
wechfelung, oder \\
Verfälfchung.
\end{tabular} & $\begin{array}{r}\text { Dert } \\
\text { Kennzeichen und }\end{array}$ & Priifungsmittel. \\
\hline $\begin{array}{l}\text { Kali carbonicum } \\
\text { purum. }\end{array}$ & 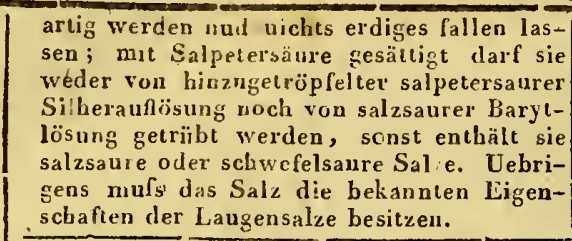 & 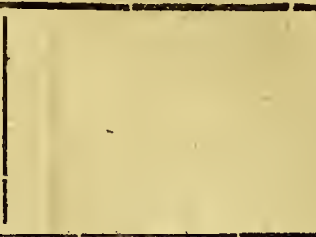 & $\cdot$ & - \\
\hline
\end{tabular}

sum.

Lapis causticus.

Aetzstein.

Kali causticum

siccum.

Trocknes ätzendes Kali.

Kaustisches fixes Alcali.

Kali citratum.

Sal Absinthii citratum.

Citronensaures

Kali.

Kali muriaticum.

Sal digestivum.
Salzsaures Kali.

Digestivsali.

Kali muriaticum - oxygenatum.

Oxygenirtes

saures Kali.

vou alch Wrigkeit befreyte und in einein eisernen Löfrel geschmolzene trockne Aetzkali, welches wie der Höllerstein in einer stählernen mit fetten Oel ausgestrichenen Form zu äbulichen dünaen Stängelcheu ansgegossen wird, die mit dex grösten Geschwindigkeit in ein crwärmtes Glas gethau und nachdem es fest verstopft worden, an einem trocknen Orte aufbewahrt werden. Der Aetzstein, welcher in sei-
nen übrigen Eigenscháften mit dem wachher folgendeu Aetzkali ibbereinkommt, darf nicht im geringsten nen übrigen Eigenscháften mit dem wachher folgendeu Aetzkali ïbereinkommt, darf nicht im
fcucht seyn, weil er dadurch viel vọn seiner aufserst scharfen uud ätzenden Eigenschaft eimbüfst.

Ein durch Verdunstung der Aetzlauge in einem eisernen Kessel bis zur Trockenbeit eingedicktes und in Stücken zerbrochenes Salz. Es bat eine weifsliche, ins Graugelbe fallende Farhe, zieht hegierig Feuchtigkeit an,
löset sich sehr leicht in Wasser, auch in Weinalcohol auf, zeigt, besonders zerflossen oder in Wasser gelöst, einen laugeuhaften Geruch und bat .einen üheraus ätzendeu, feurig stechenden Geschmack. Es besitzt einen so hohen Gratl von Schärfe, dafs es die Haut und andere weiche und harte thierische Theile, porzïgeinen so hohen Gratl von Schärfe, dafs es die Haut und andere weiche und harte thierische Theile, vorzüglich wenn sie vorher benetzt sind, schnell zerstört und Schmerzen erregt. Das Ammonium macht cs aus
seinen Verhindungen mit Säuren in ätzender. Beschaffenheit los, und mit vegetabilischen und thierischen seinen Verbindungen mit Säuren in ätzender Beschaffenheit los, und mit vegetabilischen und thierischen
Fetten bildct es halbweiche Seifen. Im chemisch reinen Zustande erhitzt es sich zwar mit Säuren, brauFetten bildct es halbweiche Seifen. Im chemisch reinen Zustande erhitzt es sich zwar mit Säuren, brau-
set abcr im mindesten nicht damit auf, und die farbenlose, belle, nicht lockichte Lösung desselben wird eben so wenig trübe; wenn man sie mit einer Säure neutralisirt, als wenn man sie mit Kalkwasser ude gelöstem' kohlenstoffsauren Kali mischt. Es unufs vor dem Zutritt dex Luft gesehützt in wohIverschlossenen Gläseru aufbewahrt werden.

A nmerk. Wenn das Aetzkali auch noch so gut bcreitet ist, so ziebt es doch bald wieder etwas Kohlenstoffsäure an, brauset dann mit Säuren und trüłıt das Kalkwasscr. Ueberhaupt lälst es sicb nur überaus schwer chemisch rein darstellen, und fast immer ist es von dell dazu gebrauchten Geschirren mit einem kleinen Gebalt von erdigen oder metallischen Theilen verunieinigt.

Ein gelblich-braunes, an der Luft leicht zerfliefsendes Salz, welches durch Sättigung des kohlenstoffsauren Kali mit abgeklărten Citronensaft und Verdampfen his zur Trocknc erhalten wird. Es hat eine pulverförmige Gestalt, riecht fast wie frisch gebacknes -Brod und schmeckt kühlend salzicht. Man znuís es in einem festverstopften Glase an einem trocknen Orte anfbewahren.

Ein aus der Salzsäure und dem koblenstofsauren Kali bestebendes Neutralsalz, welches bey vielen chemischpharmacevtischen Arbeiten als Nebenproduct gewonnen wird. In den meisten Eigenschaftcn kommi es mi dem Kochsalze ïberein, nur dafs es nicht in so ordentlichen Würfeln crystallisirt und im Gescbinack etwas schärfer ist. Die Crystallen sind an der Luft unveräadorlich, lösen sicb in drey Theilen Wasser auf, zerspringen in Feuer mit eivigen Ceräusch und schmelzen erst bey einem bohen Grade der Hitze, wobey sie blos ihr Crystallisationswasser verlieren. Die Auflösung darf nicht auf den Veilcbensaft wirken und die Anfösung des salzsauren Baryts nicht trüben.

Aus oxygenirter Salzsäure und Kali bestehend. Es bildet bald tafelförmige Rhomben, bald sechsseitige flache oder füofseitige prismatische Crystallen mit dachförmig abgestumpften Enden. Dic Crystallen sisd luftbeständig, lassen jedoch bey anhaltender Einwirkung des Lichts Sauerstoffgas fahren. Sie haben einen eigenartig kitaleud salzigen Geschmack. Im Wasser ist disses Salz leicht auflöslich, doch in gäöfserer Menge ber warner als bey kalter Temperatur, mithin durch Ablüblung selner Autösung crystallisirbal. Fis zerstört, wie die freye oxygenirte Salzsäure die Farbe organischer Stoffe; nach andern (Berlin. Jahrb. d. Pharm. 18o6, S. LII.) thut dieses a nur die noch nicht crystallisirte Lauge. Auf glühende Kohlen geworfen, verpufft es stärker als Salpeter. Mit verbrennlichen Stoffen, z. B. Phosphor, Schwefel, Kohlen v. dsl. zusammenes gerieben, orla blos für sicb iu eiver harten Reibscbale bis zu einiger Erhitzung gerieben, macht es gefahrlighe Explosionen, wie angezündetes Schiefspulver, weshalb man in dieser Finsicht sehr behutsam damit
unngehen mufs. Es entzündet sich lebhaft, wcnn es mit Zucker vermengt, mit dern vierfachen Gewicht concentrirter Schwefelsäure übergozsen wird. In der Hitze schmilzt es ruhig für sich, ohne zu knistern, und liefert in einer mit dem pneumatischen Apparat verbuudenen Retorte, dem Feuer ausgeselzt', das reinste Sauerstoffgas. Tröpfelt man in eine wäfsrige Auflösung desselben einige Tropfen starke Schwcfelsäure, so verbreitet sich alsobald der eigenartige, stechende, exstickende Geruch der oxysenirten Salzsäure. Durch die sehr auszeichnende Eigenschaft dieses Salzes, dafs es die Lösungen des salpetersauren Silbers, Quecksilbers und Blcyes nicht trübt, läfst sich bequem dessen Reinigkeit prüfen.

Kali nitricum cru-

drum.

Nitrum crudum.

Roher Salpeter.

aus Kali und Salpctérsäure bestehendes Neutralsalz, von welchern verschiedene im Handęl verkäufiche Sorten vorkommen, urimlich.

1) Deutscher roher Salpeter, wie er auf'den Salpetersiedereyen durch die Kunst häufg gewonnen wird, indem man von Schlamm, Mooreide, Gassenkotb, Mist, Uriu, Abfällen von Phanzen nuld Thieren, Kalk, ausgelaugter Asche, mit $\mathrm{Lchm}$ und Stroh vermischt, lockere pyramidenförmige Haufcn oder Wände nnter einem, nur wenig Luftzug verstattenden Ohdache auffübrt, sie vou Zeit zu Zeit mit Wasser befeuchtet und solcbe nach mehreren Jahren, wenn man bemerkt, dafs die Erde genugsam' mit Salz augcschwängert ist, mit Wasser auslaugt. Diese Lauge eutbält aber noch keinen fertig gebildeten Salpeter, sondern nur mit Kalk - und Talkerde geoundene Salpetersäure; es wird dlaler in den Siedereyen die uöthige Mcnge Asche, Ascher Monge Asche, Aschenlauge oder Tottasche hinzugesetzt, wodurch jene Erden niedergeschlagen werdell und Lange liefert durch Crystallisation den rohen Salpeter, der in mehr oder weniger regelmäfsigen Crystallen, Lange liefert durch Crystallisation den rohen Salpeter, der in mehr oder weniger regelmälsigen Crystallen,
in wcifsen oder schmutzigen gröfsern und kleiner.n Stücken vorkommt, die Feuchtigkeit der Luft stirk anzielit und noch manche andere Salze, salzsaure Bittererde, salzsaurén Kalk, Kochsalz, Digestirsalz und andere fremdartige Beymischungen enthält, von denen er zum arzueylichen Gebrauch erst befieyet werden mufs.

2) Natürlicbér rober Salpeter. Dieser besteht aus kleinen Stücken, ist aber nicht so weifs nad rein, als der deutsche, sondern siebt schmutzig und unrein aus. Er wird ${ }^{-}$in Ostindien in erstaunlicher Menge an verschiedenen Orten aus der blofsen Erde ausgelangt und von da nach Enropa verführt. Man erhält ibn zum Theil von IIamburg, wohin er mit dänischen, schwedischen und andern Schiffen gebrachs wird. Auch Holland soll davon jährlich eine grofse Menge nach Enropa führen. Im Königreich Neapel giebt es ebenfalls Gruben, in welchen der natirliche Salpeter aus Kalkstein hervorbchiefst. Auch Ungarm gesitzt Salpeterflötze.

3) Crystallisirter Salpeter (Nitrum crystallis.atum), aus dem ostindischen roben Salp-ter ausgelaugt und crystalliširt. Die Materialistea verkaufen diesen zwar für gereinigten Salpeter und uau- 


\section{Kali nitricum purum. -- Kali tartaricum.}

\begin{tabular}{c|c|c|c} 
Namen & $\begin{array}{c}\text { Sinnliche Eigenfchaften derfelben ; } \\
\text { Merkmale ihrer Aechtheit und } \\
\text { Güte. }\end{array}$ & $\begin{array}{c}\text { Fehlerhafte Be- } \\
\text { chaffenheit, Ver- } \\
\text { wechfelung oder } \\
\text { Verfälfchung. }\end{array}$
\end{tabular} \mid Kennzeichen und Priifuingsmittel.

che Apotheker gebraucheu ihn auch dafür, allein selır mit Unrecht, ' da er immer noch mit Kochsalz und erdigen Mittelsalzen verunreingt ist, und daber zun Arzneygebrauch woch einer abcrmaligen Reinigung bedarf.

Kali nitricum pum rum.

Nitrum depuratum. Gereinigter Salpeter.
Fali sulpluturatun. Hepar Sulphnris salinum. schwefelkali. Schwefelleber.

Kali sulphuratum stibiatum.

Hepar Antimonii.

Spiefsglanzhaltiges

Schwefelkali.

Spiefsglanzleber.

Kali sulplunricum.

Tartarus vitricolatus.

Schwefelsaures

Kali.

Vitriolisirter Weinstein.

Kali tartarictum.

Tartarus tartarisatus.

Weinsteinsaures

Kali.

Tartarisirter Wein. stein.
Lan crbält den gereinigten Salpeter durch|Mit längliclıt crystal- 0 Der Geschmack ist mehr bitter als scharf wiederholtes Auflösen und Crystallisiren lisirtem Glauber- und nicht so kühlend. Auf Kohlen gedes rohen Salpeters, wohey man, um die salz verfälscht. worfen verpufft er nicht. Die wälsrige Aufnoch aufgelösten erdigen Theile niederzuschlagen, elwas Kali binzusetzt. Er bilhelle, weifse, prismatische sechsseitige Cryfem Geschmack. Sie müssen sehr trockeu scyn, eiuen Klang haben, in der Hand leiclit scyn, eiuen Klang haben, in der Hand leiclit zerspringen, an der Luft uuverauderlich bleibell, auf glühendeu Koblen stark und
ohne Knistern und Aufschwellen verpuffen. In siebeu bis acht Theilen Wasser aufgelöst dart die Aufösung wedcr von flüssigem Gewächskali, noch von sal petersaurer Silberaunösung oder salzsaurer Barytaufl̈̈sung getrüht werden; auch darf sie den Violensaft nicht grün färben.

Mit erdigen Mitlellösung giebt mit aufgelöster salzsaurer oder essigsaurer Baryterde einen Läufigen weifsen Niederschlag. An der Luft zerfäl das Glaubersalz in ein weifses Pulver. sung getrübt, oder es entsteht eiu Nieder-

Mit Kochsalz oder Verknistert im Ecuer. TTröpfelt man in eine Digestivsalz ver- Aufösung desselben etwas Silberaulösung, unreinigt. halten ist.

Es ist jedoch zu merken, dafs inan selten einen, scllost durcl wiederholle $\mathrm{Cry}$ stallisatiouen zereinigten Salpeter antreffen det alsdaun grofse, lange, durchscheincnd sichter Niederschlag, wenn viel darin entwerde, der nicht durch eine mit deren beroü der sileinen einen geringęn Gebalt an Salzsänre anzei-
gen sollte.

Aus einem Theil'gepulverten Schwefel und zwey Theilen gereinigler Pottasche bey gelindem Fener zusammengeschmolzen und nach ilem Erkalten gröblich gestofsen, bereitẹt. Eine leberbraune Masse, die sich im Wasser mit einer dunkelgelben oder rothbrauneu Farbe auföset. Aus ihrer Auflösung wird der Schwefel dnrch verdïnnle Schwefelsâure nit einer sclanutzis weifsen Farbe und unter Verbreitung eines häfsliclien Geruchs, der dem nach fanleu Eyern ähnelt, niedergcschlagen. Da sie an der Luft leicht zerfliefst und dadurcb zersetzt wird, so mufs sie in trockrien luftdichten Gefäsen aufbewahrt werden. So lange sie und dadurcb zerselzt wird, so mufs sie in trockren luftdichten Gefäfsen aufbewahrt werden. So lange sie
völlig trocken ist, bat sie keinen Gernch; wird sie aher nur etwas feucht, so bemerkt man alsobald den völlig trocken ist, bat sie keinen Gernch; wird sie aher nur etwas feucht, so bemerkt man alsobald den
angezeigton Geruch.

us einem Theil roben Spiefsglanz nnd zwey Theiten trocknen kohlensanren Kali durch Scbuelzeo in einem wohl verdeckten Schnelzliegel bcreitet. Die ausgegosseue Masse, welche zerschlagen eine rotbhraune, mattglänzende schlacke bildet, wird, sobald sie erhartet ist, noch vor dem völligeo Erkalten zu.Pulver gestofsen nud da sie an der Luft lecht feucht wird und zerfliefst, in einein wohl verstopflen nnd verbunfenen Gefäfse aufbęwahrt. In Alsiclit der Güitekenuzeichen kommt dieses Mittel mil dein vorigen (Kali sulphuraGefälse aufbesvahrt. In Alsicht ziemlich übereib, aufser dafs lessen wälsrige Auflösung mit zugesetater verdüunter Schwefelsäure eınen tum) ziemlich übereib, aufser dafs lessen wäl
dunklen orangefarhenen Niederschlag giebt.

Ein aus Schwefelsuure und Kali bestehen-l In Pulverform ver-jSieht etwas röthlich aus und dart von den des Nentralsaiz, welches weifse, obnge-
fähr erbsengrofse und balbdurchsichtige, $\quad \begin{gathered}\text { Apothekern nicht gek atit werden, da es } \\ \text { leicbt nit Korbsalz nud andern fremden }\end{gathered}$ fähr erbsengrofse und balbdurchsichtige an der Luft weder fettcht noch mellig werdende Crystallen bildet. Die Gestalt ditses Salzes ist indessen sehr veränderlich; gewöhnlich bes'eht es aus zwey mit iluem Fufs gegen eimander stehenden sechss itigen Pyramiden, oder aus zusammentängenden Stücken, die áus lanter, werig zu unterscheidenden Crystallen zusammengesetzt sind. Es bat einen bittern salzichten scharfen Geschmack. In kalten Wasser ist es sebr schwer auflöslich, so dafs ser ist es sebrehu bis aclitzehn Theile, von davon sicbenzehu bis achtzehn heile, kochendem hingegen ner funf bis sechs Theile erfordert werdeu. Auf ginhende Kohlen gestreut, verknistert es. Die wäfsrige Aufösung darf, wenn es ganz rein ist, weder die Lackmustinctur noch die Feinambucktinctur umändern, mit Kaliaufösuo nicht getrïbt werrlen, von der Galläpfeltinetur nicht schwarz, und von Hydrothionsaurem Tasser nicht braun oder schwarz worden. Das sogenannte Doppelsalz (Arcanum duplicatum) ist, wenn es durch Auflösung in Wasser und wenn es durch Auftestur wohl gereinigt wordcn ist, mit diesem Salze ein und daswordcin
selbe.

Durch Sättignng des in siedenden Wasser aufgelösten Kali mit gepulverten Weinsteiucrystallen, Durchseihen der Flüssigkeit und Abdunstung derselben bis zur Trockne bereitet. Ein weilses, pulverförmiges, in der freyen Luft $z w a r$ etwas feucht miges, in der freyen Luft $z$ War et was feucht werdendes, aher nicht zerfliefsendes Salz,
von einem nicht widrigen, etwas scharfen und salzichtem Geschmack, welches sich in WVasser leicht, in Weingeist aber gar nicht auflöset. Die wäfsrige Auflösung, welche leicht schimmelt, darf die Lackinustinctur nicht röthen, das Curcumäpapier nicht

\begin{tabular}{l} 
In Pulverform ver- \\
käulich. \\
Mit metallisclıen \\
$\begin{array}{l}\text { Tlueilen verunrei- } \\
\text { nigt. }\end{array}$ \\
\hline Mit Thonerde verun- \\
reinigt. \\
\hline Zit Zink verunrei- \\
nigt. \\
Kali. \\
Nicht gehörig neutra- \\
lisirt. \\
Stait dessen ein blo \\
Weinsteinrahm und \\
von
\end{tabular}
Tbenlen verunreinigt seyu kann.

Ein mit Eis e $n$ verumeinigtes schwefelsaures Kali ist gewöhnlich gelh und die Aunösung wird durch Galtäplettinctur schwála lich. Mit K up fer verunreiuigt farbt es das Annmonitin blitu.

Hat einen a launartigen zusammenscnu umptenden Geschmack. Die Aufösung wird durch Laugensalze getrübt.

Ein mil Zinkvitriol verunreinigtes Doppelsalz, welches zuweilen im Handel vorkomnt spielt etwas ius Röthlicbe; seine Crystallen sitzen krusienförmig beysammen und stellen nicht sechsseitige, sondern verschoben vierseitige doppelte Pyramiden yor; set sich viel reichliclier in W asser ; es lögiebt unit Kaliaufösung vernish auf und Aufhrausen einen weifsen Niaderschlag, der mit Koblen vermisclit im Glübefeuer der mit Kolllen vermisclit im Glübefeuer mi blendender Flamme brennt.

Wird während der Auflösung in Wasser ein Aufbrausen erregen nud ein weifses Pulver zu Boden fallen lassen.

Zerfiefst an der Luft und ist dann entweder von Anfang an nicht gebörịg nentralisirt, oder es ist ein Theil der Weinsteinsäure frey geworden. Aufserdem zeigt dieses die Prüfung mit Lackmustinctur und Cur= cumäpapiel. nen verbrannt und ein Theil Kali wierder 


\begin{tabular}{|c|c|c|c|}
\hline $\begin{array}{c}\text { Namen } \\
\text { Ler Arzneymittel. }\end{array}$ & $\begin{array}{c}\text { Sinnliche Eigenfchaften derfelben; } \\
\text { Merkmale ihrer Aeclutheit und } \\
\text { Güte. }\end{array}$ & $\begin{array}{c}\text { Felilerhafie Be- } \\
\text { Schaffenheit, Ver- } \\
\text { wechfelung oder } \\
\text { Verfälfclung. }\end{array}$ & $\begin{array}{c}\text { Deren } \\
\text { Kennzeichen und Priifungsmittel. }\end{array}$ \\
\hline \multirow[t]{3}{*}{ Kalitartaricum. } & \multirow{3}{*}{$\begin{array}{l}\text { brann färben, und mit Laugeusalzen lver- } \\
\text { mischt, nicht trübe werden. Von jedler } \\
\text { hin/ugemischten Säure entsteht ein weifser } \\
\text { Nierlerschlag, welches wiederbergesteliter } \\
\text { Weiustein ist. Durch essigsaures Bley ent- } \\
\text { steht ebenfalls ein Niederschlag, der aber } \\
\text { in zugesetzter Salpetersänre wieder aufiös- } \\
\text { lich ist. Vou Hydrothionsaurem Wasser } \\
\text { darf die Aunösung nicbt braun oder schwarz } \\
\text { werden. In einem Schmelztiegel völl:g } \\
\text { ausgeglühet, mufs blos reines Kali zurück- } \\
\text { bleiben. }\end{array}$} & $\begin{array}{l}\text { Kupferhaitig, in kup } \\
\text { lernen Gefälse. } \\
\text { abgedunstet. }\end{array}$ & $\begin{array}{l}\text { Man löse eine Portion desselben iu lieifsem } \\
\text { Wasser auf, und stecke ein polirtes Eisen } \\
\text { hinein, wetches nach einiger Zeit einen } \\
\text { kudfernen rothen Ueberzug bekommen } \\
\text { wird. }\end{array}$ \\
\hline & & Bleyhaltig. & $\begin{array}{l}\text { Durch } \mathrm{Habnemanns} \text { Probeflüssigkeit } 2 \mathrm{u} \\
\text { entdecken. }\end{array}$ \\
\hline & & $\begin{array}{l}\text { Mit schwefelsauren } \\
\text { Mittelsalzen verun- } \\
\text { reinigt, wohin auch } \\
\text { das fälschliche Sub- } \\
\text { stituiren des Glau- } \\
\text { bersalzes gehört. }\end{array}$ & $\begin{array}{l}\text { Giefst man zu einer Aůösung des verdäch- } \\
\text { tigtu Salzes einige Tropfen yon einer Bley- } \\
\text { zuckerauflösung, so entsteht eis Nieder- } \\
\text { scblag, der sich nicht wieder in Salpeter- } \\
\text { säure auföset. }\end{array}$ \\
\hline \multirow[t]{2}{*}{$\begin{array}{l}\text { Kino. } \\
\text { Gummi Kino. } \\
\text { Gummi Gambien- } \\
\text { se. } \\
\text { Kino. } \\
\text { Gambiensergum- } \\
\text { mi. } \\
\text { Kinoharz. }\end{array}$} & \multirow{2}{*}{ 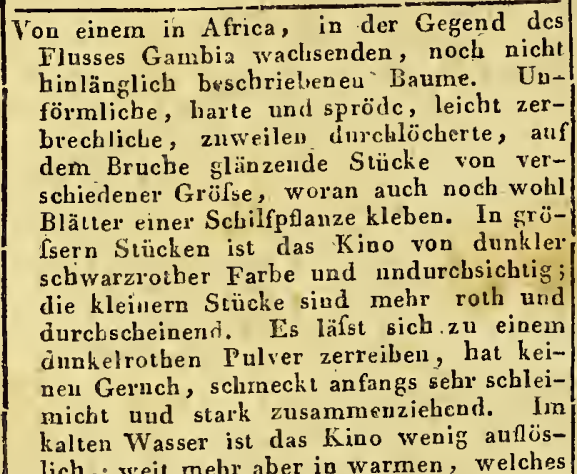 } & $\begin{array}{l}\text { Verwechselt mit dem } \\
\text { Drachenblute und } \\
\text { Catechusaft. } \\
\end{array}$ & $\begin{array}{l}\text { Vom Drachenblat } \\
\text { Kino durch seine Auf́ } \\
\text { Vom Catechus af } \\
\text { wäfsrige Auflösung } \\
\text { Klumpen gurinnt, } \\
\text { abweichenden Eigens } \\
\text { saftes. Eisenautlösnn } \\
\text { zugesetzte Kinoaúlïö } \\
\text { sondern schön dunk } \\
\text { sicb an der Luft nict } \\
\text { niedergeschlagen. } \\
\end{array}$ \\
\hline & & Nachgek & $\begin{array}{l}\text { Eine r } \\
\text { gesch } \\
\text { geist } \\
\text { der I } \\
\text { mein }\end{array}$ \\
\hline
\end{tabular}
lich, W w melches jedoc Auch der Wein unt ein mälsig starker Weingeist, valueteräthergeist lösen das Kino dunkelbraun auf. Es schnilzt nicht und entzündet sich nicht an der Flamme, soudern glimmt.blos und hinterläfst eive graue Asche.

Lacca in ramuliss. in baculis. Stangenlack. Stocklack. Rohes Lack.

\section{Lapides Cancro-} rumn.

Oculi Cancrorum. Krebsteine.

Krebsaugen.

hinterlafst eive gratue Asche. A n merk. Ueberhaupt genommen kommt das Kino jetzt sehr sei-
ten ächt zu uns und selbst unter dem ächten gicbt es manche kleine Abweichungen.

ne barte, fast durcbsichtige, barzicht-wachsartige, mehr oder weniger rothe, zerbrechliche, geruchlose, scliwach bitterlich zusammenziehend schmeckende, aus den Zweigen der in Ostindien wachsenden Vistenfeige (Ficus religios a L.) und des Op a u

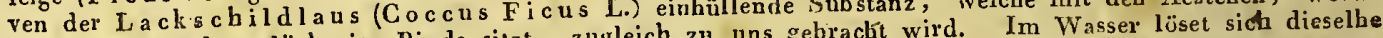
sie als eine unebene löcherige Rinde sitzt, zngleich zu Kohlen gewornicht auf, theilt ihm aber beym Kochen eine vortrefliche rothe Tarbe

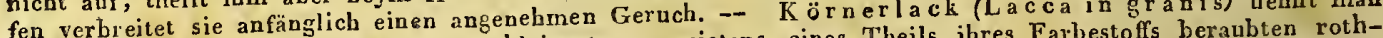
fen ver verkleinerten, meistens eines Theils ihes Tartosts ben die von den A welches seines nit Wasser auszugsartigcu Färbestofís beraubt, dann fïissig gemacht, durch einen leinenea Beutel geprefst und in dunden roth

Sie wer zuweilen Thon förmige, auf der eiren Seite $e_{j}$ erha- Nachgemacht.

bene, auf der andern flache und in der

Mitte vertiefle, glatte, harte und feste

kalkartige Körper, die sich äuf́serlich an

lieyden Suiten dos Magens der, Fluls-

krebse zur Zcit dcr Wechselung ibrer al-

teu barten Schale mit einer neuen, erzeu-

gen. Sie baben eine wcilse oder etwas

röthliche Farbe, ein blätriges Gewebe, einen erdartigen Geschmack uud keinen Geruch. An dor Zunge und an den Lippen kleben sie nicht an. In Wasser siud sie unauföslich; in verdïnnter Salpetersii ure aufgelösét, hinterlassen sie eine gallertartige Haut, welche die Fignr der unaufcelösten Steine hat. Man erbält sie in aufgelosten Steine Astrachan, wo man die grofser Menge ans Astrachan, Krebse zerstolsen faulen Fleisch mit Wasser abspült. Zum Arzneygebrauch mïssen die grofsen,

Lapides Cancro rum citrati. Cirronensaure Krebssteine.

Lapis caluminari Gallmeystein.
Die

Serbundenen Krehssteine, wodurch, wenn die Mischung bey gelindem lintem Feuer bis zur voligen weifslicht-gelbes, citroneusaures, erdiges und
woblverstopften Glase aufbewahrt werden mufs.

Ein natürlicher Zinkikalk in festen, harten, /Statt dessen kommt/Lälst sich nach Westrumb bis anf den Eiin natürlicber Zinkkalk in festen, hartcn, Statt dessen kommt aschgrauer, blaugelblichtbrauner oder rïtblichbrauner. Farbe, der gemeiniglicl neben dem Zinkkalk/ auch Eisenkalk, Thon- und Kieselerde enthält. Mán wählt

am besten den gelblichaschgranen, festen heter eisenhaltiger
Kalksinter vor. tallischen Geschmack bat. mit Tragantschleim, aufgelöstem Leim oder Hausenblase nachgemacht, verratben sich aber bald, weil sie theils nicht das blättrige Gewebe,dcr ächten Krebssteine haben, theils bey der Auflösung in Salpetersäure keine gallertartige Haut binterlasseis. Ueberdem sind sie schwcrer und we tie Zunge an, brausen mit Säure kaum merklich und zerfallen wie die von Kreide in warmen thun. 


Ner.Arzneymittel. $\left|\begin{array}{c}\text { Sinnliche Eigenfchaften derfelben; } \\ \text { Mamerkmale ihrer Ächtheit und } \\ \text { Giite. }\end{array}\right| \begin{gathered}\text { Felulerhafte Be- } \\ \text { fchaffenheit, Ver- } \\ \text {-wechselung oder } \\ \text { Verfälfchung. }\end{gathered} \mid$ Kènnzeichen tund Priifungsmittel.

Lapis Haematites. Blutstein.

Lichen islandicus Isländisches Moos

\section{Lignum campe-} cliianum. Campeschenholz.

$\overline{\text { Lignumz }}-\overline{\text { Guaja- }}$ cum.

Guajakholz. Pockholz.

Franzosenholz.

verscbalfte und ihn selbst röstete.

aul dem Harzc, in Böhmen u, s. w. watïlich vorkommcader Eisenstein. Aeufserlich ist derselbe gewöhn lich mit halbkugliehten Erhabenheiten besetzt und brangganzend; inwendig ist er derb und röthlichbratun

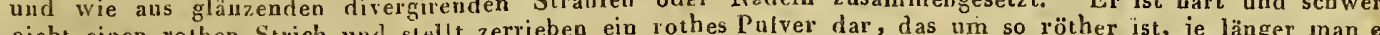
stellt zers gerieben bat. Sein Geschmack ist adstringirent. Zu pechelt mit einer/Diese hat kleinere, zartere und kransere Blät Cetraria islandica Willdeu. Eine/Verwechselt mit einer Diese hat kleinere, zartere und krausere Blättoockne, lertcrartige, mit verschierienen Abart derselben, die ter, die an ibrem Rarnle nicht mit Harchen mugleichen Einsclinitten versehene, od r $r$ in Scliweden, auch beselzt sind; ibrc Farbe ist meln bleich, ne Flechte, deren aufgebogener Rand mit $\mid$ land vorkommt. kurzen, feinen, steifien, parallel steben'kurzeu, feinen, steiten, parallel stebenden' Haaren' beselzt ist. Frisch hat sie eine grüulıch gelbroshe oder aschgriabraune, getrocknet aber eine weifslicirgrane oder grau-olıvengrüne Farbe. Hin iul! wieder finden sich eingesprengte weifse nud gegen die Spitze zu rothe Fleckeu und an einigen Stellen schildförmige, iunerhalb branne, glïnzencle, wenig ausgehöhlte Körper, wclches die Fruchnhcile sind. Sie enthalt vielen Sclileim, hat einen schleinuichien

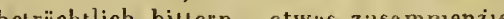
betrĭchelich bilien, etwas z lienden Geschmack und einen faden, moos-
artigen Geruch. Blatler rothbraun.

Das lolz des im wämern America wachsenclen Campeschenbaums, (Ha ematorylon Campechianum L.) Ein hartes, dichtes, festes unrl schwetes llolr in ziemlich grofsen, von der Rinde und dem Splint befreyteu Stücken, auswendig vor granbrauner, in wends, vou dunkelrother $F$ al be. Fisch gespalten zeigt es in der Iönge laufende schwalicle Adeıu, un in der Oneere \%erscbuitien kleine dunkelrothe, wellenför

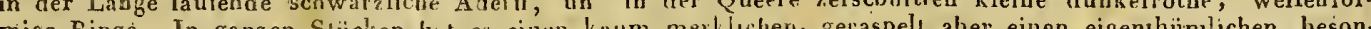
dern Geruch Fs hat einen /wsammenivheulen süflichen, zuletzt aber etwas biuerlichen Geschmack und färht beym Kauen den Speichel rotbbrännlich. lis datf nicht veraltet seyn und mufs durch den Dampf vou flüchtigem Ammonimm seine rolhe Fabe in eine: violette verämdern.

as Holz des auf den westiudischen Insela, Verwechselt mit dem |Ob inau oleich unter diesem Namen auch das besonders auf Jamaica und Domingo en- Heiligentrolz (Lig-

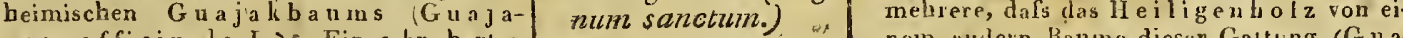
nein andern Bante diesr Gattung ( $G$ u afestes, schweres, im Wasser untersiukeudes und am Feuer gehalten, seiner has aichten Theile wegen mit beflcr Flamme and unter Ausschwitzung des flar es leicht brennendes, mit einer Rinde bekleiletes Holz. Es hat einen etwas scharf billeriichen Geschmack umul kallm merklichein, be`2n Reiben und Erwärmen aber sich stïrker entwickelndeu, angrncturen gewirzbalten Geruch. Answendig is to raut balten Gerach. Anw. rissicht and hit sohwan gragelbiche

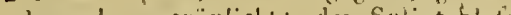
gefb und weniger fest. Wi, bekoinman es getb und weniger lest. Were Coner scinetheits in grofsten, meho cre Cencrer schue-
ren blöchen, theils in den Euglischen und Holländischen Arbeitshänser'n ze ts s lı n it ten (Scobs Ligni Guajaci), orlergt-raspelt (Rasnira Ligui Guajaci.) Die in Lie Länge gespaltenen Stücke siud einfarbig oder grünbrau mit dnukeln sefärbten Flanmen und läıslicheu schwarzen Puncten, oder auch mebrelblich, nnzen Puncten, oder auch seflament a o schwarzen Flecken bezeichnet; in die Queer oder schral durchschnitten ist der mitt lere Theil a unker schwarzlich grun, als an der âusern Flacbe. Das kleisgeschnittene und geraspelte Holz nimmt, der freyen Luft ansgesetzt nach weuigen Stunden eine blaugrüne Farbe an. Von letzterm mufs man immer das schwerste und dunkelfarbigste auswählen; das leichte, blaísfarbige ist minder gut, weil. es nicht so viele Harzthsile enthält. Es unterscheilet sich von dem ächten Gua jakholze durcli eine blafsgelbere oder gar weifsliche Farbe, ist leichter ais jenes, bat eives zartern grünetn Kern und wird fii wcuiger willisam gclialien. Andere (D ö r ffur t sind der Meinung, dafs der Unterschied blos anf das Alier, dern Standor und der Fällungszeit heruhe, dafs man zo dem Guajakholz mebr das eigentliche Holz, zu dem Heiligenbolz aber dea Splint verraspele. 


\begin{tabular}{|c|c|c|c|}
\hline $\begin{array}{c}\text { Namen } \\
\text { der Arzneymittel. }\end{array}$ & $\begin{array}{c}\text { Sinnliche Eigenfchaften derfelben; } \\
\text { Merkmole ihrer Aechtheit und } \\
\text { Güte. }\end{array}$ & \begin{tabular}{|c} 
Fehlerhafte Bc- \\
Schaffenheit, Ver- \\
weclyfelung oder \\
Verfälfchung.
\end{tabular} & $\begin{array}{c}\text { Deren } \\
\text { Kennzeichen und Priffungsmittel. }\end{array}$ \\
\hline
\end{tabular}

Lignum Juniperi. Das Holz des gemeinen Wa cholderstrauchs (Juniperù communis L.). Eiu mit ciner scliwarzWacholderholz. grauen Rinde ungebenes, unter der Rincle weifses, gegen den Kern zu aber gelblich-rothes Ilul/, welches sehr harzicht ist, éinen starken angenehmen balsamischen Geruch, besonder's wenn es angezindet wird, und " einen etwas scharfen gewürzhaften Geschmack bat. Man nimmt es von dem Stamme, den gröfsern Zwei-" gen und der Wurzel; welches letztere am wirksansten ist. Ilerr Li phard t (Briefe über das pharmacevtische Uebel, Leipzig, 1799, S. 190) erzählt, dafs einst bey einer A potbekenrisitation in Erinangelung des Wacholderholzes gutes ebrliches Buichenholz mit etwas Wacholderöl bestrichen, den Visitatoren als achtes
Wacholderbolz vorgezeigt, und von diesen für gut und frisch erkannt worden sey.

Lignum Quassiae. Quassiaholz.

Bitterholz.

Lignum Rhodii。

Rosenholz.

Rhodiserholz.

Lignuin Siassafras. Sassafrashola. tammt von der in Surinam, Jamaica,/Veraltet und verdorCayenne, Guiana und noch andern ame- ben. rikanischen Inseln wacbscnden Hochquassia (Quassia excelsa Swarzii) ber. Ein hartes, zakes, leichtes, licher oder blafsgelblicher Farbe und auf - licher oder blafsgelblicher Farbe und auf dem Sclinitt mit feinen aus der Mitte $\mathrm{gc-}$
benden parallelcn Strichen uud kleinen cthenden parallelcn Strichen uud kleinen ct-
was vertieften Puncten besetzt. Man erwas vertieften Puncten besetzt. Man er-
hălt es in walzenförmigen, geraden, seltner lrummen, ästigen oder böckerichten Stücken von verschiedener Länge und $\mathrm{Di}-$ cke, die theils rom Stamm, theils ron den Aesten und Wurzeln sind; Auswendig ist es mit der oben beschriebenen (Cortex Quassiae) leicht abzusondernden Rinde bekleidet. Es bat keinen Geruch, aber einen reinen, beym Kauen immer stärker werdenden, bittern Geschmack, welcber lange im Munde zurückbleibt. Der wälsrige Aufgufs darf vom aufgelösten schwefelsauren Eisen nicht in der Farhe verändert werden. Das beste Holz sind die dickern weifslichen und noch mit der Rinde versebenen Stücke. Die dünuern Stücke siud vou weit geringerer Güte uud láuge uicht so bitter als die dickern Stücke.

Di
Dieses Holz, dessen eigentliche Mutterpflanze noch uicht mit Gewifsheit bestimmt ist, bestelit aus langen, krummgebogenen, zwey bis drey Zoll dicken, ästigen, dichten, harten uud schweren Stücken, die mit einer weifsgrauen runzlicbten Rinde umit einer weifsgrauen runzich inuerlich mit weifsgelblichen, gelhröıblichen oder röthlichen Adern chen, gelhröthlichen oder rothlichen Adern tern balsamischen Geschmack und einen tern balsamischen Geschmack und einen lieblichen Rosengeruch, der sich besouders beym fieibeu oder Schaben offenbaret. Der wäfs'ige Aufgufs 'hat eine schöne gelbe Farbe und den Geruch und Geschrnack des Holzes. Je leichter es brennt, je schwerer und dunkler es gefärbt ist, und je stärker es riecht, un desto besser ist es.

Das Holz der Wurzel vom S as afras Iorbeer ( $L$ a urus $S$ assafras L.) in groSsen, dicken, ästıgen, knollifgen Stïcken, von einem weicben, leichten und scbwammichten "Gewebe, einer gelb - oder fablbräunlichen ins Rothe fallenden Farbe, einem süfslichen, gew ürzbaften, etwas scharnem Gehmack und fenchelartigen Geruch. fen Geschmack und mit der oben heschriebenen Rinde (S. Cortex Sassafras) bekleidet. Man mufs! die frischen, starkriechenden
und noch mit der Rinde verseheneu Stücke auswählen.

\section{Mit dem Holze de Corallenstumachs (Rlutus' metopium L.) verwechselt.}

Das im Handel verkäufliche geraspelte Quassienholz ist zuweilen ganz unächt.

Schlechtere Sorte.

Waclitolderholz
Wachen wohl substituirt.

Untauglich.
$\begin{aligned} & \text { Statt dessen wohl das } \\ & \text { W aclıolderholz } \\ & \text { substituirt. }\end{aligned}$
Die Sjücke sind alsdanu mit hraunen, nsch-
grauen, blauen oder schwäralichen Flecken oder Streifeu versehen, schmecken weni-ger oder gar nicht bitter und müssen als unwirksam verworfen werden.

Dieses Holz, welcbes die Westindier dem ächten Quassienbolz zuweilen unterschieben sollen, bat eine graue, glatle, hie und da mit schwaren fleckigen Puncten versehene und mit dem Holze dicht und fest zusammenbängende Rinde. Der wäfsrige Aufgufs des Holzes wird durch die Antósung des schwefelsauren Eisens scbwärzlich gefïht.

Ein Freund des Herausgebers erhielt uenlich unter dem Namen Lignum Quassiae raspatum ein Holz, welches meistens aus Zolllangen, sehr düunen und äufserst leichten Splittern von einer duukelgelhen Farbe bestand. Beym Kauen bemerkte man sehr wenig Bitterkeit; es färbte das damit gekochte Wasser bellroth, wie schwacher ache Waser bello Fernambuckanszag uad dirkte in demselben einew braunrothen Niederschlag.

Untauglich ist das inwendig bellfarbige, schwach riechende, und das mit einem fetten Oele durchzogene Holz.

Man erkennt es, aufscr den oben angegebenen Kennzeichen, leicht durch den Wacholdergeruch, der beym Schaben daran, oder beym Verbrennen des Holzes vorzüglicla bemerklich ist: Aeufserlich ist es mit der oben heschriebe-

Oft wird das Holz rom Stamme und den

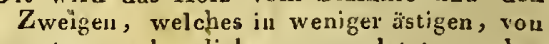
ersterm sehr dicken, vou letztern aber scbwächern Stücken besteht; mit den Wurzelholze unter einander vermischt, verkautt; es ist dies aber von weit geringerer Wirksamkeit, und mufs init $61 . \cdot \mathrm{m}$ veralteten, geruchlosen und unscbmackhaften Holze verworfen werdes.

Nach Hahnema un sollcu sich unter dem Sassafrasholze zuweilen auch Stïcke befinden, die einen Anisgerucb besitzen, ein zarteres und festeres Gewehe haben und als unwirksarn ausgeworfen werdeu müssen,

Er erwähnt auch, dafs ehedem bey dem theuren Preise des Sassafrasholzes, Fichtenholz in Fencholabsud gekocht, fïr ächtes Sassafrasholz verkauft worden sey.

Linimentum am moniatum s. volatile.

Ammoniumlinimellt.

Flüchtiges Liniment.

Tinimentum saponato camplooratum.

Balsamus Opodeldoch.
Wird nach der Prenfsischen T'harmacopoe aus drey Theilen Baumöl und einem Theile ätzender Ammoniumfüsbigkeit, die man in einem Glase so lange untereinander schüttelt, bis dadurcb eine dickliche weifsliche Misclung entsteliet, bereitet. Die Consistenz desselhen $\mathrm{mufs}$ das Mittel zwiscben einem Oele und einer Salhe balten. Es wird am besten auf jedesmaliges Verlangen frisch, oder doch kein grofser Voriatb daron, bereitet.

Eine gallertartige salhenähnliche, durch Digestion in einem gläsernen Gefäfse bereitete Mischung aus Seife, Campher, rectificirtem Weingeist, etwas Wasser, ïtzender Ammoniumfln̈ssigkeit, ätherischemn RosmarinKlumpen dariu befinden. Aucb mufs die fertige Mischng in eiuem weitnündigea, gut versiöpselten und" mit Blase verbundenen Glase anflowabrt werdoa. und Thymiä̈l. Sie mufs wohl gemisclat und die Seife gleichförmig aufgelöset seyn, so dafs sich keine 


\section{Liquor Ammonii acetici.- Liquor Ammonii pyro-oleosi.}

\begin{tabular}{|c|c|c|c|}
\hline $\begin{array}{c}\text { Namen } \\
\text { der Arzneymictel. }\end{array}$ & $\begin{array}{c}\text { Sinnliche Eigenfchaften derfellen; } \\
\text { Merkmale ihrer Aechtheit und } \\
\text { Güte. }\end{array}$ & $\left|\begin{array}{cc}\text { Fehlerhafie } & \text { Be.- } \\
\text { rchaffenheit, } & \text { Ver- } \\
\text { wechfelung } & \text { oder } \\
\text { Verfälfchung. }\end{array}\right|$ & $\begin{array}{c}\text { Deren } \\
\text { Kennzeichen und Prilfungsmictel. }\end{array}$ \\
\hline
\end{tabular}

Camphorirtes Seifenliniment.

$$
\text { sam. }
$$

Liquor Ammonii acelici.

Essigsaure Ammopaiumflüssigkeit.
Opodeldochbal-

Liquor Ammoniz anisatus.

Spiritus Salis ammoniaci anisatus.

Anisammonium -

flüssigkeit.

Anishaltiger Salmiakgeist.

Liquor Ammonii carbonici aquosils.

Spiritus Salis ammoniaci aquosus.

Flüssiges mildes oder luftrolles Ammonium.

Wäfsriger Salmiakgeist.

Liquor Ammonii callstici.

Spiritus Salis ammoniaci causticus.

Aetzende Ammoniumfiüssigkeit. Caustischer Salmiakgeist.
Liquor Ammonii pyzro-oleosi. A nnerkung. Die hierzu vorgeschriebene Seife mufs mit thierischem Fette (Unschliti, Sevum) berei-
tet seyno

Wird nach der, Preufsischen Pharmacopoe aus Sehr verdünnt. drey Unzen trucknem kohleustoffsanren Ammonium nit genugsamen concentrirten Essig gesättignt und so vielem binzugesetzinn destillirtem Wasser, dafs das Ganze vier und zwanzig Unzen an Gewicbt beträgt, bereitet. Diese Flüssigkeit, mit glcicheu Theilen Wasser genuischt, hildet sodanu den Geist (Spiritus Mindereri.) Eine reine essigsaure Ammoniumflussigkeit mufs farbenlos, völlig klar, von obstartigen, nicht hrenzlicbtem Geruche, eiuem salzigen erwärmend - stechenden, süfstichen Geschmacke, und ohue Trübung mit Weiu alcohol und geistigen Flüssigheiten mischbar seyn. Tröpfelt man Schwefelsäure oder eine andere Säure hinein, so mufs sie sogleisb den Geruch von frey werdender Essigsäure rou sich gebeu, so wie auf zugetröpfoltcr Kalilüssigkeit den stark flüch tigen Gerucl des sich entwickelnden Amigen Ges ches sich Veilclensyrups. Jie Thbe des hlauen Veilchensyrups und des Curcumapapiers dalf sie vicht verändern, obschon das Lackmuspapier wegen der, meistens selhiger noch adbärirenden Koblenstodfsäure noch etwas davon gerötbet wird, welches jedocl nach vorherigem Anwärmen oder Verdünnen mit achifaclter Menge kochendem destillirtem Wasser ebenfalls nich weiter geschielit.

iue nach der Preufsischen Pharmacopoe aus Weinalcobol, ätherischem Anisöl und ätzender Ammoniumflïssig keit bereitete Mischung. Das Oel mufs vollkommen aufgelöst seyn nind nicht in Trepfen oben auf schwimmen. Die Mischung selbst mufs eine helle weiugelbe Farhe liaben, klar nnd durchsichtigen auf schwimangenehmen, den Ingredienzen, aus welchen sie gemischt ist, entsprechenden Gerucb und Geschmack baben.

Ánmerk. Aufserdem kaun der Liquor ammonii acetici, so wie überbaupt jedes Salz, welches Essigsăure entbält, auch bleybaltis eyn, wenn der Essig, wclcber da<u angewandt wurde, mit Bley theilen verunreinigt war.
Cine Auflösung des kohlensauren Ammoniums in Wasser. Sie mufs, wenn sie gut bereitet und völlig gesättigt ist, ungefärbt und wasserhelle seyn, und wie trocknes Amınonium riecheı und schmeckstn. Mit Säuıen gemisch mufs sie stark anfbrausen, darf aber keinen Niederschlag damit grbeu. Mit Alcohol gemischt, mufs sich das Ammonium als ein gerinnender Klımpe (Olla Helmontii) abscheiden. Mit destillirtem Essig gesättigt, darf weder durch einige Tropfen salpetersaurer Silberaufösung, noch durch salzsaure Barytaufösubg eine Trübung erfolsen. Auch muls so "viel Ammoninm darin enthalten seyu, dafs sich michis mohe darin autlösen läls to

Eine Verbiudung des reinen oder ätzenden Kohlensäure enthol-llst die älzende A mmoniume Ammoniums mit Wasser. Sie mufs völ- $\begin{gathered}\text { tend. } \\ \text { nnd gut bereitet, so darf sie keine Koblen- }\end{gathered}$

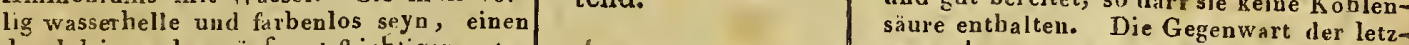
durchdringenden, äufserst flichigen, sic- , , tern erkennt man au dem Aufbrausen beym chenden und Erstickung drohenden Geruclı und brennen! ätzenden Geschmack besilzen. An der freyen Luft mufs sie bald und gänzheb verfliegen; zu eiuem Drittel mit fetten Oelen vermischt eine dickliche seifenartige Mischung hervorbringen. Das Kalkwasser und die Auflösung des salzsauren Kalks darf sie nicht trüben, und $\mathrm{mit}$ Siuren vermischt, sich zwar erwärmen, Saturen veruischt, sich zwar erwarmen, aber Auch darf ie von hinasegossenem Weingeist bicht niellergeschlagen werden und mnis dabey so leicht seyn, dals ein Glas, welcbes ein Loth dcstillirtes Wasser fafst, nnv etwa llrey Quentchen davon in sicb nimmt. Thre Stáke larst sich ubitigens schon durcb den Geruch beurtheilen.

ie aus einem, mit eiuem Flelm versebeneu, Glaskolten, durch nocbmaliges Abzieheu bis auf die Hälfte, gereinigte ammonial1scbe Flüssigkeit, welche man bey der trocknen Deftillation des Hirschlorns oder ge-
Nachgekünstelt aus asche und empyeinem Gemische vón Salmiak, Pott. damit vermischten Kalkwasser's und Weinalcohols. Man vergleiche Liquor a Weincarbonici aquosus und vimosus,

unstel man von einem solchen Hirschborn geist etwas in einem Löffel über die Flamme eines Lichts ah, so wird sich das ächte Ammonium gänzlicb ver@üchtigen, das dar in entbaltene salzsaure Kali aber zurïck- 


\section{4 \\ Liquor Ammonii pyro-oleosi. -- Liquor Hydrargyri nitrici.}

\section{Namen \\ ser Arzneymittel. \\ Liquor Ammonii pyro-oleosi. Spiritus CornuCer vi rectificatus. \\ Brenzlicht - ölichte sigkeit. \\ RectificirterHirsch- horngeist. \\ Liquor Ammonii} succinici.

Liquor Cornu Cervi succinatus. Ammoniumliquor.

Bernsteinsaurer Hirschhornspiritus.

Liquor Ammonii vinusus.

Spiritus Salis ammoniaci vinosus

Weinichte Ammoniumflüssigkeit.

Weinichter

miakgeist.

Liquor digestivus Disp. Lip.piaci Digestivliquor.

\section{Sinnliche Eigenschaften derfellen Merkmale ihrer Aechiheı und \\ Giite.}

\section{Fehlerluafte Be- Cchaffenheit, Ver- wechnfelung oder Verfälfchung.}

initer Kuochen zugleich mit trocknem A millin eine Verbindnn des tohleuftofsauren Amuiniums nit etwas empjrevmatischen Oele und TVasser. Der aut diese Art erbaltene rectificirte Hirschhorngeist besitzt gemeiniglich wegen seines Gebalts an empjrevmatischen Oele eine gelbliche Farbe, wird aher mit der Zeit meistens etwas gelbbräunlich: Bey erforderlicher Stärke bleibt etwas hineingeschüttetes Hirschhornsalz ungelöst darin liegen, und zngemischsal 2 ungelorst dinaricohol schligt einen crystallinischen Satz (kohlensaures Ammonium) darschen Satz (kohlensaures Amsonium) daraus nierler. Uebrigens muls er helle und klar seyn, entell alumoniakalischen, etwas brenzlichten Geruch und äbnlichen Geschmack haben und mit Sauren lebhaft autbrausen. Anch darf er, in einem glübenden Iöflel über Kohlen verdampft, nicht gallertartiges zurücklassen.

ne mit den brenzlichen Oelen des Bernsteins und Hirschhorns geschwängerte nelltrale Lauge des bernsteinsauren Ammoniums. Wenn die bernsteinsaure Amrnoninmäüssigkeit ächt und gut zubereitet ist, so hat sie, obne eine ölicbte Haut oder aufschwimmende Oeltropfen zu zeigen, ein völlig durcbsichtige gelbe, nach einiger Zeit sich jedoch ins Braungelbe ändernde Farbe einen cigenartigen, schwach flüchtigeu, brenzlichien Geruch uud äbulichen, etwas
stechend kühlenden, billertichen Geschmack, lälst dem Lackmus - und Curcumäpapier die Farbe, und nach abgedunsteter Feuclutigkeit bleibl davon ein in der Hitze völlig and unter Verbieituug des eignen Bet usteiusäured. revmatischen Oele, durch Auflösung in Wasser, ohne Destillation.

achgekünstelt aus Salmiak rnd Kalk schen Uel und Wasser entweder ohne Destillation oder durch Destillation.

\section{tatt des ächt berei} teten Mittels wird häufig eine mit $E s$ sigsäure, W Weinsteinsäure, Scluwe felsäure oder Salzsäure neutralisirte, brenzlich - ölichte Ammoniumflüssigkeit verkauf. mit empyrevmati-

\section{Kennzeichen und Priifungsmittel.}

bleibell. Eben das gescbiebt, wenn mian den durch Alcobol abgeschiedenen crystalliniscben Satz einer ähnlichen Behaudlung unterwirft.

m erstern Falle enthalt derselbe äizendes Ammonium und salzsaureu Kalk, brauset nicht mit Säuren auf, und giebt mit Kalifiüssigkeit eiven weifsen Niedersshlagr (tohlensaureı Kalk). Auch im zwejteu Falle br auset er nicht mit Säuren und beyın Ver-unischeu mit Alcohol scherdet sich hein kohlensaures Ammonium ah, sonderu die Mischung bleibt helle.
Die Verfälschung mit Essigsäur e entdeckt man durch das Hinzutröpfeln der concentrivteu Schwefelsäure, wobey sich der Essiggeruch entwickelt. - Die We insteius äu re durch das Hinzutröpfeln der salzsauren Barytauflösung, wobey ein Niederschlag entsteht, ter auf glühende Koblen geworfeu, wie verbrennende Weinsteinsiure riecht, und nach dem Gliihen die damit verbunden wewesene Baryterde rein zuruk-

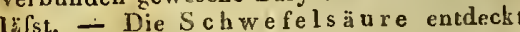
man ebenfalls durch die Trübung rnit salzmaurer Parytauflösung; der eutsteheude saur Niederschlag wird sich im Feuer in wenig atfblaben, sich aber nicht ganz in reise Salpetersäure auflisen lasscn und den erzeugten Schwerspat zurücklassen. - Di $\mathrm{SaI}$ s äur e verrätb sicb durch die federichen Crystallen, die nach einem Zusalz von gleichvieleu Weinalcobol darin anschiefsen, so wie durch die in Salpetersäure unaufüslichen Niederschläge, welche die Lösungen des salpetersauren Silber und Bleyes darin bewirken

Weun dicer Sulpen Dispensatori

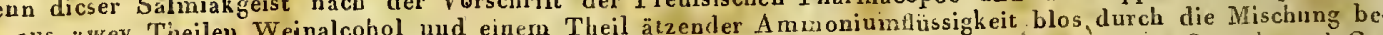
a 作 lie die gewobnliche Weise der wäfsrige Salwird, und daber aus mildem, nicht atzenden

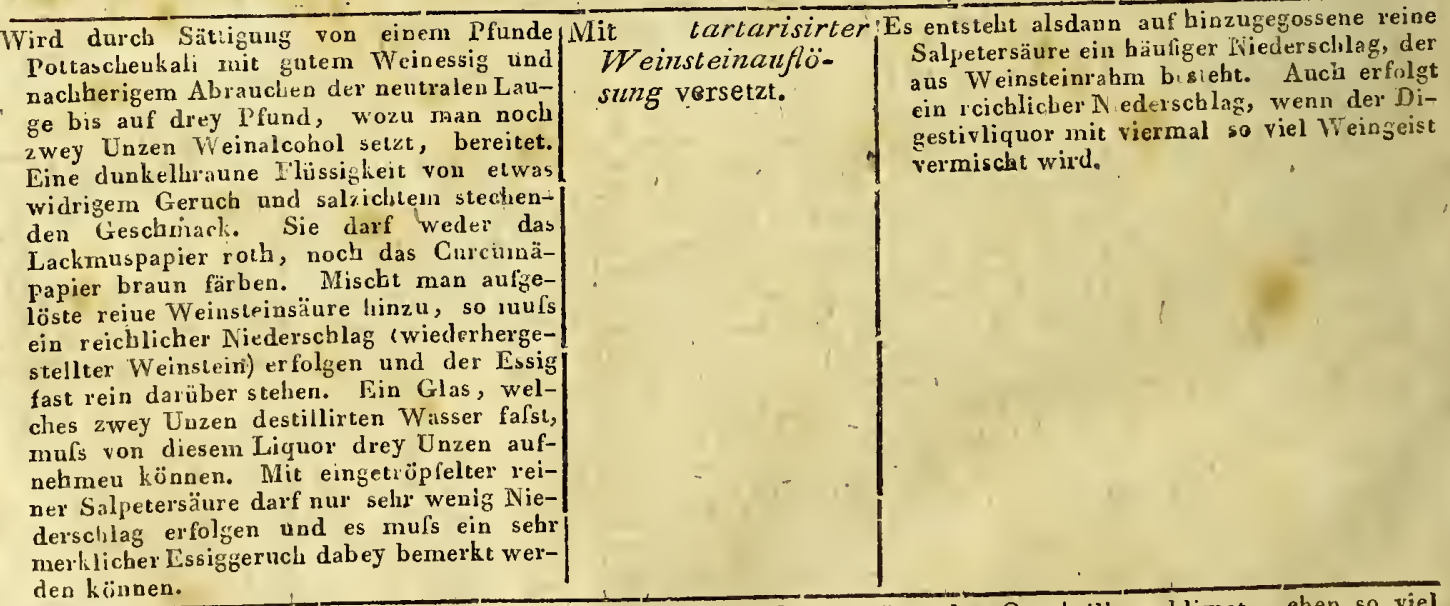
den k̈̈̈nen. den

Liquor Hydrargyri muri

Salzsaure Aetzquecksilberflüssigkeit.

Liquor Hydrargyri nitrici.

der Treulsiscben Tharmacopoe aus vier und 2 wanziš Granen ätıenden Quecksilbersublimat, eben so viel Salmiak, zwey Pfund destillirtem Wasser und einer Unze Rosenhonig durcl Aunosung und Mischung bereitet. Eine weingelbe, helle Flüssigkeit, die hit Kalkwasser vermischt einen weilsen Queksilt dessen jene fallcn läfst. - Das gewöhnliche phagedänische Wasser (Aqua phage d a e nica), sthlimat und hat Mischung vorgeschrieben ist, besteht aus atzendem, Quecksilberoxyde umgeschüttelt eine pomineranzengcibe Tarbe.

Wird nach der Preufoischcu Pharmacopoe durch Auflösung in gelinder Wărme von einer Unze Quecksilber in

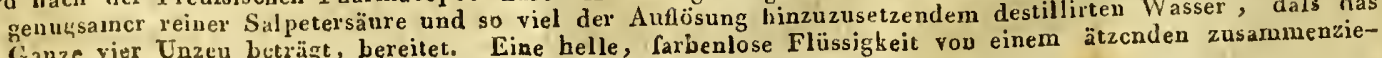




\begin{tabular}{|c|c|c|c|}
\hline $\begin{array}{c}\text { Namen } \\
\text { er Aizneymittel. }\end{array}$ & $\begin{array}{c}\text { Sinnliche Eigenfchaften derfelben; } \\
\text { Merkmale ihrer Ächtheit und } \\
\text { Güte. }\end{array}$ & $\left|\begin{array}{c}\text { lehlerhafce Be- } \\
\text { fchaffenheic, Ver- } \\
\text { wechfelung oder } \\
\text { Verfälfchung. }\end{array}\right|$ & $\begin{array}{c}\text { Deren } \\
\text { Kennzeichen und Priifungsmittel. }\end{array}$ \\
\hline
\end{tabular}

Liquor Hydrargyri nitrici.

Liquor mercurii nitrosi.

Salpetersaure

Quecksilberflüs-

sigkeit.

Liquor Kali aceti.

Liquor Terrae fo-

liatae Tartari.

Essigsanre Kaliflüssigkeit.

Blättererdenliquor.

$\overline{\text { Liquor Kali car- }}$ bonici.

Oleum Tartari per deliquium.

Kolilensaure Kaliflüssigkeit.

Flüssiges Kali.

Liquor Kali caustici.

Lixivium causticum.

Aetzkaliflüssigkeit. Aetzlauge:

Liquor Mjrrhae. OleumMyrrhae per deliquium.

Myrrhenflüssigkeit.

Zerstolsene Myrr

he.

Liquor pyrotartaricus.

Spiritus Tartari.

Brenzlichte Wein steinflüssigkeit.

Weinst eingeist. henden mctallischen Geschmack, die in einem mit eivgeriebenen Stöpsel velschlossenen und wohl verbmudemen, Glase aufhewalut werden mufs. Darf

Festeht aus einem Theile essigsaurcn $\mathrm{K}$ ali in Mit einer Auflösung| Man vergleiche die bey Kali aceticum ange-

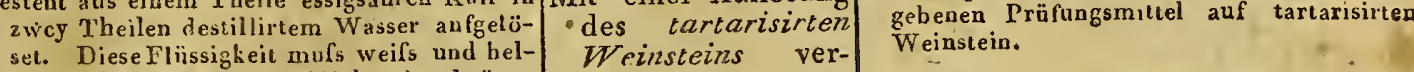
le aussehen; ist sie getblich odex bräun- setzt. lich, so war das essigsaure Kali nicht weifs, sondern anch gelb oder bräınlich. Zu sehr verdünnt. Thr Gernch ist hefenartig; der Geschmac stechend salzig. Mit vierinal so viel Weinalcohol vermiscbt, darf sie nicht trübe werden. Auch rou eingetröpfelter reiner verdïnnter Salpetersämre, darf sie nicht niedergeschlageu werden, muls aber dabey eiucn starken Essigseruch vou sich gehcn. Ein Glas von drey Loth luhalt mufs vier Lotb dieser. Flüssigkeir in sich fassen. Ausserdem mins sie alle Eigenschaften des ächt bereiteten essigsauren Kali besitzen.

Ang durch Aufiosung bereitet. Eine was us einen Theile kohtensauren Kali in 2 wey Theilen clesthlirtem Wasser durch Anfosnng bereitet. Elue Wasserhelle, farbenlose, langenartig riechende und eben so, etwas scharfbitter wirerlich schmeckende Flüssigkeit, die mit Säuren stark brauset, den Veilchensaft grüu und die Curcumätinctir braun farbt. Hinzugemischte Schwefelsäure darf dieselbe nicht gallertartig machen und uberbaupl Keine Erden darf dieselbe 'mit reiner Salpetersäure neutralisirt, durch salpetersaure Silberauflösung niclit gctrüb werden. Mufs in einem gut verstopften Glase aufbewahrt werden. Vergl. Kali carbonicum purum.

Fine Durchseihen so weit eingekochte Lauge, bis vier Unzen derselben ein Gefafs voll machen, welches nur geDurchseihen so weit eingek ochte Lauge, bis vier Unzeñ derselben ein Gefals voll machen, weiches nur genan drey Unzen gerneines Wasser falst. Eine scharfe, äufserst äzende Flussigkrit, Theile schnelt zerstört, grün färbt, das Zellgewebe, die Haare, Kuchinstücke unil andere thierische fest, Theile schnelt zerstört, fette Oele zn Seifen rerdickt, das blausanre Eisen (Berlinerblau) entfabt, im Kochen den Schwefrl aunoset, und sich mit Alcohol vermisch, ohne niedergeschlagen 21 werden. Im reinsten Zustanle darf sie von keiner Säure getrübt werden, auch nicht damit aufbrausen; das Kalkwasser darf sie nitht truben; mit Wasscr verdüut und mit reiner. Salpetersäure gesätligt darf sic weller Kiesel - noch Thouerde fallen lassen. Man vergleiche ubrigens Kali causticun siccum. Die Aetıkalilauge inufs it kleintn, gläserneu, trocknen, erwärmten, enghalsıgen, mit eingeriebenen Stöpseln versehenen Flascben, die man gan\% damit vollu, auch deren verstopselte Mündwng noch mit aufgego senem.

Vird nach der'Preufsischen Pharmacopoe duch Digwslion von zwey Unzen gepulverter Myxrbe und acht Uu-

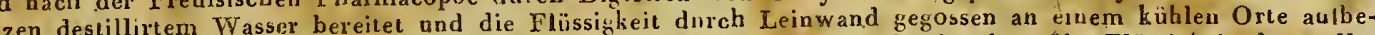
zen destillirtem Wasser bereitet und und unverdorben besitzt diese etwas dickflussig bleibende trübe Flüssigkeit den vollen wabr. Grich der Myrrhe und eine hrangelbliche Farbe. Da sie sich nicht lange häl, 'sondern bald schimmelt und verdirbt, so mufs sie vicht in zu grolsem Vorrath bereilet werden.

Die wäfsrige, hellgelbe, mit brenzlichtem Oele imprägnirte, sänerlich schneckeude Flüssigkeit, welche man durch trockne Destillation aus dem Weinsteine erhält. Sie muls sobald als möglich von dem mit übergehenden empyrevmatischen Oele vorsichtig abgeschieden werden, weil sie sonst sebr viel davon in sich nimmt und einen hittern Geschmack erhält. Der von den Laboranten und Drognisten eingekaufte Spiritus Tartari ist gewöhnlich sehr gewässert, weshalb el billig in den Apotheben selbst bereitet weaden soilte. n merk. Man hielt sonsten den Spiritus Tartari die sigsäure. Der seelige sich als eine eigene, wenn mau zar tisigkeit erhalsen werde, die bey ènem höcbst widrigen Geruche, dnnkelbrauner welidet, eine

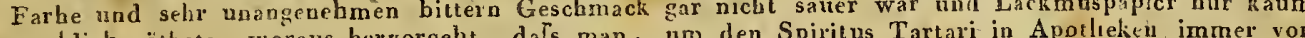
merklich rothete, woraus bervorgeht, dals man, un den Spitus Tartari in Apothek immer von gehöriger Güte und der eigentbümlıchen Beschaffenheit darzustellen, solchen ans gereinigtein Weinstein desilltiren müsse. S. Journal

Liquor Saponis stibiati.

Tinctura Antimo nii. Jacobi.

Sulphur auratum liquidum.

SpieIsglanzseifenHlüsigkeit.

Jacobi's Spielsglanztinclur.

Flüssiger Spie glanzschwefel.
Wird nach der Prenfsischen Pharmacopoe aus Zu wenig Spiefsglanz.- Dies kommt entweder dalier, dafs gleich von

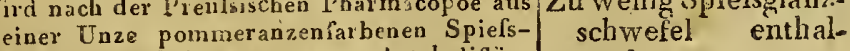
glaurschwefel in genugbamer Aetzkalifüs- tend.

siglieit aufgelöset, und Hinzumiscbung von drey Unzen niedicinischer Scife, sechs Unzen Weingeist unil eben so viel destillirtem Wasser durch Digestion und Klarspilung derFlüssigkeit bereitet. Wenn diese Tinctur gut bcreitet und noch unverdorben ist, so besitzt sie eine undurchsichtige dunkele braunrothe Farbe und einen seifenartigen, geistigen, nicht unangen ehmen Gescbmack
und Ceruch. Sie läfst sich obse Trübung und Ceruch. Sie läfst sich oho Trübung mit Wasser vcrmischen und eine hinzugesouders bey einiger Erwärmung, Schwefelwasserstoffgas daraus, wobey sich zugleich Óel und pommeranzenfarbner Spicfsglanzschwefel abscheiden. Sie mufs] dieser Tinctur ein betrügliches Geinisch aus RhaY Anfaug an die Bereitung vicht ordentich geschahe und nur wenig oder gar kell Spielsglanzschwefel aufgetöst wurde, oder weil die Tinctur wegen des öfteren Oeffnens des Glases durch den Zutritt der Luft zersetzt worlen und der Spiefsglanascbwefel sich
heransgeschieden hat. Die entstebende herausgeschieden hat. Die entstebende gröfsere oder geringere Trübung uud Fällung von Spiefsglanzschwcfel durch zugemischte Sauren jeder Art giebt übrigens das Daseyu und cie Metige des in der Tanc zu erkennen. ren, wobey sich kein Gernch nach Scluwcfelwassersioifgas entwickels und kein Spiefs-
Ist durch die augegebeneu Kennzeichen, be sonders durch die Zumischung von Säu 


\begin{tabular}{|c|c|c|c|}
\hline $\begin{array}{c}\text { Namen } \\
\text { eler Arzneymittel. }\end{array}$ & $\begin{array}{c}\text { Sinnliche Eigenfchaften derfelben; } \\
\text { Merkmale ihrer Ächtheit und } \\
\text { Güte. }\end{array}$ & $\mid \begin{array}{cc}\text { Fehlerhafte } & \text { Be- } \\
\text { chaffenheit, } & \text { Ver- } \\
\text { wechfelung oder } \\
\text { Verfälfchung. }\end{array}$ & $\begin{array}{c}\text { Deren } \\
\text { Kennzeichen und Prüfungsmittel. }\end{array}$ \\
\hline $\begin{array}{l}\text { Liquor Saponis } \\
\text { stiliati. }\end{array}$ & $\begin{array}{l}\text { in einem fest verstopften enghalsigen Gla- } \\
\text { se an einem kublem Orte aufbewahrt wer- } \\
\text { den. }\end{array}$ & $\begin{array}{l}\text { barber und Laugen- } \\
\text { salz mit Branntwein } \\
\text { digerirt. Sch a b } \\
\text { über die Güte und } \\
\text { Verfälschung einfa- } \\
\text { cher und zusamm } \\
\text { mengesetzter Arz- } \\
\text { neymittel, B. I. S. } \\
\text { I20. }\end{array}$ & $\begin{array}{l}\text { glauzschwefel zu Boden fa!lt, leicht zu er- } \\
\text { forschen. }\end{array}$ \\
\hline
\end{tabular}

\section{riatici.}

Butyrum Antimo iii.

Salzsaure - Spiefsglanzflüssigkeit. Spiefsglanzbutter. Lithargyrum, Bleyglätte.
İcopodium. Serren Lycopodii Bärlappenpulver.

Hexenmelil.

Lycopodium.

\section{Macis.}

Muscatenblüthe.

\section{Magnesia carbo} nica.

MisnnesiaSalis amari.

Kohlenstoffsaure

Talkerile.

Bittererde.

Magnesia. ne Auflösung des unvollkommnen Spiefsglanzoxydes in Salzsäure. Sie bildet eine wasserlelle, diokliche, an
dex Luft weifsc Dampfe ansstofsende Flüsigkeit von äufserst fressender und ätzender Bcschaflenheit. dex Luft weifsc Dampfe ausstofsende Flüssigkeit von äufserst fressender und ätzender Bcschaflenheit. Bèy
der Vernischung mit Wasser mufs sie unvollkommnes Spiefsglanzoxyd, das sogenannte Algarothpulver ( $P^{3} u l v i \dot{s}$ Algarotti, Mercurius vitäe) von vollig weifser Fajbe in beträchticher Menge failen sen. Sie mul's in Gläsern mit eingeschliffenen Stöpseln und mit Wachs verklebt, vor dcrn Zurritt der Luft
sehr wohl verwahrt werden.
Ein halbverglasetes Bleyoxyd, welches man Kupferhaltig. bey verschiedenen Hiittenarbeiten, z. B. beym Abtreiben des Silbers und Goldes mit Bley, wodurch alle dabey befindlicben Metalle verscblackt werden, als Nebenproduct in sehr grofser Menge aus England, Schlesien, Sachsen und vorn Harze crbält. So wie wir dieselbe in Handel bekommen, zusanimengebackeneu Schuppen oder Blättchen, die wenig zäbe sind, sich fettig füblen, einen mebr, eineq mäsigen Glanz uud eine mebr. oder weniger grauweifsliche odcr röthlichgelbe Farbe baben. Die aus' grauWelfslichen Blättchen bestebende Glätte heifst Silberglätte (Lithargyruin Argenti); drejenige aber, dcren Blättchen gelb oder rötblich sind, Gold g lä tte (Litharg. Auri); ein Unterschied, der jedocb weiter nicbt in Betracht kommt, als dafs die lctztere in höberm Grade rerglaset ist. Die Glätte löset sıch leicht in Essig anf und theilt ihm einen süfsen Geschmack mit. Auch in fetten Oelen ist sie durch Kochen auflöslich und bildet danit pelasterartige dann prlasterartige Massen. Am besten ist die Trankreich absichtlich bereitete Gläte. Bluneustan kleinsten Theilen kogelrupdc copodium clavatum L.). Xin blalsgelbes, äufserst zartes und leichtes, weich und fetticht anzufïblendes, sich an di Finger hängendes, nicht gut init $W$ asser zn Finger hängendes, nicht gut mit Wasser zn
mischcndes Pulrer, ohne Gernch und Gemischcndes Pulver, ohne Geruch und Ge-
schmack. In der Liclutlammc geblasen schmack. In der Lichtammc geblase
oder gestreut, entzïndet es sich augenblicklich ninit einem Gerüuscb; anf glüluende raucht es langsarn. bestebt sie aus kleiuen, untereiuander of

\section{Statt dessen der Blü- thenstaub vom $N{ }^{\prime \prime} / s-$ barm, von Tannen und Fichten.}

Verfälscht mit Puder und andern leichten mit Curcumädecoct gefärbten Pulvern Mit zerfallenem Kalk
verfälscht.
Die damit digerirte ätzende Ammoniumtlüssigkeit nimmat alsdann eine blauliche Farbe an. unangeuehmen Harzgeruch. autosung bey der Vermischung entetehende
Ist nicht so fein als der Barlappstaub, lia ein schrautzig - dunkelgelbes Ansehen und der vou Tannen und Fichten cinen nicht

Wird theils durch die gröfscre Schwere, theil durch den mit heifsem Wasser entstehenden Kleister, theils durch die mit IS alirothgel he Farbe entdeckt.

Verräth sich durch die grö̈lsere Schwere, durch das mifsfarbige Anseben, und dafs, wenn man etwas davon unter Wasser rïhrt, der achte Barlappstaub oben an schwimut, der Kalk aber sich zu Boden begiebt.

Mit Scluwefel ver- Wird durch den entstehenden Schwefelgernch fälssht. $\quad$ auf glühende Kohlen gestreut erkams. Mlit Aetzkaliflissightit gekocht riecht dic Lauge nach faulen Eyern, welcher Geruc! sich auf hinzugesetzte verdüunte Schwelelsiure näber entwickelt, und zugleich Schwefel dabey niedergcschlagen wird.

Das netzförmige, markige, etwas fétige, in schmale Lappen zertheilte Gewebe, welches in der birnäbnliches

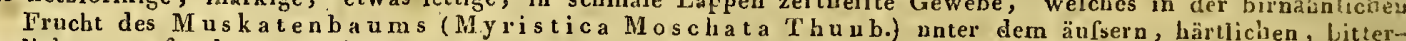
lichen, weifslichen Fleische die innere harte, dünne, schwarzc Schale, worin die Muskatenunfs als Kerubefindlich ist, iberali umgiebt. In fi ischen Zustande hat es eine earmoisinrothe, getrocknet aber cine zimmtbräunliche, ins Gelbe falleude Farbe, einen starken balsamischen Gcruch nnd einen angeuebmen, gewirz.braubliche, ins Gelbe fallende Furbe, einen starken balsanischen Gcruch nnd einen angeuehmen, gewurzmen Hällen von lebhafter Farbe und durchdringendem Geruch und Geschmack vorzüglich zu wälıleu.

Eine eigenthümliche Erde, welche entweder/Nicht gehörig ausge-/Sie hat alsdanu einen salzigen Geschmack und sus dem Bittersalze durch Auflösung in süfst. Wasser mit, welches nun weitcr zu prifen oder Natrum, oder ans einer kalkfreyen Kocbsalzmntterlange auf den Salinen gewonuen wird. Sie köınmt meisteus in blendend weifsen, mehr oder weniger leichten, festen, aber vicht harton, bej'm sanften Druck etwas zusammeuzndrückenden beyin Zerbleclen wic Stärke knackernden Ist nim die Natir des Salzes zis erforschen. nigt, so bem wefelsaurem Kali verunrescluwelichten Geruch, den eine solche 1 laruesia beym Glüben von sich uiebt.

Mit Kalkerde und Blcibt bey der Aufösung der Bittersalzerd Gyps verunreinigt.l in Schwefelsäure ein Theil unaufgelöst lie- 


\begin{tabular}{|c|c|c|c|}
\hline $\begin{array}{c}\text { Namen } \\
\text { der Arznejmitcel. }\end{array}$ & $\left|\begin{array}{c}\text { Sinnliche Eigenfchaften derfolben } \\
\text { Merkmale ilhrer Aechtheit und } \\
\text { Giite. }\end{array}\right|$ & 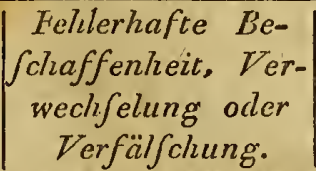 & $\begin{array}{c}\text { Deren } \\
\text { Kennzeiclien und Priifungsmitcel: }\end{array}$ \\
\hline
\end{tabular}

Wagnesia curbo- Stiicken, seltner als eiu äufserst lockeres| mica.

zartes Pulver vor, welches $z$ wischeu den Fingern eben das Gefühl als Puder hervorbringt. Sie ist völlig geruch-und gescbmacklos und von 2,155 eigentbünlichen Gewicht. In genugsam verdïnnter Schwefelsäure nufs sie sich scbuell und mit Aufbrausen antlösen, obne tribe zu werden oder eimen anflösen, obne tribe zu werden oder einen Rückstand zu binterlasscn, und verdunste und crystallisirt mussen daraus bis anf den letzten Tropfen reine Bittersalzcrystallen anschiefsen. Mit alleu Säm en mufs sie eiı bittres Salz hervorbringen. Wenn mau sie mit zehn Tbeilen destillirtem Wasser eine Zeitlang siedet, dieses dann filtrirt, so mufs es geschinacklos ablaufen und weder auf das mit Circumätinctur gefärbte Papier wirken, noch die salpetersaure Silber-oder salzsaure Barytaufïsung truben. In einem glübendeu Löffel über lebeudige Kohlen gebalten darf sie weder einen brenzlictien noch einen schwelichten Geruch von sich geben.

Die Edinburger : oder sogenannte Englische Magnesia wurde sonst ihrer besondern Leiclıtigkeit und lieinkeit wegen vorzüglich gescbützt: Es kommt jedocb derselben in beyderley Hinsicht die in den Fabriken zu Schön ebeck im Magdeburgischen und zu Salzgitter bey Branschweig aus der dortigen Kochsalzmutterlange verfertigte Magnesia theils sehr nahe, theils völlig gleich. Aufserdem wird sie in vielen Apotheken aus dem Bittersalze eben so gut kunstmäfsig bereitet. In Ansehung dcr gröfsern oder geriugern Leichsehung dcr grofsern oder beriugern Leichverfertigten hcrischt aber tin grofser Unverfertigtell horrscht aber tin grolser terschied, indem es Magnesia giebt, Theil des gleichem Crewicht den vierten Theil des Raums einnimmt, wcichen eine andere ausangenehme und nachtbeilige Folgen, besouders bey Pulvermischungen aus Maguesia mit andern stark wirkeuden Arzneymitteln, die entwedar in verschiedencn Apotheke oder anch in einer und dersclben A potheke oder abch in einer mit verschiedener Magnesia bereitet werdeu, entstehen können.. Man sebe hieruber $B$ ucholz in
Trom $\mathrm{m}$ dorfs Journal der Pharmacie. Tromm sd orfs Journat
B. XVI. St. 1. S. I u. f.

Magnesia sulpluterica.

Sal amarum s. anglicum.

Schwefelsaure Bittererde.

Englisch Salz. Bittersalz.
Ein aus Schwefelsäure und Bitterde bestehendes Mittelsalz, welches von der Natur gebildet, sich in verschiedehen Gesundbrunnen, besonders dem Elpsorner, Sedlitzer und Saidschätzerwasser befindet, von der Kunst aber aus der Mntterlange der Meer-
salz - und anderer. Salzsolen bereitet wird. salz - und anderer. Salzsolen bereitet wird.
Es schiefst dasselbe im reincn Zustande in Es schiefst dasselbe im reincn Zustande in
luftbeständigen, (sechsseitigen, glatten, grofsen Crystallen an, kommt aber im Ilandel immer in zarten Spiefschen vor, ind cm man durch Rühren der Lauge wäbrend des An- gen, oder fallt ein Theil aus der Aunösung wieder zurück, so enthält sie Kalkerde odei Gyps. -- Die Kalkerde wird ferner entdcckt, wenn man eine beliebige Menge der verdächtigen Bitterde in reiner Essicsüure auflöset (die Auflösung mufs kommen seyn), die Auflësung durch Abdampfen conceptrirt und mit dampicn concentrirt und mit wenigen Tropfen verdunnter Schwefelsäure vermischt; war Kalkerde gcgenwärtig, so wird sich in zehn bis vierzehn Stunden wirklicher Gyps aus der ersten klaren Flässigkeit abgesondert haben. -- Nach Herrn H a h n em an n wird die Verunreinignng mit Kalkerde arn sichersten eutdeckt, wenn man 24 Gran Magnesia in Salpeteroder rciner Salzsäure, oder besser in reinem destillirten Essig, so dafs' die Säure prädominirt, aufüsct, die Aufösung mit 16 Unzen destillirtem Wasser verdüunt und in eiue a Pfind baltende Flasche, worin schon eine Oraclime in Wasser gelöstes chleut kohleusaures Fatrom enthalten ist, bringt, sie fest verstopft nnd alles stark nnter einander schütelt, entsteht Lierbey keine Trübung oder Niederschlag, so war dic Magnesia von einem. Kalkerdegehalt frey, so wie das Gegentheil deren Gegenwart anzeigt.

Lit Thonerde verun-Die Auflösnng in verdüunter Schwefelsäure bis zur Sättigung hat alsdann einen süfslichen. zusammınziebeuden, alaunartigen Geschmack, und wird bey der Crystallia sation, nachdem man zuvor der Flüssigkeit etwas Kali zugesetzt hat, auch Alauncrystallen geben.

Mit Stärkemelıl ver- Giebt sich durch Entsehung eines Kleisters nach anfgegossenem kochenden $W$ asser, und durch den brenzlichten Geruch beym Glühen zu erkennen.

Anmeıkung. Nach mehreren Scbriftstellern wird auch noch jetzt die ächte reine Magnesia mit der, aus der Salpeternutterlatige gewonuenen Magnesia (Magnesia Nitri) häufig verla nge gewonuenen Magnesia (M a gnesia Nitri) bäufig ver-
fälscht, oder wohl gar diese letztere, welche, da sie neben weniger Bitterde, meistens aus Kalkerde, Thonerde, oft auch alls blofsen Gyps besteht, und auch wohl Kieseierde entbält, zum medicinischen Gcbrauche ganz untauglich ist, statt jener blos fïr sich verkauft. Man glaubte sonst diesen Bctrug, so wie iiberhaupt die mit der Magnesia verbundene Kalkerde durch die alsdann erfolgende Zersetzung des daruntar, gemengten Salmiaks zu entdecken; allein es ist in newern Zeitcn erwiesen, dafs auch die reinste Magnesia den Salmiak zersetze und das Ammonium daraus entbinde. Sicherer ist daher die von Herrn Westrillm und $S c h e r f f$ angegebene Prïfungsmethode der käuflichen Magnesia. Man koclie nämlich buadert Gran Magnesia mit tatisend Gran destillirtcm Wasser eiuige Minuten in einem gläserven Gefäfse im Sandbade, filtrire sie alsdann durch weifses Fliefspapier und theile die abselanfene Flüssigkeit in drey Theile. Fliefspapier erste Theil die Curcumätioctur brann, so enthält die Frde noch erste Tbeil die Curcumätinctur bralln, so enthält die Erde noch
Laugensalz; macht die wälsrichte Auflösung des schwefelsamen Laugensalz; macht die wälsrichte Auflösung des schwefelsanyen Silbers in dem zweyten cinen Bodensalz, so ist sie mit Kochsalzsäure veruurcinigt, und macht dıe salzsaure, Barytauflósung felsäure und ist mit schwefelsaurem $\mathrm{Kali}$ verunreinigt. Nun.löse man cie abreseibete oder ausgesuiste Magnesia in reiner Salzsäure auf; was von ihr picht aufoelöst wird, ist Kieselerde. In diese salisaure Auläsung, bey der jedoch die Säure etwas prädornniren $\mathrm{muls}$, trope wird sie trübe, so enthält die Magnesia auch Thonerde. Endlich rauche man die salzsaure Anflösung bis auf 300 Grap. Eadlich sche alsdann eben so viel Wcinalcohol nnd 800 Gran destillirtes Wasser hinzı und tropfe etrvas verdünnte Schwefelsänre hinein, Wasser hinzn und tropfe etrvas verdünnte Schwefelsänre hinein,
wird sie dadurch trübe, so enthält die weifse Magnesia Kalkerde.

Unrein, an der Luft|Dies ist häufig der Fall bey dem verkäufifeucht und schmie- chen Bittersalze, und rührt von der noch rig werdend. dabey befindlichen salzsauren Bittererde her; es hat einen durclidringendern bitterern Geschmack und purgirt stärker, als das davon befroyte gereinigte $S$ alz.

Glaubersalzhaltig. Schmeckt weniger bitter, mehr kühlend und wird an der Luft mehlicht. Um die AIenge des dabey befindlicheu Glaubersalzes z.11 bestimmen, kocht man cs mit gleichen Theileu gebrannten Kalk etwa eine Stunde lang 


\begin{tabular}{|c|c|c|c|}
\hline $\begin{array}{c}\text { Namen } \\
\text { der Arzneymittel. }\end{array}$ & $\begin{array}{c}\text { Sinnliche Eigenfchaften derfellen; } \\
\text { Merkmale ihrer Aechtheit und } \\
\text { Güte. }\end{array}$ & \begin{tabular}{|} 
Fehlerhafie Be- \\
fchaffenheit, Ver- \\
weclyfelung oder \\
Verfälfchung.
\end{tabular} & $\begin{array}{c}\text { Deren } \\
\text { Kennzeichen und. Prïfungsmittel. }\end{array}$ \\
\hline $\begin{array}{l}\text { Magnesia sulp } \\
\text { rica. }\end{array}$ & $\begin{array}{l}\text { schiefsens diese abweichende Crystallisation } \\
\text { bewirkt. Es bat einen bittern kïhlenden } \\
\text { Geschmack, ist im Wasser leicht aunöss- } \\
\text { lich, im Weingeist aber nicht, siebt weifs } \\
\text { und glänzend aus, und läfst im Wasser } \\
\text { aufgelöset und mit Kaliaufösung vermischt, } \\
\text { seine Rittererde fallen. Im Feuer schwel- } \\
\text { len die Crystallen erst auf, werden daun } \\
\text { trocken und zerfliefsen endlich. }\end{array}$ & $1 \%$ & 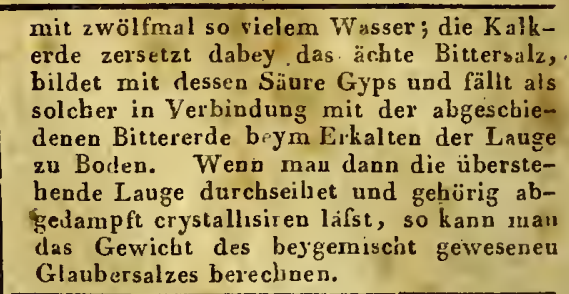 \\
\hline 8 & & \begin{tabular}{|l} 
Statt dessen blofses \\
Glaubersalz durch \\
gestörte Crystalli- \\
sation in kleine \\
spiefsichte Crystal- \\
len gebracht.
\end{tabular} & $\begin{array}{l}\text { Verräitb der mehr hühlende als bittefe Ge- } \\
\text { schmack, das leichte Zerfallen in der Wär- } \\
\text { me und dafs die Aunöosnng desselben durch } \\
\text { aufgelöstes Kali keine Bitterde fallen } \\
\text { läsl. }\end{array}$ \\
\hline $\begin{array}{l}\text { Magnesia 7ista. } \\
\text { Magnesia calcinata. } \\
\text { Gebrannte Bitter- } \\
\text { erde. }\end{array}$ & $\begin{array}{l}\text { Die durch Gliiben in einem irdenen Schınelz- } \\
\text { tiegel ihrer Koblensärre und des Wassers, } \\
\text { welches sie auch nach dern vollkommen- } \\
\text { sten Anstrocknen noch eathält, beraubte } \\
\text { Bittererde. Sie mufs ein leichies, völlig }\end{array}$ & $\begin{array}{l}\text { Statt derselben tinge- } \\
\text { brannte Magnesia, } \\
\text { oder nicht vollig } \\
\text { luftleer gebrannt. }\end{array}$ & Brauset mit Säuren auf. \\
\hline $\begin{array}{l}\text { Calcinirte Magne- } \\
\text { sia. }\end{array}$ & 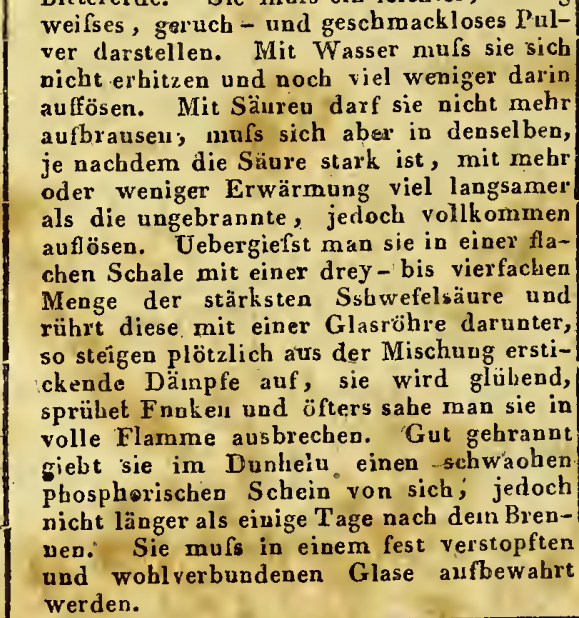 & $\begin{array}{l}\text { Mit ätzender Kalk- } \\
\text { erde verunreinigt, } \\
\text { wenn die dazu an- } \\
\text { gewandte Bitterer- } \\
\text { de kalkhaltig war. }\end{array}$ & 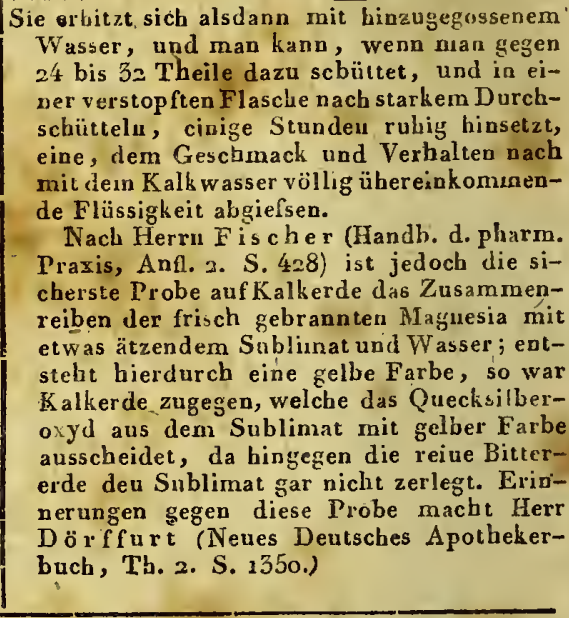 \\
\hline
\end{tabular}

Malthum Hordei.

Malz.

Gerstenmalz.

Manganesinm oxydattim nativium.

Magnesia nigra s vitriariorum.

Braunstein.

Schwarzes Braunstejnoxyd.

\section{Manna.}

мадап.

Die

Die in kaltem Wasser erwescbten und nach dem ersten Aufkeimen entweder an der Luft oder mit Hülfe künstlicher Wärme ausetrockneten Samen der hekaunten Gerste (Hordeum vulgare und Hexastychon L.) Ein gutès Malz inufs uach dem Trocknen von den Wurzelfaserchen und Keirnchen durchs Fegeu gereinigt seyn, eine schwach bräunlich-gelbe Farbe haben, gehörig miirhe seyn, angenehn'und nicht räuchericht riechen, von einem Ende bis zum andern ein weifses, lockeres, siifses Mebl enthalten, in Wasser. nicht untersinken Auszing geben.

Das natirlich vorkommende Oxyd eines erst in neuern Zeiten entdeckteu, sebr strengflussigen Metalls, des

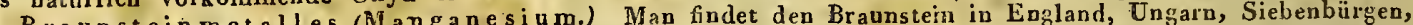
Braussteinmetalles (Mangen und in Deutscbland am laăuforster und fester Gestalt und Er kommt in der Natur yoll verschiedener Draunen crystallisirt; bald von weicher, leichter, locker erkerstens stabloder rolhschwarzen Farbe und mit Kiesel - und Kalkerent -grau oder schwarz, metallisch glänzend, kömmt in säulen- und tafelartigeu, auch pyramidenförmigen und blättrigen Crystallen vor. Im Allgemeineu ist indesseu seine Crystallisation sternenförmig, so dals er inn

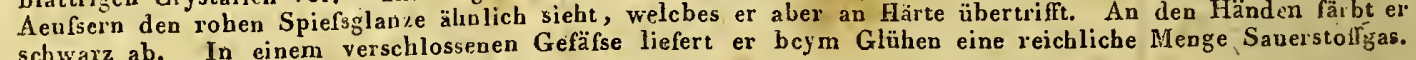
schwarz ab. In einem verschlosseven
Der schwarze dunkelbrame ist der beste.

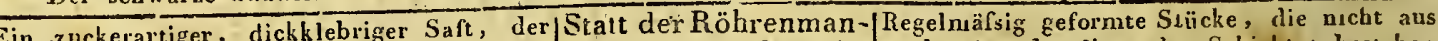
sowohi von freyen Stücken, als nach ge- na ein künstlimachten Einschuitren in die Riuden des machten Einschuitren in die Riuden der rundblätrigen Esche (Fraxinus rotundifolia Mill.) und der Mannarotundifolia Millo (Frasinas Orus.) hervoresche (Frasinus Oru us L.) hervorquillt, in der freyen Luft durch die Sonneuwärme zu einer bröcklichten, heichten, weifsgelblichen Masse von eïnem honigartigen Geruch und süfslicht - schärflichern Geschmack austrockuet, und hauptsächlich aus Calabrien, Sicilien und andern Gegenden des sỉdlichen Europa zu uns gebracht wird. Es giebt davon verschíedene

1) Die von selbst a usfiefsende Manna (Manna in lacrymis.) Siel ist selbst in ihrem Vaterlande sebr selten und kostbar, nad kommt gar nicht zu uns.

2) Die ringenförmige oder röhrichte Manua (Manna canulata) Leichte, mürbø, , trockne, einen bis sechs ches Gemisch schlechter Manna, Thomaszucker, Stärkemehl, Siammoniust und Glaubersalz.

Mit vielen bergemischten Holzspänen, Sand, Baumrinden, Stroh u. dgl verunreinigt.

tatt der schlechtern Manuasorte ein blofses Gemisch aus alfses Gemisch aus al-
ter verdorbener gestehen übereinander liegendeu Schichten bestehen
und gänzlich undurchsichtig sind. Inwenund gänzlich undurchsichtig sind. Inwelldig bemerkt man gar keine federichte Crystallisation. Das beygem ischte Stärkemeh! zeigt sich durch Kocheu der Auflösun $\approx$ mit Wasser, indem dadurch nach dem Erkalten ein Kleister entsteht. Aufserdem bleibt es, so wie das beygemischte' Glaubersalz bey der Auflösung im Weingeist am Boden liegen. Letzteres läist sich in der wittelst gen Auflösung durch eine Prüung
dés salzsauren baryts, entdecken.

des salzsauren baryts entdecken. Auflösung in Wasser und Klarseibung der Flïssigkeit.

Dieses betrügcrische Gemengsel bat gewölrt lich eine nehr oder weniger housgartige Consistenz, ist schmierig, dunkelfarbig, schmutzig, fettig, hat einen eckelbaft sü- 
Manna. - Mastiche.

\begin{tabular}{c|c} 
Namen & $\begin{array}{c}\text { Sinnliche Eigenfchafien derfelben; } \\
\text { Merkmale ihrer Ächthcic und } \\
\text { Giite. }\end{array}$
\end{tabular}

Tanna.

Zoll lauge, gegcu cinen Zoll breite, flache, rinnen - oder röhrenförmige, weifslichte oder blafsoelbe, zuveilen ins Rötbliche spielende Stïcke, die bcym Zerbrechen aus verchicter rerch Crystallisntion, seltner eine nocls dickCrystallisation, seltner eine nocl dich in Wasser völflüssige Mamna zejgen, sich in Wasser völig aunöscn lassen, auf der Zunge leich schumelzen nod weniger eckelhaft schme-
cken, als die folgcnden Sorten. Sie entsteht von dem, wach gemachten Eiuschnitten ausfliefsenden Safte, den man au kleinen angebuudenen Stäben oder Strobbalmen sich"verdicken läfst, kommt aber, $a b$ sie sleich die beste Sorte iàt, selten äch unil mnverfilscht on uns

3) Calabriscbe $\mathbb{M}$ anna. (Manna C) Calabische c a la brina.) $\Lambda$ nench gestaltete Stucke von rerschiede nes Grôse, die etwas weich, hrumelicht, leicht zerbrechlith, aus wellsen, welis clblichen, ins Röthliche spielenden und licingraulichen Stücken zusammengemengt, gemeiniglich mit Rinden oder Holzstücken, mi Sand und andern fremdartigen Theilen verunreinigt sind, einen sclswachen, etwas wid̉igsüifsen Gernch, und schleimicht süfsen, einigermafsen eckelbaften Geschmack Isen, einiger haben, Diese zum Arzneygebrauche beste Sorte in Kor nern (M a n a electa s. in granis) die aus den grölsern weilsen, blalsgelbli chen orler etwas ins Rothliche spielenden, rindeuföımigen, eiuıgermafsen durchsichtigei, ausşeböblten odcr rundlichen Stïcken besteht. Das Zurä̈kbleibende giebt die schlechiesie Sorte (Naun crassa), eiue ans unfö̀mlichen, schmntzigen, bräunlichen Klüuperchen znsammeugebackeue, weiche, klebrige, sclunierige Masse, die ibrer häuficeu Verfilschung wegen in den Apotheken billig gar nicht wegen in dentille.

7ïne gute nnd ächte Manna ist in der Kälte grey Theilen Wasser und in acht Theilen Weingeist, in der Wälme abor in gleichen Theilen Wasser und in noch geriugerer Menge, als sie selbst. wiegt, anflöslich; sie scheidet sich dann nach dem Erkalten aus der dicklichen Auflösung in unförmlichen Klumpen, die inwendig oft crystallisirt siud, wieder ab. Sie mufs ferner leicht zerbrechlich, in dünuen Sıicken durclisrbeiuend, nicht klebrig seyn; die dur trock die ganz tuock hen Silcke lassen sich ama Licbte unter schyachere Leu; sonst schmelc die anana iber Kohlenfener rnit einen dem gebranuteu Zucier älınlichen Gerucb; in Wasserbade aber wie Wachs.

Manna depurata $s$ tabulata. Gereinigte Man-

na.

Mastiche.

Gummi Mastiches.

Mastix.

Mastixgummi.

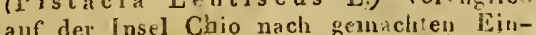
schnitten ausschwitrendes Harz in mafsig barteu, trocknen, nichs klehiigen, zor-
Fehtrertiafice Be-' chaffenheit, $V^{\top} \mathrm{er}-$ wechseluing oder Verfälfchung.

Deren

Manna, Cassona-| fsen Gescbmack und einen säuerlichen Gedenzucker, Honig, ruch. Ganz uubrauchbar.

Syrup, Meht oder Kraftmehl.

Statt der ächien Man- Bestebt aus coriagndergrofsen Kürnern, besitzi na die aus den Blät- wenıg Kräfte, verräth sich durcb ibreu terna die aus den Blat- pentinartigen Geruch und ist ganz verwerftern des Lerchen- pentinartigen Geruch und ist ganz verwerfbaums in heifsen licb. Oft soll sie nichts anders als einGeLändern ausschwi- meu mit Zucker und Honig seyn.

tzende Manna (Maularicina.)

Anmerk. Die Manna mufs immer an einem trocknen, warmen Orte anfbewalut werden, weil sie an einem feuchten Orte aufbewabrt, wo nicht zerdiefót, doch lèicht unschciabar wird.

Dic in sehr wenigem Wasser in gelinder Warme geschmolzene, schnell durchgeseihete, in eine Morsellenform gegossene und nach dem Erkalten iu kleiue Tafelchen zerschuitiene Manaa.

Ein áns der Rinde der Mastixpistacir/Er soll zuweilen mit Diese werden beym Kauen nicht weich und (Pistacia Leutiscus L.) vorzïslich klaren Sandarak- zähe, sourlern zerspringen und zerbröck.ln brechlichen, etwas durchscheint nden, auf frischem Brurbe ebenen uul glänzenden Körnesl oder. Troplen, von einer rundlichen, mcistens etwas platl gedrüichten Gechen, mcistens etwas platl gedruckten Gestalt und verscbied eller croóse, einer weifs-
lichen oder blafsgelblichen Farbe, einem lichen oder blafsgelblichen Farbe, einem schwach geWür baften, baum melklich zulsammenziehenden Gescbmack nard sufsliclien angenehinen Geruch. Zwisrlien weach Zähnen gekavet, wird der zergeht cr wie und zäbe; in der Warme zesgetr cr wie Wachs; auf glübeude Kohlen gestreut, brennt er mit einem starken und angenebmen Geruch, löset sich weder in Wasser nocb ausoprefsten Oelen, in Alcohol bis nocb ausoprefsten Oelen, in Alcohol bis körnern verfälscht zwischen den Zahnen, lösen sich in Wein\begin{tabular}{l|l} 
vorkommen. " & $\begin{array}{l}\text { gersi, aber nicht in Terpentinöl auf, und } \\
\text { besitzen weder den Geruch noch Gesclumack }\end{array}$
\end{tabular} des ëchten Mastix 


\begin{tabular}{l|c|c|c|}
\hline Nanen & $\begin{array}{c}\text { Sinnliche Eigenfchaften derfelben; } \\
\text { Merkmale ihrer Aechtheit und } \\
\text { Güte. }\end{array}$ & $\begin{array}{c}\text { Fehlerhafte Be- } \\
\text { chaffenheit, Ver- } \\
\text { wechfelung oder } \\
\text { Verfälfchung. }\end{array}$
\end{tabular} \mid Kennzeichen und Priifungsmittel.
brige, frisch fast durchsichtige, mit der doch einigermafsen werclende, sưfse und doch einigermalsen scharf und kratzend schmeckende, sich vö̈lig in Wasser und in
Alcohol anfösende Substanz, von angeAlcohol anfösende Substan 2 , von ange-
nehmen, erquickendem Geruche und weinehmen, erquickendern Geruche und wei-
fser, gelblicher oder brauner Farbe, welche aus den Honigbehältern der Blumen von den Bienen (Apis mellifica) ge-

Mel depuratum s. despumatum. Gereinigter Honig.

Mel rosatum.

Rosenhonig. Meloes majales.
Vermes majales. Maywürıner.

\section{Verdorten.}

(

micht ist unon in Gährung gerathen, schaumuls verwor fen werden. ge Honig, welcher einen sehr brandigen Geruch und Gesclmack hat, wie auch ein solcher Honig, den die Bicuen meistens ron stinkenden Blumen, z, B. dem Bĭrlauch, (Allium ursinum) eingesammlet baben, da ex mebrentheils den nuangenehmen Geruch und Geschmack derselben bat. sammlet, in ihren Körper einigernafsen verändert und zu ihrer künftigen Nabrung
in den Wachszellen der Bienenstöcke abgesetzt wird. Es riebt davon in Hinsicht der Reinheit und Güte verschiedene Sorten. Der feinste ist der Narbonniscbe aus Frankreich (Melnarbonicum.) Diesem folgt der Lippitzbonig aus der Gegend von Litthanen, welcher sich durch Gegend von Litthaten, welcher sich durch
eine fast völlis weifse Farbe und einen aueine fast völlis weilse Farbe und einen au-
genehmen Lindenblintbgeruch auszeiclnet und weifser Honig. (Mel a lbum), genannt wird. Der gewölnnliche Honig, wie er bey uns borkommt, besitzt eine gelbe oder braune Farbe. Wenn die Bienenistïcke gebrochen werden, so fliefst ein Theil des Honigs von freyen Stiicken aus den Waben $a b$; dieser ist als der feinere Honig von einer helleren Farbe, einer reincren Beschaflénheit und einem angenehmern Geruch und Geschmack und wird Jungfernhonig (Mel virgiuenm) genannt, unter welchern Namen sonst auch wohl der von jungen Bienen zusarnmengetragene Honig verstanden wird. Ein anderer Theil wird durch Auspressen der Wabeu erhalten und macht den gemeinen Honig (Mel vulgare s. crudum.) Er ist mehr oder weniger mit Wachstheilen vermischt, von dunkelgelber oder brauner Farbe, einer dickern Consistenz als der Jungfernhonig, und weniger angenehmen Geruch und Geschmack. nuch ist er of brenzlicht unid bedarf ïberhaupt noch eiver Reiuigung. Ie bellüberhaupt noch einer Reinigung. Ie bell-
farbiger, körnichter, und je auflüslicher farbiger, körnichter, und je auflöslicher
in kaltem Wasser der Honio ist, um de-in kaltem Wasser
sto besser ist er.

Mit Mehl, besonders Bohnenmehl oder Sand vermischt.

Auf eine besondere Weise verfälscht:

Wird erhalten, indem man den gewöhnlichen Honig unit gemugsamen Wasser auföset, ilın mit etwas zugesetzten Eyweifs aufkocht und die vollkommen klar durcli einen wollenen Spitzbeutel gelaufene Honigbrühe in flacheu zinnenen Kesseln ohne Kochen und besonders zuletzt bey gelindem Feuer bis zur Syrupsdicke abdaınpf. Der auf diese Art gereinigto Honig besitzt einen reinen starken Honizgeruch und Gesclinack, bey volikommner Durchsichtigkcit eine bräunlichgelbe Farbe, läfst sich ohne trübe zu werden mnit Wasser verdünnen und gerinnt in' der Kellertemperatır mit der Zeit zu einer festen dunkel gelben crystallinischen Masse. Mau bebt ibu erkaltet iu einem gut verbunden Kruge on eiuem küblen Orte auf. Durch das lange anbaltende Kochen der Honigbrïhe, wie es gewöbulich vorgenommen wird, gehen sehr vieie wirksame ge anbaltende Kochen der Honit
Theile des Honigs verloren.

Besteht aus einer Infusion ron getrockneten Blumenblätern der Centifolienrose mit Tochendem Wasser und hiuzalgesetztenn geläuterten Honig bis zur Syrupsdicke gelinde verdunstet. Mufs einen hervorstechenden Rosengeruch haben.

Käferartige Insecten, die auf sonuigen Wiesen und zandigen Brachäckern wohnen, und zu Aufange des Früblings mebrentheils einzeln herumkriechen. Mau sammlet folgende zwey Arten.

2) Den schwarzblauen May w urmăfer (Moloe Proscarabaeus L.), Ein nügelloser, fingersdieker, einen bis anderthalb Zoll lanğer, sehr weich anzufühlender Käfer mit herunterwärts gehogenem Kopfe, scbnurförmigen, zwölfgelenkigen Fühlhörnern, fast runden Brustschilden und weichen, biegsamcn, punctirten, fast glanzlosen, den eyförmig sich endigeuden Hinterl lęib kaum zur Hälfte hedeckenden Flïgeldecken. Er hat einc schwarzblaue Tarbe; der Unterleib ist veilchenblau und mit blaugrau und gelb gesprenkelteu Ringen umgeben. Kopf, Fiifse usd Bauch spielen etwas ins Röthliche; an den Vorderfüfsel bat er fünf, an den Hinterfüfsen aber nur vier Gelente. 


\section{Meloes majales. - Mixtura camphorata.}

\begin{tabular}{|c|c|c|c|}
\hline $\begin{array}{c}\text { Namen } \\
\text { der Arzneymittel. }\end{array}$ & $\begin{array}{c}\text { Sinnliche Eigenfchafien derfellen } \\
\text { Merkmale ihrer Alechtheit und } \\
\text { Giite. }\end{array}$ & $\left|\begin{array}{c}\text { Felulerluafse De- } \\
\text { rchaffenheit, Ver- } \\
\text { weclifelung oder } \\
\text { Verfälfclunng. }\end{array}\right|$ & $\begin{array}{c}\text { Deren } \\
\text { Kennzeichen und Priffungsrritcel. }\end{array}$ \\
\hline
\end{tabular}

beycle Iusectcn enthaten einen hellen, olichten, dicklcben, den Gelenkfingen, besonders aus den KnieSaft, den sic bey der leisesten Beriihrung mit den Fiugeru alls den Gelenkfingen, borsonders aus den Kniegelenken fabren lassen. Sie müssen daber bey dem Sammlen mit der grölsten Vorsicht, damit nichts rom Salte verloren gehe, mit einer kleinen Zange anfgehobeu werden, uad nachdem ihnen der Kopf rnit einer Scheere abgeschnitten worten, alsobald in Houig gethan uad so eingemacht (Conditnm Vermium majalium) aufbewahrt werden. - Mit dem gew ölulichen Maykafer (Scarabae s Melolantha L.)
dürfen sie etwa wegen der Aehnlichkcit des Namens nicht verwechselt werden.

Millepedes. Kellerwürıner.

\section{Miniumi.} Mennig.
Ous cus $\Lambda$ sellus L. Fluggllose, ling-/Auf und unter faulen- Diese werden zurn Arzneygebrauche verworlich-ovalc, Lalbzolllange, oben rundliche dem Holze lebend. Insecten, die einen gegliederten, au beydeu Seiten gekcrbten Körper haben, auf Von selbst gestorben. dem Rüicheu blafsorau oder bleyfarben, an Banche aber weifslich atrssehen, snit einem stumpfen, zweytheiligen Schwanze, vierzebu Füfsen nnd zwey borstenförmigen eiufacheu Füblbörneru versehen siud "Beym Berïtren zichen sic sich kugelicht ausamBerubren ziehen sie sich kugelicbt zusammen. Sie haber einen unargen ebmen moderigeu Geruch, und einen echelhaft suils lichen, zuletzt etwas scharfen Gesclimack Frisch gesammitet werden sie entweder mit wein gewascluen und bernach getrocknet in eirem verstopften Glasé aufhewahrt, oder es wird der darans geprefste Saft, wovo sie ohugefán den vierten Theil enthalteu, nuter einer Brülıe oder mit Wein verordnet. Auch köınen sie mit Wasser oder Wein nach Art einer. Enulsion aurestofsen und die Flijssialeit dircheseitet werd Tan findet sie an tilen, feuchten, dunk Man finder sie an kalten, fochten, duskunter Steiuen.

Die Meunige, welche in der Mennigbrcnnereyen vorziiglich in Eugland und auch in Deutschland bey bereitet wird, ist durchs Brennen iu rotbes Oxyd verwandeltes Bley. Sie stellt ein Oxyd verwandeltes Bley. Sie stellt ein
bochgelbrothes, schwcres, aus höchst feibocbgelbrothes, schwcres, aus höchst fei-
nen, und kleinen glänzenden Schuppen bestehendes Pulver dar, welches, unverfälscht und rein, in eine ausgehohlte Koble gescblossen, vor dem Löthiohre, oder mit Fett vermisclıt, in einerh glähenden eisernen Lölfel, sich leichst und-gänzlich in ein metalliscbes Bleykorn wieder berstellen lärst. Mit Salmiak zusanmengerieben, enthindet sie daraus das Ammonium. Sie ist keinesweges, wie sonst hehauptet wurde, in destillittem Essig oder concentritter Essigsäure rollkommen atü̈slich, sondern hinterlälsi nach Herru Bucholzs veuern hintcrlälsi nach Herra Bu cholzs vengrn
Versuchen (Almanach fiir Scheideküustler Versuchen (Almanach fit' Scheideküstler
und A potheker, 1809 . S. 32 u. f.) irumer, selhst wenu sie damic gekocht wird, eineu dunkelrothbraunen, fein anzufühlenden Rückstand (V a u q u elins vollkommenstes Bleyoxyd), der nicht weiter darin auflöslich ist.

$$
\begin{aligned}
& \text { Diese sind alsdann nicht kugelicht zusam- } \\
& \text { menogezogen, wie die gewaltsam getödte- } \\
& \text { ten, sondern ausgestreckt. Anch diese } \\
& \text { taugen zurn Arzueygebrauche nicht. }
\end{aligned}
$$

Verwechselt mit den Sie haben mebrere Fufse; ihr Schwanz ise Keller-oder Stein- nicht zweytheilig, sondern ganz.

asseln. (Oniscus Armadillo L.).
Mit rothem B Blus, Ziegelsteinmehl, Colcoihar, rulhem Ocher (Englischem Poth), u. dgl. verfälscht iue so verfälschte Metnige giebt sich schon duich das mifsfarbige, weniger lehbafte Auselien zu ententeu. A ufserdem lärst sie Il e rmbstad (Grandrifs der theoret. u. experimeut. Pharm. Tb. 2. S. 88 ) soll inan experimeut. Pharm. Tb. 2. S. 88 ) soll man die Verfaschum der Mennige mit Ziegelmehi aner Enylischem Roth daduch entdeckeu, dars unit elnem geringca Znsatz von Zucker die reiue Meunige sich in S.1petersaure völlig a einer fathelosen Flüssibket antlöse, die fremdartigen Beymiscuungen aher uuaufgelöst zurüçkbleihen.

Her Bucholz (a. a. O.) giebt fulgende Prufunsmethode der Mennige auf fremde Beymischungen, als Ziegelmehl, Bolus, Colcothar u.dg? an. Ilmudert Theile einer solchen verdäclatigen Mennige werden mic 300 Thctlen einer reisen Salpetersäure in einem porcellainemen Schälchen unter forteinem porcellainemen Schalchen unter fortdauernden Umrabren so lange erhitzl, bis das Gemenge gar iseinen Scbein ins Röth-
liche mehr bat; uach und nach werden 60 liche mehr hat; uach und nach werden 60 Thelle raucbender Salzsänre hiuzugesetzt, und das Grincc unter beständigem Umrüh-
reu so lange erhitzt, bis die hrauuen Flokken des vollhomneneu Bleyoryds völlig verscbwundeu sind. Nun setze man die Masse mit $\$$ bis 6 Unzen destillirtem Wasser iu Beruhrung, bringt alles zum Sieden nod erhilt es eimige Minuten in diesem $\mathrm{Zu}-$ nnd ertilt es einige Minuten in diesem $\mathrm{Zu}$ stande. Sollten sicb jetzt nur noch wenige ungelöste rothe Theilchen vorfindeu, so kants man diese nach Absonderung durch
ruhiges Hinstellen von der A tifösung, ruhiges Hinstellen von der Aufösung, durch eruedertes Behandlen mit einigen
Tropfen Salpetersäre und Salzsäute und Tropfen Silpetersäure und Salzsäute und
Scliülteln mit Wasser völlig verscbwinden Schülteln mit Wasser völlig verscbwinden
machen, und dieses ist ein Beweis für die Reinheit der Meunige. War im Gegentheil der Riickstand bedeutend und von einer andern Farhe, ais der des rothen Bleyoxyds, so kaun man sichcr schliefsen, dafs dic Mennige vei fälscht war.
Mixtura camphorata.

Julapium e. Camphora.

Flüssige Camphermischung.

Campherjulep.
Wird nach der Preufsischen Pharmacopoe aus einer Drachme mit etwas Alcohol pulverisirten Campher, einer halben Unze Zucker und zehn Unzen heifsern. Wasser mittelst Reiben und Durchseihen der in einem besehr zu billigen seyn möchte, elnzig und allein zu den Magistralformeln, die inmer frisch bereitet werdeas müssen. 


\begin{tabular}{|c|c|c|c|}
\hline $\begin{array}{c}\text { Namen } \\
\text { der Arzńeymittel. }\end{array}$ & $\begin{array}{c}\text { Sinnliche Eigenfchaften derfelben } \\
\text { Merkinale ihrer Aechtheıt und } \\
\text { Güte. }\end{array}$ & $\left|\begin{array}{cc|}\text { Fehlerluafie } & B e- \\
\text { chaffenheit, } & \text { Ver- } \\
\text { wechfelung } & \text { oder } \\
\text { Verfälfchung. }\end{array}\right|$ & $\begin{array}{c}\text { Deren } \\
\text { Kennzeichen_und Priifungsmittel. }\end{array}$ \\
\hline
\end{tabular}

Mixtura, oleoso-JEine klare, belletbliche, aus mehreren, in Weinalcohot aufgelisten gewrirzhaftcu ätleerischen Oelen bestehende balsamica.

Balsamum Vitae Mischung Holfmanni.

Balsamisch - ölichte Mischung.

Hoffm anns Lebensbalsam.

$\frac{\text { Mixtura }}{\text { pyro- }}$ tartarica.

Mixtura simplex.

Brenzlichțe weinsteinsaure $\mathrm{Mi}$ schung.

Einfache Schwitz-

tropfen.

Mixtura sulphu-

rico-acida.

Elixir acidum.

Weingeistige

Schwefelsäure.

Saures Elixir.

Mixtura vulnera. ria acida.

Aqua vulneraria Thedeni.

Saures Wundwas-

ser.
Schulswasser.

Morsuli.

Morsellen.

Mosclutis.

Biesam.

Inischt, mufs sie weifslich úd trübe werden. Sie mufs in einem, mit einem eingeriebenen Glasstöpsel versebenen enghatsigen und mit Blase wohl verbuudencn, Glase aufbewahrt werdea.

Cine aus zusammeugesetztem Angelikgeist, brenzlichter Weinsteinflüssigkeit und rectificirter Schwefelsăure zusammengesetzte Miscliung von etwas weifs gelblichter Farbe und geistigsäuerlichem Geruch und Gesclimack. Im Sandbide destillirt wird die Vermischnng inniger und bekommt die Natur einer gemischten versïfster Säure (Mixtura pyrotartarica s. simplex rectificata).

Besteht nach der Preufsichen PharmacopoelStat dessen ein Ge-1Hat eiaen eckelhaften unangenehmen Branntatis drey Theilen Weinalcohol und einem misch aus Brannt- weingeruch und minder sanren Geschmack. Theil rectificirter concentrirter schwefelsäure. Es 1 un $u$ s weils ausseben, einen ansaure. Es muls weils ausseben, einen an-
genehmen, schwach liquorartigen Gerach genehmen, schwach liquorartigen Geruch
und einen geistigeu, stark - sauren Geund einen geistigeu, stark - sauren Ge-
schmaek baben. Man muss es iu einem weifsen Crystallglase mit eingeriebenem Stöpsel anfbewahren. Das an vielen Orten gebräuchliche Elixir a eidum Halleri bestebt aus gleichen Theilen Weinalcohol und concentrirter Sclowefelsäure.

misch ans Branntwein und verdünn-
ter Schwefelsäure.

Eine aus roher Weinessig, recticirter Weingeist und verdiunter Schwefelsäure bestehende, zum waserliche Gebrauch bestimmte Mischumg, zil welcher phch der Preufsischen Pharmacopoe gelizuterter Honig, nach der

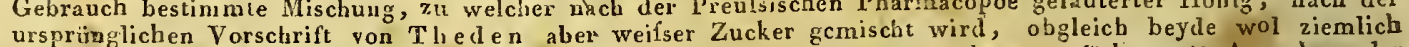
überflüssig, sind. Im ersten Falle ist die Mischnng gelblich, im letztern aber ungefärht, mit Ausnahme der von Essig hireingebrachten Farbe. Sie hat einen sauren Geruch und Geschmack.

Die Morsclien, welche theils uoter die OHicinalformeln gehören, theils aucl von den Aerzten ats Hagistralfor-

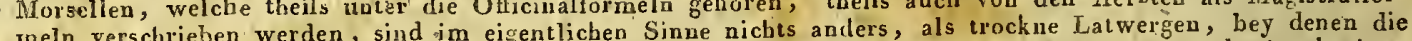
meln verschrieben werden, sind im eigentichen Sinue nichts ander, alsen mit einem so stark eingekochten dazu vorgcschriebenen pulverichten und andern zerschnittenen Ingreden arm ausegossene Masse noch vor der Zucleer vermischt' werdcn, dafs die in der, dazu gehörigen Morsellenform ausgegossene Masse noch völligen Erstartung in länglich - viereckige Stücke zcrscbnitlen werdeu kann. picousten eingekocht werde darauf an, dafs, der vorher im Wasser anfyelöste Zucker bis zur gebörigen. Tafelcousisten eingekocht werde und die dazu vorgeschriebenen Species wobl hinzugemischt und so vicl wie möglich gleichmäsig unter die einzélnen Morsellen vertheilt werden. Sie müssen trocken seyn, auf der. Zunge leicht zerliefsen und
den ihnea nach Maafsgabe der Ingredienzen zukommenden Gerueb und Geschmack frisch und rein besitzen.

Morsuli antimoniales. Spicfsglanzmorsellen. Iraben von dem dazn gehörigen präparirteh Spic\{sglanze eine schwarzbläuliche Farbe.

Morsali aromatici Geschmack.

Eine in frischen Zustaude schmierige, über-/Verfälscht.

aus stark und durchdringend, besonders in

der Entfernumg wollriechende Substanz von dunkelhrauner Farbe, in länglich-lundeu, $z$ wischen dem After und den Schaamthilen des auf dea Gebirgen des mittlercn thilen des auf dea Gebirgen des mittlercn Asiens, you China, der Turtarey nard Th-
bet zu Hause gehörender $\mathrm{B}$ ies a m thiers (Nosehts mochiferus L.) sitzenden Beuteln, mit wetchen sie zngleich getrocknct und versandt wird. Es giebt davon im Handct 'verschicdene, in Ansehung der Güte sehr ron eïuander abweichende Sorten, nüinlich:

3) Tunquiniscber Biesam (Moschus tunguinensis so orieutalis) Dieser ist bey weitcm der bessere, aber auch der theuerste. Er kormml, aus dem chivesischen lieichc, hesonders ans Tonruuden als länglichen, ausweudig mit braun elben oder rotlliehbraunen borstenfürmigen Haaren besetz.ten, inwendig mit einer feinen häutigen Denke umkleideten, festen, urvcrsehrten, inehr oder weniger dicht und dem eigentlichen Moschus angefüllten Beutelı oder Sisckchen zu uns. Der darin in einigen Ahthejlungen unzusammenluingend befindliche Moschus hat das Anselien eines geronncnen und zerhröckelten Blutes oder einer beynahe völlig ausgetrockueten Latwere nud besteht aus meitrockuelen Latwerge nnd besteht aus meistens kleinen dunkelbraunröthlichen, gelb-
Der Moschis ist, als eins der kostbarsteu Arzneymittel, manchen Verfälschungen, die zum Theil auf noch unbekanntc Weise damit vorgenommen werden, ausgesetzt. $\mathrm{Zu}$ weilen ist er mit.Sand rermischt, der sich beym 'Kauen und Zerreiben des Moschus mit inem Viesser deutlich zu erkennen rnit einem Verfilschungsgiebt. Tur seine sonstigen Verch mittel, woron doch melirere nach (len $\mathrm{Vel}-$ sucben des fferrn Thicm anns (a. a. O.) zu bezweifeln sind, hält man igewonnlich auch die gehackten Hoden des Bisamthiers, anderes geback tes Flcisch, getrocknetes Blut, Vogelmist, Wachs, Judenpech, Benzoe, Storax, Asphalt, verschiedene Gewürze, Seknupftaback u. s. w. Dergleichen Verfïlscliungeu würden sich theils durch das äufsere Ansehell, durch den eigenthümlichen Gernch der beygenischten Substanzeu, durch den Mangel des ächten Biesamgernchs und Geschmạcks, theils dur cb den stinkenden empyrevmatischen Geruch, den man bemerkt, wenu man etwąs vou doschus auf einew solchen ein glubendes Lisen streut, Schnelizen und durch das vollkonmene Schimenen ceben. Aufserden wird die crofse Aufoüslichkeit des ächten Bisams in Wasser, und der bey. der Behandlung mit Wasser mehr. oder weniger heträchuliche Rïckstand einess so verfälschten Moschns cin wichıiges Criterium über die Beschaffeulueit dusselher alygeben." 


\begin{tabular}{c|c} 
Namen & $\begin{array}{c}\text { Sinnliche Eigenfchaften derfelben; } \\
\text { Merkmale ilurer Achtheit und } \\
\text { Ger Arze. }\end{array}$
\end{tabular}

$\left|\begin{array}{c}\text { Fehlerhafie Be- } \\ \text { fchaffenheic, Ver- } \\ \text { wechfelung oder } \\ \text { Verfälfchung. }\end{array}\right|$

gen, nicht zusarumengchackenen, und dar- A unter hefindlichen g̈ ofsera, noch dunkelfarheneru, weniger harteu, metr zahe Klüm;'ercheu, welche sich 2 war trocken, doch wie fettig aufüblen lasseu, in der Nä-
be einen startiell, widrigen, den Kopf einbe einen starkell, widrigen, den Kopf ein-
nehueuden, bey eiver starkell Vertbeulung aber angenchuen Geruch, uud eiuen schar bittcrlichen Geschurack habell. Ein gute ächter Biesam mufs aufserdem beym Kaue oder Reiben init eiuem Messer auf Papieı nichts sandiges fühlen lassen, souderu in letztern Falle velıuehr einige oläncende lareache Puncte zrigen und eiue hellere harzichte Pule einem heifsen Bleche und in der Sonneneinem heilsen Brennglas mufs er mit dem hitze durch en Beruche desselben vereigeuthumlichen Geruche desselben verdampfen und verbrennen, und nur höchst weuige grauliche Asche zurucklassen. Auch bielt man es sonst gewöhnlich lür ein Zeichen, dafs der Moschus nicht äclit, sondern verfälscht sey, wenn er mit Kali znsammengeriebes, den fluchtigen Geruch des Ammoninms entwickelte. Die Versuche abtr, welcue Herr Thie man n (Berlin. Jalrb. d. Pharm 1803, S. 100-155.) lin. Jahr. diut hiertiber anstellete, and Herr Buchole (Almas künstler un's Apotheker, 180., S.169-199) wiederbolle, beweisen es zur Gnuge, dals aller ächte Moschus Ammouium enthalte nnd dieses als ein demselbeu zugehöriger Bestandtheil angesehen werden musse. Das Ausdünsten you Ammonium und die Entbindung desselben aus den Moschus durch Alkalien zeige daher keinesweges eine soust angenommene Verfalschung desselbeu mit Blut oder gehacktem Fltische an, sondern sey vielmehr als ein Zeichen vorzüglicher sey vielor schus danste dasselbe 1112 só melir aus, je schus dunste dasselier er scy. Auch ist nach diesen Verfrischer er scy. Auch ist nach diesen Wassuchen der achte Mostie als in der Wärme ser, sowobl in der Kälte als in der Warme an sich ganz, bis auf zehn Procent zuruckbleibende ibierische Haut autiöslich; der Alcohol löset 25 Procent davon auf. Die grofse Autiosbarkeit dés Moschus im Wasser in Verbindung mit dem ihm eigenthümlichen Geruch und dem Ausdünsten des Ammouiuns möchten daliex als characteristische Kennzeichen der Aechtheit desselben zu hetrachten scyn.

2) Sibirischer oder Cabardini2) Moschus (Moschubiricus s. cabardinus). Er kommt, aus Sibirien in inehr länglichten, an dem eiveu Ende zugespitzten und mit längerb, weifsen oder weifsgrauen Haaren dicht und stark besetzten beuteln. Der darin enthaltene, mit vielen Häuten verwebte $\mathrm{Mo}$ schus rrecht weit schwächer, als der vorige nod sein Geruch ist widrig, dem l'ferdeschwers äbnlich, ohne merkliche Ausdïn Seine Farbe dünstung von Aing ist heinki kleiukornig, last pulverartig. Destillirtes Wasser löset nur so Procent davon auf der Alcobol eben so viel. Er ist von weit ken verwertlich.

Der Moschus mufs übrigens in wobl verschlossetien enghalsigen Gläseru aurbewalurt $n \in$ exden, vicht aber in Bley, weil dieses davou angeyriffen werden möchte. Damir sich sein statker Gerucls nicht anderu Arzueymicteln mittheile, so ruüssen deru Arzueymictelne. Wagell, Mörser und Löffel vorrathig gebalten werden.

Myrrluae.

Gummi Myrrhae. Myrrhe. ulser den Beuteln Dieser Moschus magi wohl sehr oft inil dern verküflicher Mo- vitl woblfeilercn Sibirischen durch gewinnschus. (Müchtige Kaufleute vermischt vorkommen, wovon man sich durch seine mindere Aufvesicis). löslichkeit in Wasser üherzeugen $k a n n$ Aufserdem mag er auch wohl häfig nicht Aufserdem mag er auch wohl haveg nicht anders als ein kusstliches Gemisch seyn Ueberhapt ater ist er inmer einer Verfal schung selir verdachtig und daber zum Arzneygebrauch scblechterdings verwerflich, ob man gleich auch beym Einkauf des Bie'sans in Beuteln (Moschns in vesicis) nich immer vor Betrug gesichert ist.

nächte Biesambeuan erkenut sie an einer nicht durchgehend mit Haaren besetzten Euhabenheit, die vom breitern Enile desselben his zarn schmaler fortgeht, und an dem mangelnden iunerm düunen Häutchen, welches iı den ächten Beuteln den Biesam zuü̈chst umgiebt. Oft baben sie eine sichtbare kunstliche Natb, oder sind aus ruthrereu Stücken zusammengeleimt, in welchem Falle sie beym Erweichen mit Wasser ausrinander selen. Ueberdem weifs un an den ächten Biesam aus seidem werlo men naturtich Becteln berauszubringens und sie mit verfalschem anzughe des dann gewobulich in grölser', festern, braungraueu oder fast völlig scliwarzlichen, anf deuń Bruche glänzenden oder mittelst einex: schmierig - ölichten Materie zusammenbängenden Klümperchen bestebt.

Nach der Mtinumg des Ritter Pallas soll selbst von den Sinesen der woblfeilere sibirische Noschus zur Verfälschung des theurern chinesischen Moschus in Beuteln aufgekauft werden.

Immer sollte man auch "nur solche Moschusbeutel kaufen, in welchen man weder Einschnitte, noch kleine Löcher oder Nadclstiche bemerkt.

Mit Bley vermischt, $\overline{\text { Oft werden kleine Bleystückchen oder auch }}$ gefeiltes Bley in die Beutel gehracht, um das Gewicht des Moschus zu verruehren. Mau erkent dies durch die unverhältnifsMa mälige Schwere und entaleckt es oft schon durch das blo1se Anseben. Auch lälst sich dieser Betrug entdecken, wenn man etwas von dem Moschus in der Hitze verrauchen läfst, und den Rückstand durch Schmelzen zu einem Bleykügelchen vereinigt. Ein
ächter Biesamheutel enthält gewöhnlich von einem bis zu drey Qnentchen Moschụ.

Mit beygemischtem $/$ Noch nenerlichst machte Herr Bncbol Kirsch-oder P fau- (Jo diese Verfallar au fmerksam. Man erver- $\mid \begin{aligned} & \text { diese } \\ & \text { kennt die beygemischten Gummistücke leich }\end{aligned}$ an ihrem bellern Glanz, ibrer gröfser Durchsicbtigkeit und dem bekannten schleit michten Geschmack. 


\section{Myrrha. - Natrum carbonicum crudum.}

\section{Nomen der Arzneymittel. \\ Sinnliche Eigenfchaften derfelben; Merkmale ikrer Ächtileit und Güte.}

Mis?rica.

Natrum aceticum. Terra foliata Tartari crystallisata.

Essigsaures $\mathrm{Na}$ trum.

Crystallisirte Blättererdé.

\section{Natrunz carboliz}

cum crudum.

Soda.

Kiohes kohlensau.

res Natron.

Soda.

Micueralalcali. nit ätherišch - ölicbten Thicilen durchdı ungenes Gummibarz. Die Stïcke haben eine höckerichte Oherfäche, zeigen auf eine ungleichen Bruche einen Feliglanz und die gröfseru zugleich krummlinichte weifse Striche. Aufserbalb seben sie branngelb oder rothraun, inwendig aber gelblichoder braunroth aus. Sie baben einenziemlich bittern, erwärmend gewürzhaften Geschulack, sind grüfstentheils im Speichel aufösliclı und besitzen einen aromatischen, starken, nicht unangenebmen Geruch, der beym lieiben oder beym Anzünden noch lieblicher wird. In der Wärme schmilzt die Myrrbe vicht; am Lichte aber läfst sie sich anzünden und brennt mit heller'Flamme. In Wasser, Wein, Bier und Essig ist sie auflöslicher, als im Weingeist. Die Oele wirken uicht merklich darauf; iu versüfsteu Säuren aber und in anmoniumbaltigen Weingeist ist sie fast völlıg auflösbar Mit Campher zusammengerieben bildet sie eine weiche klebrige Masse. Gepulvert crscheint sie als eiu nar locker, zusammenhängendes, braungelbes, etwas gláncendes Pulver, wie mit eiuem fetten Oele getränkt. In Handel koumen 2 wey Sorten vor, uämlich: . 1) die bes a wor Myribe (Myrbaelecta) und 2) die gemeine. Myrrhe Myrrha insori is). Beyde Sorten, besonilers aber die letztere, sind meistentheils mit so vielen letztere,.. sind meistentheils mit so vieleu Stückeñ vermischt, dafs man, besouder fur den ivneri Arzneygebrancl dic äch e Myrthe. ( $M$ y r r a rubra s. pinguis) die sicb durch obige Eigenschaften ans zeichnet, erst davor mit Fleifs aussuohed mufs.

\section{Fehlerhafie Be- schaffenheit, Ver- wechfelung oder Verfälschung.}

Deren

\section{Kennzeichen und Prüfungsmittel.} einigermalsen durcbscheinenden, inwelldig
feltig anzúfühlenden Stiicker besteheudes,

Gunimi - und Harz stücke mit einer geistigen Myrrhentinctur sucht man dieVérfälschung der Myrrhe mit densel ben oft unkenntlich zu machen.

Mit Stücken voul Unterscheiden sich durch die dunkelhraunere Pdellium verfälscht. Farbe, llurch ihre Zähigkeit, weniger bittern Gesthmack und durch das Knistern und Soritzen, went
gehalien werden.

Anmerkung. Aufserdem soll die Myrrbe am bäufigsten mit éinem braumrothen Gummi vou einem Baume der Sassa heifst und mit dem Myribenbaume gleiches Vaterland haben soll, verfälsch werden. Eine Verfälschuug, die wahrscheinlich schon $2 u$ Galemus Zeiten vorgekommen ist.

n ans Natrum und Essigsänre besteheudes Nittelsalz. Es schiefst in ausgezeichnet schönen lan spiefsigen Crystallen mit gestreiften Seitenflächen an, die cinen eigenthümlichen, angenehn scharf stechenden Geschmack haben, an der Luf leicht zerfallen, völlig weifs sind, in geliuder Wärme in ihrem eigenen Crystallwasse zerfliefsen, sich bey miltlcrer Tcmperatur im Wasser, wie 3 zu 4 . und auch in siedendem Weingeist, wie $12: 211240$ antusen, aus welchem letztcrn sich das Salz aber sogleich bcym Erkalten wieder herascrystallisirt. Mit Schwefelsü̈ure übcrgossen', muls es den Geruch der Essiusäure entwickeln. Die Auflisung desselben darf weder die blane Farbe des Veilchensaftes verändern, noch durch salzsaure Baryt - oder salpetersaure Silberaů̈̈sung gctrüht werlen. Im Feuer 'wird es zerstört und inan entdeckt durch sein Verbrennen im Schmelztiegel, ob noch anderc Salze darnit vermischt sind; ist das Salz rein, so bleibt nur alleiu das Natruin desselben zurück, welches sieh in sehr wenigem Wasser auflöset, während die etwa noch dabey beNitruin desselben zurück, welches sieh in sehr wenigem Wasser
findlichen feuerbeständigen Mittelsalze am Boden lie blu bleiben.

Es giebt hievon für deu Arzneygebrauch zwey|Schlechtere lür dell Hauptarten, nämlich:

I) Die spanische Soda ( Soda Lispanica). Ein aschgranes festes ConcreSent, ans verscbielenen verbrännte Seeuferphanzen (Salicornia euro paea, berbacea und fruticosa, Salsola sativa, Salsola Soda, Mesembryanthemum copticum us. v.) erhalten wird, und welches ausgelaugt, das in den Apothekcn gebränchliche mineralische Alcali oder kohlensaure $\mathrm{Na}-$ tron liefert. Die beste spauische Soda besteht aus hartcn, trockuen, schweren, blaulichdunkelgrauen, klingendeu. Stückell von verschiedener Gröfses die an der Luft trokken-bleiben, nit Wasser benelzt, keinen stinkenden Gernch geben, etwas scharf und laugenartis schmecken, mituntcr kleine laugeuartigs schmecken, mituntcr kleine
weifse Flecken zeiseu, viele kleine töcher weifse Flecten zeiseu, viele kleine Lücher haben, mit Säuren sogleich aufbrausen unil nelocn weuigern Korhsalz viel mineralisches Alcali cnthalten. Eine solche Sode schätz.t man der Alexandrinischen, die ans Aegypien, Tripolis, Syrien und Astrachan über Alexandrien kommt und fïr die besto gehalten wird, aber fast gar uicht $2 u$ uns gebracht wird, gleich. Gerungere Sorten, als dic spaniselae Soda sind 1) die Französischcorlcr Languedoksche Soda, (Sodagallica); die Ĺbs. Marscille in haten klingenden Stitck on vou dunkelschwärzlichblaricr Farbe uns zugefihrt wirl. 2) Dis Carthagenische Soda (Sodacathaginensis), dio in ieher gehort is die Ti g sode (Sonde Apotleker un- de Varech, de Cherboury), die brauchbare Sorten. Juan hauptsächlich in der Normandie durch Verhrennen der Seegräser, lles See - und Blasentangs gewinnt, und womit der auf matrchen Schotisishen und den Scillyinselp matrchen Schotischen und den Scillyinselp ebeufalls drurch Einäschern mehrerer Seegrasarten gewonnene sogenannte Kelp übereinkommt. Beyde kommen in mürben, weifsgrauen, leuchtenden, sehr weniges Natron euthiltenden Stäcken, die sich mit schwefelleberartigem Geruch in Wasser aufösen, zu uns, sivil aber für den Apotheker vicht zu gebrauchen. 2) Die dentsche im Bernburgischen bereitele Soda, ebenfalls eine schlcchte, blos für Seifensieder brauclibare Sorte.

Die Soda ist übcrhaupt eine selrr gemengte Substanz, in welcher aufser dem Natron, welches den gröfsesten Bestandtheil ausmachen sollte, anch vegetabilisches Laugensalz, Küchensalz, Schwefelleber, Glanbersalz, Kalkerde, Bittersalzerde und Eiscr augetroffen wird. Je mehr sie von diesen fremdartigen Beymischungen enthält, wozı oft nocb Sand, Steine, unzerstörte Kohlen u. s. w. komunen, um desto schlechter ist u. s. W... Konder ist sie. Die beste Untersichung uber den grofsern oder geringern bestimint daher ibr Gehal a reinem $\mathrm{Na}$ iron, welcben man durch wiederholtes Auskochen nnd Crystallisiren 20 erforschen sucht.

Man hat sogar die Soda als einen läunichen Artikel aus luftsaucem Miucralalkali 


\section{Natrum carbonicum crudum. -- Natrum nitricum.}

\begin{tabular}{c|c|} 
Namen & $\begin{array}{c}\text { Sinnliche Eigenfchaften derfelben; } \\
\text { Merkmale ihrer Aechtheic und } \\
\text { Güce. }\end{array}$
\end{tabular}

Natrum carboni- granen oder grangrünlichen Stiickeu und olim crudum.

Natrim carbonicrime crystallisatTLm.

Alcali minerale purum.

Sal Sodae.

Crystallisirtes koh-

lensaures $\mathrm{Na}$ trun.

Reines Mineralalcali.

Sodasalz.

in grörsern Masses als Soude de Bourd
oder Bourdine im Handel vorkummi.

II. Die Ungarisohe Soda (Soda h u ngarica), welche'natürlich vorkomme, und in einigen von selbst austrockmenden Sümpfen in Ungars iu grofser. Menge auswächst: So wie wis sıe im Handel erbalten, ist sie bereits in eigewen lazu errichteten Anstalten von den gröbsteu Unreinigkeiten durch Auflösen gereinigt, wieder eingedickt und geylühet (Soda $h$ u $\mathrm{n}-$ garica calcinata.) Man erbält daraus durch abermaliges Aufösen in Wasser und licberer Nenge als aus der Spanischeu Soda, die abnehin von Zeit zu Zeiı schlechter wird. Auch kann man es im Handel schon crystallisirt (Soda la ungaric a crystallisata) erhalten; es löset sich volikomme lar in Wasser anf und gicbt Gitanbersalz.

Das reıne milde oder koblensanre Natrum bildet anselnuliche, farbenlose, glashelle, in sechs - bis achtseitigen Säulen, mit zwey entgegengesetzten zweyseitıgeu. schrägen oder dachförmigen Endspitzeu anschiefsende Crystallen. Es schmeckt gelinder, als de Crystallen. Es schmeckt gelinder, als das koblensanre Kali. Die Feucbungeit
der Luft ziebt es nicht an, sondern wird der Luft ziebt es nicht an, sondern wird
vieimebr auf der Oberfäche bald weifs und vieimebr auf der Oberfäche bald weifs und
mehlicht, und zerfällt endlich zu einem gung von Kälie in doppelt so vielem Wasser völlig anf. In reiner Salpeter - und wcifsen Pulver. Es löset sich unter Errentrum mit lebhaften Brausen aufösen, und die etwas übersättiogte Au@ösung darf wenn dasselbe chemisch wenn dasselbe chenisch rein seyn soll, weder :durch salzsaure Bary tanilösung noch durch salpetersaure Sil herauflösung getrübt, anch nicht durch Hydrothionsaures Wasser scbwärzlich gefärbt werdeu. Zngetrö-
felte Kaliauflösung darf ebenfalls keine felte Kaliauflösung darf ebenfalls keine
Triibung dariu hervorbringen, weil diese's sonst eiı̀e darin gelöste Erde verrathen würde. Iu der Hitze zerfiefst d.s frisch bereitete Salz in seinem eigenen Crystallisationswasser, wird danu trocken und kommit von neuem zum Flufs, wenn die Hitze bis zum Weifsolüben vermebıt wird.

Tatrum carbonicumn siccatum.

Trocknes kohlen saures Natrum.

Natrum muriaticumm.

Sal culinare. Salzsaures Natrum Nüchensalz.

Natrum nitricum. Nitrum cubicum. Sálpetersaures Natruin.

ITürflichter Salpeter. geführten Natıums besitzen. Crystallisiren ein reines Natron in reichrollkommen hlar in Waster anf nud giebt concentrirter Essigsäure mufs sich das $\mathrm{Na}$

$\left|\begin{array}{cc}\text { Fehlerhafte } & \text { Be- } \\ \text { Schaffenheit, } & \text { Ver- } \\ \text { wech Jelnng oder } \\ \text { Verfälschung. }\end{array}\right|$ Kennzeichen und Priifungsmittel.

mil Hol $\angle$ - oder Torfasche, Sand und aus gelaugter IIolzasche aut eine künstliche Weise nachzu inachen gesucht. S. von Crell chemische Annalen, 3797, St. 1. S. A1.

Mit fremden Salzen, Aufserdem, $\overline{\text { dafs man dieses dadurch er- }}$ Glanbersalz, Kiii- fährt, dafs sich das reine Salz in 2 wey chensalz, schwefel- Theilen Wasser vollkommen aullöset, entsaurem und deckt man es noch hestimmter, wenn man

saurem und salz- die klare Auflösung desselben mit Salpeterreinigt. säure oder conceguţritem Essig eiu wenig übersättigt und zu einem Theil da *on etWas salzsaure Barytautlösung, zu dem an-
dern aber etwas Silberaullösnng tröpfelt. Bleibt alles $\mathrm{klar}$, so ist das Natrum rein; wird die Mischung aber trïbe, so enthält sie im ersten Falle cin schwefelsaures, im letztern ein salzsanres $\mathrm{Salz}$

Eine leichte Trübung findet indessen fast immer statt, und weun das Salz auch keine Schwefelsäure enthält, so enthält es doch 'gewöbulich eire Spur von Salzsäure.

Mit Kali verunrei- Die Aullösung wird alsclann durch eine connigt.

Bleylualtig, wenn das Das trübt uod giebt damit einen weifsen Satz. völthg rein scheinende Natrum ist doch imaus dem Kochsalze mer hieraul zu prïfen. Es gescbieht diedurch Bleyoxyde ses, wenn man eine kleine Portion davon geschieden worden. mit reinster Essigsäure neutralisirt, und daun mit $\mathrm{H}$ a h n e ma an $\mathrm{n}$ s Probefliissigkeit vermischt. Bleibt das Saturat damit ungefärbt, so ist das Natram auch nicht bleybaltig.

A umerk, Alles in Pulverform verkäulliche Mineralalcali ist einer Verfälschong mit fremden Salzera vcrdächtig. Man mufs daher zum Arzneygebrauch'beständiz ein solches wählen, welches gut crystallisirt ist.

ie duch mälsige Wärme ihres vielen Crystallisationswassers berauben und in ein trocknes Pulver zerfallenen Crystallen des koblensauren Natrums. Das Pulver mufs eiue schneewrifse Farbe liaben, und mit Ausnabma der, von der Crystallenform abbäugenden Beschaffeubeit die übrigeu Eigenschafteu des im vorigen Titel an-

Ein sebr bekanntes aus Na'rum und Salzsäure bestelendes Neutralsalz'; welches aus den in ganz Europa, vorziuglich anch in Doutschland roskomering an Salze, zuglich allch in Doutschland vorkommeuden Salzquellen vou einem grofseru oder. geringern Gelialt an Salze, aul den Salzsiedereyen oder Salzkotben durch Verhunsten erbalten wird. Es bildet wurflichte Crystallen, die sich aber gemeiniglich in Form eines Mühlentrichters nntereiuader verbinden oder zu hublen Pyramiden
aneinander reiben. Für den Arzneygebraucb wahle man ein festes, weifses, durclisichtiges und gut crystalaneinander reiben. Für den Arzneygebraucb wahle man ein festes, weifses, durclisichtiges und gut crystal-
lisirtes Soblensalz, das in der Luft uicht feucht wird, sich in dury rnal so vielem Wasser bald und völlig autlöset und dasselbe nicht in míudesten fäbt, alas ferner in Wasser aufgelöset, von hinzugegossenem Kali nicht trühe odcr milchicht, wird, auf deın Fener im gluhenden Tiegel stark knistert und auseiuander springt ofler verprasselt, seiue weifse Farbe aber beybebält, nnd einen reinen st urken Salrgeschmack bat.

Aufserdem findet man dieses Salz als Berg-oder Steinsalz ( $S$ al montanum, Sal Gemmae) in grofsen durchsichtigen Massell schou fertig in der Erde, z. B. in Siebenbürgen, Ungarn, Pohlen und Eugland, oder es wird as dem Neerwasser und encen Laslscen durch natïrlicbe oder kïnstliche Ver-

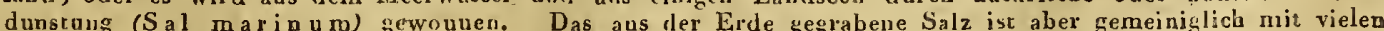
erdigen Theilen, das Meersalz mit einem gemein mit Alaun und Bittersalz verunreinint.

Eiu aus Natrum und Salpetersämre bestebenites-Mittelsalz. Es bil.let grofse regelmálsige Giystallea, welcbe die Gestalt eines verscholenen Vierccks haben, schmeckt wie der gemeine Salpetcr, ist aber.kühlender und weniger reizend wie dieser. An ler Luft wirl der würflichte Salpeter felicht, löset sjch leicht und in drey Theilen Wasser auf. In der Glibbitze wird er revlegt, auch treunt Schwefelsäare die Salpetersänre und Gewäcbskali das Natrum oröfstentheils aus desta perbundenen Glär. sern an einem tiockuen O:te aulbewabren. 


\section{Natrum phosphoricum. - Natrum sulphuricum siccatum.}

\begin{tabular}{|c|c|c|c|}
\hline $\begin{array}{c}\text { Namen } \\
\text { derArzneymittel. }\end{array}$ & $\begin{array}{c}\text { Sinnliche Eigenfchaften derfelben; } \\
\text { Merkmale ilhrer Ächtheit ünd } \\
\text { Güte. }\end{array}$ & $\left|\begin{array}{cc}\text { Fehlerhafte } & \text { Be- } \\
\text { Schaffenheit, } & \text { Ver- } \\
\text { wechfelung oder } \\
\text { Verfälfchung. }\end{array}\right|$ & $\begin{array}{c}\text { Deren } \\
\text { Kennzeichen und Prïfungsmittel. }\end{array}$ \\
\hline
\end{tabular}

Nacrum phospho- Wird durch Sättigung der aus den Koochen ricum.

Soda phosphorata.

Phosphorsaures

Natrum.

Phosphorsaure Sode.

durch Schwefelsäure geschiedenen T'hos-

phorsäure mit kohlensteffsauren Natrum,

docb so, dafs das letztere merklich bervorsticbt, weil sonst die Lauge nicht cry stallisirt, erhaten. Es lildet grolse, durchsichtige, rhomboidalische Crystallen,
die jed ocb wegen der verschiedenen Menge des freyen Natruśs sehr veränderlich erscheinen, Der Geschmack ist rein salzig obne alle Bitterkeit. In Wasser löset es sich leicht auf, nicht aher im Weingeist. Vermögre des hervorstechenden Natrums färbt es den Veilchensaft gr ün, so wie die Curcumätinctur braun. Die Crystallen verlieren zwar an der Luft ihre Durchsichtigkeit bald und bekommen einen weilsen lange ihre Gestalt, so dafs man gerueiniglich bey uälerer Untersuchung den Ker jedes einzelnen Crystalls noch unverwitter torfindet. Im Fener fliefst es nach einigem Aufschäumen leicht und schmilzt in der Glühbitze, obne zersetzt zu werden, zu einer glasälınlichen Masse, die dnrcbs Wiederauflösen im Wasser die vorigen Crystallen zurückgiebt. Die Auflösung desselben wird durcb Schwefel - Salpeter- und Salzsäure, durch Kalkwasser, ätzeodes, kohlensaures, essig - und Weinsteinsaures Kali, so wie durch natronisirten Weinstein, Alaun, Bıttersalz, salzsaurew Kalk, essigsaures Bley und Qnecksilber, salzsaures Eisen und den offizinellen Vitriolen zersetzt.

Natrum stulpluturicutn crystallisatum.

Sal mirabile Glauberi.

Crystallisirtes schwefelsaures

Natrum.

Glaubersalz.

ans Natrum und Schwefelsaure beste hendes Neutralsalz, welches theils in verschiedeneu Gesundbrunnen vorkommt, nen geschiedeu, theils durch die Kunst bereitet und bey mehrern chemischen Arbeiten in manchen Fahriken als Nebenproduct gewonnen wird. Es bildet dasselbe ansebnliche, grofse, eisklare, aus platıge- $\overline{\text { Natrum sulphuri- }}$ cum siccatum.

Sal mirabile siccum.

Getrocknetes Glaupulverichten Beschlag, 'behalten jedoch

\begin{tabular}{c|c} 
Mit Glaubersalz oder & Um dieses zu entdecken, inufs. eine kleine \\
Portion in Wasser gelünt, erst mit reinster
\end{tabular} Kochsalz verunrei- $\begin{aligned} & \text { Portion } \\ & \text { Salpeter-oder Essigsätre ein weuig über- }\end{aligned}$ nigt.

sättigt und dann zur einen Hälfte einige Tropfen von der Lösung des salzsauren oder salpetersauren Baryts, und zur andern von der Lösung des salpetersauren oder überphosphorsauren Silbers getban werden. Wird durch erstere Scheidungsmittel kein Schwerspath, und durch letztere kein salzichtsaures Silber als Niederschlag abgezichtsaures Silber als Nrederschlag abgesondert, so ist es von jenen Beymischun-
gen frey. (D ör f furt neues deutsches gen frey. (D ö $r f f$ f $\mathrm{r}$ neues
Apothekerbuch, Tl. 2. S. 1408.)

Apothekerbuch, Th. 2. S. 1408.)
Nach Herru Branden burg (Journal d Nach Herro B rande $\mathrm{b}$ urg (Journal d
Pharmacie, B. 14, St. 1. S. 121) mufs sich der weifse Niederschlag, welcber eutsteht, wenn man zu der Auflösung des phosphorsauren Natrums etwas salzsaure Barytauflösuus tröpfelt, vollkomrnen klar in reiuer Salpetersäure wieder autlösen, wenn daz Salz frey von Schwefelsäure war.

A n in erk, Etwas weniges Glauhersalz wird das phosphorsaure Natrum wohl immer entbalten, es sey denn, dafs man zll seiner Bereituug die reinste, durchs Verbrennen des Phosphors erbaltene Phosphorsäure auwenden könnte. Ein so geringer Glaubersalagebalt wird aber anch bey der medicinischen Anwendung nicht nachtheilig scyn. drückten Säulen mit sechs ungleichen, gestreiften Flächen, und zwey-, vier-oder sechsseiligen Endspitzen, bestehellde Crystallen, die einen anfangs kühlenden, nach-
ber ziemlich bittern Gesclimack baben. Im Weinalcohol ist das Glauhersalz unauföslich; dagegen löset es sich sehr leicht im Wasser auf, indem ein Theil dieses Salzes drey und drey viertel Theile kaltes, und kaum drey viertel Theile kochendes Wasser: $2 u r$ Antösusg ertorder. In Clystallisationswasser, wird dann aber, wenn letiteres verdunstet ist, wieder fest wnd scbmilzt erst in der Glühlitze. An der Luft, besonders in warner Temperader Luft, besonders in warneifsen Pulver tur, zerfallt es zu einen weilsen lind reines Glanbersalz mufs vollkommen neutralisirt, und wenn es auch anf der Oberfläche ein weuig üherzogen ist, doch inwendig lslar und durchsichtig, und übrigens ganz trocken seyn, mit Kaliauflösmug nud mit salpetersaurer Silberauflösung keinen Niederschlag/geben, mit Galläpfeltiuctur keine schwärzliche Farbe und mit Ammoniumflüssigkeit keine blauliche Farbe hervorbringen. Untauglich ist liche Farbe hervorbringen. ,es, wenn, es nur im mindesten grunlich, weun es einc molkenarlige-Undurchsichtigkeit hat, an der Luft nicht zerfällt, oder das zerfallene Pulver nicht schnecweifs, sondern gefärht ist, wenn ea die Lackmustinctur röthet, das Kalkwasser tribt, und wenn die Auflösung durch Kalin̈̈ssigkeit niedergeschlagen wird.

Mit Kochsalz, salz- Das erstere entdeckt man yorzüglich durch saurer Bitter-oder das Knistern und Prasseln im Feuer. Die Kalkerde verunrei- $\quad$ Salzsäure verräth sich üherhaupt durch den nigt. weifsen Niederschlag auf Eintröpfelung einer Silbervitriolanflösnug in die Aufösung des Glaubersalzes. Auch ist sil solches Glaubersalz beständig feucht.

Mit Eisen und Kupfer Im erstè n Falle hat das Glauhersalz eine verunreinigt, auch gelblicbe Farbe und die Auflösnng desselwohl mit Bley, ben wird durch Galläpfeltinctur schwärz lich gefärbt; im $\mathrm{z}$ wey ten Falls spielt seine Farhe ins grünliche oder blauliche und es entstebt in der Auflösung durch hinzugetröpfelte Ammoniumflïssigheit sine bellblaue Farbe. Ein in die Auflösung gestelltes, polirtes Eiseustäbchen nimmt einen lupfernen Ueherzug an. Ist das Glauberkup salz nit B le y verunr einigt, so zeigt dieses wodurch die Auflösung schwärzlich getrübt wodurch
wird.

Mit Ammonium ver- $\overline{\text { Giebt sich durch den Geruch, wenn man das }}$ unreinigt.

Bittersalz enthaltend reiht, so wie durch die weif́sen Dämpfe, wenn man ein mit Salzsäure befeuchtetes Papies darüber bält, zu erkennen.

Die Auflösung wird durch hinzugemischte $\mathrm{Ka}-$ liflüssigkeit getrübt, statt dafs sie, wenn das Claubersalz rein war, völlig belle or mit hleibt.

Zufällig auch wohl mit Verpufft auf ein glühendes Eisen gestrect; die Salpeter vermischt Glaubersalzcrystallen zerspringen anch nicht gewesen.

ter Hand, als die Salpetercrystallen.

Kastigkeit nielergeschlagen wird.

an der Luft und in gelinder Wärme zu Pulver zerfallene Glaubersalz, in welchern Zustaude es nur balb so viel wiegt, als in crystallinischer Gestalt, und.indem es das Wasser begierig einschluckt, wodurch alsdann Wärınestoff frey wird, bey Vermischnng mit Wasser, Erwärmung hervorbringt, statt dafs crystallisirte⿰ Glauher's:1\% sicb unter' Kälteerzengung im Wasser löset. Es schmeckt mehr erwärmend als kuhlcnd, und zwey Theile davon geben mit drey Theilen Wasser zusaminengerührt, eine fóste Gerinnung. Seize Farbe - muf́s schuéeweifô seyn. 
Nuces Been s. Behen. -- Olea aetherea.

\begin{tabular}{|c|c|c|c|}
\hline $\begin{array}{c}\text { Namen } \\
\text { deri:Arzneymittel. }\end{array}$ & $\begin{array}{c}\text { Sinnliche Eigenfchaften derfelben, } \\
\text { Merkmale ihrer Aechtheit und } \\
\text { Giite. }\end{array}$ & $\begin{array}{l}\text { Fehlerhafie Re- } \\
\text { |fchaffenheit, Ver- } \\
\text { wechlelung oder } \\
\text { Verfälfchung. }\end{array}$ & $\begin{array}{l}\text { Deren } \\
\text { Kennzeichen und Prüfungsmittel. }\end{array}$ \\
\hline
\end{tabular}

Vuces Been s. Be-pDie in den anderthalb Fufs lavgen, dreyklappigcu Hülsen des im Morgenlande und in Ostindien häuf́g wachsenden Oeluufsbaums (Hyperantliexa Moriuga Vablij) enthalcenen, mit einer weifsen Suhstant Behennüsse. uugebencn, dreyeckigen, mitunter länglichen, weifs - oder bräunlichgraven, in der Gröfse den IIaselnufskernen gleichkommenden Samen, welche unter der äufsern harten, dünnen, leicht zerbrechlichen Schale und einer darnnter liegenden ziemlich dicken, scbwanmichten, selur weifsen Haut, einen gelblichweifsen, ölreichen, scharf und uuangenehm bitterlich schmeckenden Kern entbalten. Die besteu sind diejenizén, ôn ölicht wird. Veraltete Behenü̈sse mit eingeschrumpiten Kernen sind zil verwerfen.

Nuces Hippocastani.

Rofscastanien.

Nuces Jugtandis immatterize. Unreife Wallnüsse.

Nuces Moschatae. Muscatennüsse.

Nirces Vomicae. Krähenaugen.

Olea a etherea. Aetherische oder wesentliche Oele.

ie von ihrer änfsern, grünen, :stachlichten Schale befreyteu Samen des bekanuten Rolscastanienbaums (A esculus Hip pocastanum L.), welche uuter einer festen, lcderartigen, braunen Oberbaut ein compactes, weifses Mark enthalten, das einen scharfeu bittern Geschmack besitzt und sich getrocknet zu einem feinen Mehle (Farina Nucnum Hippocastani) pulvern lälst.

ie hekannten Steinfrïchte des Wallnu $\mathrm{Ss}$ ba ums (Juglans regia L.) mit einer auswendig lebbaft griinen, inwendig weifsfeischichten, dícken Schale, deren Sali die Hände hraungelb färbt; von einern bitterp, herben, zusammenziehenden Gesclimack und etwas widrig gewiizhaftcu Geruch. Sie werden noch unreif in den Monaten Junius und Julius eingesammlet, wo sie sich noch leicht mit einem elfenbeinernen Pfriemen Extractes aus.

Die rundlichen, dichten, schweren, aus- Verdorben. Die angefressenen, wurmstichigen, leicht zer-

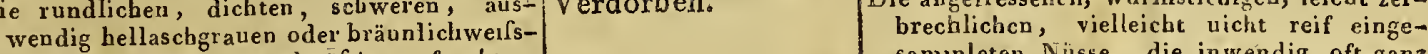
licheu, etwas unregelmälsig gefurcbten, inwendig braungelbröthlich mirmorirten, ölichten Kerne aus der Nufs von den Früchten des Muscatbaums (M y r istica Moschata), eines jelzt vorzinglicb auf der Insel Banda gezogen werileulich auf der Insel Banda gezogen wilterichen, den Baums. Sie baben einen bittertichen,
crwärmend gewürzhaften, etwas fctigen Geschmack, und, besonders gequetscht Geschmack, und, besonders gequetscht
oder geschabt, einen sehr angenebmen, oder geschabt, einen sehr angenebmen,
durchdringenden, gewürzaften Geruch. Gute gesunde Muscatennüsse müssen scliwer und fettig seyn, mit einer heifsen - Nadel durchstoclen ein gelbliches Oel ansschwitzeu, beym Durchschneiden nicht zerbröckeln, und durchsclınitten bey einer durchgebends gleichen Festigkeit und Dichtigkejt eine marmorirte, gläuzende, wie tigkeit eine mánk Otrerfläche zeigen. Den mleinen, mehr runden Muscateunüssen, die man gemeiuiglich das Weibchen uenot, die man gemeiuiglich das Wëlülichrundeu. giebt man vor den grölsern läligen Geruch und die einen weniger kraftigen Geruch and Geschmack haben und dic innelbalh nicht selten schimmlicht und braunscisärzlicher marmorirt befunilen wcrden, deb woh! das Männchen genannt. samunleten Nisse, die inwendig of ganz hoht und yon schwachem Geruch und $\mathrm{Ge}$ schmack sind, werden unter dem Nanen $\mathrm{R}$ om pen besonders rerkauft, taugen aber zum Arzney:ebranch nicbt.

Durch Destillation Gebeu sich durch eine gan e egale braune'Faroder Ausziehen mit be auf der Oberfläche und im Innern, so Weingeist ihres Ge- wie durcb einen auffallend schlechten Gewü̈rstoffes beraubt. schmack zu erkennev.

Falsche Buscaten- Benàuer Durchsicht findet man zuweilen unter den Muscatnïssen ganz frérudartigé, ihnen äbuliche, auf der Aufsenseite aber nicht gefurelite und uicht ruazlicbte Fruchte von blus mehlicbtem, ein weuig zusammen ziehenden Goschmack.

Die zu acht bis zehn Stück in den Fleische der rualdelben, harten, doch eicht zerbrechlichen Schale umgebene Frucht des in Malabar uud Ceylon einbeinischen Krähenaugenleicht zerbrechlichen Schale umgebene funtliche plattgedrückte, auf beyden baums (Strychuos Nux romica L.) äuf'erst zahe, acht his zehn Linien breite, eine balhe bis ganze Sciten flache, ein wenig gekrumme, harte, andern aber ein wenig Linie dicke, in der. Mitte auf einer Seite nit einem etwis finen ascbsrauen oder gelhlichgrauen, silberfarnitdergedrücktem Nabel bezeichuete Sainen. Sie siur mit reinen ascbsrat, bedeckt, lassen sich sanft anfühbig glänzenden Haaren, die gegen den äufs'rsten Kreis zugekehrt stebren, bedeckt, lassen sich sanft anfuhlen und zeigen, nachdem die Haare weggenommen sind, eine gelbbraune zarte Huut, und dasunter den eilen und zentlichen weifsgelben, bisweilen ins bäunlicbe fallenden ungetheilten Kern von hornatiger Beschaffenbeit. gentlichen weilsgelhen, beschmack ist böchst bitter; der Gertuch kaum ueskljch, schwach balsamissb. Sie lassen sich äufserst Ihr Geschmack ist hochste znvor geraspelt und mit Tragantschitim angestufseu und wieder getrocknet sind, schwer und recht feinen Pulver bringen. Je heller sie ansseheh, und je scbwerer sie sind, um desto besser sind sie.

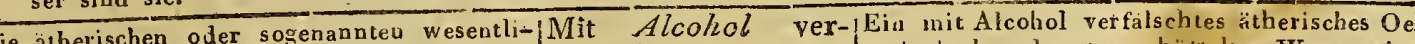

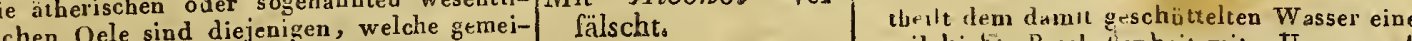

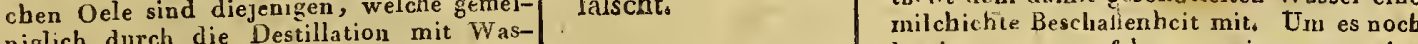
niglich durch die Destillation mit $W$ asser, seltuer durch blolse inecbanische be bandlung, (wie das ätherische Citronenund Bergamottö1) aus stark riechendell, gewürzbaften Pflanzensubstanzen erhalten werden, und in einem vorzüglichen Grad den eigenthürmlichen Gerucb und Ceschmack derjenigen Substanzen besitzen aus welchen sie bereitet sind. Sie sind aufserordentlich flïchtig, verfliegen daber lcicht, und steigen bey dem Siedegrade des wassers mit über den Helm. lbr Geschmack ist stark brennend uud igewürzhaft, zuweilen auch wobl süfslich. Sie sind ferner an der. Flamme des Lichts obne vorherige Erbitzung entzündlich. und lodern mit heller, stark infsender Flamme auf. In Weingeist lösen sie sich sehr gut rund in Menge auf, und die Auflösung erbält mit Wasser eine milchichte Farbe: Auch im Wasser sind sie mehr oder weniger, doch immer nur in sehr geringer
Menge anflöslich. Sie selbst lösen Harze, bestimmter zu erfahren, wiege mau eine Portion Oel ab, und vermische es durch Schüttelu mit böchstens eben so vielem Wasses. Wenn sich daun das Oel vom Wasser wieder ahreschieden hat, so sondere man es davon ab und wiege es. War es mic es davon ab es mic wicht um so viel als Alcobol zugesetzc war, veruindert hahew.

Aufsesdem hahen dergleichen mit Alcohol vesfälschte Dele eine ungewöhnliche. Drinnflussigkeit und eive mebr helle Farbe.

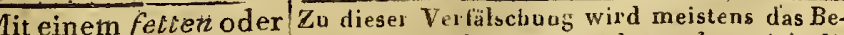
ausgeprefsten Oele henöl gemisbraucht und es ecben sich die veriälscht. so ver aliscliten Oele gemeiniglich durch ei-
ue dickftussigere Beschalfeuheit, und einen, ue dickflussigere Beschalfeutit, und einen,
der Natur des achten Oels entgegengesetzder Natur des ächten Oels eltgegengesetztci mildern Geschmack zul e1kennen. Sifetten Oele erkannt, wenn einige Tropfen, die mau von einexa solchon verfässhte. 


\section{Olea aetherea. - Oleum animale aethereum.}

\begin{tabular}{c|c|c|c} 
Namen & $\begin{array}{c}\text { Sinnliche Eigenfchaften derfellen; } \\
\text { Merkmale ilhrer Ächtheit und } \\
\text { Güte. }\end{array}$ & $\begin{array}{c}\text { Felhlerhafte Be- } \\
\text { fchaffenheit, Ver- } \\
\text { wechselung oder } \\
\text { Verfälfchung. }\end{array}$ & Kennzeichen und Priifungsinittel. \\
\hline
\end{tabular}

Olca aetherea. . natürliche Balsame, Schwefel und andere

Stoffe auf, vermengen sich gut mit fetten

Oelen und Zucker, und werden durch letz-

tere auföslicher in Wasser gemacht. Mit

Säuren vereinigen sie siclf, und machen mit denselben barzähnliche Substanzen oder eine Arr von saurer Seife. Mit Mineralsäuren erhitzen sie sich stark und mit der rauchenden Salpetersäure geht die Hitze oft bis zur Enteündung. Durch das Alter. oft bis zur Ent<undung. Durch das Alter werden sie inerklich verändert und in
schlecht verwabrten Gläsern gehen sie allmälig in cinen dickflüssi cn Zustand über und verwandeln sich endlich in Harze. Mit ätzenden Alcalien verbinden sie sich nur iun harzähnlichen Zustande.

Aufser den Pflanzen gieht es verschiedene thierische Stolle, aus denen ebenfalls durch die Destıllation ätherische Oele in grölserer oder geringerer Menge erbalien werden. Die empyrevmatischen Oele liefern gleichfalls durch wiederbolte Destillation, entiveder blos fïr sich, oder über Wasser, Kreide, gebranntem Hirschlorn, lehendigen Kalk u. dgl. abgezøgen, ähnliche ätherische Oele, die nicht etwa als Prodncte der wiederbolten Destillation oder als durch diese Behandlungsweise verfeinerte brenzliche Oele anzusehen sind, sondern eiuen wirklichen Bestandtheil dex schwarzen brenzlichten Oele ausmachen, und durch die Destillation von dem übrigeu ühelriechenden Oele abgeschieden werden. Hierher gehört besouders das ätherische Thieröl.?

Die ätberischen Oele müssen nicht iu zu grofsen Staudgläsern aufbewahrt werden. weil sie durch das öftere Erüfrnen der Flaschen theils verfliegen, theils durch Einwirkung der Luft ibr Miscbungsverhältnifs ahgeändert und ibre Kraft vermindert wird. Sie müssen daher in kleinen mit Glasstöpseln verschenen, nach Herrn D örf furt sicherer mit feinem Kork gut verstopften, und mit doppelter nasser BIase fest verbundenen oder an der Mündung mit feinem Siegellack überzogencn Guäs mit feinem vor dem Zntritt der Luft gesichert, an einem' küblen Orte aufbewahrt chert, an

Weren ihres zum Theil hoben Preises und der geringen Menge, in welcher sie erhalten werden, sind sie öftern und bäıfigen Verfälschungeu ausgesetzt, fïr welche man sich heym Einkauf sorgfältig zu büten hat. Oele vou einbeimischen P'llauzen solltc hillig jeder Apotheker sich sellist bereiten; da dies jedoch nichc immer durchaus inöglich ist, so mufs weniystcus die Acchtheit jedes eingekauften ätherischen Oels vor seiner Hinstellumg zum Gebrauch nach seinen speciellen Eigensebaften, Farbe, Geruch uud Geschinaok, so ten, Farbe, Geruch uud Geschinaok, so
wie auf fremde Beymischungen strenge geprifift werden.

Oleum animale aethereum.

Oleum animale Dippelii.

Aetherisches Thieröl.

Dippels thierisches Oel.
Wird aus dern stinkenden Thieröl durch $\mathrm{De}-$ stillation im Sandbade und durch nochmalige Rectification des übergegangenen Oels ïher Wasser bey ganz gelinder Wärme gewonnen. Aechi fund gui bereitet ist dasselbe wasserbell, vollkommen durchsichtig, farbenlos, höchstens etwas scliwach strohgelh gefürbi. Es besitzt ejnen durchdringenden starken balsamischcu, eigenthïmlichen, doch nicht ganz unangeuebmen Geruch, und einen ziemlich feurigen, doch hinterber küblenden, bitterlicheu Geschinack, ist böchst flüchtig, leicht entzuindhch, sebr düunfliissig und näcbst dem Aether die leichteste Flüssigkeit. Es läfst Aether die leichteste Flussigkeit. Es lást
sich init ätherischen und fetten Oelen, Naphteu, Weingeist und Essigsäure Innig mischen, verbindet sich mit concentrirter Schwefelsäure unter Erhitzung und Aufwallnog zu einer trïben, wanzenartig riechenden, nur wenig IIarz absetzenden
Mit Terpentinül verfälscht.

it Copaivabalsam oder dem Oele des selben. fäscht.

Schlecht aufbewahrt. rischen Oelen verfülscht.

tatt dieses Oels wird zuweilen wohl de substituirt. ätherischen Ocle auf Papier fallen laffst, sich nicht öllig so verflüchligen, dafs man auf derselben Siclle mit Dinte schreihen kanv, sondern einen Fettfleck zurücklassen. Schüttelt man einen Theil des Oels mit sech Theilen Weinalcohol untereinander, so wird nur blos das ätherische Oel aufgelöst, das ührige aher unaufcelöst am Boden lo bleibe a Oele theils auf $\mathrm{dcm}$ Wasser oben auf sclswimmen, theils aber, wie die meisten aus den Gewïrzsubstanzen der beifsen Lünder, in Wasser zu Loden sinken, das mi der, iria Wasser 2 u Boden sinken, das mit
fctten Oele verfälschte ätherische Oel'von der letztern Art, so wird das Schütteln mit Wasser die Verfälschung entdecken, indem alsdann das damit vermischte fette Oel oben schwimnt, dus ätherische aber zu Boden sinkt.

Der Geruch und Geschmack und die Vergleichung mit gutcm àchten Oele müssen hie oft allein entscheiden. Ist ein schweres, in Wasser niedersinkendes ätherisches Oel mit eincm leichten vermischt, so scheiden sich beyde nach dem Sichüteln mit Wasser in kurzer Zeit vou einander. Doch sich hiebey erinnern, dafs selbst einige ganz ächte schwere ätherische Oele eiue klein portion lichtes Oel ein welches bey gleichem Verfabren ebenfalls oben auf tritt, sich aber, da es den eigenüürnlichen Geruch und Geschmack der Muitersubstanz in einem höbern Grade, als das schwere selbst besitzt, von jenem betrügerisch beygemischten Oele binreichend unterscheidet.

Wird leicht durch den Geruch entdeckt, hesonders wenn etwas ron dern verdachtigen Oele auf Leinewand getröpfelt und diese in der Luft bin nnd her bewegt wird, wodurch das feine Oel verdunstet und der Terpentingeruch allein ïhrig bleibt. Auch kann man in dersetben Absicht etwas Oel iu einem vercia vercharnit getrânkten Papierstreifen abzhaden ad Flamme gleich wieder ausblasen, wobey ckclt. In Alcohol ist ein solches Oel weit schwerer auflöslich.

Wird anf dieselbe Weise entdeck fälschung mit Terpentinöl.
Wird, wenn es damit vermischt war, hich auf destillirtem Wasser schwimmen, sondern selbst bey gleichen Theileu sich vermischen. Das Wasscr wird zwar milchicht, bekommt aber bald seine Helliglicit wieder und es setzt sich kein Oel auf die Oberİäche ab.

Das Oel verliert mit der Zeit seine weils und dünne Beschaffenbeit, besonders ahe dann, weun es vor dem Zutrite der Lut nicht böchst sorgfältig in Acht genomine wird. Die Farbe desselben wird alsdan gelh, braun und endlich gar schwarz. Geruch und Geschunack werden zugleich seh unangenehm.

Im Wasser ist das ätherische Thicröl für slch nur in sehr geringer Menge lisslich. Dic Wäfsrigkeit des Hirschhorulıquors würd. also gar bald bey der Vermischung mit Wasser erkannt werden. 


\section{Oleum animale aethereum. - Oleum de Cedro.}

\begin{tabular}{c|c} 
Namen & $\begin{array}{c}\text { Sinnliche Eigenfchafcen derfelben; } \\
\text { Merkmale ihrer Aechcheic und } \\
\text { Güce. }\end{array}$
\end{tabular}

Oleum animale Mischung, bildec mit Salpetersäure bey cothereum.

Oleum Baccarum

Suniperi.

Wacholderbeerenöl.

Oleum Bergamottae.

Bergamoltül.

Oleum Cajiput. Cajeputöl.

Oleum Cary ophillorum. Gew ürnelkenül.

Oleum de Cedro. Cedernöl. Cedroöl.

langsamen Zusetzen, ein braunes slinkendes Harz, welches sich bey plötzlicher Vermischung enczündet, und giebt mit concentrirter Salzsäure, bey scheinbar geringer Einwirkung eine, dem Gummigutt an Farbe ähnliche, elastische Masse. Auch mit'schwachen Säuren vermiscbt, wird es bald dunkel farbig. Es mufs in kleinen geschliffenen Drachmengläsern, in deren jedes vorker einige Tropfen destillirtes Wasser gethan worden, aufhewahrt, und diese Gläser müssen, nachdem sié vorber wohl verk orkt, verpicht oder mit gesclımolzenem Siegellack überzogen sind in mit Alaun tränktem Wasser urngekehrt gestellt aufbehalten werden. sehr dünnflüsiges, ätberiscbes Oel von sebr bitzigem, scbarfen Wacholdergeschmáck und von starkem, den Wacholderbceren ähnlichen Gertich starken nud dauerbaften Woblyeruch, und cinem augenehur gewürzhalten Geschmack. Man erliält es vou den Frücbien einer au Barbados wachsendeu Spielart des Pommeranzenhanms durch eine einfache mechanische Behandluns, wodurch dic nit Oel angefiulleen Blasclen der Schalen zerrissen werden und das Oel in ein uncen stehendes Gefäls anfyefangen wird.

Ein ätherisches Oel, welches hauptsächlic anf der Insel Banda ans den dürren Blättern des $C$ a je putba u uns (Mel al e u c a Le ucadendron L.) in kuplernen Blaseu destillirt und von da ans aucb in $\mathrm{k}$ npfernen Flaschen versandt wird. Ein tiberans leichtes, in der Wärme ohve Ruckstanet verfliegeudes $\mathrm{Oel}$, von einern femis brennenden, cardanom - und rosmarinal tigen, hintennach küblenden Geschmack, und einem, in der Entfernung nud in geriujer Menge lieblichen, in Quaitität und in cler Nahe aber durchdringend starken verm: $\mathrm{scl}_{1}$ ten Campher -, Terpentin - und S rdeb iumgeticb. Seine Farbe ist urspringlich gelblich nnd völlig duschśichtig; gewöhnlich erhält man es aber von grasgrüner orler blaulichgrüner Farbe; im ersten Falle ist es wabrscheinlich mit einem Pflauzenharze (wie versichert wird, aus der Sehaafgarbe) (wie versichert wird, aus der Selaafgarbe reinight. les und durchsichiges, schwach gelblicbes, mit der Zeit aber ene dunklere, mebr ode weniger braune Farbe annehmeudes, in Wasser niedersiakendes Oel. Es muls einen reinen, starken, angenehtnen Gewiilz „ellẹngeruch nnd einen äbnlichen, star erwärmenden, nicbı allzu bitıigen, noch zurücklassen, sich aber augenblicklic rauchender Salpetersäure entzüncleu.

\section{wising}

Fehlerhafie Be-
fchaffenheic, Ver-
wechfelung oder
Verfälfchung.

Deren

Kennzeichen und Prüfungsmictel. Verfälschung.

in weifses oder weifsgelbliches, leichtes,

in feines Oel von einem sehri lieblichen,

Häufig mit Terpentinöl verfälscht.

Man sehe die allgemeinen l'rüfungsmittel de ätherischen Oele (Olea aetherea).

M. s. die allgemeinen Prüfungsmittel.

\section{Mit Mandelöl ver-} fälscht.

-

Mit Kupfertheilen Zeigt, wie gesagt, die blaugrüne Farbe, aus verunreinigt serdem aber hauptsacblich der nach de Rectification zuruckbleibende Rückstand, der mit Ammoniumflüssigkeit übergossen eine blaue Tinctur giebt. Setzt man zu dem -Rückstande etwas Scbwefelsäure und legt ein blankes Eisen hinein, so wird das selhe ülterkupfert.

Dieses Kupfergehalts wegen rnors das känfliche Cajeputöl immer über Wasser rec tificist werden; es geht dann ganz weifs und farbenlos iiber.

Nachgekünstelt aus Man entdeckt dieses, wenn man einige TroRosmarinöl und pfen anf Zucker tröpfelt und diesen in Campluer. $\quad$ Wasser zer chen läfst i der Campher scbeidet sich alsdann in Flecken ab und schirvimmet oben.

An merk. Das Cajeputöl soll aufserdem auch vorzüglich bäuf mit Terpentinö 1 , auch wohl mit $S$ abina öl verï̈lscht werden

Mit Gewïrznelkenes-p Dies ist gewöbalich bey demjenigen Nelkensenz vermischt. scharfell, fressenden Geschmack bahen. In Alcohol mufs es vollkommen auflöslich seyn, auf Papier getropft, keine Flecken

Wird in Italien and Sieilien nacb Art des Berganottüls durch eine ganz einfache $\mathrm{Be}-$ handlung aus den geritzten Oclhläschen der
Mit dem Oele des Jamaikapfeffers

Mit Mandelöl. zurïck.

Mit Terpentinöl. Mit Copaivabalsam. M s. die allgemeinen Prüfungsmittel. In Wasser getröpfelt verfärbt dasselbe seine Obertläche, wird mit eioer weifslicben Haut umzogen und fliefst nicht gern zusammen; ächtes hehălt seine völlige Klarheit. Die Tropfen vereinigen sich am Boden wieder.

Statt dessen ein mit Lafst sich durch den scbwachen Nelkengepulverisirten Cre- schmack und durch Virglcichung mit den würnelken dige- übrigen Eigenschaften dcs ächten Oels bald

rirtes geruchlose
ätherisches Oel. Mit Alcohol ver fälscht.
Das Italiänische Cedroöl lommt darnit sebr häufig verdünt vor. Es verräth sich be der Vermiscbus mit Wasser dadurch sebc wurznelken dige- erkerinen. 


\begin{tabular}{|c|c|c|c|}
\hline $\begin{array}{c}\text { Namen } \\
\text { der Arzneymittel. }\end{array}$ & $\begin{array}{c}\text { Sinnliche Eigenfchaften derfelben; } \\
\text { Merhmale ihrer Aechtheit und } \\
\text { Güte. }\end{array}$ & $\left|\begin{array}{cc}\text { Fehlerhafte } & \text { Be-r } \\
\text { fchaffenheit, } & \text { Ver- } \\
\text { wechfelung } & \text { oder } \\
\text { Verfälfchung. }\end{array}\right|$ & $\begin{array}{l}\text { Deren } \\
\text { Kẹnneichen und Prüfungsmittel. }\end{array}$ \\
\hline Oleum de Ciedro. & 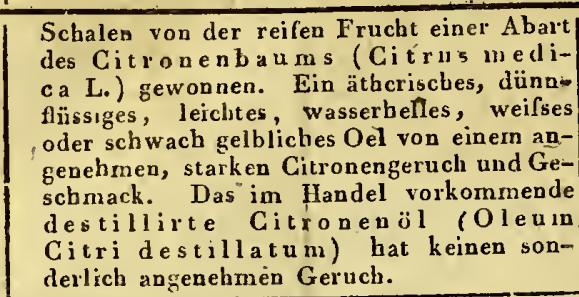 & $\begin{array}{l}\cdots \\
\cdots \\
\cdots \\
1\end{array}$ & $\begin{array}{l}\text { leicht, dafs die Menge des Oels abnimint } \\
\text { indern das Wasser milchicht wird. }\end{array}$ \\
\hline
\end{tabular}

Oleum Corticum Aurantiorum.

Pommeranzenschalenöl.

Oleum $\overline{\text { Corticum }}$ Cinnamomi.

Zimmtöl.

OTeum Florum Cas siae.

Zimmtblumenöl.

Olentm Florum Chamomillae.

Chamillenblumenöl.

Oleum Florum La. vendulae.

Lavendelblumenöl.

Olenm Florum Millefolii.

Schaafgarbenblumenöl.

Oleum Florim $\mathrm{Na}$ phae s. Aurant Oleum Neroli.

Pornmeranzenblüthöl.

Dleum Florum Ta naceti.

Rainfarrnblumenöl.

Oleum Galbani aetherentm.

Wesentliches Ga1banöl.

Olenm Ierliae Ab sinthii.

Wermubiböl.

OlenmHerbaeMa joranae.

Majoranöl.

Oleum Herbae Menthae crispae. Oleum Herbre Menthaie piperitree.

Pfeffermünzül.

ird entweder, wie das Bergamott - und Cedroöl, durch Aufritzen der Oelbläschen der frischen Pommeranzenscbaleo oder auch durch Destillation aus frischen oder getrockneten Schalen gewonnen.- Das durchs Auspressen gewonnene weifsgelbliche Oel ist von starkem bittern Geschmack und lieblichen angenehmen Geruch; das destillirte aber mehr von

Wird in Ceylon aus den Abfällen und Brocken, die man beyin Einpacken des Zímints bekommt, in Grofsen (neser zu Boden sinkeudes, wesentidestilirt. Ein weifsgebses mit der Zeit röthlichielb werdendes, imenden, gleicbwohl aber offenbar sïslichen ches Oel; von einem aufserordentlich hitzigen, scharfen und brenates Zimnts im concentrirtesten Zustande erhält. Seiner Kostbarkeit wegen, ist es überaus häufigen Verfälschungen ausgesetzt. - DiePrenfsische Pharmacopoe schreiht znr Bereitung des Zimmtöls die Zimmtsorte vor. (S. Cassia cinnamomea.)

Ciu belles, dünnflüssiges, weifsgelblicbes Oel, welches im Wasser zu Boden sinkt, sich im Weinalcohol vollkominen aulöset, zwar einen starken Zimmtgernch uud Geschmack besitzt, docb bey weitem uicht so augenehm riecht und schmeckt als'das ächte, Zimmtöl und im Geruch viel ähnliches mit dem flüssigen Storax liat.

Ein dunkelhimmelblanes, etwas dickflüssiges, ganz mit dem eigenthümlichen starken Geruch und Geschmack der Chamillenblumen begabtes ätherisehes Oel, das vor dem Luftzutritte sorgfältig verwahrt, lange Jahre seine blaue Farbe beybehält, nachlässig aufbewahrt aher bald gelb wird. Die Prenlsische loharmacopoe erlaubt wegen der Schwerflussigkeit des unvermischten Chamillenüls, wodurch die Abscheidung desselben von dem. rait übergegangeneu Wasser gehindert wird, bey ner Unze Cedroöl auf sechzig Pfund Blume.

Tin helles, sehr durchsichtiges, weifsgelhli-jHäufig mit VVeingeist, M. s. die-allgemeinen Prüfungsmittel de ches ätherisches Oel verpentinöl, ätherischen Oele, ches atherisches Oel von eigenthürnlichen und scharferm, heifsem Gesclumack. Es - wird bäufg in Frankreich und Italien bereitet und von da $z u$ uns gebracht; dieses bat eine hellere Farbe und cinen lieblichern bat eine hello Geruch, als dill bey uel, welches einen blumen destillirte Oel, weiches einen minder angenehmen und weuiger reinen,

mehr grusichten und herben Gerucb hat.

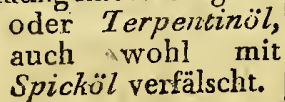

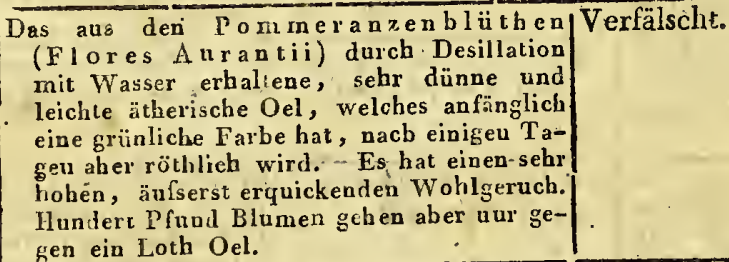

gen ein Lot von einem balsamisch campherartigen Ger nch und brennend gebeligelbes, etwas grünlich ausseliendes Oel, von sich mit der Zeit wahrer Campher ausscheidet. Wird am besten aus völlig ahgeblüheten Blumeubüscheln bereitet.

Ein farbenloses, mit der Zeit eine gelbe Farbe annebınendes ätberisches Oel, welches durch Destillation mit Wasser aus dem Mutterharze (G

Gesclumack desselben besitzen mufs.

Das aus den Blättern und Blüthenstengeln des Wermulbs destillirte, widerlich gewürzhaft bitterlich scbrneckeude Oel, von sehr unangenehmen Geruch und gelbbrauner Farbe. Aus dem friscben Kraute destillirt soll es eine grüue Farbe hahen.

mit der. Zeit dunkler werdendes ätberiscbes Oel ron eiuem brennend gewürzhaften Geschmack und Mojoran selbst. Durchs Alter verdichtet es sich zu die einige Aebnlıchkeit snit dem Campher hat. '

(1) Zeit dunkelgelber werdendes ätherisches Oel, welches ganz den eigenthümlicben Geruch der Kansemünze', und einen scharf-bitzigen' gewürzhafteu Geschmack hat.

in feimes leichtes äthcrisches Oel, von ei-lDas käufliche ist ge-/Wird durch den Geruch und Geschmack, beneru campherartigen, ungeıncin feurigeu, meiniglich aus mehmit dem Kraute gleicluartiges, aber vielfach stärkern Geruch und Geschmack. Es hat eine urijngelbliche, rectificirt aber eive wasserbelle und gleiche Tarbe, die aber ve wasserbelle und gleiche Tarbe, die aber durclis Alter wieder dunkler wird. Mit
dcr Zeit setzt es waluen Campher in crydcr 'Jeit setzt es wab. meiniglich aus meh-

rern Munzarten zu-
sammen, besonders

Mentha. Pulegium,

destillirt, oder mit

dem Oele derselben verfälscht. sonders durcb Vergleichung mit ächtern Ifeffermünzöl ezkannt. 
Olcum Herbae Origani cretici. -- Olea cocta.

\section{Namen der Arzneymittel. \\ OlenmHerbae Ori- gani cretici. spanischhopfenöl. \\ Oletum $\overline{\text { Herbae Ro }}$ rismarini s. An- thos. \\ Rosmarinöl. \\ Oleum Herbae Ru- tae \\ Weinrautenöl. \\ Oleum Herbae Sa- binae. \\ Sadebaumöl. \\ Oleum Ligai Rho- dii. \\ Rosenholzöl.}

Oleuin Ligni Sassafras.

Sassafrasholzöl.

Oleum Macis.

Muskatenblumenöl.

Oleum Radictum $Y$ alerianae.

Baldrianwurzelöl.

Oleum Serninis Anisi.

Anisöl.

$\overline{\text { Oleum }}$ Seminis

Carvi.

Kümmelöl.

Dleum Serninis $\mathrm{Cu}$ mini.

Cuminsamenöl.

Oleum Seminis

Foeniculi.

Fenchelsamenöl.

Oleurn Spicae.

Spiköl.

Oletım Terebinthi mae. Terpentinöl.

Olea cocta. Gekochte Oele.
Sinzliche Eigenfchafien derfelben; Merkmale ihrer Aechıheut und Giite.

\section{Fehlerhafie Be- \\ Schaffenheic, Ver- \\ wechfelung oder \\ Verfälfchung.}

Deren

Kennzeichen und Priffungsmittel.

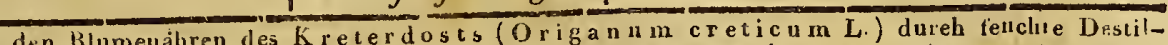
im Auslatide aus den Blnmeuahen Es besitzi cine rothbraune Farbe, einen starken, gewürzhaften, durchdrinlation erhaliene ätherische Oel. Ls besite cine rothelmack. Im Handel kommt es gewöbnlich auf die eiue oder andere Art verfalscit vor.

Vird aus den blubenden Kraute vorzüglich|Häufig mit Terpentin- Leicbt durch den Gerucb und durch Verglei-

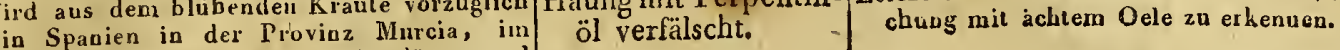

in Spanien in del Proviaz Murcia, im

leicht, fast farbeulos, von einem sehr an-

leiche,

genetmen, in der Mevge aber duch etwas pherarigen Gescbmack.

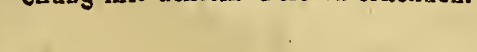

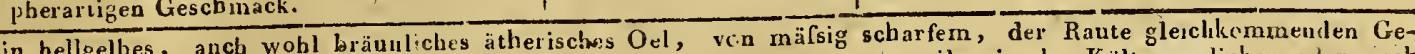
schelches sich nach Einiger Beobachtungen zuweilen in der Kälte verdicken oder auch regelun̈fsige Cıystallen abset<en soll.

Hat eine weifsgelbliche F'arbe, einen starken widrigen Geruch, wie die Sadebaumbläller, uud einen haraigbrennenden, unangenehrneu Gescbinack.

Das aus dem feiu geraspelten, einige Wochen vor der Destillation in stark gesalzenem Wasser eingeweichtem as aus dem feiu geraspelten, einige Wocher Rosenbolze ( $\mathrm{L}$ ig goldgelbes, mit der Zeit sich rölbuen Geschinack und einem

fetten Oele verfälsch. ans dern Sassa ras holze (Ligula das Holz, nur in stärkerm Grade, riechendes und schmeckendes Oel.

Ein sehr feines, flüchtiges, elwas dickliches, weifsgelbes Oel, von einem mittelmäfsig scharfen Geschunack-uuc starken gewürzhaften, Macisgeruch.

Ein grïnliches oder gelbgrünliches Oel, welches den Geruch, Geschmack und die Kräfte der Balusiauwuizel in verstärktem Grade besitzt.

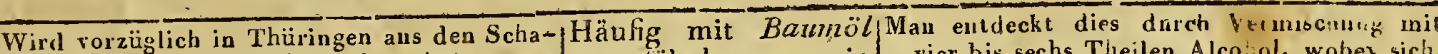
len oder Fiuchtdecken des Anissamens verlälscht, worin vier bis sechs Theilen Alcotol, wobej sich, durch Destillation mit Wasser gewonneu. man zuvor etwas waluend das, leine Anisol damit iu lerdurch weifselbliches Oel, welches einen WVallrath zerlassen bindung tritt, die fremueBeymischung ab\begin{tabular}{l|l|l} 
Eim weilselden süfsen.Geschmack und den concen- & Wrallrath zerlassen & scheidet.
\end{tabular}

milden süsen'Geschmack und dea concen- hat. trirtesten, sehr lange anhaltenden Ausge-

\begin{tabular}{l|l} 
ruch besitzt. Es gerinnt schon bey eiller & Mit Mä \\
sebr geringen Kälte zu einer eisähnlichent.
\end{tabular} spiefsigten Masse.

Ein blafsgelbes, sehr kräftiges hıtziges Oel von concentrirtem Kummelgeschmack unu Gelucli。

Ein gelbes Oel, welches den eigenthümlichen Geruch und Geschmack des Cuminsamens iu verstärklem Grade besitzt.

Ein helluelbliches, süfses, mildes, den Geruch und Geschmack des Fenchelsamens in concentrutesten Zustande besitzendes, sülses, mildes, den Gercherrendes, ätherisches Oel. Wird vorzïglich in Thürıgen uud Sachsen aus dem Feuchelsarne in destillirt.

Wird in Lauguedok und der Provence von/Mit Terpentinöl ver-/Aechtes Spikül hat éine gelbliche Fábe, und Ait Tein Gerach bleibt, wenn es in der Hand deu. Hirten und Schäfern auf freyem Fel te mischt, oder anch sein Gerach bleibt, wenn es in der Hand ans den blühendenSpitzen einer breitblatt- statt dessen bloIses verrieben wird; bis zuletzt noch lavendel-

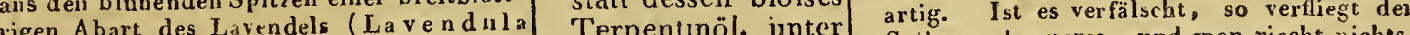
rigen Abart des Lavendichen Spike, destillirt. Ein äufserst fiüchtiges, leichtes, weifsgelblichtes, scharf und heifs schmeklendes, eben uicht lieblich, dwch bis zur vëlligen Verdunstung in der Hand gerievëligen lavendelartig riechendes äthen isches beu,
Oel.

werpentinol, unter Lavendelöl geSpikgerncb zuerst, und man riecht vichts,
als das TerpentinöL. mischt hat.

Statt dessen wird häufig das Kienöl (Oleun Pini) verkauft. er, aus dem Tuich Destillatiou mit Wras ser, aus dem Terpentin alechtes, durchEin sebr dunntissiges, lol sichtiges unil wasserhelles Oel, von einem

beifsen nnd scharfen G
Geiuche des Terpentins.

Gekochte Oele sind diejenigeu, welche man durch Kochen dés Baumö̈ls mit irgend i nem vegetabilischen Körper hereitet hat Than nirhm eimen Thell einer frischel, ber klen rershnitten $\mathrm{PA}$ anze, übergielst sie mit drey Theilen Baumöl und kocht dıses damit bey gamz gelinden Feaer so l:a$\mathrm{ge}$, bis alle wăfsrige Feurhtigkeit verdunstet ist, die Pfauzentheile briichig gewnrden sind, und einTropfen des Oels a tu et-
Nicht lange genug, oder auch zu lange gekocht.

C.
Dieses ist eigentlich das bey der Berritung des Theer's auf demselben schwimmeude $\mathrm{Oel}$, welches durch noctinaliges $\mathrm{Ab}<\mathrm{i}$ hen gereinigt worden ist. Es besitzi dasselbe einen stärkeru Har «gernch.

Werden die Oele nicht bis zur völligen Trerm dunsiung der Feuch igkeit ekochi, so bekommen sie ein schmutziges trübes Ansehen und nehmen durch die diabey gebliebene Feuchtigkeit destr geschwioder einen widrigen ranzichten Griuch an. Koch man sie dagegen uoch läuger, als es znr Verdampfung der Feachtigkeit nöthig ist, so wird die panzeusubstanz völli verso wird die panerden dadurch nicht nur kohlt; und sie werden dadureh nicht nur

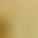




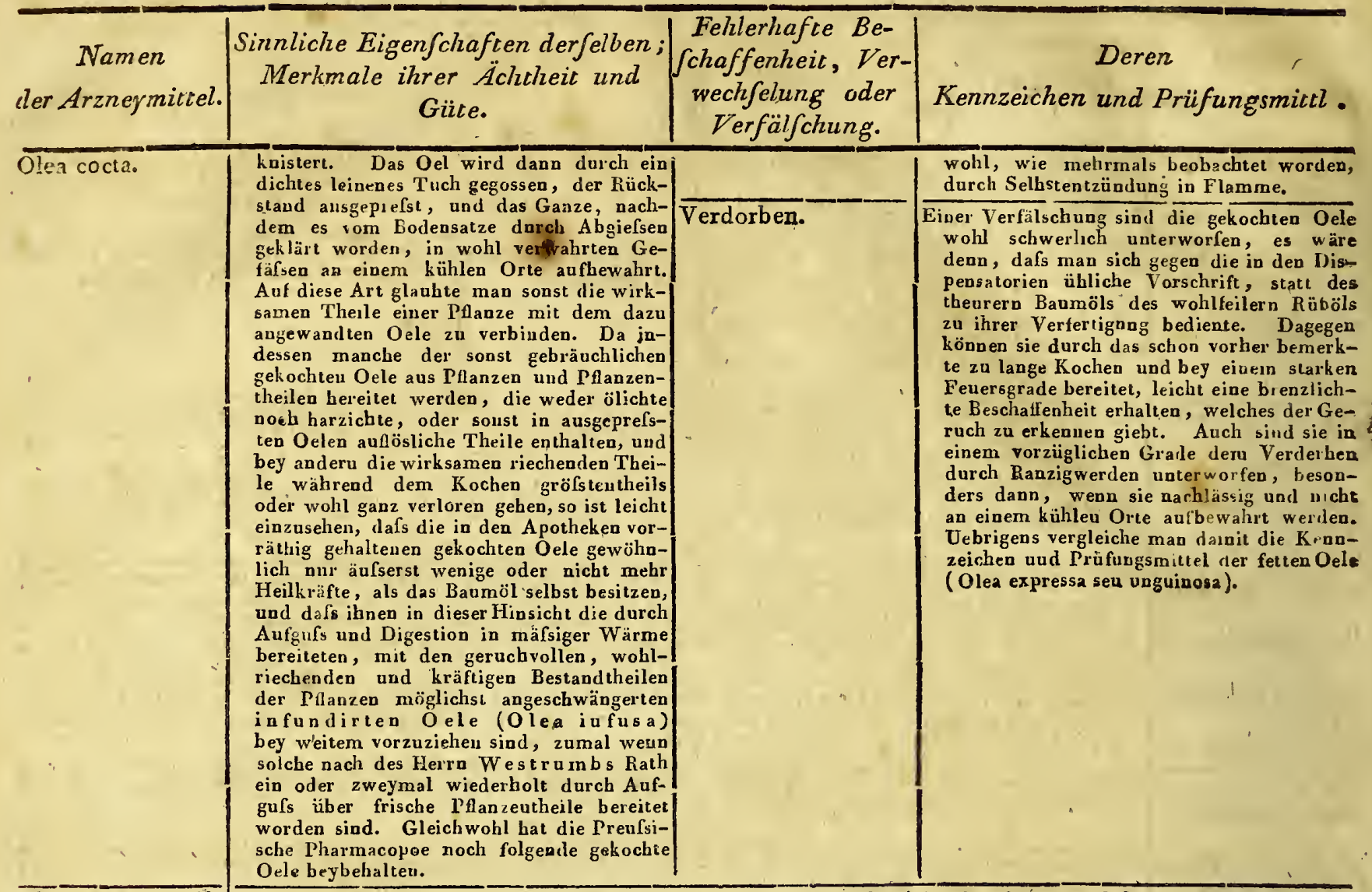

Oletim coctum $A b$ sinthii.

Gekochtes. Fermuthöl.

Oleum - coctum Chamomillae.

Gekochtes Chamillenöl.

Olenm coctum Hyoscyami.

Gekochtes Bilsenkrautöl.

Oleum coctum Hyperici.

Gekochtes Johanniskrautöl.

Olea empyrevmatica.

Brenzliche Oele.

Olenm . animale foetidium.

Oleum Cornu Cervi foetidum.

Stinkendes Thieröl.

Sinkendes Hirsch hornöl.

Oleum Asphalti.

Asphaltöl.

Oleum Cerae.

Waclısöl.

Oleum Tartari foetidum.

Stinkendes Weinsteinöl.

Oleurnsuccinicommunes. rubrum.

Rothes Bernsteinol.

s aus dem gequetschten frischen Wermutbkraut mit Baumöl durch Kochen bereitete Oel von einer grünen Far-
be. Es mufs nicht ranzig riechen, in der Wärme flïssig seyn, in der Kälte geriunen, und so viel wie mögbe. Es muls nicht ranzig riechen, in der Wärme flïssig
lich, den Geruch und Geschmack des Wermuths besitzen.

Durch Kochen der trischen Chamillenblumen mit Baumöl bereitet. Eın gelhes, nach Chamillen riechendes und schmeckendes, in der Wärme flüssiges, in der Kälte gerinnendes Oel. Weit wirksamer ist das durch die Infusion bereitete.

Hat eine angevehne grüne Farbe, einen bitterlichen Geschmack, ist in der. Wärme flüssig und gerinnt in der Kälte. Der eigenthümliche Bilsengeruch möchte wohl durch das Kochen ganz verloren gehen.

Wird aus dern blühenden Kraute durch Kochen mit Baumöl bereitet; mufs rothgelblich aussehen, balsamisch bitter schmecken, in der Wärme nüssig seyn, in der Kälte gerinnen.

Werden durch die trockne Destillation bey heftigem Fcuer aus thierischen und vegetabilischen Substanzen er'aulten und unterscheiden sich von andern Oelen durch folgende Kennzeichell. Sie hahen einen sehr nnaugeteu und unterscheiden sich von andern Oelen durch folgende Kennzeichell. Sie hahen einen sehr nnauge-
nebmen, stiukenden, hrandigen Geruch; ih. Geschmack ist berbe, bitterlich und unangenehm brennend; nebmen, stinkenden, hrandigen Geruch; ihr. Geschmack ist berbe, bitterlich und unangenehm brennend;
ihre Farhe braunroth uud heynahe schwarz; ihre Consistenz dicklich, fettig, mebr oder weniger dickflüssig. Mit Wasser. lassen sie sich nicht mischen; im Alcohol sind sie mehr oder weniger aullöslich. Einer Verfálschung sind sie wohl schwerlich unterworfen.

as durch trockne Destillation des Hirschhorns, oder anderer Hörner uud von allem Fett befreyter Knochen bey heftigem Fener erbaliene dickliche, brenzliche Oel von einer braunsclwarzen Farbe, einem eigenartigen, brandigen, hischst unangenehıneu und widrigen Geruch und durchdringend starken, scharf bitterlichen Geschnack. Im Weingeist ist es ziemlich löslich.

Wird ehenfalls durch trockne Destillation aus dem Asphalt erhalten, hat eine braunscbwarze Farhe, eine dickliche Beschaffenheit, und einen äufserst widrigen, stinkendeñ, dem Steinkohlendampfe gleichkommenden expyrevmatischen Ger.uch und Geschmack.

Fin durch trockne Destillation ans dem gelben Wachse mit Zusaiz von ungelöschtem Kalk erhaltenes brenzliches Oel von einer gelben Farbe, einem starken unangenehmen Geruch und einer butterartigen (Wachsbutter) Consistenz, wovon nach einer nochmaligen Rectification ein düuneres, flüssig bleihendes Oel erhalten wird, welches in Weinalcohol vollkommen und leicht auföslich ist.

Ein aus dem rohen Weiusteine durch trockne Destillation desselhen erhaltenes sehr stinkendes Oel von braunschwarzer Farbe.

Wird durch trockne Destillation aus dem Bernsteine erbalten, hat eine dicke, zähflüssige Gonsistemz, eine dune kelbrauniotle Farbe, und oinen brandigen, zufserst widrigen Gerucb. 


\section{Oleum Succini rectificatum. -- Oleum Amygdalarum.}

\begin{tabular}{c|c} 
Namen & $\begin{array}{c}\text { Sinnliche Eigenfchaften derfelben } \\
\text { Merkmale, ihrer Aechtheit. und } \\
\text { Giite. }\end{array}$
\end{tabular}

Fehlerliafie BeSchaffenheit, Verwechfelung oder Verfälfchung.

\section{Kennzeichen und Prüfungsmictel.} Leum Succini rec- Wird ilurch norhmaliges Abzieben des ro-
then Bernsteinöls init der sechsfachen cifrcatiu

Weifses oder rectificirtes Bernsteinäl,

Menge Wasser vermisclit aus einer gläsernen Retorte bey gelindem Feuer gewouuen. Ein. gut rectificirtes Bernsteinöl ist wasserbell, ungefärht oder doch nur schwacb geiblicl, sehr dïnnflüssig, leicht und füchtig vớn einem nicht sebr nnansenehmen Geruch und gewür/haften Gesenehruen Geruch und gewürhaften Ge-
schninck. Beym Anniliern" der Flamme schmack. Beym Anniher" der Flamme
eines Lichts entzüudet es sich schnell. Mit eines Lichts entzüudet es sich schnell. Mit Salpetwsture beliandelt girbt es ein stark
narh Moschus i iechendes Harz. (S. Resina Succini halsamica.) Am besten wird es, wie das ätherische Tlieröl in kleive Gläser vertbcilt nuter Wasser anfbewabrt.

Olea unguinosa. Olea expressa. Fette Oele.

Ausgeprefste Oele.

Die fetten, schnientgen oder ausgeprefsten Ranzig.

Oele, welche man aus den gröblich zerstofsenen, ölicbteu Samen, Kermen und Früchtel, anch wohl ans einzelnel, thierischen Theilen, wie z. B. den Ejern, durch eintaches Anspressen unter der Presse seltner durchs Auskochen erhält, haben fotgende Eigenschaltew, wollurch sie sich folgende Eigeris an ron den atherischen und hrenzlichten oelen unterscbeiden. Sie liabeu eine schmierige, dicklussige, bey einigen butteraitig Consisteos. Sie schwimmeu sammtlich au dem Wasser, lösen sich nicht darin auf, verdiegeu in der fieyen Lnft nicht, und lasseu auf dem Papier einen durchsichti-
gen ölichten Fleck zurück, der durchs Ergen ölichten Fleck zurück, der durchs Erwärmen nicht verschwindet. Einige derselhen habeu Geruch, die mebresten aber schwach; alte aber babin einen milden getiuden und nicht scharfen Gesclmack gelinden u lich, gelblich, gelb, dunkelgelb, griinlich, gelblich, gelö, Bey dein Siedegrade lich orter bräublich. Bey hem Siedegrad des Wassers lassen sie sich nicht verfiucbtigen; in einer böhern Temperatur aber werden sie rerstört. Beym sieden leiden sie eine Art rou Entmiscbung, gebeu entzündlithe Dimpfe vou sich, entzünden sicb erkaltet, leicht vou selbst, und bekommen die Eigenschaft im Dunkein zu leuchten. lu ibrem gewöhulicben Zustande sind sie nur vermittelst eiucs Dochtes die Flamme zu untertalten, gescbickt. Sie $10 ̈-$ sen Sclıwefel, Wachs, Campher, Bleyoxyde, Harze nod andere ölichte Körper oxyche, Harze un mit ätzenden Alcálien auf, vereinigen sich mit atzenden Alcalien zu Seifeu, und ati,erischen Oelen aufgelöst. Anfserdem giebt man auch ihre Unauföslichkeit in Weingeist, als ein characteristiscbes Keynzeichen derselben an, indessen leide dieses Ausuahmen, da nach der Erfabrun des seel. R ose (Berl. Jalırb. d. Ph. 180 t́ S. 8.t) das ächte fette Ricinusöl sich in ahsoluten Alcohol vüllig klar anföset und solute Alch chol z (Almanach f. Scheidek. u. A poth c herschieiene andere fet1807. S. 77.) auch verscbieliene andere fette Oele eine, wiewohi nur a ufserst geriuge Aunöslichkeit ia absolutem Alcobol zeigteu. Bienzlicht, rauzig, oder aus der oder weniger anflislich. Au der Luf trocknen die fetteu Oele, besonders gekocht, theils in feste, durclisichtige, den Kopal ahuliche $M$ assen ejn, theils bleiben sie immer schmieri. Niehutre ht:rselbeu bleiben iu del Frostkälıe flüssig; aritere geringen srbou iu sehr geringer Kälte, und einige erst hes den böclisten Kältegraden einige erst bey dell boclisten Kaltegraden wohl einigerriafsen crystatlinischen Mass
Mit rectificirtem|Giebt mit Salpetersäure behandelt, vicht das $\begin{array}{lll}\text { Bergöl (Oleum Pe- } & \text { erwähnte feste, ondern nur ein llussiges } \\ \text { Harz. Im Weingeist ist das Bersöl unauf- }\end{array}$ oder mit lösiich; das rectificirte Betros unau fälscht. löset sich darin auf.

\section{Verfälscht.}

Metallische

enthaltend.

Theile
Die fetten Oele nehmen durch zu grolse Hitze uni sonsige iible Bebandlung beym Auspresseu, durcli sorglose Aufbewahrung in warmer Temperatur oder auch durchs Al ter eineu scharfen; widrigen, bitterlichen, Lrenuenden Geschmack und einen beson deru häfstichen Geruch an oder werden'r a zig. Diese Rauzigkeit scbeint ihren in einer A Ron Gäbrung der deu Oele in einee Ant von Gathing der den Oelen anbingenden schleinichten Feltchtigkei und Oeles selbst des Oeles selust zu haben. Dergleichen ranzige Oele düren nie zmm Arzneyge braucts angewendet werden.

Die Verfälschung der fetten Oele hestehs bauptsächlich darin, dafs theils die theurern mit wachlich darin, dafs theils die theurern mit andere auch wohl uachgekünstelt wird, Man sehe hieriber die einzelnen Artikel.

Zuweilen werden eiuige derselben auch wobl mit thierischen Fetten verfälscht. Im Allgemeinen erkennc man diese Art der Verfälschung daran, dafs sich die reinen fetten Planzenöle belle und ohne Trübung mit den Naphten, z. B. Schwefeläther, lassen, die Thierfette aber, mit Ausmobmo des Wallraths sich sämmtlich in Scbube ätber unit bleibender milchartiger Trübung auf̌ösen.

ies ist sehr oft der Fall und rübrt entwede von den beym Auspressen gebrauchten metallischen Geräthscbaften oder von dem $A$ ufbewahren in metallischen Gefifsen ber. Um einen etwa statt findenden $K u p f e r$ ge $b$ alt zu entdecken, schüttele man eine Portion des verdächtigen Oels mit doppelt so viedes verdachtigen Oels mit doppelt so vieZeit den Essig ab und prüfe ibn durch SätZeit den Essig ab und prüfe ihn durch Sättigung mit Ammonjunflüssigkeit, wobey die blauliche Farhe das $\mathrm{K}$ u $\mathrm{p}$ fe $\mathrm{r}$ verrathen
wird. -- Zur Entdeck ung des Bleye Wient die Hahnema onohe Probefli sign keit. wohl einigermintsen crystatinischen Masst. prefste Oel. Eu blafsgelblich s, Aiss'ges Oel von mitdem, stifsen Gesrlimack, etwas nach Mandeln riecheird und schineckend. Eines kleinen Antheils yon Schleim wegen Eines kleinen Antheils von Schleim wegen
ist es im friscluestes Zustarde immer ein ist es im friscliestes Ztistar de immer cin wenig trübe. Lis wird bald ranzig und un-
brauchbar. Geringt erst bey einem setri
Veraltet und verdor- Je älter das Mandelöl wird, desto heller und ben.

klarer ist es; mit der Zeit wird es ranzig riechepd und schmeckebd, und brym Ausziehen wohl gar etwas zähe Es veldirbe um so eher, wenn es beyın Auspressin gar zu sehr erhitzt worden, in welchem Fall es auch eine toelor duakelgelbe, bräualiche Farbe hat. 
Oleum Amygdalarum. - Oleum Nucistac.

\begin{tabular}{c|c} 
Namen & $\begin{array}{c}\text { Sinnliche Eigenfchaftën derfelben; } \\
\text { Merkmale ihrer Ächtheit und } \\
\text { Güte. }\end{array}$
\end{tabular}

Oleit:n Anygdalarum.

Oleum Cacao. Butyrum Cacao. Cacaoöl.

Cacaobutter. Olenm Laurinum.
Oleum Baccarum

Lauri expressím.

Lorbeeröl.

Looröl.
Oleum Nucistae. Balsamum Nucis Moschatae.

Musgeprefstes Mus-
Auts catnufsöl. Muscatbalsam. bohen Kältegrade und nimmt dann eine/M schuppicht-blättrige Form an.

Ein

Ein butterartiges Oel, welcbes durcbs Anspressen aus den Cacaobohnen, Reinigung des ausgeprefsten Oels durch Digestion mit $W$ isser von den mit durchgegangenen schwarzen mehligen Theilen, vorsichtiger Zerlassung des erkalteten reinen Oels und Zerlassung des erkateten reinen Ausgiefsung desselben in einer Papiercapsel, worin dasselbe wieder erkaltet, berei-
tet wird. Eine gut bereitete Cacaobutter tet wird. Eine gut bereitete Cacaobutter oder Rindertals; sie muls sich aber nicht so fettig und schmierig anfühlen lassen die Finger nicht beschmutzeu, zwirchen denselben aber bald in ein gleichartiges Oel zerfliefsen. Frisch bereitet hat sie eine weifslichselbe oder wachsgelbe Farbe ne weilstich blässer. Sie mufs mit der Zeit wird sie blasser. Sie mufs wie Cacao riechen und schmeornig und rein ausseben. Im/ che gleichförmig und rein aussehen. Im/ Aether löset sie sich leicbt bis auf wenige niedersinkende Theile anf: der Weingeist ziehet blos einigen Geschmack heraus. Sie läfst sich, wenn sie äcbt ist, viele Jahre lang an einem küblen trocknen Orte unverdorbe

as aus den frischen und reifen, zerquetscbten, lange mit Wasser gekochten Lorbeere durchs Auspressen erhaltene, aus ätherischen und fotten Oele besteliende, butterartige $\mathrm{Oel}$, welcbes aus Italien und $\mathrm{Spa}-$ nieu zu uns gehracht wird. Gutes, ächtes Lorheeröl mufs eine körnichte, butterartige Consistenz haben, in der warmen Hand Consistenz bald zerfliefsen, von sehr starkem einen bittern Geschrnack und geruch seyn, einen bittern Geschielende Fareine grüne, etwas ins Gelhe spielende Farbe besitzen. In Schwefeläther löset es sicb es sich uicht vermischen läfst, zieht blo die Farbe und das ätherisehe Oel heraus.

as aus den gestofsenen, in einem Sieb den Dampfe des kochenden Wassers ausgesetzten und dann in Leinewand gebundenen, zwischen zwey erwärmten Platten ausgeprefste butterartige Oel. So zubereitet hat lassetbe eine im Ganzen röthreitet hat mit der Zeit mehr braun werdende Faibe, eine weichtalgartige Consigtenz, und einen gew ürzhaften starken Muscatengeruch und Geschmack. Nacb der catengeruch $\mathbf{S}$ chrader über das Muscavon Herra scitellen Untersuchung (Berl. tenuufsöl angestelten $1804, S .83$ ) bestebt dasJabrb, d. Pharm. 1804, S. selbe eigentlich aus dreyer ley Substanzen, nämlich: 1) aus einem ätherischen Oele; 2) aus einer bräunlich gelben, weichen, fettigen Substanz, welche sich auch kals im Aether und Alcohol anflöstet und nicht mit dem Wasser überdestilliren läfst, und 3 ) einer geruchlosen, weifsen, polverartigen Substanz, welche sich kalt weder im Aether noch im Alcobol auflöset, übrigens sich wie Talg rerbält und den grögensten Theil des ausgeprefsten Muscatenfsesten Theil des ausgeprelsten löset oicb
Fehlerhafte Bechiaffenheit, Verwechfelung oder Verfälfchung.

fäscht.

Mit thierischen Fetten, z. B. Hirschtalg, Rindermark u. dgl. verfälscht.

Verfälscht mitSchşeinefett.

Mit Terpentin. (Sel- Wird durcl den Geruch und Geschmack ten.)

Aus Torberen in Die Consistenz ist-gleich förmiger und schmieS riger; der Geruch weit schwächer. Mi kocht, nachgekün- Weingeist digetirt, zieht dieser kein äthestelt und mit Cur- risches Oel aus; der Aether wird davon cuma und Indigo selbe grün gefär!t.

grün gefärbt.

Aus Lorbeerpulver, Macht den Aetber milchicht, färht die AmSchweinefeft und mouiumflissigkeit blau, theilt dem Wein Grünspan nachge- $\begin{aligned} & \text { geist kein ather } \\ & \text { Schnelzen bieibt das Lorbeerpulver am }\end{aligned}$ macht. Boden liegen. im Handel vorkommell. Der verewigte Gren sahe es aus 5 P'fund gestofsenen Lorbeeren und eben so vitl Butter, und aus acht 'Handvoll' Sadebaumblätter mit funfzehn Pfund Butter, jedes für sich gekocht und auch ansgeprefst, und erkaltet mit einer Unze Oleum Calamiuthae vernischt, zum künstlicheu Loorol zusammen mischen. S. dessen Pharmacologie, Auf. 2. Th.2. S. 118.

Ferfälscht und agch-1Das Muscatennufsöl wird auf mancherley Weise verfälscht und nicbt allein von Drogekünstelt. guisten, sondern auch von manclien Apothekern, so gut es gelien will, nachgekuinstelt. Die Mittel, deren man sich mit oder stelt. Die Mittel, derea ächtem Muscatenöl ohne Zusatz von Muscatennüssen, dazu in oder gestolsenen Verbältaissen uud auf verversche scbiedene Weise bedient, sind un Butter oden Behenol dertalg, Knochenmar'k, Cacaobutler, Wachis, Hirschtalg u. dgl. Init einer kleineu Portion Orlean gefärht "Eia derglcichen erkünsteltes Gemisch läfst sich durch dea fremdartigen Geruch und Geschmack und durch Vergleichung mit ächtern Nuscatöl ziemlich leicbt erkennen. DieProbe, welche man sonst gewôlunlich angiebt, daf nämlich das ächte Oel sich hauptsäcblich durch seine helle Auflöslichkeit in Arther, dur trübe mildas erking chichte Losuag in derit gebe, ist unzuverlassig, deno das mit künstelte wixd mebr oder weniger dieselbe 


\section{Oleum Nucistae. - Oleum Seminis Lini.}

\begin{tabular}{|c|c|c|c|}
\hline Nanien & $\begin{array}{c}\text { Sinnliche Eigenfchafien derfelben } \\
\text { Merlimale itrer Aechtheit und } \\
\text { Giite. }\end{array}$ & $\begin{array}{c}\text { Fehlerhäte Be- } \\
\text { schaffenheit, Ver- } \\
\text { wechfelung oder } \\
\text { Verfälfchung. }\end{array}$ & $\begin{array}{l}\text { Deren } \\
\text { Kennzeichen und Priifungsmittel. }\end{array}$ \\
\hline Oleum Nucistac. & 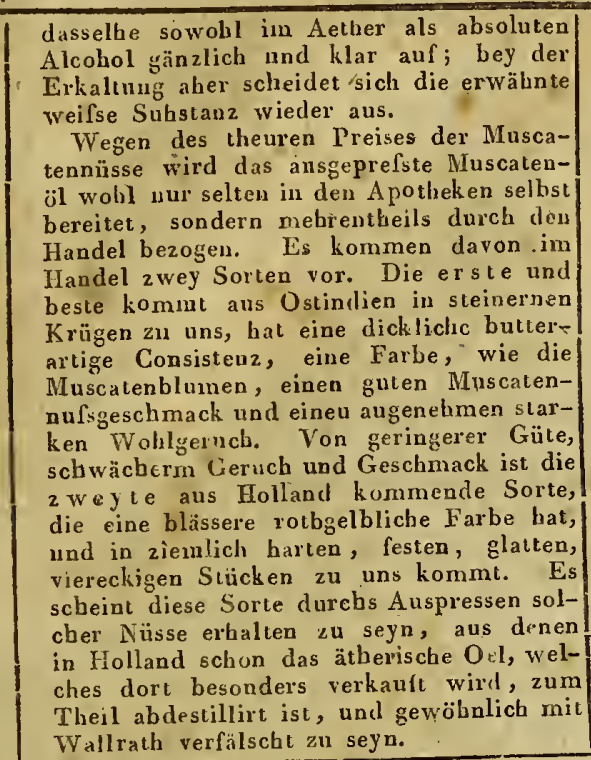 & , & 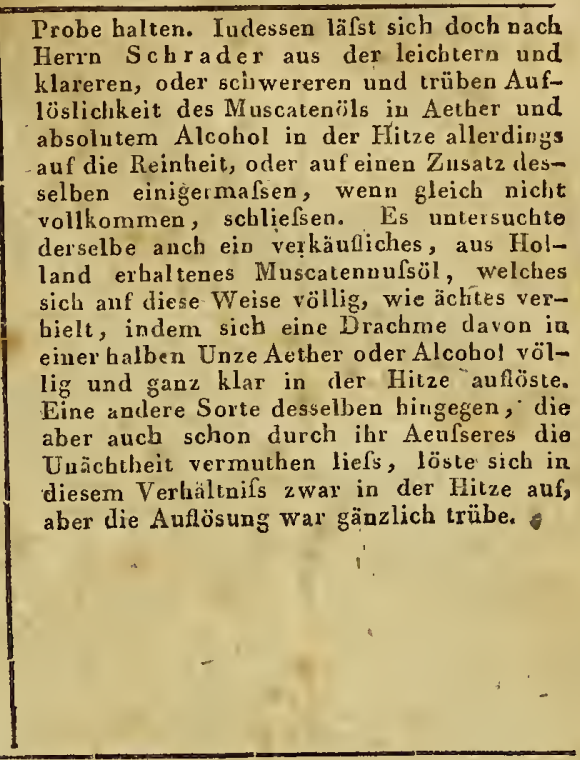 \\
\hline
\end{tabular}

$\overline{\text { Oleum Nacum Be- }}$ hen.

Behenöl.

Oleum Nucum Juglandis.

Wallnufsöl.

\section{Oleum Olivarum.}

Olivenöl.

Baumöl.
Oleum Ovorum. Eyeröl.

Olenm Seminis
Lini.
Leinöl.

s ans den Kernen ler Belenüisse (Nuces Behen) geprefste Oel, welches eine weifsgelbliche Farbe hat, keinen Geruch and Geschmack
nicht leicht ranzig wird.

Das aus den Walluufskernen geprefste Oel von weilser oder blafscitrougelber Farbe. Es hat frisch einen milden, süfsen Geschmack und ist obne Geruch. In der Kälte geriunt es vicht leicht; dagegen wird es aber bald ranzig. as aus den Früchten des in den südlichen Oelbaums (Olea enropaea L.) seprefste Oel. Zum innern Arzneygehrauch prefste muls man sich keines andern, der Provenca, rou Languedock hnd Genua kommenden Provencer oder Ge a ueseröls, welches auch Junglernö (O leum Olivarum virgineum) genannt wird, bedienen. Es wird dasselbe aus deu besten und reifsten Frucliten durch celindes Auspressen ertalten, besitzt eine blasse gelbliche Farbe, fast gar keinen Geruch und einen mildeu süfslichen Geschmack. ruch und eringen Kälte 2 einer gavz-weifsen körnigen Masse, in deeiner gavz-weifsen kob belles nicht gerinnendes Oel stehen bleibt. Das $g \times m e$ in des Oel stehen bieibtolivarum com-

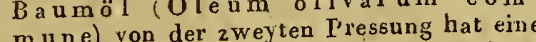
mune) von der 2 weyten selblichgrüue Farbe und ist nicht so gut als das erstere.
Mit andern fetten $\mathrm{Oe}-$ len verfälscht, das Provenceröl mit Molunt, IVufs-oder Buclıöl; das gemeine mit Rüb - oder Leinöl.

Dem ranzig gewordenen Baumöle werden zuweilen Bley oder dessen Oxyde zugesetzt, um es süfs und weils zu machen.
Das aus den bartgekocbten Eydottern geprefste Oel. Ein hochgelbes, dick füssiges Oel von einem ganz eigenartigen Geruch und mildem Geschmack. Scbon in sehr geringer Kälte gerinnt es zu einer butterhaften Masse. Da es unter allen fetten Oelen beynahe am schnellsten ranzig wird, so darf es nie in 20 grofsen Vorrath bereitet, und mufs in einem gnt verstopf ten Glase im Keller aufbewahrt werden. as auf den Oelmïhlen aus dem Le in s a $\mathrm{m}$ en (S emen Lini) geprefste Oel. cifiken, etwas widrigen Geruch und fotten
Das dunkelgelbe, grünliche, undurchsichtige, trübe, übel oder thranicht rieclende, scbarf, bitterlich oder ranzig schmeckende Baumöl ist für den Árzneygebrauch durchBaumöl ist für
aus untauglicb.

in anf diese Art verfälsclites Baumöl gerinut nicht so bald in der Kälte, oder es erfordert einen höbern Grad der Kälte $2 u$ seiner Gerinnung. Durch starkés Schütteln bekoinmt es viele Luftbiasen. Es hat eiuen mehr oder weniger veränderten $\mathrm{Ge}$ ruch wud Geschmack, und brenat nicb mit einer so reinen und bellen Flamme, als das $\ddot{\text { äcbte. }}$

Oft ist das Oel dadurch völlig farbenlos gemacht, aufserdem bat es eine eigene Süfslichkeit und eine mehr schmierige Cousistenz. Am sichersten entifeckt man es, wenn mań zu einer Portion gleich viel destillirten Lssig, dem noch einige Tropfen Salpetersäure heygennischt worden, giefst, beydes tüchtig durcheinander schüttelt und den dayon wieder abocschiedenen Essig mit Th a probefiussigkeit vermischt, Ir a b a a n wo dann de braued od schwarzlicbe Grad dieser betrügerischen Verfälschung zeigt.

Auf dieselbe Weise Eine hotlose, höchst strafhare Betrügerey, werden an vorher angezeigte Art entdeckt wird. Rïb - oder Leinö mit Bleyoxyden behandelt, und dann für ächtes Baumö] verkauft.

Virdhänfo mit Man- Ist nicht so dicklich und gelb, wie das ächte, delöl verfälscht.

und bleibt beständig mohr flïssig

Trübe, dunkelgclh, scharf und häfslich schmeTube, dunkelgcli, scisarforef Ranzigkeit am meisien nuterworfen. 


Namen
Oler Arzneymittel.
Oleumi. Seminis
Lini.
$\begin{aligned} & \text { Oleum Seminis } \\ & \text { Napi. } \\ & \text { Rüböl. }\end{aligned}$

Oleum Seminis $\mathrm{Pa}$ paveris albi. Mohnöl.

Oleum Serninis
Napi.
Rüböl.
Oleum Seminis Pa-
paveris albi.
Mohnöl.

Sinnliche Eigenfchaften derfelben ;
Merkmale ihrer Aechtheit und
Giite. $\left|\begin{array}{c}\text { Fehlerhafte Be- } \\ \text { fchaffenheit, Ver- } \\ \text { wechfelung oder } \\ \text { Verfälfchung. }\end{array}\right|$

\section{Kennzeichen und Priifungsmittel.}

eckellaften Geschmack, Es !gerinnt auch|Mit Riiluöl verunrei-Dies ist gemeiniglich der Fall, wenu man in der strengsten Kälte nicht, trocknet in nigt. der freyen Luft allmälig aus, breunt mit Rauch und übeln Geruch und wird leicht ranzig. das Lein̈̈l aus Oelmiilen erhält, wo $2 \mathrm{u}$ gleich Rüböl geschlagen wird. Oft ist es so damit verumeinigt, dafs es zu manchen Bereitungen, z. B. zum Firnils, zum Anstreichen u. s. W. gar nicht zu gehrau-
chen ist.

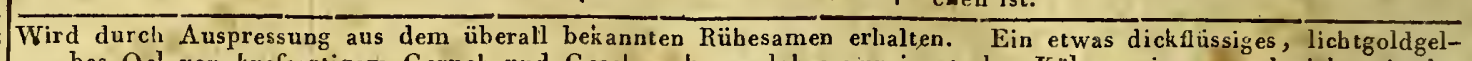
bes Oel von krefsartigem Geruch und Geschmack, welches nur in starker Källe gerinnt, und nicht wie das Leinöl, an der Luft, austrocknet. n mildes, wolulschmeckendes, klares und helles Oel, von weifslicher Farbe, welches durch Auspressen aus dem Mohnsamen (Semen Papaveris albi) erbalten wird. Bey seiner Bereitung hat man sehr darauf zu sehen, dafs es nicbt auf Oelmühlen, wo beute Leinöl, morgen Rüböl, und dann wieder ein drittes Oel geprefst wird, zubereitet werde, wcil es dadurcb immer einen fremdartigen und unangenehmen NehengeWard durch Anspressung Ricini.

Ricinusöl.

gehülseten Samen des Wunderbar ab(Ricinus communis L.) erhalten, und darf nur in ganz gelinder Wärme ausgepiefst werden. Es ist ziemlich dickflüssig, etwas zäbe, weils, ohne sonderlichen Geruch und von bigenem süfslichen Ge-
schmack. In der Kälte gerinnt es nicht. schmack. In der Kälte gerinnt es nicht.
Durcb das Alter wird es duukler, dicker Durch das Alter wird es duukler, dicker
und erhält die Consistenz eines iHonigs. Es darf nicht ranzig seyn und in Schlunde keine brenueude Empfindung zurücklassen, welches letztere der Fall ist, wenn die Samen nicbt vorher abgehülset wersich dadurch von andern fetten Oelen, daf sich dadurch von andern fetten Oelen, dals es sich vollkommen in absolintem Alcobol

Oelen in allen 'Verhẩl tnissen damit mischen lälst.

Olea sulphurata.

Balsama sulphuris.

Schwefelöle.

Schwefelbalsame.

Oleuin Anisi sulpluzratum.

Balsamum sulphuris anisatum. Schwefelanisöl.

Oleum Lini sulphuratum.

Balsamum sulphuris simplex.

Schwefelleinöl.

Einlacher Schwefelbalsam.

Oleum Terebincliinae sulphuratum.

Balsamum sulphuris terebinthina tum.

Terpentinschwefelbalsam.

Olibanum.

Thus.

Weihrauch. Büchse wohlverhudeu an einem kühlen Orte auf.

Thre Bereitung gründet sich anf die Aullösung des Schwefels in ausgeprefsten nnd ätherischen Oelen vermittelst der Wärme. Die dickn̈üsigern, undurchsichtigen, schwarzhrauneu, mit einem fettcn Oele bereitete Scbwefelbalsame siplien im Wasser untcr; die rothbraunen, mcistens durchsichtigen, ätherisch-ölichten schwimıen dagegen auf demselben. Alle baben einen stirkenden eigenartigen Geruch und höchst widrigen Gescbmack. Fette Oele lösen mehr. Schwefel auf, als die ätherischen?

Wird nach der Preufsischen Pharmacopoe aus ciner halheu Uuze reinen.Schwefel, den man durch allmäliges Hinzuthun in zwey Unzen, in einem irdenen Gefłfse im Sandbade erbitzten Mandelöl aufgelöst hat, duich Digestion dcr erbaltcnen braunen Masse mit sechs Un,en ählerischem Anissamenöl, bereitet. Es hat ein rotbbraune Farbe nud besitzt ganz den vermischten Geruch des aufgelösten Schwefels und Aujsöls.

Acht Unzen Leinöl werden in einem hinlänglich geriumigen irdenen Gefäfse ins Sandbad gesetzt und naohdem dasselhe sehr heifs 'reworden, unter bestündigen Uurïhlen zwey Unzen reinar Schwefel in kleinen Portiódasselhe sehr heifs geworden, nnter bestandigen minrihen zwey Unen reiner Schwerel in kleinen Portionen nach nnd nach hinzugethan, bis derselbe sich vollkommen darin aufgelöst, uud alles sich zu einer
gleicbartigen, zähen, festel, braunschwarzen Masse innïg vereinigt bat. Diese Masse, welche_auch Scbwe= felhalsammuter (Corpus probalsamosulpburis) genanut wird, hebt man in eiuer steinzeuguen

Wird durch Auflösung von zwey Unzen des eiufachen Scbwefelbalsams (Olenm Lini sulphuratum) in sechs Uuzen Terpentinöl, vermittelst gelinder Wärme bereitet, hat eine rothbraune Farbe und den eigenthümlichen Geruch des Terpentinöls in Verhindung mit dem des aufgelösten Schwefels.

in mit gummichten Theilcn verbundenes/Schlechtere Sorte. Harz, welches in Arabien und Acthiopicn gesanmlet, erst nach Mecca, von da nacb Cairo und endlicb über Marseille zu uns gebracht wird, und von dem es noch nicht ausgcmacht ist, ob es von $L y z$ ier- oder Weihrauchwacholder (Juniperus Weihrauchwacholder (J uniperus $\mathrm{L}$ y cia oder $\mathrm{th}$ ur if e $\mathrm{r}$ a $L$.) abstammt.
Es besteht dassel he aus meistens rundlichEs besteht dasselhe aus meistens rundichlänglichen, tropfenartigen Körneru ron verschiedener Grölse, die etwas durchFarbe, oft aueinander gekleht, ührigens aber trocken, auswcndig meblig, zerbrechlich nud auf dem Bruclie inatt sind. Der Geschmack ist etwas scharf bitterlich; dcr Geruch angenelum harzicht. Zwischen den Gän ist der Weiluruch anfaugs spröde, Zahnen ist celben anj wird zähe uud weich. Er läfst
Mit Ficlutenliarz und Lerchenbaumharz verfälscht.
Die geringere, aus unclurchscheinenden, rotbbraunen; mit Rindenstiickchen und andern frcmdartigen Beymiscbungen verunreinigte Sorte (Olibanum in sortis) ist zuverwerfen.

Tan erkennt diese an der dunkelgelben, rothbraunen Farbe, den unangenehmern Gesclumack und den terpentinartigen Gerueh auf gluhendell Kohlev. 
Olibanum. - Oxalium.

\section{Namen der Arzneymitcel \\ Sinnliche Eigenfchaften derfelben; Merkinale ihrer Ächtheit und Giite.} Olibannm.

\section{Opium.}

Opium crudum s. thebaicum.

Opium.

Molinsaft.

sich leichı entziînden, brennt mit lieller Flamme und verbreitet daun einen licbl chen Woulgeruch. Gepulvert und mit Wasser.geriehen, giebt er eine nacl kurzer Zeit Harz absetzende Milch; in Weingeist lösct ex sich gröfstentbeils auf. Ie trocknel heller, gelber, durchsichtiger ind spröder er ist, um desto besser ist er.
ist

Der aus den noch nich! ganz reifen, geritzten Samencapseln des Scblaf mobns (Papaver somn iferum $L$,) fliefsende 1nid vcrbartete, harzicht-guminichte Milclisaft. Wir erhalten das Opium aus der

\section{Opopanax.}

Gummi Opopana-

cis.

Panaxgummi.

\section{Fehlerhafie Be-, rehaffenheit, Ver- wechselung oder Verfälfchung.} Tartarcy, Arabien, Persien, Aegyptell nnd andern beilsen Gregenden Asiens, in meistens platten, rmaltichen, ein bis andertbalb Pfund schweren Kucheu, mit dem anbängenden innerı Häutchen der Mohn-
köpfe und verschiedeneo Samen bestreut, köpfe und verschiedenen Samen bestreut,
und mit Mohn- Tahacks - oder einer Art Ampferblätter uınwickelt. Gutes ächtes Opium bildet eine dichte, selbst in kleinen Stücken und an den Rändern undurchsichtige, 2wischen den Fingern sich erweichende, beym Schneiden insgemein in mebrere Stucke zerbröckelnde, auf dem Bruche etwas glänzende, nur aulserst wenige fremdartige entbaltende, im Verbältnils
des Umfangs ziemlich leichte Masse, von des Umfangs ziemlich leichte Masse, von
gleichartig röthlichgel bbrauner Farbe, eigleichartig röthlichgelbbrauner $F$ arbe, ei-
nem erst bitterlich - widrigen, nachber aber scharfen und beifsenden Geschmark, und durchdringenden cckelbafteu und betăubenden Gertuch. Es mufs zähe, trocken und gleichför mig seyv, beym Durchschneiden nicht knirschen, sondcrn in Stiicken springen, auf dem Schnitte keine Spuren von fremden Theilen, wohl aber hin und wieder Flitter flichtigen Salze zeigen; beym Kauen den fluchtigen Salze zeigen; beym Känlich färben und schaumig machen; am Lichte sich ben und schaumig machen; am Lichte sich leicht entzünden lassen und mit belier Flamme brennen; angefeuchtet auf dem Papier einen hellbrannen Strich geben, einen bervorstecbenden bittern Gresclumack haben, der im Schlunde ein gewisses Brennen zurückläfst, nicht breuzlicht oder Pulver leicut

Mit beygemischtem Sand verunreinigt

Verfälscht.

chlechtere brauchbare Sorte.

Mit Sïfsholzsaft ver-

\section{fälscht.}

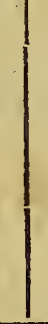

\section{Kennzeichen und Prïfungsmittel.}

Der durch Anritzung des untern Stengel - und obern Wurzeltheils der im Orient und dem süllichen Europa wachşenden $P$ anaxpastinak ( $P$ astinaca Opopanax L.) bervorquillende und erbärtete Milchsaft, ein fast aus gleichen Theilen Harz und Gummi bestehendes Gummiharz, welcies wir aus'der Levante exhalten. Es besteht aus einzel nen rundlichen Stïcken von der Gröfse einer Erbse bis zu dcr einer Willnufs, die sich etwas fettig anfühlen lassen, aher doch zerbrechlich sind. Von aufsen ist es gelbröthlich oder braungelb, mit weifslicben. Flecken besetzt, inwendig weifsgelb, ïbrigeus anch etwas klebrig. Der Gresnbmack ist schärflich, widerlich-bitter; der Geruch stark gewürzhaft, dem Liebstöckel ähnlich. Verschieden von dieser Sorte (O popanax in gradis) ist die geringere, in grofsen, dunklerfarbigen oder schwärzlichen, mit ser Sorte (O p opan ax in garchen, harten oder zu weichen Stücken vorkommende Sorte (Opopanax in vielen Unteinigkeiten vermischten, harten oder zu werfich ist. Mit Wasser gerieben, giebt das ächte $\mathrm{Pa}-$

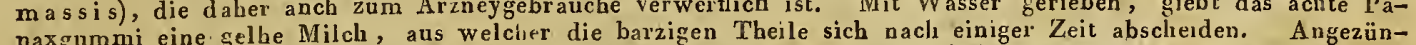

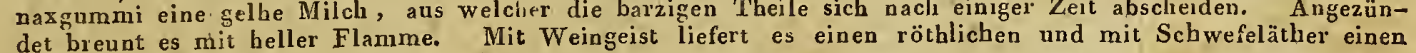
det breunt es mit heller Flanme. Mit Weingeist liefert es einen röthlichen und mit Schwefeläther einen
weingclben Auszug.

Ova gallinacea. Hühnereyer.

Oxalinim.

Sal Acetosellae. Sauerkleesalz.

Die Eyer von dem gerneinen Hubne (Phasianus gallus L) Gute Eyer mïssen unverdorben und frisch seyn und ein weifses Anseben baben. Das Innere derselbcn mufs unbeweglich seyn, und das Weifse (Alber der Eydotter (Vitellus ovi) mufs seine eigenthümliche bekannte Consistenz, Farbe, Geruch und Geschmack besitzen.

Ein ans dem ausgeprefsten und gereinigten|Mit ïbersautem $V i$-|In die Aullösung eines solchen verfälschten triolweipstein oder Salzes tröpfele man etwas Bleyessig; es

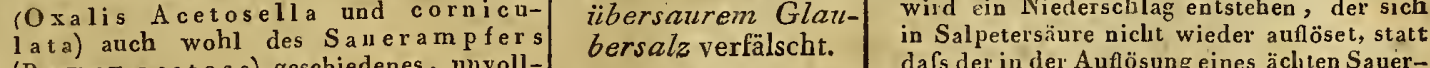
(Rumex a cetosa) geschiedenes, uuvollkommenes übersaures wcsentliches Neutralsalz, welches fabrikmäfsig in groíser Menge in der Schweiz, vornemlich an der schwabischen Gräuze, in dem Wirtembergischen Oberamte Tuttlingen, im Elsafs, in Thüringen, an Harz, auch in Scbweden bereitet wird. Es bilder kleine länglich-vierseitige, dachförmig abgestumpfte lich - viers thülichen Säure, die' zum Theil an Kali thumlichen Săure, die zim Theil an Kali gebunden ist. Es bat einen sehr sauren, unveränderlich, im Wasser schwer, im tibersaurem wird ein Niederschlag entstehen, der sich dafs der in der. Auflösung eines äcl ten Sauerkleesalzes auf diese Art entstaridene Bleyniederschlag von der Salpetersäur e sogleich niederschlag von der Salpetersaure sogleich wieder aufgelöset wird: Der Geschmack eines so verfälschten Sauerkleesalzes ist üherdem mehr berbe und zusammenziebend, die CrJstallen sind kleiner und auflöslicher
im Wasser; nach deın Verbrennen bleibt sondern schwefelsaure Kali oder Natrnm zurück.

Mit Weinsteincry - Verräth sich durcb den beym Verbrennen stallen verfälscht. $\quad \begin{aligned} & \text { anfsteigenden brenalich tsauren Geruch, und } \\ & \text { durch }\end{aligned}$ durch die noch schwerere Auföslicbleit i Wasser. 
Oxymel Aeruginis.

Unguentum aegyptiacum.

Kupfersauerhonig. Aegyptische Salbe. Oxymel squilliticutr.

Meerzwiebelsauerhonig.

Oxymel simplex. Sauerhonig.

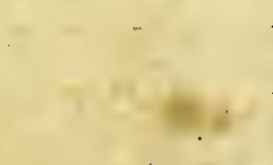

Pasta Althaeae. Altheepaste,

Weilser Lederzuclier.

Pasta Liquiritiae. Süßsholzpaste. Leglise.

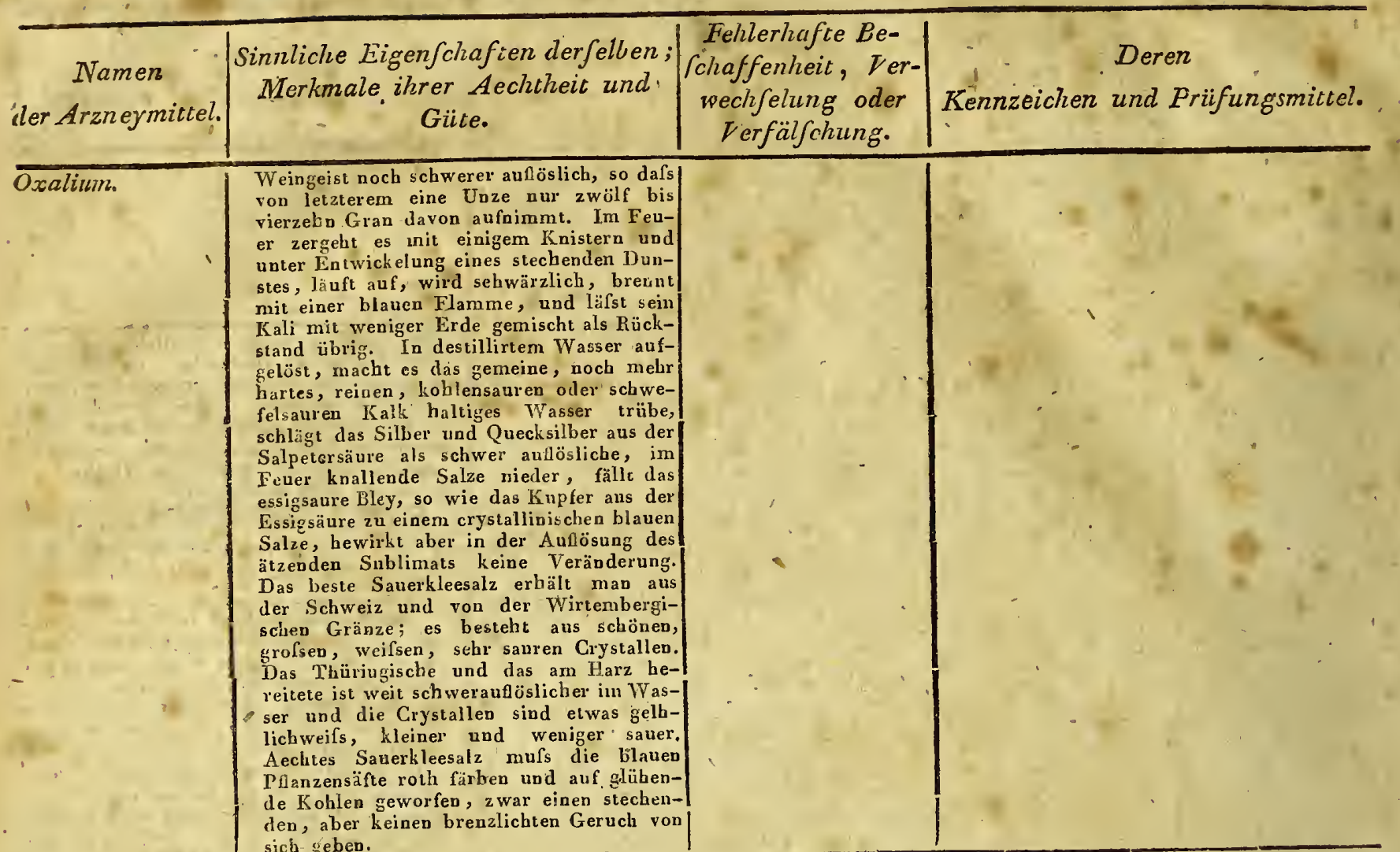

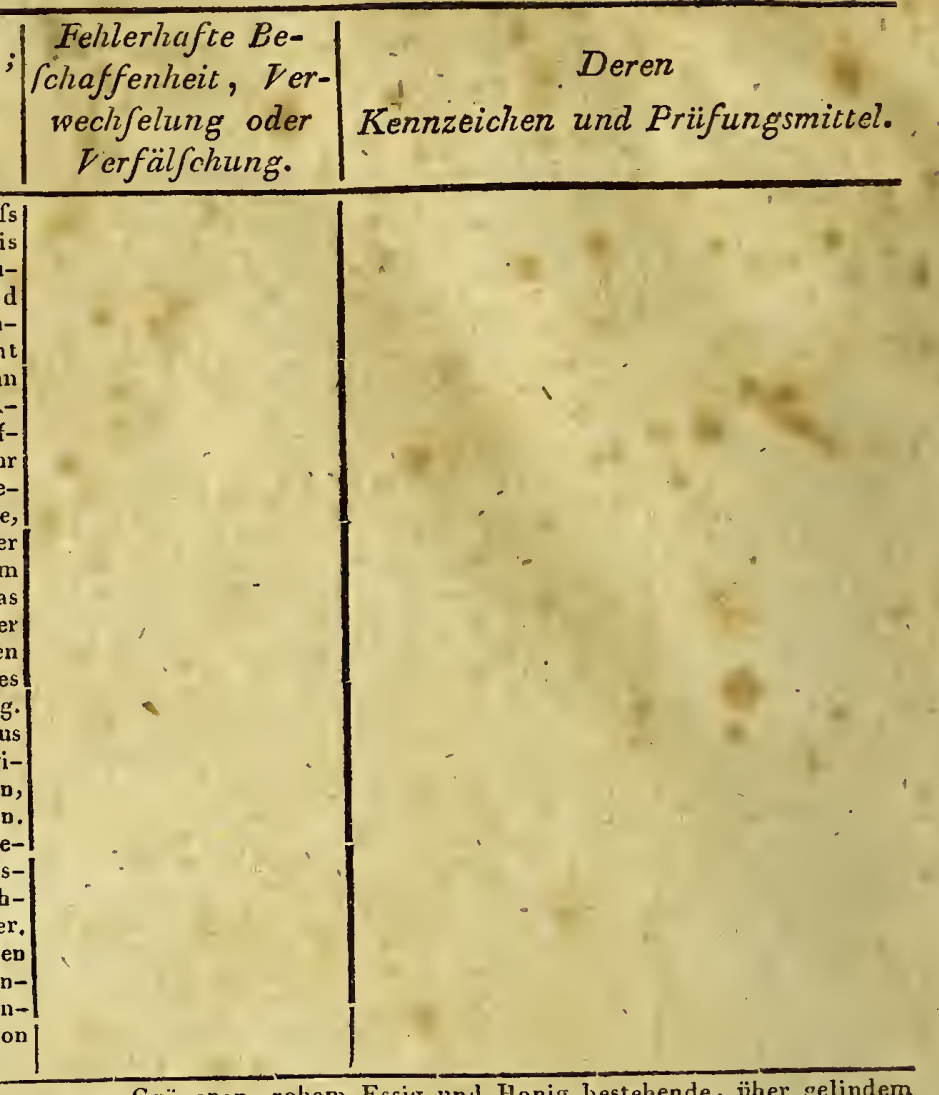

ne $2 \mathrm{um}$ chirurgischen Gebraucbe bestimnte, aus Grüuspan, rohem Essig und Honig bestehende, üher gelindem Feuer bereitcte Mischung. Sie mufs eime salhenähnliche Consistenz uud eiuen sauerlichen
tzen und in einem steinzeugnen oder gläsernen Gefälse wohlverstopft aufbewahrt werden.

\begin{tabular}{|c|c|}
\hline 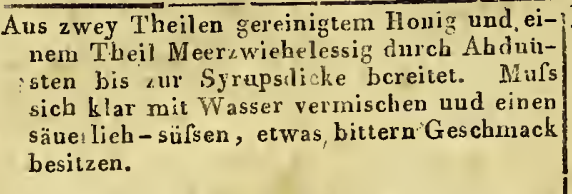 & 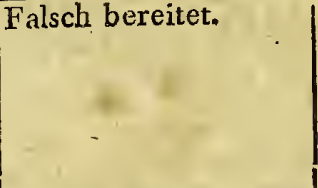 \\
\hline $\begin{array}{l}\text { Aus zwey Theilen gereinigtem Honig und ei- } \\
\text { nem Theil Weinessig durch Ablunsten über } \\
\text { gelindem Feuer bis zur Consistenz. eiues } \\
\text { Syrnps oder eines flüssigen Honigs bereitet. } \\
\text { Mufs einen säuerlichsüfsen Geschinack ha- } \\
\text { ben und ist um desto besser, je weniger } \\
\text { der gereinigte Honig durchs Kochen seive } \\
\text { Kräfte verloren hat. }\end{array}$ & $\begin{array}{l}\text { Zuweilen wohl mit } \\
\text { Bley oder Kupfer } \\
\text { verunreinigt. }\end{array}$ \\
\hline
\end{tabular}

Herr Schaub (a. a. O, S. 78) erwähnt eines Apothers, der den mit gewühnlihonig eine Zeitchem Essig ver lang mit etwas Meerzwiebelpur und ran durchseibete, oder, im Tall ex keine Meel' $\angle$ wiebeln vorrâthig hatte, stat
derselben Cardobenedictenkraut nahm.

iihrt von der Bereitung in bleyiscli-zinernen oder gar kupfernen Geschirren her. a piufe deshalh die verdünnte wä srige Mn probeAntosung rait Ha h o man firssigkeit, welche dureb einen dunkelfarbigen Niederschlag das Bley, so wie ein hineingestelltes blankes Eisenstahchen durclss Verkupiern den Kupfergehal an r eigen wird.

Durch Auflösnng von zwey Pfunden arabi- Nicht gut bereitet. Eine nicht achlässig oder tehlerbaf hereitete Altheepaste ist gelblich, auch wohl gelbrötblich, nicht loeker, sondern fest, zähe und schwer. Oft hat sie einen brenzliebep unangenehmen Geschmack. Zuwèilen ist sie von dem eigentich uñö̈thigen Bestreuen der $P$ apiercapseln mit $P$ uder, welcher das Anbarken beym Austrockneu verhüten soll, ganz mit Mehl überzogen' uud wird dadurch im Munde pappis und schlierig.
Nicht gut bereitet.

D

Die Reglise ist nicht mit Vorsicht bereitet, wetin sie untein, nudurchsichtig nnd seh. dunkelbraun geförbt ist, wenn sie fruch ist und an den Fingern klebt, wenn die Flïssigkeit nicht vorsichtig genug abgedampft wurde, etwa anbrannte und die Rexlise dadurch einen unangenehmen brenzlichen Geschmack angenommen hat. An einom feuchten Orte aufbewalhrt, wird sio 


\section{Pasta Liquiritiae, -- Phosphorus.}

\section{Namen | Sinnliche Eigenfchaften derfelben der Arzneymittel. Merkmale ihrer Ächtheic und Giite.}

\section{Felilerhafte Be- schaffenlieit, Ver- wechfelung oder Verfälfchung. \\ Deren \\ Kennzeichen und Priifungsmittel.}

Pasta Liquiritiae.| lichyelhe Farbe hahen, vollkommen klar und durchsichtig seyu, die gehörige Härte und eineu reinen silfsen Lacritzengeschmack besitzeu. Sie mufs au einem trocknen Orte aufbewabrt werden.

Petroleum.

Oleum Petrae,

Bergöl.

Steinöls
Phosphorus. Phosphor. n llussiges Erdharz, tas in der Gestalt eines ätherischen Oels grölstentheils aus Felsenritzen hervorquillt, auch wohl in eirigen Gegenden auf dem Wasser schwimmend angetroffen wird, und gemeiniglicb ans Italien, Sicilien, dem Elsafs, aus zu uns kommt. Es bat eine rom Honiggelhen lis zum brätulicbrothen abweichende Farhe, eine den fetten Oelen beykommende Dicklichkeit, einen ganz eisenhümlirben, Den nicht, thing ruch, und scharfeu Gesebmack. Es läst sich, wenn es erwarmt worden ist, eniFlamme, die viel Rauch und Rufs abset, $t$. Nit Oelen läfst es siclr vermischen. In seinem gleichen Gewichte ahsolnten Alcobol mufs sich das Bergöl, wenn es ächt ist, nach Trommsdorff (Handbuch der pharrnac. Waarenkunde, Aufl. 2. S. 13) vollkommen auflösen; ist der Alcohol nicht wasserfiey, so el folgt uur erst bey einem sechs - und melurfachen Zusatz von Alcohol eine völlige Auflösung. Gewöhulicher rectificirter-Weingeist gieht mit dem Bergöl rectifirter Weingeist gieht mit len Bexge beym Uns keit, aus der sich das Oel wieder absondert. Durch Rectifcation wird das kergö völlig weifs und leichter in wäfsrigern Alcohol anföslich. Mit concentrirtêr Schwefclsäure darf sich das äcbte Bergöl nicb erbitzen usd schwarz worden. Uebrigeas wird es durchs Alter unil durch den öltern Zutritt der Loft dunkler von Farbe, bekommt eine dicklichere Consisten . und einen widrigen Geruch und Geschmack.

Eine feinere Art Bergöl von weifser, lichtgelber, durchsichtiger Farbe, die man Bergnaphebe (Naphtha Petrolei) nennt, kommt von der Insel Sumatra, ans Persien und den Herzogthümern Modena und Parma, ist aber bey uus änfserst selten im Hapdel zu baben.

Eine ganz eigenthümliche Substamz, die einen elementarischen Bestandtheil aller animalischen und auch sehr vieler vegetabilischen Körper ausmacht und auf dem Wege der Kunst daraus bereitet werden kann. Die gewöhnlichste Bereitungsmethode besteht darin, dafs man die durch Schwefelsäure aus den Kuochen geschiedene trockne Phosphorsäure mit der Hällte ihres Gewichts Koblenstaub vermengt, das Gemenge in einer beschlagenen irdenen Retorte füllt, eine Vorlage mit Wasser vorlegt nnd nach gehöriger Verküttnng die Destill nacb gehoutger tion bey allmälig bis zum höchstev Grade verstärktem Feuer beginnt; der dabey übergehende, sich in Tropfen verdickende und in dem Wasser der Vorlage erstart zu Boden sinkende Phosphor wird dann in eine gläserne, am untern Ende zugestopfte höhre gebracht, die Röbre in siedendes Wasser gehalten, damil der Phosphor schmelzen and nach der Erstarrung in kleine düńne Stängelchen, als seiuer gewöhnlichen For'm, herausgestofsen werden kann. Man hebt ibu danu in einem mit Wasser Man hebt ibu danц in elsenen Glase anf, welches $\operatorname{man}$ in einem mit genan passenwelches man in einom mit genaa passendern Deckel versebenen, verzinnt eisenblechernen, oder noch besser kupfcrnen Futterale, in welchem man es mit Sand oder
Kleye umschüttelt, an einem dunklen Orte aufhewahrt.

Der reine Phosphor besitzt eine weifse, ins Gelblichte spielende Farbe, einen matten Wachsglanz, ist frisch bereitet, gegen die Flamme eines Lichts gehalten, durchscheinend, wird tor bewabrung unter Wasser, auf der Ober- gemeiniglich" feucht und wohl gar mit Schimmel überzogen.

Häufig mit Terpen- Wird durch die gröfsere oder geringere Anftinöl verfälschto löslichkeit in gewöhulichem Alcolıol oder Weingeist, und 'durch dell Terpentingeruch, wenn es in einem Löffel erwärmet wird, ausgemittelt.

Mit fetten Oelen ver-

\section{fälscht.}

(ird nach Hab neman $n$ dadurch erkannt dals man es mit concentiirter Schwefelsäure schüttelt; das reine Petroleum wird davou nicht veräflert, war es aber.rnit einem fetten Oele verfälscht, so wird die Mischung dick, schwarz und undurchsichMisctung dick, schwarz und unclurchsichit , und dinstet einen Gerach nacb sebweflichter Saure ans. Veril Wosser, so schel, so scheidet sich das reine Bergöl daraus wieder ab dessen Gewicht dann anf die Menge de
Verfälschnngsmittels schliefsen läfsta

Mit Schwefel ver- Da sich der Phosphor durch eine gemein fäscht.

schaftliche Destillation leicht mit dem Schwefel vereinigt, so soll er in den $\mathrm{Fa}-$ briken of damit verfälscht werden. Ist nur briken oft damit verfalscht werden. Ist nur er seine Eigenschaften nicht ab. Ist der Schwefel aber in grölserer Menge damit verbunden, so entzündet sich ein solcher Phosphor an der freyen Lnft entweder gar nicht, oder nur sebr schwer und nur durch heftiges Reiben. Immer findet ein solcber Verdacht statt, wenn der Phosphor bey einer Wärme von $76^{\circ}$ Fahr. sich nicht entzïndet, sondern blos zerfliefst und einen weifsen Rauch von sich giebt. Um es noch sicherer Wicher wenige Plo lose die rinckstàndige Saure in destillirtem. Wasser auf, und nntersuche nun, ob die salzsaure Barytanflösung dadurch getrübt
wird; geschiebt dieses, so war der Phosphor nicht rein.

Anmer Der in Fabriken bereitete Phosphor ist zuweilen sebr nmerk. Der in Fabriken berëtete Phosphor ist zuweilen seält; es liefse sich viclleicht hier aufeine Verfälschnng mit Wachs schliefsen, doch fehlen die Beweise dafir. F i scher Handbuch der pharmacevtischen Praxis, Anfl. 2. S. 464 . 


\begin{tabular}{c|c} 
Namen & $\begin{array}{c}\text { Sinnliche Eigenfchaften derfellen; } \\
\text { Merkmale ihrer Aechtheit und } \\
\text { Ger Arzneymittel. }\end{array}$ \\
\hline
\end{tabular}

fläche weif und unscbeinhar. Er hat eine fcste, etwas zähe Consistenz, läfst sich auch durch schnelles Beugen, besonders in kalter Temperafur, brechen, da er dann kalter Temperatur, brechen, da er dann einen, gewissermalsen strahlicht glanzengiebt in freyer Luft bey mittlerer Temperatur weifse, fast knoblauchartig riechende Dämpfe, und zerfliefst allmälig zur phosphorichten Phosphorsäure. Er entzüudet sich, wenn er beym Zutritt der Luft gerieben oder erwärnt wird, von selhst, und brennt mit einer, aus dem Gelblichen ins Grüne fallenden, etwas kuisternden, hell leuchtenden, leuble verbreitenden Flamme, die sich nur dureh Lintanchen in Wasser loschen lalst. Im Wasser ist der Phosphor fur sich nicht auflöslicb, wohl aber in der Verbindung mit Wasserstoff. Die Oele, sowohl die fetten als die ätherischen (unter den letzteru be sonders das Nelkenöl), der, besonders über salzsanren Kalk rectificirte, Schwe-l feläther, so wie die übrigen möglichst entwässerten Aetherarten, auch der absolute Alcohol, lösen den Phosphor, nacbdem er von dem anhäugenden Wasser auf Druckpapier befreyt Fron papier befreyt worden, jedes dieser Lösungsmittel, jedoch nur in kleiner Menge auf, und geben damit, aber auch nicht alle, in minderer Teniperatur leuchtend und beym Siedegrad des Wassers selbst entzündlicbe Lösungen.

Pilulae.

Pillen.;

iese sebr bekannte und gebräuchliche Arzneyform besteht aus kleinen Kügelchen, welche die Consistenz eine derben Teices haben. Man bat dabey auf verschiedene Puncte wolıl Rücksicht zu nehmen: Die Masse zu den Pillen (Massa pilularum) mufs sebr genau untereinander gemischt seyn; sie mufs eine durchaus gleichförm den können. Alle Iagredienzen, die in Pulverform unter die Masse kommen, müssen den höchsten Grad der Feinheit bahen. Die Consisteuz darf weder zu hart nocb zu weich seyn. So viel wie möglich müssen bey ihrer Bereitung die metallischen Mörser vermieden werden; besonders aher dürfen diese nicht bey solchen Pillen angeweudet werden, unter deren Mischung ammoniakalische und andere Salze, Schwefel und schwefelbaltige Verbiudungen, Spiefsglanzseifen, Quecksilbermittel u. dgl. kommen. Die einzelnen Pillen (Pilula e) selbst müssen genau eine und dieselbe Grölse und Schwere haben; sie müssen gut zugerundet und mit einem schicklichen Pulver, Süfsholzpulver oder Lycopodium, bestreut seyn, damit sie nicht zusammenhacken. "Werden sie mit Gold - oder Silberplättchen üherzogen, so darf dazu kein unächtes Blattcold or Blattilter gold istes, dic Masse aud denselben vourathig austrockneu und in Magen unautostich liegen bleiben. Besser ist es, die Masse zu denselben yotrathig zu halten, und aus derselhen die Pillen, so wie sie verlast worden, jedessal. risch au formiren. drey Theilen Jalappenseife und einem Theil versiistem Quecksilber; Pilulae polychrestae; Pilulae sqnil-

Die völlig reifen, runden, glatten, weifsen, Nachgekünstelt:

Piperalbum.

Weifser Pfeffer. erhsengrofsen Fruchtkörner des auf Mala cka, Java, Sumatra und Cochinchina in grofser Menge an Flüssen gehaut werdenden Pfefferstía ubs (Piper uigrum L.), von denen mau das im friscben $\mathrm{Zu}$ staude rothe Oberhäutchen durch Eiuweichen in Wasser und Reihen zwischen den Händen abgesondert, und sie nacbher an der Sonne getrockut bat. Sie haben einen etwas gewür haften Geruch und eineu scharfer, beifsenden doch aber uilderen Geschmack als der schwarze Pfeffer. Beym Cinkanf desselben hat man darallf $2 \mathbf{a}^{\prime}$ sehen oh er auch etwa schimmlicht sey ind einen modrigen Geschmack besitze, iu weleinen modrigen Galle er zư verwerfen ist.

Piper, hispanicum. Spanischer Pfeffer. .

Tiper longum. Langer Pfeffer.

\section{1}

Fehlerhafte Be-
fchaffenheic, Ver-
wechfelung oder
Verfälfchung. \\ chaffenheic, Ver- \\ Kennzeichen und Prüfungsmittel.}




\section{Piper nigrum. -- Poma Aurantiorum immatura.}

\begin{tabular}{|c|c|c|c|}
\hline $\begin{array}{c}\text { Namen } \\
\text { der Arzneymittel. }\end{array}$ & $\begin{array}{c}\text { Sinnliche Eigenfchaften derfelben; } \\
\text { Merkmale ihrer Ächtheit und } \\
\text { Güte. }\end{array}$ & \begin{tabular}{|} 
Fehlerhafie Be- \\
frihaffenheit, Ver- \\
wechselung oder \\
Verfälfchung.
\end{tabular} & $\begin{array}{c}\text { Deren } \\
\text { Kennzeichen und Prïfungsmittel. }\end{array}$ \\
\hline $\begin{array}{l}\text { Piper nigrum. } \\
\text { Schwarzer Pfeffer. }\end{array}$ & 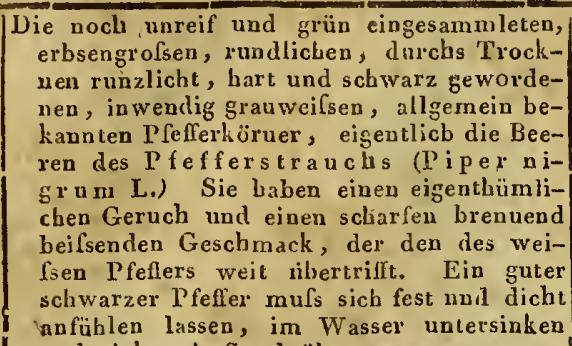 & $\sin x+5$ & 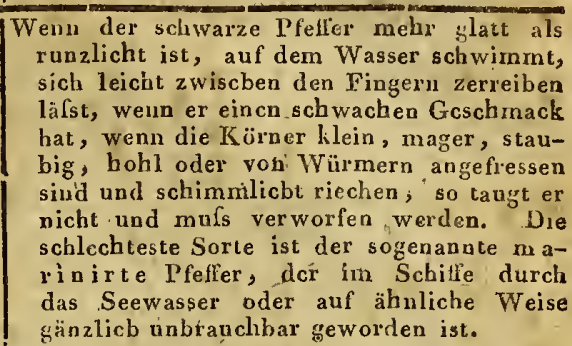 \\
\hline 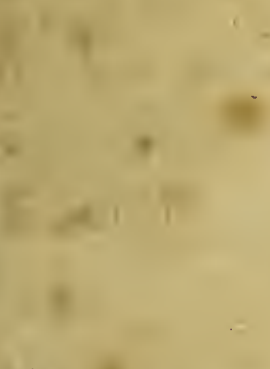 & 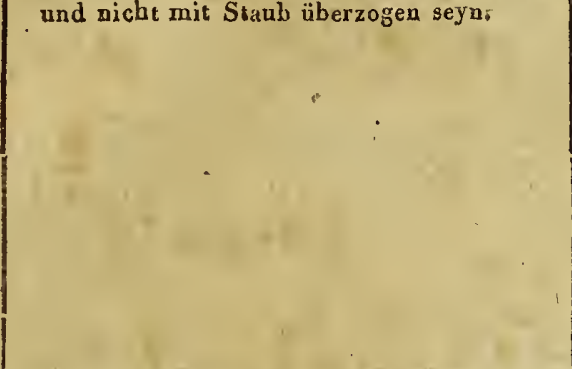 & Verfälschter Pfeffer. & 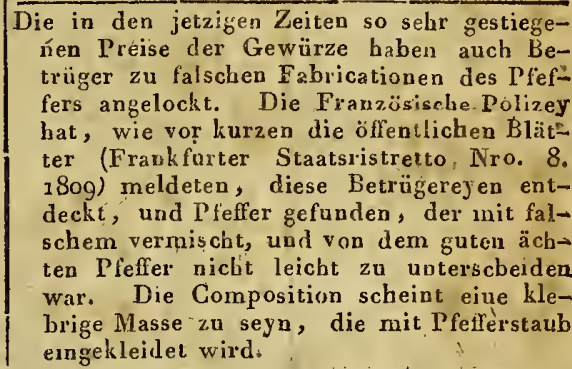 \\
\hline
\end{tabular}

Plumbum.

Bley.

rd theils oxydirt als gelhe, graue oder rothe Bleyerde, theils vererzt mit Sauren oder Schwefel als weilses, gelbes, blaues und hrannes Bleyerz oder als Bleyvitriol, Bleyglanz und Bleyschweif iu mehreren Landern, sehr häufig auch in Deutschland, angetroffen. Das Bley ist in seiner reineu Zustande ein graublauliche oder blaulichweifses, sebr weiches, wenig zähes, die Finger beym Reiben farbendes Metall, welches eilfmal scbwerer als das Wasser, und nächst dem Golde, der Platina und deñ Quecksilber das schwerste Metall
ist. Es bat fast gar keinen Klang, besitzt eine ziemliche Geschmeidigkeit, ist sehr dehnbar und lăfst sićn ist. Es bat fast gar keinen Klang, besitzt eine ziemliche Geschmeidigkeit, ist sehr dehnbar und lăfst sich in ganz dünne Blätzchen bringen. Es bat feruer cineu eigenthïmlichen Geschmack und Geruch, welcher letztere vorzüglich bemerklich ist, wenn es gerieben oder e'hitzt wird. Auf frischem Schnitte glänzt es zwar, läuft aber bald an der Luft an, wird erst unscheinbar und schwärzlich, späterbin mit granen Pünctchen, und zuletzt mit einer grauweifsen Riude oder Rost überzogen. Es schmilct in einer sehr geringen Wärme, noch ehe es glïbet, und während dem Schmelzen wird es mit einer gráuen Haut überzogen, die sich nach jedesmaliger Hinwegnahme sogleich wied r erneuert, ein unvollkommues Bleyoxyd ist und Bleya sche (Ginis $\mathrm{Pl}$ umbi) genannt wird. Diese Bleyasche giebt alstann; den Feuer eine kürzere oder längcre Zeit ausgesetzt, die übrigen Bleyoxyde, und fliefst zuletzt zu einem durchsichtigen, dünnfitissigen, honiggelben, in stärkster Hitze sich einiuerıafsen verflüchtig̀enden Bleyglase (Vitrum Saturni.) Mit den beknnten Säuren und Alculien verbundet sich das Bley, wo nicbt im metallisolien, docb oxydirten Z den bekn stande. Die Eär durch einen süstichen zusannenziehenden Geschack. Oefor Verbindung ein. Aus seiber Aulostag in Saure wir Galläpfelauszug, auch als Kalien durch Säuren fast immer weifs, durch Hydrothionsanres Wasser aber schwarzbraun, etwas metallisch glänzend, als schwefelháliges Bley niedergeschlagen. Durch Schmelzen mit Schwefel entsteht ein künstlickes Bleyerz, das sogenannte gPb an i P B ey (Plumbum ustum.)

Plumbum aceticum.

Saccharum Saturni. Essigsaures Bley. Bleyzucker.
Poma acidula. Säuerliche Aepfel.

Poma Aurantiorum immatura.

Unreife Pommeranzen. in metallisches, aus. Essigsäure und Bley- Schlecht aufbewahrt. Der Bleyzucker verliert durch freye Einwiroxyd bestehendes Neutralsalz, welches vorzüglicb in Holland und Eugland durch Aufösung des Bleyweifses in Essig, im Grofsen bereitet wird. Wir erhalten den Bleyzucker gewöhnlich in crystallinischen zusammengebackenen Klumpen in Schachteln gepackt. Dieser käuflicbe Bleyzucker ist aber meistentheils sebr unrein und bedarf erst ejner nochmaligen Reinigung durch Aufiösen in heifsem destillirien Wasser

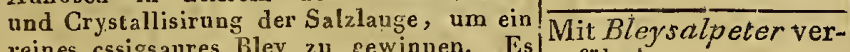
reines cssigsaures Bley zu gewinnen. Es fälscht.

seitige, halbdurchsichtige, mattglänzende weifsc Säulchen, die in Menge einen süfs licht-säuerlicben Duft von sich geben, und einen stark zusammenziehend suifsen, biutennach herbe schrnmpfendow Geschmack lıbell. Frisch crystallisirt löset sich das essigsaure Bley bey $100^{\circ} \mathrm{Fabr}$. in seinem eigenen Gewicht destillirten Wassers völlig ungefärbt und klar anf, so wie bey $113^{\circ} \mathrm{Grad}$ der Wärme in der gleichr'n Menge Weingeist. Mit der Zeit werden die Crystallen gelblich; im Sonnenlicht mifsfaibig grau; an der Lufi mehlig. Der faibig grau; an der Luft mehlig. Der
Bleyzucker mufs daher in vollen luftdicht Bleyzucker mufs daher in vollen luftdicht
verschlossenen Gläsern aufbewahrt werdeu.

Die bekannten Früchte des Apfelba ums (Pyrus Malns L.), von welchem es unzählige Abarten, gicbt. Zun Arzneygebrauch werden nur die säuerlich-herben Gattungen der Aepfel gebraucht, besonders die b ors dorfer äpfel und die Renetten.

grïnen unreifen Frïchte des Pommeranze derofse eine Erbse his zu der einer. Kirsche. Getrocknet haben sie eine braune oder schwärzlicbgrüne Farbe, sind etwas Erbse his zu der einel. Kirsche. Getrocknet haben sie eine braune oder schwarzlicbgrune Farbe, sind etwas runzlicht und scbmecken sehr bitter, aber doch dabey angenebm gewürzhaft. Die von selbst abgefaltenen, neysebrauche nielat. 
Poma Aurantionum matura. - Pulveres.

\begin{tabular}{|c|c|c|c|}
\hline $\begin{array}{l}\text { Namen } \\
\text { Arzneymittel. }\end{array}$ & $\begin{array}{c}\text { Sinnliche Eigenfchaften derfellen; } \\
\text { Merkmale, ihrer Aechtheit und } \\
\text { Guite. }\end{array}$ & $\left|\begin{array}{cc}\text { Fehlerhafte } & \text { Be- } \\
\text { rchaffenheit, } & \text { Ver- } \\
\text { wechfelung } & \text { oder } \\
\text { Verfälfchung. }\end{array}\right|$ & $\begin{array}{c}\text { Deren } \\
\text { Kennzeichen und Prüfungsmittel. }\end{array}$ \\
\hline
\end{tabular}

Porma Aurautiorum|Die reifen Frïchte des Pommeraue n a ums. Kuglichte, an beyden Seiten etwas eingedrückte, mit einem matura.

Peife Pommeran zen. Nabel bezeichnete Früchte. Answendig baben sie eine fleischichte, unglciche, mit vielen kleinen Lôchern
versehene, scbwammicbte, von aufsen rothgelbe, von inncn weifse Schale; inwendig aber ein bäutiges, saftiges, weifsgelbliches Mark, das in neun Fächern abgetbeilt ist, die achizehn ziernlich ejrunde, schwielichte Samenkerne enthalten und voli von einem angenehrm bitter und angenehm bittellich.' Die dunkelgelb oder stark balsanisch und angenehm; der Geschmack gewürzhat
braungelb aussehenden, nicht alzu alten sind die besten.

Poma Citri.

Citronen.

Die bekannten, so wie sie 20 uns kommen, vor ihrer völligen licife absenommenen Früchte des Citronenb a sm (Coürmig-länglicht, endigen sich am oberu Ende" in eine Warze, baums (Gitrus medica L.) Sie sind eyformiglaufen am uutern stumpf zu und sind daselot oder weniger dicke Schale ist äufserlich hellgelb, diese Schale schliefst angefüllte Behältnisse uneben, iunerlich aber weils, schwaunnicht und gescbian. Dachtzehn ein saures, aus vielen kleinen Saftbläschen bestehendes, gemeiniglich in ueun Facher getheiltes und achtzehn weifse eyförmige, bitterschmeckeude Samen enchaltendes Fleisch in sich. Die dünnschaligeu, von Mensina koninenden, den Vorzug.

Pulpa Cassiae. Cassienmus.

(Cas ia Fis tula) enthaltenen schwarzen Markc durch Einweichen in warmen Wasser, nachherigem Durchreiben durch ein Haarsieb und Verdunstring in gelinde Wärme bis zur Honigdicke nuit Zusatz etwas weifsen Zuckers bereitet. Es mufs einen angeuehm gcwürzbaft süfslichen $\mathrm{Ge-}$ schmack, eine schwarzbraune Farbe und schmack, eine schwarzbraune Farbe und eive eigenthïmliche zäbe Consistenz haben. Gerpach und Geschmack dürfen we-
der brenzlich, noch säuerlich oder schaal seyn.

Pulpa Prunorum.

Pllaumenmus.

Das aus den frischen reifen Pflaumen, nacbder die Steine herausgenommeu, die
Pflaumen selbst in ibrem eigenen Safte Pflaumen selbst in ibrem eigenen Safte
iiber gelindem Feuer unter, beständigem iiber gelindem Feuer unter bestandigem
Umrüuren zu einer breyartigen Masse geUochturen zu einer breyartigen Masse ge

kocht und durcb ein Hadrsieb gerieben
sind, mit Zusatz von zwey Unzen Zucker sind, mit Zusatz von zwey Unzen Zucker
auf jedes Pfund, erbaltene Mus, welches eine bräunliche Farbe und einen süfssäuerlichen Geschmack bat. Es darf' wede brenzlich riectien noch schmecken.

Pulpa Tamarin- Wird aus dem, mit genugsamen Wasser dortum.

Tamarindenmus.

weichgeliochten rolien Tamarindenmarke ( $T$ a m a r ind $i)$, nach gebörigem Durchreiben durch ein Haarsieb und Abrauchen der hreyarigen Flüssigkeit über gelindem Fener und unter beständigem Unrïhren, bis zur Honizsdicke, exlialten. Zu jedem einzclnen Pfunde des Muses werden dann noch zwey Unzen gepülverter weifser $\mathrm{Zu}$ noch zwey ckethan. Zin gutes ächt bereitetes $T a-$ marindenmus hat eine braunscliärrzliche Farbe, eincn weinartigen Gerucb, einen angenehmen sauren Geschmack und giebt mit kochendem Wasser eine rothbraune Auflösung. Ls mufs eiue gleichförmige chen noch scbmecken.

Pulveres,

Pulver.
Wird aus dem in den Cassienröhren

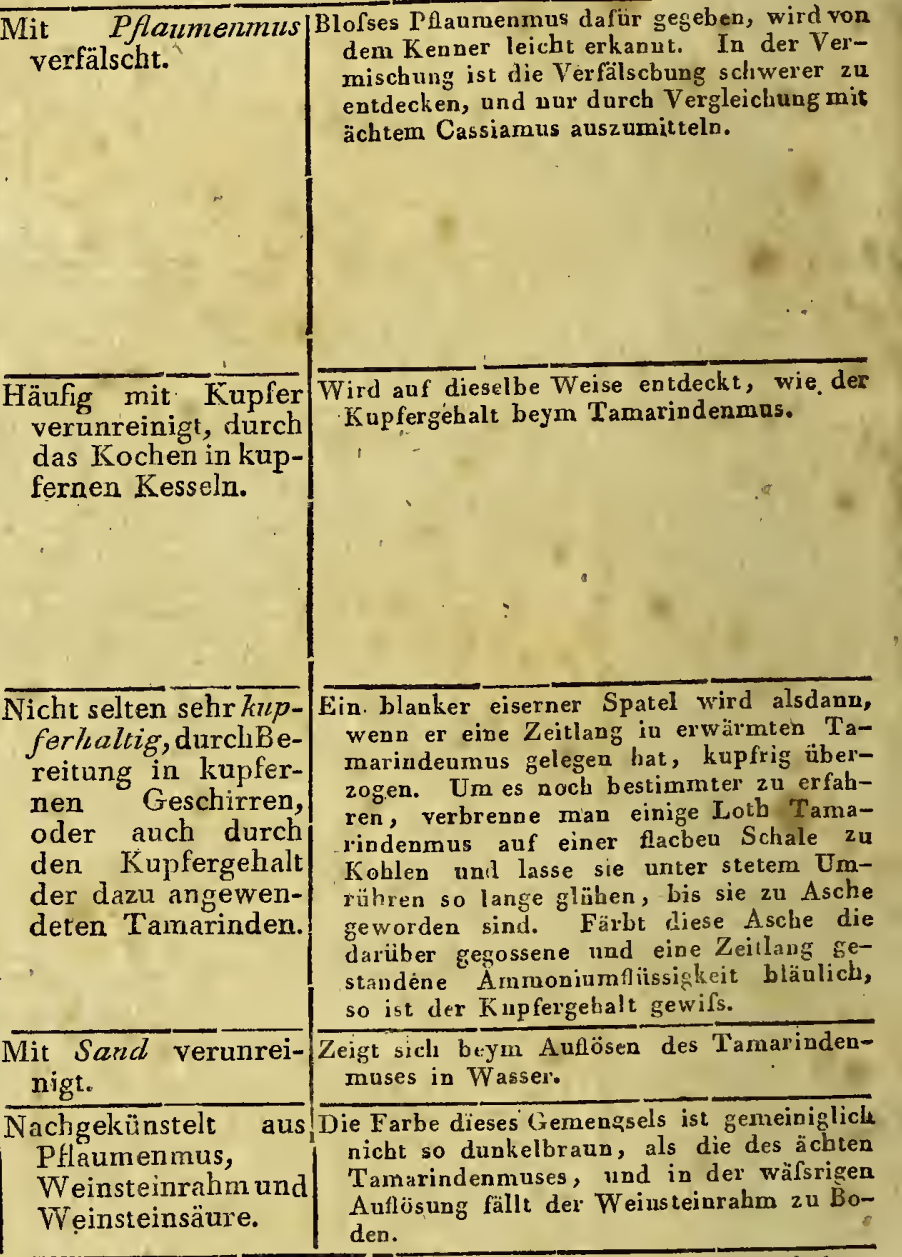
Weinsteinsäure.

ofses Pflaumenmus dafür geseben, wird von dem Kenner leicht erkanut. In der Vermischung ist die Verfálscbung schiwerer zu entdecken, und uur durch Vergleich - Eiufacbe Pulver (Pulveres simplices.) Sie mïssen den möglichsten Grad der Feinbeit baben, zwischen den Fingern unifülıbar seyn, weder zwischen den Zähneu knirschen, noch auf der Znnge oder anch durch ein Handmicroscop betrachtet etwas körnichtes, vor allen Dingen auch nicht etwa vom Mörser abgestofsene Metalltheile, in ihnen spüren, und mit Wasser vermischt, nicbts erdiges oder sandiges fallen lassen. Sie müsscn ferner den näınlichen Geschmack un'l Geruch der Muttersubstanz, so wie dieselben Eigenschaften und Kräfte bcsitzen. Auch miissen sie an eincm trocknen Orte in fest verbundesen Gläsern auf-
bewahrt, und dadurch vor dem Zutritt der Luft und Feuchtigkeit wohl in Acht genommen werden,' weil sie sonst nicht allein zusammenbacken und einen mulstrigen, widrigen Geruch aunehmen, sondern auch ihre

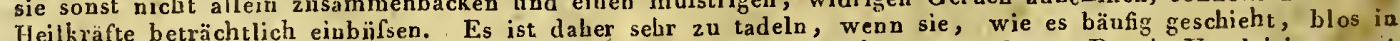
Hapiernen Beuteln, oder iu schlecht verwabrten Schachteln aufgehoben werden. Durch Versleichung mit papiernen Beuteln, oder iu schlecht verwahrten Schachteln aufgehoben werdello wohlbereiteten, friscis bereiteten Pulvern von achter Beschaffenteit lisst sich wohl am besten die Gür Rückselben und die etwa vorgenommene Vermischung mit gepulverten schlechtern Droguen, ojer gar den Rübuf, ständen ron ausgekochten kraftlosen Substanzen entdecken.

sondern immer auf den Apotheken selbst bereitet werdeu. II. Zusammengesetzte $P$ u 1 ver (Pulveres compositi.) Bey diesen bat man roring aunischt sind. Sie dürfen nicht körnig seyn, keiue zusammengebackene, unzertheilte Klumpen entbalten, und das Ange nnfs keine ungleichartigen Theile darin unterscheiden können. Aufserdem müssen sie nacì Massabe der untereinander gemischten einzelner Bestaudtheile, den ihnen eigenthìmlichen Geschnack und Geruch besitzen, und wie die vorigen an einem trocknen Orte und in wohlverbundenen Gläsern aufbewahrt werdcn.

l’ulvis alterans Eilinburg s. Plumeri. Bestelt aus gleichen Thcilen versüstem Quecksilber und pommeranzenfarbenem Spiefsolanschwefel. Es ist hierbey zu bemerken, dafs dieses I'ulver durch Aufbewahren nicht nur in'seiner äufsern'Beschaffenhcit sonderu auch in seinen Mischungstheilen, die sich gegenseitig 


\begin{tabular}{|c|c|c|c|c|}
\hline $\begin{array}{c}\text { Namen } \\
\text { der Arzneymittel. }\end{array}$ & $\begin{array}{c}\text { Sinnliche Eigenfchaften derfelben } \\
\text { Merkmale. ihrer Aechtheit und } \\
\text { Giite. }\end{array}$ & $\left|\begin{array}{cc}\text { Fehlerhafte } & \text { Be- } \\
\text { schaffenheit, } & \text { Ver- } \\
\text { wechfelung } & \text { oder } \\
\text { Verfälfchung. }\end{array}\right|$ & Kennzeichen & $\begin{array}{l}\text { Deren } \\
\text { und Priifungsmittel. }\end{array}$ \\
\hline
\end{tabular}

Pulveres. - $\quad$ zerlegen und neue Verbinduggen eingehen, wodurch das Mittel selır drastische Wirkungen erhält, verän. dert werde, weshalh cs jedesmal, weun es verschrieben wird, frisch bereitet werden mufs.

Pulvis antispasmodicus. Dieses an vielen Orten noch sehr gcbräuchliche Pulver besteht bekanntlich aus schwefelsaurem Kali, Salpeter und etwas Zinnober, und hat daher eine angeuehme rothe Farbe. State des Zinnobers substituirte cinst in Errnangelung desselben ein gewisser Apotbeker die rothe Mennige, welcher'schreckliche Betrug, wenn er ja einmal wieder vorkommen sollte, nach den beym Zinnober angegebenen l'rüfungsmittelı zu entdocken seyn würde.

Uebrigens werdeñ von zusamnengesetzten Pulvern hie und da noch eime grofse Menge, mehr oder minder gebräuchliche, anfbewahrt. Die Preufsische Pharmacopoc hat folgende: Pulvis aromnticus; dencifricius; grtmmosus s. Species Diatragacanthae; ipecacuanhue compositus s. Pulvis Doweri ; liquiritíae compositus s. pectoralis; opiatus; rhei compositus; sternutatorius; stitialus s. resolvens; temperans.

Radix Agavae.

Die erst in nenern Zeiten oflizinell gewordene Wurzel der in Sádaneriea einheimischen, auch in den südlıcben Provinzen von Spanien und Italien wachsenden und bey uns. zuwcilen in Gewäcbṣhäusern vorkommenden

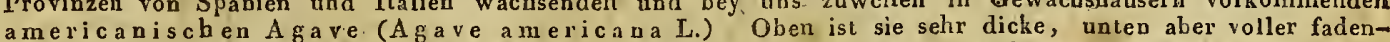
förmiger, sebr langer, mit zwey Rinden úberzozener Wurzelfasern, deren aufsere Rinde häutig, sehr zart, von graulichter Farbe, die innere dick, fast violett, von nicht unangenehmen Geruche ist.

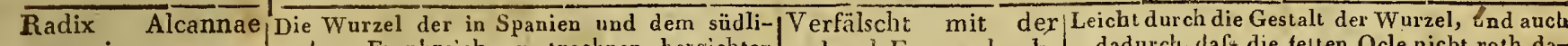
spuriae. chen Frankreich an trocknen bergichter
Oertern wachsenden färbenden OchOertern Wachsenden färbendeu Ochsenzugge (Anchusa tinctoria $L$ i)
Eine walzenförmige, nach noten etwas zuEine walıenförmige, nach mnten etwas 20 -
gespitzte, lange und et was faserichte Wurzel, von der Dicke eines Gánsekiels bis zu der eines Fingers. Ihre äufsere Rinde is dunkelroth; die innere Substanz weifslich der Geschmack etwas süfslich, nachher bitterlich. Man bedient sich ihrer in den Apotheken, um einigen, besonders ölichten und feutigen Präyaraten eine rothe Farbe zu geben. Ihr rotber Farbestof Farbe zu geben. Thr
steckt blos in der Rinde. durch Fernambuck- dadurch, tlafs die tetten Ocle nicbt roth dadecoct roth gefärb-1 von gefürbt werdeu, zu erkennen.

ten Wurzel der ge-

meinen Ochsen-

zunge (Anchusa

officinalis $L$.)

A n u e rk. Die Wurzel der in den Morgenländern wachsenden A cannalawsouse ( $L$ a wsouia inermis $L$.), welche sonst auch unter dem Namen Radix Alcannae verae gebräuchlielì war, enthält ebenfalls einen durcb Ocle und Weingeist zu extrahirenden rothen Färbestoff, kann aber sehi gut entbehrt werden.

Die Zwiebeln des bekannten Knoblauchs (Allium sativum L.), welche aus mehrern kleinen büschelförmig -zusammensitzenden Zwiebelchen oder Zehen bestehen, die mit einer aus dem Weifsen ius Dunkelrothe schillernden Hant umgeben und unterwärts mit dünuen Fasern besetzt sind. Die kleivern $Z$ wiebelchen sind länglich, gektrümmt, scharf zugespitzt,' auf der einen Seite flach, auf der andern bauchicht, übrigens fest, weifsfleischicht, saftig und jede mit einer eigenen Haut überzogen. Sie haben einen scbarfen, süfslichtest Geschmack und einen eigenen, durch!ringend starken, unangenebmen und flüchtigen Geruch. Man wendet sie nur frisch au und hebt sie im Keller nnter feuchtem Sande auf.

Radix Altheae. Altheewurzel. Eibischwurzel.

Radix Angelicae Angelikwurzel

Radix Ari. Aronswurzel.

RadixAristolochiae vulgaris.

Gemeine Osterlu-

zeywrurzel.

Die Wurzel der Eibiscbalthee (Althaea officinalis L.) Eine ausdauernde Wurzel, deren bald kürzere, bald längere Hauptwurzel sich in ziemlicb lagnge Aeste von der. Dicke eiuer Schreihfeder oder eines. Fingers verbreitet, äufserlich mit einer aschfarbnen oder graugelben Haut umgeben, inverlich aber weifs ist. Zum Arzneygebrauch befreyet man sie von der äufsern Haut, so dafs sie inwendig und auswendig weifs ist, und um desto besser ist, je weifser sie ist. Getrocknet ist sie ziemlich zäte und faserig. Sie hat keinen Geruch', enthält aler eine Menge Schleim und besitzt einen siifslichen, schleimichten Geschmack.

Die zweyjährige Wurzel der in verschiede-1Verwechseltoderver-1Diese Wurzel ist weit unwirksamer und uen Gegenden von Deutschland wachsen- fälscht mit der Wur- schwächer von Geruch und Geschmack uen Gegenden von Deutschland wachsenden Erzengelwurz (Angelica Ar-

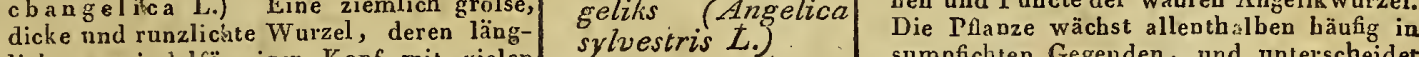
$\begin{aligned} & \text { dicke nnd runzlicate Wurzel, deren lâg- } \\ & \text { licher, spindelförmiger Kopf mit vielen }\end{aligned} \mid \begin{aligned} & \text { sylvestris L.). } \\ & \text { sumpfichten Gegenden, und unterscheidet }\end{aligned}$ \begin{tabular}{l|l} 
licher, spindelförmiger Kopf mit vielen & sich, von der Gartenangelik dadurch, dafs \\
langen Aestea und federkieldicken Fasern!
\end{tabular}

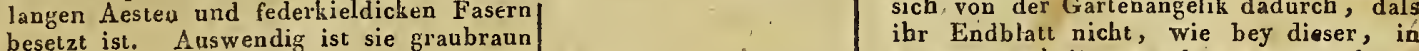
besetzt ist. Auswendig ist sie graubraun
Onder gelbröthlich, inwendis aber weifs $|\cdot| \begin{aligned} & \text { ihr Endblatt nicht, wie bey dieser, in } \\ & \text { Lappen zertheit, sonderu ganz und wie }\end{aligned}$ oder gelbröthlich, inwendig aber weifs und der Länge nach aufgeschnitten, zeigt sie kleine gelbe Rinuen oder gummiharzige Puucte und Flecken, worin vorzüglieh das ätherische Oel, welches sie liefert, enthalten ist. Sie besitzt einen angenehmen, starken, gewürzhaften Geruch, und einen erst süfslichen, dann beifsend erwärmenden, hintennach etwas bitterlichen Geschmack. Zum Arzneygebrauch tangt sie nur, so lange sie noch zaho, geruchvol und mit deu angefübrten Rinnen und Flecken versehen ist. Am kraftvollsten wird sie zu Anfang des Winters oder zeitig im Frühjahr gesammlet. Da sie leicht schimmlicht und wurmstichig wird, so mufs sie an einem trocknen Orte wohl verwabr Lappen zertheilt, sonderu ganz und wie die andern gestaltet, nar etwas gröser ist
die Blumen siad nicht gelb, sondern gemeiniglich purpurfarbig.

A n merk. Díe an kleinen Bäcben auf den Pyrenäen und Alpen gewachsene Wurzel ist weit kräftiger, als die bey uns an den Ufern der Flüsse und Gräben yorkursmeude, oder in Gärten gezogene. 'Wurzel. werden.

ie Wurzel des F leckenarons (Arum maculatım L.) Eine knollige, länglich-eyrunde, unterwärts etwas faserichte, mehlig-fleischige, von aufsen bräunlicb-gelbliche, inwendig weifse Wurzel, von der Dicke eines Fingers bis zu der eines Taubeneyes. So lange sie frisch ist, hal sie einen äufserst scharfen, dem spanischen Pfeffer äbnlichen, brennenden Geschmack, reitzı beym Quetschen die Augen und die Nase heftig, und erregt auf der Haut Röthe und Blasen. Durchs Trocknen verliert sie beynahe alle Scbärfe und zeigt sich blos meblig. Sie mnfs entweder im Anfange des Frühjahrs, ehe sie Blätter treibt, oder im Spätherbst, wenn die Blätter verwelkt sind, ausgegraben werden. Man befreyet sie von dej äufsern Haut und verwirf die alten welken Wur

ie Wurzel dergemeinen Osterlucey (Aristolochia Clematitis L.) Eine lange bin und ber gebogene, ohngefähr eines kleinen Fingers dicke, mit schuppicht kcimartigen Ansätzen und dünnen Zaseru besetzle, auf dem Queerdurchschnitt gelb anlaufende Wurzel, die ausweudig eine gelbbraune oder bräunliche, inwendig weifslich-gelbe Farbe bat. Sie besitzt einen etwas zusammenziehend bitterlicben Geschrack und einen starken, einigermafsen campberartigen Gerucb. 


\begin{tabular}{|c|c|c|c|}
\hline $\begin{array}{c}\text { Namen } \\
\text { der Arzneymittel. }\end{array}$ & $\begin{array}{c}\text { Sinnliche Eigenfchaften derfelben; } \\
\text { Merkmale ihrer Ächtheit und } \\
\text { Güte. }\end{array}$ & $\left|\begin{array}{cc}\text { Fehlerhafie } & \text { Be- } \\
\text { chaffenheit, } & \text { Var- } \\
\text { wechfelung oder } \\
\text { Verfälfchung. }\end{array}\right|$ & $\begin{array}{c}\text { Deren } \\
\text { Kennzeichen und Prüfungsmittel }\end{array}$ \\
\hline
\end{tabular}

Anmerkung. Nach Herrn Dörffurt (Apoheherb. Th. 1. S. $7 \overrightarrow{6} 6$ ) verdient diese Wuzeh var der iu den Apotheken gebräuchlichen Wurzel der langen Osierlucey (Aristolochia longa L.) als einbeimisches Mittel, da sie dieselben Kräfte besitzt, und jene gewöhnlich alt und verleggen vorkommt, den Vorzug.

Radix Aristolo- Die [Wurzel der in südlichen Enropa wachcliiae rotundae.

Runde Osterluzeywirzel. senden runden Osterlucey (Aristo-
lochia rolunda L.) Eive knollige, ruudlicbe, schwere, dicke, etwas runzlicbte Wurzel, die auswendig grau oder bräunlicb, inwendig weifsgelblich anssieht. Frisch hat sie einen scharfhitterlichen, gewürzbaften. Gescbmack und einen starken widrigen Geruch. Getrocknet scbmeckt sie blos exkelbaft und libr Geruch ist kaum merklich. In den A potbeken'trifft man sie meistentbeils als alte und vcrlegene Waare tatt ihrer wird zu-Die Wurzeln dieser Pflanze heifsen anch weilen die Wurzel wobl Radices Aristolochiac fabades grofsen Erd- $\begin{aligned} & \text { ce a s. ca va e. Kleine, harle, unförm- } \\ & \text { liche, ungleich'abgerundete, mit wenigen }\end{aligned}$ rauclis (Fumaria liche, ungleich abgerundete, mit wenigen bulbosa L.) einge- $\begin{aligned} & \text { feineu Fasern besetzle Knollen, die in der } \\ & \text { Erde klumpenweise bey einander liegen, }\end{aligned}$ sammlet. Erde klumpenweise bey einander liegen, mit einer graubräunlichen' Haut bedeckt
sind, ein meblig-saftiges Fleisch und gemeiniglich nach unten eine Höblung $h$ aben. Sie besitzen einen durcbdringendeu scharf bittern Geschmack und scliwachen balsamischen, widrigen, fast betänbenden Geruch. Beym Trocknen nehmeu sie innerhalb durch und durch eine gelbgrüne Farbe an, die sie auch beym Pulvern behalbe an sammlet sie im Anfange des Jnnius, sobald die Bläller verwelkt sind.

Radix Armoraciae s. Raphani rusticani.

Meerrettich.

Radix Arnicae. Wohlverleihwurzel.

Radix Asari. Haselwurzel.

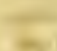

Die sehy dicke, ästige, aufserbalb bräuuliclie, in wendig weifse und saftvolle, sehr beifsend schmeckende und zerrieben, die Augen und Nase heftig reitzende Wurzel. Zum Arineygebranche dient sie nur im frischen Zulstande, da sie durchs Trockuen alle Kräfte verliert. Sie muls daber frisch unter Sand gelegt, im Keller anfhewabrt werden.

Die Wurge des leih (Arnica montana L.) Eine äufserlich gestreifte, schwarzbraune, rauhe innerlich schmutzigweifse, ungefähr eines Gänsekiels dicke Wurzel, die wcnig getheilt, ungleich, und ineistens nur anf einer Seite mit vielen langen und starken Fasern besetzt ist. Sie hat einen bitterlich scher flantälo gelich scharfen, Alantatshichen, etwas gethümlicbeu, starken, beym Zerstofsen befliges Nieseu erregenden Greruch.

Die Wurzel des Haselkrants (Asarum europaeum L..) Eine kleine, dünne, kriechende, gegliederte, gekrümmlc, seb faserichte Wurzel, äufserlicb von graubrauner, inwendig von schmutzig - weifser Farbe. Sie hat eiuen scharf biltern, eckelhaften, erhitzenden Geschinack nnd einen dem Baldrian etwas älınlichen, einigermafsen gewürzbaften Geruch. Durch das Trocknen werden der Geruch und Geschuack teträchtlich vermindert, und bey langem Liegen gehen beyde fast gänzlicb verloren, daher sie um desto unkräftige ist, Nach einigen Scbriftstellern sollon nur dic Zasern der Wurzeln eingesammlet werden.

\begin{abstract}
Wurzel des Rulhr- licls, schmeckt schleimicht-bitterlich und Thents (Thale reitzenden Gealants (Inula $d y-$ ruch der wahrea Arnicawurzel.

Ser liasst sich, ob sie gleich dern Anseben uud Wurzel des Mörz der Wirkung nacb eine Aehnlichkeit damit veilchens (Viola haben soll, durcb ibre gelblichgrüne Farbe odorata L.)
\end{abstract}

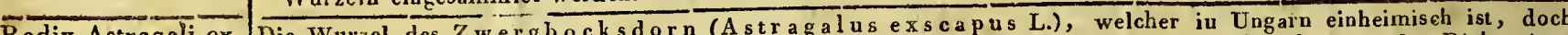
Radix Astragali exscapi.

Schaftlose Tragantwurzel.

Radix Bardanae s. Lappae majoris.

Elettenwurzel.
Radix Belladon. nae.

Belladonnawurzel.

Radix Bistortae. Natterwurzel.|

Wurzel des Zwergbocksdorn (Astragalus exscapus L.), welcher in eine auch in einigen Gegendeu von Tentschland angetroften wird. Dia Wurzel ist einfach, vou bis zwey Spanuen Federspule bis zu der enes kleinen Fie enthali unter einer getrocknet runalichten braunen Oberbaut lang und seitwärts in Faserı auslaufend, Sie enen gelhlichten, holzichten Kern in der Mitte. Sie besitzt einc weifse poröse Rinde, unt unter keinen Geruch, aber einen bin Süfsholz mitten inne stehenden Geschmack.

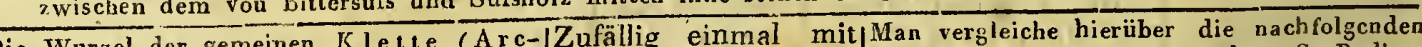

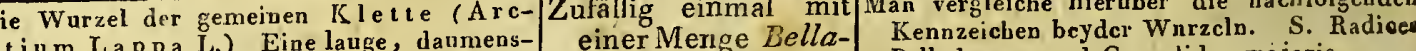

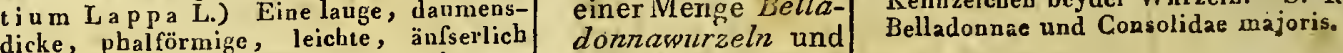
dicke, phalförmige, leichte, ansserlich donnawitzeln und

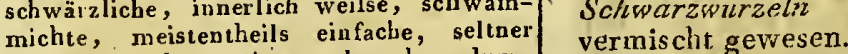
ästige Wurzel, von einem schwachen, dum- Salzburger medic. pfig widerlichen Geruch und einem scharf süfslich-bitterlichen Geschmack. Sie muls Nro. IOo, in der im Spätherbst oder im Frühjahr, che die Pflanze Stengel treibt, eingesammlet werden. Die holzjchten Wurzeln sind zu verBeylage.) werfen.

iemlich lange, bolzige, gekniete, runde Wurzel dcr Belladonna (Atropa Belladonna Lu) Sie is einen oder inehrere Zoll dick, theilt sich in verschiedene glatte, bin unt wieder befaserte Aaftig, besitzt Iserlich grau oder braungelb, znweilcn rötblichbraun, inwendig aber weifslich, weich und safté, besick. einen widrigcn betäubcnden Geruch und einen eckelbaft süfslichen, etwas zummenziehenden von wildMan sammlet sie am besten im Frühjahre von der zwey- bis dreyjährigen Pfanze, und lieber von wildwachsenden als in Gärten gexogenen Pflanzen. Sie mufs, um Verw

getrocknet, und sehr vorsichtig anfbewahrt und gepulvert werden.

Die Wurzel des Natterwurzknöterig (Polygonum Bistorta L.) Eine elwas znsammengedruecte, gebogene, fingersdicke, mil ringförmigen linzeln versebene und vielen Fasen belo Wurzel, yon eiuem kaum braunc, innerlich rüthliche oder fleiscbfarbene, mil der Zeit orangegelb anlaufende Wurz̨el, vo znerklicken Geruch. abor sebr kerben adstriugirenden Gesclumask. 


\section{Radix Brittannicae. -- Radix Chelidonii majoris.}

\begin{tabular}{|c|c|c|c|}
\hline $\begin{array}{l}\text { Namen } \\
\text { ler Arzneymittel. }\end{array}$ & $\begin{array}{c}\text { Sinnliche Eigenfchaften derfelben; } \\
\text { Merkmale ihrer Aechtheit und } \\
\text { Giite. }\end{array}$ & $\left|\begin{array}{c}\text { Fehlerhafte } \text { Be- } \\
\text { ccluaffenheit, Ver- } \\
\text { wech felung oder } \\
\text { Verfälfchung. }\end{array}\right|$ & $\begin{array}{c}\text { Deren } \\
\text { Kennzeichen und Priffungsmittel. }\end{array}$ \\
\hline
\end{tabular}

liadix Brittannicae s. Hydrola pathi.

asserampferwurzel.

Radix Bryoniae. Zaunrübenwurzel.

RadixCalamiaro misici. Kalmuswurzel.

ricis are:narice s. Sarsaparillae germanicae.

Sandriedgraswurzel.

Deutsche Sassaparille.

Radix Carlinees Cardopatiae. Eberwurzel.

Radix Caryopluyllatae.

Nelkenwurzel.

Benedictenwurzel.a

Radix Cassamuniar.

Blockzittwer.

Radix Chelidoni majoris.

Grofse Schöllkrantwurzel.

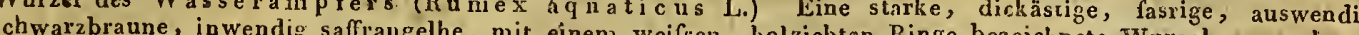
schwarzbraune, inwendig saffrangelhe, mit einen weifsen, holzichten Ringe bezeichncte Wruzel, von schwachem, möhrenartionen Geruch und herb zusammenzielacud bitterlichen Geschmack.

Die Wurzel der weifsen $\mathrm{Z}$ a u $\mathrm{r}$ übe (Bryonia alba L.) Eine sehr langc und grofse, spindelförmige, of iiber Armsdicke, an ibrer Spize stumpfe und in Aeste getheilte Wurzel. Aeufserlich ist sie graugelb und mit ringförmigen, etwas erhabenen Streifen verseben, inwendig aber weifs. Im frischen Zilstaude ist sie Ileischig, milschsaftig, zeigt in Queerscheiben zerschnitten, wechselsweise liegende Ringe und Strahlen, ha einen eckelhaften, scharf bittern, etwas zusammcnziehenden Geschmack und äufserst widrigen Geruch. trocknet ist sie schwammicht, mehlig, blafsgelb, von sehr schwachem Geruch und milerm Geschmack. Gesammlet sie im Herbste, schneidet sie in Scheiben, un trocket diere neni luftigen Orte. Von Würmern wird werden mufs. Nicht getrocknet, läfst sie sich im Keller unter feuchtcm Sande eine ziemliche Zeit aufbeabren.

Wurzel des gemeinen Kalmus/Verwechselt mit der/Sie hat eine rothbraune Farbe, ist geruchlos (Acorus Cal am us L.) Sie ist fingers- Wurzel der WVasdick, lang, etwas platt zusammengedrïckt, mit schief übereinander liegenden schei-
denartigen und ringförmigen Absätzen ver-

sehen und dadurch scheinbar gegliedert. L.). Im frish dor scheinbar gegliedert. Im frischen Zustande ist sie äufserlich braungrunlich, glänzend, an verschiedenen Stellen, besonders unterwärts, mit vielen kleinen Faser'n und vielen runden, zellenartigen Puncten besetzt; inwendig ist sie weifs, weich und einigermafsen schwammicht. Zurn Arznègebrauch wird sie im Anfange des Frühlings oder im Spätherbst gesammlet, geschält, zerschnitten und schnell getrocknet, weil sie sonst in der Luft bald lichtrotb aulänft. Itr Geschmack ist aromatisch bitter; der Geruch balsamisch.

ie Wurzel der in sallichtem Boden wachsenden $S$ andsegge (Carex are $n$ aria I.) Eine in der Erde horizontal fortkriechende, eiues dünnen Federkiels dicke, sehr lange, runde, allenthalben gleich starke, etwas holzige, zähe, gegliederte, an den Gelenken mit braunen Scbeiden oder bäutigen Fortsätzen versehelle und nur an den Knoten derselben faserichte, an den Gliedern selbst aber glatte, answendig braunröthliche, inwendig weifse und meblige Wurzel. Frisch bat sie einen barzigbitterlicben, mehligen Geschmack, und einen balsamischen, terpentinähnlichen $\mathrm{Ge}-$ ruch. Man samnilet sie am besten im Frübjahr; je tiefer sie in der Erde liest, um desto kräftigel ist sie.

terich damit zu verwechseln ist.

Verwechselt mit der Die Blätter und Stengel sind überall mit fei rauhen Serge (Carex lirta $L$ ) Pflanze ein bifichtes Ansehen bekomm Die ganz geruch - und geschack Die ganz geruch und gescbrack zel treibi nicht blos an den Griederknoten, sondern auch an den Gliedern selbst Fa sern nind Halme; auch lâst sich die Wurzel leichter spalten, als die Sandriedgraswurzel.

Mit der vielährigen Mau erkennt sie an dem höher'n, wohl zwey Segge (Carex spi- Fuls und darüher hohen Stengel und de cata L.) grofsen Aehre, die zuweılen aus dreifsig Aehrchen besteht. Die Wurzel ist dijnner lind die Glieder sind kürzer.

Mit der zweytheiligen Wächsı niemals im Sande, sonder.n auf feuch Segge (Carex di- ten Wiesen. Die Wurzel ist viel schwäSegge (Carex di-
sticha L.)

Die Wurzel der in den böbern Gegenden Deutschlands auf sonnichten Hiiceln und Bergen wachenden $Z$ wer eberwurz (Carlina acalis L.) Eine nacb oben zu ästige, runclichte, daumensdicke, gegen anderthalb Spannen lange, faserige, auf der Obertäche gleichsam wie von Würnern angefressene, auswendig braungelbe, innerhalb hell-oder weifsgelbe Wurzel ron einem scharfeu, bittern Geschmack und unangenehmen «rewürzháften Geruch.

Die Wurzel des Nelkengar affes (Geum/Verwechselt mit den/Die Wurzeln sind viel länger, brauner ge urbanum L.) Eine äufserlich braune, Wurzeln des Was- färbt, und besit/en nicht den gewürzhaften inwendig rötblicbweifse Wữzel, an deren sergaraffes (Geum Geruch der ächten Nelkenwurzel.

federkieldicken Hauptwarzel viele lang spindelförmige Fascrn sitzen. Frisch hat sie einen balsarnischen, gewürznelkenartigen Geruch und einen ähnlicben, bitterlichberhen Geschmack. Am besten gräht man sie im April und May aus, sobald ihre Blätter sich eben entwickeln, und wäblt zunz Arzneygebrauch die Wurzeln von trocknen, bergichten Standörtern, weil die von fenchten, sumpfichten Oertern weniger wirk sicliti: getrocknet und gut aufbewahrt werden.

Wir erhalten diese Wnrzel, welche nach Herrn Will de now waluscheinlich yon einer in Ostindien wachsen den Scitaminie (A momum Z erumbet L.) berrïhrt, in Scheiben zerschnitten, die von der Dicke eine Fingers, zuweilen auch noch rohl dicker und knollig sind. Aeufserlich sind sie geringelt, schwammicht und gelbran i der innere Thil der Wurzel ist me Wurzel hat einen specifiken starken Geruch und eiuen etwas scharfen, bitter gewürzbaften, dem Ingwer ähnlichen Geschmack.

Die Wurzel des grofsen Schöllkrauts (Chelidonium majus L.) . Sine ästige, daumensdicke, langzasrige, frisch brauuröthliche, inwendis wifse, Vurzel, von brennend scharf-bitterm Geschmack und unangenehmen Geruch, die aber beyde unter dem Trocknen meistens vergehen. 
Radix Chinae ponderosae. - Radix Consolidae majoris.

\begin{tabular}{c|c|c} 
Namen & $\begin{array}{c}\text { Sinnliche Eigenfchaften derfelben } ; \\
\text { Merkmale ilırer Aechtheit und } \\
\text { Güte. }\end{array}$ & $\begin{array}{c}\text { Fehlerhafic Be- } \\
\text { chaffenheit, Ver- } \\
\text { wechfelung oder } \\
\text { Verfälfchung. }\end{array}$ \\
\hline
\end{tabular}

RadixClinae pontalis.

Chinawurzel.

ockenwurzel.

Radix Cichorei.

Cichorienwurzel.

Radix Colchici.

Zeitlosenwurzel.

Radix Columbo. Columbowurzel.

Kadix Consolidae majoris.

Schwarzwurzel.

Beinwellywarzel,
Reiche häufig wachsenden $\mathrm{Chinasm}$ il ax (Smilax China L.) Eine knotige, länglich rundliche, ziennlich grolse, etwas gedrückte und gebogene, holzige, dichre und schwere Wurzel, die äufserlich mit einer braunröthlichen Rinde bedeckt ist, inwendig ein weifsröthliches Mark euthält, einen faden schleimicht - süfslicben und mebligen Geschmack, aber keinen Geruch besitzt. Eine andere im Handel vorkommende Sorte, die occidentaliscbel Pockenwurzel (Radix Chinae occidentalis s. americanae) unterscbeidet sich von der erstern dadurch, dafs se sie anfserch von der ert

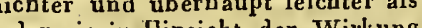
jene ist, der sie in Hinsid
auch nacbgesetzt wird. enthält.

Dirse Wurzel, desen Mutterpflanze bis jetzt Verdorberi.

noch unbekannt ist, erbalten wir aus Ceylon, theils in runden Queerscbeiben von einem balben bis drey Zoll breit und dick, und einer selir ungleichen rauhen Oberfäche. An den Seiten baben sie eine äufserlich grünlich- oder graubraune, innerhalb blafsyelbliche Rinde, the cine bis zwey Linien dick ist. Auf diese folgt ein festerer, holzichter Rino, der das innere, fester weichere, zusammengeschrumpfte, gelbgrüne und mehlige Mark einschliefst.
Diese verschiedenen Theile sind sichtlich, wenn man die äufsere Oberfiäche der Scheiben wegschneidet, durch schwärzliche Linien abgesondert. Selıner bekonmt man diese Wurzeln in der Länge uach zerschnittenen, nicht allzustarken mnd mit cken, die von nicht so alten Wurzeln zu seyn werden, als die Scheiben, wie sie denn auch einen mehr bittern und gewürzhafauch einen meschmack besitien, als die Scheiten Geschinack dickern Stückeu findet man beu. Bey den dickern Stückeu findet man immer, dals sie mit Löchern versehen sind, die-znan des bessern Trocknens wegen darin gebohrt hát. Die Wur él bat übrigeas einen gewürzhaften, dem Mktterkümmel etwas äbnlichen Geruch, und einen staken, anhaltend aromatisclicn bitter'n Geschmack, der vorzüglich in der Rinde bemerklich ist, dagegen der innere markige Tbeil gelinder und mebr schleimicht schmeckt. Dem Wurmfrafs ist diese Wurzel selır unterworfeu; auch verliert in freyer Luft bald ihren Geruch liert sie in freyer Luft bald sie etwas zerund ihre Krafte, weshalb sie verschlosschnitten, am besten in genau vahrt, und senen gläsernen Behallcrn aufbewahrt, und von dem Pulver derselben, welcles leicht die Feuchtigkeit der Lnft anzieht und verdirbt, nicbt $\mathrm{zu}$ viel in Vorratb gehalten werden mufs.
Werselben die Wurzel vom bittern Costils (Costzis amartus.) att derselben die Wurźeln der Zaunnrïbe (Bryonia alba) mit einem Auszuge von ächten getränkt - und gefärbt. (Journal d Pharmacie, B. 2 Columbowurzeln St. I. S. 255.)
Deren

Kennzeichen und Prïfungsmittel.

Beyde Wurzeln sind sehr oft warmstichig und vcraltet. Die Wurinlöcher sind oft betrügerischerweise mit bolus angefüll $t$, $\mathrm{ja}$, wieLiuige versicheru wollen, soll mau sich zur Ausfüllueng derselben der Bleyglätte bedienen. Diese Betrügereyen wären indessen durch eine sorgagltige Untersuchung bald 24 entdecken.

Die gerade in die Erde gehende Wurzel der Cichorienwegwarc (Cicboreum Intybus L.) Eine chngefähr daun gelbe, den Gärtcn gezosenen den Vorzug, da die letztere weniger bitter scbmeckt und einen mehr wälsrigeu Saft

Dio Wurel der Herbstzeitlose (Colchicumautumale L.). Eine fleischigsaftige, daumensdicke Zwiebel, die inwendig weifs, aufserhalb gelblich und mit einer besondern doppelten, äufserlich lederartigen, branen, innerlicb dưnnen, blassen, glänzenden Haut umgeben ist. Ihr Geschrnack ist mellig, scharf bitterlicb; der Geruch widerlich. Man sammlet sie im Anfange des Sommers ein, luat wendet sie blos frisch terlicb; der Geruch widerlich. Man sarnmlet sie im an manehen Orten gebräuchlich sind. Gewöhnlich zur Bereitung des Zeitlosenessigs und Honigs an, die an rnanehen Orten Z findet man an einem Schafte 2 wey Zwiebeln, von denen die alte welke neue saftige zum Arzneygebraucb ausgewählt wird, die um so wirksamer ist, je saftiger und schar ischme-
ckender sie ist.

Da die Columbowurzel dem Wurmfrafs so leicht uuterworfen ist und man zuweilen sogar Wurzeln erbält, die von Wärrnern ganz durcbwülllt sind, die dadurch bewirkte Zerstörung aber sorgfältig durch eineu gelbgefärbteu Teir von schleimichter Substanzen zugekleistert zu werden plegt, so hat man bey ihrem Einkauf hierauf genau zu seben.

Verräth sich durch ihren Nachuesch unack, welcher dem Geschmack der Violeuwurzel âbnelt, so wie üborbaupt durch die abweichende Beschaffenheit derselben.

urch genaue Vergleichung mit ächter Columbowurzel wobl ziemlich leicht zu entdecken.

Die Wurzel des officinellen Beinwells (Sympytum officinale L.) Eine ziemlich lange, in starke Acste gethe Acste getbeilte, äufserlich schwarze oder dunkelangäu, von wäfsricht-schleimichten Gescbznacke, aber glatt abbricht, auf dem Bruche schmutzig braun and ine Zeitlang aufbewahrt, zeigt sie sicb innerhalb obne Geruch ist. Bey gelinder Wärme getrocknet und eine Zeitlang aurbewahrt, zeigt sie Menge mit z»weifs, schwammichs, meblig und ist dann im Munde äulserst klebricht. Sie enthalt eiue Mchge mit zusammenziehenden Stoff, Zucker- urd Eyweifsstoff verbundenen Schleim, der mit Wasser ausgezogen unter
dem Kochen eine braunrothe Farbe aunimmt, und zur Extractdicke abgeraucht drey Viertel der dazu verw่endeten Wurreln beträgt. 
Radix Contrajervae. - Radix Filicis maris.

\begin{tabular}{|c|c|c|c|c|}
\hline $\begin{array}{c}\text { Namen } \\
\text { er Arzneymictel. }\end{array}$ & $\begin{array}{c}\text { Sinnliche Eigenfchaften derfelben; } \\
\text { Merkmale ihrer Aechtheit und } \\
\text { Güte. }\end{array}$ & $\left|\begin{array}{cc}\text { Fehlerhafte } & \text { Be-- } \\
\text { fchaffenheit, } & \text { Ver- } \\
\text { wechfelung } & \text { oder } \\
\text { Verfälfchung. }\end{array}\right|$ & Kennzeichen & $\begin{array}{l}\text { Deren } \\
\text { und Priifungsmittel. }\end{array}$ \\
\hline
\end{tabular}
Radix Contrajer-|Als Mutterpflanze dieser Wurzel gieht man die in Peru wachsende D orstenia Honstoni an; doch herrscht Contrajervenwurzel.

Giftwurzel. dünne, knotige, gekrümmte, runzlichte, feste, kopfichte Stanmwurzel von der Dicke eines balben Zolls und gegen zwey Zoll lang, die unten und auf den Seiten mit vielen langer, dünnen, ästigeu und zähen Fasern

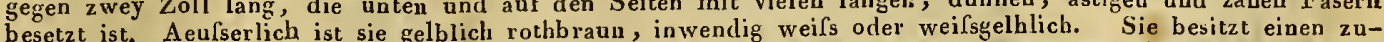
besetzt ist. A eufserlich ist sie gelblich rothbraus, inwendig weils odch weben gewürabaften Geruch. Der dickere kuotige Theil ist. wirksamer, als die Fasern.

Radix Citcrimae. Die Wurzel des in Ostindien wacbsenden Gilbwurzimbers (Amomum Curcuma Jacq.), welcbe wir ent-

Kurkume.

Gelbwurz. weder in ruuden nufsgrofoen, geringelten Kuollen (Gurcuma rotunda, oder in länglichen knotigen Stiicken (Curcuma longa), die aber beyde von einer und derselben Planze kommen und im Wesentliclien nicbt von einauder verschieden sind, im Handel erhalten. Sie ist schwer, fest, äufserlich runzlicht und nicbt von einauder verschieden sind, im tandel blafogelh, inuerlich aber dicht und sebr dunkelbraungelb, auf einzelwen Puncten glanzend. Greschmack ist bitterlich scharf und aromatisch; ihr Geruch schwach balsamisch. Diejenige Gurcuma, die in Brinche
viele harzichte, glämzeude Theile zeigt, hart und schwer ist, und beym Kauen den Speichel stark safrangelb färbt, ist die beste. Radix Cyperi escu- Die Wurłelkuollen der in neuern Zeiten berühnt gewordenen Erdmandelcyper (Cyperus esculentus L.) lenti. Haselnulsgrolse, mittelst Fasern zusamenhangende Wurzelk

Erdmandeln. $\frac{\text { sind, aufserdern aber auch durchs Auspressen ein sehr reinschmeckendes, mildes, fettes Oel liefern, }}{\text { Die Wurzel von dem in Frankreich, Italien und Sicilien wachsenden langen Gyperugrase (Cy perus lon- }}$ $g$ us L.) Sie ist lang, gegliedert, gekrümmt, von der Dicke eines $P$ feifenstiels und daı über, äufserlich a new ürzbaft; der Gescbmack aromatisch dunkelbraun

Lange Cyperwur zel.

Radix Cyperi rotundi.

Runde Cyperwuxzel.

\section{bitterlich.}

Wurzel ron dem in Aegyten und Syrien wachsenden runden Cyperngrase (Cyperus rotandns L.) Eine runde, knollige, nach unten etwas spitz zulaufende, olivengrofse Wurzel, mit parallel laufeuden Kreiseu besetzt, äufserlich röthlichbraun, inwendig weifslich. Sie hat einen besoudern, starken, angenebmen Geruch und einen etwas camphesartigef, bits sie in wohl verschlossenen Gefäsen aufbewahrt werden.

Radix Darici sa- Die Wurzel der bekannten Möbre (Da u cus Carota var, sativa.) Sie ist spiudelförmig, dick, saftig, gelb tivi.

Karottenwurzel.

Gelbe Möhre.

Radix Dictanni albi.

Weilse Diptam. wurzel oder gelbroth, und enthält einen súfsen Saft. Mau benutzt sie nur frisch und bebt sie im Keller unter Sand auf.

Radix Doronici

Wurzel des in sebirgichten Gegenden wachsendeu Weifsdiptams (Dictamnus albus L.) Die friscbo Wurzel ist ästig, länglich, dick, weifs, fleischig und saftig, in der Mitte holzicht, von einem bitteru, scharfen, gewurrzbaften Geschmack und einem starken, widrigen, hocksartigen Geruch, welche beyde im scharfen, gew urzuaften Gescheren gebcn. Man verwahrt in den Apotheken blos die vou ibrem nittlern, holTrocknen fast gänzlich verloren gebcn. Man verwahrt in den Apotheken bles zichten, unwirksamen Thcile bcfreyte, liniendicke, sich von selbst in fingerslangen und fast eben so dicken
rölurenförmigen Stücken aufrollende Rinde auf. Je dünner dieselbe ist, um desto wirksamer ist sie. Die röhrenförmigen Stücken anfrollende Rind
wurnstichigen Stücke' sind verwerflich.

Radix Doronici.
Gemsenwurzel.

Die Wurzel des in Ungarn, Oesterreich und in einigen Gégenden von Deutschland wachsenden Gemswurz Doronicum Pardalianches L.) Eine kleine, runde, auf beyden Ender schmale, raube, mit wenig Dor'onicum Pardalianches L.) Elise

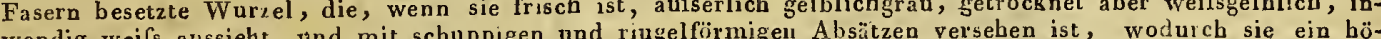
wendig weifs arssieht, und mit schuppigen and rugelförmigen Absätzen versehen ist, wodurch sie ein bö-
ckerichies Anseber bckommt. Sie riecht etwas scbwach gewurzhtheft, und hat einen süfslichen, etwas geckerichtes Ansehen lockommt. Sie riecht etwas
wïrzhaften, nicht unangenebmen Geschmack.

Radix Enulae Helenii.

'Alantwurzel.

Die Wurzel des Brustalants luula Helenium L.) Einc grolse, lange, ástige, wenig zaserichte, fleischigte Wurzel, im frischen Zustande äufserlich von braungelher, getrockuet granbräunlicher und inwendig weifslicher Farbe. Sie hat cinen anfangs etwas eckelbaften, nachber aber scharf hitterlichen, einigermafsen gecher Farbe. Geschmack, und einen frisch campherartigen, getrocknet aber melir veilcbenartigen Gcruch. Zum wïrzhaften Geschmack, und einen frisch campherartigen, getrocknet aber melir veilcbenartigen Grcruch. Zumn Arzneygebrauch wird sie im Frühjahr oder Herbst gesammlet, und wenn sie gescbält ist, in Scheiben oder
länoliche Stücke zum bessern Austrockuen zersctunitten. Die in Gärten gezogene stebt der wildwachṣenden längliche Stücke zum
an Wirksamkeit nacb.

Radix Eryngii. Mannstreuwurzel

De Wurzel des im campestre L.) Sie ist eines Daumens dick, laug, zaserig, fast spinclelförmig, von aufsen schwarzlich und c ampestre L.) Sie ist eines Daumens dick, laug, zaserig, Wastorchschnitl einen Kern zeigend. Sie mit einigen Riugen umgeben, inwendig gelblichwells und lan keret, einen gelinden gewürzhaften, etwas hat wenig Geruch, ab
scbarfen Geschmack.

Radix Filicis ma ris. Wurzel des mänulicben Farrn-lVer krauts (Polypodium Filixmas Aspidium Filix mas Willden.) welche nur sebr flach und hacrizoutal in der Erde liegt. Sie hildet eiuen länglicheyrunden ziemlich grofsen und dicken Knotlen, der alleuthalben mit länglıcheu, harten, gekrïmmten, scbuppeuförmig nabe den Ueberbleibseln der Blätterstiele, beden Ueberbleibsen welchen sicb viele rostfar bigc, häutige, spreuartige Blättchen befiuden. Die Wurzel hat fast das Ansehen finden. Die $W$ urzel hat ast eines zusammengefloch tenen treiht nach unten his viele schis aine griinFasern. Frisch hat sie auswendig eine grin-
lich schwarzbraune, iu wendig aber eine lich schwarzbraune, iuwendig aber eine
getblichweifse Farbe nnd markichte Begetblichweifse Farbe nnd markichte Be-
schaffenheit; getrocknet ist sie auswendig schwärzlicbbraun, etwas ins Riöthliche spielend und inwendig bleichbräunlicbgelb. Sie hat eiuen erdigen, etwas willrigen Geruch und einen anfaugs suifslichen, nachher aber bitterlich herben, einigermafsen her aber bitterlich herben, einigermalsen
zusammenziehenden Geschmack. Man Verwechselt mit der|Diese ist länger, dümuer, ästig, kriechend, Wurzel des Adler- auswendig von schwarzer Farbe, inwendig saum farrns (Pteris weifs gesprenkelt. In die Queere etwas aquilina $L$.) it der Wurzel des Sie unterscheidet sich dadurch, dals sie kur weiblichen Farrn- und perpendiculär in die Erde steigt, und krauts (Folypo- dafs die schuppichten Ueberbleibsel der dium Filix foemi- Blattstiele init der Spindel der Wurzel na L. Aspidium nach obeu einen spitzen Winkel bilden Filix foeminal Der Wurzelstock ist grols, an der Spitze Willden.) etwas astig, eben so dick und fast dicker als bey Aspidiun Filix mas, aber schwärzzlich und necht braun von arbe. - Die Schuppen selbst sind dinne, schwarz und
ohue derben fleischigen Inhalt, da sie hinohne derben fleischigen Inhalt, da sie hingegen bey der männlichen Farrnkrautwurzel eben so derbe und fleischicbt sind, als die Spindel relbst. Die ganze Wurzel ist Geschmack ist unangeuehmer, bitter und schleimicht.

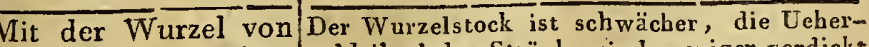




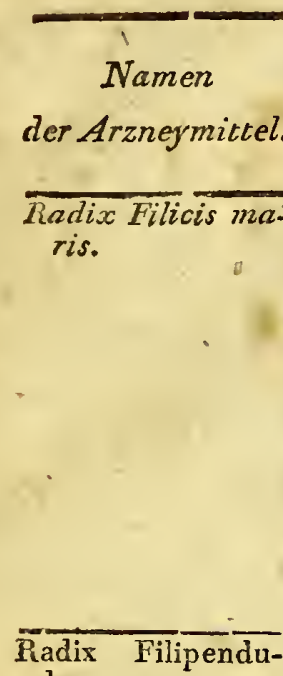

lae.

Rothe Steinbrechwurzel.

Radix Foeniculi. Fenchelwurzel.

Radix Galangae. Galgantwurzel.

Radix Gentianae albae.

Weilse Enzianwurzel.

Radix.Gentianae rubrae.

Rothe Enzianwurzel.

Radix Graminis. Queckenwurzel. Merkmale ihrer Ächtheit und
Sinnliche Eigenfchaften derfelben; $\mid \begin{gathered}\text { Fehlerhafte Be- } \\ \text { chaffenheit, }\end{gathered}$ Güte. wechfelung oder Verfälfchung.

sammlet sie im Spätberbste ein, und hebt trocknet worden, in genan verschlossènen Gefälsen auf, weil sie sonst leicht wurın stichig wird, und ihre Kräfte verliert, indem sie ihren eigenthimlichen Gcrucb und Geschnack einhuifst. Das Pulver davon, mufs, darf nicht auf $2 n$ lange Zeit in Vorrath gehalten werden. sie, nachilem sie gebürig gereinigt und ge-

\section{Deren}

\section{Kennzeichen und Prïfungsmittel.}

lostun Willden. und enthalten von der markigen Substanz (Polyporium cri-) nur selır wenig. Das scharfe l'rincip, was statum und dilata- dern Geschmack wach bey der mäunlicben \begin{tabular}{l|l} 
tum L.) & $\begin{array}{l}\text { Farrnkrantwurzel Achútichkeit mit dem } \\
\text { der Senegawurzel hat, } \text {. ist bier ungleich }\end{array}$ \\
&
\end{tabular} scbwächer. Durch die Borsten an den Zäbnen der Blattclen unterscheidet sichı überdem auch die Pflanze sehr dentlicb.

Anmerkung. Ausfïhrlicbere Anleitungen, um die Wurzeln der verschiedenen Farrnkräuter, und diese selbst, von cinander zu unterscheiden, geben die Herren Schrader (Berlin. Jabrb. d. Pharın. 1803 , S. 269-1t. f.), Krüger (Sch a ub und Piepenbring Archiv für die Pbarm. B. 1. S. 161 u. f.) und Willdeñ ow (Berlin. Jabrb. d. Pharm. 1807, S 111 u. f. mit Abbildung.)

Die Wurzel des rothen Steinbrechs (Spiraea Filipendula L.), der auf feuchten Wiesen, in TValdern und Gebüscben wächst. Sie besteht aus vielen, langen, dünnen Fasern, an welchen länglicbe oder auch rundliche, fleischichte Knollen bäugen. Ihre Fatbe ist änfserlich rotbbrath, inwendig aber weifs, bald röthlich anlaufend. Die getrocknete Wurzel hat eineu bitterlichen, etwas gewürzhaften und zusammenzichenden Geschmack, und einen etwas balsamischen Geructr.

Die Wurzel des im südlichen Europa wildwachsenden, bcy uns in Gärten gezogen werdenden Fe richeldills (Anetbum Foeniculum L.) Eue spindel!ärmige, fingersdicke, anch etwas dünnere, am Ende zweytbeilige Wurzel, die nur wenige Fasern bat, weifs aussiebt, eines süfolichen gewürzbaften Geschniack und angenehmen Geruch besitzt, beyde aber durchs Trockntn iiemlich einbîist.

Die Wurzcl der in Ostindien wachsenden Der kleine Galgant Unterscheidet sich bey einigermafsen ahnliGalgantalpiuie (Alpinia Galanga soll zuweilen mit cher Gestalt dadurch, dafs sie von etwas $\mathrm{S}$ wartzii), vou welcher im Handel zwey verschiedene Sorten vorkommen.

1) Kleine Galgantwurzeln. (Radices Galangae minoris.) Knollige, ästige, knotige, an den Knoten geringelte, barte und zäbe, fingersdicke, hin uud her gebogene, in ein bis anderthalb Zoll lange Sticke zerschnittene, auswen-
dig braunrothe odcr braungelbe, inwendig gelbbraunröthlich aussehende, anf denn Schnițte dichte und ein wenig glänzeude Wurzelı ron eineun beifsen, brennent scharfen Geschmack und cigenthümlichen durchdringenden, gewürzhaften Geruch. Je kleiner, schwerer und unversebrter die Wrrzel ist, um desto kräftiger ist sie Man crhält sie meistens aus China und den Philippinischen Inseln.

2) Grofse Galgantwurzelu. (Radices Galangae majoris.) Hat zwar mit der vorigen einerley Gestalt, unterscheiclet sich aber dadurch, dafs sic in danmensdicken, drey bis vier Zoll langeu Stücken vorkommt, die auswendig dunkelbrauner, inwendig aber heller und weifsbräunlich von Farbe sind. Die innere Substanz ist minder hart und mehr schwammicht. Geruch und Gescbmack sind weniger kräftig. Diese Sorte kommt der limgen Cyperwurzel (Rad. Cyperi longi) verfalscht werden. geringerer Dicke, lüuģer, knotig, gegliedert, gekrüinmt, von rothb aungelber oder dunkesbrauner Farhe, angenehrien Geruch, aber mehr bitterlichem als gewürzhaftem Geschmack ist. Auch soll die rnnde Cyperwirzel (Rad. Cyperi rotundi) für die tleine Galyantwuzel zuweilen ge fir die klein Galengen gegehen oder itre ureniscbt werden, welche Velwechelung man and $Z$ rreiblicbkeit der innern Substanz der Cyperwurzel und an deu viel bittererni Geschmack crkennen künne. Mau hat daher immer Ursache, die Galgantwurzeln auf diese Bry mischungen zu untersnchen.

A umérk. Nach einigen Schriftsteller'n kommen beyde Sorten von der angefübrten Mutterpflance; nach andern' wjod unr der kleine Galgant vou der angezeigten Pflanze, der gl ofse aber von dem Galgantkämpler (K a emperia Gaìang) gewonnen. Zum Arzueygebrauch darf übrigens uar der kleine Calgant angewendet werden. aus Malabar und Java.

Die Wurcel des im sidlichen Deutschland wachsenden Breitblattlasers (Laserpitinnr latifolium L.) Eine spindelförmige Wurıel von verschiedener Dicke, die mit crhahemen Ringen versebeu, inwendig gelblichweifs, von einem eigenthïmlicheu Gerucb und einem starken gewürzhaft'n, bittern, etwas scharfem Geschnack ist. Sie wird im Herbste gegraben und ist an cinigen Orten noch officincll.

Die Wurzel des auf den höbern Gelirgen in der Schweiz, Oesterreich, auf Jen Appeninischen, Pyrenäischen und Tridentiniscben Alpen wachsenden Gelbe $1 z i$ a (Gentiana lutea L.) Eine fufslange,
daumensdicke, nuch wohl nocb siärkere daumensdicke, nuch wohl nocb siärkere, walıenförmige, mit ringförmigen Runzel bezeichnete, aufserbalb brannothe, in wendig gelhröthliche, sehwammichte Wurzel, von eiuem höchst billern, und eigenem, schwach gewür. haften Geruch. Zngenem, scliwach gewur haflen Geruch. Zusammengeschrumpfte, innerthalb schwar'zzeln müssen ganz verworfen werden.

Dio Wurzel des allenthalben auf Aecker, Wiesen und in Gärten als Unkraut vorkommenden Queckweizen.Triticum repens L.) Eine wagereclut in der Exd fortkricchende, lange, strohhalmsdicke, glatte, gegliederte, an den Gliedern mit häuticen Fortsätıen und an den Knoten derselben mit feinen Zäserchen verseluene

Wurzel. Frisch hat sie eire weifse, ge-

ie sollen zuweilen|Diese urobe Verfälschung, wenn sie wirkmit den Wurzeln lic! gegrinudet ist, würde sich.leicht verrathen da diese Wureln eine nuebr araudes Schweitzerhall- rathen, blösere Farbe, feineve und hinfinenfrifses (Kanuzn- braune blistere Tabe, culus Thora L.) gere Rum, und des gelben Fi- Geschmack, anch eine ganz abweichende senltuts (Aconitum Wirkung besitzen.

Lycoctonum L. verfälscht werden.)

A n rherk. Nach einigeu Schriftstellern sollen für die TVurzeln de gelben Enzians gew öhnlich auch die Wurzeln des in Schottland und Norwegen wachsendeu purpurfarbigen Enzians (GenDerley Wurzel aber in uren Eigenschaften mit pinander ïbereinkommen.

Verwechselt mit den/Unterscheiclen sich dadurch, dafs sie weit Wurzeln des Win- kür/er, durchaus an den Gelenken selbst terlolchs (Loliumn faserig und minder weifs sind. pereme $L$.)

Mit den Wurzeln des Kommen ïberall nur sparsam vor und sin quecliartigen //aar-1 daher nicht leicht damit zu yerwechseln. grases (Elynuus caninus $L$.) 


\begin{tabular}{|c|c|c|c|c|}
\hline $\begin{array}{c}\text { Nanen } \\
\text { ler Arzneymittel. }\end{array}$ & $\left|\begin{array}{c}\text { Sinnliche Eigenfchaften derfellen } \\
\text { Merkmale ihrer Aechtheit und } \\
\text { Giite. }\end{array}\right|$ & $\left|\begin{array}{cc}\text { Felilerhafıe } & \text { Be- } \\
\text { rchaffenheit, } & \text { Ver- } \\
\text { wechfelung oder } \\
\text { Verfälfchung. }\end{array}\right|$ & Kennzeichen & $\begin{array}{l}\text { Deren } \\
n \text { und Priifungsmictel: }\end{array}$ \\
\hline Radix Grạinis. & 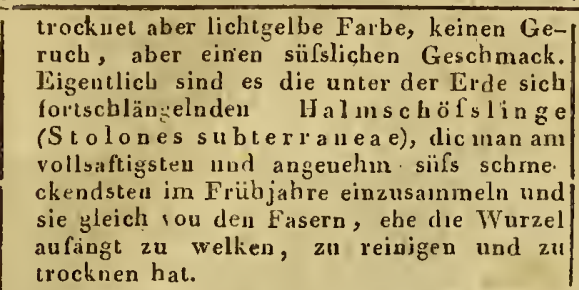 & $\begin{array}{l}\text { Anmerk. In Italiens } \\
\text { zel der Queckhirs }\end{array}$ & $\begin{array}{l}\text { soll man sich stat } \\
\text { se ( } \text { Panicum d }\end{array}$ & $\begin{array}{l}\text { tt der Queck wurzel der Wur } \\
\text { dacty lon L.J bedienen. }\end{array}$ \\
\hline
\end{tabular}

$\overline{\text { Radix Heliebori }} \overline{\text { Die Wurzel der in den gebirgichten Gegenden von Oesterreich, der Schweiz, Griechculand, Sibirien, Rufsland }}$ albi. zel. und Italien wild wachsenden Weifsniefswur \& (Veratrum a lbum L.) Diese Wurzel, wie sie getrocknet zu uns komme, bildet elch zwey Zoll lang und an dem dicksteu tide eis lichen Riug, und dieser in der Mitte ein schwammichtes graues Mark eiu. Von dem widrigen Geruche der

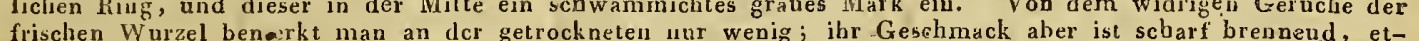

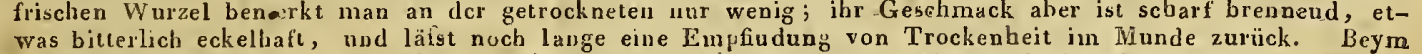
Pulvern derselben mufs man sebr vorsicbrig seyn, weil der iu die Nase aufsteigende Staub das befigste Niesen erregt.

Radix Hellebori nigri.

Schwarze

NiefsWurzel der auf den Alpen, auch in verschiedenen gebirgichten Gegenden Deutschlauds wachsenden $s c h$ warzen Christ-
w i iz (Helleborus niger L.) Es hat w u iz (Helleborus nigel L.) Es hat
dieselbe einen schwarzen, rundichen, gefurcliten Knollen, oder Kopf von der Gröfse einèr Muscatennufs, der nach alleu Seiten kurze gegliederle Aeste treibt, aus welchen wieder viele glatte, runde, strohbalnisdicke und dickere, zäbe, fleischicble, einige Zoll bis Fußslange, bey ältern Wurzein in einander geschlungene Fasern kornmen, die einancler geschingene auswellig schwarz oder schwartination, wendig weils sint, einen scharfea, bitterlichen, cckelbaften Gcschmack, und widrigen ranzigen Geruch besitzen, Daichs
Trocknen werden sie runulicht, dünuer, zerbrechlich, auswendig branngraulich, inwendig gelblichweifs, verlieren meisten ihren Gavch, nad schmecken bejm lianen weniger bitterlich, binterlassen aber noch lauge die Empfirdung eiuer Scharfe, uud verursachen eine 'Art Gefühllosigkeit und Erstarrung der Zunge. Der knollichtel Theil, welcher of mit einer oder anderu Schuppe besetzt ist, ist weniger wirksam als die Fasern (Fibrilla e Hellebori als die F a sern (Fibrilla $\mathrm{g}$ i), die daber uur allein zum Alzneygebrauch sollten gellommen werden Veraltete Wurzeln, die durchaus alle Zähigkeit der Fasern verloren haben, stanbicbi sind und keinen Geschmack mehr besitzen müssen als unkräftig verworfen werden.

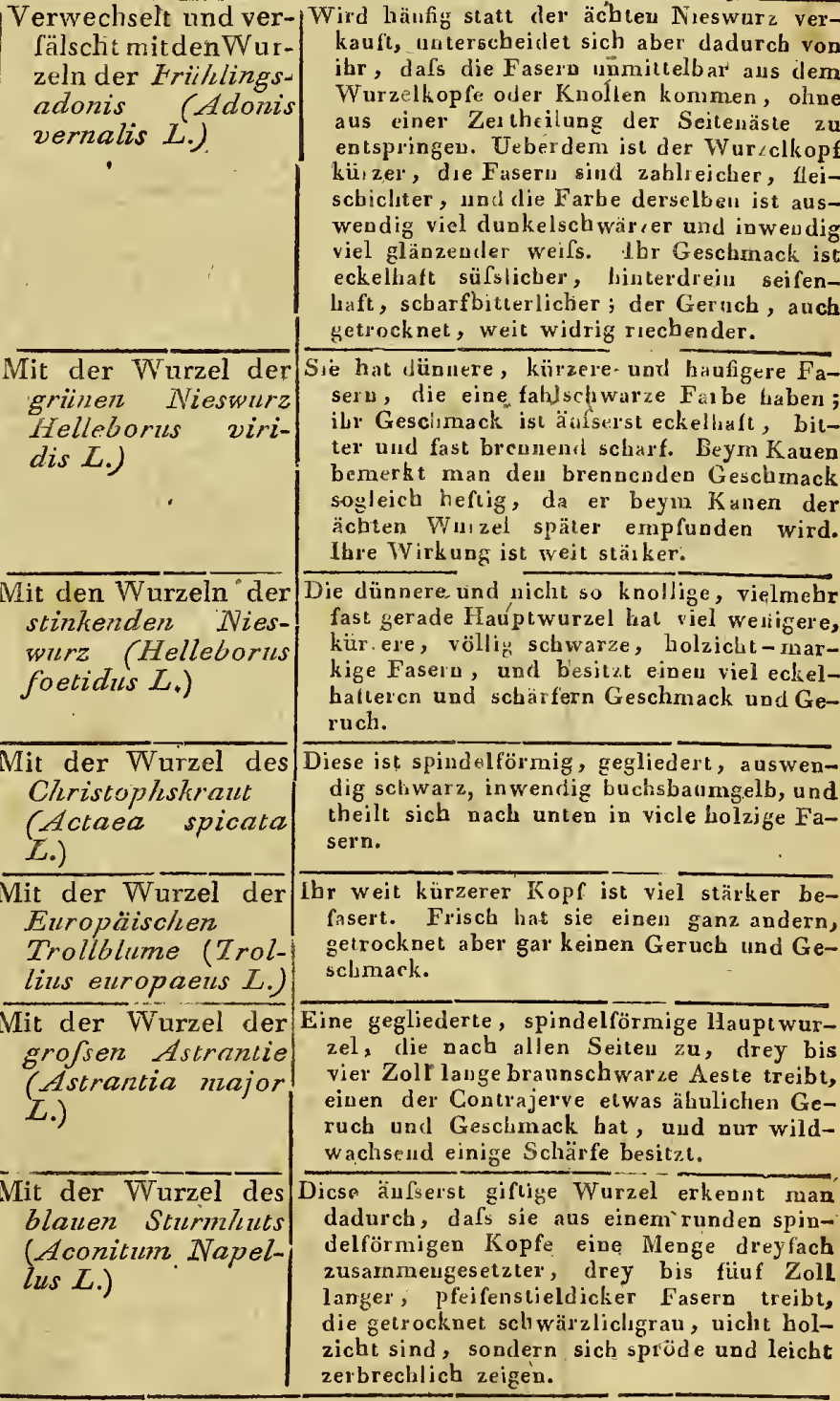

Anmerkung. Aufserdem sollen nach einigen Schrifistellem auch die Wurzeln der weifseu Nieswurz (R ad. Helleborialbi), die Arnicawurzeln (Radix Arnicae) und die Wurzeln der appeniniseben Adonis (Adonis appeniua L.) zuweilen für die ächte schwarze Nieswurzel gesammlet werden. 
Radix Jalappae. - Radix Ipecacuanhac.

\begin{tabular}{|c|c|c|c|}
\hline $\begin{array}{c}\text { Namen } \\
\text { Uer Arzneymittel. }\end{array}$ & $\begin{array}{c}\text { Sinnliche Eigenfchaften derfelben; } \\
\text { Merkmale ihrer Ächtheit und } \\
\text { Güte. }\end{array}$ & $\begin{array}{c}\text { Fehlerhafte Be- } \\
\text { fchaffenheit, Ver- } \\
\text { wechfelung oder } \\
\text { Verfälfchung. }\end{array}$ & $\begin{array}{c}\text { Deren } \\
\text { Kennzeichen und Prüfungsmittel. }\end{array}$ \\
\hline $\begin{array}{l}\text { Radix Jalappae. } \\
\text { Jalappenwurzel. }\end{array}$ & $\begin{array}{l}\text { auch auf den Maderainseln wachsendeu Ja- } \\
\text { la p en wi d e (Convolvulus Jalla- } \\
\text { pa L.) Wir erhalten dieselbe im Haudel } \\
\text { in runden Scheiben zerschnitten oder der } \\
\text { Lange nach einmal zerspalten und alsdanu } \\
\text { birnförmirgestaltet. Die Worzelstücke }\end{array}$ & $\begin{array}{l}\text { aus denen schon ein } \\
\text { grolser Theil des } \\
\text { Harzes mit Wein- } \\
\text { geist, ausgezogen } \\
\text { worden. }\end{array}$ & $\begin{array}{l}\text { ander bricht, durch die fast ganz durchaus } \\
\text { gleiche braune Farhe und durch den unge- } \\
\text { wöbnlich geringen Harzgehalt bey näherer } \\
\text { Untersuchung mit Weingeist. }\end{array}$ \\
\hline 3 & 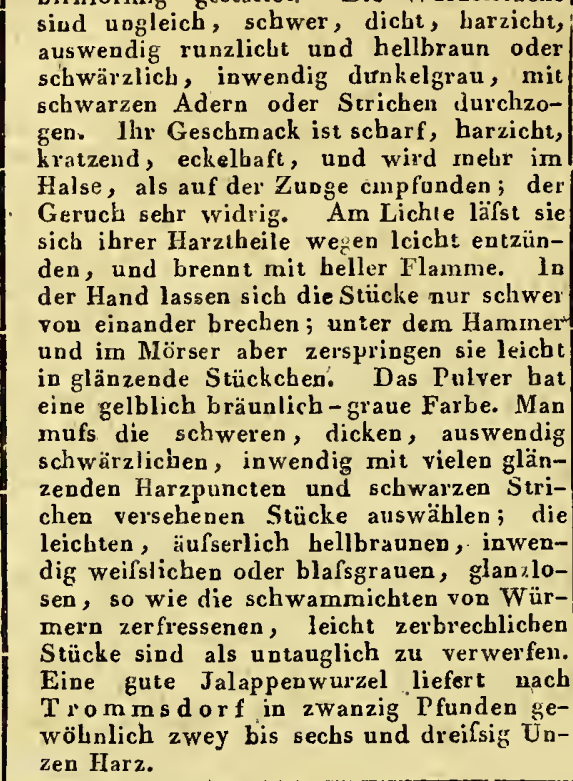 & $\begin{array}{l}\text { Mit untermengten } \\
\text { Stücken der Zaun- } \\
\text { riibenwurzel ver- } \\
\text { fälscht, } \\
\end{array}$ & $\begin{array}{l}\text { Man erkennt diese untergeschohenen Stiicke } \\
\text { an ihrer blassern oder weifslichen Farbe, } \\
\text { an ihrem schwammichten Gewebe, ihrer } \\
\text { geringern Schwere und leichtern Zerbrech- } \\
\text { lichkeit, wie auch an den Ringen und Strah- } \\
\text { len ibres inneren Banes. }\end{array}$ \\
\hline
\end{tabular}

Radix Imperatoriae s. Ostrutii.

Meisterwurzel.

Ostritzwurzel.

Radix Ipecacuan liae.

Ipecacuanhe.

Brechwurzel.

Die Wurzel des im südlichen Deutschland in wrrz (Imperatoria Ostrutium L.) Sie is! länglich, plattrundlich, einen halben bis ganzen Zol dick, einige Zoll lang, durch ringförmige Absätze gegliedert, Löckericht, mit ihren bäufigen Nehenwurzel befasert, auswendiy graugelb, inwendig weifslicht, und enthält frisch einen milchichten, gelblichen, guinmibarzigen Saft. Sie hat einen durchdringeuden, brennend gewürzbaftcn Geschmack und einen starken Angelick - und Liebstöckelartigeu Geruch. Am kräftigsten wird sie im Spätherbst oder im Winter aùsgegragelick - und Liebstöckelartigeu Geruch. Am kraft

Es kommen von dicser Wurzel rerschiedene/Mit verschiedenen
Sorten im Handel vor, nämlich :

1) Dic graue I pecacuanhe (I pecacuana grisea.) Als Mutterpflanze dieser in deutschen Apotheken nur allein gebräuchlichen Sorte giebt man die in südlichen America, besonders im Köuigreich Mexico wachsende M exít a $\mathrm{n}$ is ch h Brechpflanze (Psychotria emetic a L.) an. Eine verschiedentlich gedrehte, gegliederte, init vielen hervorragenden nngleichen Ringen und tiefen Einschnitten bezeicbnete, harte, scbarf anzufïblende Wurzel, von der Dickc eimes Strobhalms oder dünnen Federkiels und einige Zoll lang. Auswendig bat sie ein aschgraues, lang. Auswendig ba sielich aus häutchen, welches eine weifsliche, ins häntchen, welches eine weilsliche, dichte, auf dem Bruche ein wenig glänzende, te, auf dem Bruche ein wenig glanzende Splittern, gegen das Licht gehalten, durchscheinende, fasernlose, oft messerrückendicke Rinde nmgiebt, die einen bitterlichen, scharf eckelhaften Geschmack hat, und den inuern fadeuförmiges, bolzichten, gelblichweifsen, geschmacklosen Tlieil einschliefst. Die Wurzel riechı fast gar nicht; das Tulver aber besitzt, wenn es nicht; das lulver aber besitat, wenn e frisch bereit

gen Geruch.
Gute Ipecacuanbewur zeln missen dicht, Gute Ipecacuanbewurzeln mirssen dicht,
zähe, fest, dunkel grau, wulstartig geringelt seyn, eine dicke Rindensubstanz uncl dünue Kernfaser halien, und auf dem Bruche von Harztheilen glänzen. Die weifslichten, falben, rothbraunen, schwanmichteu, nicht gcringelten Wurzeln müssen verworfen, auch bey den guten Wurzeln die zuweilen nocb anhängendelı $\mathrm{Fa}$ sern davou abgesondert werden. Man inufs sie in dicht ver'schlossenen Gläser'n vor dem Butritt der Luft veral Zer, ver $z$ lange $Z$ it in Vor const leicht seine Wirksamkeit verliert. Die fremdartigen Wurzeln verfälscht. 


\begin{tabular}{|c|c|c|c|}
\hline $\begin{array}{c}\text { Namen } \\
\text { der:Arzmeymittel. }\end{array}$ & $\begin{array}{c}\text { Sinnliche Eigenfchaften derfelben; } \\
\text { Merkmale ilurer Aechtheit und } \\
\text { Giite. }\end{array}$ & $\left|\begin{array}{c}\text { Felulerhafie Be- } \\
\text { Schaffenlueit, Ver- } \\
\text { weclifelung oder } \\
\text { Verfälfchung. }\end{array}\right|$ & $\begin{array}{c}\text { Deren } \\
\text { Kennzeichen und Prüfungsmittel. }\end{array}$ \\
\hline
\end{tabular}

Fiadix Ipecactuan- Wirksamkeit hegt allein in dern rindıen bae.

Radix: Iridis $\overline{\text { flo }}$ rentinae.

Florentinische Violenwurzel. ha, einem perenniresden, krautastigen, eckel hafte: Geruch einen Thesle; das innere holzi
los und blos schleimicht.

2) 'Die bra un I I peca cuan be (I pe-

cacuauba finsca. Sie kommt nacb

Ilern Willd enow's naberer Bestim-

mung (Berl. Jahrb. d. Pharm. 1804, S. 76 u. f.) ron der Cephaelis I pecacua kriechenden, vorzïglich in Brisilien einheinischen Gewachse her, nnd ist äufserlich brau oller schwarz. Im Geschmack

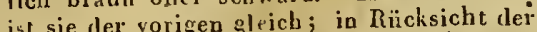
ist sie le vorigen gill man bemerlicinischen Kifs sie weit heftiger und merkt babels, dais sie weit he.

drastischer wirke, als die graue. 5) Die weifse lpecacaanha (I pec a cuanha alla.) America und Cayenne anf Wicsen wachsenden I pec a c u a $\mathrm{n}$ aveilchen (V iola I.pecacuanha L.) bel', dessen Wurzel gewunden, fingerlang, mit häıfigen halbcirkelförmigel Runzeln und Einschnittun besetzt und inwendig uni Eelblichen Kernfase mit einem schwachen churchagn

it Wur el des in ltaliea, besonders um Florenz bäugg" wachsenilen Violen-

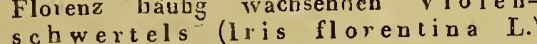
So wie dieselbe im Handel zu uns komm So wie dieselbe im thandel zu uns komeibestelst sie aus dichten, schweren, weifsen, einigermafsen flacbev, knotichten, bezeichneten, verschiedenarug gestalieten, ron der gelbrötblichei Rinde der frischen Wurzeln und den Fasern betreyten, an der Sunne getrucknetein Wurzelstückeis, von verschiedener Grïfselund Dicke. Sie besitu einen augenehmen Veilchengeruch und sict einen algect eiuen schleinicht - melligen, scharfen Geschimet sehr interworfen ist, fratse and Schiminel sehr materworfen ist, so mufs sie an eiuem luftigen nud trocknen O. le aufbewahrt werden now nach, einem getrockneten Exemplar, welches er von dem vermstorbenen Doctor K ö $1 \mathrm{ig}$ in Tranquabar erhich, Gynanclium cacuanha nennt u
Radix Iridis nostra-

blis. Schwerdtlilienwurzel.

\section{Radix Lapathi} acnti.

Grindwur $\_$el.
Radix Levistici. Liebstöckelwurzel.

RadixLiquiritiae. Süfsholzwurzel.

Wurzel des in Sachsen und der Pfalz. wachsenden Bla uscluwertels' (lris germanica L.) Sie ist langgecliedert, fisho än fscrlich gran, inwendug weifslich und unten mit Zaseru besetzt, im friscben Zustande widsir riehend und yon einem sehr scbarfen, beifsenden Geschmack. Scbnell getrocknet erbält sie einen schliwaclien Violengeruch, nnd der Geschmack wird bitterlich.

kommt zuweilen|Diese sind kieiner, dunner, 'S. Piadix Iridis mit denWurzeln der und schwatis.

lilie (Iris gernua-

iiica L.) vermischt

vor.

Trengl. Rad. Brittannicae.

Teichen, auch andern fetten Orien wild Wurzeln des WTas-

wachsenden Spilzam'pfers (Rumex) serampfers (Ru-)

a cu t u $\mathrm{L}$.) Eine lange, bald einfache, bald mex aquaticus $L$.) ästige, daumensdiche, grofse, oft etwas befaserteWurzel, die äufserlich brann, inwendiog gelbist, keinen Geruch, aber einen bittern, scharfen und zusarnmen\%iehenden.Geschinack hat, und beym Kauen den Speichel gelb färbt.

Mit der Wurzel des krausblättrichten Ampfers (Rumex
crispus.L.)

Mit der Wurzel des stumpfblättrichten Ampfer's (Rumned
Eine dicke blafsgelbe Wurzel, deren Mutterpflanze sich dadurch von dem Spizampfer unterscbeidet, dafo die Blumenblättclien ungezahnt sind, die Blätter lanzettförmig, etwas stumpf, am Rande fein gekerbt und wellenförmig gekränse!t sind.

ie Blätter der Pflanze sind gröfser, eyrund und stumpf. Die Wuzel des in verschiedenen Gegenden von Deutscbland wild wachsenden, auch in Gärten gerogen werden-

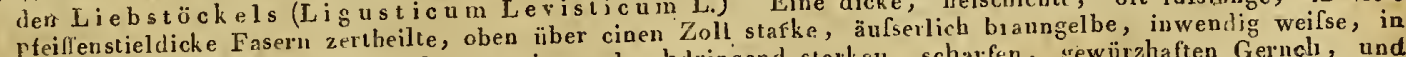

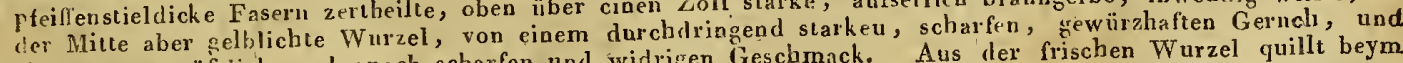
cer Mitte aber a zuerst süfsichen, hernach scharfen und widrigen Geschmack. Aus der frischen Wurzel quillt beym Zerschneirlen ein gelblicher gummibarziger Saft hervor.

Die IVurzel des Glatts üsholzes (G.ljzyrrizaglabra L.), einer ausclaueruden südeuropäischen Pflanze Sie ist lang, kriechend, walzeuförnig, holzig, zăhe nnd biegsam, von-der Dicke eines kleinen Fiugers bis zu der eilles Janmens. Aenfsenliel: ist sie braungran; dnrch das Trockncn wird sie ruazlich; iuwendig ist sie sshön grlb und anf dern Queerdurchschnitte strablig. Sie hat einen erbsenartigen Ger. Die besten Wursüfsen, hintennach leicht bitterlichen, mit einer Spur von Schärle begleiteten Geschisticht sind, und viele zclu sind diejeniceu, welche zähe und beym Zerschneiden inwendig recle gelb andelrssenen Wnzeln müssen Saftröhren bemerken lassen. Die gar zu dünuen, dunplicht riecbenden und angejrs nan die Spanische als natanglich verworfen werden. Vou den im Handel vorkommenden Sorten ziefranen auf Aeckern ge$\mathrm{S}$ ïfsbolzwnrzel der. It ali än ischen und Deutschen, welche letatere in Franken auf Aeckerse Saftbanet wird, 


\begin{tabular}{|c|c|c|c|}
\hline $\begin{array}{c}\text { Namen } \\
\text { der Arzneymitiel. }\end{array}$ & $\mid \begin{array}{c}\text { Sinnliclee Eigenfchaften derfelben; } \\
\text { Merkmale ihrer Aechtheit und } \\
\text { Güte. }\end{array}$ & $\left|\begin{array}{cc}\text { Fehlerhafte } & \text { Be- } \\
\text { fchaffenheit, } & \text { Ver- } \\
\text { wechfelung } & \text { oder } \\
\text { Verfälfchung. }\end{array}\right|$ & $\begin{array}{c}\text { Deren } \\
\text { Kennzeichen und Prïfungsmitcel. }\end{array}$ \\
\hline 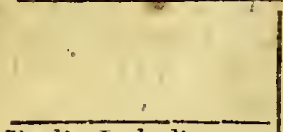 & $\begin{array}{l}\text { Anmerhung. Die in Rursland gebr } \\
\text { pflanze GG Gy y r biza ec hina } \\
\text { Die Wurzel ist gröber als die Spani } \\
\text { Stücken im Handel vor. } \\
\end{array}$ & $\begin{array}{l}\text { a ta L.), die in Rufsland } \\
\text { ische, aber sehr süfs, un }\end{array}$ & \\
\hline $\begin{array}{l}\text { Padix Lobeliae. } \\
\text { Lobelienwurzel. }\end{array}$ & 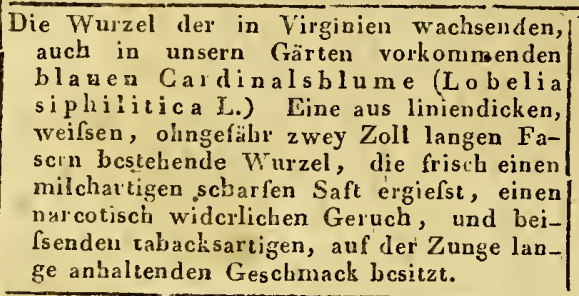 & $\begin{array}{l}\text { Verwechselt mit der } \\
\text { Wurzel der weifsen } \\
\text { Cardinalslilume. } \\
\text { (Lobelia longiflo- } \\
\text { ra L.) }\end{array}$ & Ihre Aawendung soll weit bedenklicher seyn. \\
\hline
\end{tabular}

Radix Lopezianae. Lopezwurzel.

Radix Mechoacannae albae. Mechoacanne. Weifse Jalappe?

Radix Meu.
Bärwurzel.
Radix Mezerei.
Kellerhalswurzel.
Radix Morsus Dia-
boli s. Succisae.
Teufelsabbifswur-
zel.
Radix Ninsi.
Ninsingwurzel.

Radix Ononidis spi-
nosre.
Hauliechelwurzel.

Wir bekommeu diese Wurzel, dereu Mntterpflanze nocb unbekannt ist, die aber wabrscheinlicb von einem Batime berrüht, in Stücken von verschiedener Gröfse und einen bis zwey Zoll dick. Sie ist holziclit uud hat ziemlich dicke Nebenäste. Aeufscrlich ist sie mit einen dünuen blasseu Häntchen überzogen, unter welchem sich eine dunkelbranne, weiche, runzlichte, grobe Rinde befindet. Das Holz ist weich und schwammicht, und umgieb̆ einen dicken, harten, röthlichweifsen Kern. Die dünnern Stäcke sollen wirksamer seyn, als die dicken. Der Gerucb fehlt; der Geschmack ist bitterlich. Man sa:t, dafs sie in Goa zu Hause sey, von da nach Nalacka, und von hier nach Batavia zum Verkauf gebracht werde. Sie stand ehemals in einem hohen Preise.

Die. Wurzel der in America, besouders in Brasilien wachsenden Mechoacannenwinde (Convolvulus Mechoacanna L.) Sie kommt getrocknet theils in Scheihen zcrschnitten, theils in läglicken Stücken vor, die eine grave runzliche Rinde habcn, inwendig aber weiffs oder weifsgelblich und fest sind. Ihr Gescbmacks ist süfslicbt-schleimicht, der Geruch fehlt anz. Die ganz porösen, leichten, wurmstichigen tVurzeln tangen uicht. Die Zauurübenwurzl, whit ihren bittern' Geschmack und durch die oben gegebeue Beschreibung (S. Radix Bryoniae) davon unterscheiden.

Die Wurze des auf sonnichien Wieen im Oesterreichischen, in Italien und dex Schweiz wachsendeu Bärwarzgleifses (A ethusa meum L.) Sie ist fingersdick, sechs bis acht Zoll lang, von aulsen runzlich, schwarzgrau, inucrlich weifs und in der Mitte mit einem etwas dïnnen holzigen Theil durchzosen. An dern über die Frde herver besetzt, die eincm Pinsel gleicheu, und von den abgegangenen zerfaserten Blattstielen lerrühren. Der Gerucb ist balsamisch, stark: der Geschmadk hitzig, dom Liebstöckel äbulich, aber gewürzbafter.

Die Wurzel des in waldigen Gegeuden wachseaden Kellerhalsstrauchs (Daphne Mezereum L.) Eine ästige, ziemlich lange, zäbe, holzige, eines Gänsekiels und darüber dicke WVurzel, die auswéndig eine dünae rotbliche oder brallngelbliche Rinde hat, inwendig weifslich ist. Die Rinde schmeckt anfangs buum scharf, inacht aber herracla ein beifsendes, fast unerträgliches Brennen. Die veraltete, nicht inehr brenuend schmeckende Wurzel taugt nichts. Sie muls im Anfange des Frühjihrs gesammlet werden.

Die Wurzel der anf etwas feuchten Wiesen wachsenden Abbisscabiose (Scabiosa Succisa L.) Eine dïn ne und kurze Hauptwurzel, die unteu abgestumpft, gleichsan abgebissen, etwas seitwärts gebogen und mit vielen Fasern besetzt ist. Auswendig ist sie gelblich, inwendig weifslich, übrigens geruchlos und etwas scharf' bitterlich schmeckeud. Wird blos als Vieharzneymittel gebraucht.

Die Wurzel der in China und Japan wachsenden $\mathrm{Ni}$ us iw urz (Sium Ninsi L.) Eine spindelformige, uuterwärts gemeiviglich in $z$ wey Aeste getheilte und mit wenigen dünnen Faseru besetzı Wurel, von der Dicke eines Federkiels bis zu der eines kleinen Fingers mit parallelen Ringeln versetien. Ihre Farbe ist weifslich hornartig, halbdurchichtig, bisweilen bramorelblich. Geruch nnd Geschmack sisd gew irraft, letzterer süfslich ubd hintcuuach bitterlich. Die Dnrchsichtigkeit soll davou herrühren, dafs ilie Wurzel vor dem Trocknen einige Tage in Wasser gewescht unil dann an den Deckel eines Kessels gehangen, den heifsen Wasserdämpfen ausgesetzt wirl, welche Bearbeitung indessen nicht mit allen Wurzeln vorgenommen zu werden schcint, da man öfters Wurzeln antrifrt, die ganz undúrchsichtig sind. Es stand diese Wurzel ebedem in einem so hohen Preise, dafs die Unze mit hundert und funfzig Holländischen Gulden bezahlt wurdc.

Wurzel des stachlichten Hauhechels (Onouis spinosa L.), der auf dürrem, harten und festen Boden an den Wegen und andern lungebauten Orten iiberall in Deutschlaud wächst. Eine oft fufslavge, eincs kleinen Fingers und darïber dicke, ästige, sebr zähe, bolzige, auswendig braune, inwcndig weifse Wurzel, vou einem süfslichen, schlcimichicu Geschmack, ohne Gernch. M M sammlet sie im April, bedient sich aber heutiges Tages nicht selten statt ihrer der Wurzel des Ackerhauhechels rononis arvensis), welche Planze mit jener au gleichen Standörtern wächst, aber keine Stacheln hat.

Radix Paeoniae. Wurzel" der bekamiten Pfingstrosenpäonie (Paconia officinalis L.) Eine knollige, feste, dichi Wur ccl mit rundlichen, daumensdicken, äufserlich rotbloraunen oder braunsrausu, inwendig weifsen, dichtfleischigen, seltner schwamnichten Knollenausitzon, oder aus Kuollen, die durch Faseru an einander bangen, bestehend. Frisch bat sie eiricil starken, narcotisch-widrigen Geruch, der aber beyin Trocknen verleren gebt, und ciucu bittcrlich süfsen, twas adstringirenden Geschmack, der auch nach leın T'rocknen übrig bleibt, jedoch das suifsliche verloren hat. Man gräbt die Wurzel in Frühjalı aus, befreyet sie von ibres braunen Oberiaut, schneidet sie in Scheiben uud trocknet sie. Die veralieten, dumpficht riechenden, schmacklosen Wurzeln sind untauglich.

Man untcrscheidet gewöbnlich zwey Spielarten, nümlich: a) Paeonia foemina, mit schmalen, blafsgrïneu Blittern und dunkelröthern Plunen; die Mítterplanze der eben beschriebenen Wurzel, und b) (lie

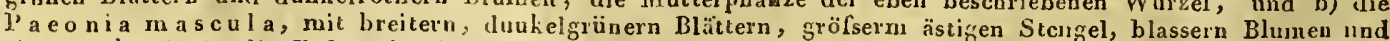
ciner seukrecht in die Ërde gehenden, und sich dann in viele von aufsen röthliche und innen weirslicbe ciner seukrecht in die tirde gehenden, und sich dann in viele von au
Aeste

Radix Pareirae braGrieswurzel.

Radix Petasitidis. Pestilenzwurzel.
Die Wurzcl des 'in sürllicheu Amcrica wachsenden Grieswurzelstranchs (Cissampelos, Pareira L.) Eine Lolzige, gekrümmte, einen halben bis drey Zoll dicke, dufserlich runzliche, schwar'zgraue, inweadig gelbe oder l,rïnnlichgelbe Wurzel, ohne Gerneb, aber von eiuem anfangs süfsbolzäbnlichen, nachber bitterliclicn Geschmack. Man er hält sie aus Brasilien.

Die Wurzel des, vorzïglich an Dämmen fliefscuder Wasser wachsenden rothen Huflattichs (Tussilago Petasites L) Eine zolldicke, ̈̈stige, stark befaserte, geringelte, änfserlich braune, inwendig weifsliche oder röthliche Wuzel, vou einem starken bitterlichen, den Angelikwurzetn einigermafsen ähnlichen, durchdringciden Gescbanack, und, frisch von starkem widrigen Geruch. Wenn man die frische Warzel queer 


\section{Radix Petroselini. -- Radix Polypodii.}

\begin{tabular}{|c|c|c|c|}
\hline $\begin{array}{c}\text { Namen } \\
\text { der Arzneymiciel. }\end{array}$ & $\begin{array}{c}\text { Sinnliche Eigenfchaften derfelben; } \\
\text { Merkmale ihrer Ächtheit und } \\
\text { Giite. }\end{array}$ & \begin{tabular}{|} 
Felulerluafie Be- \\
frhaffeitheit, Ver- \\
werhselung oder \\
Verfälfchung.
\end{tabular} & $\begin{array}{c}\text { Deren } \\
\text { Kennzeichen und Prüfungsmittel. }\end{array}$ \\
\hline
\end{tabular}

durchschueidel, so läuft der Rand mit gelben Puncten an. Nach den Untersuchungen des Herru Prof

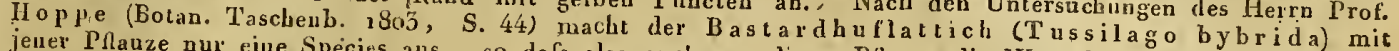
jener Phauze nur eime Species aus, so dafs also aucb von dicscr Pllanze die Wurzeln eingesamblet werden
können.

Radix Petroselini. Petersilienwurzel.

Dic bekante Wurzel des Petersilieneppichs (Apium PetroselinumL) Sie ist spindelförmig, gerade
in die Erde herabgebend, wcifs in die Erde herabgebend, wcifs, von cinem eigenthumlichen Gerucle und einem angenebmen siifslichen Ge-
schmack. Dcm Wurmfrafs ist sie sehr mnterworfen.

Radix Pencedani.

Haarstrangwurzel. Radix Pimpinel
lae.

Pimpinellwurzel.

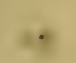

Radix PlumbagiDentariae.

Zahnwwurzel.

Radix Polygalae amarae.

Bittere Kreuzblumrenwurzel.

Radix Polygonati s. Sigilli Salomo-

Weifse Schminkwurzel. Siegelwurzel. Radix Polypodii.
Engelsürswurzel. senden ge me incu Ha a r strangs (Pe ucedanum in schattichten Gebiischen und auf Bergen wild wachvor, ișt mul, laug, mit Fașern besctzt und mit einer schwärzlichen Rinde umgeben, von der sie vor dern Trocknen befieyet wird. Inweudig ist sie weifs nud enwärzlichen Rinde ungeben, von der sie vor dem saft. Ihr Geschmack sst gewürılaft, fettigbitterlich, einigermafsen schaschen 'Zustande einen gelblicheu Milch-

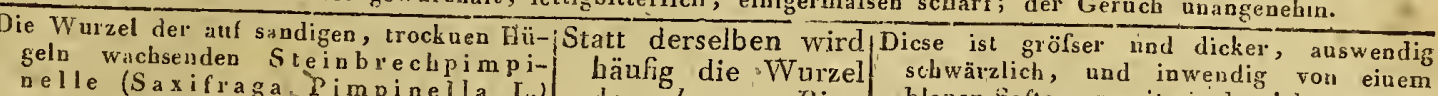
Sie ist fingerstick, spannenlang II a L.) der scltwarzenPim- blauen Safte, womit sie durchdrungen ist,

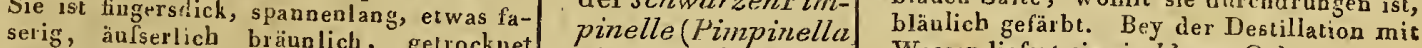

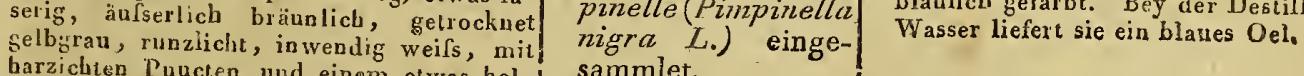
bichten Kern versehen. Sie besitzt, be-
zich zichten Kern versehen. Sie besitzt, besouder's frisch, einen flüchtigen, Niescn-
erregenden Geruch, und eincn scharf brenacnden, bilerlichen Geschmack. Man mofs sie im Frübjabre ausgraben, schuell trocknen und in wohl rerschlossenen $C$ en fäfsen aufbewabren. Veraltete, leich Gebrechliche, kaurn uoch Geschmol berde, warmstichigc W urietn miesen verwor'seu werden.

Wurzel der im südlichen Europa, aućs bey uns in Gärten fortkommenden earópäischen Bleywnra breiteude, ästige Wurzel. L.) Eine tief in die Erde gehendc, cyludrische, sich wach allea Seiteu zu ausfserst scharf und brennend.

Die Wurzel des Bitteramsels (Poly-/Verwechselt mit den Beyde Pflanzen unterscheidei sich dadurch, g a la a mara L. ), einer Pliaue, die im Wurzeln der ge- dafs die bittcre Kreuzblume melirere grö̈seuden Luropa, apch in ruehreren Ge- meinen Krenzblu- fsere, dickere, breiterc uud umgekehrt eyGenden von Deutschland anf bergichten me Polno Grasplätzen wächst. Die knoticlite $\mathrm{H}_{\text {aupt- }}$ Wurzel hat vicle astige, bis drey Zoll layge, bulzige, mit dünnen Zäserchen besetzte Fasern. Auswendig is sie gelblich oder gelbgran, inweudig weifslich. Der Geruch tehlt, der Gesci:mack ist süfslichbitter, etwas balsamisch und schwaichalzig. Sie mufs im April von bcrichlen Standörtern, und nicht von feuchten sumpfichten Wiesen, wo die Planze auch vorkommt und statt der blauen inssemei weifsliche Blimen trägt, eingesanmlet werdeu, da die Wurzeln der letztern keinen bittern, sonderu uur krautartigen Gescbmack besitzcn und viel weniger kräfti sind. An einigen Orten hält man sie mit den noch daran sitzenden ebeufalls selir wirksamen, äufserst bittern Blättern vorräthig, welches der Verwechselung were garis.) blatter und viele meistentheils aufrechte Stengel bat, die gemeine Kreuzblume aber nut mit lauter schmalcu, gleichbreit - lan $\rightarrow$. zettörmigeu und kleinern Wurzelbläuern versehen ist, ihre Stengel meistentheils darniederliegen, und die ganze Pflanze nur Verfälscht mit den Diese Wurzel ist gewöbúlich gröfser und diWurzeln des Kno- cker, braun und fast gàu geschinac!llos, tenwegerichs (Po- überhaupt bey einiger Aufmerksamkeit lygotium aviculare Ieicht davon zu unterscheiden.

L.). $r$ gut ist.

Wurzel der anf Ilügeln und buschichtcn A nhöben wacbsenden We i 5 w u r $z z$ a uke (Convallaria polygonatum L) Eine horizoutal in der Erde liegente, gegliederte, eines kleinen Fingers dicke Wurzel. Am Ende oder auch wohl zur Seite der Wurzel bcmerkt man Eindiriicke, die Aehnlichleit mit einem aufgedrückten Siegel haben. Sic ist mit wcnigen Fasern beset $z$ s, äufserlich weifslich, inwentig behet $z x$, äufserlich weifslich, inwentig
sehr von einem siifstichen, schleisehr weifs, von einem siifslichen, schlei-
nìiclsten, etwas schärnicls retrigartigen Gemichten, etwas schärnich retigartigen $\mathrm{Ge}-$
schmack, und friscb von äbnlicbem Geruch, der aber beym Trockuen fast gänzlich vergeht. In $W$ asser geweicht, zergeht sie fast gănzlich zu Schleim. Sie mufs an eincm trockuen Orte anfbewahrt werden, weil sie'soust leicbt Feucbtigkeit anziebt.

.

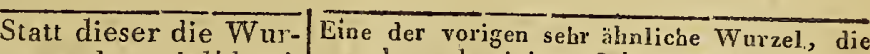
zes der vielblumi- auch nach cinigen Schriftslelleru als die gezz Zauke (Con- wahre Schminkwurzel angegeben wird. Die vallaria munltiflora Pllanze unterscheidet sich durch ibre runL.) den Stengel niad' durch die Blumenstiele, die inmer drey bis funf Blumen tragen, whatt dars die Blumenstiele der erstern gewobnlich eine, selten zwey, mipmals aber mehrere Blumeu tragew. Die Pflanze ist übrigens in allen ihren Theilen grölser.

Die Wurkel vom Engelsüfslüpfelfarrn (Polypodium vulgare L.) Eine längliche, gänsekicldicke, walzenförmige, gebogeve, kuolige odcr gezähnt gegliedcrtc, zähe, mit äufserst feunen Fasern versehene und dicht mit länglichen, dïnnen, braunröthlielıen Schuppen besetzte Wurzel, die ätifserlich braun', inwendig gelbgrïnlich ist, einen sülsen, etwas zusammenziehenilen, ranzicht-eckelhaften Geschmock und ähnlicben Gerich hat. Man sammlet sie im ersten Frühjahr, reinigt sie von den Scbuppen und Zasern, und verwirft die holziclten, bohlen, barten, gesclimack - und braftlosen Wruzeln. 


\begin{tabular}{c|c}
- Namen & $\begin{array}{c}\text { Sinnliche Eigenfchaften derfelben; } \\
\text { Merkmale ihrer Aechtheit und } \\
\text { der Arzneýmittel. }\end{array} \mid$ Guite.
\end{tabular}

Radix Pyretleri. Die Wurzel der in Asien und Afrika an den/S Bertramwurzel. Küsteu des mittellandìschen Meeres frey-
villig wachsenden, in Dentschland, bewillig wachsenden, in Dentschland, be-
sonders is B̈̈hmen, Thüringen und in Magdeburgischeu mit Flafs gebaut wcrdenden Bertram chamille (Anthemis) Pyreitrum L.) Eine olmgefahr spaunenlauge, ruozlichte, walzenfürmige, schlanke, zähe, wenig befaserte, gewöhnlich noch nicht pfeifcnstielicke, autsen branliebe, inwendis weifsliche Wurzel, von einem sich mach und nach entwickelnden, sehr scharfen brennenden, lange nachbleibenden, der Senega ähnlichen und den Speichel berbey lockenden Gesehmack, aber obne allen Gerucb. Mau erbielt sie sonst über lialien und Marseille, sichercr aber ist es, die in Deutscbland gezogrene, welche man im Frülsjabr ausgräbt, zu wäb-

\section{Fehlerliafte Be- chaffenheic, Ver- weclifelung oder} Verfälfchung.

\section{$K$}

Kennzeichen und Priifungsmittel. wird häufig die drey Zoll lange, graubraune, obenthe Wurzel der staudi- ringsum in Geslalt eines Barts staruclilose, gen Wucherblume harken we wehends, doch im mill(C/urysanthernum homsan deren Grade als dit achte, brewnesd schmekauft.
häufig für die äclite hertramswurzel verhäufig für die äclite
sendet werden soll.

tatt derselben auch Eiue lange, cyliudriscbe, ctwas gegliederte, wohl die Wurzel fast ästige, duinne, z he, stark mit Fasern des weifsen Do- behangent, aufsen graugelbe, iunen wersrants (Aclilllea lichte Wurcel, ohae Ptarmica L.) und von scliarf beifsendem, seifenhaftem, zuletzt fast stithasandantig m Gioch die ebeifalls beym Kanen den Zuthufs des Speiclsels sebr befördert.

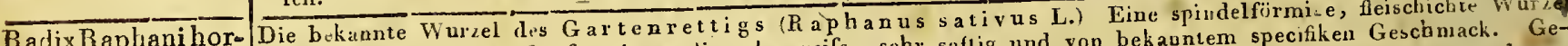

Rettijwurzel.

Radix Rhei s. Rhavon verschiedener, Gröfse, inwendig sehr. weils, sehr salg ne weilen der aus der frischen Wurzel gctrocknet wird sic jetzt nicht mehr gebraucht, wobl aber zuweilen der aus der trocknet wir barbari.

Rhabarber. ne von ibrer Rinde befieyte, festc und Verdorben.

leichte Wurzel von einer etwas schwammichten Deschaffenheit, auswenilig von geheuden Farbc, inwendig, aber poinmechen und Flecken versehen und gleiclis.ım gemasert. Sie hat eineu besondern, einigemasert. Sicurzhaften, den mebresten gen mafsen gewtrzaten widrigen Geruch цnd einen bitMenschen widrigen terlicben, etwas scharfen, einigermalsen $z u-$ sammenriebenden unangenebmen planze der Rhabarber ist man noch nicht sie nicht yon einer Species allein, sopdern von mehrern zu der Gattung $P$ be um gehörigen Arten gesanntct werde, namentRhe um palin at um L., R beum compactin L. und R be um crue ntil ber hauptsächlich in der chinesischen Tartarey und au den Grän en vou China, wo her wir sie auf verschiedenen Wegen erhalten. Aufserdem wird sie auch jetzt in verschiedenen Läudern von Europa ge-

Es kommen vorzüglicb d'ey Sorten Rhabarber in Haudel vor, nämlich:

barber in tis s ehe Rhabarber ( $R$ habarbarum rusicum, sibiricum, moscoviticum. Sie ist die theuerste und beste Sorte, und wird $2 u$ Lande von den Bucharischen Kaufleuten nach Kiacbta in Sibirien gebracht, woselbst sie geuau untersucht wird, die schlechten Stucke auf der Stelle verbrannt ind nur die gnten ausgelesenen, nochmals gesäuberten Stücke ausgelesenen, Kisten nach Moskau uod von da nach Petersburg gehracht werdea, wo abernals die schlechten und mittel miäfsigen Stücke abgesondert und vernichtet, die guten aber sodann an jedermann verkanf werden. Diese hbabarber erhatt man, weil die Siücke mil dem Messer ausgeschinitten werden, in vieleckigen, el was lauglictrunilichen, oder in platten, llachen, handgrofsen, zwey Zoll oder minder dicken, oder in pferdehufähnlichen Stiicken, die mit iertelszullweiten Bohrlöchern versehen sind, oder so starkc llöhlungen baben, dafs sie unanchinal einer Juude ähulich sehen. Thre Farbe ist matnorit, aus Rosentroth, Weifs und gelb, oft in sternförmigeu Scbatlírungeu. - Sie läfs sicb leicht zwischen den Fingern zcrbreclen, und zwischen beyn Kauen merklich zwischen ken Zähnen. Dem Schimmel und dem Wrie mehr unterworfen als chie Wurmfrals ist sie metir unterwor leichter nachfolgendc ostindische, auch leichter von Gewicht, Ibram näclusten kommt die sogegelbcr oder safranartiger , ins Rothe überins Reine; wahrscheinlich ist es woht, dafs lich !rou $R$ he u m u n d ul a t a m L. Rhapontikwurzeln (Rad. Rhapontici) verfälscht.

Mit der Mönchisrharum.)
Mit untermischten bartier (Rhabarweniger auch die ausweudig und inweudig schwarzbraune oder schwarce, so wie diejenwar jenige, welcher ander oder dumpig ist, werden gen, oder eine andre uble Eigerchalt dex Rbabarber zu rerdeckear bestreich ma sie zuweilen mit gelben Ocher oder mit Pulver von guter Kluabarber, womit maa auch wohl die Wurmlöcher ausfinllt. Dieser Betrug läfst sich aber leicb' entlecken indem sich das aufgestrichene Pulver mit der Hand wegwischen lifst. Zuwelleo wird der Ocher oder das RhabarberpnIyer mittelst eincs Gummischleims anfgcstrichen telst ein wum solchereste weshalb man che Genische an dicser Betrüdiejenigen Wurzelu, welche dicher Belrits get ey verdactig sind, aulbrechen rnufs, um die Wurneche nicht hat dringen können.

Diese rou der sim siblicheu und Rufsland cinbeimischen R bapontikrhabarber Rheum Rhapon 1 icum L.) barber (Rhe um Rhaponticum L.) kel elber fast brauner Farbe, inneslich kit demMittelpunct strahleutörmig ausgebeulen Streifeu gezeichnet. Sie hat cinen schwachen, nicbt unangenehnen Rhal, asbergeruch. Beym Kauen ist sie scl leimiger und zaher, knixscht $z$ wischen den Zähnen nicht, firbt den Speichel nur wenig, scbmeckt fillbt dcr Splur zusammenzi hend, aber schar fer, metrich und widerlich als die wenicer bitterlich un welcher. sie sich noch ächle Rbabarber, von welchs sie in längern, dadurch unterscheidet, dals sie in langern, dünnen, cyliudrischer, ineistcns gespalte-

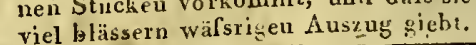

Dies Wurzel, für desen Mutter pllanze man den südlicheu Luopa, in dor Scliweiz den im sudich wachsenden A l pen a mpfer (l umex al pinus L.) augielt, unterscheidel sich darlurch ron der äcbten Rhibarber, dafs sie geschält in runzlichten, laugen, auswendig braunen und inwentio scbmulzig bräuulich - oder grïnlichelben, mit cimkelrothen Adern durchlicbgelo Sitterlich zogen viarker zasamrhabarbcrar auch den menzleheod schncck Speichel sallrangelb farhe nur ochwach purEckel erregen nnd eine 
Radix Rhei s. Rhabarbari. -- Radix Rubiae tinctorum.

\begin{tabular}{|c|c|c|c|}
\hline $\begin{array}{c}\text { Namen } \\
\text { der Arzneymiltel. }\end{array}$ & $\begin{array}{c}\text { Sinnliche Eigenfchaften derfellen; } \\
\text { Merkmale. ihrer Aechelheit und } \\
\text { Guite. }\end{array}$ & $\left|\begin{array}{c}\text { Fellerhafte } B e- \\
\text { rchaffenheit, Ver- } \\
\text { wechfelung oder } \\
\text { Verfälfchung. }\end{array}\right|$ & $\begin{array}{l}\text { Deren } \\
\text { Kennzeichen und Prïfungsmitcel: }\end{array}$ \\
\hline
\end{tabular}

Radix Rlueis.Rha- nannte türkische $\mathrm{Rb}$ abarber (Rba-

barbari.

b a rbarum turcicums. al exandri-

nen versehen ist, jetzt a der nur mit klei-

nen versehen ist, jetzt
Tlandel vorkommt.

2) Die Ostiudische, Chinesische, tartariscbe, auch wohl holländische oder dänische Rbabarber (lihabarbarum indicum, chinense, hollandicum, danicum), die wir zur Sec bauptsächlich durch die Dämen und Holländer aus Canton in China exhalten, und die aus den wärmeln $\mathrm{Ge}-$ genden des chinesischen Reichs kornmen soll, weshalb sic, so wie wegen der mancherley Verderbnisse, denen sie cherey der weited Seereise ansgesetzt ist, ful minder gut gebalten wird. Sie besteht aus meistens drey bis vier Zoll langen und einige Zoll dicken, walcenförmigen, wahrscheinlich von 'unteru Theile der Wurzel genommenen, oder von beyden Seiten, wie es scheint, gewaltsam flach gedrïickten und geprefsten, oder auch vou dem obern Theile gellommonen und in zwey Hälften gespaltenen guten und schlechten Stücken untereiuander, die nur selten durcblöchert, ziemlich schwer, bart und dicht sind.

Die Kenuzeichen, wodurch eine gute und ächte Rhabarber sich anszeichnen murs, bestehen iu folgenden. Sie muls trocken, mäfsig scbwer, äufserlich matt lichtgelb, grülichtgelb oder rothgelb, von einem einigermafsen schwammichten, doch dabey auch festen, nur nicht steinharten Gewehe seyn. Auf dem ungleichen frischen Bruche mufs sie gieich einer zerbrochenen Muscatennufs eine gelbgrünlich weifs marmorirte, mit lebbaften rosenrothen Adern und Flecken bezeichnete Oherfl̈che Sie mufs sich leicht pulvern lassen, und das Pulver mufs das Pulver mafs eine sattgelhe, ins RothTiche spielendo Farbe baben, zwischen den Zahne murs sie knirschen, den Speichel sehr bald safirangelb färben, und keinen leimichten oder schleimichten Geschrnack besitzen. Durch das Reiben mit den Fingeru darf sie ibré Farbe nicht verändern, auch mafs sie keine künstlich angefüllte Wurmlöcl:er zeigen. Durch darauf getröpfelte Mildkaliflüssigkcit mufs sie sogleich eine rotbloraune Farbe annehmen, und mit Weinalcolol eipen mit Wasser liche Tribung zu mischenden-Auszug! geben.

3) Die Europäische oder einländische $R$ babarber (R a ix Rhabarbari nostratis.) Man erbält sie durch die Cultur der angegebenen Rhabarherspecies in verschiedenen Länderu von Europa, uamentlich auch in mehreren Gegendeu von Deutschlaud. Sie besteht aus kleinern, in die Queere zerschnittenen, oder auch in die Länge gespaltenen Stücken, yon srünlich selber Farbe, die awar der ausländischen Rhabarber ähnlich riechen und schme-

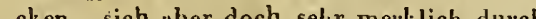
cken, sich Jbre te Beschaffeuheit, duch den weit bitterern und weniger adstringireaden Geschmack, durch den Margel des Knirschens zwischen den Zähnen, durch den gesiugern Gehalt von kieesaurer Kalkerde, die bey der ausländischen $\mathrm{Rh}$ abarber jenes Knirschen verursacht, so wie durch ihre geriugere Wirksamkeit in Hinsicht der abführenden, von dieser unterschcidet. Sie darf daher auch nicht von den A pothekern für die anslänlische verwendet werden and dar dische ver a dann zu Ar ney gebraach werden, wenn der Arzt aus besondern Rücksichten sie aus-
drücklich verorduet.

Wurzel der jn verschiedenen Gegenden von Deutscbland gebaut werdenden Färberröthe (Rubia tinc tor u m L.) Eine kriechende, ästige, sehr lange, federkieldicke, knieförmige, mit starken Seitenfasern becetzte, vou aufsen mit einer dünncn, blafsbraunen Haut üherzogene, daruncer rothgelbliche, in der Mitte markige und aunkelrothe Wurzel. Sie besitzt keinen Gerueb, áber eipen zusammenziehenden, bittorlichen 


\section{Radix Rubiae tinctorum. - Radix Scillaes. Squillae.}

\begin{tabular}{|c|c|c|c|}
\hline $\begin{array}{c}\text { Namen } \\
\text { der Ärznejmittel. }\end{array}$ & $\begin{array}{c}\text { Sinntiche Eigenfchaften derfelben } \\
\text { Merkmale ihrer Ächtheit und } \\
\text { Güte. }\end{array}$ & $\left|\begin{array}{c}\text { Fehlerhafte } \text { Be- } \\
\text { Schaffenineit, Ver- } \\
\text { wechfelung. oder } \\
\text { Verfälfchung. }\end{array}\right|$ & Deren \\
\hline
\end{tabular}

Radix Rubiael Geschmack, und färbt den Speichel, das Wasser don Weingeist, die ätherischen Oele, ja selbst die Knochen der damit gefülterten Thiere roth. Die Lolzigen, schwarzgefleckiten oder schwärzlichen, augefresscaei Wurzelı müssen verworfeu werden.

Radix Salap.

Die Wurzeln von verschiedenen, auch in Deutschland auf Wiesen, in feuchten Waldungen nnd Gehölzen wachsenden Pagwurtarten, besonders der $S$ ala pragw urz (Orchis. Morio.L.) und der Männlichen Ragwurz (Orchis mascula L.) So wie wir die Salapwurzeln im Inandel erhalten, erscheinen sie meisten. theils als länglich-ejrumdliche, knollige, bisweileu bandförmige, halbdurchsichtige, horuartige, schwere, barte, weif'sgclblicbe oder bräunlichgraue, auswendig raube, hin und wieder mit vielen 1lachen Giübche versehene Wurzeln, von der, Gı̈̈lse einer Kaffeehohne bis zu der einer welschen Nufs. Sie besitzen keinen Geruch, aber einen sebr schleimichten Geschmack, und bestehen aus lauter trockuem, innigst mit Colla gebundenen Schleim, so dafs die gepulverte Wurzel vuter fleifsigem Umrühren mit heifsern Wasser uud gebundenen Schleim, lindern Kochen fast ganz darin aurgeloset wireihet. Die braunen, welken, wurınstichigen, modrigeu Wur-

Radix $\overline{\text { Sapona. }}$ riae.

Seifenkrautwurzel.

Liadix Sarsaparillae.

Sassaparillwurzel.

Sarsaparille. zelu müssen als untauglich verworfen werden.

ie Wurzel des Speichelseifenkrants/Verwechselt mit der|Sieht nicht rothaus, sondern ist weifs un (Saponaria officinalis L.) Eive Wurzel der ge- holzicht.

walzenfürmige, kriechende, knotige, gebogene, ästigc, gegliederte, feste, befaserte, zwey bis drey Tufs lange, ohngefabr eines keiuen rinors dicke, auswendig röthliche oder rothbraune, inwendi gelblichte, in der Mitte weifse Wurzél ohne merkliclien Geruch, aber von einem anfangs süfslichern, bintcidrein bitterlichen, etwas scharfen, einigermaisen klebrigen Geschmack.

Als Mutterpllanze der Sar'saparillwurzel gab ruan sonst gewübnlich den $S$ a $\mathrm{s}$ a $p$ a $r$ ill smilax (Smilax Sarsaparilla L.) an. Herr von Il um bo ld $t$ iS. Berliuer Jahrb. d. Pbarm. 2806 . S. 86 ) zeilgte dess vorker noch nicht bekannten, an deil Ufern des Oronokollusses wachsenden dent Art, weiche er Su nemin, abstanne. So wie die blos aus Trandel vorkont, besteht deu, einige Fuls langen, federkieldicken, zälseu, biegsameu, dcr Lange nach leicht $z$ u spaltendén, mnehligen, etwas runzlichten und gefurchten, auswendig bratuen, inwondig weifsen, yerschiedentlich in einander, gelegten und vor ihrer Versendung ron deu Fasern gereinigten Aesten der. knollichten, zolldicken Hauptwurzel. Sie haben kcinen Geruch, aher einen etwas schleimichten, schwach bitterlichen, inehsebleimichien, ligen Creschmack inan enaparille entweder in eine Rllag $2 \mathrm{u}-$ da), oder in der Länge in Bündelchen ge-

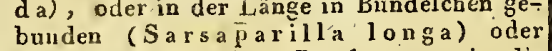
auch wolıl in grölsern Bunden, worin die ganzeu Wurzeln oder die woch zaserigen Aeste mit ihrem Wurzelkopfe vereinigt, obne Ordnnug zusammengerollt sind, als lose Sarsaparille (Sarsaparilla de Honduras.) Diesc letzle Sortc ist minJer luafic und zun Arinersebrauch weder kan den beyden ersten niger taugich. Sorten ist die runde dic theuerste; gewohnlich werden bey diser und der langen die besten, reiusten und stäkstcn Wurzeln nach aufseu gelegt, und das lwaere besteht aus kleinen schlechtern Stucken uud Abgänzen, die nebst den auswendig scliwarzen, inwendig zerreiblichen, an neu und dumpfig riechenden Wurzeln zum Arzneygebranch verwor fen werden müssen. trennteni Lychnis

L.)

Statt derselber die M
Wurzeln des Pier-
hopfens (Humules
Lupulus L.)

Tan will in Frankreich bemerkt haben, dal diese Wurzeln sehr oft fur ächte Sarsap2-illwurzeln rerkauft werden; sie lassen sich indefs durcb Vergleichung mit den äch-inderichen.

Aufserdem sollen der Sarsaparille noch verschiedene andere americanische Wurzeln, z. B. von der Aralia nudicaulis nntergeschoben werden.

Im S. 559 ) lieset man mit Erstannen, dafs jemand klein geschnittene Besenstiele betrügerischerweise der Saxsaparille substituir habe.
Radix Satyrionis. Stendelwurzel.

Radix Scillae s. Squillae.

Meerzwiebelwur-

zel.

Die Wurzel in Wälen Gebiuschen wachsenden zweyblättrigen Knabenkrauts (Orchis bifoWurzel des in Wäldern und Gebuschen wachsenden zwestite, dichte, harte, lleischichte, obngefähr einer MusIia L, Eine zwiebclartie, Wenn man sie ausgräbt, welchcs nach catennuis grolse, blafsarbige, schleinichts aligelinbeten Stengel im Ansgang des Sommers gescur die festen, dichten und saftigen nebmen, die runzlichten und saftlosen aber zuricklassen mufs.

Wurzel der an den Küsten des mittelländischen Neeres nud den sandigen Ufern von Sicilien, Spanien, partugal, Syrien und dem nördlichen Africa wachsenden Meerzwiebelsquille (Scilla.maritima L.) Eine , Syrien und dem ofter's einfornige, uuten befaserte Zwiebel, von der einem, bey jungen $Z$ wiebeln weifslichem, bey ofters einige Pfund schwer. Aenfserlich ist sie mit eir aber braunrötllichem, aus saftlosen trocknen Schuppen bestelenden, In Lendig bestebt sie ans vielen breikleidet und mit einer gerade in die Höhe gehenden Spitze verseben. 1nwend̈glich ins Grünliche spielcnden ten, dicken, an den Seiten dünnern, nervigen, feischichten, weilsen, gewönnlich ins Grëufserst scharfen, Schuppen, dic im frischen Znstande sehr reichlich uit einem dickschleinichten, weifsen, ist unbedentend;

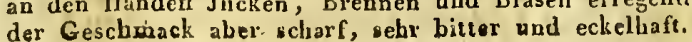




\begin{tabular}{|c|c|c|c|}
\hline $\begin{array}{c}\text { Namen } \\
\text { Ier Arzneymittel. }\end{array}$ & $\begin{array}{c}\text { Sinnliche Eigeinfchafien derfelben; } \\
\text { Merkmale itrer Ächtheit und } \\
\text { Giite. }\end{array}$ & $\begin{array}{c}\text { Fohlerliafie } B e- \\
\text { fchaffenheit, Ver- } \\
\text { wechlelung oder } \\
\text { Verfälfchung. }\end{array}$ & $\begin{array}{l}\text { Deren } \\
\text { Kennzeichen und Priffungsmittel. }\end{array}$ \\
\hline
\end{tabular}

Ranlix Scillae s.|
Squillae.

Radix Scorzonerae. Scorzonerwurzel.

Radix Senegae. Senegawurzel.

Man crhält in Handel entweder die friscien Zwiebeln, orler die schun inelr ockneten Schuppeu. -Erstere lassen sich, in Sand eingryiaben, lange aufbewabren; zurn Trockuen wextur dic saftlosen Schuppen und die Wurzelfasern abgesondert, die einzelnen saftigen Schnpncn auf einem Siebe oder einer Weidenhorde auseinander gebreitet uud in ennen erwärmten Ofen getrocknet. Darch die ehemals gebräucbliche Methode, sie in Brodteig zn backeu, leiden sie zu schr an Krafteu. Die im Handel vorkumnenten Schuppen sind länglich, etwas durcbsichtig, zerbrechlich, weifslich, inwendig glatt und mil Limeí ducchogent. Beym Kaucn sind sie sehr zäbe und schmeckeu iiberaus bitter, lassen aher doch eben keiue Srï̈rfe bemerken.
Dic leichten, saft- und geschnacklosen, schwarz gewortenen Schuppen tangen wicht. Das Pulver der Meerzwiebel zieht leicht Feuchtigkeit an, voil darf nicht in zil grofser Menge vorrithig gehalten werden.

ie wird uach einigen Schriltstellern von der Garteuscurzonere (Scorzoperabispauica L.) pach andern von der Waldscorzonere (Scorzouera humilis L.) gesammlet. Die Wurzel der erstern ist ziemlich lang, spindelförmig, uhugefähr einen Zoll dick, aufscrhath mit einer schwätzlichen Haut bedeckt,

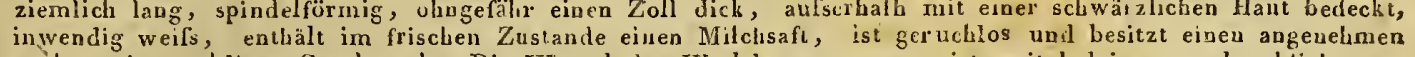
zuckerartig - - nehligen Geschmack. Die Wurzel der Waldscorzonere ist weit bolziger, zerbrechlich, geringelt, aufsen rostfabig, in wendig weifs, von bitterlich-terhern Geschmack und ebenfalls Init einem milchartigen Safte versehen.

Wurzel des im uördlichen America, besonders in den Provinzen Virginiel, Maryland und Persylvauien, iu licbten' Waldungen wachsenden $S$ euegaramsels (Polygala $S$ encga $L$ :) Liue ausdawernde Wurzel, die an ibrem obern Ende knotig ist, die Dicke eincs Federkiels bis zu der eives kleinen Fingers bat, und sich in mehrere. Aeste, die sich zuletzt in düune Fäserchen endigen, zeriheil t. Die Aeste sind un'egelmäfsig hin und her gebogen, oft gleichsam gedreht, knotig, runzlicht geringelt. Auf zwey Seiten sind sie mit einem, vicht imraer unuaterbrochen fortlaufeuden, häutigen, wulstig unehenem Rande versehen. Man unterscbeidet an der Wurzel leicht $\mathrm{zw}$ wey besondere Theile, näılich die mit einer gelblichgrauen Oberhaut üherzogene Riude und einen inwendigen holzigen Fadeu. Erstere ist ziemlich dick, dicht und gleichartig, nnd wie mit einem verdickten Ptlanzeusaft durchzogen. Thr Gesclimack ist anfangs mchlig, bald darauf süfslicb-säuerlich, znletzt scharf und einen äufsetst unangénehínen Reiz im Schlunde crregend, der ziemlich lange autält. In dieser llinde liegen die eigentlichen wirksamen Bestandtheile der Wurzel. Der iutsere Theil der Wur sel bat eine hellere, weifslich-gelbe Farbe, ist faserig, Lolzig und zeigt nur einen geringen Gescher der sursiskeit abstrahirt, einige Aehulichkeit mit den der Lacritzwurzel Gescbmack, der, wenn man von der Wishen eigenthümlichen, etwras nauseösen Geruch, der bey mochen hat. Die Wurzel zeigt allch einen schwachen eigenthümlichen, etwas nasseösen Geruch, der beym Kochen derselben mit Wasser und beym Stolsen starker wird, und der manchen Personen mit dem Geruch des
Olivenüls einige Aebnlichlikeit zu haben scheint. Zum Pülvern wird durchs Quetschen mit eiuer bölzernen Olivenüls einige Aebnlichlkeit zu haben scheint. Zum Pülvern wird durchs Quetschen mit eiuer bölzernen
Keule unid durchs Abscblageu die Riude erst von dem kraftlosen innern holzicbten Theil befreyt, und diese daun möglichst fein gestofsen, in einem fest verstepften Glase aufbewabrt.

Radix Serpentariae

Virginische Schlangenwurzel:

Radix:Spigeliae. Spigelienwurzel. Radix Taraxaci. Löwenzahnwurzel.

Radix Tormentil. lae.

Tormentillwurzel.

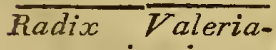
nae minoris. Baldrianwurzel.

Die Wurzel der in Virginien, Maryland und Mit den Wurzeln des|Diese Vermisclung verrath sich sowohl duw Carolina einheinnischen Virgiuienoster- virginischen Ha- die abweichende Gestalt als durch die lucey (Ar'istolochia Serpentaria) selkrauts (Asarum) sehwarze Farbe der untergemiscliten WurL.) Sie bestebt aus vielen diinnen, durcheiuander geflochtenen, einige Zoll langen, aus eiuem kleineu kuotigen Wurzelkopfe, der aucls oft noch mit iden Ueberbleibseln
des Krauts versehen ist, entspringeudeu Fasern. Auswendig Laben dicse Fasern eiue bräuulich-grüne Farbe, inwendı siud sie weifslich oder gelblich. Ihr Geruch ist sebr durchdringend, gew ̈̈rahaft,

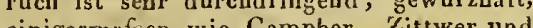
einigernatse wie Campher, Zittwer und Beschafeuheit, dabey etwas beifsend und erwarmend bitterlicb. Mall wălit die möglichst stark riecbenden, uud da gewöhnlich noch Reste von Stängeln und Blätteru daran bängen, diejenigen aus, a deren letztere noch etwas grün sind.

Da diese sewöhnlich mut dem Kraute zugleich verschricben wird und auch so im Handel vorkomint, so ist das nötlige darüber bereits oben gesagt. S. Therba Spigeliae.

Die Wurzel des Löwenzahns (Leontodon Taraxacum L.) Eine spindelförmige, spanpenlange, fingersdicke, zuweilen astige, befaserte, aufsen brauschwarze, inwendig weilse, in der Mitte einen holzichtitn

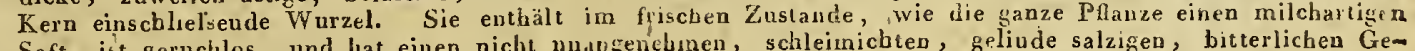
Saft, ist geruchlos, und hat einen nicht muatyenchmen, schleimichten, geliude salzigen, bitterlichen Grem
schmack. Man muls sie im Frühjahr ausgraben.

Wumel der in ganz Dentschland in Wälderu und Gebüschen, so wle auf trockneu Wiesen wachsenden Fotbleiltormentille (Tormentilla erecta L.) Eine knotichte, knollige, kurze, gebogene, 'fingersdicke, obenher scluppichte, mit vielen langen nud steifeat Fisern besetzte, aufsertalh rotohraune, innerlich hlafsruthe oder gelbrothbriunliche, of mit holzichten Siellen gefleckte Wurzel, die ohne Gerach ist,
aher einen aufserst beibeu, adstringireuden Geschinack hat.

Dje Wurzel des in trorhnen bersicbleu Ge-Statt der ächten Diese Ahart bat breitere und glä̀zendere genden wachscuden $K$ atze ubaldrians (Valeria ua of ticinalis L.) mit schinalen Blätterv. Sie bildet einen hurztu, lainslichen, gewisser mafsen abgestutaten WVurzelkopf, der "oa allen, Selten viele lange,
rabenkieldicke, schlanke, zabe, mit kurzen Haaren besetzte, auswendig brăuriliche, ins Olivenfarhige spielende, inwendìig weifslichte, mit einem gi ünlichten. Kresse $u m$ das Mark versebeoe Fasern bat. Ibr Geruch das Mark versebeoe rasern bat. Ibr Geruch
ist stark, durchilungend, von eisener Art ist stark, durchdringend, von eigener Art

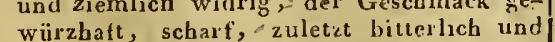
würzbaft, scharf, zuletict bitterlich und
etwas zusammenzieheud. Die Wurzeln etwas zusammenzieheud. Die Wurzeln
müssen in Frübjahr, elhe der Stamin der Pflauze hervorkomint, und zwar von trocknen bergichten Standörtern eingesammlet, die langęn scllanken Wurzelausläufer da-

Wraidbaldrianwurzeln werden häufig die Wurzeln einer an feuchten Oertern und Gräben wachsenden Abart gesammlet.

Verwechselt mit den Wurzeln des kleinen Sumpfbaldrians (V ileriana dioica $L$.)

Tit den Wurzeln des Diese sind sonst auch zuter dem Iraneu der \begin{tabular}{l|l} 
Gartenbaldrians \\
(ValeriangPluLL.)
\end{tabular} Valerianae majoris) officisell. Sis Blatter, die Wurzeln sind dickcr, weni-
ger baaricht, mehr holzicht, zerbrechlich, ger baaricht, mehr holzicht, zerbrechlich, ausweendig aschfarbenbrauu oder braun-
gelb, inwendig dinkelfar biger, 2 wwellen fast scliwarz, oft holl in der Mitle, riechen unangenehm $r$, schmeckeu scbärfer aber nicht gewürzhaft und sind vou weit geringerer Wir ksamkeit.

iese sind dunnaseriger, kriecheud, sehen vict weifser aus, riechen scluwấcher und siud weit unwirksamer.

$\checkmark a t e r i a n a e$ majoris) olacisels. 


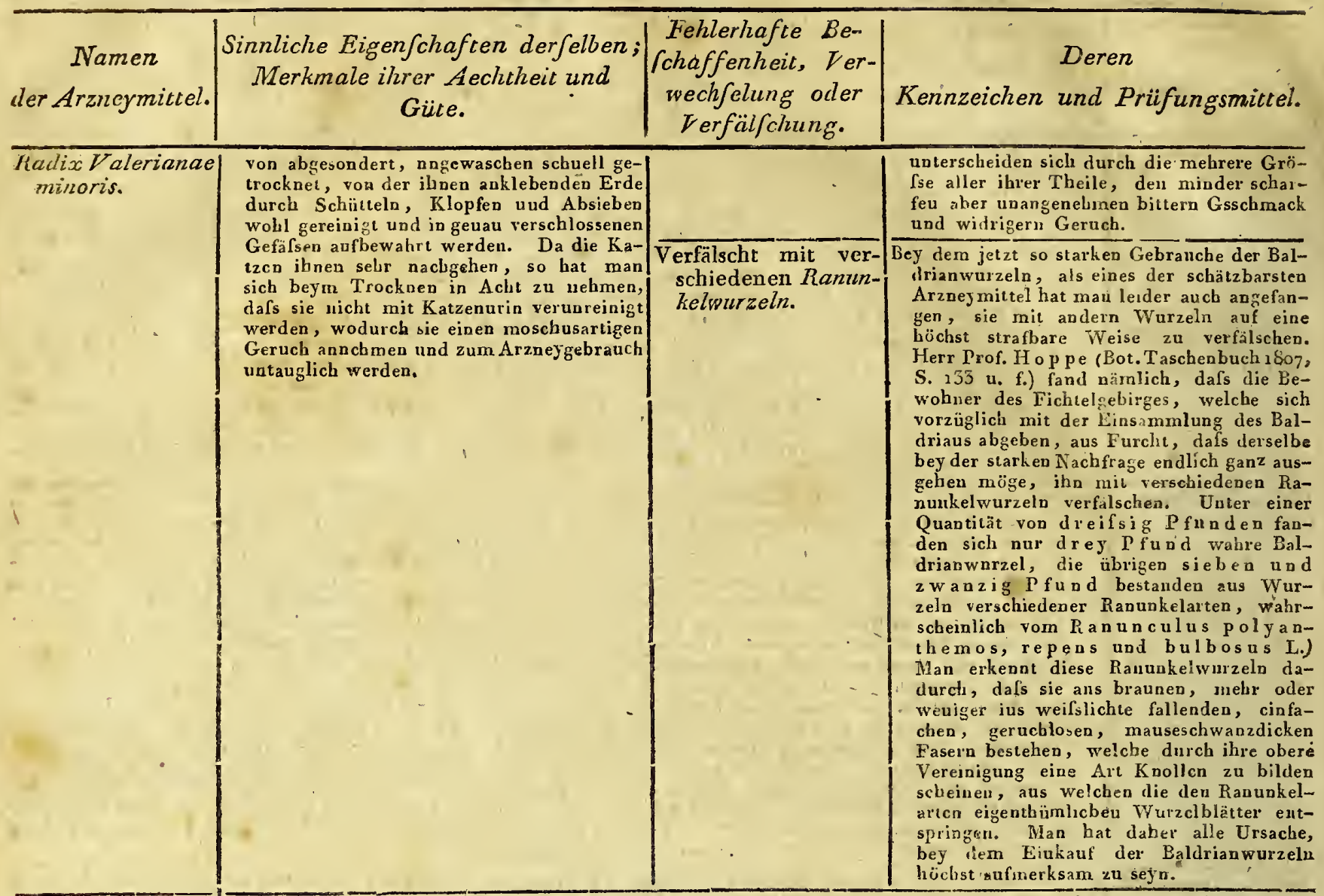

Radix Vincetoxici s. Hirundinariae. schwalbenwurzel.

Radix Zedoariae. Zittwerwurzel.

Rnadix Zingiberis albi.

Weifser Ingwer.

Kesina elastica s. cayennensis.

Gummi elasticum. Elastisches Harz. Foderharz.
Die Wurzel der in waldichteu, bergichten Gegenden wachsenden gemeinen Schwalbenw urz (Asclepias Vincetoxicum L.) Ein länglicher, rundlicher, gelbröthlicher Wurzelstamm, der sich in viele dünne, lange, in vershiedenen Ríchtungen gebogene, untereinander verwickelte, weifsgelbe Fasern zertbeilt. Im frischen Zustande bat die Wurzcl einen starken widrigen, haselwurzartigen, getrocknet aber katom merklichen Geruch; ihr Geschmack ist clst süfslich, nachler bitterlich uud etwas scharf. Da gewöhnlich viele dieser Wurzeln neben einander wachsen, so scheinen mehrere, dereu Fasern man vor dem rocknen zopfartig. zu-
sammen fechtet, nur eine Wurzel zii seyn. Die Wurzel des in Ostiudien wachsenden|Verdorben. Zittwerimbers (Amomum Zedoari a Ber g.) Eine knollige, scbwere, äufserlich weifsgraue, iuwendig etwas bräunliche Wurzel, die theils in runden, auf einer Seite unebnen, runzlichten, eines kleineii Fingers dicken Stücken als $r$ under Zittwer (Zedoaria rotunda), theils in einige Zoll langen, gegen einen halben Zoll dicken, an einem Ende stumpfen, am andern spitziger zulaufenden
Stiicken, als l anger Z it i wer ( $\mathrm{Zed}$ oaria longa), rorzǘnlich aus Malabar und Ceylon durç die Holländer zu uns kommt. Sie besitzt eíner stark bitterlichen Geschmaek und starken wewür,baften, fast camplierartigen Gerucls. Deu runden Zittwer hält man für weniger wirksam, als den langen; beyde kolnunen übrigens von den langen; beyde kominen uns einer Pflauze, nad wabrscheinlich macht
der runde den obern Theil der Wurzel aus. Gute Zittwerwurzeln mïssen schwer, zähie, fest, wenig fasericht seyn und angevehm riechen.

Die Wurzel des in Ost - und Westindien wachsendeu $1 \mathrm{ng}$ werimbers (Amomum Zingiber L.) Eine ohngefähr zwey Zoll lange, knotichte, knolligc, etwas ästige, zuweilen baudförmíge, dichtc, ruuzlichte, flach znsammengedrückte, schwere, auswendig weifslichte oder strohfarbige, inwendig harzichte und gelbweifsliche Wurzel, die einen sehr scharfen fenrigen Geschmack uud angenehmen, gewürzhaften Geruch hat. Die leichten, zerbrechlichen, weichen, mürben, sehr zaserigen und wurmstichigen Stücke nüssen verworfen werden, und nur die trocknen, schweren, auf dem Bruche glatten und harzigen Wurzeln von starkem Gcruch und Geschmack zum Arzneygebrauch ausgewätlt werden. Den meisten Ingwer crhalten wir ans Jamaika; der ostindische abcr, vou Malabar, Bcngalen und der festen Kïste von Asien wird fur dcu besten gehalten. Der sonst noch im Handel vorkommende braune oder gemeine Ingwer (Zingiber com mune s. ui g ru m) kommt mit dem weifsen von derselben Ifllanze, unterycheidet sich aber von cliesem dadurch, dafs die frischen Wurzeln vor dem Trocknen in kochenden Wasser abgebrühet und abgewabchen, und zur Ersparung der Zeit schnell in einem Ofen getrocknet werden, der weifse Ingwer abcr, nachdenn er für sich allein von der änfsern grauen Rinde befreyet worden'ist, sorgfaltig an der freyen Luft getrocknet wird. Te sehr dehnlare tastiscle Substanz, die wcder Gummi noch Harz ist, sondern ein für sich bestehendes Wesen ausmat end Wesen ausmacbt und wahrscleinlich von mehrern Jatropa elastica Linin., Caoutchova elastica $\mathrm{G} \mathrm{mel}$.) gewonnen wirl. Man erbält dieselbe aus der bis anfs Holz eingeritzten Rinde disser Bitume, aus welcher sie als cin milchartiger Saft hervorquillt uud übcr thönerue Formen gestrichen, an der Luft oder der Hitze und dern Rauch ausgesetzt, allmälig zu einer brauneu harzäbnlichcu Masse verbärtet. Wrir be- 
Resina clastica s. caycnnensis. -- Resina Guajaci nativa.

\begin{tabular}{|c|c|c|c|}
\hline $\begin{array}{c}\text { Namen } \\
\text { der Arzneymiclel. }\end{array}$ & $\begin{array}{c}\text { Sinnliche Eigenfchafien derfelben } \\
\text { Merkmale ihrer Acchtheit und } \\
\text { Giice. }\end{array}$ & \begin{tabular}{|} 
Fehlerhafie Be- \\
chaffenheic, Ver- \\
weclifelung oder \\
Verfälfchung.
\end{tabular} & $\begin{array}{c}\text { Deren } \\
\text { Kenñeichen und Prüfungsmittel. }\end{array}$ \\
\hline
\end{tabular}

Rẹsina elạstica s. vieıfilsigen Thicren u. s. w.; an gewöhnlichsten aber als grölserc oder kleinere Fiascben. Es hat das Ancayennensis. seben eines dickeu, wevig durchsicbtigen Leders, besitzt cinen sehr geriugen Geschmack und Gerucb, ist sebr biegsam und äufserst elastisch, inehrentheils braun von Farbe, zuweilen auch wohl rötblich, blan, oder weifsgelb. Es schnilzt über etwas starkcun Fener zu einer schmierigen Masse, wobey es aber seine Faderkraft einbüist, breunt anjezüudet mit beller Flamme uud vielem Raucbe, und ist im Wasser, Weingeist und canstischen Alratien unaulïslich. Die fetten Oele winken nur sehr geringe und in der Hitze darauf. Die ätberischen Ocle aber äufsern. fast alle eine autösende $\mathrm{Kraft}$ darauf, besonders das Rosmarin-, Terpentinund Berustcinül. Am leiclitesten und vollkommensten wird es nit völliger Beybehaltung seiner Federkraft vorn Schwefeläther aufgelöst.

Resina Guajaci nativa.

Gummi Guajacum. Guajakhar,

Franzosenholzharz.
Das, vol zü̈lich aus alten biameu des Pockhol \& guajack (Guajacu un of ficina$1 \mathrm{e}$ L.) vou selbst aus der aufspringenden Rinde oder aus küustlich gemachten Einschnilten aussclswitcende, sonst auch durch eine Ait von Schwälea aus dem zerstüch-
ten Holzc- erhaltene und erhärtete Harz, ten Holzc erhaltene und erhärtete Harz. Wir erhalteu dasselbe in nnfömlicben, gro-
fsen, harten Stückeu, an welchen oft noch Ssen, harten Stückeu, an weichen oft noch Stiucke rer Riude hängen. Fs hat eineu
súfsbitterlich scharfen, kratzenden Gescinmack, ist $z$ crhrechlıcb, auswendig dunkelbrano orlcr gelbbrausgrï̈lich, inwendis abcr auf dcm unebuen glazuzenden Briache mehr blänliçgrün, bräunlich und wer gelleckt, gegen das Licbt gebalten balbdurchsichtig. In mäfsiger Hitze schimilzt das Gujakharz; auf glibhender Kohlen verbreitet es einen eigenthïmlichen, vicht verbreitet es einen eigenthïmlichen, uicht
unaugeuehmen Geruch, Von der Wärme der Hand erwcicht es nicht; beym Kanen der Hand erwcicht es nicht; beym Kanen
aber wird es zäbe. Es läfst sich ohne $\mathrm{Zn-}$ aber wird es zäbe. Es läfst sich ohne $\mathrm{Za-}$ sammenkleben pulvern: das Pulver besitat eiue gravlichweilse Farbe, wird aber nacb einiger Zeit srünlich. Von den Dämpfen der Salpctersüure und von schlecht versiistem Salpeteräthergeist wird es ant kurze Zeit bläulıch gefarbt. Denselken Farbenwechsel benerkt man unter gleiches Unnständen an $d e m$ in Weingcist aufgelösten Harze. Reibt man das Pulver mit arabiHahe. Reibt man das Pul Zncker zusamschem, und setzt daun Wasser hinzil, so ermen, und setzt daun Wasser-hinzu, so er-
hält die Mischung ebeinfalls eine grünlichhält die Misch

blane Farbe.

Ein Guajakharz, weiches an der Luft nicht das sprelende Grün giebt, und das aul Koblen geworfen, einen stinkenden Gerucb verbreitet, ganz dunkel, schwärzlich oder kürnicht ist, mufs verworfen werden. tatt des natürlichen Dieses ist bräunlicber von Farbe, that einen Guajakharzes das weriger schasfen und blos larzig bintern künstliche, mit Geschmack und ist picht so wirksam als Weingeist ans dem dasmatüılıche Guajakharz. In Werngeist Holze ist es völlig aullöslich, da bingigen das natiorliche immer etwas Rüickstand lafst. Nach Herrn Dörfiurt ist es indessen nicht, wahrscheinlirh, dafs das kïnstliche Harz fur das uatülichc verhanft werdeu Harz fur das uaturlich verkant werdeu
sollte, da jenes gegen das letzterc dieysollte, da jeneš gegen das letzterc diey-
bis viermal so boch im Preise zu stehen kommen würde.

Vit Geigenharz oder Man entúcckt diese Betriigerey an dem beauch mit gemeinem kannten $\mathrm{Har}_{\mathrm{Z}}$ - und Terpentingeruch, soHarze, dem man bald etwas anf glübende Koblen gestrent vorher mit Schaf-

garbenharze eine grüne Farbe gegeben hat, verialscht.

Eine bestimmtere Prüfungsmethode dos Gu,jakharzes auf Beymischtung vou Colophonium gab Herr Scba ub (Archiv der Pharmacie, B. 1. S. 24́9) an. Mau soll nämlich das verdächtige Harz in Alcohol aullöseu, es daraus mit Wasser niederschlagen und mit Aet.lane las reine achie $\mathrm{G}$ najolbar wiinde das rene aide Guajalhan witrde sicb in dersclben volig antosen, Jas mit Gergenharz verfalschte aber du chans keine vollständige Aunösung geben. Die -Herren Bucholz (Taschenb fur Scheideküstler, 1804, S. 201) und Th $\mathrm{i}$ emann (Berliucr Jabrb. d. Pharm. 1804 , S. 34 ) nnterwarfen diese Prüfungsmethode eincr näbern Untersuchung, und ersterer schlug in diescr Hinsicht folsende vcrbesserte Prüfungsmethode vor. Mau löse das zu priz feude Harz in so wenig als möglich W pinalcobol auf, da dam $\mathrm{C}$ an zur Zertegang dieser Aufosting bedürfe. Diese filtrirle Auflösung zerlege man nun mit so viel Wasser, als cbeu nötlig ist. Zu der erhaltenen milchähılicben Flüssigkeit tröpfele man jetzt langsam Aetzlauge; es wird sich dadurcb sämuntliches Gcfällte vollkommen wieder auflösen. Ist dieses erfolgr, so fahre man fort, Aetzlauge hiuzu zu tröpfeln. War das der Prüfung untel worfene Harz rein, so wird alles hell und ungetrübt bleiben; ist alor nur undedentende Verasche unbedeatende Vernischang mit Colophoyium vorbanten, so erfo'g ein Nicderscblag, der. Am Verhaltuisse des Aetzlaugen usatzes zunimmt, dergestalt, dafs dadurch alles Colophonimm in Gestalt der Harzseife, bis auf einen kleinen Hinterhalt abgescbicden nud die Verfálschung darge than werden kann.

Herr T b i e in a nu (a. a. O. S. 48) schlägt noch folgendes Prüfuussmittcl yor, welches sich darauf gründet, dafs das ächte Guajak, auch in erhöbeter Temperatur in rcinen? Terpentín̈l una a flöslich ist, wogegen sich das Colophonium und alle Ticbten - und Tanneubarze schon in gelinder Wärme in Terpeutiuöl auflösen. in gelinder Wärme in Terpeutiü̈l auflösen. Man überyiefse demnach eine bestimnte Menge des $z u$ prüferten Gnajakharzes iu einem Glaskölbcben oder in einem kleineu Medicinglase, welches man an eincm Bande vorsichtig über Kohleufener häl, mit der vierfaclieu Menge rectificirtem Terpentinöl und bringre es dem Sieden nabe. Ist das Guajikharz rein, so erscheint das Terpentinöl, nachdem es völlıg erkaltct ist,- wasserhell und entbält nur einen sebr ist,- wasserhell und entbail uur einen sebr geringen Theil Guajakharz in sicb, wodurch seine Durchsichtigkeit nud Farbenlo-
sigkeit gar nicht leidet. Enthielt es dagesigkeit gar nicht leidèt. Enthielt es dagegen Colophoniun, so fiudet man das Ter-
pentinöl mehr oder weniger gefürbt; und 
Resina Guajaci nativa. - Rotulae.

\begin{tabular}{|c|c|c|c|}
\hline $\begin{array}{c}\text { Namen } \\
\text { deriArzneymittel. }\end{array}$ & $\begin{array}{c}\text { Sinnliche Eigenfch@ften derfelben; } \\
\text { Merkmale ilirer Aechtheit und } \\
\text { Güte. }\end{array}$ & $\left|\begin{array}{c}\text { Fehlerhafie Be- } \\
\text { fchaffenheit, Ver- } \\
\text { wechfelung oder } \\
\text { Verfälfchung. }\end{array}\right|$ & $\begin{array}{c}\text { Deren } \\
\text { Kennzéichen und Priifungsmittel. }\end{array}$ \\
\hline $\begin{array}{l}\text { Resina Guajaci } \\
\text { nativa. }\end{array}$ & & & $\begin{array}{l}\text { es hinterläfst das fremde Harz nach dem } \\
\text { Verduosten in seinem natürlichen Zu- } \\
\text { stande. }\end{array}$ \\
\hline. & . & $\begin{array}{l}\text { Mit Bernsteingrufs } \\
\text { verfälscht. }\end{array}$ & 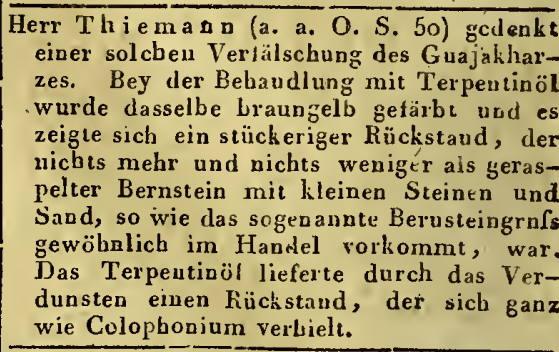 \\
\hline \multirow[t]{3}{*}{$\begin{array}{l}\text { Resina Jalappae. } \\
\text { Jalappenharz. }\end{array}$} & \multirow{4}{*}{ 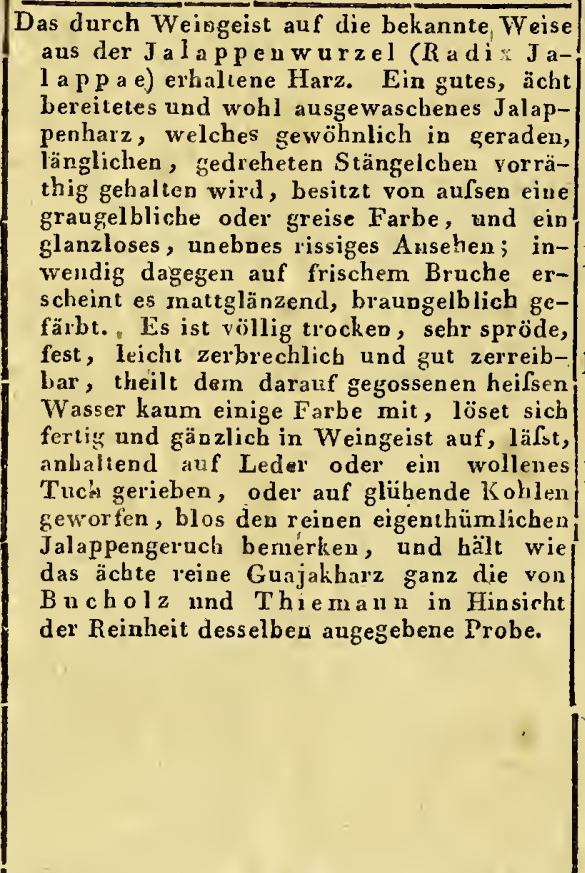 } & \begin{tabular}{|} 
Nicht gehörig ausge- \\
waschen oder mit \\
schlechtem Brannt- \\
wein ausgezogen.
\end{tabular} & 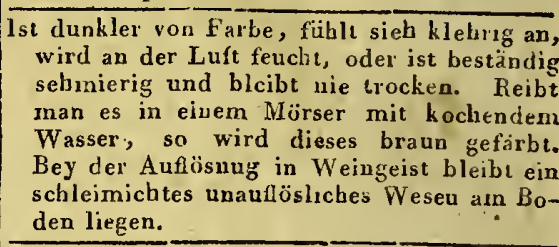 \\
\hline & & $\begin{array}{l}\text { Mit darunter gemisch- } \\
\text { ten Jalappenpul- } \\
\text { ver verfälscht. }\end{array}$ & $\begin{array}{l}\text { Entdeckt sich bey der, Aun̈usung in Wein- } \\
\text { geist, wo das } P \text { ulver zurüchbleibt. }\end{array}$ \\
\hline & & $\begin{array}{l}\text { Mit Lerchen- } \\
\text { scluwammharz ver- } \\
\text { fälscht. }\end{array}$ & $\begin{array}{l}\text { Sieht inwendig und auswendig sehr schwarz } \\
\text { bramn oder schwarz aus. }\end{array}$ \\
\hline - & & \begin{tabular}{|} 
Mis schwarzem Pech, \\
gemeinem Hare, \\
oderwie es am häu- \\
figsten geschieht, \\
mit Colophonium \\
verfälscht, \\
\end{tabular} & 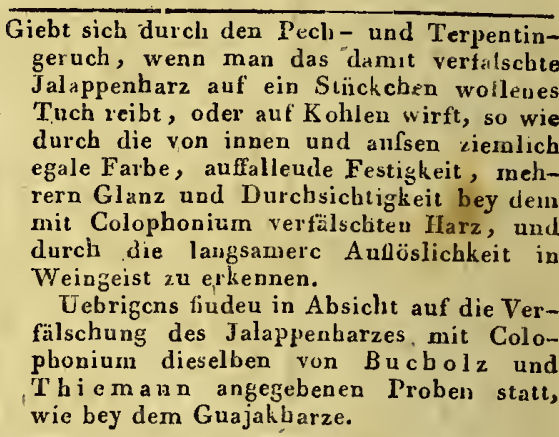 \\
\hline
\end{tabular}

Resina lutea novi Belgii.

Gelbes Harz von Neuholland. Geibes Gummi.

Resina Pini. Tiesina communis. Gemeines Harz.

Tiesina Succini balsamica.

Balsamisches Bern steinharz.

Rotulae.

Roteln.

Zeltchen. bestebt dieses Harz, welches von cinem in Neusïdwales wachseuden, nocb nicht gesau beschriebenen Baune, Wahrscheinlicb Acaroides resınifera, herrübrt, aus Stückeu von versehiedener Gröfse, an welchen zum Theil Kinden oder andere fremdartige Theile klehen. Das reine Harz hat eine schöne uelbe Farbe, is zerreiblich, fliefst bey mäfsiger Wärme, brennt am Lichte mit einer Flamme und giebt dabey einen angenehmen gewürzhaften Garnch von sich. Es löset sich bis auf einen uubedeutenden Rïckstand in Weingeis auf, und tiebt dainit eine duskelgoldfarbcne Tinctur.

Das aus der Rinde der Kien-Rothtannen- und Lerchenfichte (Tinus sylvestris, Abies, Larix L.) entweder von selbst, oder aus den mit Aexten darin gehauenen Oeffunngen, auch wohl aus den Löcher. woraus vorher der Terpentin getossen ist, hervordringende, an der Luft hart und brüchig gcwordene Harz, welehes, nachdem es für sich geschmolzen und von den Uureinigkeiten befreyet ist, eine weifse, gelbe odes welehes, nachdem es für sich geschmolzen und von den Uureinigkeiten befreyet ist, eine weifse, gelbe oder
braune Farbe bekommt, zwischeu den Fingcrn zäbe wird nnd auf Kohlen geworfen, einen unangenehmen Geruch von sich giebt. Zum Arzneygebrauch mufs man hartes, weifses, von alleu Unreinigkeiten freyes Harz auswählen.

Das burgundische Harz (Resinas. Pix burgundica), welches durchs Kochen des rohen Harzes in einem Kessel mit Wasser und nachheriges Anspressen in leinemen Säcken bereitet wird, bestelu aus grofsen, glänzenden, harten, braungclben, zerbrechlıchen, in der Hand weich und klebrig werdenden, terpeutinartig riechenden un'd schmcckendea Stückcn.: Statt dessen braucht man indcssen jetzt liäufiger des gemeine weifse oder selbe $\mathrm{Pech}$ ( $\mathrm{Pix}$ albas. flava), welches bart, dicht, in Bruobe glänend, von Farbe mehr oder weniger duskel, gelbbrann oder scbwärzlicb ist, in dér Wärme bald weicb wird, alsdann fest anklebt nad nit schwarzem Rauche und uningcnehmen, barzichten, ersticheudem Gernche brennt. Man bereitec es durch lange fortgesetztes Kochen des rohen Harzes in Wasser, bis es die Farbe und Consistcnz des gelben Wachses angenommen hat und nachleriges Durchseiben, oder auch durch Ausschmelzen des Hardes gelben Wachses angenommen hat und nachheriges Durcliseiben,
zes in besonclern Oefen miltelst eincr Art von sebiefer Destillation.

Eiu kïnstliches, gelbes Harz, welehcs durch allmälige Vermischung von eiuem Theile rectificirtcn Berustcinöl mit drey Theilen ranchender Salpctersaiue liereitet wird. Es mufs durch Answaschen mit Kaihaltigem Wasscr, nacbher aber nit reinem warueu Wasser von aller anhängenden Säure wobl gereinigt und vëllig trocken seyn, aueh in einem wohlverschlosscnen Glase aufhewabrt werden. Seines balsumiscben bisaurtigen Geruclis wegen wird es ancls wohl kin ntlicher Bis am (Moschus artificialis) genannt.

Man versteht daruıter klcine halbkngelrunde Kügelchen, die cntweder nach Art der Morsellen aus bis zur Tafelconsistenz gekochtem Zucker und rerschiedenen Pulvcrn, orler aus gepulvcricm, in einer $\Gamma$ fanne über gelindes Kohleufeuer erhitztem Zucker mit säucrlichen Fruchtsäften oder mit wenigem Wasser uud binzugesetsten itberisehen Oelen bereitet weldeu, nod ibre Gestalt dadurch erhalten, dafs man die fertige Masse tropfenweise auf ein Blcch fallen liffst und die Zeltcheu nach ar Erstarrung vollends trocknct. Sie müssen gebörig trocken seyu, anf der Zunge leicht zerfliefsen und den ihnen zukommenden Gesclumack triscb und

rcin besitzen.

Rotulae Beibcrum. Aus gepulvcrlem feinen Canarienzucker und dem Safte der Berberitzberen bereitet, Haben eiue angenelume rothe Farbe und einen aüfsäuerlichen Geschmack. 


\begin{tabular}{|c|c|c|c|c|}
\hline $\begin{array}{c}\text { Namen } \\
\text { aler Arzneymittel. }\end{array}$ & $\begin{array}{c}\text { Sinnliche Eigenfchaften derfelben; } \\
\text { Merkmale ihrer Aechtheit und } \\
\text { Giite. }\end{array}$ & \begin{tabular}{|c} 
Fehlerhafte Be- \\
schaffenheit, Ver- \\
wechfelung oder \\
Verfälfchung.
\end{tabular} & Kennzeichen & $\begin{array}{l}\text { Deren } \\
\text { und Prïfungsmittel. }\end{array}$ \\
\hline
\end{tabular}

Rotulae. Rotulae Citri. Citronenzeltcheu. Aus Zucker und Citronensaft bereitet. Weifslich von Farbe, halbdurchsichtig, von lieblichem Citronensaftgeschmack.

Rotulae Diaireos. Violenwurzelzeltcheu. Aus gekochtem Zucker und Species Diaireos bereitet. Weifslich vou Farbe; vou sïfsem Geschmack.

Rotulac Menthae piperitae. Pfeflermü口zkuchen. Aus gestofsenem feinen Canarienzncker mit hinlänglichem

Pfefferuïuzwasser und Pfeffermüuzül bereitet. Sie müssen hübsch weifs und halbdurchsichtig seyn und

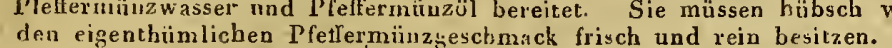

Succharuin album. Ein eigenartiger sufser Plianzenstort, der, Verlälscht.

Weifser Zucker. durm.

Kandieszucker.

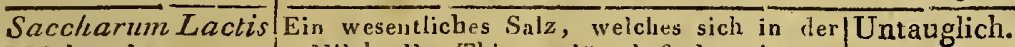

Milchzucker.

wenn er gleich is sebr viclen Pllanzen nud

Gewächstbeilen entbalten ist, docb nur

hauplsaclilich ans dem in beyden Indien

Wachsenden $Z$ uckerrohr (S a c charum
officinarum $\mathrm{L}$.), das ibn in der gröfs-

officinarum $\left.L_{1}\right)$, das ibn in der gröfs-
ten Mence enthält, gewonueu, und durchs

ten Mengc enthält, gewonueu, und durchs

artigen Theilen in den Zuckerraffinerien in

dic Gestalt cines fester Salzes gebracht

wird. Wir crbaltea denselben gewöhnlicb

in kegclförmigen' Broden, die nit dickem,

weilseu oder dunkelblanen Papier umwi-

ckelt, mit Bindfadeu umwnoden und iu

dieser Form Zuckerhüte genanot werder.

Nach der verschiedenen Reinigkeit, Güte

und Weifse bekornmt er verscbiedene $\mathrm{Na}$

men. Die erste und beste Sorte ist der

Canarienzucker ( $S$ accharum ca-

na riense; hierauf folg: dcr $R$ affiua-

dezucker (Saccharum raffinatum)

und dann dicr Meliszucker ( $\mathrm{Saccha-}$

rum meliteuse.) Geringere Sorten

sind der Cassonadeu- und Lumpen-

zucker. Ein guter Zucker mufs hart,

fest, klingend und weifs seyu und in rei-

nem Wasser šch volikommen klar auflösen

lassen. Die Auflösnug darf durch füssiges

Kali nicht getrïbt werden, und durch

A mamoniumflüssigkeit keine blänliche Far--

be annchmen. Mit Salmiak zerrieben darf

er keinen flüchtigęn Geruch bemerken

lassen.

Saccharum can- Der durch Auflösen im Wasser, Einkochen und Einfüllen in besondere, mit Fäden durchzogene Crystallisirgezwey dachförmig in die Hübe gekehrt sind, crystallisirte und geläuterte Zucker, von mehr oder weniger durchsichtiger, weifser, gelber oder brauncr Farbe. Der sebr dunkelbrauıc, in freyer Luft sich veräuderude, durchsichtiger, weilser, gelber oder brauncr Farbe. Der sebr dunkelbraune, in
meblicht oder feucht werdende Kandiszucker taugt nicht zum Arzneygebrancb.

Niilch aller Thiere gelöst befindet, hanpt-

säcblich aber ans der Kubrnilcb (Lac

vaccinum) durch Abdunsten nnd Crystallisiren der süfseu Molke in dev Schweiz und in Lothringen bereitet wird. So wie und in Lothringen bereitet wird. So wie wir den Milchzucker im Handel bekommen, fsen, halbolurcisichtigen, kleinen, festen, fsen, halbdurcbsichtigen, kleinen, festen,
untereinander zusammenhängenden, yicruntereinander zusammenhängenden, yicr-
seitige Säulen vorstellenden Crystallen in rindenartigen, auf dem Bruche matten, unteu glatten Stïcken oder in zwey Zoll dicken Scheiben. Er bat einen schwachen, zuckerartigen, etwas erdigen Geschmick, ist in acht Thcileu kaltem und vier Theilen beifsem Wasser, nicht aber im Weingeist auflüslich. Die Aufösung desselben darf weder durch Säuren und Laugensalze, noch durch Mittelsalze zersetzt und die Farbe des Veilchensafts und der Lacknustinctur nicht dadurch verändert werden. Im Feuer verbält sich der Milchzucker auf ähnlicbe Art wie der gemeine Zucker. In Salpetersäure ist er völlig auflöslich. 26. S. 293) erhielt жufalligerweise einen $\mathrm{Zu-}$ cker, der gegen wwanzig Procent Eisenviliche Farbe, liefs wach deri Sclimelzen auf der Zunge einen zusaminenziebenden Gem schmack «urück, und die Aufösung färbte die Galläpfeltinctur schwärzlich. Gleichwohl ist es Herrn S chmid t (Journal der Pharmacic, B. 7. St. 1. S. 12) wahrscheinlicher, dafs der vermeintliche Eisenvitriol vielleicht Zinkvitriol gewesen sey, welcher Meinung auch Herr Dörffurt ist (Ne Deutsches Apothekerb. Th. 1. S. 860.)

fsere surch seine lcicbtere und grölicbt und rancig.
Sagapenum. Gummi Sagapeni. Sagapengumini.

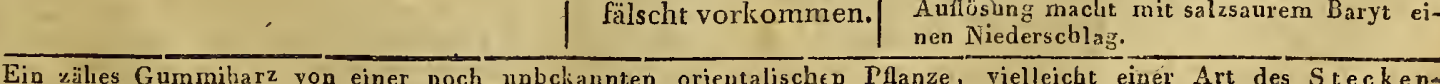
$\mathrm{kra}$ a s (FeruIa.) Wir erhalten es entweder in grofsen unförmlichen, aus vielfarbigen, röthlichen, dun-
kelbrauneu orlcr braungelben, kuglichten, bald härtern, bald weichern Brocken zusammengemengten und. kelbrauneu olcr braungelben, kuglichten, bald härtern, bald weichern Brocken zusammengemengten und
init holzichten Halmen, ganzen und zerstückelten $S * m e n$ veruureinigten Stücken ( $\mathrm{S}$ ag a p u u m in massis), oder auch in kleinen, glänzeuden, etwas durchscheinenden, answendıg röthlichen, inwendig. weifsen oder gelblichen Stïcken, Körneru oder Tropfen ( $\mathrm{S}$ ag a p en um in $\mathrm{g}$ ran is.) Is bat einen bitterlichen, scharfen und beil'senden Gescbmack, und einen starken widrigen, einigermalsen knoblauchartigen Geruch,

luängt sich beym Kauen an die Zähne, wird zwischen den Fingern weich und klebend, und ist im Wásser gröfstentheils, im Weingeist aber nur in geringer Menge auflöslicb.
Mit Hutzucker verfälscht.

auselblicher, sällerlich schmeckender, fetticht riechender, den Veilchensaft und die salzen brausender und in kleinen kegelförmigen Broden rerkăuflicher, aus saurcn Molken verlertigter Milchıucker, so wie der mehlichte, nicht crystallisirte, und werdende, mit den käsichten Theilen der Milch vcrunreinigte Milchzucker ist zu verwerfer. wcnn er init gleiohen Theilen desselhen geschiittelt wird, so wie durch seine beträcht e Sursigkeit.

Mit ölichten Theilen, Iat eine gelbliclı Tarbe, eine beständige Neigung $2 \mathrm{~nm}$ Feuchtwerden, ist nicht gnt crystallisirt und wird mit der Zeit schimm-

Theilen der Milch

verunreinigt.

Lit Kochsalz verun- $\overline{\text { Hat einen salzichten Geschmack. Die Auf- }}$ lösung desselbeı schlägt das|Silber, Bley und Queclisilber aus, ihren Auflusurgen in Salperersane nieder, welches der reine Milchzocker nicht thut. Er soll auch zuweilen Färlit die blauen Pflanzensäfte roth, schlägt
mit Alaun ver\begin{tabular}{l|l} 
mit Alaun ver- das saipetersauc Silber nieder, und die \\
fälscht vorkommen.
\end{tabular} 


\begin{tabular}{|c|c|c|c|}
\hline $\begin{array}{c}\text { Namen } \\
\text { der Arzneymittel. }\end{array}$ & $\begin{array}{c}\text { Sinnliche Eigenfchaften derfelben; } \\
\text { Merkmale ihrer Ächtheit und } \\
\text { Güte. }\end{array}$ & $\begin{array}{c}\text { Fehlerhafte Be- } \\
\text { Schaffenheit, Ver- } \\
\text { wechselung oder } \\
\text { Verfälfchung. }\end{array}$ & $\begin{array}{c}\text { Deren } \\
\text { Kennzeichen und Priifungsmittel. }\end{array}$ \\
\hline
\end{tabular}

Granula Sagu. |Kleine, sehr ذartc, melır oder weniger run- Nachgennacht aus/Man erkenut den nachgernachten Sago leich de, etwas eckige, weifsgelbliche, gelh- Bolınen-oder Kar- an seiner mındern llärte und seiner baldiSagokörner. $\quad$ röthliche oder bräunliche, aus dem Satzmehle der vorzïglich auf den Philippinisehen und Moluckischen Inseln wachsentoffelmelıl. gen Auflösung zu einern Breye, wenn or mit Wasser gekocht wird.

den Sagopalme (Metroxylon Sagu

Gmel.) geformte Körncr. Wit Wasser gekocht, erweichen sie sich, schwellen auf, werden durchsichtig und bilden damit eine schleimichte, sehr nährende Flissigkeit. Guter Sago mufs weifslich, rccht trocken uud nicht staubicht seyn.

Sandaraca.

Von dem in der ganzen Barbarey wachsendengegliederten Lebensbaume (Thuja articulata Brousse net.) So wie das Sandarakharz im Haudel vorkommt, besteht dasselbe aus tropfenförmigen, fast iundlichen, länglichen, glänzenden, durchsichtigen, citronengelben odler weifslichen, spiöden, harten, uuter den Zähnen nicht weich werdenden, soudern zerspringenden Körnern. Ihr Geruch ist auf Koblen geworfen angenehm; der Geschmack balsamisch harzig.

Sanguis Draconis. Drachenblut.

ine barzige Masse, die aus den reifen'Schlechteste Früchten des in Ostindien wachsenden brauchbare Sorte. Dracbenblutćalmus (Calamus Drac o L.) schwitzt, sie überzicht, darauf erbärtet, und nachdem sie durcb gelindes Stampfen in einer Reismiihle oder durch starkes Reiben nnd jochüttelu in einem Sacke davon losgemacht worden, durch die Wärme erweicht und in Kugeln geformt, aufser jenern Strauchgewächse aher auch wahrscheinlich von mehrern anderu Gewächscn, z. B. dem D rachenb a baum (Dracaena Draco L.) dem Flügelfruchtbanm (Pterocarpus Dr a co $\left.L_{0}\right)$, gewonnen wird. Es kommen davou verschiedene Sorten in Handel vor. Das beste und feinste Drachenblut ( $S$ a $n-$ guis Draconis in lacrymis s. is $\mathrm{g} u t \mathrm{tis}$ ) erbalten wir in rundlichen, ohngefähr wallnufsgrofsen Kugeln, die entweder einzeln oder gliedcrweise in Schilf gewickelt sind. Es bat eine sebr dunkelrothe Farbc, läfst sich leicht zerrciben und liefert eiu schünes carmoisinrothes Pulver. Für sich besites es weder Geruch uoch Fur sich besitze es weder Geruch woch Geschmack, ist im Wasser gar nicht, iu Weingeist und in Oelen aber leicht auflöslich, und theilt ilinen eine blutrothe Farbe mit; auf Kohlen geworfen verhreitet es einen lieblichen Geruch. Eiue 2. wey te Sorte kommt in unförmlichen, grölsern und ḱleinern Stücken ( $\mathrm{S}$ a $\mathrm{n} \mathrm{g}$ u is Draconis in granis) vor, und wird von geringercr Güle, gehalteu, soll aber dochı offer's reiner und besser- seyn, als die erste Sorte. Alseann folgt eiue dritte etwas schlechtere Sorte in zolldicken, vier und mehrere Unzen schweren Kuchen (S anguis Draconis in placentis), die man aus dem beym Auskochen der die man aus dem beym Auskochen der
Fruchte mit Wasser oben abgeschöpften
-Diese kommt gewöhnlich iu Tafeln vor ( $S_{\text {a }} \mathrm{n}$ guis Draconis in $t a b u l$ is), die über einen Zull dick, drey bis vicr Zoll breit und sechs bis aclit Zoll lang sinil. Sie scheint aus den schon ausgekochten Frúchten zusammengeprefst, oft aber auch eiu blofses erküusteltes Product der Drognisten aus Colophonium mit ctwas zogesetztem Drachenhlut oder rothera Sandelholz zu . seya.
Sapo guajacinus. Guajakseife.

Sapo hydrargyricus s. mercurialis. Quecksilberseife.

Jurch Aufösung von gepülvertem natürlicbem Guajakbarze in verdünnter Aetzkalilaugc nnd .Verdunstung his zur Consıstenz einer Pillenmasse bereitet. Sie muls eine oleichförmige Beschaffenheit, eine granliche Farbe, und den eigehthümlichen Geruch nnd Geschmack des Guajakharzes besitzen, auch in einem wobl verbundenen steinzeugneu orler gläsermen Gefäfse authewahrt werden.

Wird nach der von dem seel. Pic peubriug (Archiv der Pharmacie, B, 1, S, 134 u. f.) angegebenen Methode dadurch bereitet, dlafs eine in der Kälte bereitetc Quecksilberaulösung in der Salpetersämre so lange mit eidadurch bereitet, ner Aufösung von medicinischer Seife in sechszehn Theiren darnit der Nierlerschlag sich besser zusammenfallen, worauf das Granze eine Stunde durch erhitzt wird, damit der Wasser erhitzt und dann so lange begehe. Nachrlen derselbe gut ausgesülst worden, wird er mit etwas Wasser erhitzt und dann so lange caustische Kadilauge zugesetzt, bis er aufgelöst ist und geröthetes Lackmuspapier seine Farhe wieder erbält. Die Aufösung wird in einer Porcellainschale über gelindem Feuer unter beständigem Umrühren mit eineıL Spatel, so weit abgedampft, bis dic Masse nicht mehr an die Hand klebt, worauf sie in Wachspapier unil Blase gewickclt und in einem Glase gegen den Zutritt der Luft verwabrt wird. Diese Seife, welche aufser ein weuig freyem Kali uud Wasser, aus Kaliseife und oxydulirtem Quecksilber, in dem Verhältnifs wis 48 zu 12 hesteht, hat, wenn sie gut bereitet ist, in trocknen Zustande, eine grauschwarze Farbe, zieht die Feuchtigkeit der Luft au und wird dalurch dunkelfarbiger, schmeckt anfangs ein wenig scharf stechend, hinterher abor völlig seifenartig, ist leicht in kaltem, noch leichter aber in heifsem Wasser löslich und láfst aufyelöst das dario enthaliene Oxydulat uach ruhigem Stehen erst nach längercr Zeit langsam niederfallen; such Essig geröhete Lack voustinctur nicht völlig wieder "so blau, als sie vorber war. Das Quecksilberoxydulat

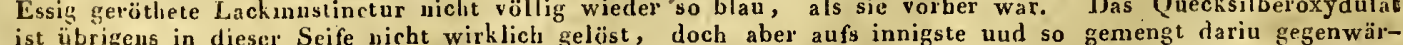
ist übrigens in dieser Seife nicht wirklich gelöst, doch aber aufs innigste uud so gemengt dariu gegenwar-
rig, dafs die aufgelöste Quecksilberseife, obne etwas zurück zu lassen, durch vierfaches Druckpapier läuft. Sapo lispanicus Durclis Kochen des Baunö̈s mit ätzender Natroulange bereitet. Vine gute spanische Seife mufs hart, weifs mnd albus. Spanische Seife. trocken seyu, die Finger nicht fettig machen, in der Luft nicht feucht werden, keinent Salzausschlag be-
kommen, in destillirtem. Wasser und höchstreinem Weingeist leicht und vollkommen, einen geringen kal- 


\section{Sapo hispanicus albus. -- Scammonium.}

Namen
der Arzneymittel.
$\begin{aligned} & \text { Sapo lispanicus } \\ & \text { albus. }\end{aligned}$
Sapo Jalnppinus.
Jalappenseife.
Sapo medicatus.
Medicinische Seife.

Spiefsglanzseife.

Sarcocolla.

Gummi $\because$ arcocollae.

Sarcocolle.

Fleischleimgummi

Scammonium. Scammonium.
Sinnliche Eigenfchaften derfelben; Merkmale ihrer Ächtheit und

Giite.

\section{Fehlerhafie Be- chaffenlueit, Ver- wechfelung oder Verfälfchung.}

\section{Deren}

Kennzeichen und Prïfungsmittel.

kichten Riickstaud ausgenominen, auflöstlch seyn, und aufgelöst kein auf der Oberlläche in Gestalt einer Hant schwinmendes Oel absetien. Mit Wasser uud Weingeist inufs sic gut schäumen, einen unilden, nicht

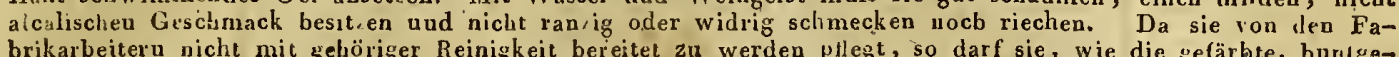
fleckte, venedische Seife (Sapo marmoratus, venetus) picht zum innern, sondern blofs zuin äufsern fleckte, venedische Seife

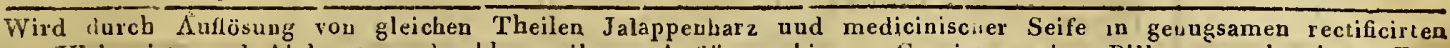
Weingeist, und Abdunstung der klargeseibeten Aulüsung bis zur Consistenz einer Pillenmasse bereitet. Eine gut bcreitete Jalappeuseife hat anfser der get, örigen Consistenz eine bráunlichgraue, gerieben weifsgraue Farbe, füllt sich seifenartıg an, hat einen eckelliaften, unverkennbar jalappharziós-sciferartigen Geseamack nnd Geruch, aud ist in Weingeist und Wasser vollkommen löslich.

Von dem Apotheker selbst aus ätzender Natronfüssigkeit und dem besten Baumöl zu bereiten. Eine gut bereitete, zum innern Gehrauch bestımmte, medicinische Serfe ist fest, weifs, macbt die Finger nicht lettig, ob sie sich gleich schlüp frì anfühlt, bät sich trocken, riecbt weder ranzig nocht sonst widrig, schmeckt seifenartig milde, nicht salcig und nur entierut ein wenig bitterlich', löset sich pöllig in destilliriem Wasser und Weingerst ohue Oelabsonderung auf, und giebt besouders mit ersterm beym Rnbren orter Schütteln eine stark schaumcnde Auflüsun. Sie wird durch alle Sänren zerlegt und das Oel dergestalt verändert dabey abgeschieden, dafs es sich nunmebr ganz oder un Theil in Weingeist antlöset. Eine gleiche Entmischung erfolgt durch alle sänerlichen Salze nnd Säfte, so wie vermöge Tauscliverbindung, durch alle erdige und metallische Salze, weshalb sie auch von hartem Brunnenwasser nicht kla: aufgelöset wird, so wie sir, auch durch Kalhwasser und allen den, adstriugirenden Stoff enthaltenden, Pfanzentauszingen z+rs tzt wird. Uebrigens darf die Auflösuug weder den Violensaft grün, noch das Curcumäpapier braun färben. Mit A tzammoniunflüssiokeit gemischt, darf sie nicht blau werden.

Anunerk. Ist die medicinische Seife, wie es seyn mufs, mit eineın Pflanzenöle bereitet, "so bleibt ihre

Auflösung inn Weingeist in gewöhnlicher Temperatur tlüssig. Wurde ein thierisches Fett dazu angewendet, so giebt die Seife mit dem Wcingeist eine geliefernde Auflüsung.

Wird nach der Preufsischen Pharmacopoe auf die Art bereitet, dafs nan eine Unze pommeranzenfarbenen Spiefsglanzscliwefcl durch Digestion in einer hinreichenden Menge Aetzkalifiüssigkeit auflüset, und in cier ertraite-

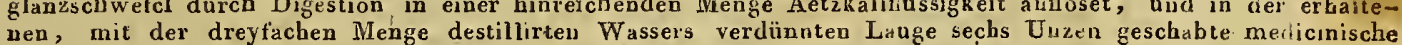
Seife aufgelöset werden, worauf man das Ganze bis zur Consisten? einer Pillenmasse bey geliudem Feuer Seife aufgelöset werden, worauf man das Ganze bis zur Consisten: einer Pillenmasse bey geliudem Feuer
verdunstet und wenn sich jetzt noch eine rothe Farbe ceigt, so lange uloch etwas Aet kalilauge zosetzt, bis verdunstet und wenn sich jetzt noch eine rothe Farbe ceigt, so lange uoch etwas Aet kalilauge zasetzt, bis
die Masse eise weifograue Farbe annimmt. Sie mufs sich, bey wenigern Uaberschufs an Alkali, völlig obne

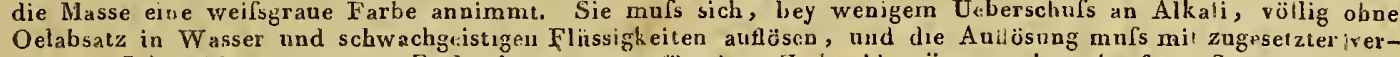
dünnter Schwefelsaurc, uuter Enth ndung von gastörmiger Hydrothionsäure, einen baufigen Saty von pornmeranzenfarbenen Spiefsglanzschwefel, wobey sich zugleich ausgeschiedenes Oel auf der Oberflache absondert, bemerken lassen. Uebrigens mufs die Spiefsylanıseife in wohlverbundenen Gefäfsen aufhewahrt werden.

Ein harziges Gunmi, welches man von dem in Aęthiopien, Persien und Arabien wachseucieu S pitzblattfleischleim ( $\mathrm{Peu}$ a a mucronata L.) über Marseille erhält. Es besteht aus leiclut zerreiblichen Kör nern und Stückchen von verschiedener Gröfse. Sie sind rundlich, laben eine weifsgtlblirbe, rus lur o.ler wenigser röthlicle, selten ganz weifse Farbe, mit hie und da sichtbaren Flimmerchen, Sie haben ktinen Geruch, aber einen anfaugs faden süfslichten, dann bitterlichen und widrig schärfliclen Geschmack. Einige Stücke sind wie rnit einer zaserichten Wolle zusammengcfügt. Im Feuer blähet sich die Sarcocolle auf und resknistert, ebe sie sich entzündet, wobey sich eir eben nicht angenebmer Gernch verbreiten soll. Im Wasser löset sıe sich fast ganz auf; der Weingeist extrabirt nur wenig barziges Wesen. Die heste Sarrocalle mufs'so rein und faiberilos als mö̈glich seyn, und beym Kauen viel záben Sichleim von sich geben. Je röthlıcber sic $1 \mathrm{st}$, um desto älter ist sie.

in aus den langen und dichen Wurzelu der Verfälscht. Selbst das Aleppische Scammonium ist man-

in Ostindien, besouders in Syrien wach-

senden Scammoniumwinde (Con-

volvulus $S$ cammoni um L.) vermittelst eines schiefen Einschnittes in deu von telst eines schiefen Eimscbnittes in deu von
der Erde entblöfsten ohern Theil ausliefsender, in eiuem Gefälse aufgefangener, fsendcr, in eiuem Gefäfse aufgefangener,
an der Sonne allsgetrochneter und erhärtean der Sonne allsgetrochneter und erharte-
ter Milchsaft von barzichter Beschaffenheit. Es kommen davon im Handel yorziiglich drey Sorten vor, närnlich

1) Aleppisches $S$ ca $m m$ on i um ( $S$ cammonium de Aleppo s. Halepense.) Die beste Sorte, welche auf obige Weise gewonnen wird, und ans grofsen, trocknen, leicliten, lockern, cinigermafsen schwammichten, brüchigen, zerreiblichen, auf dem Bruche glänzenden Stülichen, auf dem Auswendig laber dieselben cken besteht. Auswendig haber dieselben
eine dunkelgraue Farbe. Der Geruch ist eine dunkelgraue $F$ arbe. widrig; , ler Geschmack aufanglict schwach, hernach bitterlich eckelbaft und scharf. Mit einem nassen Finger gerieben, werden die Stücke weifslich; in Wasser erweicht macht diese Sorte dasselbe milchicht und theilt ibm nacherer eine etwas grünliche Farbe mit. Das Pulver davon sieht grau oder weifslich aus.

2) Das $S$ m yruische Scammonium (Scammonium de Smyrna.) Es scheint dassel be aus dem ausoeprefsten Safte scheint dassel be aus dem ausgepreisten Satte des ganzen Gewachses verfertigt zu werden, hat eine viel dunkel bratuner,
schwärzliche Farbe, ein festeres und dich. schwärzliche Farbe, ein festeres und dich. teres Gewebe, ist schwerer, läfst sich nicht gut zerreiben und giebt mit Wasser eine sehr scbmutzige Milch. Es ist viel unrei-
ner, als $d$ is A A eppische und taugt nicht zum Arzneygebrauche. chẹrley Verfälschnngen nit Mehl, Asche, Sand, Kohlen u. dol., so wie mit den Säften ähnlichér Pflanzeu, z. B, der Syrischen Seidenptlan:e, des Hundstohls Apocsischen Seidenpflan e, des Hundskohls Apocynum) u. s. w. unterworfen. Ueherhåupt ist alles Scammonium, welches in schweren, dich-
teu und schwarzen, nicht leicht zerbrechteu und schwarzen, nicht leicht zerbrechlichen Stïcken vorkormmt, welches ange-
branut riecbt, und mit Wasser zum Aufbranut riecht, und mit Wasser $20 m$ Auf-
wallen gebracht mit dem Erkalten gallertartig wird, mit Säuren versctzt Luftblasen in die Höhe wirft, auf Koblen gestıcut einen pechartigen Geruch verbreitet, und auf der Zunge nicht den. eigenthünlichen Geschmark des ächten uut reinen Scammonıums bemerkeu läfst, gänzlich zu verwerfen. 


\begin{tabular}{|c|c|c|c|}
\hline $\begin{array}{c}\text { Namen } \\
\text { der Arzneymitcel. }\end{array}$ & $\begin{array}{c}\text { Sinnliche Eigenfchaften derfelben; } \\
\text { Merkmale ihrer Ächtheit und } \\
\text { Güte. }\end{array}$ & 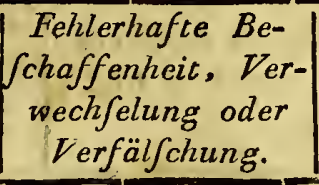 & $\begin{array}{c}\text { Deren } \\
\text { Kennzeichen und Prïfungsmittel. }\end{array}$ \\
\hline Scammo & 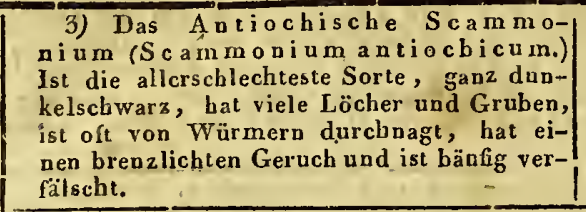 & & \\
\hline
\end{tabular}

Semen Abelmoschi. Der Saame des vorzüglich in Aegypten wacbsenden Biesamibischs (Hihiscus Abelmoschus L.) NieEisamkörner.

Semen Adiowaen. Adjowänsaame.

Semein Amorni.

Piper jamaicense.

Pintenta.

Nelkenpfeffer.

Iinglisch Gewürz.

Neue Würze.

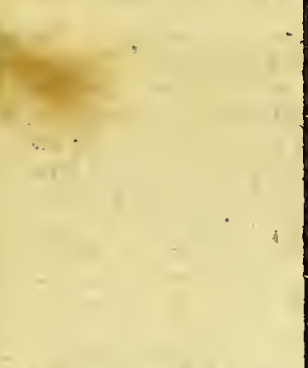

Semen Anethi.

Dillsamen.

Semen Anisi.

Anissaame.

Semen Anisi stel lati.

Sternanis.

Semen Cannabis. Hanfsaamen. renförmige, etwas zusammengedrïckte Körner von der Gröfse einer Linse, die der Länge nach von allen Seiten parallel gestreift sind, und in ihrer Aushöhlnog eine runde schwàrzliche Narbe hahen. Sie enthalten ein.weifsliches Mark, verbreiten in der Hand gerieben oder auf glubende Kohlen geworfen, einen vermischten Ambra - nnd Moschnsgeruch und besitzen eineu bitterlich erwärmenden Geschmack.

Der Saame des in Acgypten einbeimischen, auch in unsern Gärten gut forthommeuden $K$ opte a m mey (Am $\mathrm{m}$ copticum L.) Kleine, eyförmige, bauchige, auf der einen Seite'erhabene, auf der anderu etwas ausgeböhlte, grünbräunliche, mit hellern erhabenern Streifen bezeichnete Saamenkörner rou gewürzhaftem Geriacb, und Satureyartigcrn, balsamischen, gew ïrzhaften Geschmack.

Die unreifen, grün eingesammleten, runden, /Verfälscht. Jm Haudel kommt seit einigen Jahren unter erbsengrofseu, nach dem Austrocknen brau- । nell Beeren der in America; bescuder's in Mexico und Jamaica wachsenden Ge würzmyrthe (Myrtus Piment a $L$ ) Sie mithe enthalten zwey Sameu und besitzen einen sebr gewürzhaften vermischt nelken- und zirnmtartigen Geruch und Geschmack. Guter Nelkenpfeffer mufs aus dichten, scbwerell und mit parpurfarbigen Körnern wohl a usgefülltēn, fleischichten Hülsen bestọhen und einen starken Germch und Gesclomack wendig Staub bey sich führenden, tauben oder mit scbwarzen Kör vern angefïllteu, so wie die alten und verlegenen Beeren sind zu verwerfen.

\section{errälscht mit den Kockelskörnern} (Semen Coculi.) würz eine dem Nelkenpfeffer ähnliche Frucht vol, die bäufig mit dernselben vermischt wird; die Beeren sind gröfser, vre niger sewüra B in Gewürzunter dem Namen T abask a p feffer aus dem Spanischen America kommen.

Diese Verfälschung will man seit kurzer àn verschiedenen Ortcn bernerkt haben, wesbalb unan sich beym Aukauf des Nelkenpfelfers wohl in Acbr zu nehmen bat. Die Kockelsiorner haben eine rnndlich - nierenformige Gestalt, sind grolser, als die Körner des Nelkenp ferters, runzlichi und schmutzig - gran in Ansehen, und enthalten unter einer dünnen Schale einen weifslichten kuglicbt - nierenförrnigen Kern, welcher geruchlos, aber vom heftigsten, anhaltend bitteru Geschmacke ist.

Der Samen des Gurkendills (Anethum graveolens L.) Eyrunde, fahlhräunliche, auf der einen Seit flache, anf der antérn eiu wenig erhabene, mit diey Streifen gezeichnete, am Rande mit eiuer abstebeuden, trocknen, weifslichen Haut umgebene Samen, von stark balsamischen, etwas betäubendeu Geruch und durchdringenden gew ürzhaften Geschmack. Der Saame der im Thüringischen, Magdebur-|Verfälscht. $\quad$ Der Anis, besouders der in der Gegend urn gischen und andern Gegenden häufig gebaut werdenden Anispimpinelle (Pimpinella Anisum L.) Kleine, länglich ey förmige, anf der erhabeñen Seite gestreifte, fahlbräunlich - grïnlichte Saamen von einen süfsen gewürzhaften Geschmack und eigenthümlichen pflest pflegt den auslandischen spaniscben oder alicantiscber (A hen; er ist kleiner, aber nicht gewürzhafter, als anderer Anis.

Deutscben, 1 \&n8, Nro. j26) wird hänfi mit einer Art Sand oder Erdklümpchen von Letten oder Thon, welche mehrentheils die Gröfse nod Farbe des Anissaamens haben, verfälscht. Man. muls deshalb beym Einkauf des Anissaamens vorsichtig seyn. Entdecken lăfst sich diese betrügerisch Beymiscling leicht durchs Schleminen des Beymisclung Wasser oder auch dadurch dalc man den yeinen Isen Blatte Papier absondert, da man den finden wird, dafs die beygenischteu Lirdklümpcheu oft weit Uher den vierten Theil des Ganzen betragen

Verdorben. soll, vorher angefeuchtet wird, so erbitz ex sich in den Säcken oder Fässern er versandt wird und verdirbt dadurch, indem er mulstrig, schimmlicht und schwarz wird, und seinen eigentbürnlichen Geruch nud Geschmack melu' oder weniger einhüfst. Man bat sich daher vor solchen verdorbenen, wie anch ror dem unceif eiuses und len mit vieler Spreu oder mit taube $\mathrm{K}$ ör den ten Anis zu hüten.

Fine mo Tan und auf Dipan un auf den parhig und Die einzelnen Capseln sind zusants bauchi und runzlicht, inwentig glatt und gläzend, an ihrem oberd Rande semeiniglch offen scharf. Jede Saamencapsel enthült eiuen eyrunden, zusanmengedruckten Saamen, der in einer zerbrecblichen, glämzenden, glatten und braunen Schale eimen weilslichcn, fetten und Weicheu Kern einschlielst. Die Saamen selbst siud ohoe merklichen Gcschmack; die Capseln aber besitzen enen sehr ankeselsca, strshchen Geruch und Geschmack. Man mufs diejenigen answählen, die nicht unrein und vicht pulvcricht sind.

Die Saamen des bekannten $\mathrm{Hanfs}$ (C annabis sativa $L$ ) Eyrude, etwas gedrückte, glatle, an einem Lincle stumpfe, am audern mit einen ruuden Grübchcu versehene, grauweifse Saamenkörner, deren harte, zerbrechgelblichen Häutchen umgeben ist. 


\section{Semen Cardui benedicti. - Semen Foenugraeci.}

\begin{tabular}{|c|c|c|c|}
\hline $\begin{array}{c}\text { Namen } \\
\text { Iler Arzneymitcel. }\end{array}$ & $\left|\begin{array}{c}\text { Sinnliche Eigenfchaften derfelben; } \\
\text { Merkmale ihrer Aechcheit und } \\
\text { Giite. }\end{array}\right|$ & $\left|\begin{array}{c}\text { Dehlerhafte } \text { Be- } \\
\text { rchaffenheit, Ver- } \\
\text { wechfelung oder } \\
\text { Verfälfchung. }\end{array}\right|$ & $\begin{array}{c}\text { Deren } \\
\text { Kennzeichen und Priifungsmitcal: }\end{array}$ \\
\hline
\end{tabular}

Semen Carduibs-/Der Saame der Benedictflockblume (Centanleabenedicta L) Ein langer, gestrcifter, oben mit zarnedicti.

Cardobenedictensaamie.

Semen Cardui Mariae.

Mariendistelsaame.

Semen Carvi.

Kümmel.

Semen Cataputiae minoris.

Springkörner.

Purgirkörner.

Semen Cinae s.

Santonici.

Wurmsa amen.

Zittwersaamen.

Semen Coriandri. Coriandersaamen.

Senuen. Cumini s. Cymini.

Römischer Kümmel.

Mutertümmel.

Semen Cydoniorum.

Quittenkerne.

Semen Dauci vul garis s. sylvestris wilder Möhrensaame.

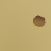

Semen Foeniculi. Fenchelsaame.

Semen Foenugrae-

Bockshornsaanie. Griechischer Hen saarne. ten, steifell Borsten besetzter Saame, (Cer einen süfsen ölicbten Kern enthält.

Der Same der M a riendistel (Ca rdu u M arianus L.) Glatte, braunglänzcnde, eyföımige, etwas flacbe und gebogene Saamen, mit einer einfachell aufritzenden Haarkrone, dic sicb leicht abstreift, weshalb sie gewöhulich ohne diese angetrolfen werden. Sie enthalten einen süfsen ölichten Kern.

Der Saame von der $\mathrm{K}$ ii $\mathrm{mmel} g$ arbe (Carum Carvi L.) Kleinc, eyförmig längliche, gestreifte, etwas gebogcue Samen von braugelblichter Farbe, einem starken, gewürzbaften, erwärmenden Geschmack nnd angenebmen, starken balsamischen Geı uch.

Die Samen der in Frankreich, Italien und der Schweiz wild wachsenden, auch bey uns in Gärten vorkommenden Springwolfsmilch (Enphorbia Latbyris L.) Ejrunde Saamen, die etwas gröfser als der Hanfsaame sind, mit einer braunen, runzlichten, leicht zerbrechlichen an dem einen Ende abgestumpften Scbale uod cinem weifsen ölicbten Kern. Ihr Gesclimack ist anfägs milde, bintennach abcr scharf.

Als Mutterphanze dieses Saamens giebt die/Verfüscht mit dem/Dicser ist langlich, etwas gekrümmb mit tiePreufsische Phurmacopoe den Wurinbey- Samen des Rain- fen Furchen bezogen, an dern cineo Ende fus (Artemisia 5 a deul farrns (Semen Ia- etwas schmaler und anf dem obern breitern

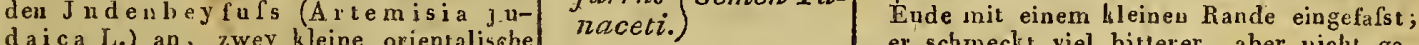
daica L.) an, zwey kleine orientalische Sträucher, die hänfig in Persien, Syrien und Palästuva wild wachscn. So wie dieser Saanc im Haudel vorkommt, bildet er kleine, lan liche, glatte, grüngelbbräun-
liche oder gelbgr üne Körner, die mit vieliche oder Eelbgr üne Körner, die mit vie-
len Blumenkelchblättern und kleinen dünlen Blumcokelchblattern und kleinen dün-
nen Stielen vermischt sind, einen eigennen Stielen vermischt sind, einen eigen-
thümlichen starkeu, eckelhaften, der Zittwerwurzel älunliches Gexuch, und einen etwas scharfeu, bilteru, barzicbten widrigen Geschmack haben. Es gieb widrigen Geschmack haben. Es giebt daron verscbicdene Sorten. Die beste Sorle ist der Aleppische oder Levantische Wurmasmen, weil er an reinsten und an wenigsten mit fremdartigen Thcilen vermischt ist. Auf diesen folgt der Ostindische oder Orientalische, der gelbgraz aussieht, gröfstentbeils aus kleinen Blümchen bestelbt, leicht, stau.bicht und viel schwächer von Geruch und Geschmack ist. Die schlechteste Sorte ist der Afric a uis chcoder Barbaris che, mit sehr vielen Stengeln verunreinigte er scbmeckt viel bitterer, aber vicht ge-
würzhaft.

Mit dem Saamen des Hat eine lichtgelbere Farbe und viela AehnStaublrauts (Se-) lichkeit mit klein gestofsenem Stroh; ist \begin{tabular}{l|l} 
men Abrotani.) & $\begin{array}{l}\text { licbleit mit klein gestolsenem Stroh ; } \\
\text { sebr bits angenehm gewürbaft. }\end{array}$
\end{tabular} Wurmsaame.

Der Saamc des in südlichen Enropa wild wachsenden, in verscbiedenen Gegenden vou Deutschland, besonders in Thüringen gebant wercenden $W u r c o r i a n d e r s$ (Coriandrum sativum L.) Kugelrunde, feinEestreifte, graugelblicbe oder gclbbräunliche Saancn. $\operatorname{lm}$ frischen Zustandc haben sie einen unaugenebmen betäubenden, gctrocknet aber einen gewürzhaften Geruch und einen süfolichen aromatischen, etwas scharfen Geschmack.

Der Saame des $\mathrm{Kramk}$ üm mels (Cnminum Cyminum L.), einer orientalischen Pflauze, die im südlicben Europa hänfig gebanet wird. Längliche, gestreifte, dem gemeinen Kümmel ähnliche, aber noch einmal so lange Saanes:, von einem aromatischen, starken und anffallend widrigen Geruch und einem unangenebmen scharf-bitterlichen, gewürzhaften Geschmack.

Die Saamen der Quittenbirne (P yrus Cydónia L.) Länglichc, zusammengedrickte, eckigtc, ungleich gestaltete, an dem einen Ende stumpfe, an den anderu spitzige, auf einer Seite platte; auf der anderu banchichte, answendig branoe, glänzendc, inwendig weifse Saamen. Sie besitzen keinen Gernch, haben aber einen sebr schleinichten Geschmack und enthalten eine reichliche Menge Schleim. Znweilen mögen sie einen sebr schleimichten Geschmack und entisalten eine reichliche Menge Schleim, Zuweilen mögen sie
wohl mit Kernen von andern Obstsorten verfalscht vorkommen, die sicb bey, gebauer Durcbsicht leicht wer-

Sare wild wa re (Daucus Carota L.) Ein runuli- me ler Gartencare (Daucus Carota L.) Ein rualli- me der Gartencacher, aufder einen Seitc platter, auf der rotten.

andern erhabever, aus zwey Köner'n zu-

sammengefugter und mit kleinen Borsten

besetzter Saane von grauer Farbe und ge-

wirzhaften bitterlichern Geschmack und Geruch.

Der Same des Fenchel dills (Anetbum Foeniculnm L.) Längliche, auf einer Seite platte, auf der andern banchichte, gestreifte, schmale, ochwere, znweilen etwas gekrümmte Saamenkörner von blafsgraugelher Farbe, einem eigenen starken angenehmen Geruch und gew ̈̈r zhaft süfslichem Geschmack. Der in Deutschland gezogene Saame ist nicht so sïfs und ölreich, als der It aliänische oder Cretische (F ocniculuxn dnlce), welcher länger, schmal, gekrümmt, nicht so glatt als der Deutsche, und mehr hellgelb von Farbe ist.

Der Saame des Fönugräkbockshorn (Trigon’ella Foenum Graecum L.) Läuglicbrunde, fast viereckige, zusammengedrickte, an beyden Enden abgcstumpfte, mäfsio harte, mit einer schiefen Furcbe beeckige, zusammengedrickte, an beyden Enden abgcstumpfte, malsig harte, mit einer schiefen Furcbe bezeicbuete Samen, von bräunlichgelber Farbe, eincm starken, siifslich - widrigen Melilotengeruch nud en nein aibulich an Scbleim. 


\begin{tabular}{|c|c|c|c|c|}
\hline $\begin{array}{c}\text { Namen } \\
\text { Arzneymittel. }\end{array}$ & $\begin{array}{c}\text { Sinnliche Eigenfchaften derfelben; } \\
\text { Merkmale ihrer Aechtheit und } \\
\text { Güte. }\end{array}$ & $\begin{array}{c}\text { Fehlerhafte Be- } \\
\text { fclıaffenheit, Ver- } \\
\text { wechfelung oder } \\
\text { Verfälfchung. }\end{array}$ & Kennzeichen & $\begin{array}{l}\text { Deren } \\
\text { und Prïfungsmittel. }\end{array}$ \\
\hline
\end{tabular}

Semen Hordei.

Der Same dergemeinen,zwey-und scebszeiligen Gerste (Hordeum vulgare, distichon, heGerstensaame.' xastichonL.) Er bestebt aus liuglichen, in der Mitte bauchichten, an beyden Enden zugespit,len, glattell, strohfarbigen Körnern, deren oberes Evde sich iu eine linienformige Giner Furche bezeichnet, anf lem theils abgebrochen ist; am Banche sind die Kurner dcr Lange nach nit eind die Gerste abgebiulset, so heifst Rücken und an den Seiten sind sie eckig. Sie enthalten vieles Mehl. Wirdien Körner noch besondes absiegeschälte Gerste (Hordeumexcorticatum) und wenn die einzelaen Keinern Sorten zum Ar 2 eygerundet werden, Perlgraupen" (Hordeam perlatum), wovon man die feinern Sorten zum Ar<neygebrauch vorzieht.

Semen Hyoscyami.

Der Same des Schwarzbilsens (Hyoscyamusniger L.) Ein kleiner, fast nierenförmiger, etwas zusamBilsensaamen. menter bitterlichen Geschmack.

Semen Lini.

Leinsaame.

Der Saame des F achsle breit dë̈le, glatte, oläzende Samen, die mit einem scharfen Rande versehen sind, und in einer braubreit gedrückte, glatte, glänzende Saaen, die menentbalteu. Er liefert eine Menge Scbleim, welcher nen Schale einen weilseu, olicht - sch deu fünften Theil seines Gewichts im Kerne entbalteneu, aus:eprefsten Oels.

Semen Lithospermi s. Milii solis. Steinhirse.

Steinsaame.

Semen Melonum. Melonenkörner.

Semen Nigellae. Schwarzer Kümmel.

Semen Oryzae.

Reis.

Dcr Same von der Peir Ibirse (Lytho-1 s per $\mathrm{m}$ u of $\mathrm{m}$ ic in ale L.) Kleine, runillich eyförmióse, sehr luarte, mit einer perlmen, die eiuen ölichten und süfslich schmeckenden Kern enthalteu. Verwechselt mit dempieser ist dem vorigen sehr ähnlich, aber
Saamen von der dunkler gefärbt.

purpurblauen
Steinhirse (Lutlo-
spermum purpu-
reo-caeruleum L.)

Die Samentörner der Meloneucuc umer (Cucumis M elo L.) Eyförmig - länglicb - ellipcisabe, breitge-

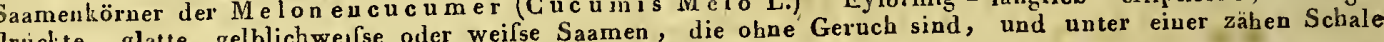
druckte, glatte, gelblichweifse oder weilse Saamen,
einen weifsen, mit süfsem Oel erfüllten Kern einschliefsen.

er Same des Garten mibels (Nigel-/Verwechselt mit den Diese Samen sind etwas gröfser, nicht drey-

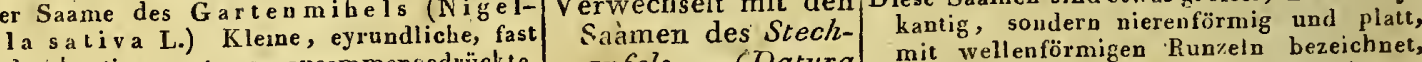
dreykantige, etwas zusammengedrückte, apfels (Datura mit wellenförmigen Runzeln bezeichnet, rumzlicbtrauhe, anfsen schwarze, innen $\begin{aligned} & \text { Stramonium } L .) \\ & \text { ohne Gerueh und von keinem gewurzhdten }\end{aligned}$ weifsgrüblichte Saamen, von einem nicht unangenehmen Geruch und gewür $\mathrm{haft}$ beifseud, entferut sassafrasähnlichen GeGeschmack. Eirue sebr gefabrliche Vergeschiebt, als man glaubt. schmack.

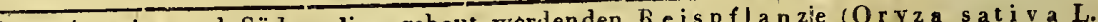
ie Samen der in Ostindicn, America und Südcarolina gebaut werdenden So wie die retfen Saaneuköruer gewonnen werden, sind sie mit gelbyza excorticata) sind länglıch, ¿ubefreyet zu uns gebracht werder. Diese abgebulseten Reisköner oför zwey Linien lang, weifs, Lalbdurchsammengedrückt - rundlich, an beyir sichlig, an dein untern End geben duichs Kochen einen Scblein von sich.

Semen Paeoniae. Die Samen der Pfingstrosenpäonie (Pacinia officinalis L.) Ruudliche, glänzend schwarze Saamen, ölichten Kern enthaltend, der von seiner äufsern harten Schale befreyet, eiohne Greruch und einen weilsen

Päonienkörner. gentlich nur gebraucht Der weifse Mobnsaame, den man

Semen Papaveri albi.
Weilser Mohnsaame.

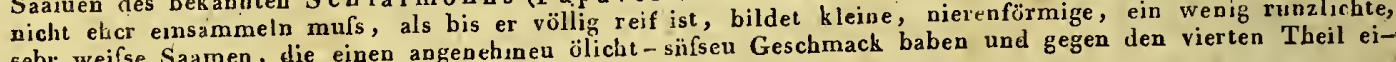
sebr weifse Saamen, die einen angenehineu ölicht-sïfseu

Semen Petroselini.

Petersiliensaame.

Semen Phellan-

drii s. Foeniculi aquatici.

Peersaamen.

Wasserfenchel:

Semen Psyllii.

Flölisaamen. nes angenehm scbmeckenden, ansgeprefsten Oels lic fern.

er Sanme der gewöhnlichen Petersilie (A pium Pctroselinum L.) Kleine, länglich-eyförmige, gekrimmte, auf der eincn Seite flache, auf der andern erhabene, und auf ersterer mit vier gelbeu Streifen brimmte, auf der eincn Seite fache, aufe haben.

Der Samc des in Teichen, Sümpfen und ste- Verwechselt mit dem Ist mehr eyförmig, oberbalb zugespitzt uud henden Wassern wachsendev Wasserfenchels (Phellandrium aquáticum L.) Länglich - eyförmnige, kaum merklich gekrümunte Saamen, die ans zwey mit einem Häutchen verbundeneu Kornern besteben, anf der einen Seite flacb, auf der andern bauchicht und mit scbwachen Streifen bezeichnet, sonst aber glatt sind;
oben haben sie einen klcinen, finfmal gezäbnten Kopf, anf welchen oft noch trockne Staubfäden sitzen. Der Saame hat ïbrigens die Gröfse rind Gestalt des Fenchelsaamens, eine gelbgrünlicbe Farbe, einen starkicn unangenehmen, $\mathrm{z}$ wischen An-

guch und ähnlichen Geschmack.

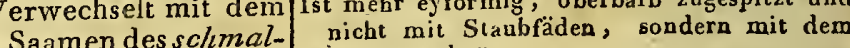
blättrigen Was- Griffel gekrönt.

sermerks (Simum

angustifolium $L$.)

Mit dem $\overline{\text { Ist kleiner, einwärts gékrümmt, stärker und }}$ breitblätrigen gleichförmiger gerippt, zwiscbrn den RipW a penwarz und von einem dem Mutter-

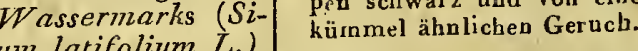

umn latifolium L.)

it dem Saamen des Dieser giftige Saame ist rundlicht, baucbicht,

\begin{tabular}{l|l} 
Giftwïtherichs & $\begin{array}{l}\text { zusamme gedrückt, mit zebn Streifen ver- } \\
\text { sebeu, stumps winklicht und von grüner }\end{array}$ \\
\hline
\end{tabular} (Cicuta virosa $L$. Farbe.

Semen Ricini.

Ricinussaame.
Ucr Saaruc des Flöhkrantwegerichs (Plantago Psyllium L.) Kleine, eyrund-längliche, auf einer Seite flache, auf der andern erbalene, glituzende, schwarzbraune Saamen, die geruch- und geschmacklos sind,
und vielen Schleirn enthalten, so dafs ein Theil derselben vierzig bis acht und vierzig Theile Wasser eyweifsartig schleimicht mach.

Die Saomen des in beyden lndien, in Africa und dem südlichen Europa einheimischen, bey nns in Gärten geDie Samen des in beyden Indien, in Afen Wuderhaums (Kicinus communis L., einer einjäbrigen zogen werden kömenten sogenanuten weifstachlichte, dreyfächerige Capsel bildet. Die Saamen selbst sind Planze, deren Frucht eine rundliche, wellste von der Gröfse einer Zuckerbohne und. enthalten unter einer länglich-eyfürmig, auf beyden Sciten platt, von der Grofse einorirten, mit einer hervorstelienden, gelblidiinnen, glänzenden, zerbrechlichen, gran ind schwärzlich marmorirten, chen Narbe versehencu Scbale einen weifsen ölichten, zuna chist mit einem weifsen bittern, beifsend scharfen um; ebenen, zweychciligein Kcrn. Der Saamc besitzt keinen Gerucb, aber eine bit. 


\begin{tabular}{c|c|c|c} 
Namen & $\begin{array}{c}\text { Sinnliche Eigenfchafien derfelben; } ; \\
\text { Merhmale ihrer Acchtheit und } \\
\text { Giite. }\end{array}$ & $\begin{array}{c}\text { Fehlerhafte Be- } \\
\text { chaffenheit, Ver- } \\
\text { wechfelung oder } \\
\text { Verfälfchung. }\end{array}$
\end{tabular} \mid Kennzeichen und Prüfungsmituel.

Semen Sabadilli j $_{k}$ Der Same der Sabadillniefswurzel (Veratrum Sabadilla Retzii), einer im Spanischen America Sabadillsaameu. besonders in Mexico wachsenden I'lanze. So wie wir denselben im IFandel erhalten, ist er eiu Gemengscl von blufsen, Samcucapseln oder uoch in den Capseln sitzenden Saaneu mit unternuischten ganzen und zesdrückten Capselu und Blnmenstielen. Die Saamencapseln siud eyförmig-länglicb, haben der Liange nach aut jeder Seıte eitc Nath, woraus sich zarte und ästige Rippen schief erbeben, sitzen immer zn dreyen an ejneur kurzen Stiele, haben eine brïunlich strohgelbe Farbe, und enthalten; wenu sie noch geschlossell sind, vier Samcnkörner in jeder einzeluen Hille. Gemeiniglicb sind aber die Saamenkörner schou zum Theil herausgefallen, und die Capseln oben offell. Die Saamen selbst sind linglich, an dem einen Ende stumpf, an den andern zugespitzt, auf der einen Seite ziemlich platt, auf der andern baucbicbt, scharfrandig, etwas zusammengedruickt und runzlicht. Auswendig sehen sie dunkelbraun oder schwärzlich aus, inwendio

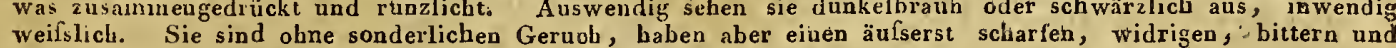
weilslich. Sie sind obne
stecheuden Geschmack.

Semen Sinapis al- Der Same dcs weifsen Senfs (Sinapis alba L.) Kleine, kuglichte, gelbliche oder weifsgelbe Saámen

bae s. Erucae.

Weilser Senfsaamen.

Semen Sincupis ni* Schwarzer Senfsaamen.

Semen Staphidis agriae. Stephanskürner.

Seinen Stramonii. Stechaplelsaamen.

Semen Xanthii s. Bardanae minoris.

Spitzklettensaamen.

Sevim cervinum. Hirschtalg.

\section{Sevum ovillum vervecinum.} Hammeltalg. Schöpstalg. Siliqua dulcis. Johannisbrod.

Siliqua liirsuta. Juckende Fasel. Kublirätze. ron einem flüchtigen Geruche und einem eigenthümlichen scharfen Geschmack, der abet docb schwäcber ist, als bcy desn schwarzen Senfsamen. Der weifse Senf wird auch wobl von dem Raukekobl (Brassica El u ca J.), eiser l'llanze, die im Oeslerteichischen und in der Schweiz sebr hiufig wild wächst, und in

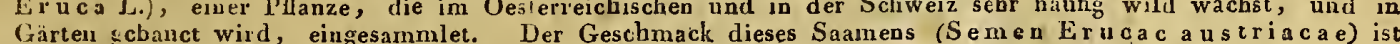
dem des vorigen äbnlich, und zugleich etwas rettigartig.

Der Same des schwarzen Seafs (Si-jMit Kohlsaamen vor-flst grö́fsel nud besitzt nicht den scharfen Genap is nigra L.) Kleine runde, etwas züglich vom Busch- schmack des schwarzen Seufsaanens.

plattgedrückte, mit coucentrischen Stri-

chacn bézeichnete, braunrothe oder schwärz- bellata L.) ver-

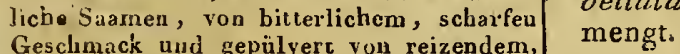

Gesclınack uud gepülverc voli reizendem,

Niesen und Thränen erregenden Geruch

Guter Senfsaame mufs im Wasser zu Bo-
den sinken.

Same des in Dalmatien, Apulien, Creta und Franhreich eiubeimischen Stephansrittersporns (Del-

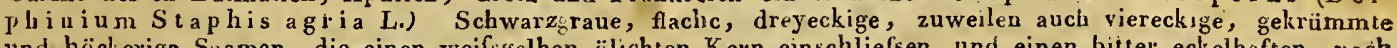
und höckerige Samen, die einen weifsyelben ülicbten Kern einschliefsen, und einen bitter eckelhaften, wach andern selir bittern und höchst scharfen Geschráack besitzen.

Dcr Same des Stechapfels (Datura Stramouinm L.) Nierenförmige, platle, mit wellenförmigen bunzelu bezeichnete, aufsen scbwarze, innen weifse Samen, die ohne Geruch sind uud einen widrigen narcotiscben Geschmack besitzen. Sie sítzen in einer eyförmigen, sehr stachlichten Capsel und gehören unter die gcben Gesclimack besitzen.
gifiag witkenden Saamen.

Der Saame von der an verfallenen Orten, an Mauren, Zäunen und auf Schutthaulen wachsenden Kropfbettlerlaus (Xanthium strumarium X.) Man sammlet die geschlossenen Samencapseln selbst ein; sie sind trockeu, länglich, zweybörnig, stachlicbt, haben inwendig zwey Fächer und entbalten kleiue, länglichdie einen widrigen Geruch und eineu scharfen bittern Geschmack baben.

Das ans den Fettcapseln der Nieren und des/Verdorben. Altes, gelbcs oder braungelbliches', schmu

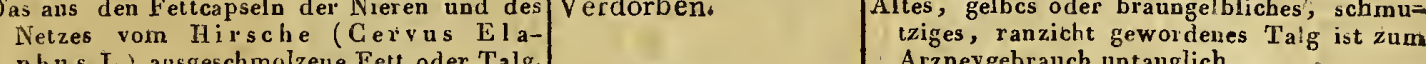
p bu s L.) ausgeschmolzeue Fett oder Talg. Gutes Hirscbtalg snufs frisch, reinlich; schön weifs, hart und fest seyu, eisen
milden Geschmack und einen angenebmen Fettgeruch besilzen. Es ist, wie die meisien 'Thierfette in Scbwefeläther, so lange es frisch ist, unir milchtrübe auflïslich, dagegcia dic felten Pflanzenöle sich bell dariu tziges, ranzicht gewordenes Talg ist zum
Arzneygebrauch untanglich. Kupferhaltig vom Hat eine grünliche Farbe.

Auslassen und Er-

kalten in kupfernen Gefäfsen. aullösen.

Das Talg vom Il a mel und allen übrigen zun Geschlecht des Scha afes (Ovis aries L.) gebörigen Tbieren Es mufs dieselben Eigenschaften habcu, wie sie beym Hirschtalg angegeben sind. Ehell so auch das $R$ in dertalg (Serumbovinum.)

Die Früchte des im Morgenlande, auf den Verdorben.

Inseln des Arcbipelagus und im südlichen Europa häufig wild wachsenden SodEuropa häufig wild wachsenden Sod-
brodbaums (Ceratonia Siliqua brodbaums (Ceratonia Siliqua
L.) Vier bis fün Zoll lange, gegen einen L.) Vier bis fünf Zoll lange, gegen einen Zoll breite, ztsammengedrückte, leder-
artige, mehr oder weniger gebogene, im artige, melr oder weniger gebogene, im
frischen Zustande grïne, getrocknrt duukelbraunrothe Schoten, die ein süfses, dickes, weiches, bellbraunes Fleisch haben, in welchem eyrunde, flacbe, den Sternaniskernen âhnlicbe, sehr barte, inwendig lornartige, braune Saamen enthalten sind. Man hat bey ihrem Eiukaufe dahin zu sehen an hat die Schoten recht reif sind, und hen, dafs die Scboct and bey ibrer Schwere ein leiscbiges, im Bruche weils marmorirtes Mark zeigen, welhat.

Die Schoten der in den beyden Indien an andern Bãumen aufklimmenden $J$ ü $c k$ fasel (Dolichos priniens L.) Eine ledcrartige, $z$ wey bis drey Zoll lange, findcrartige, 2 wey bis drey Zoll lange, fingersdicke, wie ein S gebogene Schote, die auswendig dicht mit steifen, spröden, gelbrothbräunlicben, glänzcnden, leicht
abgehenden, auf der äufsern Hant des

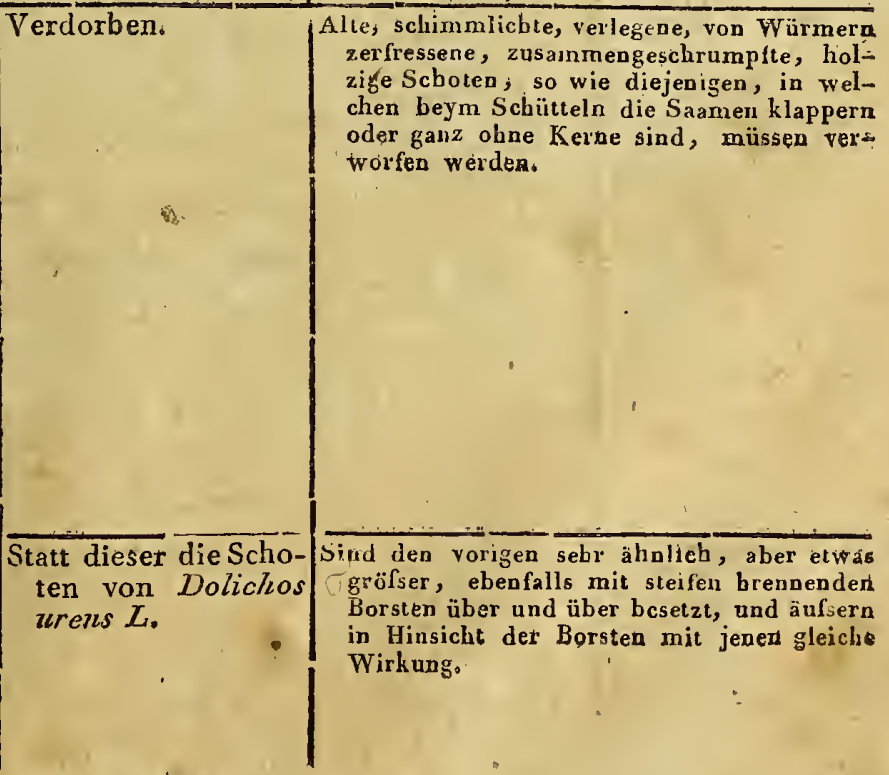


Siliqua hirsuta. -- Spiritus acetico - acthereus.

\section{Namen der Arzneymittel.}

Siliqua livirsuta.

Siliqua Vanillae.

Vaniglia.

Vanilschote,

Vanille,

Species.

Species.

Spiritus aceticoaethereus.

Liquor anodynus

vegetabilis. geist.

Körpers das unerträglichste und brennend-

ste Jucken erregenden Haaren besetzt ist.

Diese Hare (Setae s. Lanugo Sili-

quae hirsutae, Stitzolobiumserden, mit Syrup oder Honig verches Wurm mittel empfoblen. dron Vanilla L. Vanilla a rom a

tica Willd.), ciner in Jamaica, Cayen-

ne und dem sildichen America wacbsen-

den an alle nabe stehende Bäume sich hinauf windenden Schmarotzerpflanze. Obn1gefähr seclıs Zoll lange und drey bis viel Linien dicke, an beyden Enden stumpf zugebende, am Stielende etwas gekrümmte, dunkelbraune, dex Länge nach fein gernnzelte, schimmernde, aher vicht glänzende, auf der Oberfläche fettig anzufühleude, zwar biegsame aber doch zerbrectliche Schoten, die inwendig mit einem ölichten dunkelbraunen Marke und sehrelen run den, leinen, glänzenden, schwarzen Sa men augefullt sind, einen starken, ange nehm gewurzbaften, den Perubalsam ab: haften, nicbt minder angenehmeu $\mathrm{Ge}$ mischt seyn. seyn, welche
vers baben. ten, theils gequetscht. Ien Weinalcolol, oder durch Destillation $\left|\begin{array}{cc}\text { Fehlerhafte } & \text { Be- } \\ \text { fchaffenheit, } & \text { Ver- } \\ \text { wechfelung } & \text { oder } \\ \text { Verfälfchutung. }\end{array}\right|$ Kennzeichen und ${ }_{i}$ Priifungsmittel.

Uie Schoten der Würzvanille (Epidenden, kleinen, glanzenden, schwarzen Saa schmack haben. Man erhält sie in Bündeln gewöhnlich zu funfzig Stück, die von der besten Sorte, worin die inwendigen Schoten mit langspiefsigen, glänzęden, der Benzoesäure ähulichen Salzblumen besetzt sind, wenigstens fiinf Unzen wiegea. Mehrere dergleicben Bündchen erbail man mit geschlanem Bley umwickelt in dishte bölzerne Kisten repacki. Die Scioten werderreingesammlet, ehe-sie ihre völlige Reife Gährung untërworfen, dann ausgebreitet, Gäbrung unterworfen, dann ausgebreiter, und wenn sie halb trocken sind, mit einem fetten Oele bestricben nnd endlich völlig getrocknet. Je stärker sic riechen, und je
scbwerer sie sind, um desto besser sińd sie.

Mit geringern Sorten

Lit geringern Sorten Aulser der beschriebenen besten Loy oder Le vorkommt, giebt, es noch verschietene geringere Sorten. Żu diesen gehört 1) diejenige Sorte, welche ans dickern, kïrzern platteren, mit Senfkorugiofsen Saamen und einer schmierigen Materie angefüll ten Schoten best ht, einen stärkern, Kopfweh erregevdeu Geruch hat, und von den Spaniern Posnpolla oder Bona genaunt wird. 2) Di vorzüglich von st. Domingo kommende stardvanille oder Silnaroma stardvanille oder Sinnaroma, sie entbäly ei trockes Mtark, sebr kleine scbrarze Saamen, ist aulserlich vou gelbbranuliche Firbe und hat fast gar-keinen Geruch Noch unträftiger ist 3) die von Hindostan korumeude Vanille, welche aus kurzen, dicken Schoten, die fast wie Pllaumenmus riechen, besteht.

Au'serdem hat man sich in Aclit zu nehmen, dafs mau kcine ihres Markes beraubten und dafür Init einer fremden Materie ten unilteu und wieder angeleimten Schoangefillten ur waie tea erbalte, die auch manchmal unter die guten verstackt seyn köunen. Zuweilen giebt man auch alten verlegeneu Schoten Init peruvianischem Balsam ein frisches $A n-$ sehes, oder bestreicht die trockuen Schoten mit etwas Oel, wodurch sie aber ein gar zn glänzeudes Anseben bekomineu unı in kurzer Zeit ranzig ricchen.

Eine Vermischung ron mehreren einfachen festen, hauptsäcblich vegetabılischeu, Arzneymittela, die entweder klein zerschnitten oder gröblich zerstofsen sind. Gut bereitete Species Inüssen eiue ganz gleichfürınige Beschaffenheit baben; die einzelnen Stücke müssen von mögiichst gleicher Gröfse und zu einem solchen Grade der Zerkleinerung gebracht seyn, als der verschiedene davon zu machende Gebrauch es erfordert. Alles, was demnach von den Ingredienzen zerschnitien wcrden kann, mofo anf dem Schneidcriesser zerscbuitten und nicht im Mörser gequetscbt oder zerstofsep werden, weil man ani diese letztere Alt zn viel pulverichtes erhält, und diese letztere Art der Zerkleinerung nur bey solchen Sachen vorgenommen wird, die sich tes erhäl, und diese lassen. Uebrigens müssen die Spccies ein zierliches und friscles Auschen hahen. Man mufs es gleich auf den ersten Blick seben können, dafs sie aus fiscben, guten uud mutadelhaften Kräutern, Wurzeln, Rinden u. dgl., nicht aber aus alten, verlefenen Vegetabilien bereitet wordet sind.

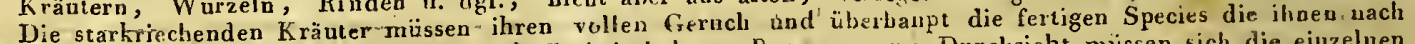
Die starkrrechenden Krăuter müssen-ihren vescheit haben. Bey gestauerer Durchsicht müssen sich die einzeluen Ingredienzen desselben einen geübtén 'Angc leicht bifenbaren. Sie müssen an einem tròcknen Orte aulbeIngredienzen desselben einem geñbten 'Angc leicht ollo Wahrt und zu den stark riechencen Species glaserne Gefälen, nit Holzspänen, Sand, Staub u. s. w. ver-

In IVinsicht der Verkleinerung findet mehrentheils ein dreyfacher Grad statt. So erhalten nämlich 1) diejenigen Species, welche za Aufgüssen, zum Thee, zu Decocten u. dgl. bestimmt siud, den iu deu A potheken bekanuten Grad der gxöblichen Zerkleinernng. Fciner müssen 2) die Spccies seyn, die zu Kräuterküssen und 211 trocknen Umschlägen angewendet werilen. Am feinsten aber müssen 3) diejenigen Speries seyn, welche zn Breyumschlägen dienen sollen; diese müssen fast die Form eines gröblich zcrstolsènen Pul-

Von den mancherley sonst gebräuchlichen Species liat die Preufsische Pharmacopoe folgende aufgenommen: $\quad$ Die Ingredienzen dazu werden theils zerSpecies aromaticae s. pro Cucuphis. Aromatische Species. Die Jagredienzes Pulver vorstellt.

schnitten, theils zerquetscht, so dafs alles cin gröblicies, mögliclist gleichartiges Pulver bilden.

Species ad Cataplasma. Species zum Breyumschlag. Mussen eill gröblicbes

Species ad Decoctum Lignorum. Species znun Holztrank'. Gröb.

Species ad Enema. Clystierspecies. Gï̈blich zersclinitten.

Species ad Fonientum. Species zn Bähunger. Grühlich zerschnilten.

Species ad Gargarisma. Species zum Gurgeln. Gröblich zerschuil

Species ad Infusum pectórale. Brusthee. Gröblicb zcrschnitten. Species resolventes externae. Zertheilende Species. Fein zerschnitten.
Species ad suffiendum s. Pulvis fumalis. Specics zum Räuchern. Znm gröblichen Pulver theils zerscinit-

Wird entweder durch blofse Vermischung/Freye Essigsäure ent-lMan vergleiche Acther aceticus.

von einem Theil Essigäther mit vier Thei- lialtend, oder auch nach der beym Éssigäther angezeigten $\mathrm{Me}-$ nach der beyn Essignther angezeigten Me

Alcohol gewonnen, die eshaltene Flüssig-

Alcohol gewonnen, die ellialtene lussig-

keit aber noch einual über eineu absorbi-
renden Stofl (gebraunter Magnesia) recti-

chend. 
Spiritus acetico-aethereus. - . Spiritus nitrico-aethereus.

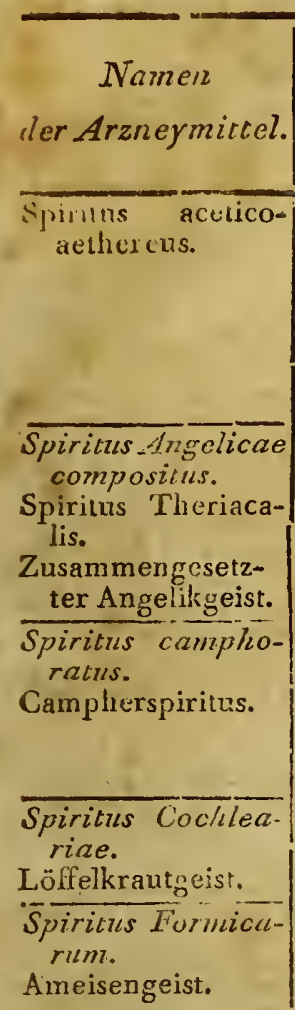

Sinnliche Eigenfchaften derfelben; F'ichlerhafte BcMerkmale ilurer Ächtheit und Gïre.

\section{Deren}

Scliaffenlieit, Ter-

wecliselung oder

Verfülfclung.

Kennzeiclien und Priifungsmittel.

ficirt. Er muls einen durchiringenden,

angenehmen, exquickicuden, dem Essigätber äbulichen Gcruch und einen gcwïrzhaften Gescbrrack habeu. Das Lackmuspapier darf uicht davon geröthet werden; auch dart er wicht schweflicht riechen. Ein darin geworfenes Stückcben trocknes Kali darf nicht feucht. werden.

darf nichtio

Angeliswurzeln, Lacbenknoblauch, Baldrianwurzeln und Wacholderbeeren durch Destillation mit eine hinreichenłcn Menge Wasser abgezogener Weingeist, in welchem nachher Campler aufgelöset wird. Er mufs völlig wasserbell und durchsichtig seyn, den eigeutbümlichen vermischten Geruch und Geschmack jencr Suhstanzen baben, mit Wasser vermischt, milchicht truibe werden, nnd aufserdem die dem rectificirten Weingcist (Spiritus vini rectificatus) zukornmenden allgeneinen Eigerschaften besitzen. Ist in eimen enghalsigen wohlverbuudencn Glasfläschgen aufzubewahren.

Aus Campher in rcctificirtem Weingeist auf-|Mit wäfsrigem Wein-|Ist nicht Jurchsichtig heil und es schwinmen

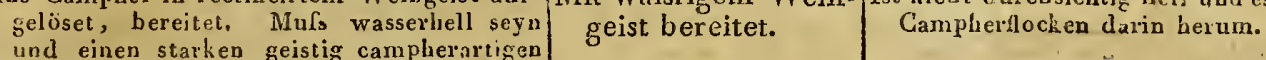

Geruch und Geschmack besitzen. Bey der

Vermischung unit Wasser inuls sich der

Camphar abscheiden.

Ueber frisches blïbendes Löffelkraut ahgezogener Weingeist, stark vach Löffelkraut riechend und schmeckend. Mufs völlig klar und wasserbell seyn.

Uebcr Icbendige, von allen Unreinigkeiten gesä̈berten Ameisen und deren Puppen durch Destillation, mit hin
zugesetzlem nöthigen Wasser, abgezogener Weingeist. Er stellt, gut bereitet, einen schwachcn Arneisenzugesetzlem nöthigen Wasser, abgezogener Weingeist. Er stellt, gut bereitet, einen schwachon Ameisenäthergeist dar, mufs belle uud durcbsichtig seyn, und einen angenehmen, schwach ätherischen Gernch besitzen.

Spiritus Frumenti: Kornbranntwein.

Spiritus Lavenduiue aus verschiedenen Getreydearten, be sonders dem locken, nach vorbergezangever Gäbrung durch dic Destillation erm halteve sche dütre, helle, farbenlose, brembare Flüssigneit vun starkem flüchiischrnack. Jiin reiner und guter Branntwein mufs völlig wasserhelle seyn; wenn cr geschütielt wird, viele, aber schne!l zerplatzenle Bläschen oder Perlen geben; wenn er etwas hoch herab gegossen wird, Wenin er en mit seinen bläschen einen langsam wieder zergehenden Girkel billen, den man den Rosenkranz nennt, und zwischen dreifsig bis vierzig Procent reinen Spiritus nach Ticliters Alcobolometer enchalten. In eine Kälte ohne Brenuen verursacben, keineu fremdeu oder breszlichten Geruch haben, und ein darin getropftes fettes Oel mufs uicht zu schnell zu Boden sinken. Tupferhaltig. Wird mit Ammoniumflüssigkeit blaulich ge-

Durch Zusatz vonflst schwer/u entdeckén; immer aber ein solscharfen Materia- cher Zusatz zú vernuthen, wenn der lien, z. B. Pfeffer u. Brauntwein eimen brenuenden Gesclimack dgl. bey der stillation scharf gemacht.

Mit metallischenThei- Der hranotwein kann unter diesen Umstänlen verunreinigt, den entweler tribe oder hell seyn. lst wenn die Destillir- er trübe uud man vermischt ilin mit congeläfse, besonders ceutrirtem Essig oder Salpetersäure, so löder Helm und die sen diese Sâuren, wenn sie eine Zeitlang Töo damit stehen, die in dem Branntwein bcTonre eine Zeit- findlicheu Metalitheilcben an lang ungebraucht hell. Ist der mit mellischer whd stehen und nicht nreiniste Branotwein gehörig gereinigt helle, so verüh die trit a n a sich

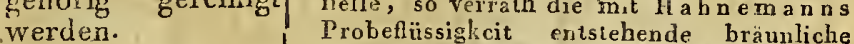
oder schwärzlicbe Farbc deu Metallgehalt. farbt, und ein darin gelegtes Stückchen farbt, und ein darin gelegtes
ungelöschter Kalk wird grünlich.

lae.

Lavendelgeist.

Spiritus Masticles compositus. Zusammengesetzter Mastixgeist.

Spiritus muriatico aethereus.

Spiritus Salis dulcis.

Versüfster Salzgeist.

Ueber getrocknete Lavendelblumen mit Zusalz von nöthigem Wasser abgezogener Weingeist, von augenehmen, erquíckcodes Laveudelgcruch.

We Weistig sewürzhatten Gcruch und Geschmacts. Es ist dieses Icr sonst sogenannte, Spiritus matricalis.

Wril nach der Prenfsischen Pharmacopoe aus Freye Säure enthal-flöthct das Laclimuspapier und branset mit sechszebn Unzea Küchensalz und sechs tend.

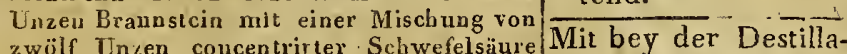
und acht und vicrzis Unzen Weinalcohol tion verflüchtigtem durch Destillation aus einer Glasgeräth- Braunstein verunduxch Destillation aus einer Glasgerathschaft, so dals von dem Ganzeu sechs und Dcr versüfste Salzgeist mufs völlig farbencr versüste Salagelst muls völig farbenos und wasserbelle seyn, einen angenehmen gewürztuaften Geruch uud einen durchdringend starken nelkenartigen, etwas bitterlichen Geschmack besizen. Lackinuspapier darf nicht davon gcröthet werden; mit flüssigem Kali darf er nicht aufbrausen-und elwas hineingelcgtes trockenes Kali darf nicbi darin sclimeizen oder sebr angefeuchtet werden.

Spiritus nitrico-

netlerels. . ner Mischung von vier und $z$ wanzig Unzen Spiritus Nitri dul- Weinalcohol und sechs Unzen Salpetersäure, wovon ans einer gläsuriaen Destillirgerâthschaft z.wanzig Unzen bey dem geliudesten Feuer abgezogen werden und das Destillat über eiue halbe Unze ge-

reinigt. Alcalien auf

Giebt mit Kalifüssigkeit vermis cht einen Nisderschlag.

drannter Magnesia rectificirt wird, berei-

Schlecht versüfst.

Durch langes Aufbewahren, auch wenn das Glas öfters geöfnet wird, wird er sauer.
Brauset mit Alcalien und farbi das Lackmuspapier roth.

Man erkennt dieses schon daraa; dals der Stöpsel dcs Glases gelb gefärbt wird. Aufserdem riecht und schmeckt er sauer, röthet die Iackmustinctur und brauset mit Alcalien. Schüttelt man ihn mit aufgelö- 


\begin{tabular}{|c|c|c|c|}
\hline $\begin{array}{c}\text { Namen } \\
\text { ler Arzneymittel. }\end{array}$ & $\left|\begin{array}{c}\text { Sinnliche Eigenfchaften derfelben; } \\
\text { Merkmale ihrer Aechtheic und } \\
\text { Giite. }\end{array}\right|$ & $\left|\begin{array}{c}\text { Fehlerhafce Be- } \\
\text { chaffenheic, Ver- } \\
\text { wechelung oder } \\
\text { Verfälfchung. }\end{array}\right|$ & $\begin{array}{c}\text { Deren } \\
\text { Kennzeichten und Prüfungsmittel. }\end{array}$ \\
\hline $\begin{array}{l}\text { Spiritus nitrico- } \\
\text { aethereus. }\end{array}$ & $\begin{array}{l}\text { Tet. Der versiifste } \\
\text { er gut bereitet is } \\
\text { wasserhelle seyn, } \\
\text { deu Borsdor'feräpfe } \\
\text { einen starken sü } \\
\text { habeu. Mit Kali } \\
\text { aufbrausen nnd } \\
\text { röthen. Etwas h } \\
\text { Kali darf nicht d }\end{array}$ & & 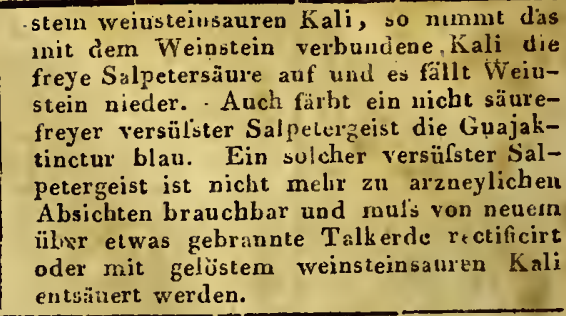 \\
\hline
\end{tabular}
ser entbält. Er ist um desto besser, jc mehr er von einem Gummiharze, z. B. Ammoniak, Myrrhe u. dgl. aúlöset.

Anmerkung. Das sicherste Mittel, den versilisten Salpetergeist auf längere Zeit gut und unverändert 211 erhalten, ist das, wenn anfiullt, genau verschlosscn, an einem kühlen Orte aufbewahrt wird. Doch sollte er auch nie in gar zu grofser Menge in Vorrath bereitet werden.

Spiritus Rorisma-

rini s. Anthos.

Spiritils Sapona-

ins.1

Seifengeist.

Spiritus Serpylli. Quendelgeist.

Spiritus sulphurico-aethereus. Liquor anodynus mineralis.

Versüfste Schwefelsäure.

Schiwefeläthergeist.

Schmerzstillender

Liquor.

Ueber Rosmariublätter und Blumen mit Zusatz des uöthigen Wassers abgezogener Weingeist vọn einem sebr augenebmen lieblichen Geruch.

Aus einem Theil geschabter Spanischer Serfe in drey Thcilen rectificirten Weingeist und einem Theil Rosenwaswasser durch Digestion in gelinder. Warme berestet. Hat eiue dafenclich

eber blühendes Quendelkraut mit Züsatz des nüthiøen Wiassers abgezogener Weingeist vou abgenehmen geistiggew ïrzbaftem Quendelgeruch. Wird entweder nach der Preufsischen Phas- Freye Säure enthal-pöthet die Lackmustinctur, brauset mit Laumacopoe durch Vermischuug von einem tend:

Theil Sehwefeläther und drey Theilen Weinalcohol, oder auf die gew öhnlıche Weise aus einem Theile coucentrirter
Schwefelsäure und drey Theilen Alcohol Aurch die Destillation bey gelindem Feue bereitet. Er muls ungefäıbt and rvasserhelle seyn, eluen starken, angenebmen, Mit schlechlen Weingensal 2 ca serribt.

erquickenden, aus Aether' und Weinalcogeist bereilet. Hat einen weuiger atigenebmea Geruch nud Ceschmack; riecht und schmeckt prleginatischl.

hol vermischten Geruch und eineu crst

küblenden, dann feurigen eigessartig gewürzhaften Geschmack besilzeu. Er darf peder stechend schwetisch schmecken. Schon in geringer pflegmatisch schmecken. Schon in geringer
Wärme mufs er sich verflüchtigen, leicht Wärme mufs er sich vertüchigen, leicht trocken wegbrennen. $\mathrm{Er}$ schwimmt eine Zeitlang auf dem Wasser, woranl er gegossen worden, und ist, so wie mit Alcohol und geistigen Flüssigkeiten, $z$ war auch mit zwey und mehreren Theilen Wasser völlig mischbar, setzt jedoch mit gleicien Theilen Wasser oder Aetzbalilauge unterTheilen Wasser oder Aetzkalilauge untereiuansler seschuttelt, nach einiger Zeit gegen den vierten Theil Aether obenauf ab. Mit Zuckersäften muls er sich nicht so leicht, wie der Weingeist mischen lassen; die Lackmustinctur darf er nicht rothen und mit Laugensalzen uicht aulbrausen. Völlig wasserfrey darf er dazu geschütteltes trocknes Kali weder breyicht, noch weniger dünnflüssig machen."Je mehr er Grummiharze auflüsct, un destó besser

Spiritus sulpluturico - sethereus martiatius.

Liquor anodynus martialis.

Eisenhaltige versüfste Schwefelsäure.

Bestuscheffsche Nerventiactur.

Spiritus Vini gallici. Franzbranntwein. ist er.

nach der Preufsischen Pharmacopoe bercitet, indem inan reine Eisenfelle in einer hiulinglichen Meuge, vorher mit dem vierten Theil Salpetersäure vermischten Salzsänre auflüset, die Auflüsung bis auf den dritten Theil abdampft, den erbaltenen gesättigt braunen Liqıor durch Schütteln mit der doppelten Menge Schwefeläther vermischt, den auf diese Art nit anf gelöstem Eisenoxyd geschwängerten Aether ahsoudert und ibn mit doppelt so vielem. Weinalcohol vermischt, das crhalteue Gemische in länglielie wohl verschlossene Gläser füllt und so lange dem Sonnenlichte aussetzt, bis die weingelbe Farbe gänzlich verschwunden ist, wouf sorgältig anfhewahrt. Der eisenhaltige Schwefeläthergeist hat, wie gesagt, unmittelbar nach wird, und nimmt au einem. dunkeln Orte die vorige gelbe Farbe wieder au. Uebrigens mufs er helle und klar , eisenartigen Geschinack besitzen. War derselbe der Einwirknng des Sonnenlichts nicht ausgesetzt, oder anch, wenn er vorher demselben ausgesetzt, durch länger'es Stehen die vorige goldgelbe Farbe wieder angeuommen hatte, so her de zugesetzten gelüsten Alcalien einen gelben; war er aber kürzlich entfärbt worden, einen bläıgiederschlag. Nit blausaurem Kali liefert er im erstern Falle mit Wasser verdünnt, einen vüllig duukelblauen, in letztern dagegen einen lichtbläulichen $S$ atz, so wie mit Galläpfelauszug im ersterı eine dunkelschwarze Dinte, in letztern aber eine helle schwarzblaue Mischung. Vorber nicht ausgebleicht lärst er nach langer Autbewahrung im Dunkeln einen gelbeu Satz fallen, der beym Eleiclien in Sounenlichte wieder darin verschwindet. Die Gläser worin man ihn aufbewahrt, müssen nicht mit Korkstüpseln, sondern mit Glasstöpseln versehen seyı.

Wird durch die Destillatiou a us Franzïsischen Nachgekünstelt, aus|Man erbitze eine Probe des verdachtigen Weinen oder ans Weinhefen erbalten nud Kornbranntwein, Franzbranntweins anf einer heifsen Stelle, aus Frankreich zil uus gcbracht. Ursprïng- mit welchem der dergestalt, dafs er uicht zum Kochen kommt, lich bat der Franzbranotwein eine weilse ächte Franzbrannt- so lange bis vich der Dumst davon nichi 


\section{Spiritus Vini gallici. -- "Spongia marina.}

Namen
der Arzneymittel.
Spiritus Vini gallici,
Spiritus Vini rec-

\section{cificatus.}

Rectificirter Weingeist.'
Spiritus Vini reciificatissimus.

'Alcohol Vini.

Höchst rectificirter

Weingeist.

Weinalcohol,

Alcohol.
Spongia marina. Meerschwamm.
Sinnliche Eigenfchaften derfelben, Merkmale ihrer Aechilueit und Guice.

Farhe; so wie er aber zu uns kommt, ist er von den eichenen Fässern, oder auch vou andern beygemischten färhenden Dingen mehr oder weniger gelblich gefärht Er bat einen lieblichen gewürzhaften Geruch, schmeckt angenelimier als der Kornhranutwein, entloalt melir Weingeist und läst den Alcoboloneter tiefer einsinken, als jener.

Franzbranntwein von unangenelimen Geruch, vou säuerlich-ölichtem, oder vielmelar fuselichten Geschmack und dessen gelblicbe Farbe mit einer Auflösung des schwefelsauren Eisens nicht scbwarzlich wird, die mithin von etwas andern, als vom Eichenbolz herriburt, ist gemeiniglich nachgekiinstelt und taugt nicht. Indessen würde man sich doch öfters sehr irren, wenn man umgekebrt vom Scbwärzlichwerden desselben bey gedachter. Probe, auf dessen Alecbebeit schliefsen und diese

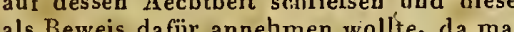
ja ja aucb dem Fruchbranntwein durch langeres Liegen auf einem eichedeu Fasse oder Sägespänen ence gelbliche Farbe leicht verschatlen kann.

an erbalt ihn, wenn man entweder den Kornbranntwein oder Franzbranntwein durch neue Destillation so weit abziebt, als er ohne Wässrigkeit übergeht. Er mufs vollkormen belle und farbenlos seyn, keine fremden Geruch upd Geschrnack baben sondern rein und angenehm schmecken und einen feinen starken Woblgeruch besitzen Dabey mufs er so leicht seyn, dafs ein Glas, welches zehn Unzen. Wasser fafot, nur neu Unzen Weingeist in sich aufnehmen kann.

Man erbalt ibn, wenn man den rectificirten Weingeist von neuem im Wasserbade so weit abzieht, als sich noch mit dem ühertröpfelnden Geiste getränkte und angezündete Baumwolls, nach Verbrennung des Geistes, in Ascbe verwandeln läfst. Der so bereitete Alcohol stellt eine leichte, farbenlose, wasserhelle und ganz klare Flüssigkeit dar, vou einem sehr starken durchdringenden, flüchtigen, reiugeistigen $\mathrm{Ge}$ ruch und einem feurigen Gescbrnack. I einem Glase geschüttelt mufs der Alcobol stark perlen und mit gleichen Theilen Wasser verunischt sich erwärmen. Er mufs ser forner leicht anzänden lassen und ohne die mindeste Flïssigke die mindeste Flussigkeit 2 u binterlassen, mit aulserst beller andicben Flamme, völlig wegSeiten bläulicben Flamme, völlig wegbrennen. In einem balben Pfunde vollkommen wasserfreyen Alcohol darf ei nicht zerfliefsen, sondern es mufs darin völlig trocken,bleiben und nichts wäfsriges anzieben. Sein specifisches Gewicbt darf gegen Wasser nicht unter 0,820 seyn. Total wasserfrey, wie er nur als absoluTotal wasser let A m ) durch Rectifcation über sala l utum) durch Rectification uber salzsanre Kalkerde gewonnen wird, beträgt scin specifiscbes Gewicht in milterer Tomperatur 0,791 , oder mit audern Worten ein Glas, welches bey $16^{\circ}$ Reaurn. Gran Wasser hält, darf uur $7: 1$
soluten Alcohol in sich fassen.
Fehlerhafte Be-
chaffenheit, Ver-

wechfelung oder

Terfälfchung.

Kennzeichen und Priifungsmittel.

wein auch wohlj mehr anzünden läfst. War der Franzverfälscht wird.

mehr anzünden lälst. War der Franzblos weinsäuerlıch und etwas scharf sclimecken, und einen süfslicben Geruch, wie gekocbter Wein haben. War er aher aus Kornbranntwein nachgekünstelt oder damit verfälscht, so hat das rückständige Pflegma den widrigen brenzlichten Fuselgeruch, oder einen, dem gehrannten Mebl ähnlichen Geruch und den hinten am Gatumeu kratzenden Fuselgeschmack.

u wärsrig und folg lich zu schwach.

Dieses zeigt das specifische Gewicht. Nach Herrn D o r f f u t t (N. d. A pothekerb. Th. 2. S. 1968) bat derjenige rectificirte Weingeist, welchen man aus einem vermittelst geist, welchen man aus einem vermittelst
Holzkoblen gereinigten Branntwein durch eine einmalige Destillation erhält, ein specifisches Gewicht von 0,875 , oder es geben daron in einem genau $z$ wey Unzen und $\mathbf{z w e y}$ Scrupel destillirtes $W$ asser fassenden Glase gegen 44 Scrupel, wobey er in 100 Tbeilen 67 . Alcohol und $33 \mathrm{~W}$ asser enthält. Anı sichersten erfäbrt man den Getalt des Weiugeistes an Alcobol durch den $B$ ichterschen Alcoholometer. S. d. nachf. Titel.

Kupferhaltig. ein darin gelegtes Stiıckchen ungelöschte Kalk wird grünlicb gefärbt.

Nicht völlig entwäs- Die gewölınlicben Proben in dieser Hinsicht, sert. bestehen darin, dafs mau trocknes Scbiefspulver oder trockue Baumwolle mit dem zn prüfenden Alcohol übergiefst und ibn anzündet. Ist er wirklich ganz wasserfrey, so werden sich diese Dinge, nachfrey, so werden sich dies Weingeistes abdem der letzte. Tzeil des Weibielt er aher gebrannt ist, entzinden; , entbielt er aher
Wasser, so feuchtet dieses die Körper an Wasser, so feuchtet dieses die Korper an, und sie entzzïnden sich nicht. Disse Proben sind aber ans leicht begreiflicben Gründen nicht ganz sichęr. . Zuverlässiger is die angefubrte Probe mit dem trocknen milden Kali, welches nicht darin feuch werden darf. Am sichersten aber ist die Untersuchung des specifischen Gewicht. nach dem angegebenen Verbältıifs.

Anmerkung. Ganz vortüglich bequem, um nicht nur in weni Augenblicken die Stärke des Alcohols, sonılern auch die Stärke des gew öbnlichen Branntweins mit Sicherheit bestimmen zu können, ist der von dem verewigten Ricbter in Berlin, angegebene Alcobolomete Seine äufsere Gestalt ist von einer gew Ölchereden; er ist mit gewornter Bratwe einer Scale verseben, dic von o bis 100 in destillirtes Wasscr, bey einer Temperatur von $16^{\circ}$ Rean. in destillintes Wasscr, so sinkt er bis auf o. Senkt man ing in den reinsten Alcohol, so sinkt er bis 100. Hätte inan nun 2 . B. einen Weingeist, de im Hundert 20 Procent Wasser entilele, so wird der Alcoholometer auch nur bis auf 80 Grad einsinken. Auf diese Ar lärst sich also der Gehalt an Wasser sehr genan bestimmen, und der Apotheker kann rnit diesem Instrumente aucb zugleich den Gebalt des einzukaufenden Branntweins an wabren Alcohol sebr genau fiuden.

Eine gestaltlose, zähe, biegsame, rauche, dichthöch erichıe, zuweilen ästige, insgemein auf einer Seite erhabene, auf der andern flache, leicht Wasser einsaugende und davon anfschwellende und elastische Substanz vor anf weilsticher, gelber oder braunlicber Farke, dille, Venedig u, s. w, zu uns gebracht wird. Zum äufserligend antrifrt und iiber Livoruo, Triest, Marseille, Weichen, nachgiebigen, foinlöcherichten, weifslichen oder chen und chirurgischen Gebrauclie mïssen die sehr W 


\begin{tabular}{|c|c|c|c|}
\hline $\begin{array}{c}\text { Namen } \\
\text { der Arżeymitcel. }\end{array}$ & $\begin{array}{c}\text { Sinnliche Eigenfchaften derfelben } \\
\text { Merkmale ihrer Achtheit und } \\
\text { Giite. }\end{array}$ & $\mid \begin{array}{c}\text { Fehlerhafte } \text { Be- } \\
\text { fchaffenheit, } \\
\text { wech } \text { Velung } \\
\text { Verfälschung. }\end{array}$ & $\begin{array}{c}\text { Deren } \\
\text { Kennzeichen und Prüfungsmitcel. }\end{array}$ \\
\hline
\end{tabular}

Spongiamarina. hellgelben sogenanten Fenster-oder Badeschwämme (Spongia officinalis) ausgewäblt werden. hu Zu dem gebranuten oder gerosteteb.

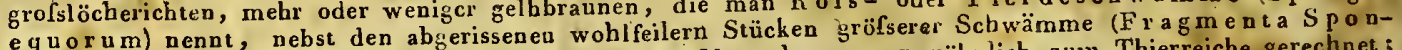
e quorum) nennt, nebst den abgerissenen wohideilern Meerschwamm gewöbnlich zum Thierreiche gerechnet; er scheint aber doch mebr vegetabiliseben, als thierischen Ursprungs, und nur die Wohnung gewisser Poly-

Spongia cerata.

Prefsschwamm.

Wachsschwamm.

\section{Stannum.}

Zinn.
Hierzu werden dünne, durch biegeu, Dreben und Schlageu von den darin enthaltenen Schwammsteineu und Sandkörnern wobl gereinigte und recbt ausgetrocknete feine Badeschwämme in geschmolzenes gelbes Wacks getaucht und zwisclieu heifsgemachten metallenen Platten möglichst stark geprest. Der Schwamm verliert dadurch seine löcbrrichte Beschaffenheit und stellt, nachdem er erkaltet ist, dünne, bräuulichte, dichte, steife und zähe Scbeiben vor, die alsdann von allem noch etwa an den Seitell anliangenilem Wachse gesarubert und aufgehoben werden. Andere wollen, dafs man den Schwamm in erwärmten arabisclsen Gummischleim legen, und nachdem er sicb techt voll gesogen, ibn zwisclien zwey zinnernen Prelsplatten, so stark als möglich zusammen pressen, und so lange in der Presse lassen soll, bis ervöllig trocken geworden. Noch andere schlaget vor, den woblgereinigten und ausgewascbenen Nieelschwamm noch nifs mit Bindfaden dicht und fest zu umwickeln, ihn so austrocknen zn lassen und jedesmals so viel loszuwickeln

und fest zu umwickeln, ibn so austroche Der Trefschwamm dient übrigers nur zum chirurgischen Gebrauch. Wird eutweder oxydirt in Verbindung mit/Kupfer/caltig. Nan entdeckt dieses durch die bimauelblaue Fisenoxyd als Ziunstein, und mit diesem

Eisenoxyd als Ziunstein, und Kornisch ZinnOxyde und etwas Arsenik als Kor gleichviel erz, odcr in erbindung mit fast gichviel Kupfer und wenigem Eisen mit Schwefel vererzt als Zinnkies in versehiedeneu Ge-
genden von Ostindien, den Englischen genden von Ostindien, den Englischen Grafschaften Devan und Cornwallis, so
wie im säcbsischen und böhmischen Erzwie im säcbsischen und böhmischen Erzist das Zinn ein fast silberweifses, weicbes, wenig zähes und elastisches, daher beynahe klangloses, dehnbares, beym Biegen hnirschendes, der Einwirkung der Luft und des schendes, der Einwirkung der Lucer Zeit mit einem scbmutzig gramen, dïnnen Ueherzuge sich bedeckendes ojer vielmehr nur zuge sich bedeckendes ouer vetall, das geriebcn oder erwärmt einen widerlichen, gewisseroder erwärmt einen widerlichen, gewiser mafsen knoblauchartigen Geruct hat und nur siebenmal sclowerer als das Wasser, oder nach andern von 7,180 bis 7,299 eigenthümlichen Gewichte ist. Es ist das leichttlïssigste Metall, indem es noch vor dem Glühen schmilzt, und gerührt sich in verwandelt. Die eigentlichen Auflösungsmittel desselben sind das GoldAuflösungsmittel die Salzsäure. Von- der Scheidewasser undersäure wird es unter starker Erhitzung und Aufbransen nur zu einem weifsen Pulver zer fressen. Die Schwefelsäure vereinigt sich nur unter gewíssen Bedingungen daınit. Auch die Gewächssäuren losen es, wo nicht im metalischen, dirten Zustande mer amalgamirt es sicb Mit dem Quecksich auch leicht mit den übrigen Metallen und macht damit sebr nützliche Verbindungen. In Köuigswasser aufgelöset, giebt es den rothen Farbebrüben mehrere Lebhaftigkeit und sch.

Goldauflösung purpurfarbig niederDas reinste und beste Zinn erbält man ans Ostindien, entweder in cylin $P$ fund schweren Massen oder Zainen ( $B$ a $n$ c a z in $n$ ), oder in pfundschweren Klumpen von der Gestalt eines Jesuiterhutes (Merachtet, wenu man es des ist aber dem icherern Wege, als durch nicht auf einem sichern land oder Dännemark erhalten kann, nicht land oder Dännemark ertsh. Das Englischc selten mit Bley vcr'linu (S tan $\mathbf{n}$ um angoder Cornwalliscbe Zinu (St a n num a licum) bekommen die Grolstandler bëch, wöhnlich in grofsen viereckigen Blöck des schinclzcn es aber zur Erleichtige Massen um. "Nächst dem Ostindischen wird dieses für das beste gehalten, ob es gleich auch nicht immer gauz rein und uuverfälscht ist. Ueterbaupt ist alles bey uns verkäufliche Zinn gemeiniglıch mehr oder weniger mit Kupfer, Bley oder Wismuth versetzt. und verfälscht. Zuweilen, jedoch immcri nur verfälscht. zufäligerweise und in hochtliches VerQuantität, niemals als eigentliches
fälscbiungsmittel ist dem Zinne auch wohl muth verfälscht.

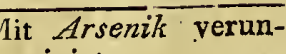
reinigt.
Mit Bley oder $\overline{\text { Wis- }}$ Farbe, wenn man gefeiltes Zinn mit ätzender Ammoniumflüssigkeit digerirt. Auch kann man das Zinn in Goldscheidewasse auflösen, und die Auflösung mit der Ammoniumflüssigkeit versetzen, wo ebenfalls eine blaue Farbe entste
Zinn hupferhalug war.

Man übergiefse ein Loth des zu prüfenden, vorber sefeilten Zinns in einem Glase mit vorber gefeilten Zinns in einem Glase mic vier Loth remer Salpetersäure und lasse
dieses vier und zwanzig Stunden ruhig stedieses vier und zwanzig Stunden ruhig ste-
ben. Wäbrend dieser. Zeit wird das Zinn ben. Wäbrend dieser. Zeit wird das Zine cher eine etwas getrübte Flüssigkeic steben bleibt. Diese soodere man von der zerfressenen Zinnmasse $a b$ und filtrire sie. Um nun zu erfahren, ob die filtrirte Flüssickeit Wismulh entbalte, Vermische sigkei Wit zweymal so man die Halfe deselben vielem destillirten Wasser alles kiar, ohne dals sich ein weirser Niederschlag bildet, so ist das Zinn frey yon Wismuth. Zu der andern Halfte der Flüssigkeit giefse man etwas verdünnte Schwe-
felsaure. War das Zinn rein, so bleibt alles klar; enthielt es aber Bley, so wird sogleich ein weifser Niederschlag entstehen, welcher Bleyvitriol ist.

Man kann auch das Zinn in fünf Theilen Salzänre mit einem Theil Schwefelsäure vermin Boden liegen vernischt, alcu bleibt, ist Bleyvitriol ducirt werden kann.

metallischem Biey reduche Probe giebs

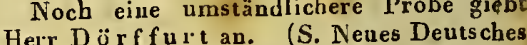
Herr Dörffurt an. (S. Neues
Apothekerb., Th. 1. S. goz u. f.)

aus dem stärkern Knirschen des Ziunes beym Biegen, und aus der gröfsern Leichtigkeit desselben in Hiusicht seines specifischen Gewichts auf seine Reinheit und auf die Abwesenae fremder Metalle Es berubet hie heit frem die im gemeinen Leben der Zinngiefses, die aber, wie leicht za

erachteu, nicht zuverlässig ist. Eheu so unzuverlässig ist das Kochen des Zinnes mit Essig, um durch den süfsen Geschmack desselben die Anwesenheit des Bleyes zu entclecken, da das Zinn mit Sãı-

ren naher verwandt ist Gri n d el (Russisches Jabrb. d. Pharunacie, 1808 , S. 168 u. f) dic Bemerkung, dafs cine Menge Stangenzinn im Handel vorkomme, welches arseuikhaltig ist. Es hat dieses Zinn nicht die schöne weifse Farbe des englischen Zinns, kommt auch in dünnern Stangen vor. Es ist daher die Früfung des Zimnes auf Arsend das Zinn äufsersten Wichtigkeit. Sobh vollendeter Arseuik eothalt, so wird watro Autlösung desselben in concentrirter Salzsäure ein scbwarzer Niedlerschlag deutlich zu bemerken seyn. Dieser Niederschlag nähert sich dem regulinischen Arsenik, und ist, nachdem er, um den unangenehmen
Geruch, den selbst die salzsaure Zinnauf- 


\section{Stannum. - Stibium oxydatum album non ablutum.}

\begin{tabular}{|c|c|c|c|}
\hline $\begin{array}{l}\text { Namen } \\
\text { Ner Arzneymiti.l. }\end{array}$ & $\begin{array}{c}\text { Sinnliche Eigenfchaften derfelben; } \\
\text { Merkmale ilhrer Ächtheit und } \\
\text { Güte. }\end{array}$ & $\begin{array}{c}\text { Fehlerhafie Be- } \\
\text { fohaffenheit, Ver- } \\
\text { wechselung oder } \\
\text { Verfälfchung. }\end{array}$ & $\begin{array}{c}\text { Deren } \\
\text { Kennzeichen und Prüfungsmirtel. }\end{array}$ \\
\hline Siannutum. & $\begin{array}{l}\text { Arsenikmetall beygemischt, wovon indes- } \\
\text { sen das Sächsische Seifenzinu ganz frey } \\
\text { seyn soll. }\end{array}$ & 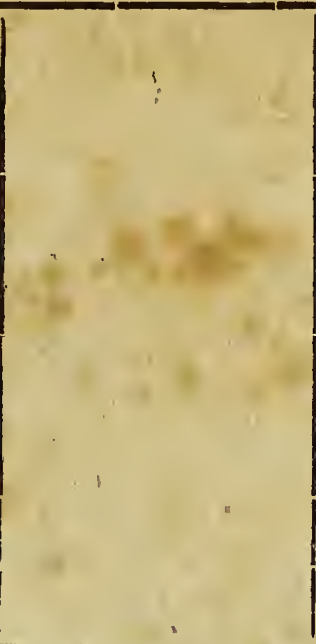 & 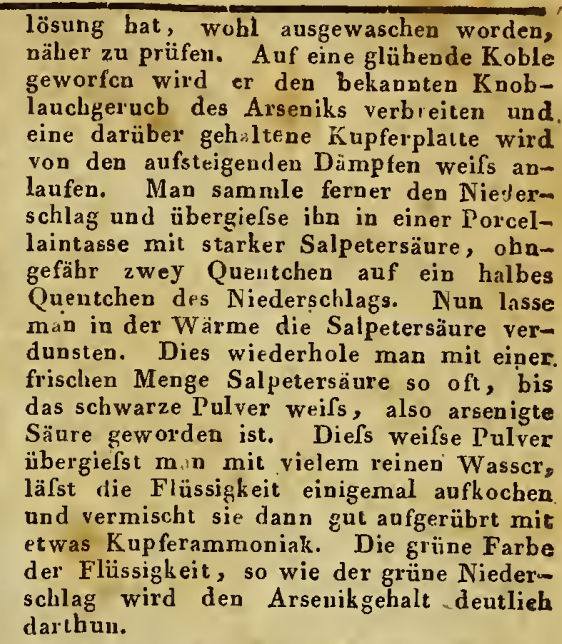 \\
\hline
\end{tabular}

tum s. pulverisatum.

Zinnfeile.

Stibium oxydatum album ablutum. Antimonium diaphoreticum ablutum.

Weifses Spiefsglanzoxyd. Schweifstreibendes spiefsglanz.

gegossen, durch schnelles und slarkes Schütteln gepiilverte, und durch ein Sieb von den grëfsern Körnern geschiedene Zinn.

Ein vollkommnes, mit et was $K$ ali verbundenes Spiefsglanzoxyd, welches dadurcb ge wonnen wird, dafs man eincn Theil gepul vertes rohes, Spiefsgl $l_{\text {anz }}$ mit drittebalb Thei len gèpulverten Salpeter vermischı, löffelweise in einen glübendeu Tiegel trägt, di worden, unit zehn bis funfzehn Tbeilen kochend. $m$ ' Wasser übergiefst, sie eine Zeitlang stark umrührt, die Flüssirkeit abfiltrirt und den weifsen Kalk noch so oft mit kochendem Wasser aussiifst, bis dieses geschmacklos abläuft, worauf der weifse Satz vorsichtion a weilse Satz vorsichtig getrocknet wird. Das wohlausgesüfsle scbweifstreibende Spiefsplanz mufs cine blendend weifse $\mathbf{F}$ rbe haheń, völìg geruch- und geschmacklos seyn, sich leicht
in Stücken brechen und fein reiben lassen, in Stücken brechen und fein reiben lassen,
und innerlich angewendat, kein Erbrechen erregen. Es darf mit ilen Säuren nicht aufbrausen und von der Salpetersäure nichı aufgelöst werden. Für sich allein ist es böchst feuerbeständig und schmilzt erst iu stärkster Glut $2 \mathfrak{n}$ einer gelben glasichten Schlacke: Wenn es mit schwarzem Flusse (ein Gemenge, welches man erbầlt, wenn man z.wey Theile rohen Weinstein mit einem $T b c i 1$ Salpeter verpufit) versetzt, in einem Tiegel bey einem starken Feuersgrade geschmolzen bey einem starken Feuersgrade geschmolzen wird, so erhält man wieder metallisclien
Spiefsglanz. Mit dem acliten Theil Schwefel vermischt, liefert es durch Schmelzen ein röthlicbbraunes byacinthfarbnes Glas. És mufs dieses Mitiel in gut verstopften, den Sonnenstrablen nicht ausgesetzten, am sichersten schwarzangestrichenen gläsernen oder steinzeugnen Gefälsen aufbewahrt werden. verpuffte Masse, nachdem sie zerstofse

it unvollkommnen/Diese höchst gefährliche Beymıscbung des \begin{tabular}{l|l}
$\begin{array}{l}\text { Spiefsglanzoxyd } \\
\text { verunreinigt. }\end{array}$ & $\begin{array}{l}\text { unvollkommien Spiefsglanzoxydes, das } \\
\text { für sich schon in ler kleinstel: Gabe tödt- }\end{array}$
\end{tabular} liches Erbrechen verursachen kann und aIso auch dem schweifstreibenden Spiefsglan $/$ e. eine Brechenerregende Eigenscbaft mittheilt, entrecht man, wenn man das letaterc mit elwas destillirtem Essig übergiefst, und ihn eine Zeitlang darüber steben läfst. Setzt man alsdann der abfiltrirten Flüssigkeil elwas von $\mathrm{Habnemans}$ Probefivssigkeit zu, so entsteht ein ziegelvother Niedersching anf zugesezies ouf rother Niderschlng; anf zugesetzles aufNiederschlag, welcher blausaures Spiefs-
Nigästes glanzoxyd ist.

Mit Fisen oder $\overline{\text { Hat keine vollkommen weifse } \mathbf{F} \text { arbe, sondern }}$ Brannstein verun- ist mehr oder weniger gelb, grau $u_{0} s_{0} w_{\text {. }}$ reinigt, wenn der gefärbt.

gebrauchte Spiefs glanz dergleichen enthielt.

Mit unreinem, Kochoder Digestivsalz enthaltendenSalpeter bereitet.

Das in Fabriken berei- $\overline{\text { Ist dies der Fall, so verräth sich die Kreide }}$ tete schweifstrei- durch das sogleich erfolgende Aufbrausen, bende Spiefsglanz wemn man es mit einer Saure, z. B. desoll bisweilen mit stillirtem Essig übergiefst, durch den bitKreide verfälscht terlich kalkartigen Geschmack, den der seyn. Lssig, wenn er eine Weile dartiber gestanSa Salz, welchen Kuighisgigkeir alsclann darm aus absondert, zugetrop pelte salzichte Säure aber nicht tarin bewirkt, sondern vielmebr den durch Kali entstandenen wieder verschwindcu macht.

Auch wohl mit Bleyweifs. einen sü lsen zusammenziebenden Geschmack all, und giebt mit $\mathrm{H}$ a ho e man $\mathrm{n}$ s Probeflüsiokeit vermischt, bydrothionsaures Bley, als eineu schwarzen Nierierschlag.

A merlur der zum schweifstreibenden Spiefsglanzoxyde angewendete role Spiefsglanz arsenikhaltig, mit Mifspickel oder angewendete rohe Spielsglanz arsenikhaltig, mit Milspickel ode Arseniks Spiefsclanz nicbt frey von dieser gefährlichen Beymischung. bende Spiefsclanz nicbt frey von dieser gefahrichen neymischung Der Apotheker hat sich daher aulserst in Aches arsenikhaltig ist. er kein rohes Antimonium erbalte,
Vergl. Stibium sulphuratum nigrum. Die durchs Verpuffen der znin schweifstrei Schlecht aufbewahrt|Es bat alsdann seine weifse Farbc verlore \begin{tabular}{l|l|l} 
benden Spiefsslanze bestimmten Mischung & und zu alt. & $\begin{array}{l}\text { und ist gelb oder grau; in diesem Zustande } \\
\text { ist es scharf und schädlich geworden und }\end{array}$
\end{tabular}

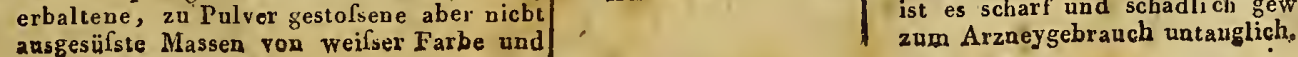


$144^{2}$ Stibium oxydulatum fuscum. - Stibium sulphuratum nigrum.

\begin{tabular}{|c|c|c|c|}
\hline $\begin{array}{l}\text { Namen } \\
\text { Arzneymitcel. }\end{array}$ & $\begin{array}{c}\text { Sinnliche Eigenfchaften derfelben } \\
\text { Merkmale, ihrer Aechiheit und } \\
\text { Güce. }\end{array}$ & $\begin{array}{c}\text { Fehlerhafte Be- } \\
\text { Jchaffenheit, Ver- } \\
\text { wechfelung oder } \\
\text { Verfälfchung. }\end{array}$ & $\begin{array}{c}\text { Deren } \\
\text { Kennzeichen und Prïfungsmitcel. }\end{array}$ \\
\hline $\begin{array}{l}\text { Antimonium dia- } \\
\text { phorcticum non } \\
\text { ablutum. } \\
\text { Jngewaschenes } \\
\text { schweifstreiben- } \\
\text { des Spiefsglanz- } \\
\text { oxyd. }\end{array}$ & $\begin{array}{l}\text { einem Salzichten Geschmack. AIufs in ei- } \\
\text { nem wohl verschlossenen Glase an einem } \\
\text { trucknen Orte aufbewahrt werden. }\end{array}$ & & \\
\hline $\begin{array}{l}\text { Stibium oxydula- } \\
\text { tum fuscum. } \\
\text { Crocus Metallorum. } \\
\text { Braunrothes Spiels- } \\
\text { glanzoxydulat. } \\
\text { Metallsaffran. } \\
\text {.. }\end{array}$ & \multicolumn{3}{|c|}{ 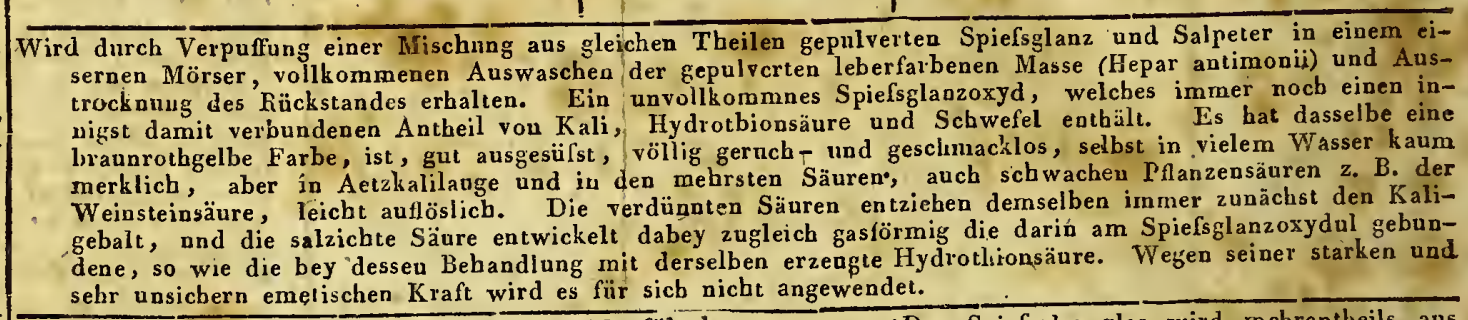 } \\
\hline $\begin{array}{l}\text { Stibium oxydula- } \\
\text { tum vitrificatum. } \\
\text { Vitrum antimonii. } \\
\text { Verglastes Spiefs- } \\
\text { glanzoxydul. } \\
\text { Spiefsglanzglas. }\end{array}$ & 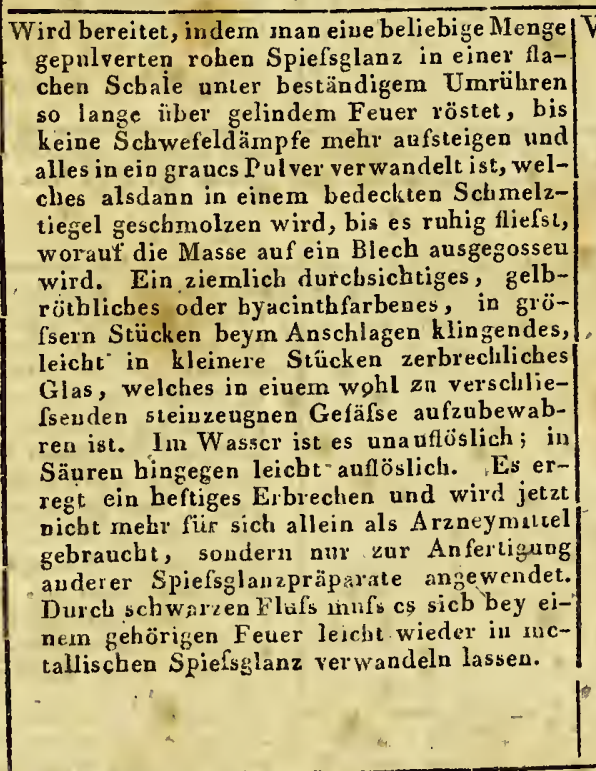 & Verfälscht. & 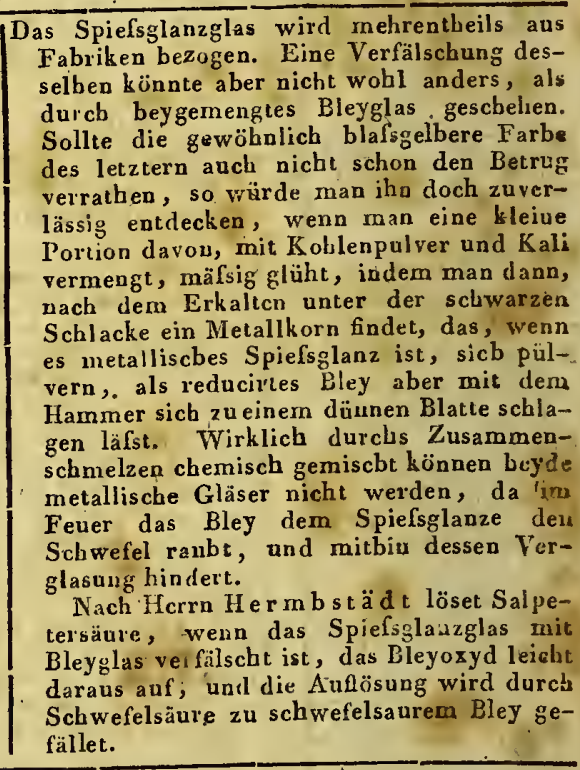 \\
\hline
\end{tabular}

Stibinun purum. Regulus Antimonii. Spiefsglanzkönig.

Stibium sulplutura. tum nigrum.

Antimonium crudum.

Schwarzes, Schwefelspiefsglanz. noher Spiefsglanz. Spiefsglanz.

Wird du Zum durch Zusammensclimelzen von sech Salpeter zu der zusammengeflossenen Masse, die alsdaun, wenn sie mäligem Hinzusetzen von vier Theilen der Erkaltung das unter der schwarzen Schlacke befindlicbe Spiefs-

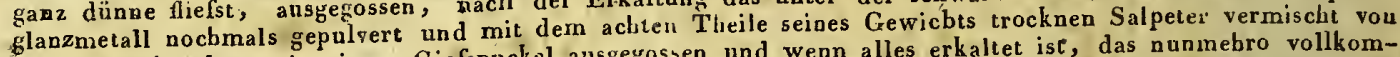
glanzmetall nocbmals gepulvert und mit den acsoss und wenn alles erkaltet ist, das nunmebro vollkom-
neuem geschmolzen, in einem Ciefspuckel ausgegossen un neuem geschmolzen, in einem
men reiue Metall von den Schlacken abgesondert wird, bereitet. Das reiue Spiefsglanzinetall ist von eiuer
Es ist schönen zinuweifsen Farbe, mäfsiger. Härte und so grolser Sprödigkeit, dals es sice Gefüge, welches, wenn etwas mehr als sechsmal schwerer wie testillirtes es nach vollkommnen Schmelzen recht lasgsam erkaitet ist, sich auch ausen Stern, der sich auf der merkeu lasst. An der Luft sitzt keinen Geschinack, wobl aber, Wëfst es sich in Weifsglübfeuer völlig sublimiren. Bey dem Zugange es scbwer. In versch Glähfener einen weifsen Rauch, der sich als ein unvollkommnes Oxyd in glämzendea Nadeln sublimirt. Die Auflösung desselben in salpetrigter Salzsäure giebt hit blansaurem Kuli vermischt

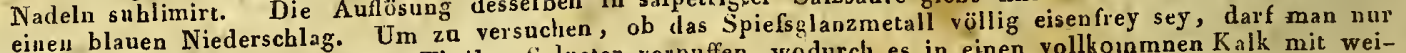

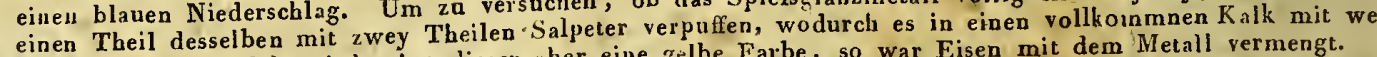

einen Theil desselben mit zwey
fser Farbe verwandelt wird; hat dieser aber eine gelbe. Farbe, so war Eisen mit dem Metall vermengt.

Das durch eine Art von Saigerung oder Ausschmelzung von seiner Bergart und andern fremden Tbcilen gereinigte Spiefsglanzerz welches man aus Ungarn, Siebenbürgen, Kärnthen, Böhnnes und Schwedern bekömmt das Ungarische aber für das beste bält Wir erhalten den rohen Spiefsglanz in dicken, stumpfen, kcgelförmigen Massen odes Eroden. Wr bestiht ohogefähr aus drcy Theilen Spiefsglanzmetall und cinem Theil Scliwefel, ist schwer, ausweudig rauh, vou schwarz - oder bley"araluer Farbe, ohre Geruch und Gescbmack, sebr sprodc uud briichig, läst sich gut pulivern, ist inwen dig glänzend und straliend, im Fever leich Aïssig und völlig flüchtio. Die dichtern
und schwerern Mlassen oder Kucben, welche im Queerbruche nur wenig gläuzcn und gleichsam gctäfelt erscheinen, der Läug nach cerbrechen aber breite und lauge sehr glänzeurle blangraue, theils parallele theils äberzwerch laufende Streifen zeigen, sind die besten. Zu pharmacevtisclien $Z u-$ bereitungen wählt inan auch nur den un-
tatt des rohen Spiels- $D$
glanzes bekommit
bläıtrichtes als spiefsichtes Auseben, lüset sich auch in Salpetersäure, nicbt aber in salpetersaurer Salzsäure oder Königswasser auf, da bingegeu der ächte rohe Spiefsglanz durch die Salpetersäure in ein weifses Pul-
ver verwandelt und in Königswasser auf- gelöset wird.
Mit Eisen verunrei- nigt.
Mit Braunstein ver- unreinigt, vielleicht auch absichtlich da- mit verfälscḷt.
Me vermischt einen Thcil Spiefsglanz mit drittehalb Theilen Salpeter und verpuff das Genenge in einem kleinen Schmelztie- gel. War der Spielsglanz frey von Eisen, wcifs, war er aber eisenhaltig, so ist'sie wcils,
gelb. Wird auf dieselbe Weise, wie der Eisenge- halt erforscht; die Masse wird, wenu Braunstein vorhanden war, grün. Ist der Braunstein dem Spiefsglanze nicht einge- schmolzen, sonder'n nur in losen Stücken beygemengt, so läfst er sich schon durchs beygemengt, so lact gut davon unterschei- blofse Ansehen recht gut daven Gerize Spiefse weniger haber 
Stibium sulphuratum nigrum. -- Stipites Diervillae.

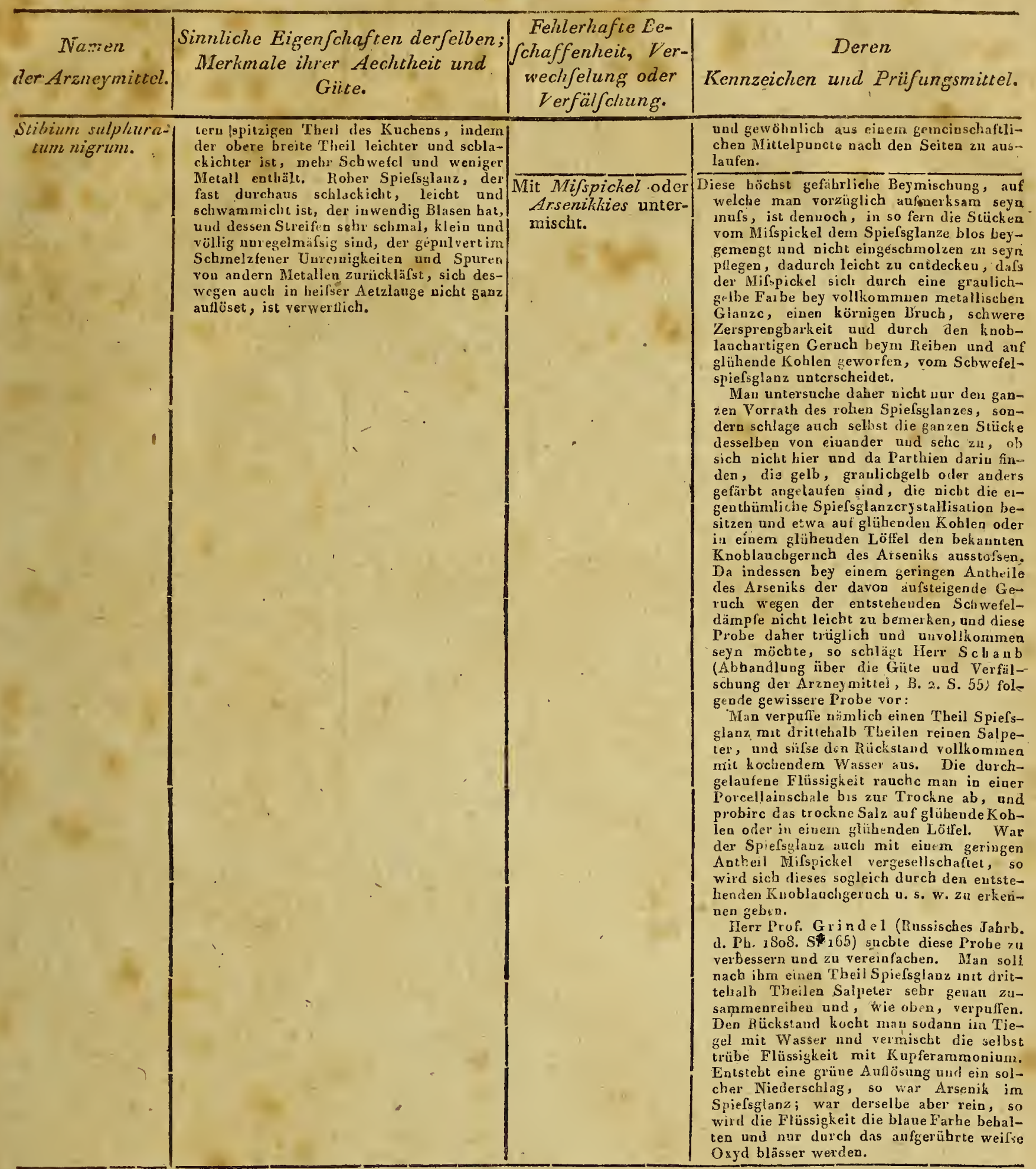

Stibium snlphuratum nigrum laevigatuin.

Antimonium crudum praeparatum.

Pröparirter Spielsglanz.

Stipites Agarici
uuscarii.

Fliegeuschwamm.

Stipites Diervillae. Diervillenstengel. as vorher ausgelesene, in einem eisernen Mörser zerstofsene, durch ein Sieb geschlagene und nachler auf einem platten harten Reibsteine mit etwas wenigem hinzugegossenem Wasser bis zur böchsten Feinheit geriebene und au einem warmen Orte wieder getrocknete Spiefsglanzpulver. Es nufs den möglicbsten Grad der Feinheit baben und durchaus keinen Glanz mehr zeigen. Das Reiben darf uiclit, wie einige Dispensatoria vorschreiben auf einer Marmorplatte geschehen, weil diese zu weich ist und sich Theile davon abreiben würden.

Der in der Erde steckende unterste Theil des Struukes von dem in trockuen, sandigen, bergichteu Wildern wachsenden Fliegenschwa mme (Agaricus muscarius L.), der isn Herbste gesammlet, naci dem Theinigen und Schälen bey gelinder Wärme getrocknet, gepulvert und in einem wohl verstupften Glase anfl,wahrt werden mufs. Der Fliegenscbwanm selbst ist vor seiuer völligen Entwickelung kugelförmig, nimmt aber alliuälig die Form einer Glucke, dann eines flachen Gewölbes und zuletzt die eines Tcllers an. Die Oberflache desselben ist zuweilen fleckenlos blutrota oder mean gfarben, zuweilen mit weilfen Warzen wie besäet und geren den Rand zu gelbweifs oder braungelb gestreift. Mit der Zeit wird er gewinhlich gold-

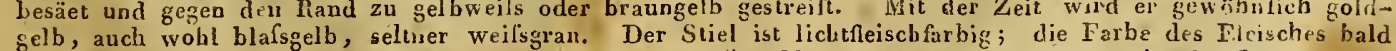
gelb, auch woht blafsgelb, seluer weilsgran. Der Stiel ist liclitfeischfarbig; die Farbe des Ficisches bald weifs, gelb oder roth. Die an der untern Fläche in groiser Menge zusammengchräugt stehenden Elätier wer-
den mit dem Alter des Schwammes gelhlich oder brau. Er hat übrigens einen widerlichen Gernch, pinen scharfen Geschmack nnd ist hü Menschen und Thiere giftartig wirkend.

Die Stengel oder dünuern Zweige der canadisçben Dierville (Diervilla canadensis Willd. Lonicera Diervilla L.), eines in Nurdanerica, besonders in Canada einhcimischen, auch iu unseru Gärien 


Namen $\quad \begin{gathered}\text { Sinnliche Eigenfchaften derfelben } \\ \text { Merkmale ihrer Aechtheit und } \\ \text { Güte. }\end{gathered}\left|\begin{array}{c}\text { Fehlerhafie Be- } \\ \text { chaffenheic, Ver- } \\ \text { wechfelung oder } \\ \text { Verfälfchung. }\end{array}\right|$ Kennzeichen und Prüfungsmittel.

Stipites Diervillae.

Stipites Dulcamarae.

BittersüIsstengel.

Stroluuli Lupuli.

Coni Lupuli.

Hopfen.

Bierbopfen.

Styrax.

Storax.

Storax.'

Styrax liquidus.

Flüssiger. Storax.

Succi Herbarum. Kräutersäfte. zähe, lrolzige Stengel von braunrother Farbe und einem eckelhaften Gerncb und Geschmack.

Die Stengel des Bittersü usnacbtsusbat-|Veraltet. $\quad$ Durch die Länge der Zeit verłterben die Bittens (Solan am Dulcamara L),

nes überall in Deutscbland an Hecken und Zäunen wachsenden hliminenden Strauches. Lange, runde, biegsame, ästige, glatte, holzichte, markige Stengel, von
der Dicke eines Gänsebiels und dariiber. Bey den jüngern Stengeln ist die ninde inwendig und auswendig grün; bey den ältern und diqkern ist sie bräunlichgin̈n runzlicht und rissig. Im Queerdurchschnitte sieht man erst einen weifsen, dann einen grünen Ring und endlich cine mit schwammichten Marke ausgefüllte Röbıe, die aber bey ganz jungen $Z$ weigen hohl ist. Frısch babeu sie einen betäubenden, dumpficht widrigen Geruch; ihr Geschmack ist anfangs bitterlich, hernach süfslich. Zum Arzneygebrauch mufs man die jüngern, nock grunen oder gelbliehgrünen, aber doch schon markigen Stengel, und zwar so viel wie möglich von trockuen Standörter bey trockner Witterung, am besten im Frubjahr, einsammlen.

ie reifen weiblichen Kätzchen oder Frïchte des allgemein bekanuten Bierhopfen (Humulus L upulus L.), welche eyrundlängliche, aus häutigen, dünnen, fast
durchsichtigen, weichen, weifselblichen Schuppen zusammengesetzte Zapfen bilden, kleine, rundliche, scbwarze Saamen und viel feines Mebl enthalten. Sie besitzen ciuen angehehmen, stark gewürzlıaften , in Nenge betäubenden Geruch und einen bittern, etwas erwärnenden Geschmack. Je klebriger sie sich anfüblen, schmack. Je klebriger sie sich anfulen, je mehr sio Mebl exthallon und je starker ihr Geruch und Geschmack ist, bcsser sind sie. Ilopfen, dessen Saarne ond Mehl schon anssefallen ist, und der iu
der Hand gericben, nicht anhämøt oder der Hand gericben, nicht anhänst oder-
klebt, ist untauglich.
Verwechselt mit den Stengeln des gemeinen Nachitschattens (Solanum vulgare $L$.) tersifstengel trocken aus und Geschmack unil Kräfte. Sie siud daher um so mehr verwertich, da sie sehr hequern alle Jahre frisch eingesammlet werden können und da sie ein sehr vorzügliches Arzneymittel abgeben.

Diese sind kürzer, ohngef.hr nur eineu Fufs lang, eckig, and haben weder dew eisenthüinlichen Geruch noch Geschmack der BittersïLsstengel.

Statt dessen die Zap-

\section{fen des wildwach} seriden Hopfens.

Sind kleiner, haben weniger Deckblätter und Samen, und sind mit gar kuinen Mehl bestreut.

durch künstliche Einschnitte aus der Rinde des im Orient uud auf den Inseln des Archipelagus wachsenden Quittenblattstoraxbaums (Styrax officinalis L.) ausfliefsendes balsamisches Harz, wovon man drey Sorten zählt, die insgesammt aus der Levante über Marseille zu uns kommen. Die erste uud beste Sorte $(S t)$ clien oder gelbröthlichen, durchsichtigen, erbsengrofsen, wachsweichen, zähen Körnern, kommt aber nur As Seltenheit in Cabinetten vor. Die $z$ w e y te Sorte in gelblichen oder braunen, weniger durchsichtigen, mittelst einer klebrigen Masse zusammen verbundenen und unreinern Körnern, wird auch nur selten is Apotheken augetroffen. Sic wurde eliemals in Schilf oder Rohr eingepackt und deshalb von den Alten Robrstorax (Storax calamita) genannt, wird aber gegenwärtig mehrentbeils in Blasen verschiclst. Beyde Sorten be sechen Güraften Gescbmack nnd sind an der Lichtilamme entzïdlicb. Die dritte Sork, Sore, welchen, rundre 1.is.) Sie behtebt in grofen,

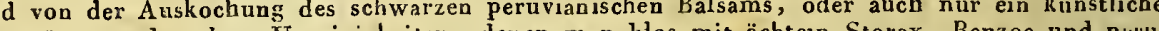
Genuisch aus Sägespänen und andern Unreinigkeiten, denen man blos mit achten Storax, Benzoe und purlnvianischen Balsam den Geruch gegeben hat. Auch diese Sorte erbalt man seit einigen Jahren immor
schlchter, welches dem Todc des Fabrikanten dieses Kunstgemisches in der Levante zugeschrieben wird.

Eiı́: natirlicher vou $\mathrm{cm}$ in deu wärmeru Gegenden des mitternächtlichen Anerica wachsenden $\mathrm{S}$ to $\mathrm{r}$ ax a mberbaum (Liquidamber. Styracillna L.) berrïbrender Balsam, von welchem es zwey Sorteu giebt. Die brer sogenante nïssige Ambra (Liquidambra, Ambraliquida.) Er hat die erste und thellerste ist der sogeunnte hissige Ambra (Liche, alter eine rothlraunschwarze Farbe, einen Dicke des venetianischen Terpentins, frisch eine gelbrothliche, aler eine rörmenden Gcschmack. Gemeivermischten Aunbra- uud Storaxgeruch nnd eisen itulichen gewurzbatten erwärmellen Groch erhärtet er za niglich ist er mit ler gestofsenen Rinle des Baums vermischt. Bey langeler Aufbewahrumg erhärtet er za einem braunschwarzen zerreiblichen Harze. Er fliefst entweder von selbst oder Ilacb gemachten Einschnitten aus der Rinde des angeführten Banmes. Die z w eyte Sorte ist der gewöhnlich im Handel vorkommende flüssige Storax. Er ist viel wohlfeiler im Preise, that die. Consistenz einer Salbe oder eines gerounenen Honiqgs, ist meistentheils brïunlichgrau, aschgran odcr röthlich, sehr unrein, kaum durchsichtig, bat eineu ïberaus starken, in der Menge widrigen Storaxgerúch und einen bitterlichen, etwas scharfeu Gesclumack. rnag er aber wohl nichts andcrs, als ein Kuustproduct seyn.

Tie frischen Kräutcr- oder Ṕlauzensăfte werden exbalten, indem man frische Pflanzcu und Gewächse zerstöfst und mittelst cer Presse die 1lüssigen 'Theile aus ihnen abscheidct. Die ausgeprefsten Säfte werden entweder so für sich gegebcu, in wclchem Falle sie 'mchr odcr weniger grün von Farbe, undnrclssichtig, und unangenehumer und widriner zu nehmen sind, oder sie werden abgeklärt, um sie von den dickern unauflöslichern Theilen $2 u$ frey. Dies geschieht znm Thcil dadurch, dafs man den Saft rubig stchen läfst, bis sich di Ithesteu aber ist es, gr'ausichten diese durch öfteres Eintanchen in heifser wenn tVan

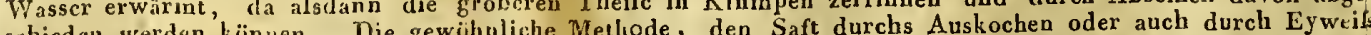
bulle zu machen, ist deswegen nicht ratheam, weil dadurch nicht allein die meisten wirksame Theile nnis 


\begin{tabular}{|c|c|c|c|}
\hline $\begin{array}{l}\text { Namen } \\
\text { der Arzneymittel. }\end{array}$ & $\begin{array}{c}\text { Sinnliche Eigenfchaften derfelben; } \\
\text { Merkmale ihrer Ächtheic und } \\
\text { Giite. }\end{array}$ & $\begin{array}{c}\text { Fehlerhafte Be- } \\
\text { Schaffenheit, Ver- } \\
\text { wechfelung oder } \\
\text { Verfälfcluning. }\end{array}$ & $\begin{array}{c}\text { Deren } \\
\text { Kennzeichen und Priffungsmittel. }\end{array}$ \\
\hline
\end{tabular}

Succi Herbarum.

aboutschieden werden, sonderu auch die tlüchtigern Bestandtheile, besonders bey den brefsartigen Ptlanzen

Die ausgeprefsten Säfte mïssen frisch hercitet seyn, weil sie sich nicht lange halten, sondern sehr bald iu Gäbrung gehen, saner werden und verderben, welches man theils an der sich erzengerden Schimmelbaut, theils an dem sauren Geruche und Geschnacke wahrnelsmen kann.

Succinum

Ein testes und hartes Eroharz, welches man/Nachgemacht und Dafs der Bernstein zu kunstlichen Arbeiten aus Preufsen: Pohlen und Pommern cr- verfälsch \begin{tabular}{l|l} 
halt. Dio grofste Menge desselben wird in & verfalscht. \\
wird, ist bekannt genug. Aufserden soll
\end{tabular} Prenfscn anı Kurischen und frischeu Ham gefunden und mit kleinen Netzen aus der See gefisrht ( 5 uccin $u$ m hastile) aufseriem trïlt manibu auch aus der Erde (S u c ciu urabt manitu

ucciun un fossile.) Der Bernstein kommt in mehr oder we niger grofsen, durchsicbtigen oder durchscheinenden, hartell, zerbiechlichen, auf dem Bruche ebeuen, glatten und glänzenden Stücken vor, von einer lichtcitronengelben oder in verschiedenen Graden dunkelgelbcu, selbšt röthlichbramen Farbe Er hat nur eineu geringen Geschmack, für sich auch keineu heträchtlichen Geruch gerieben oder frisch gepulvert, hesonders anf gliibende Kohlen geworfen oder angezindet, verbreitet er einen in der Entfer nung angenebruen, in der Nähe dagege den meluesten Personen widerlichen Gelen mehrested Purch gelindes Reiben wird der Bernsteiu electrisch und zieht leichte Körper au. Die melıresten Auflösungsmittel baben nur eine sehr geringe Wirkung auf ihn. Wasser wirkt gar nicht darauf, und der Weingeist zietst nur eine geringe Menge Harz heraus und wird bey anbaltende Digestion licbtgoldgelb damit gefärbt. In concentrirter Schwefelsäure löset er sich mit purpurrother Farbe auf, wird abe daraus mit Wasser und jeder anderu Flis daraus witer sigkeit wieder niedorgescalagen. Nur wenn er vorher geschmolzen und zum Theil verschell und fetten Oelen auf und bildet damit ziemlich baltbare Firnisse. Unterwirft man ihn einer trocknen Destillation, so wird er zerstört und hefert eiu saures Salz und ein empyrevruatisches Oel. Der Rückstand wird Bernsteincolophonin In (Colophonium $\mathrm{S}_{\text {un }} \mathrm{cini}$ ) genanat und zu Firnissen gebraucltt.

Am besten ist der bellgefärbte oder schwach gefärbie, auf Kohlen gut brennende rnd dabsy den bekanuten Bernsteinneruchi vou sicb gebeude, durch Reihen geruch vou sicb gebeude, durch Reiben
vorzüglicb stark electrisch werdende Beruvorzüglicb stark electrisch werdende Ber'n-
stcin. Von den verschiedenen in Hinsicht stcin. Von den verschiedenen in Hinsicht der darans zu verfertigenden Dreharbeiten vorkommenden Sortcu bedürfen die Apotheker zu ibren Präparaten nur des Abfalls oder des sogenanoten $A b$ bäusels ( $R$ a dichten Bernsteiustiicke, dio unrein, undurchsichtir und löchericht sind, und die unter dem Namen $S$ and steine vorzügunter dem in Destillation verwandt werden.

Stuccus, Citri.

Citronensaft.

Limonensaft. $\frac{\text { Destillation verwandt werden. }}{\text { Der aus dem fleischichten Theile der völlig }}$ reifẹn und geschälten Gitronen, nach $A b$ sondernng der Kerne ausgeprefste und abgeklärte Saft. Der Citroưensaft besteht als eine gernischte Säure aus Citronen - und Apfelstinre nebst vielen schleimicbten Theileu, von welchen letiteren er, um sich länger balten zu $\mathrm{können,} \mathrm{möglichst} \mathrm{befreyt}$ länger balten zu können, möglichst bcfreyt
wer.ten mufs. Nachilem er abgeklärt ist, werden mufs. Nachlemn er abgeklärt ist,
füllt man iłn auf gläserne Flaschen; befüllt man ihn auf gläserne Flaschen; be-
deckt die Oherflïche mit etwas Oliven: deckt die Oherfliche mit etwas Oliven:jl
und heht sie gut verwahrt im Keller auf und heht sie gut verwahrt im Keller auf. Seine ihm eigenthümlicben Ligenschafien bestehen durin, dafs er mit Kali gesätigt, die Kalkerde aus salzichtsaurem Kalk zwar fället, sie aber nachher, wenn man ibn unverbunden in gehöriger Menge beymischt, auch wieder aufouset; dafs er mit den Alcalien und der Littererde leicht aufösliche, zerniefsbare Salze bildet, mit der Kalkerde aber eicezum Theil schwer auflösliche Ver-

\section{Mit Colophonium} verfälscht. man ihn anch mit dem Loockgummi (Grummi look), einem, voll einer noch unbekannten PAanze aus Japan oder A frica lerrutrebclen Gummibarze, das im Aeufserlichen viel: Aehnlichkeit mit eiuer seriugerı Sorte Bernstein hat, beygemengt ver-
fälschen. Es hat dasselbc eine gelbe, bald hellere, bald duaklere Farbe, ist mehr oder wenizer durchsiclstig, brüchig und auf dem Bruche glänzend, besitzt fast gar keinen Greruch und einen nur schwachen barzigen Geschrnack, knirscht zwischen den Zäbıen und läfst sicb durch Kauen uich erweichen. An der Flamme entzïndet erweichen sich und verbeilet keinch anangenehmen Geruch. Wasser löset nur wenig davon
auf; der Weingeist lesto mebr.

ies geschieht besonders bey dem sooenannten Abbausel (R as ura Succini.) Sie ist ohnehin immer sebr unrein, und mit kleinen Steinen, Sand, Holzspäneı u. dgl mebr oder weniger verunreinigt. Einer meiner Freunde: el hielt aber nealich eine Parthie davon, die segen den vierten Theil zerkleinertes Colophonium beysemengt enthielt, wie sich dasselbe durcb den Geruch auf glühende Kohlen und darch dis Verbalten mit Weingeist deutlich zu erkennen $\mathrm{gab}$

Verdorben.

Wenn der Citronensaft von'seinen schleimichten Theilen nicht möglichst befreyet ist, so geht er bey längerer Anfhewahrung in Gäbrung, fängt au zu schimmeln und inekommt einen bitterlichen wiurigen $\mathrm{Ge}^{-}$ schmack und Geruch. ine halbe Unze gehörig starker Citroneusaft

Mit Essig verfälscht. muls sechszebn Gran trocknes mildes Kali vollkommeu sättigen. Ist el mit Wasser verdünnt, so wird daza eina gröfsere Nenge Saft erfordert. Nach Herrn Dör ffurt mufs ein gehörig starker Citronensaft wenigstens den achten Theil seines Gewichts an M:ldkali sättigen.

Entdecht sich, wenu man den Saft mit Kal sáttigt, diese neutrale Vcrbindung zur Trockne abdunstet und etwas mäfsig starke Schwefelsäure hinzutröpfelt, durch den deutlich aisdann entstehenden Essiggeruch. 
Succus Citri. - Succus Liquiritiae.

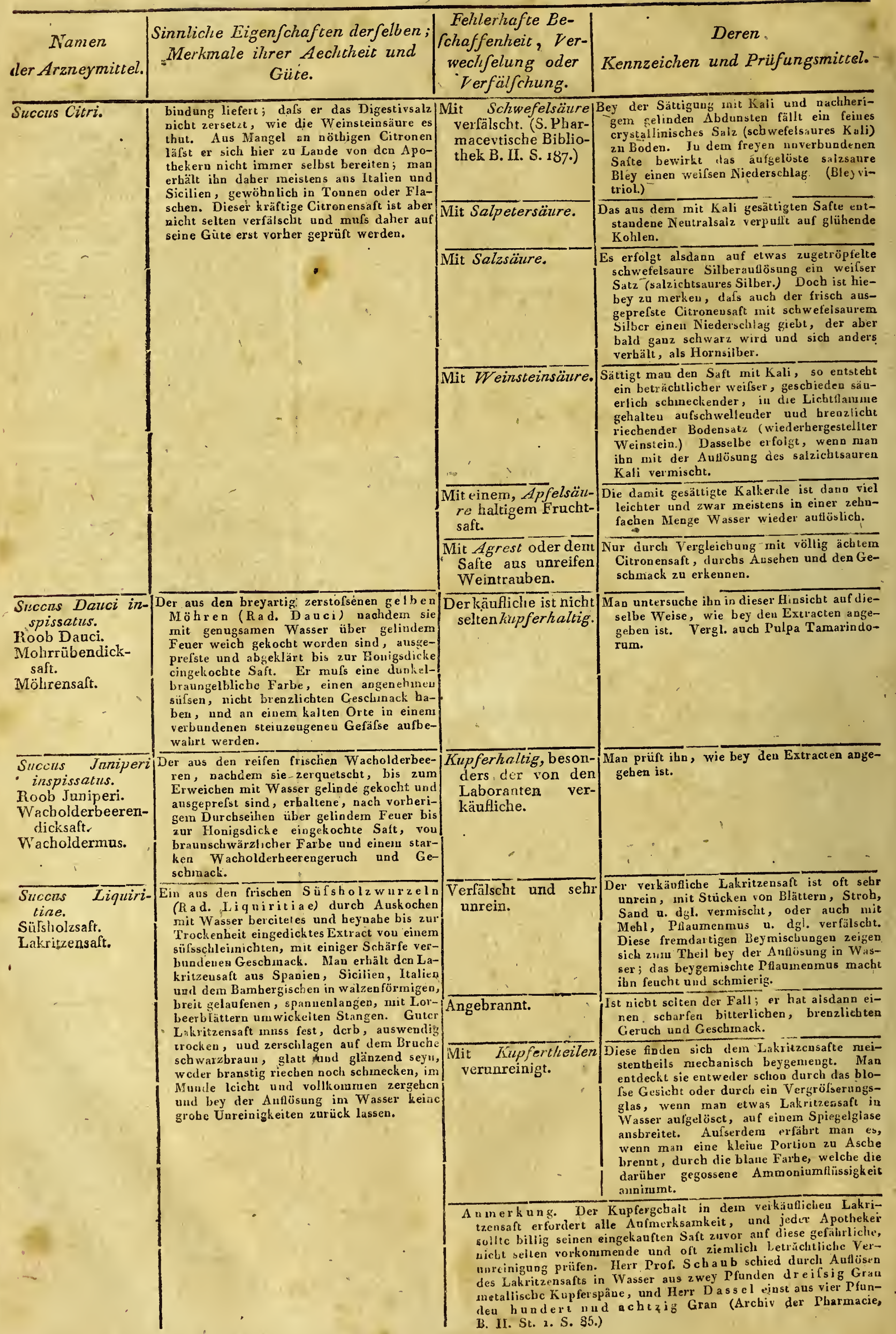


Succus Liquiritiae depuratus. -- Sulphur.

\begin{tabular}{|c|c|c|c|}
\hline $\begin{array}{c}\text { 'Namen } \\
\text { ler Arzneymittel. }\end{array}$ & $\begin{array}{c}\text { Sinnliche Eigenfchafien derfelben } \\
\text { Merkmale ilurer Aechtheit und } \\
\text { Giile. }\end{array}$ & $\left|\begin{array}{c}\text { Fehlerliafte } \\
\text { rchaffenheit, } \\
\text { wechfelung oder } \\
\text { Ferfälfchung. }\end{array}\right|$ & $\begin{array}{l}\text { Deren } \\
\text { Kennzeichen und Priifungsmittel. }\end{array}$ \\
\hline
\end{tabular}

Succus Liquiri-|Per in heifsim Wasser aufigelöste, - durch ein/Auch dieser ist nicht/Nach,der im vorigen Titel und bey, den Extiae depuratus. wollenes Tuch feseibetc und bis zur Dicke selten kupferhaltig. tracten angegebenen ilethode zu prïfen.

Gereinigter Lakrit- eines harten Extr:cts oder einer Pillenrereinigter Lakrit- $\begin{aligned} & \text { masse über geliudeın Fener eingediclitc und } \\ & \text { zensaft. }\end{aligned}$
auf die Ait von seinen etwa bey gemisch-

Succus Siambuci inspissatus.

Rool, Sambuci.

Hollunderbeerendicksaft.

Hollundermus.

Sulpluur.

Schwelel. auf die Alt von seinen etwa beygemisch-
ton Uureinigkeiten gereinigte Lakritsensaft.

Der aus den leifen, frischen, zerquetschten Iloll underbeeren (Baccae 'S a mb u ci) ausgeprefste, mit Znsat $\%$ von'etwas weifsen Zucker bis zur Honigsducke eingekochte Sift. Ein guter Hothurdersaft iat eine braunschwärzliche Farbe; einen süfseine bramuschwärzliche Farbe; einen süfsden Hollnumabeeren ähnlichen Geruch. den folinuderbeeren ähnlichen Geruch.
Er mufs sich in Wassel ganz andösen.

Ein bekauter, bis jetzt noch unzerlegter Körper. Man fiudet den Schwefel theils natürlich oder gediegen ( $\$$ is phur nat i $n \mathbf{m}$, vi v un), theils aber uudzwar an Ineistcu wird er aus schwefelreichen EiSenerzcn durch trockne Destillatiou auf den
Schwefelbütten, auch als Nebenproduct bey dem Rösten schweflichter Erze gewonnen. Der reine Schwefel bildet einen trockneil, barten, dichten, zerreiblichen, citroncngelhen oder auch grïnlichgeiben, entzündlichen, an der Luft unverändert bleibenden, für sicb geruch- und gescbmacklosen, gerieben oder erwärmt aber eineu eigentbimlichen. Geruch won sich gehenden und negative Electrizität zeigenden, in der warnegative Electrizität zeigenden, in der war-
men Hand gehalten knisternden und zuweimen Hand gehalten knisternden und zuwei-
len iu Sítickea zerspringenden Körper. Bey len iu Sïickea zerspringenden Körper. Bey
geliudem Fcuer schmilzt der Schwefel mit seliudem Fcuer schmilzt der Schwefel mit
eiscr rorben durchsichtigen Farbe, bekommt eincr rorben durchsichtigen Farbe, bekommt
aber bey lángsamen Erkalten seine vorige Härte und Farbe wieder. Er brennt mit einer blauen Flamme und einenz ersticken. den sauren Geruch. In Laugensalzeu und Oelen, besonders in fetten Oelen ist er auf verschiedeuen Wegen auflöslich; in Wasser und Weingeist ist er unauflöslich. Den gewöbnlichen Scbwefel bekommen wir in walzenförmigen Stangen, dalier er auch walzentörmigen Stangen, dalser er auch
Stangenschwefel (Sulphir citrinu m Stangenschwefel ( $\mathrm{S}$ l $\mathrm{pb}$ ir c it rinum
s. factitiun in bacillis) genannt s. factitiu in in b a cill is) genannt
wird. Guter Scbwefel mufs hellgelb seyn, wird. Guter Schwefel mufs hellgelb seyn, sebr leicht selten kupferhaltig.

Angebrannt.

\section{Mit Birnen- oder Siebt mehr rothbraun aus.}

at ei upu breuzlichten Geruch und Geschmack, eine fast schwarte Fasbe und gemcinigligh PRaumenmus verfälscht.

Kupferhaltig.

Arsenikhaltig, weil $\overline{\text { Diese sehr gefährliche Vernnreinigung des }}$ die Erze, aus wel- Scbwefels macht es böchist nothwentig, chen der Schwefel dafs der Apotheker allen zum innern Cegewonnen wird, brauch bestimunten Schwefet-in dieser Hinöfters zugleich Ar- linnt zwar dulch den Arscnikgehult eine senik bey sich füh-l kommt zwar dutch den Arscnikgehult eine
mebr odcr weniger bochgelhe Fat be, die ren. näher oder entfernter an die Farbe des Operments gräazt, jedoch ist dieses nicht entscheidend; deon weun dcr Schwefel nur sebr wevig Arsenik cullaält, so verändert dieser die Farbe des Schwefels fast gar nicht, und dieses ist g wöblich der Fall. Man mufs daher chemische Prütun smittel zı Hülfe nehmen, nın diescn schädlichen Gehaltzu eutdecken und hiezu giebt es verschiedene Methoilen.

1). Man schmelze einen Theil des ver1) Man schmelze einen Theil des ver-
däcbtigen Schwefels mitzwey Theilen reinem Kali hey geliudem Feutr zusammen; und löse das Gemisch noch heifs gepülvert in einem rehofacheu Gewichte kochendem destillirten Wasser auf. Die noch heifs filuirte Aufösung der eutstandenen Schwefolleher lasse man bis zur gänzlichen Verschwindung des Schwefellehergeruch in freycr Luft stelien, sondere den den den gefalicnen Nierterschlag ab, silfse iht aus nnd trockue ibn. War der Schwefel arsenikhaltig, so wird sich, weln man von den Nielerschlage etwas auf glühenle Koblen oder in einem glïhendeı Lötlel wirft, dcr. Alsenik durch den anfsteigenden Knoblauchgeruch entdecken. ( $\mathrm{H}$ a hnem a n Apothekerlexicou, Th. 2. Ahth, 2: S. $I S_{1}$.)

2) Herr Westrumb (Handb. der Apothekerkunst, Th. 2. 5.658 ) gieht folgende I'robe an. Fünfhundert Gran Schwefel werden mit 600 Granen Salpetersäure und 400 Granea Salzsäure nebst goo Granen Wasser gekocht nnd der Rückstand sergfal iig mit ser gekocht nnd der Ruckstand sergfaliig mit
Wasser ansgesilst. Die Anioüsung, welWasser ansgesüfst. Die Anfiösung, wel-
cle man dadurch erhält, wird bis anf bunche man dadurch erhäl, wird bis anf hun-
dert und zwanzig Gran abgetampft, dann
mit achthun lert Grancu Weingeist vermit achthun lert Grancu Weingeist vermengt und eine glän revde Zinkstange hinengestellt. Entbä!t der Schwefel Arsenils, so wird der Ziuk mit sclıwar en oder bleygrauen metallisctien Blritchen überzogen werdeu, welche, wenn sie anf der Spitze eines Messers ethitzt werden, durch den entsteheuden $\mathrm{Kuob}$ anclogeruch den $\mathrm{Ar}$ den entsteheuden Kuoblanch

Eivige schlssen zum Auskochen des Schwefels bey dieser Probe blos eine mäfsig starke Salzä̈ure vor. Um sich von der arsenikalischen Natur der Blätchen noch mehr zu überzeugen, kann mau dieselben auch noch in Salpetersäure auflösen. Die Aufösung wird, wenn sie arserikalisch ist, durch Galläpfeltinctur gelblicbbraun, durch Blutlauge weifslichblau, durch bydrothionsaures Wasser citroneugelb, durch Schwefelammoninm (Besuins Geist) dulbel ciroun un kel citrou grungelb niedergescblagen, und diese Niederschläge werden, dem Feuer ansgcsetzc, durch die Farbe und den weifsen Andlug, welchen 


\section{Sulphur. -- Sulphur praecipitatum.}

\begin{tabular}{c|c} 
Namen & $\begin{array}{c}\text { Sinnliche Eigenfchafien derfelben; } \\
\text { Merkmale, ihrer Aechcineit. und } \\
\text { Güice. }\end{array}$
\end{tabular}

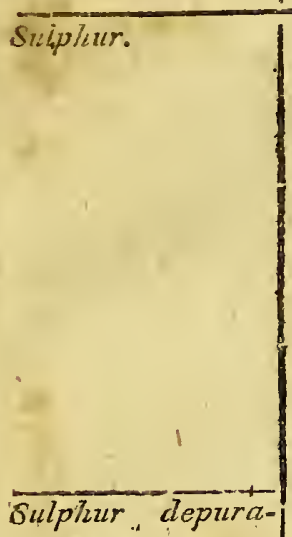

tum.

Flores Sulphuris.

Gereinigter Schwe-

fel.

schwefelblumen.

Sulphur griseum. Grauer Schwefel.

Sulphur praecipi. tatzim.

Lac Sulphuris.

Gefällter Schwe

Schwefelmilch.
Gemeiner Schwefel, der durch Sublimation gercinigt, und in ein hellselbes, hüchst feiues, glatt und schlïpfrig anzufühlendes Pulver verwandelt ist, welches übrigens alle Kennzeichen des Schwefels an sic hat. Reine Schwefelblumen dürfen weder
Geruch noch Geschmack baben; auch müsGeruch noch Geschmack baben; auch müssen sie mit gleichen Theilen Salpeter oder schweifstreibeuden Spiefsglanz zusammengerieben, keiuen unangenelsmen Geruch von sich geben. Mit kochendem destillirWas nicht getrübt werdeot. Zum Arıneygebrauch müssen daher die verkäuflictieu Englischen oder Holländischen Fabriken Englischen oder Holländischen Fabriken
bezogen werden, vor ilirem Gehrauche bezogen werden, vor ilirem Gebrauche
mit kochendem Wasser wohl aboewaschen werden. wurde.

\section{Deren \\ Kennzeichen und Priifungsmittel. wechfelung oder Verfälfchung. \\ Fehlerhafte Be-}

derselbe an einer darïber gebalrenen Kun ferplatte macht, das Daseyn des Arseuiks unverkennbar beweisen.

3) Die ron dem rerewigten Richter (Berl. Jalurh. d. Pharm, 1799, S. 219) angesebene Methode zur Prüfung des Schwefels auf Arsenik besteht in folgendem. Man verpulft einen Theil Schwefel mit vicr - bis füufmal so vielem ganz reinen Salpeter, löset den Rückstaud in destilliztenz Wasser auf, filtuirt die Aufüssung, und giefst etwas ron einem mit neutralesn Silbervitriol gesättigtem $W$ asser binzu. War Arsenik mit dem Schwefel in Verbindun wewesen, so entsteht and nach ein rothbrauner Niederschlag, wel-

Die gewöhnlichen verkäuflichen Scbwefelblumen enthalten meistentheils freye, ihnen anklebende Säure. Arsenikhaltig. Sie mit Weizenmelth verfälscht vorkommen.

\section{cher ar'seniksaures Silber ist.}

Daranf gegossenes destillirtes und abfiltrirtes Wasscr wird alsdann von der Lack mustinctur ger öthet und vou der salzsaureu Barytbemerkt man einen salpetersasuen Geruch.

D

Da auch die Schwefelblumen eben so, wie der Stangenschwefel, al'seniklialtig sey könneu, so muissen sie auf dieselbe Weise wie jeuer in Minsicht dieser gefährlichtn Vernareinigung g, prüft werden.

Werden mit hocluen lem Wasser übergossen nach dem Erkalten eine Art von Kleister bilden. Auch wird das bey'gemengte Melil beym Schmelzen und Abbrennen leicht $z_{4}$ erkennen scyn.

Der bey der heinigung des rohen Schwefels zurückgebliebene grauerdige hückstand atis Eisen, Gyps und wewigem Schwefl bestend, welcher uur in der Thierarno wird, und in dessen Ermangegung einst von einem Apothcker durch trockne Erde mit etwas Schwefel vermischt, betrüglicherweise ersetze

Wird nach der Preufsischen Plrarmacopoepie von den Labo- Dies ist der Fall, wenn, wie es nicht selten luch Aü̈̈richt, zur Fällung der schwefelbaltidetzalilaue: Fôlung detzkalilauge keinc Sclswelelsäure, in A tzkalila heten und mit Wasser verdünnten Lauge gewöbnlich vielen sondern wird, wodurch zugleich die in durch verdünnte Scbwefelsänre, vollkomm- Verfälschungen aus- wendet wird, wodurch zugeich die in ner Aussïfsung des erhaltenen Niederschlags vermittelst fleifsigen Wasseranfyielscns und sorgfältiger Austrocknung desselben bereitet. Eine gute, ächt bereitete Schwefelmilch mufs eine ziemlich lockere und selir gesetzt und zwar Thonerde.

von blendend weilser Farbe und giebt mit Wasser benctzt, eine etwas scblüpfrige Masse. Hält man etwas davon in einem eisernen Löffel über glühende Kohlen, so verdamptc sie nicht ganz, sondern es bleibt ein Rückstand, welcker Thonerde ist und mit Vitriolsäure und etwas Kali beluandelt, Alaumcrystallen liefert, die leicht erkannt werdev. Uebergir $\int_{s t}$ man diese Schwefelmilch mit verdiunter Scbsefelsäure und digerist sie damit, so rimmt dieselbe ebeufalls einen adstringirenden Alanngeschmack an.
scuralls ein

Mit Bittersalzerde.

fel niulo sie sich röllig rerflïchtigen, ohne

den nindesten Rückstaud zu hiuterlassen

in versclalosseven Gefífsen mufs sie sich gänzlich aul'teiben lassen. Sie schmilı sehr leicht mit der dern genreinen Schwefel eigenthumlichen tourbe.

- Man betrachtet gcwöhnlich die Schwefelmilch blols als einen sebr fein zertheilten Schwefel, dcr weiter keine Veränderung erlitten habe. Greichwohl zeigt sie verscbiedene von dem gewöhnlicheu Schwefel abweichende Eigenschaften, denu ihre wei-
fse Farbe abgerechuet, läfst sie auch mit Sse IFarbe abgerechuet, lälst sie auch mit Säurn zusammengerieben einen auffallenstoffsas bemerken, und man kann sie dahcr als einen mit $S c h w e f e l w a s s e r s t o f f$ verbundenen Schwefel betracliten, weshalb man ihr auch den Namen bydrogenisirten Schwefel ( $S a l p h u r$ bjdrogena(u $\left.x^{-}\right)$begeben

Mit Kalkerde, durch den zur Bereitung der Aetzkalilauge gebrauchten gebrannten Kalk, verunreinigt.
Etweder durch Fällung der sciswefelbaltigen Lauge mit einel Bittersalzaufósung gen absichtlich danit verfilscht. Man entdeckt dicses' weun man den nach

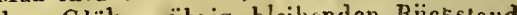
dem Gchwefelsäure behanielt, durch das mit Schwefelsäure behandelt,

Fine solche Schwefelınilch verräth sich dem Kenper, wenn die Menge der damit verbundenen Kalkerde nicht zu geringe ist, durch einc viel weifsere Farbe und dnrch die beträchtlichere Schwere. Nach dem Verflücbtigen bleibt Kalkerde übrig. Unu Verflücbtigen bleibt Kalkerde ubrig. Uru sie uäher zu prüfen, laann man den Rückstand mit etwas verdünnter Salzsäure übergiefsen; bemerkt man wäbrend der Eiuwirkung dersclbeu eiu Aufbrausen, so wird schon dadurch muttmalslich kohlensaure Kalkerde angedeutet; wenn aber in die helle Auflisung eiugetröpfelte Schwefelsäure sogleich einen erdartigen weifsen Satz, oder später das $\Lambda$ hsetzen einer dercleichen crystallinischen Binde (Gyps) bewirkt so ist dic Gegenwart der Kalkerde wocht, siebr bestätigt. 


\section{Sulphur praecipitatum. - Sulphur stibiatum rubeum.}

\begin{tabular}{c|c} 
Namen & $\begin{array}{c}\text { Sinnliche Eigenfchaften derfelben; } \\
\text { Merkmale ihrer Ächtheit und } \\
\text { Guite. }\end{array}$
\end{tabular}

Sulphur praecipi-

catrum.
Feluterhafie Befriaffenheit, Verwechselung oder Verfälfchung.

\section{Deren}

Kennzeichen und Prïfungsmittel:

Mit Kreide oder $A u$ - Ist weifser, schwerer, fäb die Fiuger beyın sterschalen ver- Anfuhlen meiklich weifs und hinterlälst fälscht. $\quad$ beym Verfücbugen einen Rückstand, ded auf vorber aurezesgte Weise näher zu prüfen ist.

Mit Puder oder Stür - Fühlt sich zwischen die nassen Finger gekemelıl verfälscht. nommen schlüptrig an, giebt mit kı chendem Wassel eiuen Klejstcr und nach dem Verbreunen bleibe ein kohlichter RuckVerbreunea
stand inhrig.

Sulpluur stibiatum aurantiacum. Sulphur Antimonii auratum.

Pommeranzenfarbner Spiefsglanzschwefel.

Spiefsglanzgoldschwefel.
Sulplutr stibiatum rubeum.

Kermes minerale. BraunrotherSpielsglanzschwefel. hy drothionsaures, schwefelhaltig s SpiefsFlanzoxydul, welches durch Kocheu von gleichen Theilen präparirtcn Spiefsglan und Schwefel in einer hineichendt n Mensc Aetzkalilauge, bis beybahe alles zergangen ist, diranf rorgenornunever VerJïndung und Klarseihung der Fliissigkeit, Fälung derselben mit verdinuter. Scbwefelsäure nod vorsichtiger Austrockunng au
einem schattichten Orte des wohlausgesüfsten Nierlerschlags gewonnen wird. Der auf diese Weise gut und mit Sorgfalt bereitete Spiefsolanzgoldschwefel stellt ein feines, leichtes, lockeres Pulver von fellriger Orangefarbe, ohne allen Gerucb und Geschmack dar. In einem Tiegel erhitzt, mufs sich der Spiefsglanzoldschwefel vollmuls sich der Spiefsglanzgoldscliwefel vollkommen verflüchtigen, ohue etwas zurúck-
zúlassen. Dem damit gekochten Wasser zúlassen. Dem darait gekochten Wasser
darf er keinen salzichten Gescbmack erdarf er keinen salzichten Gescbmack er-
theilen. In Wasser xind im Alcohol ist er unauflöslich. Auch löset er sich keinesweges beym Kochen in Aetzkalilauge gänzlich auf, wie man dieses sonst als ein Zeichen seiner Aechtlieit ubd Güte angesehen wissen wollte; es hlejht vielmehr davou bey dieser Behaudlung, zum.l je lä̀ger er der Einwirkung der Luft, woraus er allmälig Sauersioff einsaugt, ausgesetzt gemasrn, eine um so berdeutendere Menge von einem weifsen, mithin um einige Grade von einem weifsen, mithin um einige Grade
stärker, als im unzerlegtes Spiefsolanzstärker, als im unzerlegteu Spiefsglanz-
schwefel, oxydulirten Spiefsglauz ungeschwefel, oxydulirten Spiefsglauz ungelöst am Boden zurück. -- Vielleicht aber, dafs bydrothionsames Schwefelkali, allenfalls mit einem Zusatz von Aetzlauge găgzliche Auflösung bewirken und zur Prüfung dienen liönute, welches untersucht $z u$ werden verdiente (Berl. Jahíb. d. Pharm. 1806. S. LV.)

Uebrigens mufs der Spiefsglanzgoldschwefel, wcil er allruälig durch die Luft und das Licht eine Zetsetzung erleidet, in gutverschlosseven, nulurchsichtigen Gläsern aufhewabri werden.

we welches dadurch bereitel wird, dafs maı ein Gemenge von 2wey Theilen gepulvertem Spi fogl $\neq \mathrm{n}$, und eiuem Th $\mathrm{jl}$ trocknen kohlensauren Natium bey märsigent Feuer schmelzen läst, die erkaliete Masse puvert, sie wiederloolt mit Wasser horht mud
die Flitssigkeir noch kochend scharil filusit die Fliissigkei noch kochend scharil filısirt, worauf dieselbe wäbrend dem E:kilten ei-

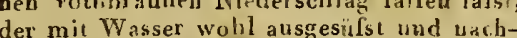
her in Schaitru getlockift, las genoune Präparat darstelli. Der ächte, gut bereitete Ket mes bat ejue braubroche Farbe und bildet gericben ein sammlartig feil und weich anzufihlendes, völlig gel uchloses, woich allem salziceu Gescbmacke freyes Pulvon allem salzigeu Gescbmacke frey es Pul-
ver. lu einem glubenden Löffel über Koblen gehalien, inufs der Kermes sich völlig verilüchtigen. Durehs Alter, $2.0 \mathrm{mal}$ wenn er dabey der Einwirkung der Luft and des Lichts ausgeselzt gowesen, erleilet er eirse Zersetzung, wird dunkler von Farbe nud enthält davn etwas Schwefel. In Actzkalilange ist er eben so wenig wie der Spiefsglanzgoldschwefel, hesonders bey längerer Aufbewabrung, vollständig anflöslich. In erwärmler dunstförmiger oxygenirter Salzsäure geschïttelt, entziindet sich der K ersäure geschiltelt, entziuneller weifser, ins rotbe schielender Farbe. Er mufs in einem
Niclıt gelıörig ausge- Er hat alsdaun einen mebr oder weniger salsüfst.
zichten Gcsihmack, b auset mit Säuren auf und entwickelt mit Salmak zis sammengerieben einen flichtigen A mmoniumgeruch.

Ticht gehörig von Eine zu dunkle, braunrothe Fube diests $P_{1}$ aFarbe. glanzgehalt, so wie umgekebrt eime zu bieiche und zu belle Farhe anf einen gegen den Spiefsglanz zu starken Schweticlohalt, ein ganz mifsfarbices Ansehn desselbeu aber auf eine unsaubere, felilerbafte Bereitung auf eine nusaubere, felile

Mit Kalk-, Thon oder Es kann dieses theits nufillig, theils absichtBittersalzerde ver- lich, 7. B. durch Falluug ter Lause mit unreinigt. Alaun-oder Bittersalzanio ösuvg geschehen. Mau prüft deu Spiefsgl uzscisw fel in dieser Hinsicht es bey der Schwefilutich (Sulphur praeci-
pitatum) pitatum) ngegehen ist. Alle ubige Verfalschungeu dieser Art,
welche etwa ron Laboralten damit vorgewelche etwa ron Lahoralten damit rorge-
nommen wesd.n höuuten, I.15seu sich bey der Verflichtiguny des Spiefsglanıgrildschwefels oinfehbar entdecken, indem alsdaue die beygemischten Stolfe zurückblẹiben werden.

A un erkung. Vor állen Dingen kammt es bey "er Bereitung des Spiefsglanzgoldschwefels darauf an, dafs man dazn einen von $\mathbf{A r}$ senihgehalt freyen Spiefsglanz und Schuefel anwende, weil soust auch der Spiefsglanzschwefel arsenikbalt, ausfaileo würde. Man crfährt dieses, wenn Verdacht dazu vorhanden seyn sollte, auf die schon mehruals angegebene Weise. So Stibium sulphuratum pie grum, Sulphur u. s. w.

Nicht gehörig ausge- Glebt alsdann mit' Salmiak gerieben einen süfsi. $\overline{\text { Mit noch ungelösten }} \frac{\text { scbuttelt, wie faule Ejer. }}{\text { Dies geschieht oft zúnliic beyur Filtrirehter }}$ freyen Spiefsglanz- Lange hey nicht gebüriger Vorsicht. Der theilchen verunrei- Kermes bat alsdaun ein schmutzig-graurigr.

lit andern fremdar- Weun sich der Mjufralkermes börnicht oder tigen Stoffen ver- sanflig aufiihlell lä fot und im Feuer niche unreinigt oder ver- vollkommev verflüchtigt wird, so ist er fälscht. entweder zuflliy, etiva cbenfalls dul entweder zufalliğ, etwa ebenfalls dux ch nachlassıges. unvolistanaliges Aussursen mit

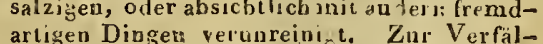
artigen Dinges: velunreinir $t_{\text {. Zur Verfäl- }}$ schulng desselben soll inau sich, wie Eivige anfibreu, wohl zuweilen des Ambra bedienen; eher mögte nuch das rotbe Eisenoxyd dazu gemifshraucht werden. Es lasseu sich indessen dergleicben erdige Beymisclıungeı, wie gesagi, by del Verflüchtigung des Keimes bald pntitecken, so wie sich andere anfl̈̈sliche Beymischurgen mit Wasser ausziehen lassea. 


\begin{tabular}{|c|c|}
\hline $\begin{array}{c}\text { Namen } \\
\text { der Arznsymiccel. }\end{array}$ & 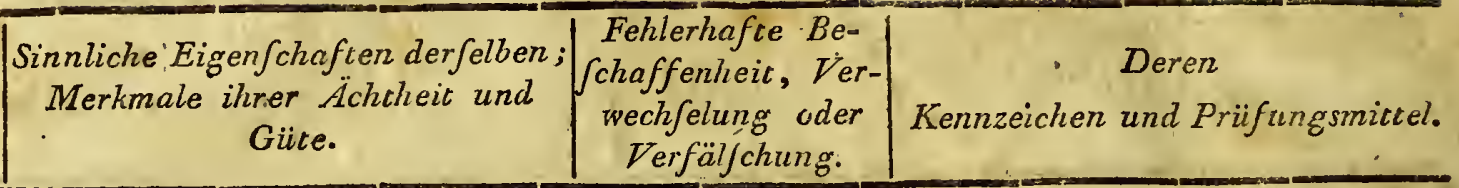 \\
\hline & $\begin{array}{l}\text { wohlverschlossenen undnrclisichligen Glase } \\
\text { aufbewahrt werden. }\end{array}$ \\
\hline $\begin{array}{l}\text { uppositoria. } \\
\text { uhlzäpfchen. }\end{array}$ & 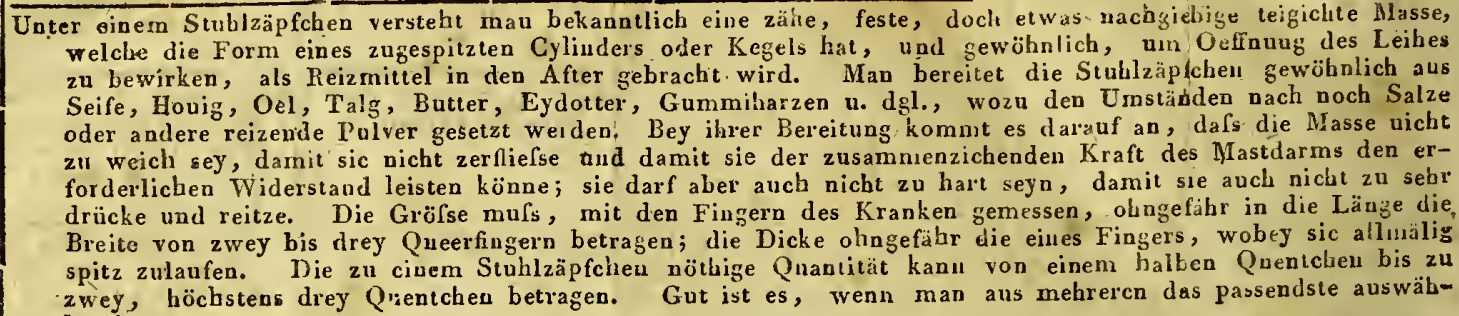 \\
\hline
\end{tabular}
zowey, hann.

Syrupi.

Zuckersäfte. oter $S$ yrupen oder $Z$ uckersäften versteht man zum innerlichen Gehrauche bestimmte, dickntüssige, meistens hervorstechend süfs schmeckende Arzneymittel, welche aus einer gesätligten Auflösung des Zuckers in wâfsrigten Flüssigkeiten, Decocfen, Aufgüssen, destillirten Wässern, säuerlichen Pñanzensäften u. s. w. bcreitet werden. Dey ihrer Zubereitung kommt es darauf an, dafs sie eine getörige Consistenz erhaltelı und weder zu dick noch fiüssiz. werden. Frisch bereitet ist es ein Zeichen ibrer gehörigen Consistenz, wenn einige herausgenommene Troufen, die man auf einem kalten Teller fallen läfst, beym Auf- und Niederbeúnige herausgenoms nicht verlaufen, und wenn man schief darauf bläset, eine ruuzlichte Haut bekommen, auch gen des Tellor

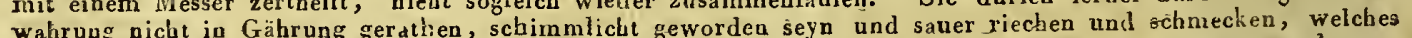
Wabrung nicht in Gährung geratien, schimmlicht geworden seyn und sauer xiechen und schnecken, wer aus vorzz̈glich danu in kurzer Zeit geschieht, wenn ihre Consistenz entweder anfanglich zn dünne war, oder aus dern 20 dicken Syrup sich der Saft heraus crystallisirt hat. Anch gährcn die Zuckersäfle leicht, wenn sie nicht an einern kïhlen Orte aufbewahrt werden, sondern an einem warmen Orte stelea und scilecht ver-

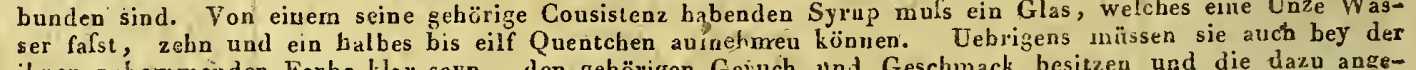
ihnen zukommeuden Farhe klar seyn, den gehörigen Geruch nnd Geschnnack besitzen und die dazu angewendete Flüssigkeit in ibrer mögrfichst unveränderten Beschaffenheit enthalıen, so dafs hey ihrer Bereitung keine Zersetzung der Bestandeheile oller Verminderung der Arzueykräłte bey leicht zu ersetzenden Flüssigkeiten, z. B. bcy den Ánfgüssen geruchvoller Pflanzen, destillirten Wassern, Saamenmilchen to. s. w. statt findet. Von den minder gehräucluliehen Syrupen mufs in der Officin selbst nur eine geringe Quantität vorfä̉el. Von den das. Verderben an diesem gewöhnlich wärmern Orte zu verbüten. Die Hauptvorräthe müs-

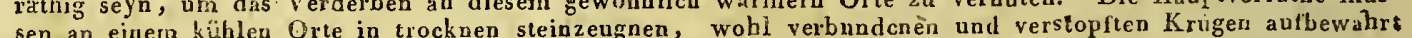
serden. Die Syrupskrüge in der Officin müssen auch sorg filtig bedeckt unil verschlossen seyn, damit nicht etwa Fliegen, Aneisen und andere Insecten, wie es im Sominer nicht selten zu geschelien pflegt, hineinkricchen können, und besonders dann geschielt, wenu die Syrupskrüge an ilren Miñäungen eine Rinue báben, welche der Kork uicht ausfüllen kann. Man hat ferrier darauf $\mathrm{zu}$ schen, dal's bey der Bereitung keine kupferne Kessel gebraucht werden, welches vorzäglich die Syrupe aus sauren PGankensäfteu knpferlialtig machen könnte. Eine Verfalschung mit Honig erkennt man dadurch, dafs mau den verdächtigen Syrup noch-

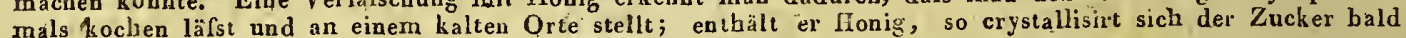
beraus und der ührice Syrup riecht und schmeokt wie Honis.

Syrupus Althacae. Altheesyrup. Aus einem Decocte der Altheewurzeln mit Zucker bereitet, von einer Syrupus Althacae. Altheesyrup. Aus eisem Decocte der Alblwater durchsichtigen, weilsen Farbe, dern eigenen Geschach, besonders in den Sommermonaten, kaun einige Wochen, ohne in Gährung zu gehen und sauer zu werden.

Syochs Ammoniaci. Ammoniaksyrup. Bestelut nach dem Lippischen Disnensatorio aus'einer Aunösung des

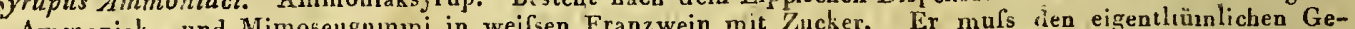
Amnoniak - und Mimosengnmıni in weirsen Franzwein mit Zncher. Er tribe, nicht aber durchsichtig seyn ruch und Geschmack des Ammoniakgurnmi besitzen, etwas milchicht trübe, nicht aber derch inufs er eine und mit Wasser vermischt, demselhen eiin milchähnliches Ausehen mitheilen. Ausch durch Uruschütteln gleichtormige Bescha tenteli haben,

Syrupus Anygdalarunn s. emulsivus. Mandelsyrup. Aus eincr Emulsion von süfsen und etwas bittern

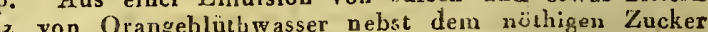
Bereitet. Er bat eive undurchsichtige graugelblich weifse Farbe, mufs mit Wasser rcriliunt eiue angebereilet. nebm schimeckende Mandelmild

nur kurze Zeit unverlorhcn. Syrupus balsamicus. Balsamischer Syrnp. Aus cinem Aufgusse des schwarzen peruvianischen Balsams mit kochendem Wasser und den nöthigen Zucker bereitét. Er mufs bell

licheu augenehrnen Geruch und Geschmiack des Perubalsarns hesitzeu. Syrupus Berberum. Berherisheerensyrulp. Atis dem ansseprefisten Safte der Berberisbeeren (Ba c cae Be herum) mit 'Zucker bcreitet. Mufs eine rothe Farbe und einen süfssäuerlichen Geschmack besitzen. Syrupus Cerasorum. Kirschensyrup. Wird ans den auseprehsten Safte saurer Kirschen

Syrupus Cinnanomi. Zimmtsyrup. Aus einem Auf'gnsse von Zimmtcassia mit weinichtem Zimmtwrasser nand etwas Roseuwásser mit Zucker bereitet MIufs cine bräuuliche Farbe und einen angenehmen Zimmat nagd etwas hosechack haben. Wird er, wie es einige Dispensatoria vorschreihen, blos aus Zimmetwasser mit 'Zucker bereitet, so sieht er weifs aus.

Syrupus Corticum Aurantiorum. Pomneranzenschalensyrup. Besteht nach der Prenfsischen Pharmacopoe Syrupus Corticum Aurantioram. aus einem mit weilsen Firanzwen weiuichten Pommeranzengeschmack.

gelhe Farbe und einen angenehmen weiuichten Fommeranaengater Syrupus Croci. Saffransyrup. Aus einem Aufgusse von Sallran Syrupus Fiorum Aurantii. Pommeranzenhlüthensyrup. Aus Poinmeranzenblüthwasser und Zucker be-

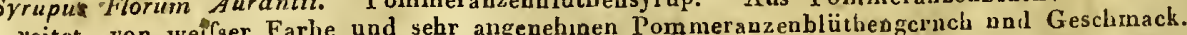

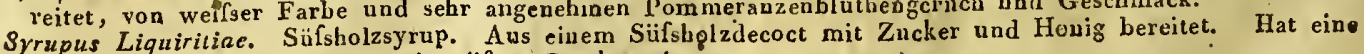
bräb Lique süren Geschmack.

Syrüunlichle Farbe und einea sehr sus Anem Aufuusse von Sennesblätter, Fenchclsaamen und Wasser mit Syrupus Mannae. Mannasyrup. Has einem Aufgusse von Sennesbifsen, etwas fenchelartigen Geschmack. Zucker und Manna hereitet. Hap. Aus dren: Safte der schwarzen Maulbeeren mit Zucker bereite. Dun Syrupus Mororum Maulheersyrup. Aus den: Safte der sch.

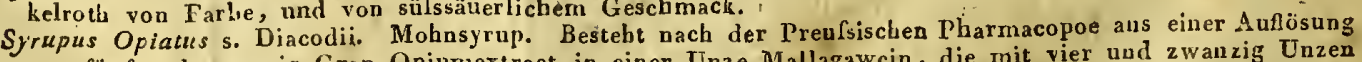
von fünf und zwaurig Gran Opiumextract in einer Unze Mallagawcin, die mit vier und zwanzig UnzenSiifsholzsyrup vermisclst worden. Bräunlich von Farbe. Eizs Uuse davon entbălt einen Gran Opiumextract. 


\section{Syrupi. -- Tamarindi.}

\begin{tabular}{|c|c|c|c|c|}
\hline $\begin{array}{c}\text { Namen } \\
\text { dler Arzneymittel. }\end{array}$ & $\begin{array}{c}\text { Sinnliche Eigenfchaften derfelben; } \\
\text { Merkmale ihrer Aechtheit und } \\
\text { Giite. }\end{array}$ & $\left|\begin{array}{c}\text { Fehlerhafte Be- } \\
\text { fchaffenheit, Ver- } \\
\text { wechfelung oder } \\
\text { Verfälschung. }\end{array}\right|$ & Kennzeichen & $\begin{array}{l}\text { Deren } \\
\text { und Prifungsmitte?. }\end{array}$ \\
\hline
\end{tabular}

Syrupus Rhei, Rbabarbersyrup. Wird nacb der Preufsischen Plarmacopoe ans cinem Aufsusse vou Rha-

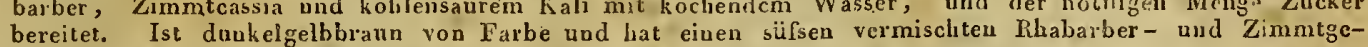
schmack. Brauset mit Säuren auf.

Syrupus Rhoeados s. Florum Papaveris rhoeados. Klatschrosensyrup. Aus einem Aufgrsse von frischen Syrupus Rhoeados s. Florum Papaveris rhoeados. Klatschrosensyrup. Aus einem Aufgusse von frischen
Klatscbrosen mit Zucker bereitet, von dumkelroher Farbe. Zuweileu wird dieser Syrup auch in ErmanKlatscbrosen mit Zucker bereitet, von dumkelrocher Farbe. Zuweilen wird dieser Syrup auch in Ermangelung der frischen Klatschrosenblumen aus trocknen Blumeublatielı mit einem Zusatz von verdtinnter Sclıwefelsäıre, un die Farbe des Aufousses zu erböbeu, bcreitet; doch ist dieses nicht zu billigen, da
dieser Syrup öfters zu Salzauflösungen verordnet wird, die dadurch wegcu der darin befindlichen Schwefelsäure eine nachtheilige Zerselzang exleiden könnteu.

Syrupus Rilium. Johaunisbęerensaft. Aus dem Safte der reifcn Johannisheeren mit Zucker bereitet. Von einer angenelimen rothen Farbe und eiuem süfssänerlichen Geschinack.

Syrupus Riubi idaei. Himbeerensaft. Aus dem Safte dri rothei Hinbeeren mit Zucker bereitet. Ein angenehm nach Hinbeeren riechender und schmerkender Symp von einer schönell rothen Farbe.

Syrupus Senegne. Senegawurztsyrup. Ans ein tn Decocte der Senegawurzel mit Zuckel bereitet. Ein schwach gelbbräuulicher Syrup, von binteunach merkliciı scharfen Ciesclimack.

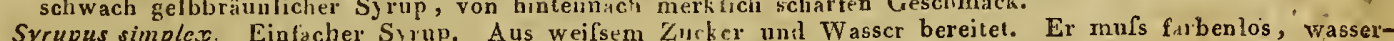
Syrupus simplax. Einfacher Syrup. Aus weifsen Zurker und Wasscr ber

klar, sehr süfs, obue Geruch uud ohne Neben und Nacbgeschinack seyn.
Syrupus succi Citri s. Acetusitatis Citrí. Citronensyrup. Aus völlig schleimfreyen Citronensaft mit Zucker

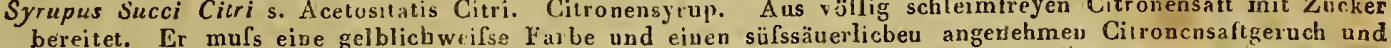
bereitet. Er mufs eive gelblicbweifse $F$ a be und einen süfssäuerlicbeu angersehmen Citroncnsaftgeruch und Geschmack haben. Der Saft, welchen man dazu anweudet, darf nicht verdorben seyn, wril soust der
Syrup einen widerlicben Geschmack bekomnt. Wäre statt des Citronensafts Essig substituiret, so würde dieses an dem Essiggeruch zu bemerken seyn.

Syrupus Violarum. Violensyrup. Aus eiuem Aufgusse der. von deu Kelchen befreyten frischen Blumenblätter der Märzviole mit Wasser und dem nöthigen Zucker bereitet. Er mufs eine schöne durkelblatue Farbe und einen angenebmeu Veilchengeruch und Geschmack baben. Durch Säurcn wird er rotb, durcb Alkalieu grün gefärbt. Bey längerer Aufbewahrung verlicrt er seine schöne Farbe unl verbleicht. Es ist dieser Syrup, besonders in Gegenslen, wo er stalk gebraucht wird, oder wo die frischen Veilchen nicht gut zu haben sind, manchen Verfälschungen ansgeselzt. Häufig wird er aus den Aufgüssen anderer blauen Blumen, z. B. von der Agley, dem Fiejsamveilchen, Feldrittersporn u. dहl. unil einem gerin $n_{i}^{\prime} Z_{u-}$ satze Floreutiuischer. Violenwurzeln naclgekiunstelt, welche Verfälschung kaum anders, als durch V↔rsatze Floreutiuisch gleichung mit achtem Sicheriberen der blauen Farbe nothig ist, versetzter Auszug des biaden Kopto Sy und des Blauholzes angewendet, der auf diese Weise erkunstelte Syrup aber auch daduch leicht erkaunt, dass er nicht mit Alcalien griu wird. -- Aufserdem wird er aucli woln aus einem Lackmusaufgnsse mit Zusatz yon etwas Violenwurzeln nashgekünstelt, welche schmutzige Verfalschung sich dadurch entilecken läfst, dafs ein solcher Syrup durch Alcalien nicht grün gefürbt wird, und wenn man uiber den mit fixem Alcali versetzten Syrup einen mit Silzsăure befeuchteten Papierstreitcn hält, ein weifsrr Dampf erzeugt wird. - Endlich wird die blaue Farbe auch durch eine Indigoauflösung erkünstelı, der mit Hiilfe derselben erbaltene blaue Saft aber dadurch erkannt, dafs er weder mit Säuren nocb mit Alcalien seine Farbe verändert.

Tacamaluaca.

Tacamahak.
Tamarindi.

Fructus Tamarindorum.

Tamarinden, Der walure Tacamahak stammt nach La- 1 i Der wahre Tacamahak stammt nach
mara-
marcks Untersuchungen von deul marcks Untersuchungen von deu Ta--
camabakschönblatt (Cal ophyllum In ophyll u $\mathrm{m}$ L.) her, einem in Ostindien und auf der Insel Madagaskar wacbsenden, sebr ansehnlichen Baume, aus dessen verletzter Rinde er fiiefst. Er bildet
ein etwas weichs, bald getbliches, bald ein etwas weicbes, bald gelbliches, bald
röthliches oder gelbgrünliches, in Weinrötbliches oder gelbgrünliches, in Wein-
geist völlig auflüsliches Harz von einem geist völlig auflösliches Harz von einem
vermischtén Anbra - und Lavendelgeruch, vermischtén Anbra- und Lavendelgeruch,
nnd eiuem gewürzhaften bitterlicbeu Gescbmack. Indessen ist diese Sorte, welche in kleinen Kürbisscbalen oder. Muscheln vorkomint ( $\mathrm{T}$ a camah ac a sublimis s. in testis) iiheraus theuer und fast gar uicht zu bekommen. Die gewöhnlichere Sorte ( $T$ acamahaca com inunis s, in sortis) kommt in Stücken von verschiedener Grïfse vor, die gelblich, weifs ge-

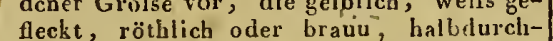
sichtig und briichig sissd, auf Koblen gesichtig und briichig sind, auf Koblen ge-
worfen angenehm riectien und sich auch worfen angenehm rieclien und
meistens in Weiugeist auflösen.

Uie von ihreu Hülsenschalen oder den äussern Dechcu abgesondertes oder enthülseteu, zu Brey oiler Mns zerstofsenen Fiirlite teu, zu Brey oiler Mns zerbtolsenen Friflite

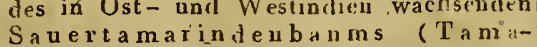
Sauertamarindeubat ms (Tanr
rindus indica L.) Wir ertalien rindus indica L.) TVir erhalien sie als eine mussıge, schleimichte, zähe Misse, harten, glänzenden, selbbrä unlichen Saamen, und den stuken Fasesu, wodurch die Saamen in den Hülsen befestigt. sind, vermengt. Die Farbe ist scl,wäızlichothbraun, der Geruch weinartig und der Ceschmack angentim wcinsaner. Die Osiindiscben Tumarinden buben vor den Westindischen oder Amerikaniscbeu den Volzug. Das Mark vou jeuen st trockner, schwärzer, saurer uud baltist trockner, schwärzer, saur $\rho$ r wud balt-
barer, so wie die Fruichte selbst noch einmal so grofs sind. Die Westindischen sint dagegen viel weicher, feuchter, weniger zäbe, und haben wegen des Zuckers, der ie gemeine Sorte ist Giebt sich durch deu Harz.
häufig verfälscht,
den Koblen zu erkeumen.

besonders mit gemeinem Harz oder Colophonium.

Kupfer/laltig, wahrscheirilich von der Einweicliung und Durcharbeitung der zerguetschten Tamarindenschoten in kupfernen Geschirren:
Ian crfäbrt dieses, kenn man ein polirtes Eiseu in die mil heifsem Wasser gemachte. Auflösung der Tamarinden legt, indern solches, wenu Kupfer darin zagegen ist, nach kurzer Zeit roth oder kul ferfarben anläuft. Dafs diese Prüfungsmetlode, wio Herr. II ahnemaun (Apothekerlesicon,
Th. 2. Abth. 1. S. 13̈) sagt, nicht nns.cher Th. 2. Abth. 1. S. 134) sagl, nicht nns.cher
und falsch sey, zeigt Herr Dörffurt und falsch sey, zeigt Herr Dörffurt (Neues deut. Apothekerb., Th. 1. S. 944.) Aufserdem kauli man auch eivige Unzen Tamarinden zn Asche brenzen, ind diese mit. Ansmoniumillissigkeit übergiefseu; nimmt dieselbe eine blane Farbe an, so ist der Kupfergehalt um desto gewisscr. 


\begin{tabular}{|c|c|c|c|c|}
\hline $\begin{array}{c}\text { Namen } \\
\text { eler:Arzneymittel. }\end{array}$ & $\begin{array}{c}\text { Sinnliche Eigenfclaffien derfelben; } \\
\text { Merkmale ihrer Alechtheit und } \\
\text { Güte. }\end{array}$ & $\begin{array}{c}\text { Fehlerhafte Be- } \\
\text { schaffenheit, Ver- } \\
\text { wechyelung oder } \\
\text { Verfälfchung. }\end{array}$ & Kennzeichen & $\begin{array}{l}\text { Deren } \\
\text { und Prüfungsmitte }\end{array}$ \\
\hline Trancindi. & $\begin{array}{l}\text { ihnen, um die Verderbnifs zu verbüten, } \\
\text { zugesetzt wird, einen schwächern und min- } \\
\text { der sauren Geschmack. Gute Tamarinden } \\
\text { müssen nicht zu feucht und nicht schimmm- } \\
\text { licht seyn, hcine aufgequollene, weiche, } \\
\text { glanzlose Saamen entbalten, auch nicht } \\
\text { dumpficht, sondern angenehm weinsäuer- } \\
\text { lich riechen und schmecleu, vor allen Din- } \\
\text { gen aber atch von Kupfergebalt ganz frey } \\
\text { seyn. }\end{array}$ & 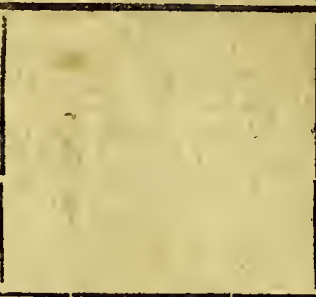 & & \\
\hline
\end{tabular}

Tartarus.

Tartarus cru
Weinstein.

Weinsalz.

Roher Weinstein.

Tartartes ammoniatzus.

Tartarus solubilis.

Ammonium-Wein-

stein.

Auflöslicher Weinstein.

Tartarus boraxatus.

Cremor Tartari solubilis.

Boraxweinstein.

Auflöșlicher Weinsteinrahm.

\section{Ein a}

aus jungeu, berbeu und sänerlichen Weinen an den Wänden der Fässer durch Zeit urd Rube, in der Gestalt eiver zierulich barten und schweren, aus festen, untereiuander zusammenbängenden Crystallen bestehenden Riude, sich absetzendes natürliches übersaurcs Neutralsalz, dessen eigenthürnliche Säure zum Thei an Kali gebunden ist. Der robe Weinstein bat einen säuerlichten Geschmack, ist schwer, zerbrechlich, au dem Bruche oläazend, an der Luft unveränderlich, init hefichten, färbenden, auszugsartigen Theilen verun reinigt und von schmutzigweifslichter oder rother Farbe, je nachdern der. Wein weifs oder roth war. Er löset sich nur schwer in Wasser auf, so dafs von kaltem Wasser 120, von heifsem aber 28 Theile zur. Anf lösung erfordcrt werden, wobey sich twas geschmaoklose Erde absondert. Die Außösung macht die Lacksuscinctur roth, uud brauset, obgleich nur schwach, mit Laugensalzen auf. Der weifse Weiustein (Tartarus albus) wird für besser gehalten als der rotbe (Tartarus ruber.)

Ein dreyfaches, aus Weinsteinsäure, Kali|Statt dessen wird häu-|Ist leicht zu erkennen, weil sich daraus mit und Ammonium bestehendes Nevtralsalz, fig in den Apothe- Kali oder Kalk gerieben, kein Ammonium

welches dadurch gewonnen wird, dafs man gereinigten Weinstein mit kochendern Wasser übergiefst und nach und nach so lange anfgelöstes toblensaures Ammoninm $z$ thsetzt, als zur vəllkemmnen Sältigung ersetzt, als zur vollkemmnen Sätligung erforderich sie erkaltet und klargeseibet worden, deru sie elkaltet und klarges eibet worden, entweder zur Crystallisation befördert oder
bey sehr gelinder Wärme zur Trockne abbey sehr gelinder Wärme zur Trockne ab-
gedampft wird. In erstern Falle bilde das $\mathrm{Sal} z$ melrentheils geschobene Würfel zuweilen auch vierseitige Säulen mit z.weyflächiger Zuspitzung, im zweyten, wie es gewöbnlich bereitet wird, ein sehr weifses trocknes Pulver. Es bat einen bitterlichen, kühlenden, etwas stechenden Geschmack, bleibt an der Luft trocken, lärst aber nach und nach eine Portion des eingemischten Ammoniums fahren, wodurch besouder das crystallisirte, welches damit zugleicl an seinem Crystallisatiougwasser verliert, auf der Oberfläche, von sich zunäcbst bildenden flüchtigen Weinsteinrabm meblig wird. Es ist nicht in Weingeist, aber frisch bereitet im Wasser sehr leicht, und in einer Unze zu fünf Drachmen auflöslich. bey län dayegen mebr oder weniger des.erzengten Weinsteinrabms pulverförmig ab: Auch Weinsteinrabms pulverformig ab: Auch die gesättigte Auflösung schimmelt sehr sie anch durch beygemischte Säuren jeder Art, in so feru sie mit dem Ammoniun in Verbindung treten und dabey wiederbergestellter Weinsteiu zu Bodeu fïllt, zersetz wir.d. Die Keuuzeichen seiner Güte und Aechtheit bestcben hauptsächlich darin dafs es siclı hey gebörigem Geschmack leicht nnd $\mathrm{klar}$ in Wasser auflöse, und leicht nnd klar in tVasser alose, und dafort einen starken Ammoniumgeruch entwickele. In Schnelztiegel geglühet, mufs reines Kali mit etwas $\mathrm{K}$ oble gemischt, $z u-$ rüclibleiben. Es mufs in, einern gut verstopften Glase aufbewahrt werden.

Wird aus drey'Theilen gereinigten Weinsteın und einen Theil Borax durch Aufösen in Wasser und Abdampfung der filtrirteu Lauge, bis eine kleine Quantität davon auf eincn kalten Stein oder andern Körper gebracht, nach der Erkaltung zerbrechlich erscheint, bereitet. "Es entsteht alsdann eine gelblichweifse, zähe, uncrystallisirbare, gummiartige Masse, die, sobald sie iı gelinder Wärme auf den Stubenofen völlig ausgetsooknet ist, in eivern erwärmten Morser fein zerriebcn wird, und dann eip Mörser fein zerriebcn wird, und dann ein
völlig weifses, die Feuchtigkeit der Luft völlig weifses, die Feuchtigkeit der Luft
leiclt anziehendes Pulver darstellt, welleicht anziehendes Pulver darstellt, welches in einem fest verkorkten Glase ad ei-
nem trocknen Orte aufbewahrt werden nem irocknen Orte aufhewahrt werden
mufs. Der Boraxweinstein mufs cinen auffallend sauren, wicht unangenelimen Geschmack liaben, sich sehr leicht und bey mittlerex 'Tempreratur fast in seinem gleisoure Kali ge- Tartarus tartarisatus. braucht.

A n ner $k$. Mlan verlangt 2 war gewöhnlich, dafs die Sättigung de Weinsteincrystallen mit Ammonium bey der' Bereitung dieses Salzes so genan seyu solle, dals nicht nur blaues Lackmuspapier davon weiter vicht gerötbet, sondern auch geröthetes nicht wieder blau werdc. Indessen ist wegen des in der Wärme ans der Lauge sich leicht verflüchtigenden Ammoninms letzteres trüglich und sow่ohl schwer zu erreichen, als anch ein kleiner Ueberschufs vom Ammonium iu so fern nicht nachtheilig ist, indern dadurch der Entstehung des flïchtigen Weinsteinrabms (Ammonium tartaricum acion cun acidulur. schon wirch Soll das Salz inges überdem nothwendig, dafs die Salzlauge etwas tuberschüssiges Ammoauf diese Punete Rücksicht zu nohmen.
Mit metallischenThei- $D_{\text {a es }}$ Plicht eines jeden A pothekers ist, dielen verunreinigt.

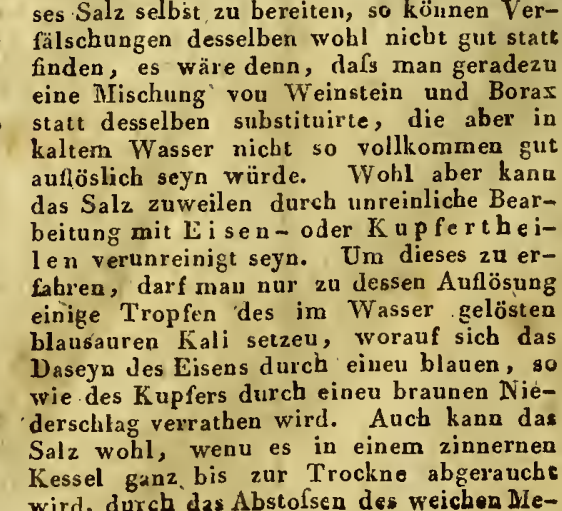




\section{Tartarus boraxatus. - Tartarus natronatus.}

\begin{tabular}{c|c} 
Namen- & $\begin{array}{c}\text { Sinnliche Eigen fchaften derfelben; } \\
\text { Merkmale ihrer Ächtheit und } \\
\text { Guite. }\end{array}$
\end{tabular}

Tartaris boraxa-1 susa,

Tartartus depura-

tus.

Cremor Tartari.

Crystalli Tartari.

Gereinigter Wein-

stein.

Weinsteincrystal-

len.

Tartarus ferratus.

Tartarus chaly-

beatus.

Eisenweinstein.

Tartartus natronatus.

Sal polychrestum de Seignette. Natronweinstein. Seigniettsalz. .

chen Gewichte Wasser, nicht aber seiner räthschiaften vermieden werden, weil durch ger Durchseibung gerenigte und cryotallinen pulveriormigen Crystallen, dem sogeKàli zurückbleibeu. trum mit gepulverten Wessteincrystallen

sätigt, die Flussigkeit filtrirt an 1 sie durch ganzen Mischung pacb in Weingeist autösen lasser. Die Auilösung im destillirten Er mufs sicb klebric anfühlen und an de Luft leicht zerfiefsen, wobey er Anfaugs ein glasartiges Ausebeu bekömmt. Bey seiner Bereitung müssen alle metallene $\mathrm{Ge}-$ die überschüssige Sänre desselben das Metall aufgelöset wird. Das Abrauchen der Lauge inufs daher in gläsernén oder porcellaiuenen G+schirren gescbehen.

Der durch Aufösung des roben Weinsteins in kocbendem Wasser, durch Zusatz von Thov, Eyweifs, Tischlerlein, auch wobl Ocbsenblut oder Kobleupulver, und nachherisirte Wriustein, dessen Bereitung in besondern Fabriken in Frankreich, Italieu nnd Dentscbland in Grofsen betrieben wro del vorkommt, besteht aus kleinen, weifsen, lualbinrchsichtigen, vierseitig pyraInidalischen, theils einzelnen, theils aneinander hängenden Crystallen, oder auch einander hangenden Crystallen, oder auch wen a beym Abdusten der Finsigkeit di auf der Oberlaclie entstehende Salzrinde bestandig weggenomnen wird, ans sehr feinannten Weinste in rah m (Cremor äufseres Ausehen verschieden, laben cinen kübieuden, säuerlicben Gesclrnack und sind im Wasser scliwer auföslich. In Glïhefener rerbrennt der gereînigte Weinstein gleich dem rohen mit virlem und stark ruIsenden Rauche und mit Flamme; er stöfst dabey eineı sänerlicben, brenzlicbten Geruch aus, und hiuterläist eine scbwarze, koblichte Materie, aus welcher man das reinste Kali ziehen kann. Wasser mufs völlig klar und belle seyn. Der grreinigte Weiustein, wie el im HanTartari.) Beyile sind aber nur durch ibr

Fehlerhafte $B e-$
chaffenheit, Ver-
wechfelung oder
Verfälfchung.

Deren

Kennzeichen und Prïfungsmitcel.

talies mit eisem eisernen Spatel, mechanisch beygemengte Zinntherie enthalten, welches sich bey der Aullösung in Wasser zeigen würde.

Mit scluwefelsaurem Kali (Tartartus v)itriolatus, Arcantum duplicatum) verfälscht.

Mit Alaun verfälscht.

an entdckic dieses, wenn man zu eine Anfösung des verdächtigen Weinsteins etwas Bleyessíg tröpfeit, wodurch ein Niederschlag entsteht, der siç̂ nicht wieder in Salpetersäure anföset. Auch sind die Crystal'en melir glänzend und durchsicbtig, sclmecken bitter, etwas eckelbaft und nich so sauer.

Brennt man eine Portion desselhen unter stetem Umrühren zu Asche, laugt dieš aus uud dampft die Flüssigkei bis zum Häutchen $a b$, so wird das schwefelsaure Kali sich in der Kaite das schwefelsaure Kali sich in ren, wenu der gereinigte Weinstein dami verfach Asche mit Essig sälligen und eintrocknen, das Kaliessigsalz mit Weinalcohol auszier ben, den Rückstand mit Wasser auskochen und zur filtrirten Aufösung essigsaure Bary tauflösung tröpfeln; der niederfallende S,cb werspach wird dann die Schwefelsäure, und die davon aboegossene Fliissigkeit nach dem Eintrockneu und Glïhen das Kali des schwefelsauren Kali beweisen; wenn das letzlere beysemische war.

Der durch Bleyessig in einer Aufiösung des verdächtigen Weinsteins entstehende Niederschlag wird in reiner Satpetersäure nich völlig wieder aufgelöset. Bey der Sättigung mit Kali wird ein schleinichter Satz abgesondert.

\begin{tabular}{lll} 
Mit Gyps. & $\begin{array}{l}\text { Beibe bey der Aufioisung in Wasser als schwe- } \\
\text { rer aullöslich zurück. Der in der Aufiö- } \\
\text { sung durch Bleyessig entstehende Nieder- } \\
\text { schlag wird in Salpetersäure nicht wieder. } \\
\text { aufgelöset. }\end{array}$ \\
\hline Verpufit auf glühenden Kohlen.
\end{tabular}

Mit Salpeter, ob- Verpufit auf glühenden Kohlen.

gleich wohl nur selten und zufällig. Kupferhaltig.

Mnthmafslich scbon durch die ins Grünlich oder Gelbrôthliche spiclende Farbe der gewöhnlich grölsern und olänzeudern Crystallen, gewisser aber durch das Verkup fern eines in die Aunösung desselbent fern eines in die Aunosung desselben gestellten eisernes polinen Stabchens, und durch die moniumflüssigkeit nach der Sättigung da-
mit erzengt, zu entdecken.

Ein dreyfaches, aus Eisenoxyd, $\mathrm{Kali}$ und Weinsteinsäure bestebenies Salz, welcbes dadurch gewonnen wird, dafs man cinen Theil reiucu Eisenlaanmerschlag mit vier Theilew gepulveiten Weiustcincrystallen und ben do twen Theil renca Lisenhannerschlag mil vier Theiles gepnlverten Weibstcincrystallen und eben so viele War Orte stehn lifst, uud dann so lange mit Wasser horh, his aller saurc Geschmack verschnunden ist, worauf man die milchichte Flüssigkeit von dem unaufgelösten Eisen abgiefst und gehörig gereinigt bey geliudem Feuer zur Trorkenheit abdampft, lias erbaltene pulverföımige $S$ alz aber in einem gnt verstopfteu Giase aufbewahrt. Es hat dasselbe eine graulicble Farbe, wird an der Luft etwas fencht, Iöset sich ju kocbendem Wasser schwer, auf und bat einen eiseubaft zusamm niehenden Gescbmack. Die Auflösung desselben muf den Galläpfelaúszıg stark schwärzen. Iin Glüheleuer mufs ein reines mit Koble und Eisenoxyd gernengtes

Ein dreylaches, ans Weiusleiusäure, Kali|Statt dessen Glauber-/Wird durch den unangenebmen Geschmack und Natrum bestehendes Neutralsalz, w 1- salz, besonders in und dusch die eigenibümlicbe Crystallisaches berfitet wird; indern nai iu korben- Pulvern oder Mix- tion des Glauhersalzes, wenn man das dadem Wasser gelöstes kuhlinstoffsaures $\mathrm{Na}$ - turen. löset und crystallisiren läfst, entdeckt. Aufserdem erkennt man die Verfailschung darlurch, dafs sich der aus einer Auniisung des verdächtigen Sal xes in destillirtem WVasser durch hiuzuctröpfelten Bleyessig entser duch hieder standene in reiner Salpere gelindes Abraurlieu zur Crystallisation befördert. Das Seignetusalz bildet sechsseiche, säulenfüirnige Crystallen mit pech winklichten ahgestumpften Eudspitzen, die vorzüglich schön und grofs sind, je langsamer die Lange; worin sie sich bildeten, 


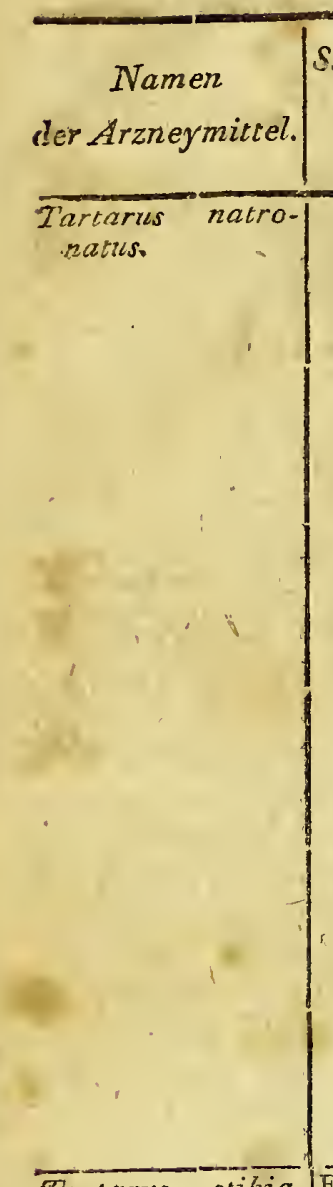

Tartert

Tartarus, emeticus Spiefsglanzweinstein.

Brechweinstein.
Sinnliche Eigenfchaften derfelben; Fehlerhafte BeGüite.

schaffenheic, Ver-
wech

\section{Deren}

Kennzeichen und Priifungsmittel. Merkmale ihrer Aechitheit und

Verfälschung.

abgedunstet winde, da lingegen eive $z$ sclinell ahgerauchte Lauge nur kleine unformliche krumige Crystallen liefert. Si sind weifs und durchsichtig, nnd haben einen ebeu nicht widri den, etwas bitterlichen nnd inildern Gesche Weinalcohol ist das Seignettsalz völlig unWüstich; in Wasser dacegen selır leicht auföslich, so dafs dazu nur vier Theile aufloslich, so dafs daser erfordert werden. Die Auflösung in wenig Wasser wird, aufser der lösung in wenig Wassel wird, aulser der
Kohleustolfsänre, durch jede Säure zerKohleustọlfsänre, durch jede Säure zer-

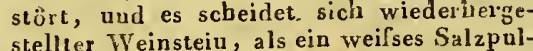
ver darans ab. An der freyen Luft werden die Crystalien auf der Oberfäche mehlig uvd zerfallen in warmer Temperatur. glinälia zu einem weifsen Pulver, indern das Crystallisationswasser entweicht. Nit demelben noch versehen, zerfliefsen sie demselben noch veritzun. dariu bey vorsichtiger Erhitzusg- Im Giuhefeuer werden sje mit den empyrevmatischen Weinsteingeruch zerstort, und es bleibt eine schwammichte $k$ alisch - natrische Koble zurtick. Uebrigens darf die Auflösung den Veilchensalt nicht verändern nnd der Niederschlag, welchen das aufgelöste essigsaure Bley und das salpetersaure Silher darin hervorbringen, mufs in Salpetersäure wieder antïslich seyn. Das Kali und Natrum, welche das Salz bey dem Glühen im Feuer hinterläfst, müssen mit reiner Sal petersäure gesättigt, die salzsaure Bary tauflösung uicht niederschlagen.

in dreytaches, ans Weinsteinsäure, Kali und unvollkommnen Spiefsgelanzoxyd bestebendes Salz, welcbes nach der Preufsischeu Pharmacopoe aus gin Weinstein und Metallsaffran durch nochen mit Wasser in einem glãsernen oder Kochen mit Wasser in einem geăsernen od machherigem Filporcellainenen Gefäfse, nachherigem Filtriren del Lauge und wiederholtes Crystal- lisiren derselben bereiter wird, sammtligetrocknet sind, alsdann in einen gläserden oder steinernen Mörser fein untereinander zerrieben, und das $P$ ulver in cinem wohlverschlossenen Glase aufbewalirt wird. Aufserdem ist es bekannt, dafs es zur Bereitung des Brechweinsteins mehrere Vorschriften gieht, uuter welchen die ron Hrn. Bucbolz (Journal der Pbarmacie. B. $X$, St. 2. S. 24 u. f.) angegebene, nach welcher zwey Theile gepulverte Weinsteitcrystallen mit andetthath Theilen bochst fe zerriebenen Spiefsglanzglase genau untereinander gemengt und init hinreichenden Wasser zu einem mäfsig dicken Brey verrnischt werden, welcheu man iu einer Porcellainschale vierzeisu Tage lang an einem warmen Q.te stellt und das Gemenge täglich melreremal gut durchrührt, dann die Mischung unit siedendem Wasser überdie Mische einige Ninuten anfwallen läfst, sie gossen, einige stallisation befördert, ohnstreitig den Yorzug verdient.

Stat des Spiefsglanzsaftrans und des Spiefsglanzglases werden übrigens von melrern auch das Algarothpulver und die Spiefsglanzasche vorgeschlagen.

Der Brechwcinstein, dessen Güte banptsächlich von der Genauigkeit bey seinel Besầchlich von der Giang kleine, durchsichrcitung abhangt, bilet kife, nur etwas tige, feste, wenig metallisch eckeliaft schmeckende scher (Handb. d. pharm. Praxis, Auft. 2. sche r (Handb. d. pharm. Praxis, Auft. 2 S. 559) bey Bcfolgung der erstern Bereitungsmethode die gemeine vierseitige, oft allch, wenn eine Seltenfaches sehr scheyden Enden $z$ ugespitzte Sïule ist, dereu Zuspitzungen gröfser als das Prisina selbst sind und daber dem $\mathrm{Cry}_{\mathrm{w}} \mathrm{all}$ ein octaedrisches
Mit scluwe felsaurem oder salzichtsaurenn Kali verunreinigt.

urch Inspissation bereitet.

Zu wenig Spiefsglan oxyd enthaltend.

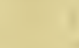

es bleibeu die Laucensalze, das Kali uuc Natrum, mit Kohle gemiscbt zurück. Das Glaubersalz hingeoen, so wie audere feuerbestäudige Salze, nit welcben es verunbestäudige Salze, noit welcben es rerun-
reinizt seyn könnte, w. z. B. das schwereinigt seyn könnte, w. z. B. das schwe-
felsaure Kali, wird man unzerlegt in dem felsaure Kali, wird man unzerlegt in dem ckeu und durcb $\Lambda$ ullösen und Crystallisiren fír sich darstellen könuen.

ias kann der Fall seyn, weun das Seignettsalz nach andern Methoden auf dem Wege der doppelten Wahlverwandtscbaft aus kohlensaurem Kali, Weinsteincrystallen und Glaubersalz oder Kochsalz bereitet worden ist. Um dieses zu entdecken, theilt man eine Aufösung desselben in zwey Theile, und tröpfelt in dem einen Theil eine AufIösung von essigsaurem Bley. Es wird au jeden Fall ein Niederschlag entstehen, weljeden finl ein Nalu cher, wiéses löset sich weinsteinsaure reine Salpetersäure zugetröpfelt wird, yollkommen wieder auf; gefelt wird, vollkommen wieder auf, geschieht dies nicht, so war Schwefelsaure zugegen und der uuaufgelöste Niederschla: ist 'schwefelsaures Bley. In dem andern Theil tröpfele man et was salpetersaure oder schwefelsaure Silberaufösung; hewirkt diese einen kasichsalz oder Digestivsalz vorhanden.

er a diese Art, wie einige Vorschriften ihn zn bereiten lebren, erbaltene Brechweinstein hat eiue mehr oder weniger schmutzig-oder grawweifse, graugelhliche oder auch wohl gelbgrinuliche Farbe. Er ist weit schwerer auflöslich in Wasser als dor durch Crystallisation bereitete Brech-' weinsin und es grïndet sich nach Herrn $\mathrm{B}$ u $\mathrm{c}$ z lie sonst gewölunliche aber irri-

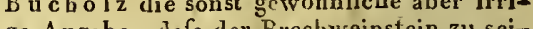
ge Angabe, dals der Breeheinstein an seiner Auflösung 80 Theile $W$ asser erfordere, bauptsächlich auf die bey einem solchen durch Eindickung der Salzlauge bereiteter Brechweinstein befindlichen schwerauföslichon Salze, dem Eisenweinstein und Weinsteinseleuit. In Hinsicht des Apzoneykräfte ist dieser Brechweinstein stärker Brechenerregend, als der durch Crystallisation bereitete. An der Luft wird er feucht.

Dies ist der Fill; wenn bey der Bereitung des Brecbweinsteins, etwa nach der sonst gebräuchlichen $I$ ö p f nerschen Methode, zu wenig Spiefsglauzglas gegen den Weinstein genommen wird, da alsdann der Brechweinstein noch unverãnderten freyen Weingtein enthält, orler nicht alle Säure des Weinsteins mit Spiefsolanzoxyd gesätdes Weinsteins init Spiefs la los tigt ist nnd die Aufusung des Broweinsteins sehr merklich sauer reagart. Znr Erforschung der Gegenwart des Spiefsglanzoxyds im Brecbweinstein kann man nun $z$ war denselbeu auf einer glühendeu Kohtc vor dem Blaserohre bebandeln, um durch die Reduction metallischen Spiefsglanz daraus herzusiellen. Indessen ist drese Zersetzungsmethode als Prüfuuģmittel auf den Gehalt an Spiefsglanzoxyd deshalb niche wohl anzuwenden, weil sich das reducirte Metall leicht verlïchtigt. Am das reden eigentlisicher chen Gebalt an Spielsglanzoxyd, wenn man den Brechweinstein in sehr verdünter Salzsäure auföset und in diese Auflösung eine hlanke Zinkstange stellt. Das Spiefsglanzoxyd setzt bier seinen Sauerstoff an den Zink $a b$, und seheidet sich in metallischer Gestalt aus. Von diesem erbaltenen Metall sind 0,5, gleich $z$ u rechnen 0,57 unvollkemmenen Metalloxyd. Statt der Zinlstange kann man sich nach $H_{2} g \in n$ auch einer Fiseustange bedienea. 
Tartarus stibiatus. -- Terebinthina laricina.

\begin{tabular}{|c|c|c|c|}
\hline $\begin{array}{c}\text { Namenz } \\
\text { der Arzneymitcel. }\end{array}$ & $\begin{array}{c}\text { Simnliche Eigenfchaften derfelben; } \\
\text { Merkmale, ihrer Aechutheil und } \\
\text { Giice. }\end{array}$ & $\left|\begin{array}{cc}\text { Fehlerhafie } & \text { Be-. } \\
\text { cchaffenheit, } & \text { Ver- } \\
\text { wechfelung oder } \\
\text { Verfälfchung. }\end{array}\right|$ & $\begin{array}{l}\text { Deren } \\
\text { Kennzeichen und Prüfungsmictel. }\end{array}$ \\
\hline
\end{tabular}

Trurtaris stibia-1 Ausehen geben. Nacb Herrn Hermb-|Mit Eisen verunrei- Da das Spiefsglanzglas fast immer etwas Ei-

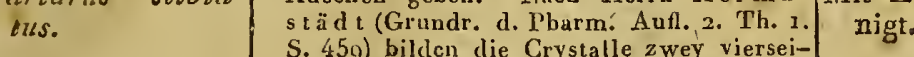

S. 459) bilden die Crystatle zwey vierseitige mit ilreul Basen aneinander gestlitzte len. Die Crystalleu sind an der Luft unveränderlich; nach einigen Schriftstellern veränderlich; nach einigen Schriftstellern
werdeu sie jedoch nit der Zeit undurchwicbtig. Sie geben zerrieben ebenfalls ein sicbtig. Sie geben zerrieben ebenfalls ein
vollkommen weil'ses Pulver und verlieren volkommen weilses Pulver und verlieren
durch behutsames Trocknen und Pulvern nichts bedeutendes an Gewicht. Ein Theil davon erfordert nach lierrn $\mathrm{Bucholz}$ nur 14. bis 15 Theile destillirtes Wasser mittlerer Temperatur zu seiner Aufösung, und uur 2 Theile siedendes Wasser. Auf einer flühenden Kohle vor dem Blaserohre behandelt, wird dieses.Salz zerstört und es erscheinen kleine Kügelchen von Spiefsglanzmetall. Wird zu seiner Aufösung eine Auflösnng von Scliwefelkali, liydroeine Auflösnng von Scliwefelkali, liydro-
thionsaures Wasser, oder auch Schweftthionsaures Wasser, odcr auch Scbwefetpommeranzentarbenes l'räcipitat, welcbes sich mit dem pommeranzenfarbenen Spiefsglanzschwefel ziemlich gleich verbält. Uebrigeus mufs die Auflösung des Brecbweinsteins rollkommen klar seyn und ein wenig saller reagiren, so dafs die Lackmustinctur, schwacb davon geröthet wird. Von der Schwefelsäure, der Salpetersäure, der Salzsäure, Sauerklce - und Gallusm der Salzsaure, Sataerklce - und Gallussâure und von den diese Saurcn in Ueberscbuls oder frey enthaltendeu Salzen; inser und absorbircnden Erdev, auch von zuser und absorbircnden Erdev, auch von zu-
sammenziehenden Pflanzenauszigen wird sammenziehenden Pflanzenauszïgen wird
der Brechweiustcin zerseizt. A Aus eben dem Grunde mufs auch zur Auflösuug desselben immer destillirtes Wasser geuommen werden, -weil dic $1 \mathrm{~m}$ gemeinen Brnnnenwasser enthaltene freye Kalkerde eine Zerlegung bewirken kanu, nud wegen des oft auch iu demselben befindlichen Kochsalzes sogar durch Zersetzung desselben salzsaurer Spiefsrlanz entsielen kann, der immer selır nacbtheilig wirkt. Metalle, z. B. Eisen, Kupfer, Zinn, Biey n. s. w. z. B. Eisen, Kupfer, Zinn, Biey n. s. w.
müssen bey seiner Bercitung ebenfalls vermüsen bey seiner Bercitung ebenfalls ver-
mieden werden, Weil sie' eine näherc Vermieden werden, Weil sie eine naberc wandschaft zur Weinsteinsänre baben, mit Spiefsglanzoxyd ansscbciden kann.

Kupferhaltig. in kupreitet.

zinnernen Geschirren bereitet.

it Salzsäure verun reinigt. durch Weile malaxirt, in-daumensdicke Stangen gedrebt und der freyen Luft ansgesetzt wird, bis er völlig ausgetrocket malaxirt, in daumenstick Stangen gedrebt uch - und geschmackloses, hartes, weifslichtes oder gelbtrocknet und erbärtet ist. Er bildet sodann ein geruch
weifslichtes, leicht zerbrecbliches, pülverbares Harz.

Gekochter Terpen tin.

Terebinthina commumis.

Gemeiner Terpentin.

Terelintluina laricilla.

Terebinthina vene-

ta.

pentin.
Lerchenterpentin.

Ein aus dem adebohrten Stamme oder durch Anfbauen der Rinde des gemeinen Ficlutenbaum (Pinus sylvestris L.) zur. Sommerszeit in untergesetztc Gefäfse lliefsendes, dickflüssiges, zähes, natürliches flarz von einer trüben graugelblichen Farbe, einem eigenen starken Geruch und bitterlichen, etwas scharfen Geschmack. Er kommt gröfstentheils aus Frankreich von Marscille, Toulon und Bourdeaux. Der Stra $\int_{s-}$ burger Terpentin (Terebinthina argentoratens is s. abiegna), welcher ehedern artheisten von Strafsburg versandt wurde, jetıt abcr selteu im flandel volkomnt ist feiner wie jener, durcbsichtig, weifsgelb von Farbe, ziemlich dünnflïssig, von einem angenehmen, frisch etwas citronenartigen Geruch und einem bervorstecbenden bittern Geschmack, wird jedoch im Alter dunkler und

meu Geruch. Man erbalt ibn vou der. Weifs in aus dem Stamme der LerchenfichtelMit gemeinem Ter- Hat eine dickere Consisteuz, ist woniger (Prinus Larix L.) thcils von selbst, pentin verfälscht. durchsichtig und von Geruch unangenebtheils aus eiugebohrten Löchern hcrausflicfsendes weiches Harz, welches chedem ans Venedig gebracht wurde, jetzt aber aus Nordamerica, Ungarn, dem südlichen Dentschland, Savoyen, Kärntben, Tyrol, Dauphine und ans mebrern bohen gebir'mcr. Die Auflösung in Weinalcohol ist mebr gefärbt und riecht, wenn man vier Theile Wasser damit vermischt, stärker nach Terpentin, als nach Weingeist; auck län der bcygenischle gemeine Terpentin as die Seiten des Glases als eine klehrige Masse fest. gichten Gegenden" zu uns kommt. Es hat dieser Terpentin die Dicke eines Syrups dieser Terpentin die telck oder eines von selbst aus den Waben tile
fsenden Houigs, ist zähe, sehr klar, durch fsenden Honigs, ist zähe, sehr klar, durchsichtig, von wcifslichblafsgelber Farbe, einem beifsend erwärmenden, bitterlicben, cutfernt muscatenuufsartigen Gescbmack, und etwas citronenähnlichen, harzichtem Geruch, Er mufs nicht zu alt und ausgetrocknet, sondern flüssig, weifslich und durchsichtig seyn, sich völlig klar in

Statt dessen ein künstliches Gemisch aus gemeinem Terpentin, Baumöl und Geigenharz.

Dicser nachgemachte Terpentin verräth sicl/2 durch seine dunkle, scbmuzige Farbe und unangenebmeru Geruch und Gescbraack. In höchstreinem Weingcist löset er sich nicht rollkommen auf und das Banmül setzt sich in kieinen gefäbten Tropfen zu Boden; giefst man zn dieser Anflösung vier Theile Wasser, so steigt das Banmöl auf die OberGäche und das Geigenbarz fäll: 213 Boden. 


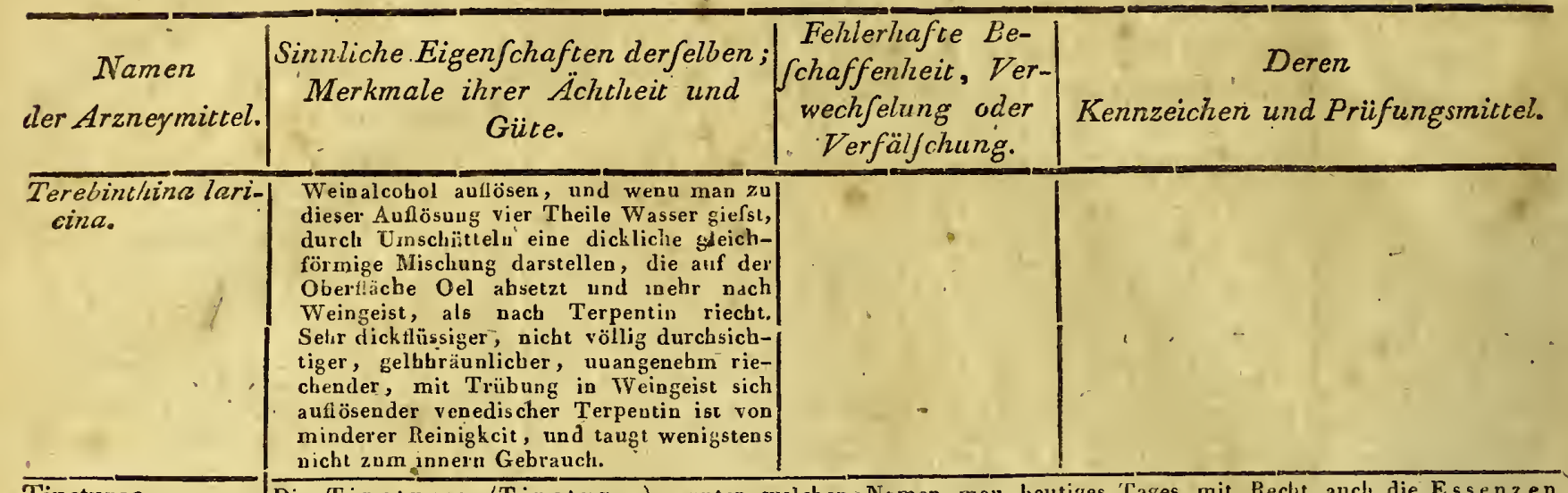

Tincturen,

Die Tinctureu (Tinctnrae), unter welchen Namen man heutiges Tages mit Recht auch die Essenzen (Essentiae) begreift, sind flüssize Arzneymittel, wclche durch Uebergiefsen inebrentheils vegetabilischer aufserdem anch einiger thierischen und mineralischen ISörper mit irgend einer z.weckmälsigen Flüssigkeit, aufserdem anch einiger thierischen und minerassen Bestandtheile entwerler durch kïrzcr oder länger furtgedie, nachdem dieselbe ans jenen Körpern gewisse Bestandtheile entweeler durch kiurzcr oder langer furtge-
setzte blofse Maceration oder durch Digestion in gelinder Wärme ausgezogen und in sich aufgenommen hat, davon abgegnssen, dor Rückstand vollends ausgeprefst "und die sämmtliche Flässigkeit durch 1uehrtägiges rubiges Steben oder Filtriren geklärt worden ist, bereitet werdeu. Mau unterscheidet einf ache (T in et urae simp!lices) und zusmmengesetzte (Tincturae compositac) Tincturen; zu jenen wird nur eine einzige Substanz, zu deu letztern werden nnehrere Körper mit der dazu' bestimmten Flïssıgkeit oder dem Aus íebungssnittel übergossen und ausgezogen. Von den Elixiren unterscheiden sich die 'Tincturen durch ein belleres, mebrentheils durchsichtiges Ausehen und einc weniger gèsattigte Farbe. Sie enthat teu, nachdem-sie entweder blos mit Weingeist, Wässer und Weingcist, Wein, mit blofsem Wasser, mit ätherıschden

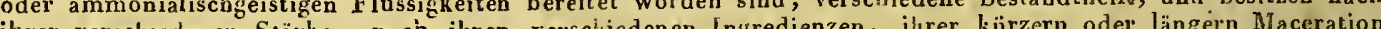
Wer weriger seoder Disestion, iber medr oder wenger sorgenthen Inesältigte Farbe; mehr oder weuiger Heilkrâtle. Eine gehörig bereitete Tinciur muf, die ibr zukommende Stärke, ibren eigentbümlichen Gernch und Geschnnack und ihre natürliche Farbe besitzen; sie 1nufs nicht trübe, sondern klar und durchsichtig seyn, wenigsteus, das letztere in kleinern Quantitäten. Kalt zu bereiteude Tincturen, besonders diejenigen, welche sehr flüchtige Bestandtteile enthalten, müssen nicht in der Wärme, sondern in der Kälte und zwar lange genıg macerirt seyn. Um eine gesättigtc Tinctur zu erhalten, darf der Apotbeker aber keinesweges olne ausdrücliliche Vorschrift des Dispensatorii etwa Laugensalz. Blătteresde oder tartarisirten Weinstein u. dgl. zusetzen. Ersteres wïrde sich durch das Aufbrausen mit Säureı und durch das Blaufärben des gerötheten Lackinuspapiers, die Blattercrde durch den sich entwickelndeu. Essigdampl nach zusesetzter Schwefelsäure, der tartarisirte Weiustein durch den bremzlichten Weinckelner delt, verrathen.

Die vor, üglichsten Prüfinssmittel der Tincturen in Absicht anf iture Aechtheit und Güte sind wohl hauptsäcblich der Geruch und Geschmack und die Vergleichnog mit ächt bereiteten Tincturen. Vorzüglich haptes Gütc dazu geuomkomm! es darauf an, dafs die Ingredienzen in dev, gebörigen Nenge und in der bestcn Guitc dazu geuommen sind, und dafs die dunkle Farbe der Tincturen, wodnrch man scheinbar anf ihre vorzïgliche Stärke schliefsen könnte nicht etwa erkünstelt sey, z. B. durch gebrannten Zucker (Tinctura Sacchari) oder Sufs-

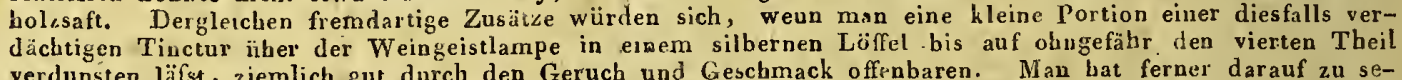
verdunsten lä́st, ziemlich gut durch den Geruch und Geschmack offrnbaren. Man bat ferner darauf zu sehell, 'daf' $z u$ den geistigen Tincturen ein guter reiner Weingeist und nicht etwa genneiner Brauntwein genommen wcrde, welches letztere, wenn etwas von der Tinctur in der HInd gerieben wird, sich dureh den fuselichten Geruch zu erkennen giebt. Endlich müssen die Tincturen gut aufhewahrt werden, und nicht durch nachlässige Verstopfung der Gläser iłrer flüchtigen Bestandtheile zum Theil oder ganz be-

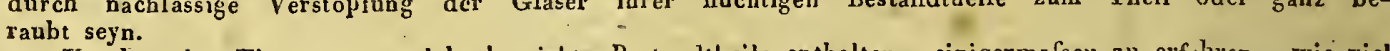

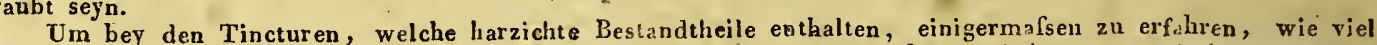
oder' wenif von densellen mit einer gleichen Menge Wasser. Die dadurch entstehende mebrere oder mindere Trübung oder Fällung wird daun ohngefähr ihren Gehalt zu erkennen geben. Bestimmter und genauer erfäbrt man es dureh Verdunstung einer kleinen Quantität der zu untersuchenden Tincturen und durch das Wägen des Rückstandes.

Bey den Tincturen, die eine schöne grüne Farbe haben sollen, bat man noch zu untersuchen, ob jeve Farbe auch etwa durch Zusatz von blauem Vitriol, oder durch Digestion in einem kupfernen Gefaifse erzwungen wortlen sey. Man entdeckt dieses, wensil mant et was reiue Kaliflüssigkejt zu der vertärhhigen Tinctur mischt; entsteht nach yeschehener. Umschiittelung und erfolgter Ruhe ein Niederschlag, der durch Fliefspapier abgesondert, so wie der verbranute Rïckstand einer solchen Tinctur der Ammoniumflüssigkeit uach papier abgesondert, so wie der verbrabläliche Farbe miltheilt, so entbält die untersuchte Tinctur Kupfer. vorhergegangener kurzcr Digestion eine blatiche Farbe mitheiltiuctur einen rotbbraunen Nicderschlag, und Hydrothionsaures Wasser verursacht ibberdeen in enner solchen Ti, so

ein darin gelegtes blankes Eisen nimmt einen Kupferbeschlag an.

Tinctura Absinh hii. Wermuthtinctur. Aus den getrockneten Spitzen des gemeinen Wermuth mit recti-
ficirtem Weingeist bereitet. Hat eine dunkel bratunlichgrüne Farbe und einen sehr bittern Wermuthficirtem W.
geschmack.

Tinctura ainara. Bitteressehz. Aus Tsusendgüldenksaut, unreifen Pommeranzenfrüchtcn; Gentianworzeln, Zittwerwurzeln und Weiogeist bereitet. Die nach dieser Vorscbrift bereitete Tiuctur hat eive hranne, nur schwach ins Grüue swielende Farbe uud eiueu sehr enzianbittern, -etwas gewürzhaften Gehranne, nut

Tinctura Ancinonii Therleni. Thedens Spiefsslauztinctur. Bekanntlich eine Tinctur, die aus seler weni-

Statt dieser wnrle einst, wie gen Spiefsglanztheiles eine Herr Schatub erzählt, ein ubcr Weingeist fälscblicher weise verkauft; diese Tinctur batte eine mehr gelb.

Tie streugste Untersnchung keintur. Ans Zimmtcassia, Cardamomen, Nelken, Galgant- und IngwerTinctura aromatica. Gewhirztinctur. Alis Zimme braune Farbe, einen beifsend gewrirzhafien Geschmack und woiz. lin mit Weingeist bereitet. Sie hat eine brant

Tirclura aromatica acida. Sanre Gewirztinctur. Ans einem Pfunle Gewüratinctur und einer hałben Unze concentrirter Schwefelsäure bereitet. Von Farbe wie die vorige, aber sauer gewiirzhaft schmecke d.

Tinctura Asae foctidae. Stinkasanttinctur. Aus zwey Unzen Asa foetida und einem Pfunde Weinalcohol berentet. Sie hat eine 'gelbrollhbräunliche Farbe mud riecht und schmcckt wie Stinkasant.

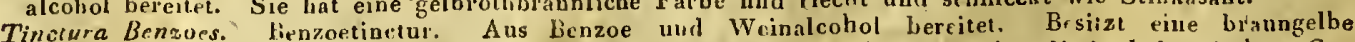
Farbe, einen angenelimen Geruch und einen schärflichen, suifslichen und gelinde balsemischen Ge- 


\begin{tabular}{|c|c|c|c|}
\hline $\begin{array}{c}\text { Namen } \\
\text { deriArzneymittel. }\end{array}$ & $\begin{array}{c}\text { Sinnliche Eigenfchaften derfelben; } \\
\text { Merkmale', illrer Aechtheit und } \\
\text { Giite. }\end{array}$ & $\left|\begin{array}{c}\text { Fehlerhafte Be- } \\
\text { fchaffenheit, Ver- } \\
\text { wechfelung oder } \\
\text { Verfälfchung. }\end{array}\right|$ & $\begin{array}{c}\text { Deren } \\
\text { Kennzeichen und Priifungsmitcel. }\end{array}$ \\
\hline
\end{tabular}

Tincturae. schmack. Mit Wasser vermischt, macht sie eine milchartize tribe Miscbung, die als Waschmittel ge-

braucht wird.
Tinctura Benzoes compostta s. Balsamum Commendatoris. Znsammengesetzre Benzoetinctur. - Aus Benzoe,
StoratiStorax, Aloe, schwarzen Perubalsam und Weinalcohol bereitet. Hat eine braune Farbe, einen lieblichen gew ürahiaften Gernch und äbnlichen bitterlichen Gescbrnack.

chen sewürzhaften Geruch und abnlichen bitterlichen Geschrnack.
Tinctura Cantharidum. Spanische Fliegentinctur. Ans spanischen Fliegen mit rectificirten Weingeist be-

Tinctura Cantharidum. Spanische Fliegentinctur. Ans spanischen Fliegen mit rectificirten Weingeist be-
reitet. Einc schwach grinlichtgelbe Tinctur voil eigentbürulichen cantharidenartigen Geruch, die auf die reitet. Einc schwach grinlichtgelbe Tinct
Haut gerieben, Rö̈be und Blasen erregt.

Tinctura Cascarillae. : Cascarilltinctur. Ans Cascarillrinde mit rectifcirtem Weingeist bereitet. Hat eine

dunkelbranue Farbe imd den eigentlichen Cascarilleugeschmack.
Tinclura Castorci. Bibergeiltinctur. Aus achtem Bibergeil mnit Weinalcohol bereitet. Besitzt bey einer braunen Farbe den Geruch und Geschmack des Bibergeils in hohem Grade.

Tinctura castorei actherea. Aetherische Bihergeiltinctnr. Aus ächten Bibergeil mit Schwefeläthergeist bereitet. Ebenfalls von brauner Farbe, - aber von angenehmern Geruch und Gesclimack als die blos mit

Weingeist hereitete Tinctur,
Tinclura Caleclue. Catechutinctur. Aus Catechu mit Weingcist bereitet. Hat eine sehr duskelbranne Farhe und einen sehr zusammenziehenden Geschmack.

Tinctura Chince sehr zusammenziellenden Geschmack.

Tinctura Chinae composila s. Elixir roborans. Zusammengesetzte Chinatinctur. Ans bereitet. Eine hraune,
wurzeln, Pommeranzeischalen, rectificirten Weingeist und einfachen Zimmtwasser ber wurzeln, Pommer anzeilschalen, rectificirte
bitter gewürhaft scbmeckende Tinctur.

Tinctura Cinnamomi. Zimmtinctur. Aus Zimmtcassia mit rectificirten Weingeist bereitet. Hat eine brauue Farbe und angenehmen Zimmtgeruch und Geschmack.

Tinctura Colocynthidis. Coloquintentinctur. Aus Coloqniuteh mit etwas Sternanis nnd rectificirten Wcingeist bereitet. Hat eine hellgelbe Falbe, einen schwachen Sternanisicbten Geruch und sehr bittern krazzenden Geschmack.

Tinctura Corlicuml Aurantiorum. Pommeranzenschalentiuctur. Aus den vorher von dem inwendigen weifsen Marke gereinigten Pommeranzenschalen mit rectificirten Weingeist bereitet. Hat eine braungelhe Farbe und den bekannten Pommeranzengeruch und Geschmack.

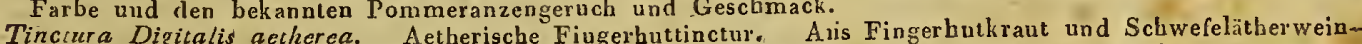
geist bereitet. Aine gethea. Aetherische Fingerhuttinctur. Ans Fingerhutichau Geschmack, den die mit blofsein Weingeist 'aus dern Fiugerhutkrant bereitete Tinctur besitzt, weniogstens von vorne herein ziemlich vcrsteckt ist, ob er sich gleich hintennach mit dem bratzend beifscaden auch zn erkénziemlich vist

nen giebt.
Tinctura Euphorliit. Euphorbiumtinctur. Aus Euphorpium mit rectificirtem Weingeist bereitet. Von

bräuulicher Farbe und sehr scharfen Euphorbjumgeschnack.
Tinctura Ferri acetici aetherea. Aetheriscle essigsaure Eisentinctur. Eine ätherischgeistige, auś gelöstem uiberessigsaurem Eisenoxyd, Essigälleer und Weinalcohol zusammengesetzle Eisentinctur von einer dunkelhraunen Farbe, angenelimen geistigätherischea Geruch nod adstringirenden Eiseugeschmack。 Mufs in einem sehr genaa verschlossenen Glase anfgchoben werden.

Tinclura Ferri inurialici, Salzichtsaure Eiseniinctur. Durch Auflösung von drey Unzen reiner Eisenfeile in genugsamer Salzsäure, Abdampfung der Auäösung bis auf sechs Unzen und Vermischung mit achtzehn Unzen rectificirten Weingeist bereitet. Hat eine gelblichrothe Farbe und einen stark zusammenziebenden Geschmack. Wenn sie ius Grünliche spielt, so entbält sie zu viel Säure; sieht sie schwärzlich benden Geschmack. Wenn sie ius Grünliche spielt, so entalt sie eichenen Fässern verunreinigt; ist sie aus, so ist der Weingeist mit adstringirenden Stofien, z. B. alls eicheren

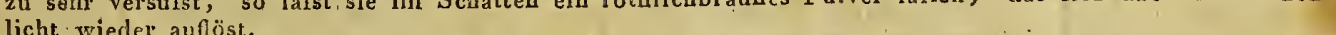

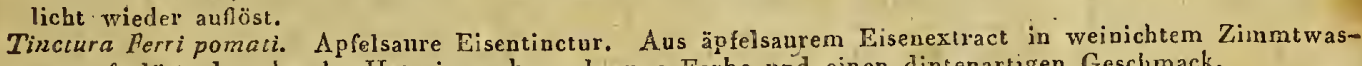
ser aufgelöst, bestehend. Hat eine scbwarzbranne Farbe und einen dintenartigen Geschmack.
Tinctura Galla.uin. Galläpfeltinctur. Aus Galläpfeì und rectfficirten Weingeist bereitet. Hat eine

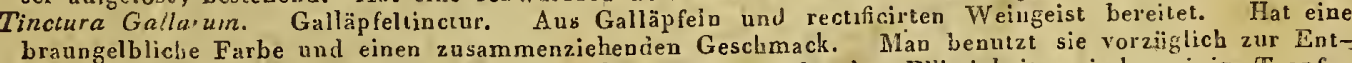
deckuug der Gegenwart des Eisens in mineralischen Wässern und andern Flüssigkeiten, indem einize Tropfen schoun hinreichen, $\frac{1}{24}$ Gran. Eisen in einer Kanue Wasser aufgelöst, durch Hervorbriugung einer purpnrvioletten Farbe zu verrathen. Bey einem gröfsern Eisengchalt wird" die Flüssigkeit sch wärrilich letten gefarbt.

Tincura Gentianae. Geutianwurzeltinctur. Aus Gentignwurzeln mit Weingeist bereitet. Hat eine gelbbraude Farbe und einen sehr bitteru Gentianwurzelgeschmaok.

Tinctura Guajaci ammoniala s. volatilis. Ammonisirte Guajaktinctur. Aus zerriebenen natürlichen GuaTincura Guajaci ammoniata s. volatilis. Ammonisirte Guajaktinctur. Aus zerriebenen natürichen Gua-
jakgummi mit weiuichter Ammoninmfüssigkeit bereitel. Hat eine dunkelbraune Farhe und einen amjakgummi mit weiuichter Ammoniumflüssigkeit bereitel. Hat eine
monialisch flüchtigen Geruch. Mufs in der. Kälte bereitet werden.

Tinctura Kalina. Tinctura salis Tartari s. Antimonii acris. Kalitinctur. Wird nach der Prenfsischen Pharmacopoe aus einer Unze' frisch verfertigtem trocknen Aetzkali und zwey Pfunden Weinalcohol durch Digestion bereitet. Sie mufs, gut bereitet, eine gesättigt durkelrothe, ins Branne 'fallende, Farbe und einen feurig brennenden Geschmack baben, sich sowohl mit ätherischen als fetten Oelen leicht verbinden, und mit letztern eine füssig durchsichtige Seiła bilden. Die Gefäfse, worin sie aufhewahrt wird, den, nnd mit letztern eine flüssig durchsichtige Seife bilden. müsen genan verscblossen seyn, weil das Aetzhali sonst Koh za verbüten, dieser ätzeuden Tínctur einen scheidet. Auch ist es nöthig, dafs man,
besondern Platz in der Aporheke anweise.

besondern Platz in der Apotheke anweise. Ans Guajakhôlz nnd Weingeist bereitet. Hat eine branno
Tinctura Ligni Guajaci. Guajakholztinctur. Ans Farbe.

Tinclura Myrrkae. Nyrrbentinctur. Aus Myrrhe und Weinalcohol bereitet. Sie besitzt bey ciner hellbraunen Farbe ganz den eigonthümlichen Geruch und Géschmack der Myrrhe.

Tinctura Opii henzoica s. Elixir paresoricum. Benzoegesäuerte Opiumtinctur. Aus Opium, Benzoesä1re, Campher, ätherischen Anisöl und rectificirtem Weingeist bereitel. Sie hat eine lichțelbbräunliche Farbe und den vicht leicht $z \mathbf{z}$ verkeunenden vermischtisen Geruch und Geschmack der genannteu Ingrediẹnen. Eine Unze davon enthält das Auszngsiä́tige von drittehalb Graneu Opium.

Tinctura Opii crocata s. Laudanum liquidum Sydenhami. Opiuntinctur mit Safr'an. Aus Opium, - Sartran, Gewïrznelken, Zimmtcassia'und Maliagawein bereitet. Hat eine dunkelbraune, ins Goldgelbe

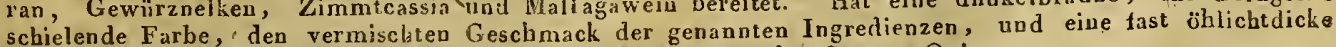
schielende Farbe,' den vermisclaten Geschmack der genannten Ingrenten Opinm.

Consistenz. Eine Drachme cnthält das Auszigstahige von zcha Graninn mit rectificirten Weiugeist uud

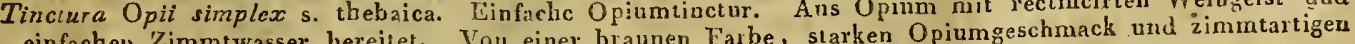
einfaches Zimmtwasser bereitet. Voul einer braunen Farbe, starken Opium

Geruch. Fine Drachme enthält das Auszngsfähigc von zehn Granen Opium,

Tinctura Pimpinellae. Pimpinellwwrzeltinctur. Aus Pimpiisellwurzeln und rectifirten Weingeist
Hat eine liclt fahlgelbe Farbe und deu eigenthümlichen Pimpinellwurzelgeruch und Gescbmack.

Hat eine licht fahlgelbe Farbe und deu eigenthümlichen Pimpinellwurzelgeruch und Gesclumack.

Tinctura Pini composita s. Liguorum. Zusammeugeset/te Kiefersprossentinctur. Aus Kiefersprossen, Gnajakholz, Sassafrashol, Wacholderbeeren mnd rectificirtern Weingeist bereitel. Hat eine braune the Farbs. 


\begin{tabular}{|c|c|c|c|}
\hline $\begin{array}{c}\text { Namen } \\
\text { er Arzneymitcel. }\end{array}$ & $\begin{array}{c}\text { Sinnliche Eigenfchaften derfelben; } \\
\text { Merkmale ihrer Ächtheit und } \\
\text { Güte. }\end{array}$ & $\left|\begin{array}{c}\text { Fehlerhafte } \text { Be- } \\
\text { fchaffenheit, Ver- } \\
\text { wechlelung oder } \\
\text { Verfülfciung. }\end{array}\right|$ & $\begin{array}{c}\text { Deren } \\
\text { Kennzeichen und Prüfungsmittel. }\end{array}$ \\
\hline
\end{tabular}

Tincturae. Tinclura Rhei aquosa. Wälsrige Rhabarbertinctur. Aus Rhaharber, kobleusarurem Kali und kochendem gemeinen Wasser bereitet. Sie hat eine undurchsichtig braunrothe Farbe, den eigenthümlichen Rhabarbergernch und Geschmack, schmeckt zugleich alkališch und brauset mit Sáuren auf. Da sie leich schimmelt nid verdirbe, so darf sie nicht auf zu lange Zeit in Vorrath herestet werden.

Tinctura Rhei vinosa. Weinichtc Rhabarbertinctur. Aus Rhabarher, Pommeranzenschalen, Cardamomen, Mallasawein, Alantextract und weifsen Zucker bereitet. Hat eine etwas dickliclie Consistenz, eine braune Farbe und den vermischten Geruch und Geschmack der genannteu lngredienzcn.

Tinctura Rosarum acidula. Säuerliche Rosentinctur. Aus gctrockneten Rosenblumenblättern mit kochendem I Wasser und etwas verdünnter. Schwefelsäure bereitet. Sic besitzt eine angenehme rothe Farbe und einen säuerlichen, schwaeh zusammenziehenden Geschmack.

Tinctura Succini. Bernsteintinctur. Aus'leicht geröstetem Bernstein mit höchst rectificirtem Weingeist bereitet. Eine gelhbräuslichte, seistig bernsteinartig riechende und scbmeckende, das Wasser milchicht machende Tinctur.

Tincura Succini aetherea. Aethorische Bernsteintinctur. Aus leicht geröstetem Bernstein mit Schwcfel-

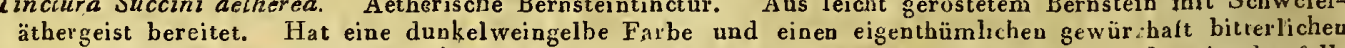
Geruch und Geschmack, den schon wenige Tropfen davon mehreren Unzen Wasser, das sie ebenfall weifslich trülst, mittbeilen.

Tinctura Valerianae acthèrea. Aetherische Baldriantinctur. Aus Baldrianwurzeln und Schwefeläthergeist bereitet. Mufs eine lichtbräunliche Farbe und einen starken Baldriangeruch und Geschmack hesitzen. Tinctura Valerianae ammoniala s. volatilis. Ammonisirte Baldriantiuctur. Aus Baldranwureln mit weinichter Ammoniumflüssigkett bereitet. Die gesåttigte und durchsichtige Tinctur lat einc hraune Farbe und einen nüchtigen Baldriangeruch uud muf́s in einem genau verstopften und- verbundenen Glase aufbewahrt werden.

Turiones Pini. Fichtenknospen. Kiefersprossen.

Unuuenia.

Saiben.
Die walzenförmigen, einen bis zwey Zoll langen, kaúm aufgeschlosseven zarten Spröfslinge, die sich an den Enden der Zweige von der gemeinen K i fer ( in ms s l I vestris L.) im Frïhjatr ansetzen, auswendig mit dünnen, rothbrắunlichen, lanzettartıgen Schuppen bedeckt, inwendig grun stud, sich hdrziclit und klebrig anfühlen, leicht zerbrechen lassen, und einen augenehmen, gewürzhafien Geruch uvd bittern balsamiscben Geschmack baben. Sie dïrfen nicht mit den Knospen der Kothtanue (Pinus Abıes L.), oder mit den juugen Zapfen und den jungen $Z$ weigen, den Verschlägen der Kiefer, verwechselt werden. Aeufserlıche Arzneymittel von einer butterlıficn Consistenz, deren Gruncllage gewöbolich aus fetten, ölichren und harzichten Theilen, z. B. aus Schmalz, Butter, Oel, Wachs, Tals, Harzen, Terpentin, naturlicheu Balsamen, den Lösungen dera Bleyo yde in fetten Oelen u. s. w. besteht, wozu denn nocis zuweilen manch andere Mittel, Gummiharze, Seife, Campher, 'pulserhafte Diuge, Quecksilher uud drssen Praparate, Bleymittel u. dgl. gesetzt werden. Sie sind von den Pflastern blos in finsicht ilurer Consisteuz'verschieden, weicher als diese und die Cerate, aber härter als ein Liniment. Man hereitet sie entwecler durclss Kochea oder durch blofse einfache Zusammenschmelzung odcr Mischung, Zu den erster'n gebören die aus, verschitoder durch bleyoxyden úd Oelen, oder aus Schmalz, Oel und frischeu Vegetahilien und Schleimeu gekochten

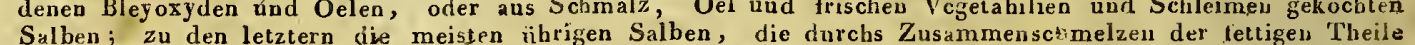
Sulben; zu den letztern die meisten ührigen Salben, die durchs Zusammensckmelzen der lettigen Theile
durch Hinzumischen der ührigen Mittel und bas zur Erkaltung mit einem bölzernen Agıtakel fortgesetztcs Unurühen zubereitet werden.

Gut bereitete Salben müssen die ihnen zukommende Farbe und den eigenthümlichen Geruch derjenigen Ingredienzen haben, aus welchen sie zusammengesctzt sind. Sie nüssen lie gehörige Consistenz besitzcn und weder zn hart noch zu weich seyn. Tbre Bestandheile müssen genan und gleichı̈rmig durcheinander. gemiscbt seyn; sie dürfen daher nicht körnicht seyn, und die dirin enthaltenen Pulver missen aufs feinste gepülvert seyn, so dafs mań überbaupt keine einzelue Gemengtheile dariu unterscheiden kann." Auch dirfen sie nicht ranzicht seyn, keine fremdartige Theile enthaltcn, und von denen, die nicht häutig gebraucht werden, keine zu grofsen Quantitäten in Vorrath bereitet werden. $O b$ inbrigens eine Salhe genau nach ier Dispensatorialvorschrift verfertigt worden sey, lï st sich bey den meliresteu durch Vergleicuung mit einer Dispensatorialvorschrift verfertigt worden sey, litst sica bey den meliresteu durch Vergleicuung mit einer
ächt bereiteten nach Geruch, Ansehn und Gefühl erkennen, bey einigen aber auch noch auf audere Weise ächt bereiteten.nach Geruch, Ansehn und Gefühl erkennen, bey einigen aber auch noch aut audere Weise
näher bestimmen. Von den vielen sonst vorrathig gehaltenen, meisteus aber überlässigen Salben, bat die Preufsische Pharmacopoe folgende aufgenommen.

Unguenium Alchaeae. Altheesalbe. Aus einem mit kochendem Wasser crtaltenen Schleime von Altheewurzeln und Bockshornsaamen, mit Schweinefett uud gepülverten Curcumawurzelu durch gelindes Kocben bis zur Verdunstung der Feuchtigkeit und nachheriger Zusammenschmelzung der durchgeprefsten Fettigkeit mit hinzugesctztem gelben Wachs und Fichtenharz bereitet. Mufs eine schüne gelbe Farbe besitzen, eine gleichförmige und nicht krimelige Besclaffeubeit, wie es oft der Fall ist, haben.

Unguentum basilicun. Basilicnmsalbe. Aus Baumöl, Wachs, Gcigenharz, Hammeltalg und Terpentin durch Zusammenschmelzen bereitet. Eine'bräunlichte Salbe, deren Farhe sonst auch wohl, da iu jedem A pothekerbuche dazu die Ingredienzen nnd deren Verbältnisse verschieden angegeben sind, von der blalsApothekerbuche dazu die Ingredienzen nnd deren

gelhen bis zur schwarzbraunen abweicbend ausfallt.
Unguentum Cantharidum s. irritans. Cantharideusalbe. Wird nach der Preufsischen Pharmacopoe, und Unguentum Cantharidum s. irritans. Cantharideusalbe. Wird nach der Preufsischen Pharmacopoe, und
zwar nach der zweyten Ausgabe, dadurch berestet, dafs man zwey Unzen gestofsene Spanische Fliegeu zwar nach der zweyten Ausgabe, dadurch berettet, dafs man zwey Unzen gestofsene Spanische Fliegen mit acht Unzen Mandelöhl sechs bis acht Stunden digeriren lafst, und die Colatur mit vier Unzen
weifsen Wachs zusammenschnelzt. .Nach der ersten Ausgabe warde Bamöl und gelbes Wachs dazu Weifsen Wachs zusammenscbmelzt. Nach der ersten Ausgabe wurde Baumöl und gelbes Wachs dazu
vorgesclurieben. Im letztern Falle bat die Salhe cine schmutaig lichigelhgrüne, im erstern aber eine hellere, ziemlich weifsliche Farbe. Nach andern Dispeusatorien hereitet man eine ăboliche Salbe aus Digestiv - oder Basilicumsalbe mil gepulverten spanischen Fliegen, wohey man daranf zu seben hat, dafs dieselbe eine gelı̈rige'Menge grüngläncender Theile von den Spanischen Fliegen euthalte. Ungreencum cereum. Wachssalbe. Aus Baumöl und weifsen Wachs durch Zusammeuscimelzen bereitet. Hat eine weifsluche "Farbe.

Unguentum Cerussae s. album simplex. Bleyweifssalbe. Aus Schweineschmalz und Hammeltalg, denen nach der Zusammenschmelzung anfs feinste gepülverter Bleyweifs durch fortgesetztes Agitircn zugemischt nach der Zusammenschmelzung ans feinste gepuñ und der Bleyweils aufs feinste darunter verthcilt seju. wird, bercitet. Mufs cine sebr weifse Farbe haben und der Bleyweils aufs feinste darunter verthcilt seyu.
Unguencum Cerussae camphoralum. Bleyweifsalbe mit Campher. Zu cinem Plunde der einfachen Unguencum Cerussae camphoralum. Bleyweifssalbe mit Campher. Zu cinem Plunde der einfachen
Bleyweifssalbe wird eine halbe Uize Campber gemischt. Mlufs ebenfalls seht weils seyn und nach Cainpher riechen.

Unguentum Elemi s. Balsanım Arcaei. Elemiharzsalbe. Bestebt nach der. Preufsischen Plarmacopoe aus Elemharz, venedischen Terpertin, Hammeltalg und Schweineschmalz, von welchcn śleiche Theile hey schwachen Feuer zusamm ngeschmolzen und die Mischung noch warm durch Leinewaud geseihet wird. Die Salbe hat eine weifogelbliche Farbe und angeuehmen Harzgeruch. Nach andern Dispensatorien kommt etwas Sandelholz oder Alcannawtrzel hiuzu, wodurch die Salbe eine melir oder weniger rothe Farbe belḱrmint.

Unguenıum Hydrargyri cinereum s. neapjolitanum. Aschgraue Quecksilbersalbe. Zwälf Unzen Quccksilhex: werden mit achit Unzen Ilammeltalo bis zur vollhommen. Tödtung oder Oxyinlation des Quecksilbers gerieben uad dann noch sechszchn Unzen Schweiuefett hinzugemischt. Dio fertigo Salbe bat eine grau- 
Unguenta. - Vinum gallicum.

\begin{tabular}{|c|c|c|c|}
\hline $\begin{array}{c}\text { Namen } \\
\text { aler Arzneymittel. }\end{array}$ & $\begin{array}{c}\text { Sinnliche Eigenfchaften derfelben; } \\
\text { Merkmale ihrer Aechtheit und } \\
\text { Giice. }\end{array}$ & $\left|\begin{array}{c}\text { Fehlerhafte } \\
\text { Schaffenheic, } \\
\text { wech Velung oder } \\
\text { Verfälfchung. }\end{array}\right|$ & $\begin{array}{c}\text { Deren } \\
\text { Kennzeichen und Priifungsmittel. }\end{array}$ \\
\hline
\end{tabular}

Unguenta. - blaue Farbe. Weun sie gut bereitet ist, so mufs man weder mit blofsen Augen nocb mit einem Mi-
croscop Quecksilberkïgelchen darin unterscheiden können. Zuweilen ist das Quecksilber nicbt fein genug zerrieben, der $S$ albe aber durcb zugemiscbten Kienrufs die nöthige Farbe gereben; zuweelen enthält die Salbc auch nicht die gehörige Neuge des vorgescbriebenen Quecksilbers. Man lasse daber etwas von del Salbe in gelinder Wärme tüssig werden, wodurch das Quecksilber vermöge seiner Schwere zu Boden fallen wird, und das Gewicht desselben in einer gegebenen Quantität der Salbe sich berechnen lifst. Ist das Quecksilber nicbt so fein zerrieben, als es seyn sollte, so werden dieses die erscbeinenden Quecksilberkïgelchen, wenu man etwas von der Salhe auf der Haud verreibt, entdecken lassen.

Unguentum Hydratgyri citrinum s. Balsamum mercuriale. Gelbe Quecksilbersalbe. Aus einer warm bereiteten Aufösung von einer Unze Quechsilber in Salpetersäure und zwölf Unzen zerlassenen Schweinefett bercitet. Eine lichtrvachsgelbe, steife Salbe, die gewöbulicb in Papicrcapseln noch flüssig gegossen wird und nach der Erkaltung gegen die Einwirkung des Lichts geschützt, wovon sie grau wird, am besten in einer verbundeuen steinzengnen Bücbse an einem kühlen Orte aufbewabrt werden mufs.

in einer verbundeden steinzention Angeusalbe. Wird nach der Prenfsischen Plarmacopoe aus einer balben Un7e aufs feinste zerriebenem rothein Quecksilberoxyd und Preulsiscben Phariuacopoe aus eicer Die Salbe mufs.aufs innigste gemischt seyn, eine ziegelrothe gleichfünf Unzen Rosenpomade bereitet. Die Salbe muls.aufs innigste gemischt se Orte gegen den Einflifs der förnige Farbe haben und in woblverwabrten Gefäfscn an einem kuhlen Orte gegen den Einflifs der
Luft und des Lichts, wovon sie grau wird, gesichert, aufbewahrt werden. Auch mufs sie bey sparsamern Gebrauch nicbt in zu grofser. Menge vorrathig gebalten wcrdcn.

Unguentum Linariae. Leinkrautsalbe. Aus zerstofsenem frischen blühenden Leinkraut und Scbweinefett durch Kochen ïber gelindem Feuer bis zur Verdustung der Wälsrigkcit und nachberiger Auspressung bereitet. Die erkaltete Salhe hat einc licbtgelblichgrüne Farbe.

Unguentum Majoranae s. Butyrum Majoranae. Mayransalbe. Aus frischem Mayrankraute und Schweinefett, wie die Leinkrautsalbe bereitet. Hat eine grüue Farbe und einen schwachen Mayrangerucb.

Unguentum Rorismarini compositum s. nervinur. Zusammengesetate Rosmarinsalbe. Aus frischern Rosmarinkraut, Mayran, Gartenraute, Lorbeeren und Bertramwurzeln mit Schweiuefett und Hammeltalg bis Inarinkrall, zur Verdunstung der. Wars eine bränrlichgelbo wachs und ganz zuletzt Rosmarin - und Wacbolderob hinzugemiscb werdomenen Ingredienzen haben, und in eines und den vermischten stark aromatiscbell Geruch der dazu genommenen

mit Blase und Wachspapier fest verbundenen Büchse aufbewabrt werdcn.
Unguentum rosatum s. pomadinum. Rosensalbe. Aus Schweinefett und weifsen Wachs mit etwas zugesetztem und darunter agitirien Rosenwasser und Citronenöl bercitet. Muls sehr weifs seyn und einen angenelımen Geruch besitzen.

Unguentum Saturninum s. Ceratnm Saturni. Bleysalbe. Durcb Zusammenschmelzen von Baumöl und weifsen Wachs, womit nachler nocb Bleyessig und Rosenwasser durcb fleifsiges Agitiren in Verbindung gebracht werden, bereitet. Hat eine mittelmärsig steife Cousistenz, eine ziemlich weifse Farbe und einen eigenartigen Geruch. Da diese Salbe leicbt ranzig wird, so mufs davou nicbt zu viel in Vorrath gemacht werden.

gemacht werden. '
Unguentum sulphuratum s. ad Scabiem. Schwefelsalbe. Aus gercinigtem Schwefel, schwefelsauren Zink,

Unguentum sulphuratum s. ad Scabiem. Schwefelsalhe. Aus gercinigtem Schwefel, scbwefts
Lorbeeröl und Schweinefett durch blofsc Mischung bereitet. Hat eine grügelblicbe Farbe.

Unguentum Terebinthinae s. digestivam. Terpentbinsabe. Aus veuedisclien Terpenthin, Rosenhonig, JaUnğzentum Terebinthinae s. digestivam. Terpentbinsalbe. Aus veuedisclien Tespenthin, Rosenhonig, Jo-
hannisöl und gepulverter Aloe durch genaue Untereinandermiscbung bereitet. Eiue gelbrothbrännliche hannisöl und gepulverter Aloe durch genaue Unteleinandermiscbung hereitet. Eiue gelbrothbräent

Unguentum Zinci s. de Nihilo albo. Zinksalbe. Aus weilsen Ziukoxyde und Wachssalbe (Ungueut. cereum) durch genaue Miscbung bereitet. Mnfs eine sehr weifse Farbe haben.

Vinum gallicum. Franzwein.

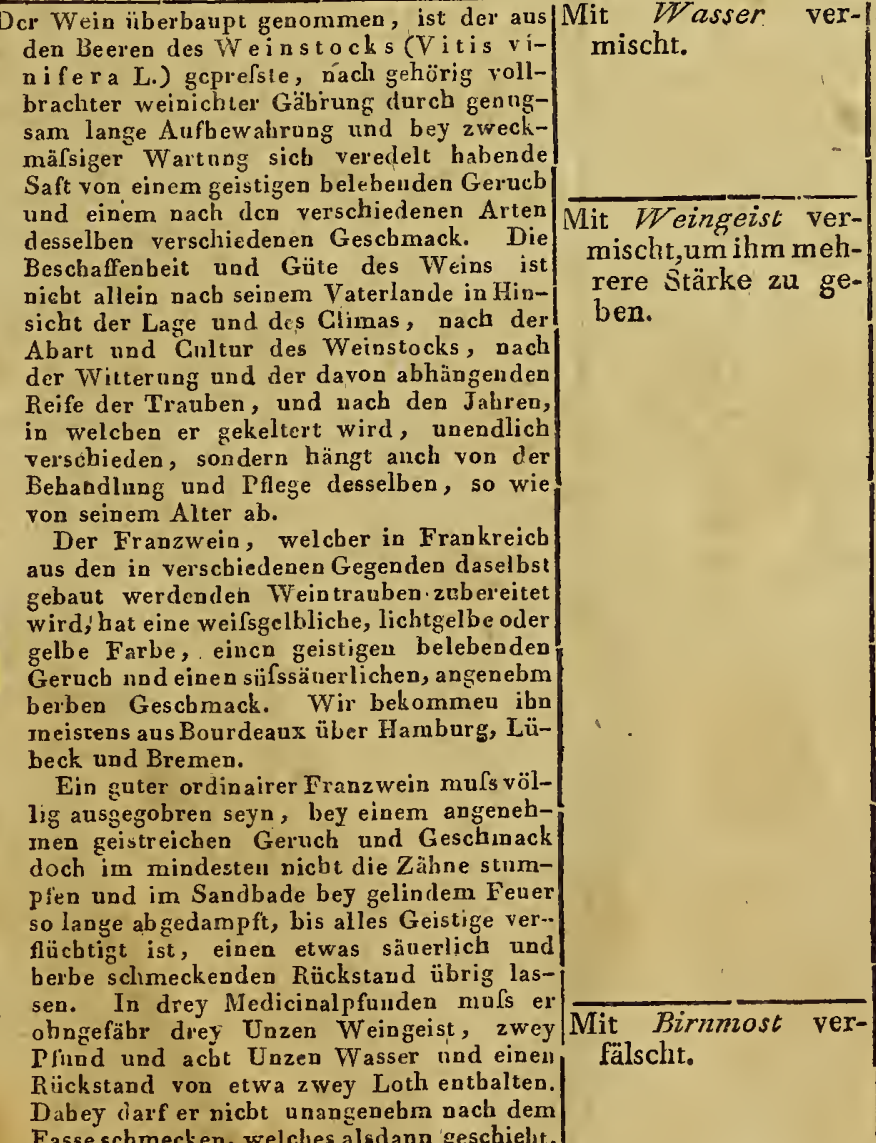

Dabey ciarf er nicbt unangemebm nach dem

Fasse scbmecken, welches alsdann geschielit, reichen Gerucb und Geschmack zu eutdecken. Aufserdem soll sich ein solcher Wein an ein mit Oel bcstrichenes Rohr oder Siroubalm anbangen, den lebendigen Kalk löschen, und weun man kocbendes Baumöl darin giefst, spritzeln.

in solcher Wein ist sebr berauschend, pfleg gerne Kopfschmerzen zu crregen und läfst immer deu eigenthümlichen Branntweinoder Weingeistgeruch deatlich bemerken. Docb ist eine solcbe Verfälschung, wenn die Zusammenmiscbung vor langer Zeit geschah uud die Verbindung der beyden
Flüssigheiten inuiger gcworden ist, durch Flüssigkeiten inniger gcworden ist, durch
chemiscbe Mittel kaum zu entdecken. Man chemiscbe Mittel kaum zu entdecken. Man
behauptete sonst, dafs der dem ächten Weine eigenthümliche Weingeist bey der Destillation des Wcins er'st bey der Siedehitce des Wassers $\left(212^{\circ} \mathrm{Fabr}\right.$.) aufsteige der dem Weine zugemischte Weingeist aber weil seiue Vereiniguug niemals so inn folse, schon bey einer ins tze (270 bis $205^{\circ} \mathrm{F}$ ) als derigern $\mathrm{Hi}$ tes ( $170^{\circ}$ bis $25^{\circ}$ Fahr.) als der Siedpunct des Wassers, ibergebe als der Siedpournal der Pharmacie, B, 16. St. 1.) zcigte aber durch deshalb angestcllte Versuche, dafs diese Prüfungsmethoule wcnigstens nicht bey alleu Weinen an dürfte, indem er an fünfjährigen Pfalzer. and Rheinweinen fand, lafs schon bey einer Destillation ans dem Wasserbade, worin die Hitze nie $167^{\circ}$ Falur. erreicbte, ein Flüssigkeit übergieng, die ibrem specifischen Gewicbte nach einen grofsen Theil Alcobol enthielt.

Wird theils durch den eigentbumlichen Ge schmack, theils durch das grölsere specifische Gewiclut eines solchen Weins erkannt. Noch bestimmter erfährt man es, wenu man eine Quantităt des Weins in gläsernen 


\begin{tabular}{|c|c|c|}
\hline $\begin{array}{c}\text { Namen } \\
\text { der Arzn eymittel. }\end{array}$ & $\left|\begin{array}{c}\text { Sunnliche Eigenfchaften derfellen } \\
\text { Merkmale ihrer Aechtheit und } \\
\text { Güte. }\end{array}\right|$ & $\begin{array}{c}\text { Fehlerhafte Be- } \\
\text { fchaffenheit, Ver- } \\
\text { wechfelung oder } \\
\text { Verfälfchung. }\end{array} \mid$ \\
\hline Pinum gallicum. & $\begin{array}{l}\text { wenn er auf ein nicht hinreicheud gerei- } \\
\text { nigtes Fafs gefüllt, oder dasselbe nicht ge- } \\
\text { börig verspündet worden. } \\
\text { Die Weine zum Arzneygebraucb müssen } \\
\text { vorzüglich rein, von bester Güte und von } \\
\text { allen fremden Beymischnngen frey seyn. } \\
\text { Eine geübte Zunge ist zwar das bcste Mit- } \\
\text { tel, die Güte des Weins zu erforscben; in- } \\
\text { dessen wird auch diese dnrch die geheimen }\end{array}$ & \\
\hline i & $\begin{array}{l}\text { Künsteleyen der Weinhändler nicht selten } \\
\text { betrogen. Oefters werden die Weine mit } \\
\text { Fleifs, zuweilen aber aucb zufällig, bald } \\
\text { mit unschuldigen, bald mit schädlichen Din- } \\
\text { gen vermiscbt nnd verunreinigt. }\end{array}$ & $\begin{array}{l}\text { Mit Alcalien ver- } \\
\text { fälscht, um den Wei- } \\
\text { nen ihren sauren } \\
\text { Geschmack zu neh- } \\
\text { men, oder säuerlich } \\
\text { werdende Weine }\end{array}$ \\
\hline
\end{tabular}

\section{Mit absorbirenden Erden, Kreide oder Kalk, in gleicher Absicht verfälscht.}

Zu stark.geschwefelt.

Mit metallischenTheilen verunreinigt, besonders mit Bleyoxyden vergiftet.

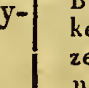

kelbrauin, den Spiefsg la $\mathrm{n} z$ pom dus

zenfan, den Spiefsglanz pommeranniederschlägt. Wenn die Farbe dcs Weins durch diese Probetiüssigkeit nicht verändert wird, so enthäl er gar kein Metal oder höchstens Eisen,- welches missels Galläpfeltinctur durch die schwärzliche oder purpurfarbne, und initlelst blausaurem Kali durch die blaue Trübun erkaunt rem Kali durch die blaud Tribung erkant wird. Aufserem we die angefinhte Weiuprobe die Gegenwart eines Metalles entdeckt ist, das Daseyn des Bleycs durch einen weifsen Bodensat auf zugernischter Schwefel- und Salzsäure, das $K$ u p f e $r$ durch eincn braunrothen Niederschlag mit der Blutlauge, so wie durch den Kupferiberzug eines darin gelegten polirten Lisens odel eiues Stückcben Pbosphors, und durch die blaue Farbe der über die Asche des abgedampften und verbrannten Weins gestandenen Amrnoniumflissigkeit, mit mehrerer Gewifsheit erforscht.

erforscht. Ein mit ätzendem Quecksilbcr-
sublimat vergifteter Wein wird durch zugesetzte Blutlauge ganz weifs tribe, uud zugesetzte Blutlauge ganz weifs trube, uud giebt mit Kalk wasser einen pommeranzenfarbenen Nicderschlag. Eubielte dcr Wcin kann, weun er mit arsenikbalitgen Schwefel gesebwefelt wird, so würle die Kilpferammoniumauflösung einen gelbgriinen, 'setrocknet nach der Erhitzong knoblauchartig riechenden Niederschlag bcwirken. 
Vinum hispanicum. -- Zibethum.

\begin{tabular}{|c|c|c|c|}
\hline $\begin{array}{c}\text { Namen } \\
\text { der Arzneymittel. }\end{array}$ & $\begin{array}{c}\text { Sinnliche Eigenfchaften derfelben; } \\
\text { Merkmale, } \text { ihrer Ächtheit und } \\
\text { Giite. }\end{array}$ & $\left|\begin{array}{c}\text { Fehlerhafie Be- } \\
\text { rchaffenheit, Ver- } \\
\text { wechselung oder } \\
\text { Verfälfchung. }\end{array}\right|$ & $\begin{array}{c}\text { Deren } \\
\text { Kennzeichen und Prïfungsmitcel. }\end{array}$ \\
\hline $\begin{array}{l}\text { Tinum lispani- } \\
\text { cum. } \\
\text { spaniscluer Wein. }\end{array}$ & $\begin{array}{l}\text { Ein heller, durchsichtiger Wein von einem } \\
\text { angenehm siifsesil, geistigen Geschmack und } \\
\text { gelher Farbe. Er konmmt aus Spanien, be- } \\
\text { sonders aus der Gegeud von Valeucia, Gra- } \\
\text { nada u, s. w. }\end{array}$ & $\begin{array}{l}\text { Mit Zucker, Syrup } \\
\text { oder Honig ver- } \\
\text { fälscht und erkün- } \\
\text { stelt. }\end{array}$ & $\begin{array}{l}\text { Man erkennt dies, wenn er die Flasche be- } \\
\text { schlägt, wenn er abgedampft einen trock- } \\
\text { nen zuckerhaften Rückstand giebt, und } \\
\text { wenn man ein kleines enghalsigcs Glas, } \\
\text { welches mit dem verdächtigen WWeine ange- } \\
\text { fullt ist, umgetehrt in ein Glas voll rei- } \\
\text { nem Wasser hält, das Wasser alsdann ei- } \\
\text { nen süfsen Geschmack antimmt. }\end{array}$ \\
\hline $\begin{array}{l}\text { Tinum malacense. } \\
\text { Mallagawein. }\end{array}$ & $\begin{array}{l}\text { Hat eine gesättiğ gelhröthliche Farbe und } \\
\text { einen geistigen, süfsen, hintenach wie ein } \\
\text { wenig. bitterlichen Geschmack. Kömmt } \\
\text { von der Insel Morea, Candia und Gre- } \\
\text { nada. }\end{array}$ & $\begin{array}{l}\text { Nachgekünstelt aus } \\
\text { Zucker, Brannt- } \\
\text { wein und einigen } \\
\text { Gewürzen. }\end{array}$ & $\begin{array}{l}\text { Liefert bey der Destillation einen aromatisck' } \\
\text { riechenden und schmeckenden Spiritus, } \\
\text { und binterläfst' einen extractartigen Riück- } \\
\text { stand. }\end{array}$ \\
\hline
\end{tabular}

$\overline{\text { Vinturl }}$ mariia-

Aus Eisenfeile, Zimmtcassia und Rbeinwein durch gelinde Digestion bereitet. Hat einen vermischten Zimmt-

Vinum chalybeaund Eisengeschmack und eine schwärzliche Farbe.

tum.

Eisenwein.

Stahlwein.

Vinum rluenanum.

Kheinwein.

\section{Vinum rubrum. \\ Vinum gallicum}

Rother Franzwein.

Rother Franzwein.
Ein gelblicher, durchsichtiger Wein von et- Bleyhaltig.
was sauerlichem Geschinack, der sus den was säuerlichem Geschmack, der :us den
an den Ufern des Rheins wachsenden Trauben gekeltert wird.

Ein

in duukelrother Franzwein von geistigem angenebin herben, etwas zusammenziehenden Geschrack, der seine Farbe eigentlich dem Pigmente, welches sich in der Schale
der Beeren befindet, verdankt und folglich nur von rothen Weintrauben gewonuen werden kann- Es gehören hierber der $\mathrm{Ca}$ horswein, der Pontak und der Me dok.
Mit Heidelbeeren, Entdeckt sich beym gänzlichen Abzapfen des Hollunderbeeren, Weins durch den im Fasse befindlicben Campeschenholz, Rückstand von Heidelbeerkernen, den SpuFernambuckholz ren der färbenden Hölzer u. s. w., so wi durch den dicbten Beschlag der Bonteillen, u. dgl. gefärbt. worauf der Wein gefüllt ist, und durch den gefärbten Rüclistand beym Durchseiben.

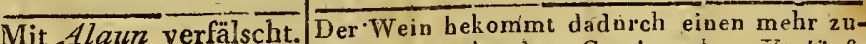
sammenziebenden Geschmack. Vorläufig sammenziebenden Geschmack. Vorläufig entdeckt man diese Verfalschung durcb den wenu mau etwas Kaliauflösung oder ätzende Ammonitumflüssigkeit hinzutröpfelt. Gewisser erfährt man sie, wenn man den Wein bis etwa zum vierten Theil abdampft und init Alcohol vermischt in einem Glase und mit Alcolöfst, durch Auschiefsung der eigcntbïmlichen Alauncrystallen.
Vinum stibialnun. Vinum emeticum. Aqua benedicta Rulandi.

Spiefsglanzwein.

Viscrsm album.

Lignum Visci quercini.

Weifse Mistel.

Eichenmistel.

\section{Zibethum}

Zibeth.
Aus

As vier bereitet. Er hat die Farbe des Mallagawcins, mufs aber dabey durchaus helle seyn nud weder auf dem Boden des Gefáfses noch an den Seiten desselben Crystalle angesetzt haben. Von der Gegenwart des darin enthaltenen oxydulirten Spiefsglanzes üherseugt Crystalle angesetzt haben. Fy drothionsaure Flüssigkeit hirzutröpfelt, wodurch ein pommeranzenfarbener Niederschlag bervorgebracht wird. Uebrigens darf der Spiefsglanzwein doch nicht auf zu lange Zeit in Vorrath bereitet werden, weil er mit der Zeit seinen Grebalt an Spiefsglanzoxydal fallen läfst und dadurch in Hinsicbt seiner Wirksamkeit eine Abändernng erleidet.

Die ziemlich dicken, festen, schweren, knotichten, frisch mit einer dunkelgrünen, getrocknet aber dunkelgranen oder gelbbräunlichten Rinde bekleideten holzichten Stengel oder Zweige mit deul lanzetı)örmigen, stumpfen, lederartigen Blätteru des Eicbenmistels (Viscum alb n m L.), eines in die Rinde uud das Holz vieler Bäume, aber nicbt in die Erde.wurzelnden, immergrüuen Schmarotzerstranchs. Im frischen Zustande haben sie einen eckelbaften, Larzichten Geruch ind etwas zusammenziehenden Gescbmack. Durch das Trocknen vergeht der Geruch und der Gescbmack wird bitterlich, etwas zusammenziehend. Man sammlet rien Mistel, dessen frische Riude, vorzüglich aber die Beeren, eine grofse Menge Leim enthalten und daher zur Bereitung des Vogelleims (Viscus a cuparius) dienen, im December, und hebt das gleich nach dem Trocknen davon zu bereitende Pulver in fest verstopften Gläsern auf. Der au den Eichbäumen wachsende Misteliist von
jeber zum Arzneygebrauch, vorgezogen worden.

Eine dickliche, salbenähnliche, schäumige,/Verfälscht und nach-/Eio so theures Mittel, als der Zibeth ist, vo

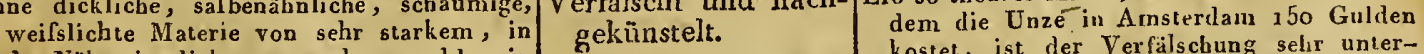
weifslichte Materie von sehr starkem, in gekünstelt. der Nähe ziemlich unangenehmen, blos in der Entfernung lieblichen, lange hägen bleibendem, dem Ambra etwas ähnlicben Geruch und bitterlichem, scharfen Geschmacke, die aus einer drittebalb Zoll langen Ritze mit hervorrageuden Ränder'n, der Oeffnnng eiues bühuereydicken, drüsichten Beutels gewonnen wird, welche 2 wischen den Zeugungstheilen und dem Af$t \in r$ sowohl des mäunlichen als weiblichen Zibetthiers (Viverra Zibetba L.) liect, das in Arabien, , Malabar, Siam und anf den philippinischen Inseln einheimisch ist, zu Cairo und Amsterdam abor zur Geist, zu Cairo wisto winnung des Zibeths in eisernen Käfigen eingesperrt, sorgfaltig genahrt, und der Zibeth die Woche 2 wey - bis dreymal mit einem kleinen Löffelchen aus der angeführ-
ten Oeffnung herausgenommen wird. Durch kostet, ist der Verfälschung selır unterworfen. Man vermischt ihn mit ranzigem. ibn aus Muscatennufsöl, Fett, Moschus, Bocksblut u. dgl. nach. Ein solcher nachgekünstelter Zibeth ist durch Vergleichurg mit den angegebenen Merkmalen seiner ächten Beschalfenheit bald zu erkennen. 


\begin{tabular}{|c|c|c|c|c|}
\hline $\begin{array}{l}\text { Nam } \\
\text { der Arzne }\end{array}$ & yen & $\begin{array}{c}\text { Sinnliche Eigenfchaften derfelben } \\
\text { Merkmale ihrer Aechtheit und } \\
\text { Güte. }\end{array}$ & $\begin{array}{c}\text { Fehlerhafte Be- } \\
\text { Schaffenheit, Ver- } \\
\text { wechfelung oder } \\
\text { Verfälfchung. }\end{array}$ & $\begin{array}{c}\text { Deren } \\
\text { Kennzeichen und Prüfungsmittel: }\end{array}$ \\
\hline Zibethum. & & $\begin{array}{l}\text { längeres Aufbewahren wird der Ziheth äu- } \\
\text { fserlich mnd innerlich gelblich oder bräun- } \\
\text { licb. Guter aufichtiger-Ziheth mufs eine } \\
\text { gleichförmige Beschaffenheit haben, ohne } \\
\text { undurchsichtige Theile und dickliche } \\
\text { Klïmpchen seyn, sich gleichförmig auf } \\
\text { Papier ausbreiten lassen, ans Lichr gehal- } \\
\text { ten keinen andern Geruch als den des Zn- } \\
\text { beths ron sich geben, sich dann entzünden } \\
\text { und splitzeln, beym Verlöschen aher blos } \\
\text { wie versengte Haai e viechen. }\end{array}$ & & . \\
\hline $\begin{array}{l}\text { Zincum, } \\
\text { Zink. }\end{array}$ & & $\begin{array}{l}\text { Ist bis jetzt noch nicht gediegen in der Na- } \\
\text { tur angetroffen, sondern kommt theils oxy- } \\
\text { dirt als Gallmey, theils miueralisirt und } \\
\text { mit Eisen oder Schwefel verbunden in den } \\
\text { eigentlichen Zinkminern oder Blenden vor, } \\
\text { woraus er durch eille Art lateraler Destil- } \\
\text { lation gewonncn wird. Der reine metalli- } \\
\text { sche Zink ist ein weifshläuliches, zähes, }\end{array}$ & $\begin{array}{l}\text { Mit Zinn versetzt und } \\
\text { verfälscht. }\end{array}$ & $\begin{array}{l}\text { Hat ein viel matteres Ansehn als gewöhnlich } \\
\text { und ist im Brucbe rauh nud unebell, aber } \\
\text { nicht blättricbt. Er liefert nur wenig Zink- } \\
\text { blumen, dagegen aber eine Menge graues } \\
\text { Zinkoxyd. Set } 2 t \text { man ihn in einem ver- } \\
\text { schlossenen Gefäfse einer hinreichenden } \\
\text { Hitze aus, so sublimirt sich der Zink in } \\
\text { die Höhe, das Zinn aber bleibt znrück. }\end{array}$ \\
\hline & & 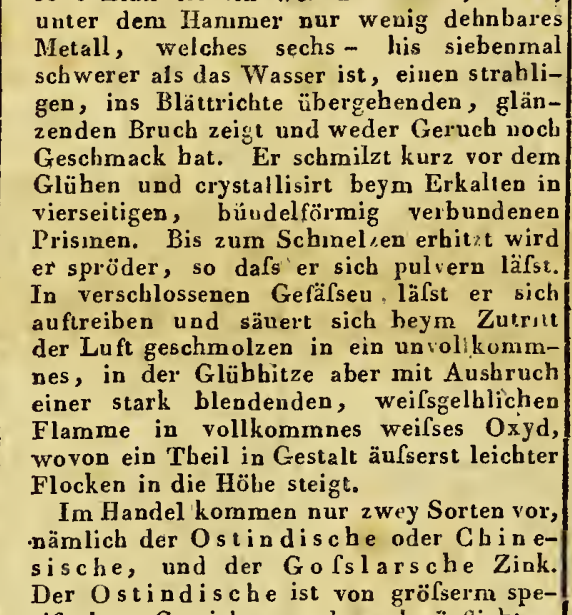 & $\begin{array}{c}\text { Mit Bley und Eisen } \\
\text { verunreinigt. }\end{array}$ & 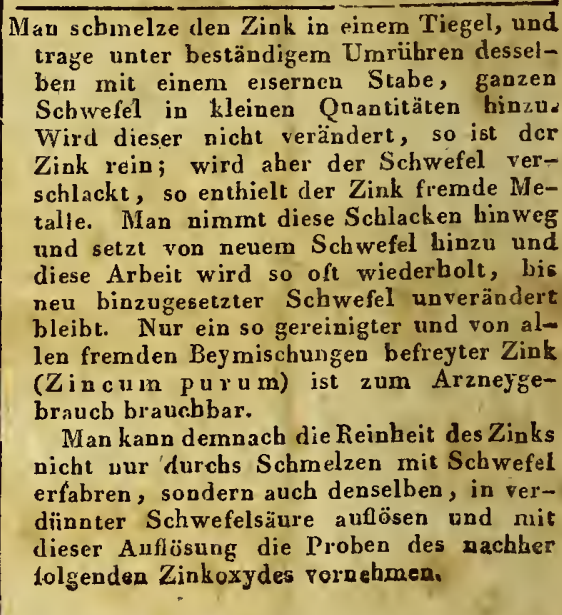 \\
\hline
\end{tabular}
seyn sollte, ihn zuvor davon reinigen mufs. album.

Flores Zinci.

Weifses Zinkoxyd.

Zinkblumen. der Preufsischen Pharmacopoe dadurch lieder Preufsischen Pharmacopoe dadurch liereitet wird, dafs man eine beliebige Menge
reinen schwefelsauren $Z$ ink in zelnmal so reinen schwefelsauren Zink in zelanmal so
vielem kocbenden Wasser auflöset, die
Der Ostindische ist von gröfserm specifischen Gewichre und grobwürflichtem Brucle, kommt in länglich viereckigen
Blöcken von achtzehn bis zwanzig, auch vierzig $P$ fund Schwere zu uns und wird für den reinsten gebalten. Der G of s l a r s che Zink, welcher als Nebenproduct beym Schmelizen des Rammelsberger Erzes gewonnen wird, ist specifisch leicliter, von strahlicht blättrichtem Bruche, und kömmt im Handel in drey bis acht Pfund schwcren, mit dem Braunschweigischen Pferde cen goll me Oejer und wenu auch dieser nicht von fremden metallischen Beymischungen völlig frey Auflösung filtrirt und mit im Wasser gelösten kohlensauren Natrum fället, den erhaltenen weifsen, vollhommen ausgewaschenen und getrockneten Niederschlag aber, um dic Kohlensäure daraus zu entferncn, eine Viertelstunde lang in einem bedeckten 'Tiegel gilühet, und ibn dann in bedeckten 'Tiegel givet, ufhebt.

Nach der ältern Methode bereitet man die Zinkblumen, wenn man den in eiucrn Tiegel geschmolzenen ostimlischen Zink, naciodem das Feller verstärkt worden, mis einem langgestielten eisernen Spatel nur etwas an der Oberfläche berührt, worauf sich durch den Zutritt der Luft der geschmolzene Ziuk eutründet und mit einer hellen weifsgrlben Flamme brennt, die sich in einem weifsen Raucb verwandelt und au den Seiten des 'Tiegcls cin flockiges, trocknes, weifses Oxyd bildet, welches man nes, wilses Oxy liket, welces ma Metallplatte legt. Man wiederbolt dies so ach der erstern $\mathrm{Me}$ thode bereitet, aber nicht geglühet.

Mit metallischenZinktheilen verunreinigt $_{i}$

Mit Bleyoxyd verunreinigt, wenn das Zinkoxyd aus Goslarischem Zink bereitet wurde.

Mit Eisenoxyd verunreinigt. rauset mit Säuren aur. -- Ist das nach àieser Methode bereitete Zinkoxyd nicht gehörig ausuesüfst, so hat es einen bitterlicb salzigen Geschmack.

Dies kann der Fall bey dem wach der ältera Methode bereiteten Zinkoxyde seyn. Es hat alsdann ein grauweifses Ausehen und schlemmen $m i t$ Wasser uberzengt $m$ an sich gewisser davon.

Theilt dem darauf gegossenen Essig eınen süfsen Geschmack mit, und hat eine graugelbe Fabe, Noch mèbr übcrzeug man sich von dem Bleygehalte, wenn beym Lösen des Oxyds in verdïnter Schwefelsäure sen des Oxy in verdun ela weirser Satz and Boden liegen bleibt, oder wens eine gesaligte salpetersaure Aurlosung des Oxyds mit zugesetriter Schwefelsaure orler einem schwefeloauren Salze, oder anch mit Kochsalzanflösung, eive weifsen Niedcrschlag gicbt, der dann, wis jener schwefelsaures, und von letzterer salzsaures Bley ist.

Das geghühete Zinkoxyd wird alsdann nach und die Aufösung desselben in Salpeterdeck vollig weils, 


\begin{tabular}{|c|c|c|c|}
\hline $\begin{array}{c}\text { Namen } \\
\text { der Arzneymitcel. }\end{array}$ & $\begin{array}{c}\text { Sinnliche Eigenfchaften derfelben; } \\
\text { Merkmale ihrer Ächtheit und } \\
\text { Güte. }\end{array}$ & $\left|\begin{array}{cc}\text { Felilerhafie } & \text { Be- } \\
\text { fcliaffenhcit, } & \text { Ver- } \\
\text { weclifelung oder } \\
\text { Verfälfcluung. }\end{array}\right|$ & $\begin{array}{c}\text { Deren } \\
\text { Kennzeichen und Prüfungsmitcel. }\end{array}$ \\
\hline \multirow[t]{3}{*}{$\begin{array}{l}\text { Zincum oxyda- } \\
\text { tum album. }\end{array}$} & \multirow{3}{*}{ 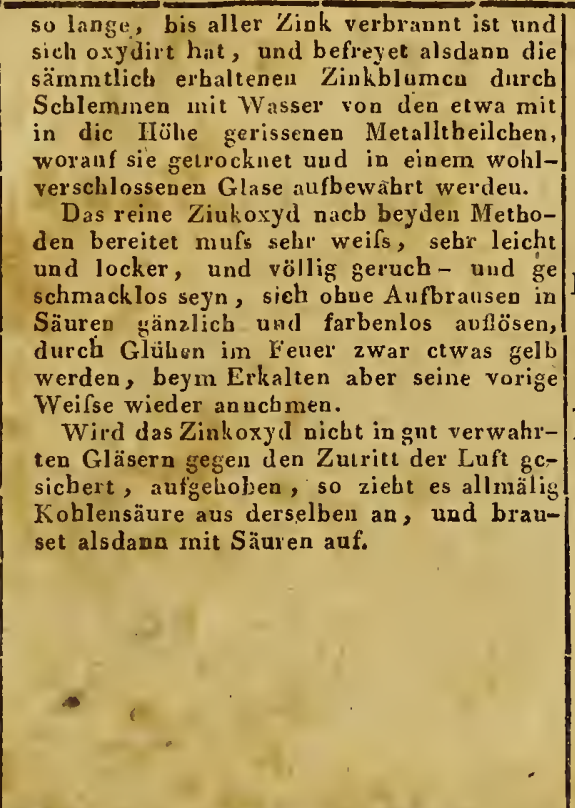 } & 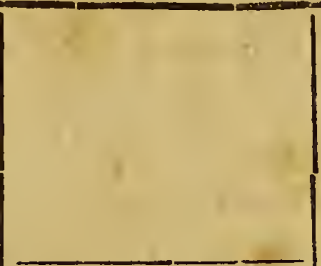 & $\begin{array}{l}\text { säure wird durch blausaures Kali bläulich, } \\
\text { durch Galläpfcltinctur schwärzlich getrïbt. } \\
\text { Noch sicherer wird dieser fremdartige Ge- } \\
\text { halt enteckt, wenn man zu einer kleiuen } \\
\text { Portion der Aufösung desselben in Salpe- } \\
\text { tersäure Ammonium in Ueberscbufs zu- } \\
\text { setzt, da denn das Zinkoxyd vollständig } \\
\text { aufgelöset wird, das Eisenoxyd aber, wel- } \\
\text { ches dabey war, unaufgelöst bleibr. }\end{array}$ \\
\hline & & $\begin{array}{l}\text { Mit Kupferoxyd ver. } \\
\text { unreinigt. }\end{array}$ & $\begin{array}{l}\text { Hat sowohl für sich, als in scinen Autö̈sun- } \\
\text { gen in Säuren eine ins Grüuliche spielende } \\
\text { Farbe. Uebersättigt man eine der letztern } \\
\text { mit Ammonium, so entstebt eine bläuv } \\
\text { lichte Miscbung. }\end{array}$ \\
\hline & & \begin{tabular}{|l} 
Mit ko/hlensaurer \\
Kalkerde, Kreide \\
oderBittersalzerde \\
verfälscht.
\end{tabular} & 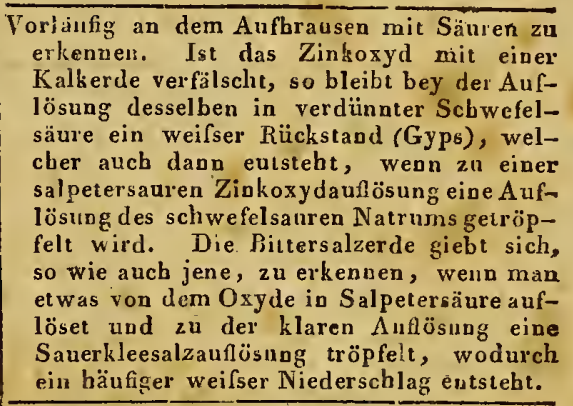 \\
\hline $\begin{array}{l}\text { Zincum sulplutri- } \\
\text { crun. } \\
\text { Vitriolum Zinci } \\
\text { purificatum. } \\
\text { Schwefelsaurer } \\
\text { Zink. } \\
\text { Zinkvitriol. }\end{array}$ & 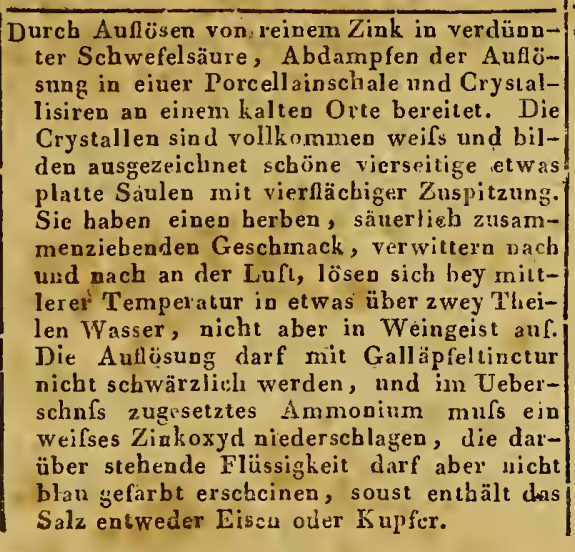 & $\begin{array}{l}\text { Statt dessen verkänf } \\
\text { licher weifser } \\
\text { triol } \\
\text { album.) }\end{array}$ & $\begin{array}{l}\text { Der in Handel vorkommende weifse Vitriol, } \\
\text { welcher 2u Goslar aus zuvor gerösteten, } \\
\text { Rammelsberger. Bleyerzen auselaugt wird, } \\
\text { 'und den man in Zuckerbutfömigen, wei- } \\
\text { fsen, festen und schweren Massen erbält, } \\
\text { ist immer nocl mit andern metallischen } \\
\text { 'Theilen, besonders mit Kurfer und Eisen } \\
\text { rerunreinigt, wovon man sich auf die an, } \\
\text { gezeigte Weise überzeugen kann. }\end{array}$ \\
\hline
\end{tabular}

\section{D r u c k f e h l e r.}

Seite 1 Col. 4 Z. 23 nach apfelsaures setze ein,

- $2-2-14$ lese man: bereitet. Der

- $4-2-23$ st. geronnene l. gewounene.

- 5 - 1 - 9 v. u. lese man Acidum muriaticum oxygena-

tum s. oxydatum.

$-15-4-6$ u. 7. lese inan: ein weifser käsichter Satz.

- 17 - $2-19$ st. Woblgeruçht l. Wohlgeruch.

- 18 - 2 - 29 l. m. Cudowaerwasser.

- $21=1-22$ st. Kernsbeeren 1. Kronsbeeren.

- $24-2-50$ l. m. amygdaloides.

$-28-2-23$ v. u. st. ansetzt l. ansitzt.

-42 - 2 - 5 st. Kauem 1. Kauen.

$-43-2-43$ st. verbreitet 1 . vorbereitet.

- $45-2-13$ st. hinzumischenden 1. hinzuzumischenden.

- 51 - $3-30$ st. salivina l. salicina.

- 53 - $2-10$ st. abscheidet 1 . abschneidet.

- 53 - $1-18$ st. Wohlkrautblumen 1. Wollkrautblumen.

- 54 - $4-36$ st. wurden 1. werden.

- 55 - $4-15$ v. a. st. Macb 1. Nacb.

$-63=2-3_{7}$ v. u. lese man: ganz unwirksam.

- 63 - 3 - 2 v. u. st. Cyparissius 1. Cyparissias.

- 65 二 $4=15$ v. u. st. von l. den.

-65 - $4=7$ v. u. st. schmähllere 1. schmälere.

$-67-2=2$ v. ul. st. mirtel förmig 1. wirtelförmig.

$-67-2-33$ st. Saponaria 1. Saponariae.

- $69-2=31$ v. u. st. Stickgänsefúfses l. Stinkgänsefufses.

$-74-2-8$ st. Füllung 1. Fällun:.

$-79-1-20$ st. vitricolatus 1 . vitriolatus.

$-80-3-2$ vo uo st. caluminaris l. calaminaris.
Seite 86 Col. 4 Z. $\cdot 9$ v. u. st. den 1. dem.

$-87-2-9$ v. u. st. Elpsomer 1. Epsomer.

$-87-2-8$ v. n. st. Saidschätzer 1. Saidschützor.

$-88-2-27$ v. u. st. den l. dem.

$-88-5-12$ v. u. l. Scarnmoninm.

- $89=3-15$ i. m. Manna laricina.

$=92-2-24$ sl. wässerlichen 1. äufserlichen.

$-92=2$
-92

92
-92
-92

$-92=2-19$ v. u. 1 . tunçuinensis.
$=93$
-93

$-93=1-3$ v. u. st. Myrrbae 1.
$-100-2=23$ st. erbält l. enthält.

- $100-2=23$ st. erhält l. enthält.

二 $104=4-5$ st. ge frirt l. scfriert.

= $111=4-15$ v. u. statt derselben 1. desselben.

- 113 - 1 - 11 st. Altheae 1. Althaeae.

$-123-2-37$ st. Bitleramsels 1. Bitterransels.

- 123 - $3 .-11$ u. 12. st. Wurzes l. Wurzel.

- $127-2-32$ v. n. st. deren I. dehen.

二 $130-2$ - 9 si. Kügelchen 1. Küchelchen.

二 $151=4 \div 13$ si. has l. batte.

- $131-4 \div 13$ si. hac lo hate.

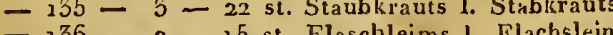

- 136 - 2 - 29. si. Gartemmibels. I. Gartennichels,

二 $138-2=47$ st. Vermischung 1 . Vermengung.

NB. Im Bogen D müssen die Seitenzahlen slatt der daselbst gesezzien: $13,14,15$ und 16 heifsen. - Das Wort $\mathrm{S}$ a me sollie immer nur mit einem einfachen a gedruckt seyn, und uicht wie es häufig gescheben ist mit eivem doppeltę (Saame.) 


\section{Vergleichende Uebersich t \\ d e r}

in der Preussischen Pharmacopoe aufgestellten neuen Arzneymittelnamen und der bis dahin gebräuchlichen alten Benennungen.

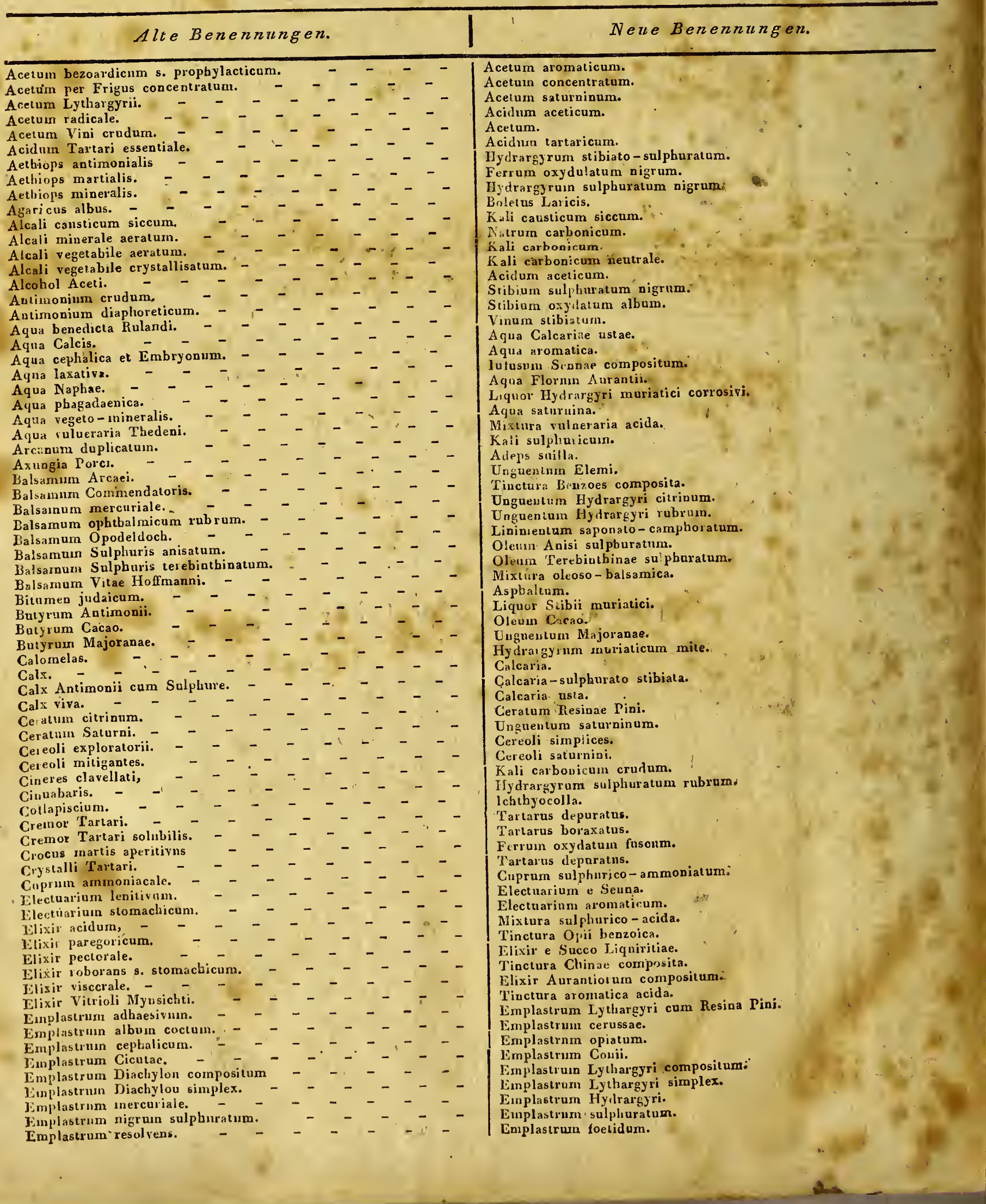




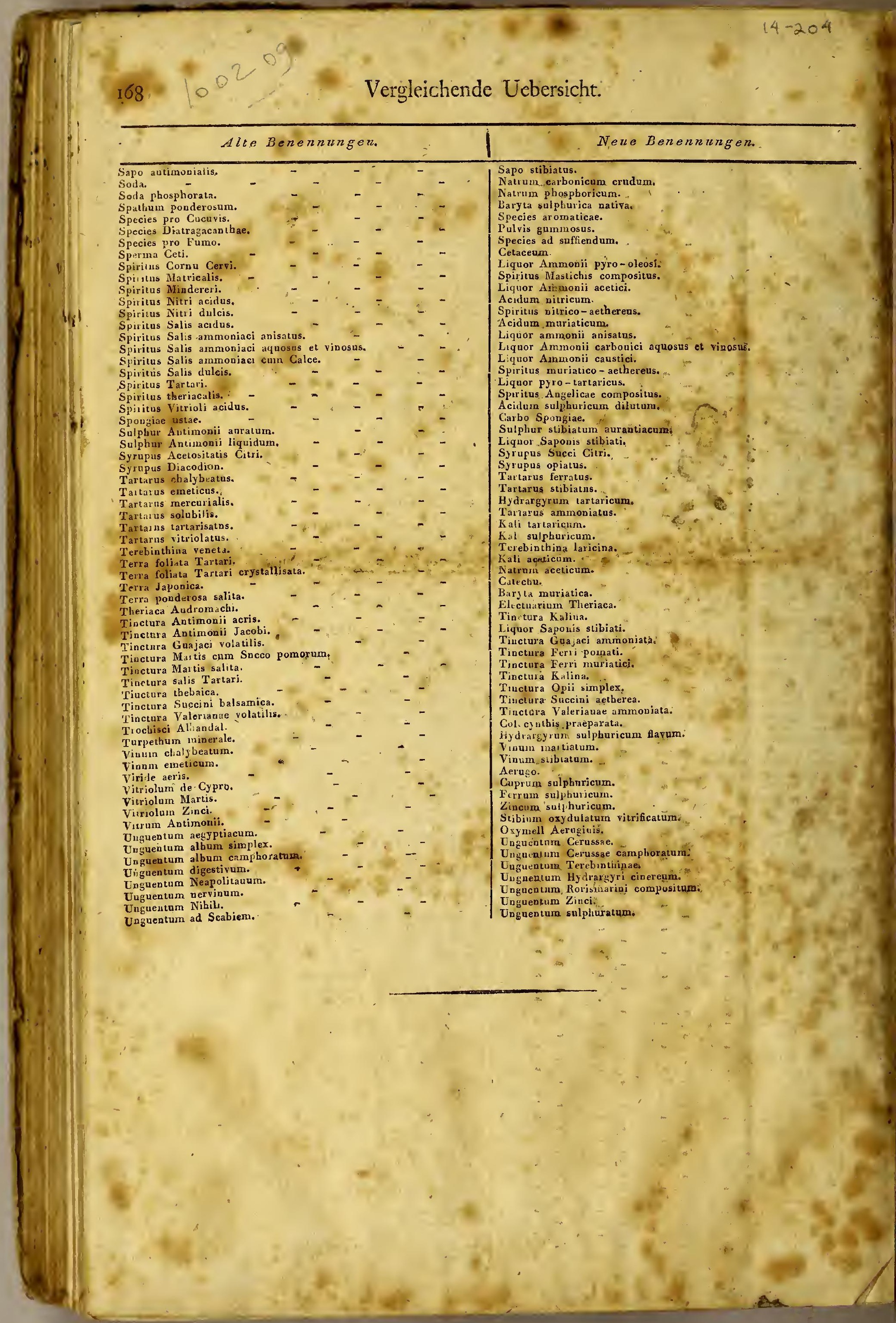




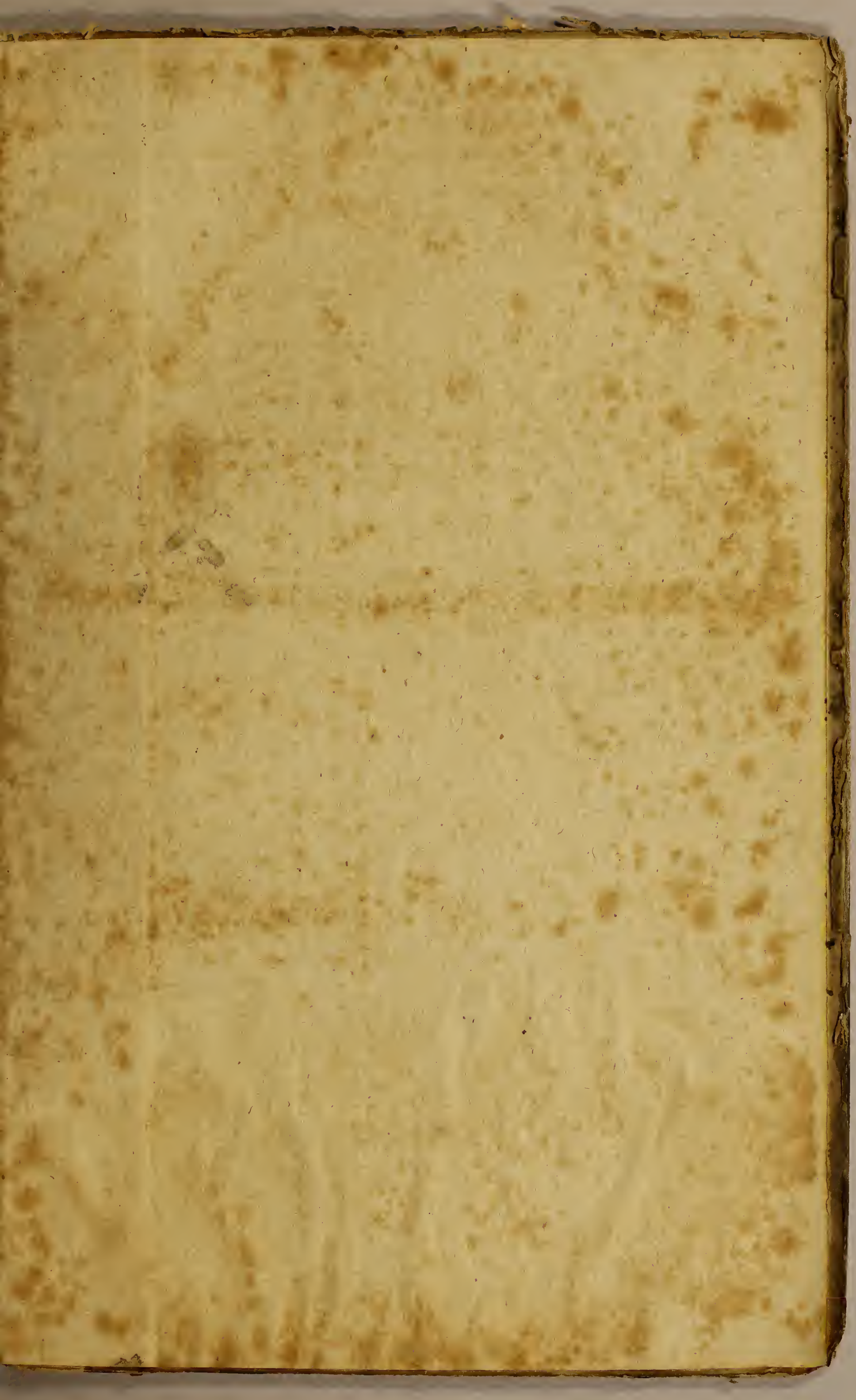




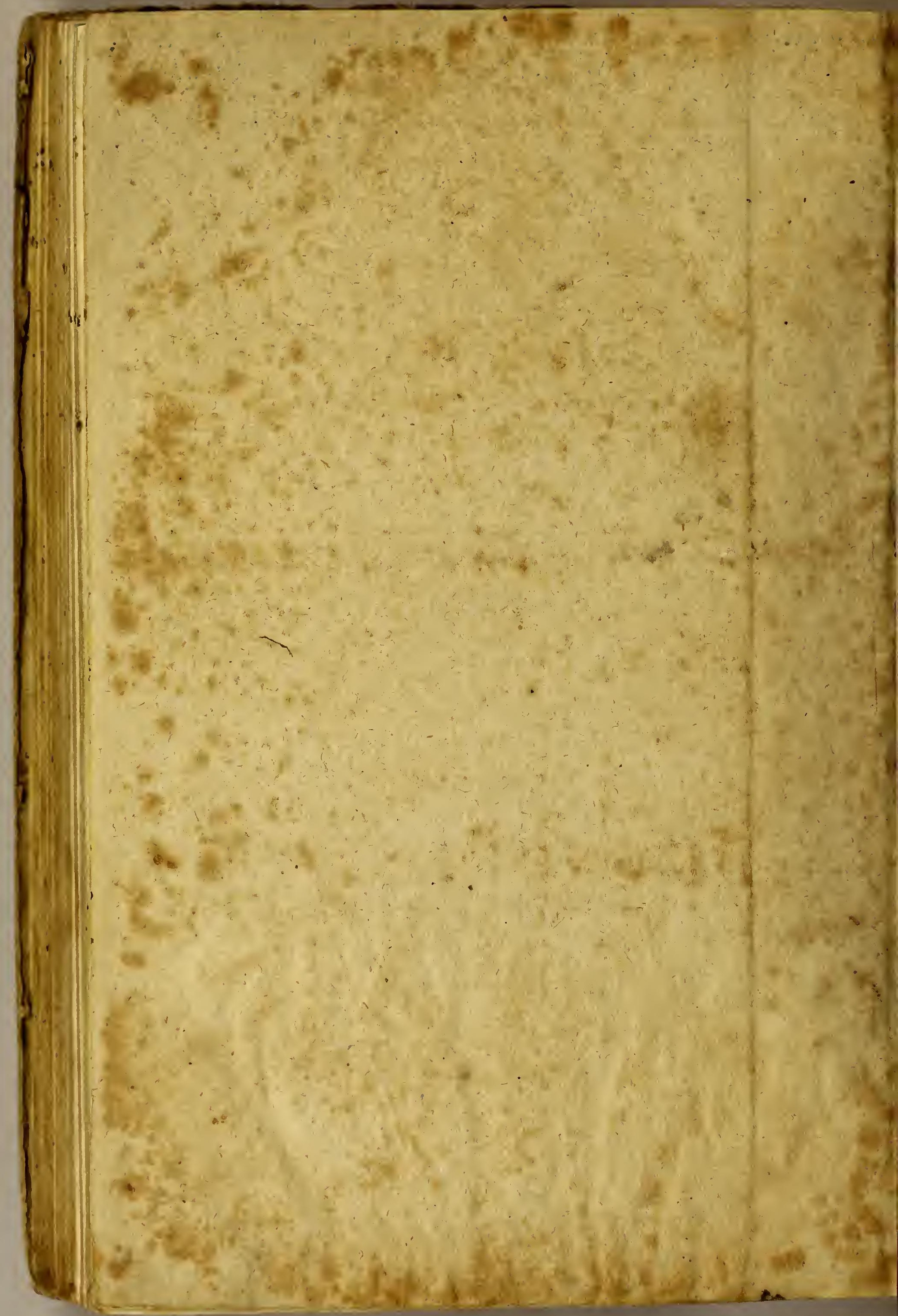




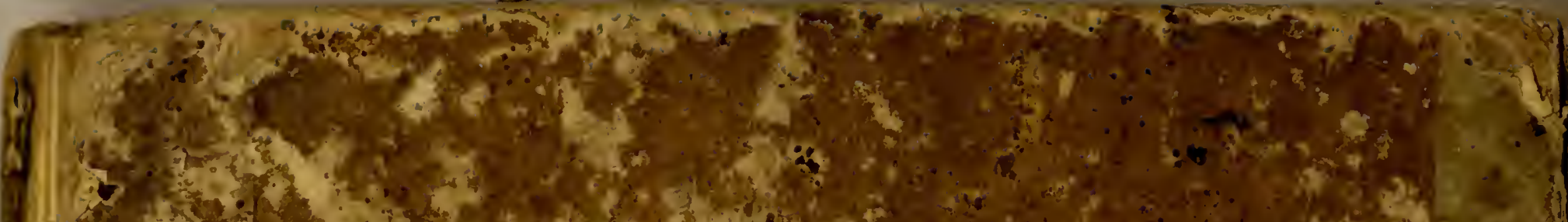

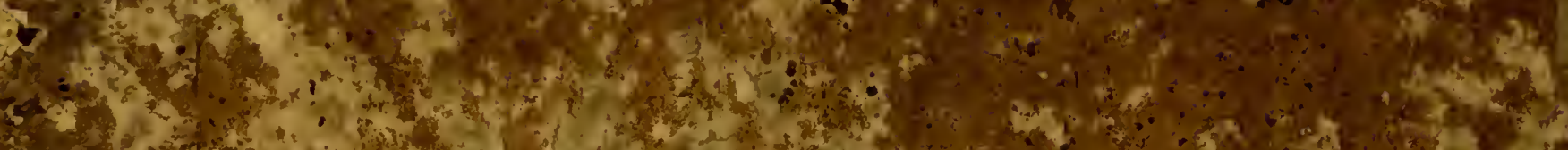

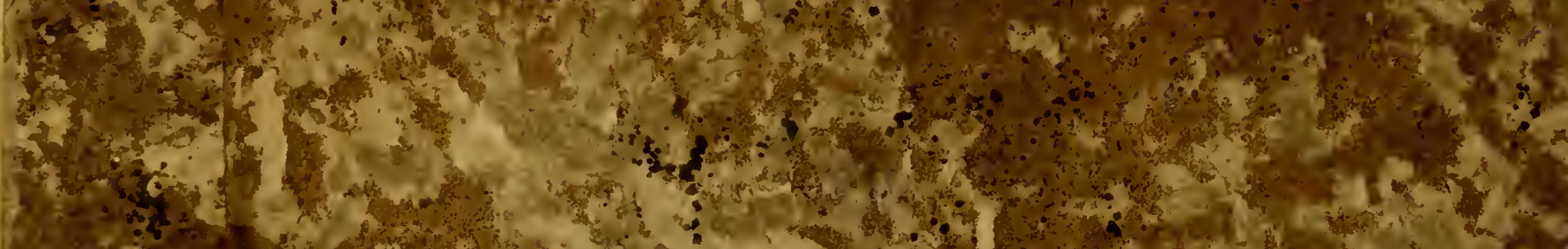

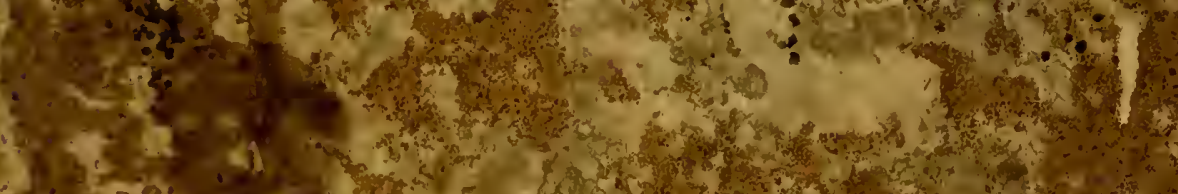

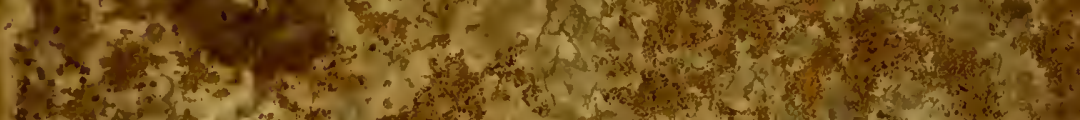

(i) (3)

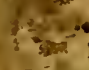
t.

.

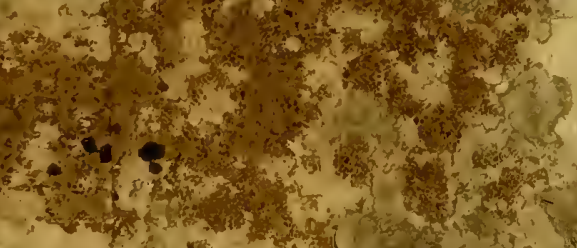

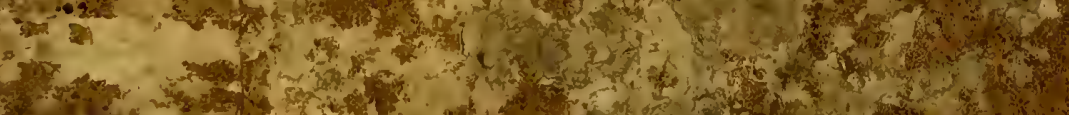

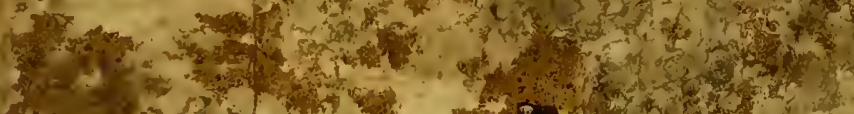

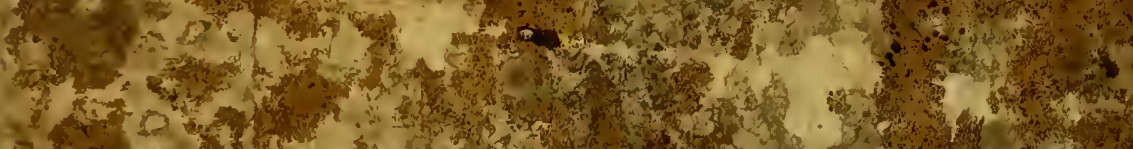

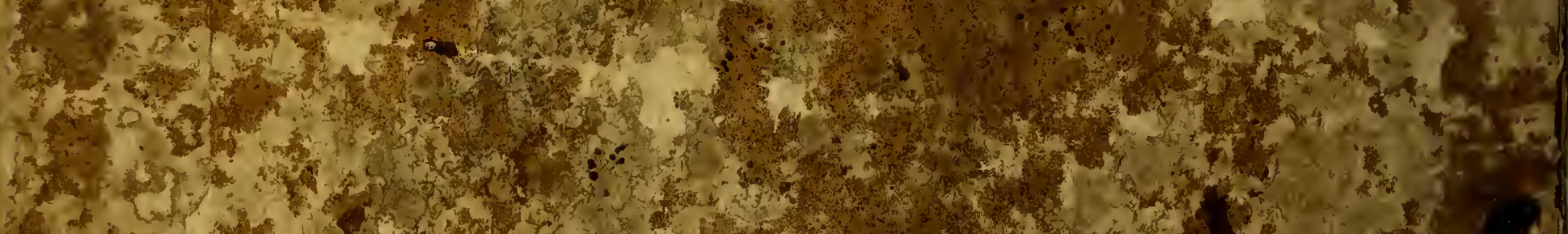

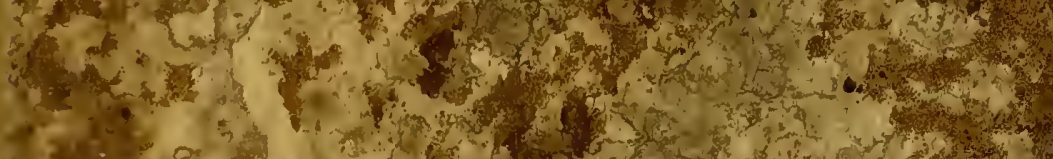

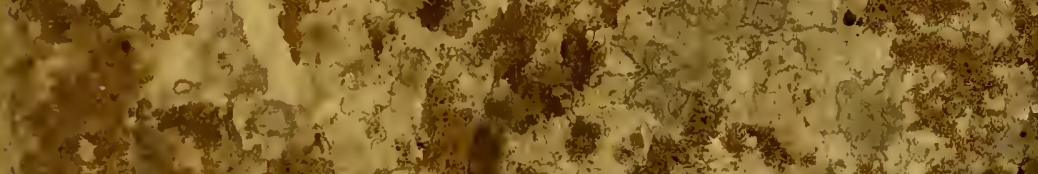

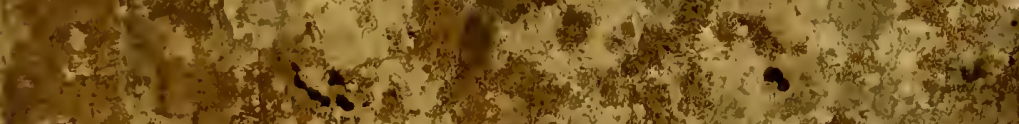

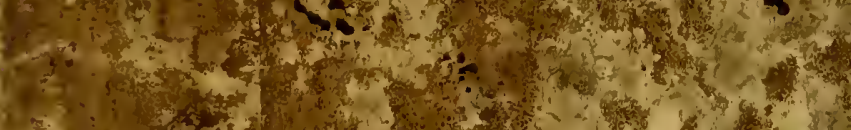

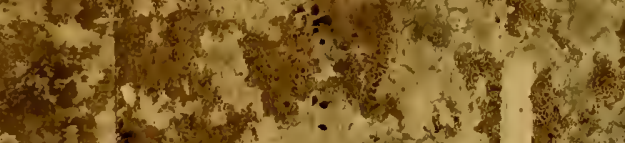

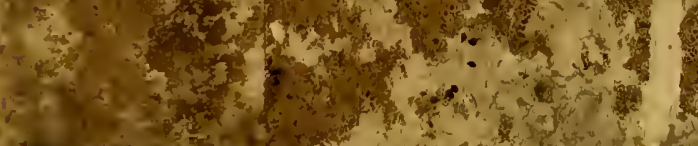

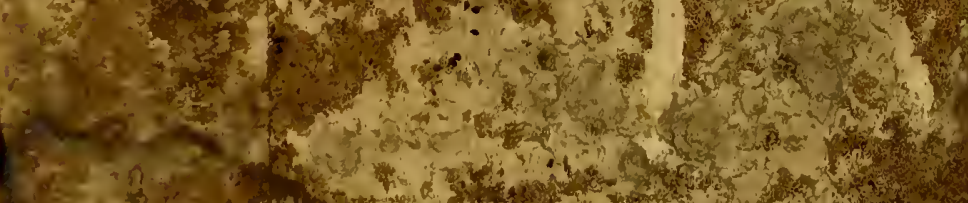

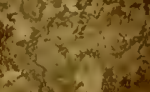

C. $1 x^{2}$ 